Marietta Messmer / Armin Paul Frank (eds.)

\title{
The International Turn in American Studies
}

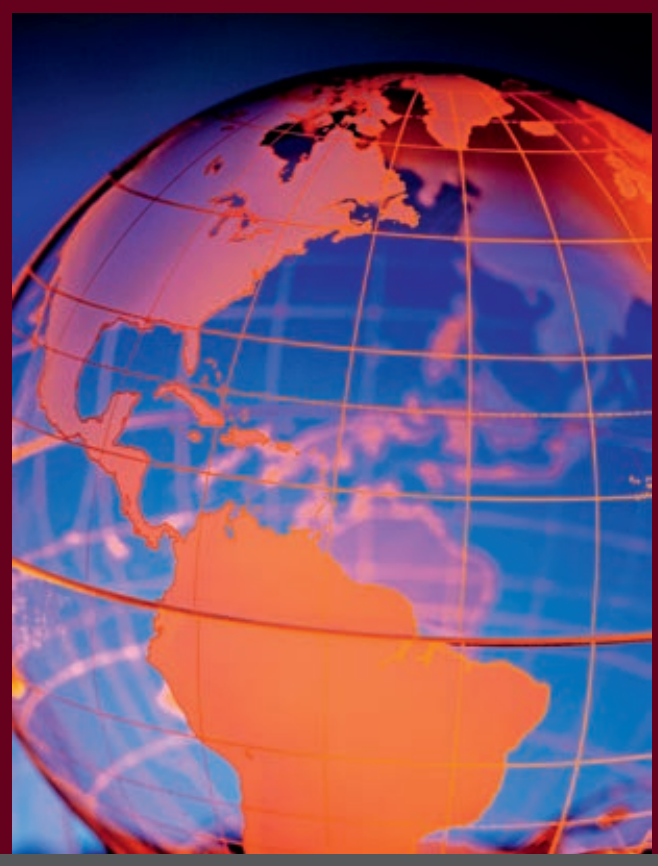


Marietta Messmer / Armin Paul Frank (eds.)

\section{The International Turn in American Studies}

The volume is a contribution to the ongoing debate on the internationalization of American Studies. The essays by European, American and Latin American scholars provide critical evaluations of a wide range of concepts, including trans-national and post-national, international, trans-atlantic, trans-pacific, as well as hemispheric, inter-American and comparative American studies. Combining theoretical reflections and actual case studies, the collection proposes a reassessment of current developments at a time when American nations experience the paradoxical simultaneity of both weakened and strengthened national borders alongside multiple challenges to national sovereignty.
The Editors
Marietta Messmer is Associate Professor of American Studies at the University of Groningen (The Netherlands). She works on inter-American cultural and political relations with a special focus on migra- tion studies.
Armin Paul Frank is Professor Emeritus of English Philology at Göttingen University (Germany) and founding director of the Göttingen Center of Advanced Studies in Literary Translation. 
The International Turn in American Studies

Marietta Messmer and Armin Paul Frank - 978-3-653-98855-0 Downloaded from PubFactory at 01/11/2019 10:57:20AM

via free access 


\title{
INTERAMERICANA \\ INTER-AMERICAN LITERARY HISTORY AND CULTURE HISTORIA LITERARIA INTERAMERICANA Y SUS CONTEXTOS CULTURALES HISTOIRE LITTERAIRE ET CULTURE INTERAMERICAINES
}

\author{
Editors: \\ Marietta Messmer (University of Groningen / editor-in-chief), \\ Barbara Buchenau (University of Duisburg-Essen), \\ Michael Drexler (Bucknell University), \\ Graciela Martínez-Zalce Sánchez (Univ. Nacional Autónoma de México) \\ and Gabriele Pisarz-Ramirez (University of Leipzig) \\ Founding Editor Emeritus: \\ Armin Paul Frank (University of Göttingen) \\ Reviewers and Advisors: \\ Ralph Bauer (University of Maryland), Robert Dion (University of Québec at \\ Montreal), Yolanda Minerva Campos García (Universidad de Guadalajara), \\ Manfred Engelbert (University of California at Los Angeles), Earl Fitz (Van- \\ derbilt University at Nashville), Carole Gerson (Simon Fraser University at \\ Burnaby/B.C.), Daniel Göske (University of Kassel), Markus Heide (Uppsala \\ University), Djelal Kadir (Pennsylvania State University), Efraín Kristal \\ (University of California at Los Angeles), Kurt Mueller-Vollmer (Stanford \\ University), Carla Mulford (Pennsylvania State University), Denis St. \\ Jacques (Laval University at Québec) and Jeanette den Toonder (University \\ of Groningen)
}

\section{VOLUME 7}

Notes on the quality assurance and peer review of this publication:

Prior to publication, the quality of the works published in this series is reviewed by external referees appointed by the editorship. 
Marietta Messmer / Armin Paul Frank (eds.)

\section{The International Turn in American Studies}

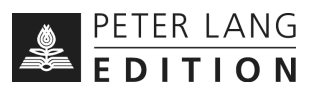




\section{Bibliographic Information published by the Deutsche Nationalbibliothek}

The Deutsche Nationalbibliothek lists this publication in the Deutsche Nationalbibliografie; detailed bibliographic data is available in the internet at http://dnb.d-nb.de.

\section{Library of Congress Cataloging-in-Publication Data}

The international turn in American studies / Marietta Messmer, Armin Paul Frank (eds.).

pages cm. -- (Interamericana, ISSN 1618-419X; volume 7)

ISBN 978-3-631-64799-8 -- ISBN 978-3-653-03657-2 (e-book) 1. United States-Civilization--1945- 2. United States--Civilization--Study and teaching. I. Messmer, Marietta, editor, author. II. Frank, Armin Paul, editor, author.

E169.12.I478 2015

973.071--dc23

2015028479

Cover illustration:

Globe 3

(OiStock.com/DNY59

ISSN 1618-419X

ISBN 978-3-631-64799-8 (Print)

E-ISBN 978-3-653-03657-2 (E-Book)

DOI 10.3726/978-3-653-03657-2

(C) Peter Lang $\mathrm{GmbH}$

Internationaler Verlag der Wissenschaften

Frankfurt am Main 2015

All rights reserved.

Peter Lang Edition is an Imprint of Peter Lang GmbH.

Peter Lang - Frankfurt am Main · Bern · Bruxelles · New York ·

Oxford $\cdot$ Warszawa $\cdot$ Wien

All parts of this publication are protected by copyright. Any utilisation outside the strict limits of the copyright law, without the permission of the publisher, is forbidden and liable to prosecution. This applies in particular to reproductions, translations, microfilming, and storage and processing in electronic retrieval systems.

This publication has been peer reviewed. www.peterlang.com 


\title{
Table of Contents
}

\author{
Marietta Messmer
}

Introduction: Transcending Borders: The International Turn in

Michael Boyden

The Semantics of Self-Denial: The New American Studies Through the Lens of Luhmann's Social Systems Theory.

Ricardo D. Salvatore

If Bolton Were to Awake Today: Early Efforts Towards a Comprehensive Hemispheric History of the Americas

Jane C. Desmond

"And Never the Twain Shall Meet?": Considering the Legacies of

Orientalism and Occidentalism for the Transnational Study of the U.S

Earl E. Fitz

Inter-American Literary Studies in the Early Twenty-First Century:

The View from the United States.

Josef Raab

Difference Matters: Toward an Inter-American Approach to 'Race,'

Ethnicity, and Belonging .

Amós Nascimento

Inter-(African-Latin-)American: An Experiment in "Inter-Location"

Gabriele Pisarz-Ramirez

Transnationality and Temporality in Early African American Texts 209

Armin Paul Frank

A Rationale for a Comprehensive Study of the History of United States Literary Culture

Daniel Göske

The Literary World in the "American Renaissance" and the International Context of American Studies 


\section{Reprinted Essays}

Earl E. Fitz

Inter-American Studies as an Emerging Field: The Future of a Discipline ..... 305

Claudia Sadowski-Smith \& Claire F. Fox

Theorizing the Hemisphere: Inter-Americas Work at the Intersection of American, Canadian, and Latin American Studies

Liam Kennedy

American Studies Without Tears, or What Does America Want? 359 


\section{University of Groningen, The Netherlands \\ Introduction: Transcending Borders: The International Turn in American Studies}

Carolyn Porter's 1994 essay "What We Know That We Don't Know" is often cited as the first call "to break away from the bounded unit of the U.S. nation" (Levander and Levine, "Hemispheric" 397 ), and at least since Janice Radway's provocative 1998 presidential address to the American Studies Association, in which she pondered the need to rename the ASA in accordance with ongoing changes and developments within the discipline, the definition of what constitutes the domain of American Studies has come under increasingly sharp scrutiny. As Djelal Kadir has confirmed in his own presidential address to the International American Studies Association in 2003: "The challenge of being an Americanist has become more challenging than ever" ("Devotees" 13). In very general terms, the debate's most controversial questions have centered on the need to redefine (i.e. extend) the field's geographical and disciplinary boundaries, and in his speech, Kadir provides a detailed sketch of the various forms that this internationalization of American Studies is currently taking: First, due to an ongoing series of geopolitical shifts, the U.S. has started to lose its former role as the main exporter and "sponsor" of American Studies programs abroad, especially in Europe, which in turn means that the U.S. gradually stands to lose its hegemonic role as "generator of [the most privileged] epistemic [and scholarly American Studies] paradigms" (Kadir, "Devotees" 14). In other words, at a time when American Studies practitioners in different parts of the world become more self-confident and independent of their U.S. role models, an increasing number of internationally influential scholarly approaches, methodologies, and analytical criteria no longer originate in the U.S. itself so that "we are witnessing," in Kadir's words, "a reconfiguration of American Studies as an international intellectual enterprise" (Kadir, "Devotees" 14). At the same time, the U.S. also increasingly loses its status as "an object of devotion" (as it used to be for many members of the Cold War generation of U.S.-based American Studies scholars as well as the Marshall Plan generation of European

1 See Levander and Levine's essay "Hemispheric American Literary History" for an exhaustive survey of early transnational publications. 
American Studies scholars), and more and more often the U.S. has become a subject of criticism and even disidentification instead. All of this has led, thirdly, to an increasing challenge to the "ideologically circumscribed reduction of [the name] America, and of American Studies, to the U.S.", which leads Kadir to conclude that American Studies is currently turning more and more "into a transnational, hemispheric field" (Kadir, "Devotees" 22, 23).

Of course international, transnational, or hemispheric (economic, cultural, political) relations have shaped the literary and cultural productions in the Americas from the start, even if attention to this aspect by American Studies scholars has been selective and was often guided by specific national political or ideological interests. ${ }^{2}$ According to Armin Paul Frank, internationality has been at the core of North, Central, and South American literary productions for centuries, and positioning themselves in relation to selected European "mediators" as well as to literatures on other continents has been a common strategy for authors throughout the Americas to develop the concept of a national literature (Frank, "An Invitation" 19). ${ }^{3}$ Yet while scholarly attention to these international literary connections was strong during the early stages of ninetheenth-century U.S. literary historiography, for example, a narrowly national lens started to prevail from the early decades of the $20^{\text {th }}$ century on and has dominated the field to such an extent that a turn towards internationalization could emerge as a "new" paradigm again during the 1980s and 1990s. ${ }^{4}$

While international, hemispheric, transatlantic, and transpacific relations have thus shaped literary and cultural productions in the Americas in earlier centuries as well, what can indeed be called new at this moment is the extent to which recent developments - including the cumulative effects of an accelerating global political

2 Marc Chenetier reminds us that most of what Kadir terms new developments in American Studies are very common practices for European-based Americanists and have been so for decades (7). For this reason, Jared Hickman argues that the current emphasis on internationalizing American Studies is both presentist and redundant because the U.S. has always been a nation of nations (11). On this question, see also the contributions to this volume by Fitz, Boyden, Salvatore, Göske, and Frank.

3 These international (literary) connections have been explored in depth by a range of publications developed under the aegis of the Göttingen Center for Advanced Study on The Internationality of National Literatures. See, among others, the volumes edited by Frank and Essmann, Frank and Mueller-Vollmer, Buchenau and Paatz, Frank and Lohse, as well as Kurt Mueller-Vollmer's studies on German-American literary transfer, including his most recent Transatlantic Crossings (forthcoming 2015).

4 For a detailed discussion of this increasing loss of an international perspective in the context of U.S. literary historiography, see Messmer, "Toward a Declaration." 
and economic interdependence, as well as the increasing mobility of people and commodities worldwide - have, since the last decades of the $20^{\text {th }}$ century, started to challenge many of the established assumptions of the discipline of American Studies and have thus prompted scholars to call for a radical redefinition of the entire academic field. ${ }^{5}$ This redrawing of disciplinary boundaries has prompted Donald Pease to conclude in 2011 that "[t]he 'transnational turn' in American studies has effected the most significant reimagining of the field of American studies since its inception" (Introduction Re-Framing 1). In this context, "nationalized identity, nationalized belonging, regional classification, citizenship, borders, and territory" are increasingly scrutinized "not as givens but as fabricated categories, tropes, and narratives" (Pfister 17). This scrutiny may ultimately lead to a renaming of the entire discipline, as Radway had suggested, but it will most likely also include some degree of decentering of the U.S. within American Studies as well as challenging the dominance of what is frequently referred to as American American Studies. ${ }^{6}$ Part of this decentering will also consist of challenging the still widespread hegemonic use of the term "America" as a synonym for the United States.

5 In this sense, nationalism is increasingly associated with provincialism, as Joel Pfister has observed (20).

6 Kadir, who wrote his presidential address in light of the U.S.'s invasion in Iraq, emphasizes that this international turn in American Studies, ironically enough, occurs "at a time when the most powerful nation in America, the USA, is exerting the greatest military and economic influence in the rest of the world," and adds that "[t]he very hyper-power and the quality of influence exerted by [the U.S.] at this historical moment may well be the ultimate cause of these shifts" (Kadir, "Devotees" 15).

7 The imperialist gesture to conflate "America" with the "United States" can already be found among the founders of the U.S.; Thomas Paine's Common Sense of 1776, for example, already uses America as a synonym for the United States (McClennen 397). Latin American authors such as Simón Bolívar, José Enrique Rodó, or José Martí have attempted - often in direct response to the Corollary to the Monroe Doctrine - to rescue "America" semantically and conceptually (in his invitation to participate in the Panama Congress of 1826, written in 1824, Bolívar, for example, refers to the previous Spanish colonies as American republics; cf. McClennen 399). Some, like Martí, however, then exhibited an analogous form of imperialism by conflating North America with the U.S. and omitting Canada/Québec. Amós Nascimento's contribution to this volume not only challenges the U.S.'s appropriation of the term "America" but also reminds us that "African American" is often used in a similarly reductionist way (to refer to the people of African descent currently living in the United States exclusively) and should, as a matter of course, be extended to include all people of African descent in the Americas. 
Such redefinitions of the field have not remained without criticism, with Leo Marx being one of the harshest opponents. Agreeing with Alan Wolfe's 2003 diatribe titled "Anti-American Studies," Marx considers the majority of internationally oriented American Studies scholars "America haters" who have lost or abandoned their belief in the founding ideals, or what he refers to as the "ur-theory" of their discipline. Other critics such as Heinz Ickstadt have focused on the practical difficulties inherent in reorganizing teaching and research in light of transnational paradigms, while still others, including Bryce Traister - who views the current internationalization as yet another version of American exceptionalism and a form of "academic imperialism" ("The Object" 3,17 ) - feels that if the nation is the enemy, we should study it rather than trying to transcend it because "without that national construct, understood as both practice and theory, ... the practical value of Americanist inquiry loses far more than it gains" ("The Object" 23). A similar stance is shared by Winfried Fluck, in whose view it would be a mistake to regard withdrawing from "analyzing the center" as an effective point of resistance and a "saving utopia" ("Inside" 28) because "globalization does not mean that American power becomes porous or is going away" ("Inside" 29). Drawing our attention to the ways in which current developments within American Studies have been viewed by other disciplines, Emory Elliott has reminded us that the international turn in American Studies "can also be seen as yet another infringement upon territories already occupied by scholars doing similar work in other departments and programs" ("Diversity" 9).

Still other critics have adopted a more strategic scepticism. In light of the fact that on U.S. campuses, many American Studies programs have started to be closed down due to financial reasons, and many ethnic studies programs have started to be assimilated into American Studies (Rowe et al., Introduction 11-12), many scholars have argued for a strategic need to preserve American Studies in its traditional form. As Amy Kaplan summarizes this view: "[T]here are strategic reasons, nationally and internationally, for maintaining the authority of American studies as a discipline" (Kaplan, "Violent" 11). Similarly, Winfried Fluck has repeatedly emphasized the distinctness of "American" Studies as a discipline and has voiced his concern that "'an association that redefines the object of study as a hemispheric system risks losing the rationale for the existence of American Studies, the specific relevance of the United States as a paradigm-setting modern society"' (qtd. in

8 In Fluck's view, "there is no automatic equation between outside location and outside perspective" because even those who are located outside the U.S. have often adopted U.S. research paradigms to further their academic careers ("Inside" 25). 
Pease, "Politics" 82). But beyond the so-called "American Century," the U.S. may never have been the only relevant paradigm-setting society in the world, and we should not forget the extent to which a U.S.-centric version of American Studies simply tends to foreground certain research paradigms that fall within the interests of the United States while at the same time obscuring at least as many alternative paradigms that concern other American nations' interests. Don Pease, finally, also warns us that it is difficult for many U.S. Americans and maybe others to replace patriotic loyalties "with loyalty to a nonterritorial transnation" - but "[p]erhaps the invention of such an imaginary describes the central political task of Postnational American Studies" (Pease, "Politics" 90). And Paul Giles asks whether American Studies "can [indeed] morph itself successfully into a [new internationally perspectivized] field" ("Response" 22), but his comment obscures the fact that the Americas have, from the start, been a relational project, while it was U.S. American Studies as a discipline that has ignored this fact for quite a long time. Fredric Jameson therefore rightly views these oppositional voices as "occupational hazard of American Studies programs" because they "have a vested interest in preserving the specificity of their object and in preserving the boundaries of their discipline" (Jameson 35; qtd. in Giles, "Response" 20). Yet at least since the end of the twentieth century, even hard-core Americanists such as the traditionally very nationalist ASA have started to recognize the need for reconceptualizing the field by demanding "new ways of thinking the relationship among geography, culture, and identity" (Radway 4).

In the debate about this most recent international turn within American Studies, a wide range of terms and concepts have been introduced, including transor postnational, international, or global American Studies, (trans-)Atlantic and (trans-)Pacific American Studies, as well as intercultural, hemispheric, transborder, comparative, or inter-American Studies, to name only some of the most frequently circulating ones. ${ }^{9}$ While (trans)Atlantic American Studies has had a longer history in both the U.S. and Europe, three groups of terms have come to stand out as the most prominent and influential ones since the 1980s and 1990s, which I will examine more closely in the following: (1) transnational or postnational American Studies; (2) (critical) international American Studies (often

9 Often, connections are also drawn to related fields such as diaspora studies, subaltern studies, or postcolonial studies. In many ways, postcolonial studies with its "critiques of the modern nation-state as an ideological or 'imagined' construct of Western capitalist culture based on imperial or neocolonial forms of economic exploitation" can be viewed as a precursor of this current international turn, as Ralph Bauer reminds us ("Hemispheric Studies" 236). 
used in opposition to American American Studies); and (3) hemispheric or InterAmerican Studies. Some scholars use these terms almost interchangeably in an attempt to highlight the commonalities of current dynamics in the field, yet on closer examination, one can observe significant geopolitical and ideological differences in the usage of these concepts. In the following, I will first concentrate on the so-called post- or transnational approach, which has been favored by a substantial number of U.S.-based American Studies scholars since the 1980s and 1990s and which, within a U.S. context, has currently become the most frequently used concept (Pease, Introduction Re-Framing 1) that has assumed the role of an umbrella to cover different forms of internationalization. One reason for this preference, I will argue, is that many U.S.-based Americanists, feeling under a certain degree of pressure to adopt a more international perspective - were at first drawn to this paradigm because it allowed them to challenge traditional notions of U.S. nationalism and exceptionalism while at the same time retaining the U.S. and U.S.-based epistemological and theoretical research paradigms at the center of American Studies. The second approach, a (critical) international American Studies perspective (represented in this volume by Jane Desmond) can in many ways be seen as a more radical alternative to this paradigm, yet as Gabriele PisarzRamirez demonstrates, whose contribution explicitly decenters the U.S. in a postnational approach to nineteenth-century African American texts, current uses of "transnational" have also moved beyond its earlier scope. The third approach, a hemispheric or Inter-American Studies paradigm, is seen by many critics - including Fitz, Nascimento, Pisarz-Ramirez, Raab and Salvatore in this volume - as a highly enabling alternative that transcends the limitations inherent in studying one nation in isolation and can successfully address the multifaceted economic, political, and cultural interrelations of the Americas in an age of global interconnectedness and migratory movements. Yet Inter-American Studies has also met with scepticism - in particular in its U.S.-centric variant - because of the ways it can and has been (ab)used as a form of neo-colonialism or neo-imperialism. ${ }^{10}$

\section{Post- or Trans-National American Studies}

At the start of this current wave of internationalization, a substatial number of U.S.based interventions began to privilege a post- or transnational framework, with the two terms frequently being used and defined in interrelated or even synonymous ways. It was Shelley Fisher Fishkin's influential 2004 ASA Presidential Address

10 For a detailed discussion of this topic, see Fitz's contributions to this volume. 
that placed the term center stage by calling for a "transnational turn in American Studies" and asking the famous question: "What would the field of American Studies look like if the trans-national rather than the national were at its center?" ("Crossroads of Cultures" 21). The increased relevance of transnational paradigms within a U.S. academic context has frequently been attributed to the U.S.'s early twentieth-century rise to the role of a global police force ("extending its jurisdiction across national boundaries" to control immigration or decide about who is a failed state [Pease, Introduction Re-Framing 11]), of worldwide migration movements, the global spread of capitalism, transnational and cosmopolitan forms of citizenship, as well as global challenges such as sustainability, security, and social justice that require the "coordination of military, environmental, and monetary policies" (Pease, Introduction Re-Framing 9). These developments have radically expanded the U.S.s sphere of influence and hence "redefined the state's mission, requiring that it downplay its obligations to the constituencies within a bounded national territory so as to meet the extranational needs and demands of global capital" (Pease, Introduction Re-Framing 8). ${ }^{11}$ The need to "investigate how transnational processes problematize the nation state as a point of reference for political, social, economic, and cultural systems" (Hebel, Preface 6) thus struck a chord. For many scholars, transnational American Studies has become "both the methodological tool and the political program to address [the] pressing issues of the $21^{\text {st }}$ century" (Hornung, "Transnational" 628). ${ }^{12}$ Since then, transnational American Studies has - especially within the United States - become a kind of umbrella term that is often employed to highlight the field's post-exceptionalist and anti-imperialist stance, but that in other respects refers to several different forms of internationalization. ${ }^{13}$ A large number of journals, book publications and conferences have

11 Donald Pease has linked the rise of transnational American Studies also more specifically to the state of exception installed by George W. Bush in the aftermath of 9/11 in order to "regulate the national community's relationship to the social, economic, ideological, and cultural structures of exchange taking place across the planet" (Introduction, Re-Framing 8). At the same time, however, Pease also emphasizes the role of the nation-state as the guarantor of transnational rights (Introduction Re-Framing 10).

12 Some critics such as Günter Lenz have focused on the less political/politicized concept of transculturality instead, emphasizing the extent to which it enables "a new processual and performative understanding of 'culture"' and allows for a non-neoimperialist cross-cultural perspective without simply dismissing the boundaries of the nation-state (Lenz, "American Transcultural Studies" 396).

13 Kristin Hoganson cautions us that this very use of "transnationalism" as an umbrella term "ends up reifying the very unit that transnationalism aims to challenge: the nation state. It implies that the nation is always a fundamental unit of analysis" (Hoganson 622). 
contributed to the concept's proliferation, including the Routledge Transnational Perspectives on American Literature book series (launched in 2004), the journal of Transnational American Studies (founded in 2009), the collection of critical essays titled Re-framing the Transnational Turn in American Studies (edited by Winfried Fluck, Donald E. Pease, and John Carlos Rowe in $2011^{14}$ ), as well as the volume Transnational American Studies (edited by Udo Hebel in 2012) that collects contributions to the 2011 conference of the German Association for American Studies on the same topic.

While definitions differ and, in Pease's words, "multiple and contradictory versions" of trans- and postnationalism have appeared during the past 20 years (Introduction, Re-Framing 17), the concept originally evolved on the basis of a range of common denominators. Janice Radway's and Donald Pease's initial explorations of the concept can be illustrative in this context, as they also echo those of a much larger group of scholars who subsequently contributed to this debate (including Carolyn Porter, Lisa Lowe and Shelley Fisher Fishkin). In her famous 1998 presidential address "What's in a Name?," Radway insisted that "American national identity is constructed in and through relations of difference" (Radway 5) - a statement she expanded upon with the following definition of difference: "The very notion of 'the American' is intricately entwined with those 'others' produced internally as different and externally as alien through practices of imperial domination and incorporation" (Radway 6). Similarly, in his essay "The Politics of Postnational American Studies" of 2001, Donald Pease notes that post-national can have many different meanings, including "after" nationalism, "anti"-nationalism, "supra"-nationalism, as well as "sub"-nationalism. He then continues to suggest, however, that in his view, a postnationalist paradigm stages "the encounter between the historical nation and its internal and external others" (Pease 87), and it looks, among other issues, at globalization embodied by transnational corporations but also at "globalization from below" as represented by subnational collective practices (Pease 78).

It is interesting to note that both Radway and Pease define trans- respectively postnational as having an external as well an internal dimension. ${ }^{15}$ The first, the

14 In his introduction to this volume, Donald Pease offers a very detailed critical discussion of the historical and geopolitical origins as well as current usages of the concept of "transnationalism," including its link "to the doctrine of Manifest Destiny to justify expansionist U.S. policies designed to realize what Thomas Jefferson described as an 'Empire of Liberty'” (Introduction Re-Framing 4).

15 John Carlos Rowe defines postnationalism in a similar way as having local, national, and global dimensions (Introduction 8). 
external dimension, in both cases includes a critique of U.S. exceptionalism and U.S. imperial power relations, combined with an attempt to develop alternative, i.e. critical visions of U.S. foreign policy measures and U.S. economic policies as exemplified, for example, by Amy Kaplan and Donald Pease's volume Cultures of United States Imperialism (1993), ${ }^{16}$ or Pease's most recent essays, including "Rethinking 'American Studies after U.S. Exceptionalism"' and his Introduction to Re-Framing the Transnational Turn in American Studies. While this version of postor transnationalism does indeed go beyond the borders of the U.S. nation state, critics have nonetheless pointed out that this framework is at least "to a degree consistent with U.S. economic policies promoting globalization" and neoliberalism (Sadowski-Smith/Fox 23), a danger that is ultimately also recognized by Don Pease himself, who agrees that the post-national framework may be abused by "supra-nationalists" like Frederick Buell "who have reinscribed the foundational terms of the U.S. political vocabulary - democracy, capitalism, free enterprise, human rights - within the newly globalized discourse of neo-liberalism" (Pease, "Politics" 85) $)^{17}$ - a maneuvre which might then, in Marc Chenetier's words, lead to a "new' version of American transnational exceptionalism" (Chenetier 6). In his "Politics" essay, Pease has therefore included a section titled "Is Postnationalism a Form of U.S. Cultural Nationalism?" (Pease, "Politics" 83), and he goes so far as to conclude that the transnational elite of corporate managers can actually be said

16 Guantanamo is Amy Kaplan's example of "historicizing and defining the relational meanings of America," for example. The goal here is, in Wiegman's words, to "rethink ... [the] material effects of the transnational history of U.S. empire" (Wiegman 581).

17 Cf. also: "Does not post-exceptionalist American studies also simply ignore the ways in which two of the core tenets of the discourse of American exceptionalism - the rule of law and neoliberal market ideology - have saturated the global processes in which America is embedded?" (Pease, "Re-thinking" 22). In this latter essay, Pease also quotes Farshad Araghi, who refers to globalization as "invisible colonialism - the third phase of the Euro-American colonization of the globe" (qtd. in "Re-thinking" 24). For this reason, Pfister asks whether "American globalizing" is not merely "a form of Americanizing" (20). Cf. also Pease's more recent comment: "Was [transnational American Studies] a form of disciplinary imperialism designed to refashion social relations and cultural practices after the U.S. neoliberal model? Did the transnational framework foster an alternative to U.S. cultural and economic hegemony or embody the standpoint that Americanization assumed in the present juncture?" (Introduction Re-Framing 2-3). Johannes Voelz has devoted an entire essay to the interdependence between transnationalism and neoliberalism yet emphasizes that most transnational Americanists do not see themselves as conscious "ideological agents of the normalization of neoliberalism" (Voeltz 359). 
to reinscribe U.S. nationalism (Pease, "Politics" 85). Donatello Izzo has thus asked very poignantly: "Could it be that American Studies is turning into a U.S.-based transnational enterprise, displaying a remarkable capacity of homogenizing both its products and its practitioners within a globalized flow of cultural capital?"; or formulated differently, isn't transnational American Studies "an engulfing project intent on unintentionally reconfiguring the whole world as a 'contact zone"' with the U.S. yet again at its center? (Izzo 595, 598). ${ }^{18}$ Winfried Fluck agrees, arguing that transnational American Studies has "merely extended long-dominant paradigms beyond borders" ("New Beginning" 379) because the fluidity, flexibility, and movement inherent in the concept of transnationalism "can also be seen, not as subversion of the political system but, on the contrary, as adaptation to a neoliberal logic in which movements of peoples and ideas are now the instruments of a new order of global capital" ("New Beginning” 379).

On the basis of such reflections, many scholars have started to emphasize the ambivalence inherent in the concept of transnationalism - in Pease's words: "Transnational initiatives can refer to efforts to expand the exercise of American power or to impede it." Transnationalism therefore has become a "mobile category" that has been taken up by people who are critical of the state and by those who are supportive (Introduction, Re-Framing 5, 6). Others, including Izzo come to the conclusion that, analogous to Derrida's il n'y a pas de hors texte, "American Studies [the version that is more and more often termed American American Studies] has no outside" (Izzo 598). This inherent U.S.-centeredness has most recently been confirmed by Bryce Traister, who observes: "Contemporary transnationalism as articulated by most North American critics, remains a deeply insular critique: one committed to and prompted by a largely U.S.-identified set of political, intellectual, and curricular problems; one largely argued by and for U.S.-identified Americanists; and one that makes the most sense, politically and professionally speaking, to U.S.-based scholars in American Studies" ("Everything Old” 160). While, according to Traister, international American Studies scholars are best equipped to contain "the insular, parochial, and self-serving tendencies of U.S.-based American Studies, ... [t] he desire to be more 'like' American Studies programs in the United States continually impinges on our work." For this reason, Traister continues, "[t]ransnationalism, or the new globalism, has become an unavoidably 'colonialist' aesthetic, in which the interests of the center or national

18 Cf. also William V. Spanos, who argues that the "Global English of transnational capital" is not simply a neutral "vehicle of communication empty of ideological cultural content" but "an essential agent of transnational capitalism's project" that represents U.S. interests (398-399). 
metropole (the U.S. academy) are exported to the international hinterlands for implementation" ("Everything Old" 161). Such sentiments are also echoed by Salvatore's, Boyden's, and Fitz's contributions to this volume, which highlight the extent to which many calls for transnationalization launched by U.S.-based American Studies scholars are actually covert attempts at recentering - rather than decentering - the United States within the discipline and hence can still be considered appropriative and neo-imperialistic gestures, or a form of what Amy Kaplan calls "imperial internationalism" ("Tenacious" 36). ${ }^{19}$

Yet what is even more striking in both Radway's and Pease's early definitions of transnationalism is the concept's internal dimension, which in effect refers to the multicultural composition of the U.S., i.e. to racial, ethnic, gender, class, or other non-dominant populations within the boundaries of the U.S. nation state. ${ }^{20}$ But how and why can or should the U.S.'s internal cultural heterogeneity be regarded as a form of postnationalism ${ }^{21}$ Scholars like Pease and Radway argue that they view "multiculturalism and the politics of difference as postnationalist strategies" (Pease, "Politics" 84) because when the "work on difference" first emerged in the U.S. in the form of the so-called New American Studies during the 1960s and 1970s, it "explicitly began to engage the question of how American nationalism was actively constructed" (Radway 4) and it therefore "intended to discredit the foundational belief in U.S. exceptionalism" (Pease, "Politics" 84). As a consequence, "American Studies practitioners could no longer sustain the fiction that Americans 'shared' [one] national character based on [a common cultural identity as well as] common experiences" (Rowe et al., Introduction 5) and instead had to acknowledge the nation's internal heterogeneity. ${ }^{22}$ In other words, the multicultural turn within American Studies "conceived [itself partly] ... in opposition to older understandings of the American nation" (Radway, Gaines, Shank, von Eschen 3) - older understandings that had dominated the discipline from its origins during the 1930s right through the Cold War era, and which had

19 See also Siemerling and Casteel, and Gillman on this issue.

20 Pease reconfirms this sub-national dimension in his Introduction to Re-Framing 5-6.

21 In "Left Alone with America," Kaplan argues that the U.S.'s internal heterogeneity (in terms of race, for example) can historically be related to "the global dynamics of empire-building" (16).

22 Radway repeatedly refers to internally different communities as "non-national identification" (Radway 4), because "postnational might be described not only as what has come after but also as what has established a kind of resistance to U.S. nationalism" (Pease, "Politics" 85). 
often emphasized the national unity and cultural as well as political and ideological coherence of the United States (Temperley and Bigsby 1).

Yet by locating what Lisa Lowe has termed "the international within the national" (qtd. in Wiegman 581), these critics tend to conflate the potential to transcend the boundaries of the U.S. nation state with what in practice results in a focus on subnational groups located within the U.S., an approach which helps to criticize specific, older understandings of U.S. nationalism but at the same time reaffirms the U.S.'s geopolitical borders. ${ }^{23}$ It could be argued that this attempt to view the U.S.'s internal heterogeneity as an integral part of a trans- or postnational approach to American Studies is a very clever strategy that allows for a participation in the internationalization debate while at the same time reinscribing the U.S. firmly at the center of this debate. ${ }^{24}$ What is more, by constructing a new "origin" myth according to which the international turn of the 1980s and 1990s has its roots in the multicultural turn of the 1960s (and thus within in the United States and U.S. academia itself), scholars like Radway or Pease implicitly suggest that the current impetus to internationalize American Studies has not come from abroad but has actually originated within the U.S. itself. In other words, it is not an external challenge to American Studies' disciplinary limitations, but a U.S.-based initiative. ${ }^{25}$

23 See also John Carlos Rowe, who has termed the ethnic nationalisms of the ethnic identity movements during the 1960s "particularist nationalisms" (Rowe et al., Introduction 5). Djelal Kadir agrees with Rowe in regarding "debates about race, gender, and sexuality as nationalist" (Kadir et al. in Wiegman 583).

24 John Michael offers an interesting explanation for this phenomenon, arguing that "a fascination with, and affection for, excluded identities ... who have suffered injustices in the form of 'exploitation, abjection, and disdain' at the hands of the dominant national discourse" (413) allows U.S.-identified Americanists to be both critical of as well as loyal to their nation and discipline, concluding that "[c]ritical distance does not equal exteriority" (Michael 417).

25 With this critique I of course do not wish to imply that the multicultural challenges to the consensus paradigm and the preconceived unity and coherence of U.S. national identity have not and do not produce highly valuable and immensely important work. In this context, Werner Sollors's pioneering project "Multilingual America" particularly stands out as a response to the paradoxical situation that many studies exploring multiculturalism within the U.S. still adhere to a monolingual ideal. Sollors himself has commented on this fact, reminding us that language is "the blind spot in the debates about multiculturalism in the United States" (13). Cf. his books and also his anthology The Multilingual Anthology of American Literature (edited together with Marc Shell, 2000). To my knowledge, Sollors's Longfellow Institute at Harvard is currently the only U.S.-based institution devoted to the study of the multilingual United States, but it has made clear, as Olm Øverland has formulated it, that "[o]ne challenge now facing 


\section{International American Studies vs. American American Studies}

Apart from scholars engaged in trans-/post-national work, a group of U.S.-based critics, including, among others, Djelal Kadir, Emory Elliott, John Carlos Rowe, Jane Desmond, and Virginia Dominguez, have started to call for a more radical and less ambivalent version of internationalism, or what Jane Desmond and Virginia Dominguez have termed critical internationalism (Rowe et al., Introduction 7). ${ }^{26}$ This form of international American Studies strives to dismantle the power differential between U.S.-based and non-U.S.-based American Studies institutions and radically critiques "the organizational hegemony of U.S. American Studies, and the American Americanist" (Wiegman 579) as well as the hegemonic place of socalled American American Studies within the discipline by "emphasizing foreignbased scholarly perspectives on U.S. culture ... [and] thereby resituating the field's traditional institutional sites of power" (Desmond and Domínguez, 1998, qtd. in Sadowski-Smith/Fox 6). In Rowe's words, "[t]he new American Studies requires a new internationalism that will take seriously the different social, political, and educational purposes American Studies serves in its different situations around the globe" (Rowe, "Post-Nationalism" 27-28). While many American Studies scholars have always encouraged dialogue between U.S.-based and non-U.S.-based scholars, the former have often tended to over-emphasize, as John Carlos Rowe terms it, their "nativist expertise" (Rowe, "Post-Nationalism" 27). This attitude has radically been challenged by Emory Elliott, who reminds us that "[f]ar too often, we do not see ourselves as others see us" ("Diversity" 4), and who therefore insists that "genuine inclusiveness and broad international collaboration are especially crucial

the community of American Studies scholars is that of the theoretical, practical and organizational questions involved in recognizing that the 'American Mind' does not function in English alone" (Øverland 4). Many comparatists and Americanists in the larger sense of "Hemispheric American Studies" (like Doris Sommer or Debra Castillo) have also started to challenge this monolingual ideal at the core of American Studies; cf. Debra Castillo, Redreaming America: Towards a Bilingual American Culture (2005).

26 For my purposes here, it is important to distinguish between definitions and actual usage. Ian Tyrrell has pointed out that, on a basic level, "international' concerns state interactions," while the term "'transnational' additionally incorporates non-state actors" (Tyrrell 82), yet concrete usage has revealed that "international" has come to be employed in a much more radical way (dislocating the U.S. from the center of American Studies while highlighting the significance of other national actors) than "transnational," which, as has been demonstrated above, has served as an elegant way to direct attention back to both national as well as subnational dimensions within a U.S.-centric context. 
to our work in the twenty-first century" ("Diversity" 6). For this reason, Elliott, who draws an enabling link between the current turn towards internationalization and diaspora studies, reminds us that "it is our responsibility" "[to] speak out as 'citizens of the world' against American imperialism, militarism, unilateralism" ("Diversity" 2), and "[g]iven the many pressing problems we face today, we need to and can approach multiple problems on multiple fronts" ("Diversity" 10). In other words, we should not waste our energies in fighting for the recovery or perpetuation of an overarching meta-narative that holds together the discipline of American Studies but instead concentrate on training future generations of scholars to recognize the value of multiple points of view. ${ }^{27}$

Apart from the European Association of American Studies (an umbrella organization consisting of 23 national American Studies organizations), which, as Rob Kroes has recently outlined, constitutes an influential community of European American Studies scholars that strives for greater independence from U.S.-inspired scholarly paradigms (qtd. in Chenetier 6), thus creating a counterweight to the preponderance of "nativist expertise," one of the most important initiatives in this respect has been the founding of the International American Studies Association (IASA) in the year 2000. In his presidential address at their inaugural conference in Leiden (The Netherlands) in 2003, Kadir provocatively called "for a transcendence of the 'tautological Americanness of American Studies' through [placing more emphasis on] perspectives that do not 'originate in America itself'" (Kadir, qtd. in Wiegman 582). In other words, he emphasized the need for "non-Americanized Americanists" (Kadir, "Devotees" 21-22), i.e. Americanists whose outlook is neither ideologically inflected nor circumscribed by so-called American American Studies. ${ }^{28}$ Such "international perspective[s]" are increasingly "born in the refusal to identify with American American Studies, [a development] which would enable the field 'to arrive', as [Kadir] puts it, 'at a discriminating and self-critical position by and on America"' (Wiegman 583). Kadir in this context also rejects as too strongly nationalist (i.e. "defined by U.S.

27 In this context, Amy Kaplan has cautioned us against an overly simplistic reification of geographical location, as U.S.-identified scholars are also found outside of the U.S., and any rigid division between U.S.-based and non-U.S. based practitioners "risks resurrecting the rigid binary divisions between inside and outside" ("Tenacious" 37); cf. also Fluck in fn 8 above.

28 Kadir thus views American American Studies as a discipline in the full sense of Foucault's notion of governmentality, i.e. as a discipline that has "disciplined the practitioners of American Studies to deny that their practices form and are formed by a discipline" (Kadir, "Devotees" 27). 
cultural politics") the disciplinary priorities that have dominated the field in the U.S. for quite some time (including literature, history, popular culture, and ethnic studies) and pleads for a stronger shift of emphasis to other disciplines such as political science, international relations, economics, information technologies and media assessment (Kadir, "Devotees" 14; cf. also Wiegman 582-583). Kadir concludes his essay with the words: "The best hope for American Studies ... is for it to cease to be American" (Kadir, qtd. in Wiegman 583), and he welcomes all non-Americanized Americanists to IASA with the words that "being outside American American Studies today is one of the most intriguing and paradoxical ways to make one's home within it" (qtd. in Wiegman 584).

\section{Inter-American and Hemispheric American Studies}

A third paradigm that currently receives much attention in the context of American Studies' international turn is the hemispheric or Inter-American Studies approach. In very broad terms, an Inter-American Studies paradigm challenges traditional Old World-New World configurations by focusing on the American hemisphere (inlcuding Canada, the United States, Latin American nations, and the Caribbean) and is built on the premise that "the United States is not synonymous with America or the Americas" (Rowe, Post-Nationalist xvi). Usually Inter-American Studies practitioners foreground this perspective by drawing heavily on scholarship produced in the context of Latin American Studies and "by refusing to limit [their] understanding" of the culture of the Americas to a mono-lingual one [in English only] (Wiegman 581-582). In his survey of the potential inherent in InterAmerican Studies, Wilfried Raussert observes that "Inter-American Studies ... conceptualize the Americas as transversally related, chronotopically entangled, and multiply interconnected. In that sense Inter-American Studies envision a postterritorial understanding of area(s)," "a horizontal dialogue beyond constructed areas, cultures, as well as disciplines" ("Mobilizing" 63). Far from agreeing with Donald Pease's critique of the concept of "inter" as a mode of analysis in which "either nation in the transaction will remain self-enclosed" (Pease, Introduction, Re-Framing 5), Raussert links the concept of "inter" to the notion of "entanglement" that goes "beyond closed national and area spaces" ("Mobilizing" 63) and strives to deconstruct the binary between hegemony (U.S.) vs. periphery (Latin America). ${ }^{29}$

29 Some scholars, including Pease, as I have pointed out above, emphasize the advantages of the concept of "trans" over "inter" in this context because the former "forecloses the possibility that either nation in the transaction will remain self-enclosed" (Pease, Introduction, Re-Framing 5). Yet for a critical commentary on the limitations inherent 
Quoting Ana Luz, Raussert defines "inter" as "overlapping, concurrence, layers of interaction, juxtapositions, connectivity," in this way envisioning the focus of Inter-American Studies as the analysis of "multi-layered connections, multidirectional flows, conflicted and overlapping imaginaries and complex entanglements within the Americas" ("Mobilizing" 69). For Raussert, Inter-American Studies often builds on comparative methodologies but should also employ "relational and processual strategies" that examine power constellations, movements, developments, translocations as well as "the channels, circulations, flows, itineraries and shifting imaginaries that have crisscrossed and transversally linked the Americas from the colonial times to the global present" ("Mobilizing" 69-70). Raussert thus envisions the Inter-American project primarily as collaborative and transdisciplinary, as moving beyond the limitations of earlier versions of area studies paradigms ("Mobilizing" 63) by "challeng[ing] the artificially drawn boundaries between academic fields, disciplines, and departments" and "complement[ing], bridg[ing], and fus[ing]" their insights ("Mobilizing" 91).

This hemispheric turn within the discipline of American Studies has led to the founding of a number of new research centers, including, among others, the Center for the Americas at the University of Groningen (The Netherlands), the Center for the Americas at the University of Graz (Austria), the Center for Inter-American Studies at the University of Innsbruck (Austria), and the Inter-American Studies program at the University of Bielefeld (Germany). In addition, France has established a nation-wide research institute called Institut des Amériques in 2007, and on a global scale, this approach has found its most visible representation in the founding of the International Association of Inter-American Studies in 2009 and its electronic journal Forum for Inter-American Research (fiar), which, in its December 2014 issue, has collected a wide range of contributions that strive to offer a foundation for Theorizing Hemispheric Studies of the Américas.

What has led to the popularity and proliferation of this approach is the realization that an increasing number of (contemporary as well as historical) problems and issues (including economic and political interdependencies as well as migratory movements across the Americas) can only be fully understood by considering the dynamics within the American hemisphere as a whole. This has prompted scholars such as Juan Poblete, for example, to reflect on the potential inherent in a more intense cooperation between Latino/a and Latin American Studies. One

in the notion of "trans" and the enabling potential of the alternative concept of "inter" as connector that foregrounds interactions, see Amós Nascimento's contribution to this volume, as well as Raussert's essay "Mobilizing." 
of the first areas within American Studies to adopt a more hemispheric approach was the field of Early American Studies. ${ }^{30}$ Another discipline that has started to profit immensely from a more international and in particular an Inter-American perspective is the field of Native American/First Nations/indigenous studies. ${ }^{31}$ As Helmbrecht Breinig reminds us, "Native Americans ... are a case where 'the nation could not contain or even describe the forms of life and power' that one finds in the local: the specific that is simultaneously sub-national and, in terms of sovereignty claims, transnational" (620). This combination of subnational and transnational aspects could make indigenous studies an ideal candidate for a transnational approach as discussed above. ${ }^{32}$ Other scholars, however, have also emphasized the relevance of the Inter-American paradigm for the field of indigenous studies. Two comprehensive proposals for a hemispheric approach to the Native communities of the western hemisphere have been launched by Earl Fitz and Antonio Barrenechea/Heidrun Moertl..$^{33}$ Yet while emphasizing the need to recover the "larger coherences" of native cultures across the borders of contemporary nation states, Barrenechea and Moertl also caution us against the "pitfalls of an undifferentiating pan-tribal approach" that mimics colonialist strategies of homogenization ("Hemispheric Indigenous Studies" 113, 110), and they argue instead for the need to negotiate "between pan-Indian and tribally specific critical and cultural contexts" ("Hemispheric Indigenous Studies" 113). While emphasizing that "the recognition and embracing of difference ... lies at the heart of the comparative method," Earl Fitz even goes so far as to insist that "Native American literature represents the cultural and historical foundation of the entire interAmerican project" because it is "our common American denominator" across all American nations ("Native American Literature" 142, 124, 125).

30 See the pioneering work of Ralph Bauer in this context.

31 Even though the three terms are used interchangeably here, I do not wish to obscure the fact that "Native American" is commonly used in the context of the U.S., while "First Nations" is the preferred choice in a Canadian context, and "indigenous" is often employed to refer to the native populations of Latin American countries.

32 Breinig cites "the new alliances of indigenous peoples ... across the Pacific or in circumpolar formations" as prime examples of a need to transcend the nation-state approach (620).

33 Additional examples include the collection of essays titled Comparative Indigeneities of the Americas (2012), edited by Castellanos et. al.; Native America (forthcoming 2015), edited by Den Toonder et. al.; as well as a special forum in the 2012 edition of the journal Transnational American Studies, edited by Huang et al. 
Yet, as Earl Fitz points out in his contribution to this volume, the current revival of the Inter-American Studies paradigm within American Studies should not obscure the fact that Inter-American Studies per se is not a new approach; it is, in fact, an approach with a long institutional history, and it is this history that some critics also consider its liability. For an in-depth evaluation of the potential inherent in the Inter-American paradigm, see Fitz's, Raab's, Nascimento's, and Salvatore's contributions to this volume. I will in the following restrict myself to briefly addressing three of the major concerns that have been raised in the context of a hemispheric turn within American Studies.

\section{"Inter-American Studies as Imperial American Studies?"34}

Institutionally, as Salvatore also outlines in his contribution to this volume, InterAmerican Studies begins to find a place in academia during the phase of the socalled Good Neighbor Policy between the U.S. and Latin America (roughly from 1933 through 1945). During this time, in 1932, Herbert E. Bolton delivered his influential presidential address to the American Historical Association - titled "The Epic of Greater America" - in which he argued against a purely nationalistic, U.S.-centered vision of American history, which he termed "chauvinistic" (qtd. in McClennen 404), and instead advocated a broader understanding of American history as ranging from Canada to Tierra del Fuego. ${ }^{35}$ These developments led, in 1959, to the foundation of the Journal of Inter-American Studies by the Institute for Inter-American Affairs, established at the University of Florida during the 1930s; in 1965, "a group of businessmen led by David Rockefeller founded the Center for Inter-American Relations" (McClennen 405); and in 1966, the Latin American Studies Association was established. However, as Sophia McClennen has pointed out, very soon after WWII, the Cold War ideology started to overshadow most of these enterprises, and knowledge generated under the Inter-American paradigm was from then on for the most part used "to support [U.S.] hegemony" (McClennen 407) and to protect and promote U.S. interests in Latin America. This Cold-War ideologization of the Inter-American Studies paradigm has thus led critics such as Sadowski-Smith to argue that a hemispheric

34 This subtitle is based on Sophia McClennen's essay title.

35 Similar proposals were launched by Latin American scholars around the same time. The Mexican Lucas Alamán, for example, observes in 1926 that "the similarity of their political institutions has bound [the countries of the Americas] even more closely together, strengthening in them the dominion of just and liberal principles" (qtd. in Levander and Levine, "Essays" 4-5). 
approach to American Studies "may simply extend American exceptionalism to the Americas" by "expanding the national framework spatially to the hemisphere" ("Introduction: Comparative Border Studies" 277). It is for these reasons that this approach (especially in its "U.S.-led hemispherism" variant [Fox, Introduction Critical Perspectives 391) is currently viewed with a lot of scepticism, especially by Latin Americanists. In an essay provocatively titled "Inter-American Studies or Imperial American Studies?," Latin Americanist Sophia McClennen, for example, asked in 2005: "Do inter-American studies represent the latest variation on the Monroe Doctrine [?] ... What do we make of the fact that inter-American studies blossoms just as Latin Americanism becomes increasingly more powerful in the academy?" (393). ${ }^{36}$ And Claire Fox wonders why Latin American Studies, which has, for a very long period of time, already been "transnational, comparative, and polylingual, and ... historically engaged with the U.S. 'empire' in ways that U.S. Americanists are just beginning to explore," is so rarely cited as a role model for the internationalization of American Studies (Introduction to Critical Perspectives 387) ${ }^{37}$ Similar to Emory Elliott, Ralph Bauer, highlighting the "explosion of hemispheric scholarly activity" in American Studies since the year 2000, also worries about the potential overlap with the research agendas of disciplines such as Latin American Studies or Comparative American Studies ("Hemispheric Studies" 235).

While these concerns are well-founded, one could nonetheless argue that in the context of current efforts to internationalize the discipline of American Studies, Inter-American Studies also has the potential to become a paradigm "committed to disarming the intellectual hegemony of the United States" (McClennen 402), and in this way it might also be able to displace U.S. culture and U.S.-based American Studies approaches from the center of American Studies scholarship (McClennen 393-394). One form that this decentering of the hegemon could take has been outlined by Claudia Sadowski-Smith in her proposal for "Comparative Border Studies," which explicitly moves beyond the U.S.-Mexican border "as a privileged site for the emergence of transnational models of study" and includes an invitation to develop comparative models that focus on borders in the Americas, Asia, and Europe in order to "examine[] the impact of globalization on borders;

36 Cf. also "What would an inter-American studies housed in English and History departments in the United States and taught by monolingual faculty be, if not an example of U.S. intellectual expansionism?" (McClennen 402).

37 On the contrary, it seems, according to Fox, that knowledge production about Latin America is increasingly shaped by the U.S. academic marketplace "in which the role of the professoriate, the publishing industry, and the very languages of Latin America are structurally marginalized" (Introduction to Critical Perspectives 388). 
the enforcement of national boundaries in response to nation-states' security concerns; the relationship of borders to ethnic, national, and regional identities; the development of border cities; and struggles for environmental protection and natural resources in border zones" ("Introduction: Comparative Border Studies" $273,275) .^{38}$

This gradual displacement of the U.S. from the center of attention is all the more realistic, I would argue, in the context of the above-mentioned critique of U.S. imperialism as well as the critical forms of internationalism that have started to dominate American Studies discourses, and which have, in Robyn Wiegman's terms, produced a generation of Americanists who refuse to fully identify with their object of study. As Wiegman formulates it: "[W]hole generations of scholars have now been trained to practise refused identification as the means by which they approach the normative assumptions of their disciplines, undoing canons, transforming methodologies, and resisting not simply particular histories, but the privileges such histories ascribe to specific critical vocabularies and habits of thought" (Wiegman 579). ${ }^{39}$ In other words, what could emerge at this point is a form of what Caroline Levander and Robert Levine have termed a polycentric (Inter-)American Studies paradigm based on a "polycentric American hemisphere with no dominant center" (Levander and Levine, "Essays" 7; Levander and Levine, "Hemispheric" 401; see also Fitz's contributions to this volume). Such a polycentric approach would also lead to diverse forms of internationalization (depending on specific local contexts [Rowe, "Post-Nationalism" 31]) and would entail "fundamental changes in the way most modern universities educate," including their disciplinary organization (Rowe, "Post-Nationalism" 29). In a more extreme version, this polycentric approach could then even be complemented by an Inter-Latin American Studies variant (McClennen 394; see also Sadowski-Smith/Fox 12), which, in its most radical form - as suggested by Claudia Sadowski-Smith and Claire Fox in an essay that has been reprinted in this volume - could even bypass the U.S.: "we do not imagine that all inter-Americas scholarship will necessarily contain a U.S. component" (Sadowski-Smith/Fox 23).

38 In an earlier essay titled "Canada-U.S. Border Narratives," Sadowski-Smith had already argued that Inter-American border studies need to move "beyond their current emphasis on the Latin-American-U.S. relationship" by including the U.S.-Canadian border as well (63).

39 Wiegman defines "refused identification" as "affective investments that have motivated [young post-Cold War and post-Marshall Plan generations of] Americanists everywhere to find a means for transcending complicity with their object of study" (Wiegman 579). 


\section{Hemispheric American Studies vs. the Role of Nation States}

A second criticism that has frequently been levelled against a hemispheric American Studies paradigm in the context of current debates on internationalization is the question of how relevant a transcendence of national borders actually is for Canada and Latin American nations. ${ }^{40}$ Sadowski-Smith and Fox, for example, emphasize that both Canada and Latin American nations view the nation state (as opposed to nationalism) more positively "as a potential vehicle for the protection of its citizenry against neoliberal forms of corporate globalism and as a guarantor of sovereignty from the United States" (Sadowski-Smith/Fox 8). In addition, these countries also find the nation state a tool that may help them to "protect natural resources in the face of transnational corporate expansion" (Sadowski-Smith/Fox 9). ${ }^{41}$ Moreover, as Helmbrecht Breinig and Ralph Bauer have pointed out, the concept of the nation state also still has a great significance for indigenous American populations (Bauer "Hemispheric Studies" 238), especially in the context of land claims and sovereignty assertions. Yet, as Bauer adds, while Latin American Studies scholars recognize this significance of the nation state, their discipline has never had a "narrowly nationalist orientation" ("Hemispheric Studies" 236).

But even in a U.S. context, as John Carlos Rowe has observed, the nation-state still plays a crucial role: "[D]ebates about the movements of capital and people across national boundaries intensify, nationalist nativisms are repeatedly mobilized to appease immigration; [and] transnational corporations continue to rely on nation states for labor control" (Introduction 1). Similarly, Johannes Voelz argues that globalization has not weakened all nation states to the same extent since the U.S. "largely controls international institutions like the International Monetary

40 One might also pose this question in more general terms, i.e. how relevant is an inter- or trans-national American Studies research paradigm at a time when, despite the global spread of neoliberalism, "the number of national borders has actually increased since the dissolution of former Eastern Bloc countries" (Sadowski-Smith, "Introduction: Comparative Border Studies" 273). Yet Sadowski-Smith continues to answer her own question by highlighting the simultaneity of U.S. border enforcement and U.S. global involvement, and she cites Wendy Brown, who has argued that "[n]ew and reinforced national borders ... do not so much signal the resurgence of state power as the attempt by nation-states to performatively symbolize their sovereignty in a context where they actually can no longer govern many of the powers unleashed by globalization and late modern colonization, including transnational flows [of migrants, for example], neoliberal forces, and international economic and governance institutions" (Brown 20-24, qtd. in Sadowski-Smith, "Introduction: Comparative Border Studies" 274).

41 A similar view is shared by Ralph Bauer ("Hemispheric Studies" 236). 
Fund (IMF) and the World Bank" (365). Moreover, globalization is also not a phenomenon that is external to the nation state but rather "permeates it, e.g. by altering the nation state's internal structure," in this way "making the nation-state significantly less democratic by reducing checks and balances" on the executive, for example (Voelz 365). This paradoxical and deeply ambivalent simultaneity of both weakened and strengthened nation-states and national borders is at the core of Mita Banerjee's edited volume Virtually American?, which addresses the fact that " $[t]$ his is a time seemingly without borders, an era of an unprecedented flow of goods, capital, and labor," while at the same time, "particularly after September 11,2001, borders are being policed," even militarized, and citizenship rights acquire a new significance (blurb on Winter Verlag website).

One way to address this paradoxical simultaneity would be to combine a hemispheric approach with the realization (central to the earlier-mentioned "critical internationalism" paradigm) that any transcendence of national borders "of necessity entails an ongoing recognition of the process through which nations are embedded in and develop gradually out of local and transnational circumstances" (Levander and Levine, "Essays" 6) and should therefore be complemented by a "critical internationalist' awareness of our own institutional locations" (SadowskiSmith/Fox 7). This could result in, as both Earl Fitz and Sadowski Smith/Fox propose, an “'inter-Americas studies' that would enable the collaboration of a larger number of national (U.S.-based and non U.S.-based) institutions and disciplines which have traditionally studied the hemisphere, including Latin American and American Studies, Comparative Literature, Canadian Studies, Caribbean Studies, as well as Latina/o and other ethnic studies" (Sadowski-Smith/Fox 6; see also Fitz's contribution to this volume). ${ }^{42}$ Yet it is important to remember that the opposition national vs. international may be a false binary altogether, as John Carlos Rowe reminds us, as global, national, and local forces (and frames of analysis) are intersecting in more and more complex ways (Introduction 8).

42 A good example in this context is the anthology Hemispheric American Studies edited by Caroline Levander and Robert Levine: they emphasize that they do not wish "to abandon the concept of the nation" completely "but rather to adopt new perspectives that allow us to view the nation beyond the terms of its own exceptionalist selfimaginings" (Levander and Levine, "Essays" 7); they view the nation as a "relational identity that emerges through constant collaboration, dialogue, and dissension" and intend to examine national issues (a national literature, for example) in the context of a hemispheric paradigm (Levander and Levine, "Essays" 5). 


\section{Practical Considerations}

Last but not least, one of the pioneers in the field of Inter-American Studies, Earl Fitz, has also drawn our attention to a range of methodological problems and institutional barriers that Inter-American Studies often had (and in some cases still has) to face (see both of Fitz's contributions to this voulme). First and foremost, language competence remains a core issue. Frequently neither students nor teachers in traditional American Studies departments are trained well enough in languages other than English (and perhaps Spanish), ${ }^{43}$ which is why Fitz maintains that scholars trained in Comparative Studies are frequently much better equipped to practise Inter-American Studies than traditional American Studies scholars. Another factor that Ian Tyrrell foregrounds in his discussion of why U.S.-based historians are still so reluctant to embrace an international paradigm is the structures of the commerical textbook market as well as the national history requirements at U.S. high schools ("In the Shadow" 91). Yet rather than allowing such limitations to pre-determine the scope of research, as Sean Wilentz has insisted, ${ }^{44}$ such practical matters most certainly need to be addressed in a structural way by implementing changes in our curricula and in the way we train future generations of American Studies scholars.

But another way of alleviating these concerns would be by promoting what John Carlos Rowe has termed a "new intellectual regionalism" with different American Studies approaches practised at different institutions (depending on local resources), combined with a structural cooperation between emerging and established institutions and between local and national or international resources (Rowe, "Post-Nationalism" 33, 30). ${ }^{45}$ These cooperations should not be limited, as Günter Lenz reminds us, to an analysis of "the impact of a politically and economically more powerful culture on other cultures," but should instead lead to "a genuinely dialogic notion of cultural critique" (Lenz 474). As Djelal Kadir insists: "The America we have to investigate, historicize, and teach today, ... is certainly hemispheric, global, transnational, transoceanic, intercontinental, omnipotent,

43 And of course, as Fitz argues, English and Spanish alone are not sufficient (Fitz, "InterAmerican"15).

44 "[W] e must ... have a unified American Studies discipline, department, program, and professional organization ... because we haven't the resources, the time, or the expertise to do more" (qtd. in Rowe, "Post-Nationalism" 28, fn 18).

45 Cf. also Donald Pease and Robyn Wiegman, who argue that at this point in time, the field of American Studies cannot be reduced to a single overarching paradigm, and they thus envision several futures for the discipline, including a comparativist, differentialist, counter-hegemonic, and posthegemonic one ("Futures" 4, 23). 
and ubiquitous" (Kadir, "Devotees" 27), which "makes a revisioning of American Studies as an international field imperative" (Kadir, "Devotees" 28). Yet such a revisioning can only be accomplished if American Studies scholars across the globe develop ways to cooperate more closely, and if everyone's voices are heard, no matter their position.

A crucial technical tool in realizing this vision could be Shelley Fisher Fishkin's recent proposal to develop so-called "Digital Palimpsest Mapping Projects" or DPMPs (pronounced "Deep Maps") ("Mapping” 47). Such Deep Maps would be "multilingual digital archives in multiple locations" ("Transnational" 621) that "embed links to archival texts and images (along with interpretive materials [and translations]) in nodes on an interactive map"; they would focus on "events, topics, people, or phenomena" "that cross borders, and would include links to texts and images in different locations" ("Mapping" 47, 48, 47). By drawing on materials that are already available in digital form while spurring the digitalization of new materials, Deep Maps could "lay the groundwork for new [i.e. truly international as well as truly interdisciplinary] collaborative modes of research" ("Mapping" 48). As Fisher Fishkin envisions: "Literature scholars may find themselves ... seeking out conversations with scholars in diplomatic history and international relations, in foreign language departments, and in translation studies," which will eventually make artificial disciplinary divides that nonetheless still tend to shape many academic environments around the globe "look increasingly arbitrary" ("Mapping" 64). "By requiring collaboration - across borders, languages, nations, continents, and disciplines - Digital Palimpsest Mapping Projects would bring our interdependence as scholars, as citizens, as human beings - to the foreground" ("Mapping" 66).

This collection of critical essays intends to offer an intervention in the ongoing debate on the internationalization of the discipline of American Studies by bringing together a selection of current perspectives that evaluate both its potentials as well as its pitfalls. While most recent publications in this field tend to focus on only one, or a small selection of, specific concepts and paradigms (e.g. transnationalism), it is the express aim of this collection to address a wider range of different and often competing terms, including trans- and post-national, international, global, (trans-)Atlantic, (trans-)Pacific, as well as hemispheric, trans-border, Inter-American and comparative American Studies. By combining both theoretical reflections and actual case studies, this collection of essays tries to provide possible answers to the question of "What happens once cross-fertilization is no longer merely our object of study but also the reigning paradigm of research practices, which in turn become both cross-disciplinary and solidly comparative?" (Benesch 617). Mindful of the fact that, as Klaus Benesch has observed, "the gains and losses, the universal and the parochial, the liberating and the reactionary ... 
are ... often snuggly nested together" (618), this volume attempts a reassessment of the international turn in American Studies at this juncture when, as Kristin Hoganson reminds us, "[o]ur enthusiasm" for internationalization "should not blind us to boundary drawing and border-making"; it should not blind us to the fact that patterns of connectivity almost always also produce patterns of exclusion (Hoganson 624). "It may mean that American Studies is a place we set out from and return to instead of the place where we always stay" (Hoganson 624).

Positionality - and in particular concerns about the neo-imperialist reinscription of the U.S. at the center of many new versions of international American Studies constitutes a recurrent theme for several of our contributors, in particular Ricardo Salvatore, Earl E. Fitz, Michael Boyden, and Claudia Sadowski-Smith/ Claire F. Fox. Many of them explore the question of how, in Bryce Traister's words, "transnationalism [might] look as a non-U.S.-identified set of critical practices" conducted by non-U.S.-based and/or non-U.S-identifed Americanists ("Everything Old" 162). Placing the current hemispheric turn in the context of Herbert Bolton's call for a comparative history of the Americas during the early twentieth century, Salvatore, for example, warns us that calls to "widen the horizon" are often tied to hegemonic political designs and interests. Concerned that U.S.-based scholars trained in American Studies, despite their critical perspectives on the U.S., still tend to follow U.S. intellectual agendas, Salvatore sees most current forms of internationalization as new versions of U.S. hegemony or neo-imperialism prone to replicating old forms of appropriation and colonization typical of the 1930s and 1940s (when Hispanic American history projects flourished in the context of the U.S.s Good Neighbor Policy and Pan-American foreign policy interests).

Salvatore's concerns are shared by Michael Boyden, who analyzes the rise of the so-called New Americanists through the lens of social systems theory and concludes that, rather than moving from self assertion (i.e. celebrating the U.S.'s democratic and exceptional role in the world) to self-criticism (i.e. challenging the U.S.'s manifold forms of oppression and imperialism), the international turn of the New Americanists actually constitues a new form of self-assertion through self-criticism. Focusing on interrelations between Latin America and Canada, and proposing an inter-Latin-American-Canadian Studies approach, SadowskiSmith/Fox share this position, criticizing the postnational approach favored by many U.S.-based American Studies scholars as nothing more than an attempt to internationalize U.S.-based American Studies methodologies and theory paradigms. They insist that Canada and Latin America should not just be seen as passive recipients of what the U.S. academic industry has to offer.

Sadowski-Smith/Fox as well as Earl E. Fitz, and Ricardo Salvatore also draw attention to the fact that Canada (especially francophone Québec) and Brazil are 
still far too often excluded from current hemispheric studies of the Americas due to the linguistic challenges they pose. ${ }^{46}$ Especially hemispheric turns launched from within the discipline of American Studies, according to Fitz, are often limited to a dyadic study of the U.S.'s relation to Spanish America, thus placing U.S.-based Americanists in a kind of "hemispheric isolation." Other disciplines, in particular Comparative American Studies or Comparative Latin American Studies, but also indigenous/Native American Studies (understood in Nascimento's sense of including all aboriginal populations of the Americas), or Caribbean Studies (with its multilingualism and its bridging function between North and South America, as Édouard Glissant describes it) are much better equipped, in Fitz's view, to take the lead in internationalizing American Studies because the professionally trained comparatist by definition avoids the hegemony of and does not grant any exceptionalist stance to any single nation as "the question of nation hardly obtains" (Fitz). Earl Fitz's contribution offers a powerful assessment of the current state of the field of Inter-American Studies as well as a convincing proposal for a comparative hemispheric methodology as the best training for future generations of scholars who should study at least three of the languages of the Americas (English, Spanish, French, Portuguese) plus one of the main Native languages and hence would be able to understand all of the Americas in their full complexity rather than limiting their analyses to a dyadic U.S.-Hispanic America axis (which ultimately just enshrines the hegemonic role of the U.S. again).

Liam Kennedy's 2009 essay (which has been reprinted here), finally, offers a slightly different slant on positionality by comparing the various foci of U.S.based Americanists and European Americanists. Insisting that even for non-U.S. based Americanists, there is no "neutral" or external position, i.e. no truly ethical stance, Kennedy observes that for European Americanists, the United States has for a very long time been the site of the new, the dissenting, the subversive. Hence we as European Americanists cannot simply blame U.S.-based scholars for their potentially biased (i.e. U.S.-centric) perspective but also need to be aware of the limitations inherent in our own perspectives by acknowledging the fantasy image of the U.S. that structures our own sense of what American Studies should be or do. ${ }^{47}$ A similar view is voiced by Jane Desmond, former President of the

46 Cf. also Braz, who has drawn attention to "Canada's (non)place in inter-American discourse" (79), and Adams and Casteel, who fear that, as a young discipline, Canadian Studies might ultimately just be absorbed into a hemispheric framework in a kind of "neo-imperial conquest" (7).

47 As mentioned above, the extent to which an "external" (e.g. a European) perspective can have positive effects on the discipline has been controversially discussed. While 
International American Studies Association, who discusses some of the practical pitfalls in the process of internationalizing American Studies by drawing on her experiences of organizing IASA's second World Congress in Beijing, China. She illustrates how orientalism and occidentalism still subtend Western (i.e. U.S.American and European) thinking today, reminding us that even as we are aware of these discourses, we are not immune to them. Desmond's current essay is thus in keeping with her earlier work, which had also focused on the local specificities of "doing" American Studies and in this way highlighted "in concrete practices the limitations that cross-national collaborative work by its very nature will encounter" (Wiegman 582). By focusing on the specificities of knowledge production in national university systems, Desmond also recognizes "the continuing importance of nationalism and national contexts in shaping knowledge" (Wiegman 582). To address this issue, she had earlier (together with Virginia Dominguez) called for new, cosmopolitan paradigms of research developed on the basis of international cooperation ${ }^{48}$ (qtd. in Rowe et al., Introduction 7), and she returns to this idea in her contribution to this volume by proposing Edward Said's concept of "an ethic of cosmopolitan care" as a viable remedy. As all of these essays addressing the problem of positionality illustrate, all of us, irrespective of the geographical region we hail from, need to reflect very carefully on the far too often hidden and unconscious epistemes that shape our thinking. They may have an unanticipated and larger-than-expected impact on our international and cross-cultural collaborations as we enter into the project of internationalizing American Studies from our respective vantage points.

It is in particular critical race and ethnicity studies that can profit immensely from a transnational, international, or Inter-American paradigm that neither stops at national borders nor subdivides ethnic or racial minorities into pre-defined, monodimensional identity categories that often acquire essentialist overtones. Amós Nascimento, Josef Raab and Gabriele Pisarz-Ramirez draw attention to this limitation inherent in traditional American Studies approaches to race and ethnicity by offering both conceptual discussions and specific case studies that illustrate

Emory Elliott has explicitly called for a more diasporic approach to American Studies, and Paul Giles believes that European American Studies scholars will be able to escape the lure of U.S. exceptionalism, Kennedy is more sceptical in this essay, regarding distance not necessarily as beneficial but as potential source of disengagement or mistakes.

48 Cooperation between U.S.-based and international scholars has also been at the heart of Emory Elliott's efforts, as discussed above, even though, as Marc Chenetier highlights in a recent EJAS article (2008), European and other international ways of doing American Studies still remain pretty unknown to U.S.-based scholars (3). 
how an Inter-American (or transnational, or critically international) approach by definition challenges both national and subnational boundaries. Arguing in favor of the highly enabling insights gained by expanding critical race studies to the entire Western Hemipshere, Josef Raab compares Barack Obama's and Evo Morales's approaches to race, arguing that during public appearances Obama tends to relativize the divisive potential of race in his attempt to create post-racial unity and cohesion within the U.S., while Evo Morales emphasizes his indigeneity, thus taking a more separatist approach to difference. At the same time, however, Morales has also tried to form alliances with indigenous groups in the U.S. and Canada, in this way highlighting the extent to which transnational ethnoscapes and mediascapes have led to the deterritorialization of ethnic groups as well as to transnational forms of collectivization. In addition, the possibility of or the need for multiple affiliations has moved center stage, as Raab illustrates through an analysis of new indigenous movements in Brazil, Ecuador, Peru, Mexico, Canada, and the U.S., for whom race is often only one of many factors (in addition to class, gender, sexual preference, religion, age, language, education, political leaning, regional background, nationality, or consumer orientation) in the creation of solidarity for strategic purposes on issues that are linked to but at the same time also transcend the context of race (and include questions of political representation, neoliberalism, or ecological issues). These developments illustrate how group identities and coalitions have become more flexible and shifting since the Civil Rights era: "[W]hat exactly the distinctive marker of collective identity is, depends on the situation and issues at hand" as identity groups keep redefining themselves through context-specific acts of self-positioning (Raab). For this reason, Raab proposes "belonging" as an alternative for "race" as the former concept is better able to capture the dynamic, fluid, and non-exclusive nature of the communities that are forming throughout the Americas at this point in history. In the twentyfirst century, as Raab argues, differences have not decreased, but they have become more dynamic and more complex.

Illustrating the importance of a hemispheric paradigm for African American Studies, Amós Nascimento's contribution focuses on the experiences of dislocation by people of African descent in the Americas and demonstrates how an Inter-American approach, by transcending national boundaries, allows for a new perspective on and new answers to issues such as slavery, racism, and citizenship struggles. He argues that these experiences are only insufficiently captured by traditional disciplines such as African American Studies (which only focuses on the U.S.), or Latin American Studies (which often tends to neglect the African dimension in the Americas). Inter-American Studies is furthermore uniquely equipped, according Nascimento, to shed light on the lacunae in traditional forms 
of Black Atlantic Studies, Caribbean Studies, and Brazilian Studies, all of which offer important insights but often fail to notice interactions that transcend their specific disciplinary or nation-based boundaries. For Nascimento, the inter in Inter-American Studies thus functions as an important connector. His case studies on Afro-Brazilian quilombas, confrarias, and terreiros de candomblé illustrate his points and show why this Inter-American paradigm and its redefinition of African Americans as people of African descent in all of the Americas should also influence the way African American Studies is practised in the U.S.

Gabriele Pisarz-Ramirez's contribution, which likewise focuses on African American texts, offers a vivid illustration of the extent to which an Inter-American Studies approach can complement traditional transatlantic perspectives on the revolutionary and early national period in the U.S. Arguing that during this period, temporal discourses are at least as important as spatial ones in the construction of nationhood, Pisarz-Ramirez demonstrates that between the 1780s and the 1850s, many African Americans living in the U.S. constructed their cultural and political identity in a transnational, Inter-American framework because for them, the Haitian Revolution, for example, was far more important than the U.S.'s war of independence against Britain for negotiating their own role within U.S. society.

Pisarz-Ramirez's contribution thus illustrates the importance and relevance of an international, hemispheric American Studies approach also for earlier periods within U.S. history, a conviction that is shared by several other contributors, including Armin Paul Frank, Daniel Göske, and Earl E. Fitz. All three of them, additionally, address this issue in the context of the question of how "new" this current turn towards internationality actually is. According to Fitz, the current trend towards internationalization has only recently been discovered by the discipline of American Studies but has been at the center of Latin American Studies, Canadian Studies, and Comparative American Studies for decades. In the context of European American Studies, the analysis of transatlantic connections also has a long tradition as an established variant of internationalization that has shaped the discipline of American Studies since its inception during the post-WWII years. Armin Paul Frank's and Daniel Göske's contributions focus on this dimension, thus providing a historical contextualization for current forms of internationalization. According to Göske, who specializes on German-American relations, the current international turn's historical foundation lies in the internationalization of the transatlantic literary and cultural scene around 1850. Göske (like Frank) insists that internationality was a commonplace during earlier historical periods but needs to be re-emphasized and re-kindled today in an age of decreasing language abilities and declining forms of intercultural literacy. One of Göske's central insights is the fact that internationalism does not necessarily have to contradict 
national interests since much depends on the specific forms of nationalism and internationalism that are favored by an author (some literary authors may move away from British influences and open up to German ones instead, for example). Armin Paul Frank's contribution builds on his research conducted within the framework of the Göttingen Center for Advanced Study on the Internationality of National Literatures and proposes a complex and nuanced model for producing an international history of national literatures in the Americas by highlighting the significance of what he terms "enclave-exclave" writers, i.e. writers that are frequently excluded from conventional literary histories because they fail to fit traditional categories (in the U.S.'s case, this often includes American authors writing in languages other than English). Drawing on Ole Edvart Rölvaag as a case study, Frank foregrounds the limitations inherent in traditional forms of classification (is Rölvaag a Norwegian-American author or an American author writing in Norwegian?) by contextualizing his work in relation to European-Norwegian literature, to Norwegian-American literature, to English-American literature, as well as to other enclave literatures (especially German) produced within the U.S. In this way, Frank proposes the concept of "reading culture" (rather than nation-based labels such as "Norwegian-American") as a more productive research paradigm that allows for the analysis of a much wider range of factors shaping the work of a literary author (including the transfer and transformations associated with moving from Europe to the U.S., as well as book markets, distribution centers, or the inscriptions of other works into the author's own), which might lead to a much more comprehensive history of the literatures of the Americas.

What all of the contributions collected in this volume highlight is the range, but more importantly, the complementarity (rather than competition or mutual exclusiveness) of the many different and innovative strategies that have been devised to internationalize American Studies. As Paul Giles has put it very aptly:

[I]t would seem absurdly utopian to imagine that nationalist templates could ever simply mutate into a benign hemispheric [or international] multilateralism. What is more interesting to consider is the way in which hemispheric [or international] studies might interface and interfere with dominant national typologies, deconstructing their ideological agendas and elucidating various blind spots in their intrinsically self-perpetuating narratives. ("Commentary" 652)

What we need, in other words, is no new orthodoxy or "ur-theory" of American Studies, but instead an encouragement towards heterodoxy (Giles, "Commentary" 654 ), an encouragement that all contributors to this volume have wholeheartedly embraced. 


\section{Works Cited and Consulted}

Accosta-Belén, Edna. "Reimagining Borders: A Hemispheric Approach to Latin American and U.S. Latino and Latina Studies." Color-Line to Borderlands: The Matrix of American Ethnic Studies. Ed. Jonella E. Butler. Seattle and London: U of Washington P, 2001. 240-264.

Adams, Rachel, and Sarah Phillips Casteeel. "Introduction: Canada and the Americas." Special Issue of Comparative American Studies 3.1 (March 2005): 5-13.

Araújo, Susana, João Ferreira Duarte, and Marta Pacheco Pinto, eds. Trans/ American, Trans/Oceanic, Trans/Lation: Issues in International American Studies. Newcastle upon Tyne: Cambridge Scholars Publishing, 2010.

Barrenechea, Antonio, and Heidrun Moertl. "Hemispheric Indigenous Studies: Introduction." Special issue of Comparative American Studies 11.2 (June 2013): 109-123.

Banerjee, Mita, ed. Virtually American? Denationalizing North American Studies. Heidelberg: Carl Winter Universitätsverlag, 2009.

Bauer, Ralph. The Cultural Geography of Colonial American Literatures: Empire, Travel, Modernity. Cambridge: Cambridge UP, 2003.

Bauer, Ralph. "Hemispheric Studies." PMLA 124.1 (2009): 234-250.

Belnap, Jeffrey, and Raúl Fernández. José Martís 'Our America': From National To Hemispheric Cultural Studies. Durham, NC: Duke UP, 1998.

Benesch, Klaus. "Transnational American Studies - Looking Backward to the Future." Transnational American Studies. Ed. Udo Hebel. Heidelberg: Carl Winter Universitätsverlag, 2012. 615-618.

Bolton, Herbert Eugene. “The Epic of Greater America." American Historical Review 38.3 (1933): 448-474.

Braz, Albert. "North of America: Racial Hybridity and Canada's (Non)Place in Inter-American Discourse." Comparative American Studies 3.1 (2005): 79-88.

Breinig, Helmbrecht. "Six Theses on Transnational American Studies." Transnational American Studies. Ed. Udo Hebel. Heidelberg: Carl Winter Universitätsverlag, 2012. 618-621.

Buchenau, Barbara, and Annette Paatz, eds., in cooperation with Rolf Lohse and Marietta Messmer. Do the Americas Have a Common Literary History? Interamericana series. Frankfurt/Main: Peter Lang, 2002.

Castellanos, M. Bianet, Lourdes Gutiérrez Nájera, and Arturo J. Aldama, eds. Comparative Indigeneities of the Americas: Toward a Hemispheric Approach. Tucson: U of Arizona P, 2012.

Castillo, Debra A. Redreaming America: Toward A Bilingual American Culture. Albany, NY: State U of New York P, 2005. 
Chanady, Amaryll, George Handley, and Patrick Imbert, eds. Americas' Worlds and the World's Americas / Les mondes des Amériques et les Amériques du monde. Ottawa: Legas, 2006.

Chenetier, Marc. “New' 'American Studies': Exceptionalism Redux?” European Journal of American Studies 2 (2008): 2-9.

Den Toonder, Jeanette, and Fjære van der Stok, eds. Native America: Indigenous Self-Representation in Canada, the U.S., and Mexico. Interamericana series. Frankfurt/Main: Peter Lang, forthcoming 2015.

Desmond, Jane, and Virginia Dominguez. "Resituating American Studies in a Critical Internationalism." American Quarterly 48.3 (1996): 475-90.

D'Haen, Theo, Paul Giles, Djelal Kadir, and Lois Parkinson Zamora, eds. How Far Is America From Here? Selected Proceedings of the First World Congress of the International American Studies Association, 22-24 May 2003. Amsterdam: Rodopi, 2005.

Edwards, Brian T., and Dilip Parameshwar Gaonkar, eds. Globalizing American Studies. London: U of Chicago P, 2010.

Elliott, Emory. "Diversity in the United States and Abroad: What Does It Mean When American Studies Is Transnational?” American Quarterly 59.1 (2007): $1-22$.

Fisher Fishkin, Shelley. "Crossroads of Cultures: The Transnational Turn in American Studies. Presidential Address to the American Studies Association, November 12, 2004." American Quarterly 57 (2005): 17-57.

Fisher Fishkin, Shelley. "Mapping Transnational American Studies." Transnational American Studies. Ed. Udo Hebel. Heidelberg: Carl Winter Universitätsverlag, 2012. 31-74.

Fisher Fishkin, Shelley. "Transnational American Studies in the Twenty-First Century." Transnational American Studies. Ed. Hebel. Heidelberg: Carl Winter Universitätsverlag, 2012. 621-622.

Fitz, Earl E. "Inter-American Studies as an Emerging Field: The Future of a Discipline." Rethinking the Americas: Crossing Borders and Disciplines. Ed. Cathy L. Jrade. Special issue of Vanderbilt E-Journal of Luso-Hispanic Studies 1 (2004): $13-28$.

Fitz, Earl E. "Native American Literature and Its Place in the Inter-American Project." Comparative American Studies 11.2 (June 2013): 124-147.

Fitz, Earl E., and Sophia McClennen, eds. Comparative Cultural Studies and Latin America. West Lafayette: Purdue UP, 2004.

Fluck, Winfried. "Inside and Outside: What Kind of Knowledge Do We Need? A Response to the Presidential Address." American Quarterly 59.1 (2007): $23-32$. 
Fluck, Winfried. “A New Beginning?: Transnationalisms.” New Literary History 42.3 (2011): 365-384.

Fluck, Winfried, Donald E. Pease, and John Carlos Rowe, eds. Re-Framing the Transnational Turn in American Studies. Hanover, NH: Dartmouth College P, 2011.

Fox, Claire F., ed. Critical Perspectives and Emerging Models of Inter-American Studies. Special issue of Comparative American Studies 3.4 (2005): 387-515.

Frank, Armin Paul. "An Invitation to Inter-American Literary Studies." The Internationality of National Literatures in Either America: Transfer and Transformation. Vol. 1.1 Cases and Problems. Ed. Armin Paul Frank and Helga Essmann. Göttingen: Wallstein, 1999. 11-27.

Frank, Armin Paul, and Helga Essmann, eds. The Internationality of National Literatures in Either America: Transfer and Transformation. Vol. 1.1 Cases and Problems. Göttingen: Wallstein, 1999.

Frank, Armin Paul, and Rolf Lohse, eds. Internationality in American Fiction: Henry James, William Dean Howells, William Faulkner, Toni Morrison. Interamericana series. Frankfurt/Main: Peter Lang, 2005.

Frank, Armin Paul, and Kurt Mueller-Vollmer. The Internationality of National Literatures in Either America: Transfer and Transformation. Vol. 1.2 British America and the United States, 1770s-1850s. Göttingen: Wallstein, 2000.

Gernalzick, Nadja, and Gabriele Pisarz-Ramirez. Transmediality and Transculturality. Heidelberg: Universitätsverlag Winter, 2013.

Giles, Paul. "Commentary: Hemispheric Partiality." American Literary History 18.3 (2006): 648-655.

Giles, Paul. "Reconstructing American Studies. Transnational Paradoxes, Comparative Perspectives." Journal of American Studies 28.3 (1994): 335-358.

Giles, Paul. "Response to the Presidential Address to the American Studies Association, Hartford, Connecticut, October 17, 2003." American Quarterly 56.1 (2004): 19-24.

Gillman, Susan, Kirsten Silva Greusz, and Rob Wilson. "Worlding American Studies." Comparative American Studies: An International Journal 2.3 (2004): 259-396.

Hagenbüchle, Roland, Josef Raab, eds., in cooperation with Marietta Messmer. Negotiations of America's National Identity. 2 vols. Tübingen: Stauffenburg, 2000.

Hebel, Udo. Preface. Transnational American Studies. Ed. Hebel. Heidelberg: Carl Winter Universitätsverlag, 2012. 1-9.

Hebel, Udo, ed. Transnational American Studies. Heidelberg: Carl Winter Universitätsverlag, 2012. 
Hickman, Jared. "On the Redundancy of 'Transnational American Studies." The Oxford Handbook of Nineteenth-Century American Literature. Ed. Russ

Castronuovo. Oxford Handbooks Online, 2012. 14 pages.

Hoganson, Kristin. “Transnational American Studies - Whereto?” Transnational American Studies. Ed. Udo Hebel. Heidelberg: Carl Winter Universitätsverlag, 2012. 622-624.

Hornung, Alfred. "ChinAmerica: Intercultural Relations for a Transnational World." Transnational American Studies. Ed. Udo Hebel. Heidelberg: Carl Winter Universitätsverlag, 2012. 13-30.

Hornung, Alfred. "Transnational American Studies and Life Writing." Transnational American Studies. Ed. Udo Hebel. Heidelberg: Carl Winter Universitätsverlag, 2012. 625-628.

Horwitz, Richard P. “The Politics of International American Studies." Exporting America: Essays on American Studies Abroad. Ed. Horwitz. New York: Garland, 1993. 377-418.

Huang, Hsinya, Philip J. Deloria, Laura M. Furlan, and John Gambler, eds. "Charting Transnational Native American Studies." Journal of Transnational American Studies 4.1 (2012).

Ickstadt, Heinz. "American Studies as Area Studies as Transnational Studies? A European Perspective." Comparative Studies of South Asia, Africa, and the Middle East 27.3 (2007): 633-640.

Izzo, Donatello. "Outside Where? Comparing Notes on Comparative American Studies and American Comparative Studies." American Studies: An Anthology. Ed. Radway, Gaines, Shank, and von Eschen. Chichester: Blackwell, 2009. 588-604.

Jameson, Fredric. Signatures of the Visible. New York: Routledge, 1990.

Kadir, Djelal. "Defending America Against Its Devotees." How Far Is America From Here? Ed. Theo D'Haen, Paul Giles, Djelal Kadir, and Lois Parkinson Zamora. Amsterdam: Rodopi, 2005. 13-34.

Kadir, Djelal. "Introduction: America and Its Studies." PMLA 118.1 (2003): 9-24.

Kaltmeier, Olaf, ed. Transnational Americas: Envisioning Inter-American Area Studies in Globalization Processes. Trier: Wissenschaftlicher Verlag Trier, and Tempe, AZ: Bilingual P, 2013.

Kaplan, Amy. "Left Alone with America: The Absence of Empire in the Study of American Culture." Cultures of United States Imperialism. Ed. Kaplan and Donald E. Pease. Durham: Duke UP, 1993. 3-21.

Kaplan, Amy. "The Tenacious Grasp of American Exceptionalism: A Response to Djelal Kadir." How Far Is America From Here? Selected Proceedings of the First 
World Congress of the International American Studies Association, 22-24 May 2003. Ed. Theo D'Haen, Paul Giles, Djelal Kadir, and Lois Parkinson Zamora. Amsterdam: Rodopi, 2005. 35-42.

Kaplan, Amy. "Violent Belongings and the Question of Empire Today. Presidential Address to the American Studies Association, October 17, 2003." American Quarterly 56.1 (2004): 1-18.

Kaplan, Amy, and Donald E. Pease, eds. Cultures of United States Imperialism. Durham: Duke UP, 1993.

Kroes, Rob. "National American Studies in Europe, Transnational American Studies in America." American Studies in Germany: European Contexts and Intercultural Relations. Ed. Günter Lenz and Klaus Milich. New York: St. Martin's P, 1995. 147-158.

Kunow, Rüdiger. "American Studies as Mobility Studies: Some Terms and Constellations." Re-Framing the Transnational Turn in American Studies. Ed. Winfried Fluck, Donald E. Pease, and John Carlos Rowe. Hanover, NH: Dartmouth College P, 2011. 245-264.

Lenz, Günter H. "Towards a Dialogics of International American Culture Studies: Transnationality, Border Discourses, and Public Culture(s)." The Futures of American Studies. Ed. Pease and Wiegman. Durham and London: Duke UP, 2002. 461-485.

Lenz, Günter. "Toward a Politics of American Transcultural Studies: Discourses of Diaspora and Cosmopolitanism." Re-Framing the Transnational Turn in American Studies. Ed. Winfried Fluck, Donald E. Pease, and John Carlos Rowe. Hanover, NH: Dartmouth College P, 2011. 391-425.

Levander, Caroline F., and Robert S. Levine. "Introduction: Essays Beyond the Nation." Hemispheric American Studies. Ed. Levander and Levine. New Brunswick: Rutgers UP, 2007. 1-17.

Levander, Caroline F., and Robert S. Levine. "Introduction: Hemispheric American Literary History." Special Issue of American Literary History 18.3 (2006): 397-405.

Lowe, Elizabeth, Earl E. Fitz, and Ilan Stavans. Translation and the Rise of InterAmerican Literature. Gainesville, FL: UP of Florida, 2007.

Lowe, Lisa. "The International in the National." Cultural Critique 40 (1998): 29-47.

Madsen, Deborah L. Native Authenticity: Transnational Perspectives on Native American Literary Studies. Albany, NY: State U of New York P, 2010.

Marx, Leo. "On Recovering the 'Ur' Theory of American Studies." American Literary History 17.1 (2005): 118-134.

McClennen, Sophia A. "Inter-American Studies or Imperial American Studies?" Comparative American Studies 3.4 (2005): 393-413. 
Messmer, Marietta. “Toward a Declaration of Interdependence; or, Interrogating the Boundaries in Twentieth-Century Histories of North American Literature." PMLA 118.1 (January 2003): 41-55.

Michael, John. “Transnational American Studies or, Tainted Love.” New Literary History 42.3 (2011): 409-417.

Mueller-Vollmer, Kurt. Transatlantic Crossings and Transformations: GermanAmerican Cultural Transfer from the Eighteenth to the End of the Nineteenth Century. Interamericana series. Frankfurt/Main: Peter Lang, forthcoming 2015.

Øverland, Orm. "Introduction: Redefining 'American' in American Studies." Not English Only: Redefining 'American' in American Studies. Ed. Orm Øverland. Amsterdam: VU University Press, 2001. 2-11.

Pease, Donald E. Introduction. Re-Framing the Transnational Turn in American Studies. Ed. Winfried Fluck, Donald E. Pease, and John Carlos Rowe. Hanover, NH: Dartmouth College P, 2011. 1-46.

Pease, Donald E. “The Politics of Postnational American Studies." European Journal of American Studies 20.2 (2001): 78-90.

Pease, Donald E. "Re-thinking 'American Studies after US Exceptionalism." American Literary History 21.1 (2009): 19-27.

Pease, Donald E., and Robyn Wiegman, eds. The Futures of American Studies. Durham and London: Duke UP, 2002.

Pease, Donald E., and Robyn Wiegman. "Futures." The Futures of American Studies. Ed. Pease and Wiegman. Durham and London: Duke UP, 2002. 1-42.

Pfister, Joel. "Transnational American Studies for What?" Comparative American Studies 6.1 (2008): 13-36.

Poblete, Juan, ed. Critical Latin American and Latino Studies. Minneapolis: U of Minnesota P, 2003.

Porter, Carolyn. "What We Know That We Don't Know: Remapping American Literary Studies." American Literary History 6.3 (1994): 467-526.

Raab, Josef, ed. New World Colors: Ethnicity, Belonging, and Difference in the Americas. Trier: Wissenschaftlicher Verlag Trier, and Tempe, AZ: Bilingual P, 2014.

Raab, Josef, and Alexander Greiffenstern, eds. Interculturalism in North America: Canada, the United States, Mexico, and Beyond. Inter-American Studies / Estudios Interamericanos Vol. 8. Trier: Wissenschaftlicher Verlag Trier, and Tempe, AZ: Bilingual P, 2013.

Radway, Janice. "What's In a Name? Presidential Address to the American Studies Association, 20 November, 1998." American Quarterly 51.1 (1999): 1-32. 
Radway, Janice A., Kevin K. Gaines, Barry Shank, and Penny von Eschen. Introduction. American Studies: An Anthology. Ed. Radway et al. Chichester: Blackwell, 2009. 1-7.

Raussert, Wilfried. "Mobilizing 'America/América': Toward Entangled Americas and a Blueprint for Inter-American 'Area Studies." Forum for Inter-American Research 7.3 (December 2014): 59-97. Available at www.interamericana.de.

Raussert, Wilfired, and Reinhard Isensee, eds. Transcultural Visions of Identities in Images and Texts - Transatlantic American Studies. Heidelberg: Universitätsverlag Winter, 2008.

Rowe, John Carlos. "Areas of Concern: Area Studies and the New American Studies." Re-Framing the Transnational Turn in American Studies. Ed. Winfried Fluck, Donald E. Pease, and John Carlos Rowe. Hanover, NH: Dartmouth College P, 2011. 321-336.

Rowe, John Carlos. "Post-Nationalism, Globalism, and the New American Studies." Post-Nationalist American Studies. Ed. Rowe et al. Berkeley: U of California P, 2000. 23-37.

Rowe, John Carlos, et al. Introduction. Post-Nationalist American Studies. Ed. Rowe et al. Berkeley: U of California P, 2000. 1-22.

Sadowski-Smith, Claudia. Border Fictions: Globalization, Empire, and Writing at the Boundaries of the United States. Charlottesville, VA: U of Virginia P, 2008.

Sadowski-Smith, Claudia. "Canada-US Border Narratives and US Hemispheric Studies." Comparative American Studies 3.1 (2005): 63-77.

Sadowski-Smith, Claudia. "Introduction: Comparative Border Studies." Comparative American Studies 9.4 (2011): 273-287.

Sadowski-Smith, Claudia, and Claire F. Fox. "Theorizing the Hemisphere: InterAmericas Work at the Intersection of American, Canadian, and Latin American Studies." Comparative American Studies 2.1 (2004): 5-38.

Saldívar, José David. Border Matters: Remapping American Cultural Studies. Berkeley: U of California P, 1997.

Saldívar, José David. Trans-Americanity: Subaltern Modernities, Global Coloniality and the Cultures of Greater Mexico. Durham: Duke UP, 2012.

Salvatore, Ricardo Donato, Gilbert M. Joseph, and Catherine C. LeGrand, eds. Close Encounters of Empire: Writing the Cultural History of U.S.-Latin American Relations. Durham: Duke UP, 1998.

Shell, Marc, and Werner Sollors, eds. The Multilingual Anthology of American Literature. New York: New York UP, 2000.

Siemerling, Winfried. The New North American Studies: Culture, Writing, and the Politics of Re/Cognition. London: Routledge, 2005. 
Siemerling, Winfried, and Sarah Phillips Casteel, eds. Canada and Its Americas: Transnational Navigations. Montreal: McGill-Queens University Press, 2010.

Sollors, Werner. "For a Multilingual Turn in American Studies." American Studies Association Newsletter 20 (June 1997): 13-15.

Sollors, Werner, ed. Multilingual America: Transnationalism, Ethnicity, and the Languages of American Literature. New York: New York UP, 1998.

Spanos, William V. "American Studies in the 'Age of the World Picture." The Futures of American Studies. Ed. Donald E. Pease and Robyn Wiegman. Durham and London: Duke UP, 2002. 387-415.

Temperley, Howard, and Christopher Bigsby. Introduction. A New Introduction to American Studies. Ed. Temperley and Bigsby. London: Longman, 2006. 1-6.

Thies, Sebastian, and Josef Raab, eds. E Pluribus Unum?: National and Transnational Identities in the Americas / Identidades nacionales y transnacionales en las Américas. Münster: LIT Verlag, and Tempe, AZ: Bilingual P, 2009.

Traister, Bryce. "Everything Old Is New Again: Transnationalism and American Literary History." Transnational American Studies. Ed. Udo Hebel. Heidelberg: Carl Winter Universitätsverlag, 2012. 147-164.

Traister, Bryce. “The Object of Study, or, Are We Being Transnational Yet?” Journal of Transnational American Studies 2.1 (2010): 1-28.

Tyrrell, Ian. "In the Shadow of the Nation? Space and Time in the Practice and Problems of U.S. Transnational History." Transnational American Studies. Ed. Udo Hebel. Heidelberg: Carl Winter Universitätsverlag, 2012. 75-96.

Voelz, Johannes. "Utopias of Transnationalism and the Neoliberal State." Re-Framing the Transnational Turn in American Studies. Ed. Winfried Fluck, Donald E. Pease, and John Carlos Rowe. Hanover, NH: Dartmouth College P, 2011. 356-373.

Wiegman, Robyn. "Romancing the Future: Internationalization as Symptom and Wish." American Studies: An Anthology. Ed. Radway, Gaines, Shank, and von Eschen. Chichester: Blackwell, 2009. 578-587. 


\title{
Michael Boyden
}

\author{
Uppsala University, Sweden
}

\section{The Semantics of Self-Denial: The New American Studies Through the Lens of Luhmann's Social Systems Theory ${ }^{1}$}

\section{The New Americanists}

The New Americanists form a rather loose grouping of literary and cultural critics who in different ways oppose the presuppositions of the "Old" American Studies of the Cold War era, as embodied by the writings of Richard Chase, R.W.B. Lewis, Lionel Trilling, Leslie Fiedler, and others. The label "New Americanists" was first applied by Frederick Crews in an article for the New York Review of Books in which he referred to a number of scholars (among them Donald Pease, Jane Tompkins, David Reynolds, Philip Fisher, Walter Benn Michaels, and Myra Jehlen) whose critical practices diverged markedly from and in many respects clashed with those of the previous generation through their joint focus on the ideological implications of American literature. ${ }^{2}$ Crews intended the label "New Americanists" pejoratively, as he detected in these authors' insistent questioning of the established canon of great American authors (especially those associated with the so-called "American Renaissance" of the mid-nineteenth century, a term introduced by F.O. Matthiessen in a 1941 study of the same name that counts as one of the master-texts of American Studies) an attempt to displace the old guard and assume a position of power in the academy. ${ }^{3}$ As happens so often with the rise of a new critical school (a term that hardly seems applicable to such a motley group of critics as the New Americanists), the label was internalized and transformed into a badge of pride after Donald Pease slyly used Crews's critique

1 An earlier version of this essay was published in Hannes Bergthaler and Carsten Schinko, eds., Addressing Modernity: Social Systems Theory and US Cultures (Amsterdam: Rodopi, 2011: 131-150).

2 Frederick Crews, "Whose American Renaissance?” New York Review of Books 35, 16 (October 27, 1988): 68-9.

3 F.O. Matthiessen, American Renaissance: Art and Expression in the Age of Emerson and Whitman. London/New York: Oxford University Press, 1941. 
as his cue to introduce the widely-read 1990 special issue of Boundary 2 devoted to "The New Americanists: Revisionist Interventions into the Canon."

If we can discern a silver thread running through the contributions collected in that seminal Boundary 2 issue - it was reprinted four years later as the second volume of Pease's New Americanists book series at Duke University Press but significantly without an explicit reference to the self-assertive identifier "New Americanists" in the title -, it is probably a shared commitment to teasing out the imperial implications of U.S. culture, which heretofore literary scholars had associated predominantly with the genre of the romance and what it evokes. ${ }^{5}$ This shift from innocence to guilt, or from a belief in the "Adamic" nature (as in R.W.B. Lewis's 1955 bestseller The American Adam) of American culture to a persistent questioning of its involvement in the spread of U.S. empire, becomes apparent if we compare the New Americanists' dominant concerns to those of a prominent Americanist of the foregoing generation, Robert E. Spiller, who is best known as the editor-in-chief of the monumental Literary History of the United States (1948), a landmark publication that remained practically unrivalled in the field until the publication of Emory Elliot's Columbia Literary History of the United States exactly four decades later. ${ }^{6}$ Towards the end of his career, when plans for a new history of American literature were on the table, Spiller looked back on the rise of American Studies as a legitimate struggle against a "lingering colonialism" supposedly ingrained in U.S. culture. ${ }^{7}$ In the Literary History of the United States, Spiller and

4 Donald E. Pease (ed.), The New Americanists: Revisionary Interventions in the Americanist Canon. Boundary 2 17, 1 (1990). It is interesting to note that the New Americanists appear more as a unified school in Europe than is the case in the United States. This can be explained by the strong institutional link between the Futures of American Studies Institute which Donald Pease directs at Dartmouth on the one hand, and, one of the most distinguished European centers of American Studies on the other, namely the John F. Kennedy-Institut in Berlin. Another way of accounting for this optic illusion may have to do with the realization that presenting oneself as more marginal than one really is tends to make one appear more central than one really is.

5 Donald E. Pease (ed.), Revisionary Interventions in the Americanist Canon. Durham \& London: Duke University Press, 1994.

6 R.W.B. Lewis, The American Adam: Innocence, Tragedy, and Tradition in the Nineteenth Century. Chicago: University of Chicago Press, 1955. Robert E. Spiller (gen. ed.), Literary History of the United States. 3 Vols. New York: Macmillan, 1948. Emory Elliot (gen. ed.), Columbia Literary History of the United States. New York: Columbia University Press, 1988.

7 Robert E. Spiller, “A Letter to American Literary Historians." Milestones in American Literary History. Westport, CT: Greenwood, 1977. p. 140. 
his team had attempted to overcome this colonial complex by stressing the "cosmopolitan" (as opposed to the narrowly "Anglo-Saxon") roots of American literature and by conceptualizing U.S. culture in terms of a series of waves beating in from the Atlantic but also rolling back to the Old World. Spiller claimed that American literature had reached its first "literary fulfillment" when Emerson, Thoreau, Hawthorne, Whitman and Melville, the five authors Matthiessen had singled out for discussion in his American Renaissance, began to assert their intellectual independence from Europe.

It is significant to note, given the New Americanists' revisionist agenda, that even a sidelong glance at some of their most outstanding publications reveals a persistent preoccupation with precisely this handful of mid-nineteenth century writers. Donald Pease's Visionary Compacts, David Reynolds's Beneath the American Renaissance, John Carlos Rowe's At Emerson's Tomb, and oft-quoted multiple author collections such as The American Renaissance Reconsidered or Ideology and Classic American Literature direct their critical gaze for the most part, if not exclusively, to the authors canonized in the Spiller history. ${ }^{8}$ Even though Spiller's wave theory of American literature, inspired for a large part by Vernon Louis Parrington's Main Currents in American Thought and The Reinterpretation of American Literature edited by Norman Foerster, has long since fallen into disrepute because of a growing defiance of grand narratives; and even though his evolutionary philosophy has meanwhile been replaced by alternative, in some respects more sophisticated models - the leading New Americanists seem to have a predilection for French intellectuals such as Althusser, Lacan, and Foucault -, the continued investment in "classic" American literature has left Spiller's original design relatively intact and thus testifies to its continuing institutional success. ${ }^{9}$ It is true that a number of formerly neglected or excluded authors have

8 Donald E. Pease, Visionary Compacts: American Renaissance Writings in Cultural Context. Madison: University of Wisconsin Press, 1987. David S. Reynolds, Beneath the American Renaissance: The Subversive Imagination in the Age of Emerson and Melville. New York: Alfred A. Knopf, 1988. John Carlos Rowe, At Emerson's Tomb: The Politics of Classic American Literature. New York: Columbia University Press, 1997. Walter Benn Michaels and Donald E. Pease (eds). The American Renaissance Reconsidered: Selected Papers from the English Institute, 1982-1983. Baltimore: Johns Hopkins University Press, 1985. Sacvan Bercovitch and Myra Jehlen (eds). Ideology and Classic American Literature. Cambridge: Cambridge University Press, 1985.

9 Vernon L. Parrington, Main Currents in American Thought. 3 Vols. New York: Harcourt, Brace \& World, 1927-30. Norman Foerster (ed.) The Reinterpretation of American Literature: Some Contributions toward the Understanding of Its Historical Development. New York: Harcourt, Brace \& World, 1928. 
been foregrounded (e.g. Frederick Douglass or Margaret Fuller), but the main difference between the New and the Old Americanists does not principally lie in the kind of authors that receive discussion but rather in the way their centrality is highlighted or asserted. ${ }^{10}$

In his introduction to American Renaissance, Matthiessen famously asserted that his main reason for grouping together Emerson, Thoreau, Hawthorne, Melville, and Whitman, despite their obvious differences in terms of temperament and philosophy, had been these authors' shared "devotion to the possibilities of democracy" (Matthiessen 1941: ix). Spillers's Literary History of the United States almost literally reproduces Matthiessen's rationale when stating that all five authors address, however different the results, "the central goal and problem of democracy" (Spiller 1948: 353). This assumption, fed to generations of American literature students, that the great American authors somehow embody the democratic principles of the American nation and its people, appeared as a dangerous incommensurability to the New Americanists, most of whom received their education in the 1960s and 1970s when the foundations of American democracy were increasingly called into question by the democratization of higher education, the movements for Civil Rights and the protests against the Vietnam war. The New Americanists no longer envision the rise of American literature in terms of a continuing struggle against (English, and, by extension, European) colonialism, but rather in terms of the imperial violence inflicted by the U.S. as an emergent neo-colonial world power on the rest of the world.

While for Spiller and company mid-nineteenth century U.S. culture was associated with the growth of personal liberties and freedom, the New Americanists have reinterpreted that culture, often with interesting results, in light of Jackson's Indian Removal policy, the "peculiar institution" of slavery, nativist hysteria against immigrants and Catholics, or Polk's expansionist war against Mexico. This is particularly evident in Emerson criticism, where the standard-bearer of Transcendentalism has been transformed from a leading spokesperson of democratic liberalism into a much more complex but also more dubious persona whose writings reflect or, according to some critics, even justify the ideological workings of imperialism. To give just one example, in his book The Emerson Effect Christopher Newfield argues that in his well-known essay "Self-Reliance" Emerson did not, as a long line of eminent Emerson critics suggests, embrace individualism and

10 Significantly, Emory Elliot's Columbia Literary History of the United States, which was profiled explicitly as a reaction against the Spiller history and the kind of master narrative it conveys, leaves Matthiessen's original grouping intact in a section straightforwardly entitled "American Renaissance." 
democracy but rather "consistently repudiated both at the same time." ${ }^{11}$ A similar reframing is noticeable in scholarship on other canonical authors as well. The central opposition between American democracy and European-style aristocracy, which for many decades structured critical debates on classic American literature, therefore seems to have been replaced by another guiding distinction, namely that between submission or resistance to Euro-American imperialism.

It is beyond the scope of this essay to evaluate the adequacy or inadequacy of this remarkable interpretative shift of American culture. What I hope to do, rather, is to show how this apparent inversion of values has taken shape. Niklas Luhmann's social systems theory offers a sufficiently complex and worked-out framework for tracing this paradoxical dynamic. What bears remarking, from such a Luhmannian perspective, is not so much that the established literary canon and the dominant interpretations of it, as the New Americanists claim, should be revised because they would embody sexist, classist, racist and other values considered oppressive; the thing to note when it comes to the institutional logic of American Studies, is rather that this institution can continue to exist at all given all the above objections. Indeed, as indicated above, what is surprising is that, in spite of all the criticisms leveled against the authors sanctified by Matthiessen and Spiller, their writings have remained largely unchallenged at the center of the American canon. What is of interest, therefore, is not so much the supposed paradigm shift from self-assertion to self-criticism, a conflict often dramatized as a form of patricide by "Old" and "New" Americanists alike, as the disciplinary dynamic of self-assertion through self-criticism. This dynamic, as I will argue, is by no means peculiar to the New Americanists but has characterized the field of American Studies from the beginning.

\section{Social Systems and the Functionalist Tradition}

The relative neglect in American universities of Niklas Luhmann's social systems theory, which in Europe and elsewhere is commonly regarded as one of the most ambitious attempts of the late twentieth century at grounding modern society in a comprehensive intellectual design, has been explained in terms of its high level of abstraction, often consciously fostered by Luhmann through his predilection for relatively obscure thinkers such as the mathematician George Spencer Brown, along with the translation problems involved in conveying the subtle ironies of Luhmann's disengaged writing style. In the introductory note to the English-language edition

11 Newfield, Christopher. The Emerson Effect: Individualism and Submission in America. Chicago: University of Chicago Press, 1996. p. 22. 
of his principal work Soziale Systeme, which appeared more than a decade after the publication of the German original, Luhmann himself admitted rather dryly that what he had written was "not an easy book." ${ }^{12}$ Characteristically, instead of mitigating this problem, Luhmann's "Instead of a Preface" withholds from the reader any personal information on how he came to write the book, but instead elaborates on his systematic exclusion of the "subject" (or what Luhmann calls psychic systems) from the realm of the social. Yet, the willful complexity of Luhmann's theory alone does not suffice to account for the reluctant reception of his work in the United States, all the more so because other major thinkers have of late found their way into the American humanities in spite of such obstacles (note, for instance, Hegel's remarkable resurgence in postcolonial studies).

What, in my opinion, makes Luhmann's social systems theory particularly challenging in the American context is its reconciliation of an old-fashioned belief in a supertheory that would explain everything with a concomitant realization of the impossibility of a credible outside position, a Cartesian vantage point from which society can be observed. The complexity of Luhmann's theory architecture derives in large part from what he (following Spencer Brown) would call the "unfolding" of this contradiction between the construction of a supertheory and the apparent unavailability of an objective point of view for doing so. Unlike contemporary philosophy, which sees this necessary but impossible project as part of the postmodern predicament, Luhmann has made original use of insights from cybernetics and evolutionary biology to develop a self-referential theory which conceptualizes modern society as a horizontally ordered concatenation of subsystems, each of which can make universalist claims within its own realm but none of which can impose such claims onto other functional domains. Thus, even while it aspires to explain all of society, social systems theory belongs to the subsystem of science, which means that the rest of society can function quite well without it, a conclusion which Luhmann lards with masterful self-irony.

It is not hard to see why such a perspective should generate resistance among American scholars, who are generally more receptive to immediate social concerns than their European counterparts. On the one hand, Luhmann's taste for high theory and his attempt to position himself in relation to an "Old" European philosophical tradition squares badly with the postmodern defiance of grand narratives which permeates the U.S. academic world. This defiance also characterizes the New

12 Niklas Luhmann, Social Systems. John Bednarz with Dirk Baecker (trans.), Eva Knodt (fwd.). Stanford University Press, 1995. p. xxxvii. Soziale Systeme: Grundriß einer allgemeinen Theorie was published in 1984 by Suhrkamp in Frankfurt am Main. 
Americanists, whose critique of the myth and symbol school, for instance, derives its momentum largely from their refusal to summarize "America" in terms of a couple of unifying ideas (such as innocence), which for them indirectly serve to explain away deeper inequalities (the not so innocent treatment of minorities under the banner of freedom). On the other hand, Luhmann's anti-essentialist design seems to go against what the New Americanists would label a "counterhegemonic" discourse, a counternarrative through which they hope to effectuate social change. Luhmann's theory does not deny such forms of agency, but his systematic theorization of the self-implicative logic of society, a logic from which, as we noted, not even his own theory of society is exempt, implies that the revisionism of the New Americanists can only acquire meaning in relation to, by enveloping it within, the society against which it reacts.

From the perspective of the New Americanists, Luhmann's systems theory thus seems at once dangerously overambitious and not ambitious enough, which may at least in part indicate why it has hardly percolated in American theory debates. But, in line with Luhmann's cybernetically-inspired language, such "limited connectivity" may at the same time contain the promise of communicative acceptance. I want to stress from the beginning, though, that by applying Luhmann's systems theory to the New Americanists I do not mean to deny the legitimacy of their oppositionalism by suggesting that they would be somehow less radical than they claim to be. On the contrary, I hope to analyze this radical revisionism as an indispensable operational feature of modern society. I want to approach this by resituating social systems theory in the familiar tradition of functionalism from which it emerged. Most Luhmann textbooks transmit his ideas rather dogmatically, thus naturalizing concepts and models that were meant to provoke new ways of approaching social theory. Pointing attention to systems theory's connection to functionalism, a tradition well-known in the American social sciences, can make his theory more tangible even while indicating where it goes beyond some of the more problematic assumptions of traditional functionalism.

A functionalist argument is normally regarded as a special type of causal explanation, whereby the consequences of an institutional or behavioral pattern indirectly serve to explain it. A well-known example is that of a rain dance promoting group solidarity. While the dance ostensibly functions to appease the gods, its hidden function is to reinforce the tribal hierarchy. A valid functional argument thus needs to conform to two basic conditions. First, there has to be a degree of circularity. The ritual dance is indirectly sustained by its effects, i.e. the maintenance of peace in the tribe, which results in a reverse causal loop that keeps such traditions alive. What further sets functional reasoning off from other types of consequence explanations, such as those invoking individual aims, is 
the condition of latency. According to this criterion, a rain dance can only fulfill its solidarity-enhancing function if those performing it do so without realizing what it is really about. As the argument goes, if the dancers would find out that by performing such a ritual they were unwittingly strengthening the social order, the idiosyncrasy of individual intentions would start competing with the common good of maintaining solidarity.

I have deliberately used a relatively simple example from early anthropology to bring out some of the problems involved in the functionalist paradigm, most of which have to do with its speculative or anti-empirical slant. After all, how can we ascertain whether a rain dance really serves the purpose that the ethnologist assigns to it? Why should such a ritual help to preserve the group (why, for instance, could it not do the exact opposite)? Perhaps we simply impute this function to the group assuming that what is, is right? And, even if it can be ascertained that there is indeed a reverse causal mechanism working underneath the surface, it still remains to be seen to what extent this feedback mechanism is indeed produced unintentionally and whether it really remains unrecognized. Such functional reasoning thus adopts the kind of Cartesian viewpoint that according to postmodern thinkers can no longer be maintained. The emphasis on group stability as the ultimate functional requisite of clan society can be identified as an ideological ploy that denies its members any right to agency. This is a familiar charge leveled against Alfred Radcliffe-Brown's notion of the "ritual attitude" on which primitive cultures would depend for their survival. ${ }^{13}$

Although functionalist theory has become much more sophisticated since the days of Radcliffe-Brown, most of the problems (both real and imagined) associated with it have not gone away. In the 1960s, for instance, Talcott Parsons's structural functionalism, which had dominated sociological theorizing for about two decades, came under heavy attack from C. Wright Mills and others on the assumption that, through its emphasis on system maintenance and equilibrium, the notorious Parsonian four-function model sanctioned rather than analyzed the established order at a time when the United States was assuming absolute world power. ${ }^{14}$ During the

13 Alfred R. Radcliffe-Brown, Structure and Function in Primitive Society. New York: The Free Press, 1965.

14 Parsons distinguished four functional requisites or imperatives necessary for system maintenance: adaptation, goal attainment, integration, and latency. Together, these have become known as the AGIL scheme, which Parsons then further refined and differentiated to analyze diverse social phenomena. Parsons's model was criticized by C. Wright Mills in The Sociological Imagination. New York: Oxford University Press, 1959. 
1980s and 1990s, attempts have been made to rehabilitate Parsons by opening up his rather top-heavy theoretical framework to social change. This "neofunctionalist" turn, which has been relatively short-lived, can equally be interpreted in light of the persistent charge of conservatism. ${ }^{15}$ In Germany, the Parsonian legacy has been kept alive thanks to Luhmann and Jürgen Habermas, both of whom have drawn extensively on structural functionalism. The label, however, has retained very negative connotations, as appears from the well-known Luhmann-Habermas debate in the early 1970s, whereby the latter accused the former of being a functionalist. ${ }^{16}$

However, Luhmann's 1984 masterpiece Soziale Systeme revealed that his brand of systems theory, even if it remains strongly indebted to Parsons's structural functionalism, at the same time departs from it in significant ways. ${ }^{17}$ The first thing to note is that Luhmann shifts emphasis away from the maintenance of stability to the management of complexity. How, Luhmann asks, does modern society deal with the problem of (ever growing) complexity? ${ }^{18}$ Controlling it from the top down seems futile. Instead of imposing a system of unilateral control, Luhmann argues that modern societies have developed sophisticated ways of channeling complexity through strategies of selection, differentiation and temporalization. That means, very simply, that complexity is countered by internalizing it, or by reproducing it on another level. The result is a state of "dynamic stability," whereby the social system exerts control in paradoxical fashion by anticipating, as it were by inviting, its eventual contestation (Luhmann 1995: 49). This shift from stability to dynamic stability, or from continuity to contingency, presents a major

15 Jeffrey C. Alexander, Neofunctionalism. Beverly Hills: Sage, 1985. Meanwhile, Alexander has already declared the end of this return to Parsons. See: Neofunctionalism and After. Malden, MA: Blackwell, 1998.

16 Jürgen Habermas and Niklas Luhmann. Theorie der Gesellschaft oder Sozialtechnologie: Was leistet die Systemforschung? Frankfurt am Main: Suhrkamp, 1971.

17 Luhmann's status as a highly innovative thinker became even more apparent in 1997 after the appearance of the two-volume Die Gesellschaft der Gesellschaft (Suhrkamp), which remains as yet untranslated in the English language.

18 The main focus of Luhmann's systems theory is modern society, which he relates to the emergence of self-referential function systems (such as the economy, law, art, and so on) on the one hand and the development of distribution media (such as writing and print) on the other hand. Luhmann argues that these structural conditions, which started to manifest themselves in their full force around the eighteenth century, have not undergone such fundamental changes in recent times as to warrant the use of the label "postmodern." 
step forward in relation those approaches which regarded class stratification as a "natural" fact of society. ${ }^{19}$

What does all of this entail for functional methodology? Above, we defined functional arguments as special forms of causal argument, whereby the end (the hidden function) justifies the means (the item to be explained). The problem with this means/end logic of traditional functionalism was that it could never fully answer the question as to what it is, in the end, that justifies the end that justifies the means. Does the item become dysfunctional if it reaches its goal (stabilizing the group)? In response to such obstacles, Luhmann adopts an anti-teleological approach, which envisions only one end, namely the end of the social as such, which is probably the only end which everybody would want to avoid. From this perspective, the aim of functional analysis is no longer merely to discover causalities, but above all to compare different but functionally equivalent solutions to the problem of society (which obviously only becomes a problem because there is not just one, ready-made solution). Put differently, the explanatory value of functional arguments no longer resides primarily in uncovering a kind of invisible hand pulling the strings of society, but rather in examining how society puts forward specific answers (which are equivalent, since all of them come from within society, which also means that all of them can in principle be replaced) to the question of its existence. The attention thus shifts from the determination of functions to the process of function attribution. In other words, causal arguments become subtypes of functional ones instead of the other way around.

This shift from causalities to equivalences also leads us to redefine the condition of latency. One recurring problem in traditional functionalism was that the researcher can never really know for sure that society does not really know what it is not supposed to know. Luhmann addresses this issue by consigning psychic systems to the "environment" of the social, a drastic theoretical move that has often been misunderstood as a form of anti-individualism (it is, in fact, the exact opposite). In social systems theory, latency therefore no longer just refers to a lack of awareness on the part of individuals, but rather entails a lack of themes to push forward communication (1995: 335) ${ }^{20}$ In every society, there are things that

19 For the functional theory of stratification, see Kingsley Davis and Wilbert Moore, "Some Principles of Stratification," American Sociological Review 10 (1945): 242-49. I should add that by saying that stratification is not a functional necessity of modern society, Luhmann does not therefore assume that it does not exist. But it is no longer the primary form of differentiation.

20 The elementary building block of society, for Luhmann, is communication. This is another major departure from Parsons, who based his theory on actions and their 
cannot be communicated because they affect the very structure of that society. Each society thus creates its own latency needs. A hierarchical order will protect itself through counter-discourses that help it to let off steam but that do not, in general, constitute an alternative to that order (carnivals cannot last forever). In modern society, by contrast, alternatives are already abundantly present. As a matter of fact, its legitimacy depends on its capacity for offering equivalent solutions, for stimulating criticism. Put differently, all those things that pose a threat to a hierarchy constitute a condition of possibility for a horizontally structured society. What needs to be kept latent, in such a context, is not what keeps individuals from speaking out against domination but rather the selectivity of public opinion as such.

The overall criticism directed against functionalism was that it largely ignored conflict and change. Even if these factors were recognized, they were often approached as "dysfunctional" for the equilibrium of the sociopolitical order. Social systems theory, by contrast, explicitly highlights the importance, even the productive potential, of paradoxes and contradictions in the formation and maintenance of modern society. The complexity of Luhmann's prose style, so disconcerting and irritating to the uninitiated reader, thus needs to be understood in terms of his attempt to create a theoretical framework commensurate with the exigencies of an increasingly complex world society, which operates precisely on the basis of perpetual internal unrest. According to Luhmann, modern society constitutes a "self-substitutive order" (1995: 409). Simply put, this means that the social system protects itself against annihilation by including its own negation as a condition of possibility, by inviting its own replacement, which results in a remarkably high tolerance for uncertainty. The problem for such a self-substitutive order is no longer how to control dissent but how to exploit it, given that there are so many options available, all of them apparently equally valid.

Conceptualizing modern society as a self-substitutive order has far-reaching implications for the role of the critic in it, which is where my discussion of systems theory reconnects to that of the New Americanists. The problematization of latency in the modern world signifies that virtually everything can become the object of critical scrutiny. The one thing that has to remain latent, in such a context, is the very bankruptcy of the idea that there are certain things that cannot be communicated. In a functionally differentiated order, such latencies (for instance,

functional components. The communicative approach, at least on the level of theory, has the advantage of steering free from the thorny problem of intentionality. Whereas actions necessarily presuppose an ulterior design, communication can very well babble on without it. 
the mystery of the afterlife) can no longer self-evidently block critical inquiry since this would offend the premises of structural selection. This dehierarchization of the social, however, comes at the price of the decreasing social relevance of criticism. In a somewhat sardonic turn, Luhmann states that the modern critic becomes "radical in a peculiarly hopeless fashion" (1995: 342). The authority of the critic no longer depends primarily on uncovering latent truths, because such mechanisms of manifestation are already built into modern society's operational structure. All that is left for the critic to do, it seems, is anticipate such self-falsificatory gestures by communicating his ignorance.

\section{American Studies as a Self-Substitutive Order}

The prominent European Americanist Winfried Fluck has described the revisionist program of the New Americanists in terms of a larger predicament of the humanities, which he relates to the professionalization of criticism and more broadly to the "cultural radicalism" ingrained in postmodern society. ${ }^{21}$ This radicalism, for Fluck, is the cause of the current plight of the humanities, for it means that professional advancement is only possible by negating or reinterpreting the claims of other critics, which therefore results in a hopeless fragmentation of meaning as every truth claim immediately gets absorbed or aborted by an institutional matrix geared toward dissent. Fluck identifies the New Americanist paradigm as a prominent instance of numerous attempts to overcome this fragmentation, all of which however unwittingly stir up the disease they set out to cure. In order to accomplish their revisionist goals, Fluck argues, these radical critics cannot but reproduce the operational structure that undergirds the humanities in the age of "expressive individualism," which constantly disqualifies or de-futurizes the theories that are produced to understand its deeper meaning. Every critic is therefore doomed to "out-radicalize" his fellow-critics, thus constantly deferring final meanings and values (217).

In this regard, it seems ironic that Fluck's compelling analysis of the New Americanists' revisionism appeared in Pease and Wiegman's The Futures of American Studies, a volume in the New Americanist Duke series, which makes one wonder whether and to what degree Fluck's diagnosis does not itself fall victim to the "paradoxical professional logic" that he identifies as the source of the current crisis in the humanities (211). Fluck takes care, however, to set his critique apart

21 Winfried Fluck, "The Humanities in the Age of Expressive Individualism and Cultural Radicalism," Donald E. Pease and Robyn Wiegman (eds), The Futures of American Studies. Durham \& London: Duke University Press, 2002: 211-30. 
from that of, on the one hand, conservative critics who deplore the loss of the traditional canon and values (an impulse that Gerald Graff has identified as a peculiarly prevalent "humanist myth" in literary studies, by which he means the mistaken idea of a founding consensus), and, on the other hand, Neo-Marxist critics who remain stuck in inadequate models of class analysis. ${ }^{22}$ As Fluck indicates, assuming that the radicalization of criticism can be attributed to class differences or market factors results in a "crude sociologist bias," which he observes in the Bourdieu-inspired approach of John Guillory (224). Such an economic analysis, Fluck argues, does not solve the problem of escalating radicalism for it assigns political significance to a development which is in fact a consequence of a cultural development toward ever increasing dehierarchization and individuation.

What Fluck fails to mention in his article is that there is in fact a worked-out theoretical apparatus in place that addresses these issues and avoids such problematic (at once too specific and too vague) terms as "individualism," "professionalism," or "culture." By restricting his argument to the post-World War II period, and by rather intuitively positioning the U.S. academic world against that of Europe, Fluck neglects some of the larger issues involved, such as the operational autonomization of function systems apart from the economy or science, the explosive growth of these systems beyond the reach of the nation-state and its limited instruments for policing the social, and the development of worldwide distribution media. Moreover, his far from neutral rhetoric when describing the American critic's move away from enlightenment values to a meaningless "white-collar race for distinction" betrays that his stance is perhaps closer to the conservative side of the debate, which pretends to counter the defects of professionalization through unspecified cure-all "returns to culture," than he is ready to admit (214). ${ }^{23}$ Rather than pursuing this critique, however, I would like to contribute constructively to the debate by showing how social systems theory can amplify and strengthen Fluck's evaluation of the New Americanists. Luhmann's approach, which I have presented in rather too condensed fashion, can offer a highly reflexive, "polycontextural" (as opposed to a monocausal) framework for redescribing the New Americanists' revisionism in terms of the functional toppling of society in modernity.

To drive home my point of view, I want to concretize things somewhat by focusing attention on what I consider to be a conspicuous but at the same time

22 Gerald Graff, Professing Literature: An Institutional History. Chicago: Chicago University Press, 1987.

23 The phrase "return to culture" is taken from Edward Said's Culture and Imperialism. London: Vintage, 1994: xiii-iv. 
fairly representative instance of the New Americanists' counterhegemonic project. In his 2000 book Literary Culture and U.S. Imperialism, John Carlos Rowe, a professor of English at UCIrvine and a self-described spokesperson of the New American Studies, offers a broad-ranging interpretation of the ways in which American writers roughly between the late $18^{\text {th }}$ up to the mid- $20^{\text {th }}$ century have been implicated in U.S. imperialism, both on the American mainland and elsewhere. ${ }^{24}$ Following the lead of postcolonial thinkers such as Edward Said, Rowe reinterprets a number of established and less established American literary texts, from Charles Brockden Brown's Wieland to Zora Neale Hurston's Tell My Horse, in view of their complex relation to U.S. (neo-)colonialism during a period that was up until recently seldom associated with such ideological forces. ${ }^{25}$ Rowe's project, therefore, is designed to make manifest the ways in which the selected works have been put to the service of, but have also reacted against, the burgeoning imperial ambitions of the young American nation.

My concern is not with the quality of Rowe's textual analyses, which are on the whole admirably executed and yield compelling insights. Rather, I am interested in the reasons as to why his book should center almost exclusively on what Fluck describes as the "possibility or impossibility of opposition" (217). The main objective of Literary Culture and U.S. Imperialism, Rowe states, is "to learn how to tell the difference between literary practices that serve or challenge the dominant ideology while recognizing how all cultural acts remain to some degree captives of their historical and thus ideological situations" (79). "[O] ur best teachers" as Rowe phrases it, are those authors (Melville, Twain, Du Bois as opposed to Brown, Poe, or Henry James, with a number of ambivalent cases in between) who recognize at once the need and the danger of opposing American hegemony and therefore knowingly anticipate their apparently inevitable incorporation into the ideological machinery of U.S. exceptionalism. For instance, Rowe states that Typee poses the first real "resistance" to American neocolonialism because Melville, unlike others, "recognizes the difficulty of combating forms of cultural imperialism at home and abroad that rely on the very rhetorical powers that are the resources of the imaginative writer" (17). Twain's vigorous anti-imperialism, by contrast, would have instilled in him a belief in universal democracy through which he "unwittingly

24 John Carlos Rowe, Literary Culture and U.S. Imperialism. Oxford: Oxford University Press, 2000.

25 In the preface, Rowe describes his book as a prelude to another study dealing with the cultural implications of U.S. foreign policies in Southeast Asia around the time of the Vietnam War. To date, this study has not yet appeared. 
anticipat[ed]" American neo-imperalist practices that use such democratic ideals to justify territorial expansion (18).

Rowe takes pains to differentiate his approach from that of deconstructionist and other textual critics, whom he blames for failing to take into account variables such as sexuality, gender, race, and class in the production of culture. Arguing that we are bound to make judgments no matter what, Rowe does not hesitate to issue bold claims regarding the involvement of certain authors in the American imperial project, or even to extend the history of that project into the colonial period, as when he argues that the modern reader "must recognize the secret complicity" between Brown's gothic romances and the genocides perpetrated by the British on Native Americans during the French and Indian Wars (39). Even while his natural addressee remains the American nation ("our best teachers"), Rowe spreads the burden of U.S. imperial violence over three centuries of European presence in the Americas. The problem with such sweeping arguments is that it becomes very difficult to ascertain whether the critic does not project his own concerns onto the object of study. Is it really true that Brown's fiction "helps distort and disguise" colonial massacres (28)? Or, why, alternatively, should it be that Du Bois "comes closest ... to understanding U.S. imperialism" (196)?

One could venture that Rowe's book is guided by what the political philosopher Philippe Van Parijs at a certain point identified as the "principle of suspicion" inherent in traditional functionalism, meaning a tendency to consistently read certain phenomena symptomatically in terms of their hidden meanings. ${ }^{26}$ The problem with this principle of suspicion is that, in the end, it tends to become itself highly susceptible to suspicion. The critic is faulted, not so much for having poked at power structures that were supposed to remain hidden, but for not having done enough to point out what to other critics seems manifest. ${ }^{27}$ The quasi-universalization of the principle of suspicion thus presupposes a concomitant expansion of an underlying semantics of ignorance. ${ }^{28}$ In his Observations on Modernity, Luhmann defined the

26 Philippe Van Parijs, Evolutionary Explanation in the Social Sciences: An Emerging Paradigm. Totowa, NJ: Rowman \& Littlefield, 1981: 129.

27 Indeed, as it appears, Rowe is by no means immune from his own anti-imperialist critique. In his article "Imperial Literary Culture," Paul Giles wonders whether Rowe's argument "might not in itself constitute a more emollient form of American cultural imperialism.” In: Novel: A Forum on Fiction 35.1 (2001): 137.

28 By a semantics of ignorance I do not mean a lack of knowledge on the part of the scholar but rather a lack of communicative themes that indirectly urges on communication. In this sense, ignorance (or what Luhmann calls communicative latency) constitutes a necessary condition for an institution to establish itself. If we could completely unravel 
modern expert as "someone who, when asked questions he cannot answer, can be led back to a mode of uncertainty." ${ }^{29}$ By this, Luhmann means that, in modern society, a critical judgment can only find acceptance when it can (at least in principle) be contested, revised, or negated, in other words when it is improbable. It is this communicative deficit or ingrown uncertainty at the core of the critical enterprise that drives it forward and ultimately legitimizes it.

I claim that Rowe fails to capture this self-substitutive dynamic because of his emphasis on creating a counterdiscourse to American imperialism. Note, for instance, how he describes the role of criticism in his chapter on Henry Adams: "The ideological means by which a society refuses to accept responsibility for dominating and exploiting others must always be central to our cultural criticism, insofar as the ultimate aim of such criticism is an understanding that brings about social change" (166). In a context where change is not so much an obstacle but a constitutive requirement, merely calling for change (yes we can!) does not therefore upset the established order, which establishes itself precisely through its continual replacement. This is not to say that anything goes or to trivialize concerted efforts at reducing inequalities, but rather to point attention to the fact that in a complex world society structural conditions prevail that can mobilize enormous amounts of resistance without disintegrating. Greater "understanding" does not help here because there is no vested interest in keeping things hidden, or, rather, things are kept hidden through the demand for greater openness. Rowe surely comprehends this paradox but, in his insistence on the all-pervasiveness of U.S. power, he fails to grasp its deeper implications for modern society as a whole.

It is remarkable that, in the above quote, Rowe rather negligently juxtaposes terms like "our" and "others," terms that he promises to question by showing how they are constructed through literary culture. Social systems theory can lift Rowe's approach to a higher level of reflexivity by redescribing such counterconcepts ("America" versus the rest) as part of the self-referential semantics through which a social system emerges and reconstructs itself. Rather than once more "out-radicalizing" existing position-takings, I want to stress what connects the "New" and the "Old" Americanists. Where the so-called old guard reacted against the "Anglocentrism" of earlier critics such as Barrett Wendell and Charles F. Richardson, the so-called "postnational" critics of today oppose the "Eurocentrism" or even "Americocentrism" of the earlier generations. What has remained

what the great works of American literature are all about, we would have to close the books and take up another profession.

29 Niklas Luhmann, Observations on Modernity. William Whobrey (trans.) Stanford: Stanford University Press, 1998: 70. 
intact in spite of these "paradigm dramas," as Donald Pease would call them, is the self-corrective incentive structure at the basis of American Studies as a field, which has from the beginning defined itself ex negativo by opposing earlier versions of itself, like a snake sloughing off its old skins. Before we cast off the "New Americanists" in favor of yet another renaissance, therefore, there may be some value in focusing more attention on the societal conditions that produce such disciplinary reversals to begin with. Reading Luhmann would be a good start.

\section{Works Cited}

Alexander, Jeffrey C. Neofunctionalism. Beverly Hills: Sage, 1985.

Alexander, Jeffrey C. Neofunctionalism and After. Malden, MA: Blackwell, 1998.

Bercovitch, Sacvan, and Myra Jehlen, eds. Ideology and Classic American Literature. Cambridge: Cambridge University Press, 1985.

Crews, Frederick. "Whose American Renaissance?" New York Review of Books 35.16 (October 27, 1988): 68-69.

Davis, Kingsley, and Wilbert Moore. "Some Principles of Stratification." American Sociological Review 10 (1945): 242-49.

Elliot, Emory, gen. ed. Columbia Literary History of the United States. New York: Columbia University Press, 1988.

Fluck, Winfried. "The Humanities in the Age of Expressive Individualism and Cultural Radicalism." In Donald E. Pease and Robyn Wiegman, eds. The Futures of American Studies. Durham \& London: Duke University Press, 2002. 211-30.

Foerster, Norman, ed. The Reinterpretation of American Literature: Some Contributions toward the Understanding of Its Historical Development. New York: Harcourt, Brace \& World, 1928.

Giles, Paul. "Imperial Literary Culture." Novel: A Forum on Fiction 35.1 (2001): 136-138.

Graff, Gerald. Professing Literature: An Institutional History. Chicago: Chicago University Press, 1987.

Habermas, Jürgen, and Niklas Luhmann. Theorie der Gesellschaft oder Sozialtechnologie: Was leistet die Systemforschung? Frankfurt am Main: Suhrkamp, 1971.

Lewis, R.W.B. The American Adam: Innocence, Tragedy, and Tradition in the Nineteenth Century. Chicago: University of Chicago Press, 1955.

Luhmann, Niklas. Die Gesellschaft der Gesellschaft. Frankfurt am Main: Suhrkamp, 1997.

Luhmann, Niklas. Observations on Modernity. Trans. William Whobrey. Stanford: Stanford University Press, 1998. 
Luhmann, Niklas. Social Systems. Trans. John Bednarz with Dirk Baecker. Fwd. Eva Knodt. Stanford University Press, 1995.

Luhmann, Niklas. Soziale Systeme: Grundriß einer allgemeinen Theorie. Frankfurt am Main: Suhrkamp, 1984.

Matthiessen, F.O. American Renaissance: Art and Expression in the Age of Emerson and Whitman. London/New York: Oxford University Press, 1941.

Michaels, Walter Benn, and Donald E. Pease, eds. The American Renaissance Reconsidered: Selected Papers from the English Institute, 1982-1983. Baltimore: Johns Hopkins University Press, 1985.

Newfield, Christopher. The Emerson Effect: Individualism and Submission in America. Chicago: University of Chicago Press, 1996.

Parrington, Vernon L. Main Currents in American Thought. 3 Vols. New York: Harcourt, Brace \& World, 1927-30.

Pease, Donald E. Revisionary Interventions in the Americanist Canon. Durham \& London: Duke University Press, 1994.

Pease, Donald. E., ed. The New Americanists: Revisionary Interventions in the Americanist Canon. Boundary 2 17. 1 (1990).

Pease, Donald E. Visionary Compacts: American Renaissance Writings in Cultural Context. Madison: University of Wisconsin Press, 1987.

Radcliffe-Brown, Alfred R. Structure and Function in Primitive Society. New York: The Free Press, 1965.

Reynolds, David S. Beneath the American Renaissance: The Subversive Imagination in the Age of Emerson and Melville. New York: Alfred A. Knopf, 1988.

Rowe, John Carlos. At Emerson's Tomb: The Politics of Classic American Literature. New York: Columbia University Press, 1997.

Rowe, John Carlos. Literary Culture and U.S. Imperialism. Oxford: Oxford University Press, 2000.

Said, Edward. Culture and Imperialism. London: Vintage, 1994.

Spiller, Robert E. “A Letter to American Literary Historians." Milestones in American Literary History. Westport, CT: Greenwood, 1977. 140.

Spiller, Robert E., gen. ed. Literary History of the United States. 3 Vols. New York: Macmillan, 1948.

Van Parijs, Philippe. Evolutionary Explanation in the Social Sciences: An Emerging Paradigm. Totowa, NJ: Rowman \& Littlefield, 1981.

Wright Mills, C. The Sociological Imagination. New York: Oxford University Press, 1959. 


\section{Ricardo D. Salvatore \\ Universidad Torcuato Di Tella, Argentina \\ If Bolton Were to Awake Today: Early Efforts Towards a Comprehensive Hemispheric History of the Americas}

This contribution aims at placing the current discussion of the "international turn" of American Studies-in particular, its turn towards Hemispheric American Studies-in the context of discussions that took place during the 1930s and 1940s about the importance of writing a comparative history of the Americas. The program of a Hemispheric History, made explicit in Herbert E. Bolton's 1932 call for an "Epic of Greater America," was already underway during the post-WWI period. In fact, it was part of the agenda of those US historians who built the field of Hispanic American History in the United States. This essay reviews some of these early efforts in writing a comprehensive history of the Americas in order to underscore the neo-imperialist tendencies inherent in this kind of scholarship. The new discipline (Hispanic American History) emerged and consolidated in tandem with the US's cultural diplomacy strategy of Pan-Americanism and the achievement of economic supremacy over Latin America by US products, corporations, and financial capital.

Calls to widen the scope of historical inquiry are often associated with specific geo-political designs by nation-states located at the centers of power. In its effort to "incorporate" neighboring nations within its own sphere of influence and cultural supremacy, the hegemon tries to represent them as a totality guided by a common cultural logic. US historians' attempts to grasp the totality of Hispanic and Portuguese America during the inter-war period constitutes a clear case of a regional history being subordinated to or placed at the service of US foreign policy interests. This particular intellectual configuration should warn us against the dangers implicit in current pronouncements to transnationalize American Studies. Inter-temporal comparisons of knowledge projects are a dangerous exercise. But something useful can nonetheless be learned from them as well. The "lesson" this essay would like to present is thus the following: to follow the imperial impetus to bring home the knowledges of the world might not be the best way to "level the playing field" of world knowledges. Re-examining these earlier discussions will contribute to a better understanding of the true "novelty" of today's calls for 
Hemispheric or New World Studies. More importantly, it could make us reflect critically on the possible dangers of such knowledge configurations. This essay, in particular, might thus serve to send out some warning signals. The new tendency emerging in US humanities departments could well be just another manifestation of a new "turn" in imperial power relations (globalization) as it unfolds and manifests itself in the various devices and instances of university-based powerknowledge productions. The story of the making of Hispanic American History, it seems to me, tends to confirm this suspicion.

In the first part of this essay, I will review Bolton's call for a hemispheric history of the Americas, challenging L. Hanke's view that silence and misunderstanding were the responses from historians North and South of the Rio Grande. In the second section, I will present some organizing categories_coordinates of time and space - that were purported to guide the writing of Hispanic American History, a discipline that in turn was presented as superseding the existing parochial histories of individual Latin American nations. Following this, I will examine some textbooks of Hispanic American History of the interwar period in order to show how US historians tried to "calibrate" the time and location of the subcontinent in their historiographical narratives. A fourth section is devoted to underlining the complicities between Hispanic American History and the US's Good Neighbor Policy. Historians' contributions to map anti-US-American resistance in Latin America during the 1920s and 1930s constitutes a clear manifestation of this collaboration. Finally, the essay puts the current "transnational turn" in American Studies in relation to these earlier debates about the wisdom and productivity of a Hemispheric History of the Americas. To disengage these new, more comprehensive agendas from the hegemon's cultural policy, this essay argues, would necessitate a critical evaluation of the geopolitics of knowledge-production in which US universities and US scholars are currently immersed.

\section{Bolton, the Boltonians and the Hemisphere}

In 1963 Lewis Hanke, one of the central figures of Latin American History, convened a conference to discuss the relevance of the so-called "Bolton theory." The conference and the subsequent book were titled Do the Americas Have a Common History?, in honor of Herbert E. Bolton's 1932 address to the American Historical Association in Toronto. This address, titled "The Epic of Greater America" (Bolton 1933), constituted a timely call to change the then dominant "American History" approach (US history, in actuality) into a truly continental field of historical inquiry (Hanke 1964). At the height of the Great Depression and at the start of the Good Neighbor Policy, Bolton asked US historians to consider the hemisphere 
(the Americas) as the true framework of US history. Not only because, as pioneer Latin Americanists B. Moses and W. Sheppherd had shown, Hispanic traditions and culture were an important part of US history, but because the comparison between Anglo-America and Latin America promised to render important insights that could serve as the bases of a composite or comprehensive history of the continent.

When Hanke, assisted by a group of historians from the United States, Canada, and Latin America, re-examined this issue in 1963, he presented a pessimistic appraisal of Bolton's impact on US historiography. Though Bolton and his students had firmly established the study of the Hispanic Borderlands as a component of US national history, Bolton's proposal for a hemispheric history had received only "apathy and silence" from the profession (Hanke 26). US historians dealing with national history continued to teach "American History" as if the 1932 address had never taken place. In Latin America, few historians acknowledged or gave credit to Bolton's approach (among them Argentinian historian E. de Gandía), others called for the essential unity of the continent (Colombian historian G. Arciniegas), and still others, such as Mexican historian Edmundo O'Gorman, rejected Bolton's proposal outright.

In a 1939 essay, O'Gorman suggested that Bolton had failed to understand the incommensurable gap in the spirit and mindset between the two Americas (O'Gorman 1939). ${ }^{1}$ Later, in his intervention during a 1941 meeting of historians in Chicago, O'Gorman again maintained his view about the separatness of the two Americas. He presented Spanish colonization as based upon a medieval conception of religion, while Anglo-American colonization was invested with the spirit of modernity and sustained by the ideal of religous freedom. To re-affirm his belief that Anglo and Latin America deserved different histories, he aligned in his support José Enrique Rodó, José Martí, and Simón Bolívar, writers who had seen US-America as endangering the cultural integrity of "Our America" (Hispanic America).

The project of a common hemispheric history clearly had a political dimension. If not in political and diplomatic practice, the Americas could be united in history. If historians could show that enough similarities existed between their individual historical trajectories, a new "commons" would emerge in the area of the humanities, an intellectual domain where representatives of Anglo and Latin America would find a common understanding of the past and, likely, be able to imagine

1 For a discussion of O'Gorman's work, see Kozel, La idea de América en el historicismo mexicano (2012), chapter 2. 
a common future for the continent. Against this lofty ideal stood the reality of a discipline established by US-Americans in order to support the US's hegemony over the Americas. Latin American intellectuals had little to say in this common history enterprise and, to the extent that they were invited into the project, their work contributed to intellectual agendas designed at US universities.

Bolton delivered his famous presidential address (1932) during a period in which historiography in the United States was inextricably intertwined with the policies of Pan-Americanism. His intervention at the Toronto meeting of the AHA had the double intention of making US historians reconsider the forgotten Hispanic component of US history and also of turning the attention of US historians to the countries South of the Rio Grande. Bolton and other historians of his time thought that these histories were important to the Unites States as a nation seeking international recognition as a new world competitor for power and in need of allies in the hemisphere. In other words, we cannot simply divorce the project of a Hemispheric History from the US's policy of "intellectual cooperation" and soft (cultural) Pan-Americanism. ${ }^{2}$ Though Bolton wanted to complicate the historical bases of "American (US) identity", he at the same time tried to provide food for thought to the foreign-policy community who was dealing with a vexing and old problem at that moment: how to isolate Latin America from European conflicts and influences.

Hanke's pesimistic view of the impact of Bolton's proposal among US and Latin American historians alike was probably exaggerated. Not only because a Program for the History of the Americas had been introduced and carried out by the Pan-American Union, but also because the idea of a comparative history of the Americas had already been established by the American Historical Association in the form of a Hispanic American History project. Long before Bolton's 1932 speech, starting in the post-WWI period, US historians had already been writing histories of "Latin America" that included comparisons to the US's historical experience and culture. These historical narratives presented the United States and its exceptionalist position as the measuring rod of modernity and progress on the subcontinent. Empowered by the sense of a relocated Occidentalism, US historians endeavored to colonize the field of the history of Latin America, presenting their own comprehensive view of the Americas as the superior one. ${ }^{3}$

2 On the policy of "intellectual cooperation" see Salvatore, "The Making of a Hemispheric Intellectual."

3 For a different, non imperialist rendering of the making of Hispanic American History, see Delpar 2008. 
In the domain of history, the ideals of Pan-Americanism led to the formation of the Pan-American Institute of History and Geography, under the auspices of the Pan-American Union, and funded by the Rockefeller Foundation. One of the Institute's initiatives was the History of the Americas Program. Under the leadership of Silvio Zavala and Arthur Whitaker (a collaboration between a USAmerican and a Mexican historian), this program produced a general outline for the writing of historiographical narratives of continental scope, and proposed a list of authors and works to carry the Program's objectives into practice.

In 1959 Silvio Zavala reported on the progress made by the Program of the History of the Americas to date. ${ }^{4} \mathrm{He}$ stressed that two of the central objectives of the program were to design textbooks that would carry the idea of a Hemispheric History into the classrom, and that the writing of these textbooks would lead to an international cooperation among historians. As a byproduct, this would generate a greater exchange of research on the history of the two Americas. The grand plan implied dividing the task into three parts: anthropologists would deal with PreColumbian America, a group of US and Latin American historians would work together on the volume on Colonial America, and the third volume would be a compilation of as many contributors as the countries in the hemisphere.

In addition to this division of labor, the program committee worked hard to impose a uniform periodization on the histories of the "national period." These were: 1) the gaining of independence (1778-1830), 2) the consolidation of the American nation states (1830-1870), 3) the growth of diversity witin American nations (1870-1910), and 4) a new revolutionary era in the Americas (1910-1950). Contributors were asked to deal with all four sub-fields of the discipline of history (political, economic, social, and cultural). Zavala expected that with the cooperation of historians from the two Americas, the program would be able to avoid the narrow vision of a single imperial nation (Britain, France, Spain, Portugal) trying to present their own view of history. In the new history of the Americas there was no place for the tensions between a Protestant history of Spanish colonization and the Spanish patriotic view of its own colonization process. The history would be told from the perspective of "Americans at large."

In his introction to the project (1957), professor Arthur Whitaker of the University of Pennsylvania emphasized that this would be a collaborative history dealing with the entire Western Hemisphere. ${ }^{5}$ It was, in this regard, to be considered

4 Silvio Zavala, "International Collaboration in the History of America," reproduced in Hanke 1964, 226-231.

5 Arthur Whitaker, "Introduction to the Project for a History of America," reproduced in Hanke 1964, 192-201. 
a "grand history" comparable to projects such as Toynbee's history of civilizations or Gibson's history of the British empire. As Whitaker acknowledged, the main difficulty for the planned volumes would be to keep a balance between national and regional particularities and the generalities or common denominators uniting the entire hemisphere. This was particularly problematic for the discussion of the "national period," where historians endeavored to impose their own national perspectives onto the history of a whole sub-region (Mesoamerica, the Andean nations, or the River Plate region). Meetings in Havana, 1953, Washington, 1956, and smaller-scale meetings in New York and Mexico had tried to smooth out these differences.

By 1959, through the agency of the Pan American Institute of History and Geography (IPGH in Spanish), the program had managed to publish nineteen contributions or booklets: ten on the pre-Columbian period, five on the colonial era, and four on the post-independence and modern periods. I have been unable to examine these texts. Consequently, I cannot at this point determine whether the resulting volumes reflected the consensus reached and, to this extent, constituted a more comprehensive or alternative history of the American hemisphere. Yet it is clear from the project leaders' remarks that the work done before 1959 was only preparatory: Whitaker stated that the volumes published were small booklets, nothing more than preliminary surveys, which could serve as the basis for the writing of "a monumental history of America" that was still lacking at this point.

Yet while the number of books was indeed limited and the publications took time to reach readers, this program nonetheless represented an advance, however modest, over US practices in the realm of intellectual cooperation. The cultural policies of Pan Americanism had managed to produce the groundwork for a Hemispheric History. Later events, such as the Cuban Revolution, would dramatically change the climate of cooperation between historians and the US State Department. ${ }^{6}$ Another important aspect is the fact that the very process of specialization would later refocus the attention of historical inquiries onto "national histories," and even later onto multiple dispersed "local histories." Yet the impulse during the 1930s and 1940s was clearly to place the findings of historical inquiries into Latin America within the context of a comprehensive sub-discipline (Hispanic American History) that found itself in permanent comparison with the hegemonic model, US historical experience and culture.

6 See, in this connection, Berger, Under Northern Eyes. 


\section{Hispanic American History (History With a Purpose)}

The project of Hispanic American History matured in the US around 1918, with the founding of the Conference on Latin American History (CLAH) and the launching of its journal, the Hispanic American Historical Review (HAHR). As the founders of this project envisioned, their subdiscipline would try to understand the past of Hispanic- American nations ${ }^{7}$ from the perspective of the United States. It was thus in Chakravarty's sense a located, "provincial" history. Yet it was also a regional history, not a collection of national histories, but a grand narrative about the evolution of the whole subcontinent called "Latin America." Even though at the beginning its practitioners wanted to be in conversation with top-of-the-line US historians practising "American History," in actuality the American Historical Association tolerated these poor cousins in its organization without fully engaging with them.

To be regarded as useful knowledge, this regional history had to be comparative in nature. That is, historians needed to frame their findings in relation to the experience and culture of the United States. To this extent, Hispanic American History was, from its inception, US-centric. It reflected the perspectives of US scholars and, indirectly, the values of the "American nation" (as understood by white, male, university-educated US-Americans). And it considered as part of its field the foreign-policy issues faced by the State Department and the US's political elites. It was, without doubt, a history with a purpose, a neo-imperial engagament with Latin America's past.

At the time of the constitution of the CLAH and the start of the journal, the $H A H R$, the discipline of "American Studies" was actually in its beginnings and, consequently, historians were relatively free to enunciate what they considered to be "America" (US culture, traditions, values, etc.). Bolton, for example, was a disciple of F.J. Turner and actually tried to apply Turner's frontier thesis to the Spanish Borderlands (with quite negative results). ${ }^{8}$ For other Latin American historians contemporaneous with Bolton, the idea of "America" included the idea

7 Though occasionally confusing, the term in practice also included the past of Portuguese-speaking Brazil. Later, "Hispanic America" was gradually replaced by the more comprehensive term "Latin America." If Brazil was sometimes excluded or given little space in some textbooks, this was simply due to the more limited expertise about Brazilian history in the United States. For the case of Brazil (the empire, late abolition, and an apparently peaceful republic) was an enticing case for Hispanic American historians.

8 See Weber 1986. 
of territorial expansionism, democratic governance, economic competitiveness, ample individual liberties, and so on. ${ }^{9}$

The project of Hispanic American History had two primary goals: (a) to reorganize the historical narrratives of the twenty nations South of the Rio Grande into a coherent totality, in order to render these societies more transparent-or at least legible-to US university students and the scholarly community; and (b) to try to locate Latin American nations within the context of "American exceptionalism," understood as the constellation of differences that distinguished US government, society, economics, and culture from Europe. Re-defining regional history towards a greater totality (the Western Hemisphere) in order to pose within this enhanced terrain the problem of US exceptionalism was, to these historians, an enormously difficult but enticing challenge.

The first goal entailed recognizing the existence of cultural similarities between and a shared historical experience of the nations of Latin America. This required abolishing the "national" history projects practised in each of the twenty Latin American republics by proposing a comprehensive view of their collective past. By disavowing the claims of national historians to the specificities of their own country's histories, US historians claimed to be creating a superior type of knowledge. The second goal implied placing Hispanic America at a temporal and geocultural distance from the United States. Numerous publications had positioned "(US)America" at a unique location in world history. This was a nation formed by people of European stock who, due to a number of reasons, were able to successfully experiment in the new world with forms of government, religious and civic liberties, economic competition, and forms of social interaction that were considered "exceptional." In this regard, given the assumed cultural and technological superiority of the United States vis-á-vis Latin America, it was only natural that the twenty nations South of the Rio Grande would be "less than exceptional."10

US-based historians of Hispanic America strove to establish a delicate balance between sameness and difference. They had to present Latin America as

9 Multi-culturalism was clearly out of the horizon. Carlos Castañeda (a historian specializing on Texas and the US southern borderlands who lectured on Latin American history) was the only Chicano within the group. The rest of the group, particularly in relation to Bolton and Hanke, showed a degree of admiration for Hispanic (and Hispanic American) culture that was in retrospect surprising.

10 Other renderings of the American ideal, such as the "American dream" did not seem to be central to this generation of historians. Yet, the New Deal climate made them present ideas of social equality and social welfare as an essential component of US modernity. 
lagging behind the United States while being part of the same "American" spirit and legacy. In particular, since their independence, many of the new republics South of the Rio Grande had adopted legal institutions and policies modelled upon those of the United States. Yet by the end of WWI most of them had "failed" to achieve self-government, competitive free markets, and a minimum of welfare for its populations. This "backwardness," I suggest, was constitutive of the field to the extent that it informed almost all historical narratives of the subcontinent. At the same time, US historians had to acknowledge and measure the difference produced in the making of the Latin nations by 300 years of Spanish colonialism, and by the influx of European ideas, technologies, trade, and capital in the $19^{\text {th }}$ century. A late-comer to the game of international commerical and financial competition, the United States needed to carve out a cultural space from which to interpellate and entice Latin American elites. The successful construction of US cultural supremacy necessitated the deployment of a believable relationship between the "example" or "role model" and the "imitator" - the "leader" and the "follower"-within the framework of US-American exceptionalism.

This was, to be sure, an exercise in calibrating time and space. In terms of place, historians had to locate "Latin America" at an appropriate distance from the United States on the one hand, and from Europe on the other. By necessity, the region was to be an "in-between" area, a collectivity in between the attractions and influences of Europe and the Colossus to the North. Yet also a region that needed to be internally fragmented in order to gain greater comprehension hence, the various strategies to establish differentiations between Eastern and Western republics, Andean and Atlantic nations, Caribbean dictatorial states and progressive European implants in the River Plate. In terms of time, US historians replicated the assertions of early $20^{\text {th }}$-century travelers. ${ }^{11}$ In terms of economic progress and social modernity, the $\mathrm{ABC}$ countries (Argentina, Brazil, and Chile), were only 50 to 60 years behind the United States. The Andean nations, on the other hand, were living in ways similar to colonial societies 200 or 300 years earlier. Here were the large areas of "pure" indigenous villages untouched by foreign investment and European modernity.

In terms of geo-cultural location, reaching a synthesis for a quite diverse region-where modernity and tradition competed for primacy—proved difficult. In cities such as Buenos Aires, Montevideo, Santiago, and Rio de Janeiro, scholars acknowledged the strong presence of European cultural modernity. In the rural landscape and agricultural production of the $\mathrm{ABC}$ countries, scholars could also

11 See Salvatore, "Early American Visions" (2002): 58. 
point out signs of US modernity: grain elevators, trucks, farm machinery, corn markets, banks, insurance companies, and modern port facilities. In the rest of South America, US or European modernity was restricted to foreign enclaves created by petroleum, mining, and banana companies. The influence of British, French, and German business methods and culture had imprinted certain ports and cities of South America with a "European flavor." The vast majority of Andean cities (Cali, Bogotá, La Paz, Quito), on the other hand, had retained traits of Spanish colonial life. There, signs of modernity were hard to find. The visitor who immersed herself into the highlands and valleys of Bolivia, Peru, and Ecuador was sure to find villages almost uncontaminated by European/American progress. Travelers marked these villages and countrysides as "Indian," for the majority of its population appeared to be of indigenous descent. By extension, they called Peru, Ecuador, and Bolivia "Indian nations," encapsulating in this label the largest possible distance, in time, progress, and customs, from the US's exeptional civilization.

US historians of Hispanic America replicated the assertions of Euro-American $20^{\text {th }}$-century travelers, contributing empirical evidence for "placing" some of these regions-Andean nations in particular-in a distant Spanish colonial past. The Caribbean, called "the American Mediterranean" at the time, was a geo-political location disputed since the $17^{\text {th }}$ century by England, France, and Holland, and now, since 1898, under the United States' orbit of influence and intervention. This area lived in a perpetual time of revolutions and dictators and was, consequently, denied the possibility of ever entering modernity. Though many located some of the roots of this failure to attain modernity (in particular, self-government) in the tropical climate or in the African origins of the population, others took as a given the inability of the Caribbean nations to attain progress and civilization. The $\mathrm{ABC}$ countries stood at the opposite end of the spectrum, very close to the time of European modernity, but still lagging behind the United States. Here were the US-Americans' closest cousins, people of European stock developing similar institutions with a remarkable degree of success in terms of political stability and economic progress, who only needed to sustain the effort a little longer.

\section{Calibrating the Time and Space of Hispanic America}

In 1919 William W. Sweet published one of the first comprehensive histories of the region. His A History of Latin America treated the territory of the Spanish empire as a whole, establishing the traditional difference between the core areas (New Spain and Peru) and the fringe areas. Yet, starting with independence, nations needed to be placed in certain groups in order to account for both similarities and differences in their development. Sweet took the decision to divide the countries 
into "backward" and "progressive" ones, based mostly on their ability to embrace political modernity. Those countries that had failed to break the vicious circle of revolutions and dictators were grouped under the label of "backward states." Among them were Venezuela, Colombia, Ecuador, Peru, Paraguay, and Bolivia. Those other countries that had attained some degree of political stability and a minimum of political participation were grouped as "progressive states." Among them were Argentina, Brazil, and Chile. ${ }^{12}$ Whereas in the "backward states," history assumed the form of an endless succession of dictators-interrupted by liberal interludes and the enactment of "paper constitutions"-in the "progressive states" it was important to ponder the merits of "capable presidents" who had promoted reforms that served to establish forms of "self-government" similar to those of the United States before the Civil War.

With time, this dividing line acquired the fixity of a geographical and cultural boundary. S. Guy Inman's Latin America (1942) took the Andes as the dividing line between nation-states that looked towards Europe and those which could be seen as falling under the influence of the United States and embracing some modernity. Yet it was more likely that nations to the West of the Andes would remain trapped between Spanish medievalism and Inca times:

East of the Andes, the peoples of the continent look toward Europe. West of the Andes, one gets the feeling, as in crossing the Rockies in the United States, that here is a different world, a world in which the former Inca civilization blends with the Spanish colonial to form a unique culture. (Inman 1942: 115)

Inman characterized Argentina as "the most European of American nations," because of its successful inmigration policy and its predilection for European ideas and fashions. Its governing elites tried to keep a safe distance from the United States while selectively adopting the novelties coming from Europe. Uruguay was presented an an "international center"-the Switzerland of America-where most progressive movements found a home. While not particularly European, Chile formed an example of a nation in which an appropriate racial mixture (the blending of "strong Basques" with "virile Araucanians") was able to establish a centralized and stable government. Peru, Bolivia, Ecuador, Colombia, and Paraguay were examples of the opposite. Ecuador under García Moreno was an "experiment in theocracy." Bolivia was a failed nation, with the record of 60 uprisings in 70 years. Peru represented the typical case of an aristocratic mestizo elite ruling over an unassimilated Indian majority. Colombia was an example of a country of

12 According to Sweet, Uruguay belonged to this group only because of its economic progress, because it continued to be engaged in endless civil wars. 
continuous upheavals where principles and rhetoric led ruling elites (liberals and conservatives) into recurrent bloody confrontations. Venezuela was a land rich in caudillos. The fall of the last caudillo, Juan Vicente Gómez, in 1935, promised the incorporation of this country into the modern world.

A double matrix governed Inman's classification of Latin America: the success or failure with respect to political modernization; and the relative distance to distinct geo-cultures (to Spain, Europe, the United States, or Africa). Colombia and Venezuela, whatever their successes in overcoming dictatorship or caudillista governments, were closer to the Caribbean, that vortex of revolutions and upheavals, than the rest of South America. Brazil had some points of contact with the United States, but in racial matters, the country had advanced towards a policy of racial miscegenation. By doing so, Brazil remained closer to Africa than the rest of South America. In general, due to its peculiar mixture of races and its institutional borrowings from Spain, France, and the United States, Latin America had developed "a unique civilization" located "in-between Orient and Occident" (Inman 21). Inman wrote:

They [Latin Americans] can give us special help in solving one of the greatest problems in race psychology — an understanding, in this shrinking world, between Oriental and Occidental civilization. For here in Latin America dwell people who have borrowed much from the civilizations of Asia, Europe and America. Living more or less isolated from the rest of the world, they have worked out a philosophy which embraces some of the major points of view of all three of these continents. (Inman 21)

Latin Americans had inherited certain Oriental attitudes from the Arabs, intellectual aspirations from Europe, and the enthusiasm to build a new world from US-America.

If the Andes functioned as a geo-cultural divide, the Panama Canal also served to separate two distinct areas according to US strategic thinkers. To the North of it were the Caribbean and Central American nations, areas prolific in revolutions and financial mismanagement that could bring about opportunities for European interventions. This circumstance alone justified (according to US policy makers) the US's right to intervene in the politics and finances of the region. To the South of the Canal was a vast territory dominated by European culture and commerce. In this region, European cultural and business supremacy could only be contested through innovative business methods, counter-propaganda, and government investments in transportation. Here military intervention was deemed impossible and unpractical, as the Venezuelan situation had proven. South America was the land of a potential informal empire, a place where the Monroe Doctrine could not be enforced with the same duress and efficacy as in the Caribbean and Central 
America (Munro 588-89). To the North of the Canal were countries of revolutions, volcanos, and tropical diseases; to the South were more diverse polities and peoples, struggling to emulate European and US modernity. This "Great Divide," discursively constructed on the basis of strategic foreign policy thinking, was subsequently uncritically adopted by most historians of the region.

The presence of progress in the Southern Cone prompted a comparison between the civilizations of North and South America, a field in which US historians of Hispanic America willingly intervened. Their contributions were to map a world of differences that enhanced and made more complex the ongoing debate about the existence of two different "Americas" and the possibility of a comparative, hemispheric history. As the Bolton debate made clear, US historians held conflicting positions in relation to this problematic. Yet at the same time the adventure of a hemispheric history was also contemplated by many Hispanic American historians, though practised only by a few. During the times of the Good Neighbor Policy, there were many historians who raised this possibility and tried to persuade the profession to move in this direction. The call was to move towards a hemispheric and comparative history of the Americas. Behind the question posed by Lewis Hanke- "Do the Americas Have a Common History?"-lurked the intriguing possibility of uncovering the mindset of the typical "Latin American" as it differed from what was considered the mindset of the typical "(US)American."

While the lavishness of nature and, to a certain extent, frontier life gave the Americas a common destiny, a world of difference still separated Anglo-Saxon from Latin America. The Anglo-Saxon was practical while the Latin American was theoretical. The former was devoted to science and material progress, whereas the latter dedicated most of his time to human relations. The importance attributed by "Latin Americans" to juridical forms was counterposed by the importance attached to practical governance in Anglo-America. Family and honor (dignidad) constituted high values for the Latin American, whereas the Anglo-American attributed greater value to material welfare and efficiency. ${ }^{13}$ Accustomed from childhood to confuse the ideal with the real, Latin Americans copied without modification the US constitution in the belief that this would produce an ideal democracy. This naiveté had a price: in order to learn the lesson of self-government, Latin Americans had to stumble many times into anarchy, dictatorship, and corrupt government (Inman 22-24, 28-30).

13 Inman wrote: "The Latin American values his dignidad more highly than a full stomach, paved roads, smallpox vaccine, and other blessings of efficiency" (Inman 24). 


\section{Policing Anti-Americanism}

Because of its relational nature (in connection with US exceptionalism) and its useful purpose, early attempts at producing a comprehensive and long-term view of the Latin American past could not avoid dealing with contemporary United States expansionism and Latin American reactions to this process. Early books usually contained a foreign-relations section in which authors dealt with the US's policy of Pan-Americanism, the actuality of the Monroe Doctrine, and/or the expansion of US companies and capital into the subcontinent. Often, these early histories of the subcontinent drew attention to the existence, throughout Latin America, but particularly among South American nations, of a growing "apprehension" and "distrust" towards the Northern Colossus. Even though this anti-American resistance manifested itself in different types of print culture, it was more readily apparent-and more dangerous - in the writings of leading intellectuals of the region.

From the late 1920s through the 1940s, the emerging discipline started to inform readers about Latin American "reactions" to US policy measures. These scholarly interventions were tantamount to policing anti-imperialism. Some of the anti-Americanism prevalent in the nations South of the Rio Grande was alternatively called "distrust," "misgivings," "apprehension," "suspicion," or "fear," and presented as the product of anti-American propaganda by European nations, if not as the result of purposeful misrepresentations of the United States and its people. The intelligence gathered by US historians visiting the region called attention to the growing nationalism of South American elites, a new phenomenon that could de-rail the progress made by Pan-Americanism since the first decade of the $20^{\text {th }}$ century.

The fact that anti-Americanism was articulated by some prominent members of the ciudad letrada of South America, in terms that presented a clear defiance against the economic, political, and cultural hegemony of the United States in the region, was a source of concern for US experts in the field as it constituted an unexpected resistance from scholars and litterati who were otherwise genearally considered to be the leading civilizing force of the region. In fact, the most serious anti-American critique came from the cultural elite most knowlegeable of-and in contact with-US culture and academic life. Surveying the extent and diffusion of anti-American feelings, US scholars "discovered" new types of national cultural and political awareness, such as nationalism and indigenism. They attributed to these discourses a disruptive potential vis-á-vis the ideal of US Pan-Americanism and the Good Neighbor doctrine. Here was the "native informant," usually a collaborator in the informal empire's enterprise of knowledge, now turned into a critic of the intellectual, moral, or cultural superiority of the United States. 
Anti-Yankee imperialism was a new development that deserved the attention of US scholars, the US foreign-policy community, and the common US reader. Hence, it was not unsual that historians, producing scholarship connected to the formulation of US foreign policy principles, took up the issue and tried to understand it. Among them were C. Haring, F. Rippy, L. Hanke, A. Whitaker, J. Lanning, and other leading figures in the field of Hispanic American History. Here, I shall deal with only a few of these scholarly interventions. (A full examination of these intelligence-gathering activities by scholars, and in particular by historians, is still needed). ${ }^{14}$

C. Haring, in South America Looks at the United States (1928), formulated a strong argument in this direction. He called the attention of his fellow US-Americans to the growing anti-American nationalism in South America, nurtured as he thought by a "mistrust" propagated by intellectuals and the periodical press. Anti-American propaganda had produced a proliferation of misrepresentations of the United States. "The Yankee is generally pictured as lacking in subtlety, sentiment or esprit, rude, pugnacious, a boaster with whom brawn obtains preference over brain, and for whom everything is 'made to order' in a mechanical civilization" (134). South American newspapers took pleasure in criticizing the United States for the activitities of the Ku Klux Klan, the war reparations problem, Prohibition, New York murder rates, the frequency of divorce, or the immodesty of American women.

In addition to the Pan-Hispanicists and the Pan-Latinists, intellectuals and publicists from Mexico were actively discrediting the United States. The "rapprochement" between intellectuals from Mexico and the ABC countries promised to further nurture anti-Americanism. To Haring, the creation of the Unión Latino-Americana by Argentine scholar José Ingenieros, and the journey of José Vasconcelos to the River Plate countries was detrimental to the US's reputation in the region. Ingenieros exhorted Latin American nations to morally resist foreign imperialism, denouncing the Monroe Doctrine as a "right of intervention" by the US (143). Ingenieros' successor at the Unión, socialist Alfredo Palacios, became a "violent Yankee-baiter [sic]" (145). In Uruguay, the Centro Ariel had continued Jose Enrique Rodós anti-US preachings. The Nicaragua imbroglio provoked reactions among students in Argentina, Uruguay, Peru, and Chile. Vasconcelos' Mexico-City based Unión de la Juventud de Hispano-América turned into the headquarters of anti-US propaganda for many Latin-American students.

14 See, for another discipline, Harris and Sadler, The Archaeologist Was a Spy (2003). 
Sociological essays by Latin Americans-by C.O. Bunge, M. Ugarte, R. BlancoFombona, and Monteiro Lobato, among others-contributed to discredit the US's policy of Pan-Americanism by proposing a union of Latin-American nations in opposition to the United States. Even the poets of the region-Rubén Darío, José Santos Chocano, and others-raised their pen to warn their countrymen against the "Yankee peril." To Haring the three most eloquent and persistent critics of the US were Venezuelan Blanco Fombona, Mexican Carlos Pereyra, and Argentinian Manuel Ugarte. In addition to challenging the historical parallelism between Anglo and Hispanic America, these writers denounced the US's attempts to promote its economic predominance in and cultural penetration of Latin America. In short, intellectuals from the region were forging a new "continental consciousness" that spread live-fire among many university students of the region.

Historian Fred Rippy also contributed to unmasking the rhetoric and practice of anti-imperial thought in various books and articles. He devoted one chapter of his widely-read Historical Evolution of Hispanic America (1936) to examine the phenomenon of "Yankeefobia." Anti-American feelings emerged as a reaction to US economic imperialism: "considerable distrust, fear, and hostility developed along with our hegemony" (536). The great newspapers of the $\mathrm{ABC}$ countries were severe in their condemnation of US interventions in the Caribbean. This, added to the anti-American propaganda disseminated by Spaniards, Frenchmen, and Germans, produced a generalized distrust among Latin American elites against the intentions of the United States.

Anti-Americanism also figures prominently in D. G. Munro's The Latin American Republics (1942). The two Pan-American conferences of 1923 (Santiago) and 1928 (Havana) brought forth an increasing "unfriendliness" of South American nations vis-à-vis the United States. The US's continued interventions in Haiti and Nicaragua caused great uproar among the southern republics (Munro 596-97). In 1933 President Franklin Delano Roosevelt stated his new policy of non-intervention, which contributed to improving the relations between the US and Latin American nations. Yet, as Munro acknowledged, economic nationalism was the true basis of the new anti-Americanism during the 1920s and 1930s. Since the mid- $19^{\text {th }}$ century, foreign capital had dominated the economic life of the new republics. As their citizens saw the best jobs and business opportunities taken over by foreigners, resentment grew against foreign investors. This resulted in a demand for greater control over foreign property, the nationalization of natural resources, and efforts to substitute imports with local industry (Munro 599-602).

We cannot claim today that early Pan-American historiography was unconcerned with imperialism and its resistance. Early US historians in the region did consider this problem. They seriously interrogated the roots of Latin American 
"distrust," and presented policy suggestions to ameliorate and counteract antiAmerican resistance and "propaganda." In fact, we may say that US-based Latin Americanists of the 1920s and 1930s made efforts to incorporate the Latin American Other into their narratives, precisely because theirs was a hemispheric history connected to and useful for US foreign policy interests. Yet, this Other was mainly an invention: an abstract and compact discursive subject, the product of US scholars' superficial encounters with a few members of Latin America's educated elite.

In addition to featuring this educated, elitist, and well-mannered Other, the histories of Latin America authored by US scholars also posited the existence of a multitude of Others still to be incorporated into civilization, progress, and history. These were the vast numbers of Indians, Blacks, and mulattos that constituted the majority of the populations of countries such as Ecuador, Bolivia, Paraguay, Peru, and the whole of Central America and the Caribbean. The failures of the white and mestizo elites' political leadership in these countries offered a direct reflection on the lack of opportunities, poverty, and marginalization of these majorities. US scholars, while acknowledging their presence, presented them as the beneficiaries of the future. Only in the future, when their nations would have achieved US modernity-when the Andean nations would be able to replicate the type of democracy, social welfare, and technological progress already enjoyed by the US-would these majorities inherit the promised land of "American welfare." Besides this minimal gesture towards a massive and unknown Other, US historians dealt mostly with Latin American elites and studied and reported the attitudes and writings of these intellectuals.

This is not the place to reflect on the ways in which US scholars visiting the sub-continent "pictured" their Latin American colleagues. ${ }^{15}$ Yet it is clear from their dismissive gestures towards local intellectuals and, particularly, from their critical views on the region's universities, that US scholars advanced and fedwith their inquiries, reflections, and opinions-the agenda of US intellectual hegemony. Early US historians of the region stated clearly that US universities were better places for the study of Latin America's past, because there scholars could find extensive collections of documents and books, a strong concentration of scholars, and publications devoted to a comprehensive view of the region. These scholars were in fact in the process of establishing the institutional apparatus (the faculty, the graduate programs, the specialized libraries, the conferences,

15 In contradictory ways, US scholars elevated the work of Latin American scholars and intellectuals to the terrain of lofty ideas, high spirituality, and pure doctrine, while considering their scientific or academic production lacking in rigor and substance; their histories were seen as ineffective, self-serving, and little-known. 
the recruitment of students, and the fund-raising) needed for this enterprise of knowledge-production to function and prosper. Theirs was a perspective that, due to its large scope and comparative capacity, was bound to produce a more truthful and useful history of Latin America.

Whether intentionally or not, the project of a US-centered history of Latin America (and by extension, of a comparative US-Latin American history) was to colonize the national histories of individual Latin American nations, to the point of rendering them subaltern. In the midst of the Good Neighbor Policy, US historians were not at liberty to critique the Latin American intelligentsia and the countries' universities outright. In order to build bridges of cooperation between themselves and these aristocratic, pompous, and overly rhetorical Others- "native scholars"-, US academics usually employed a condescending tone. Moreover, they often made efforts to align the policy of "intellectual cooperation" with their dismissive views of Latin American scholars. Guy Inman, for example, suggested a possible complementarity between two types of scholarship: the "Latin" scholar given to theoretical principles, the contemplation of beauty and spirituality, is compatible with the "Anglo-Saxon" scholar, governed by practicality, scientific procedures, and a commitment to improve common welfare. (One cannot fail to notice a dose of Arielismo in Inman's friendly gesture towards intellectual complementarity and cooperation). ${ }^{16}$

\section{The Relevance of the Bolton Debates Today}

If H.E. Bolton were to awake today and look into the emerging field of New World or Hemispheric American Studies, he would find many of the propositions, definitions, and calls for action quite familiar. Yet he would have difficulties in understanding the geopolitical and institutional context in which these intellectual challenges take place. He might argue that historians of the 1930s and 1940s already discussed many of these issues and, at the same time, be quite intrigued by the unfamiliar mix of disciplines attempting to re-examine the study of "the Americas at large." In the years of the Good Neighbor Policy, history and literature were the two disciplines trying to incorporate the unfamiliar Other

16 Other historians such as Clarence Haring, Arthur Whitaker, and Fred Rippy, imagined Latin American historians as producers of empirical historical data to be interpreted in the emerging centers of Latin American Studies in the United States. Or they regarded "national histories" as the raw materials which, put in comparison with other national histories, would render new revelations and insights about the Latin American past, the character of its peoples, and its potential for the future. 
(Latin America) into the self (US-America). If pressed, Bolton might concede that he and his disciples made good progress in the field of the Hispanic Borderlands, but they were less successful in developing a continental history of the Americas. The Pan-American Institute of History and Geography later took up this initiative, yet with relatively little impact on the profession. Enthusiasm for a Pan-American history subsided when the Second World War demonstrated that the continent was not as united as US policy-makers had thought.

Bolton might see a certain degree of similarity between efforts launched during the 1930s and 1940s to study the common but divergent destiny of Anglo versus Spanish America and today's emphasis on studying the multiple voices, experiences, and cultures of "a greater America," that is, an "America" of continental dimensions. He might be surprised to find that after so many years, a custom union (NAFTA) was only formed among the US and its immediate neighbors (Mexico and Canada), while the rest of Latin America has negotiated separate agreements with the United States or refuses to start such negotiations. The hemispheric custom union imagined by Blaine in the 1890s was later boycotted by the River Plate republics (in particular, by Argentina). But today, it seems that defiance against the Colossus of the North is emerging from multiple directions at once: from the jungles of Yucatan, from the highlands of Bolivia, from Buenos Aires's industrial belt, or from the favelas in Rio de Janeiro. He would find out that, to his regret, the union of the American republics that was behind the project of a Hemispheric history got de-railed somewhere between the formation of the OAS (1948) and the Chiapas uprising (1994).

Bolton's unfamiliarity with (and perhaps surprise about) the present would stem from the new arrangements within the humanities and the social sciences in US institutions of higher education. For a person attentive to the territorial boundaries set by empires and nation states in their struggle for sovereignty and power, such as Bolton, these peculiar creations-Cultural Studies, American Studies, Ethnic Studies, Gender Studies, Gay and Lesbian Studies, Latino Studies, Post-Colonial Studies, Global Studies, etc.-would not seem to be particularly useful ways to organize knowledge. In particular, Bolton would be at odds to understand the "turn" towards multi-culturalism and post-colonialism, as well as the recent proliferation of knowledge projects under the guise of transnational or hemispheric "American Studies." Why turn towards the Hemisphere at a moment in which an already global power had persuaded others to go for "globalization"?

He might protest against my own attempts to present US historians of the interwar period as collaborators of US cultural and foreign policy interests in Latin America. Yet he would see in the past, and during the years of the Good Neighbor Policy in particular, a clearer picture of historians trying to complicate the story 
of what was "US-America" and how it became what it is today. He only wanted to contribute to this story by introducing Hispanic traditions, institutions, and historical events into the history of the USA. Yet in the present, the question of a "greater America" would trigger the even more difficult question of the location of "US-America." Where can US-America (its ideals of government and civil rights, its mass-consumer culture, its literature, its ethnic and racial diversity, even its multiple sexual identities) be found in Latin America today? Hated and rejected everywhere on the subcontinent, US global polices would, at the same time, be pondered as the only possible rationale for modernity. More than ever, in today's Greater America, the US would be functioning as a role model, albeit an un-reachable one. Yet at the same time, "US-America" would continue to present an inexhaustible source of criticism and reflection on alternative modes of social organization and political life.

Clearly, Pan-American cultural diplomacy, the exercise in persuasion carried out throughout Latin America during the inter-war period, had produced mixed results. Some in the region would accept the US's cultural and technological superiority, while others would continue to reject outright these accomplishments as impositions on their own cultures and societies. Bolton would be particularly surprised to see that the policy of multi-culturalism that had taken at least three decades to become hegemonic in the United States, was rapidly adopted by regimes that the Washington establishment calls "radical politist regimes." $\mathrm{He}$ would find the recognition of the rights of indigenous peoples and the descendants of Africans in Colombia, Ecuador, and Bolivia refreshing news, policies quite in agreement with the progressive climate of the New Dealers.

If Bolton were to awake today, he would be particularly curious about the current connection between scholarship and state policies and, more generally, about the usefulness of the knowledge produced under the banner of New World or Hemispheric American Studies. In particular, Bolton would find current-day humanities scholars' disengagement with the US's political commitments towards its Spanish- and Portuguese-speaking neighbors difficult to understand. Many US scholars today see their work as more autonomous and independent of the work of the State Department and the US's "national interest" in the region. In Bolton's times, US efforts to understand Hispanic American history were intricately intertwined with questions posed by the foreign-policy community about how to best create friendly relations to the intellectuals South of the Rio Grande. Hispanic American history was a collective project guided by questions opened up by the penetration of US capital and trade into Latin America and by the need to adapt the Monroe Doctrine to the then-current condition and past trajectory of each nation of the totality called "Latin America." Looking North-to-South, US 
historians framed the regional history of Hispanic and Portuguese America as a means for understanding the "mindset" of Latin America, in order to incorporate this imagined collective subjectivity into the Pax Americana. In the specific geopolitical context of the interwar years (1919-1939), there emerged the possibility of launching a comparative history of the Americas that could account for the similar resources and the divergent paths of Anglo versus Latin America.

\section{The Past in the Present (Contemporary Concerns)}

There is a danger that New World or Hemispheric American Studies may in fact replicate the mode of intellectual appropriation and colonization that characterized the consolidation of Hispanic American History as a sub-discipline. Like US historians of the 1930s and 1940s who construed the intelligentsia of Latin America as the "resistant Other" opposing the project of US hemispheric expansionism, or as a collaborationist "native informant" participating in the imperial project of "intellectual cooperation," New World Studies in their literary variety may continue to dig into the treasury of literature (elite literature in Latin America, minority literature in the United States) to better understand the multiple positionalities and voices coming from the imperial hinterlands. Rather than forming an exhaustible resource, the Otherness of the multiple subalterities of the sub-continent may continue to nurture reflections, currents of thought, and "theory" for decades to come, incorporating into the US's power-knowledge discourse a wealth of "difference" that serves to reproduce US (Western) cultural superiority / hegemony.

In their origins, the literatures of Latin America-just as the region's pastconstituted a precious object of study, something to be revealed, understood, and translated, for it contained, it was believed, much of the "Latin American mindset." Hence, something similar to the process I have described about Hispanic American History occurred with the field of Latin/Hispanic-American Literature.

Am I wrong in saying that New World or Hemispheric American Studies are searching for a "generic subaltern" or an abstract alterity-a postconial racialized Other that could well match ethnic and gender alterities in the United States-in ways that look quite similar to those explored by Bolton and his colleagues in the 1930s and 1940s? Is this extension of the scope of "American Studies" towards the whole American continent going to produce a more in-depth interaction among different sites of intellectual knowledge production and different forms of scholarship throughout the Americas? Or, on the contrary, is this expansion only going to consolidate the intellectual hegemony of US universities vis-á-vis Latin American institutions? 
My point is: unless we first undo the uneven relationship between scholars working at US universities and scholars working in the developing world, particularly in the most underdeveloped regions of Latin America, it is difficult to see how an expansion of the spatial and temporal scope of "American Studies" would have an emancipatory potential, or how it would contribute to creating a more integrated, socially responsible, and mutually beneficial community of scholars in the Americas producing knowledge in the humanities that is both insightful and useful.

Am I mistaken in suggesting that the international diffusion of American Studies-particularly in the form of US popular culture studies-contributes to the transnational hegemony of the American way-of-life? The French and the German ministries of culture would be delighted if "French Studies" and "German Studies" could enjoy the same global popularity as the field of American Studies does today. Argentinian policy-makers may probably be more hesitant to attain such a global diffusion of "Argentine Studies," not only because such a field of studies does not exist, but also because when eventually articulated, it would probably revolve around an assortment of mythical figures (Evita Peron, Carlos Gardel, Diego A. Maradonna).

In this essay, I have endeavored to show that the proposition "let us see how the rest of the world looks at us" is less novel than promoters of transnational or international American Studies tend to think. Hispanic American History (a sub-branch of American History since its recognition in 1918) already did this during the years of the Good Neighbor Policy. In fact, since the late 1920s, the State Department had systematically been conducting or sub-contracting opinion polls in South America to gauge the level of anti-American feeling (Salvatore, "Yanke Advertising"). The relevant question is: where will the new peripheral opinion/knowledge about the United States go? Which will be the central offices and clearing agencies of the knowledge thus gathered? How can we ensure that the world-wide diffusion of centers dedicated to the study of the Americas will not replicate the center-periphery logic of Hispanic American History?

One should never forget that US corporations and private benefactors contributed greatly (perhaps as much as the United States government) to the formation of the field of Latin American Studies by funding graduate programs, building up special collections, and establishing centers for the study of the sub-continent. These centers were all located in the United States: in Madison, Tulane, Berkeley, Princeton, Austin, San Diego, Yale, Harvard, etc. They also funded the copying of archives in Spain and the wholesale purchase or copying of Spanish archives in Mexico, Central America, the Caribbean islands, the Philippines, and the exMexican territory of the United States. Only in certain subfields of Latin American 
Studies, such as Maya archaeology, where US research institutions could actually colonize the field, did these governmental and corprorate funds move abroad. It would not be too far-fetched to suggest that the extension of historical and archaeological practices of US scholars into Latin America consolidated, expanded, and reproduced a centripetal logic of cultural capital accumulation. Masses of empirical data-be this literary texts, Maya stone-work, folkloric collections, Latin American periodicals, or colonial manuscripts-had to flow into US centers of knowledge as a necessary condition for the production of regional, US-centered, knowledges.

\section{Intellectual Cooperation Is Not the Answer}

During Bolton's and Haring's times, intellectual cooperation was the Empire's preferred policy to gain the consensus of Latin American intellectuals. If a declaration of non-intervention was offered, and the US promised to desist from additional embroglios in Central America and the Caribbean, Latin American intellectuals could be persuaded to lower their animosity against the Colossus of the North. If, in addition, the southern educational elite was invited to the banquet of EuroAmerican civilization as knowledge-producer-e.g. as active participants in the project of Hemispheric History - then, it was believed, nothing more was needed. The full cooperation of Latin American intellectuals would be ensured. Yet this foreign-policy consensus, extrapolated into the terrain of cultural production and intellectual cooperation, as we now know, did not work so smoothly. Latin American intellectuals proved time and again to be willing to defy the powerful Colossus for the sake of channelling their own alternative views on progress (now called "development") and civilization (now separated from "Americanization"). Yet these same intellectuals would also endeavor to reach the very goals cherished by US intellectuals of the New Deal period: social equality and social justice.

Bolton, if he were to awake today, would find that so many years of Latin American cultural propaganda for US literature, for US universities, and for US social sciences have rendered so little in terms of intellectual consensus between US and Latin American scholars. Few of the new radical populist leaders-and the intellectuals who support them-would ever recognize the works of Veblen, George, Ellis, Ross, and other progressive thinkers. In fact, apart from a ritualistic reference to Whitaker's classic (the idea of a Western Hemisphere), most of the works of this generation of US historians have been forgotten, their names appearing neither on the programs of Latin American history taught in the universities South of the Rio Grande, nor in the articles and books written by professional historians of the region. Every now and then, the name of F.J. Turner is resuscitated 
in relation to a new paper on frontiers, but the names of Haring, Whitaker, Hanke, Rippy, and the others have vanished from contemporary discussions.

If Bolton were to awake today, he would find new configurations of knowledge being produced in a multiplicity of locations throughout the Americas. He would find Latin American students travelling to study and conduct research in the United States who only view it as a secondary option to do the same in neighboring countries of the region. He would find that in terms of per capita income as well as in terms of library collections, the gap separating the United States from the rest of its "Latin" neighbors has widened. In fact, the "sister republics" are striving to educate scholars with budgets smaller in proportion (in relative terms) to those of the 1930s and 1940s. And he would find the youth of the countries South of the Rio Grande, though more healthy than in the past, still visited by the plagues of corrupt governments, incontrollable poverty, violence, and turbulent social life. It would be evident to Bolton (or to any historian of the period) that there is little room for or profit gained by a policy of intellectual cooperation.

Let me pose then what I consider the most radical alternative in reconfiguring the current geopolitical distribution of knowledge in the Americas: the formation of new and powerful centers of learning in the currently most underdeveloped areas of Latin America-or, of the Americas, to the extent that some areas of the US's "cultural South" deserve to be included in this map of marginality as well. These areas would include places such as Manaos, Cuzco, Port au Prince, Medellín, La Rioja, Iquitos, Oruro, Sao Luis, or Oaxaca, where centers of excellence focusing on a critical study of life (experience and culture) in the various American nations could emerge. It is precisely those places that are now only noticed for their unbeareable poverty, exotic cultures, racial miscegenation, and persistent resistance to learning the lessons taught by the benevolent US Empire that could turn into centers at the forefront of developing a new way of organizing the study of the Americas. Those places where racism, sexism, and poverty hurt the most-not just because of the "colonial wound" but also due to the multiple wounds inflicted by modernity-perhaps contain the potential for a radical unmaking of American Studies. Nothing is gained from adding the study of Quechua at Yale or Nahuatl at the $\mathrm{U}$ of Chicago. What we need is a radical decentering of knowlege, not a further concentration of knowlege in already prestigious centers of excellence.

There, in those marginal and excluded places, study centers could emerge that are radically diverse and plurinational in their composition, trying to produce a more integrated and, at the same time, more differentiated and plural understanding of the diversity we call "the Americas." Centers in which past experiences, shared predicaments, and possible futures for the continent could be examined from truly "pluriverse" perspectives. In a way, I am calling for knowledge production to move 
from the center to the periphery, to blend with a multiplicity of local knowledges, and to stay there. In tomorrow's centers of today's periphery the practical will finally join the theoretical, the philosophical will meet the technological, the humanities will converse with the social sciences, and the various subalternities (gender, ethnic, racial, national, religious, etc.) will strive for a synthesis: producing knowledges that can incorporate the local and the global for the benefit of the commons, that is for the benefit of "Americans" in the wider sense of the word.

Regardless of whether these lofty objectives will ever be met (this New Jerusalem of a geographically dispersed excellence in "American-at-large Studies"), the main gain of such a radical departure from the traditional geo-political arrangement of knowledge-production would consist in its very making. That is, the very investment in knowledge centers in the periphery of the Americas would dramatically change the landscape of knowledge, generating unexpected outcomes in terms of the re-concentration of innovation, of markets, as well as of human and financial capital. A move in this direction would almost certainly begin the long process of "levelling the playing field," to the extent of undermining the existing US and European intellectual superiority in the humanities, which is, more than any misguided Orientalism, the true and solid basis of a continued hegemony of the United States, dressed in its "Western" evening gown.

\section{Works Cited}

Bannon, John F. Herbert Eugene Bolton: The Historian and the Man. Tuczon: The University of Arizona Press, 1978.

Bannon, John F., ed. Bolton and the Spanish Borderlands. Norman: University of Oklahoma Press, 1964.

Berger, Mark. Under Northern Eyes: Latin American Studies and U.S. Hegemony in the Americas, 1898-1990. Bloomington: Indiana University Press, 1995.

Bolton, Herbert E. “The Epic of Greater America." The American Historical Review 36.3 (April 1933): 448-474.

Brown Holmes, Vera. A History of the Americas: From Discovery to Nationhood. New York: Ronald Press Co., 1950.

De Gandía, Enrique. Nueva historia de América: Las épocas de libertad y antilibertad desde la independencia. Buenos Aires: Editorial Claridad, 1946.

Delpar, Helen. Looking South: The Evolution of Latin Americanist Scholarship in the United States, 1850-1975. Tuscaloosa: University of Alabama Press, 2008.

Hanke, Lewis, ed. Do The Americas Have a Common History? A Critique of the Bolton Theory. New York: Alfred A. Knopf, 1964. 
Haring, Clarence H. South America Looks at the United States. New York: Macmillan Co., 1928.

Harris, Charles H., and Louis R. Sadler. The Archaeologist Was a Spy. Sylvanous G. Morley and the Office of Naval Intelligence. Albuquerque: University of New Mexico Press, 2003.

Inman, S. Guy. Latin America: Its Place in World Life. New York: Books for Libraries Press, 1942.

Kozel, Andrés. La idea de América en el historicismo mexicano: José Gaos, Edmundo O’Gorman y Leopoldo Zea. Mexico: El Colegio de México, 2012.

O’Gorman, Edmundo. "Hegel y el moderno panamericanismo." Letras de México 2.8 (August 1939).

O’Gorman, Edmundo. La invención de América: el universalismo de la cultura de Occidente. México: Fondo de Cultura Económica, 1958.

Rippy, J. Fred. Historical Evolution of Hispanic America. New York: F.S. Crofts, 1936.

Salvatore, Ricardo D. "Early American Visions of a Hemispheric Market for South America." In B. Ostendorf, ed. Transnational America: The Fading of Borders in the Western Hemisphere. Heidelberg: C. Winter, 2002. 45-64.

Salvatore, Ricardo D. "Yankee Advertising in Buenos Aires." Interventions: International Journal of Postcolonial Studies 7.2 (2005): 216-235.

Salvatore, Ricardo D. "The Making of a Hemispheric Intellectual and Statesman: Leo S. Rowe in Argentina (1906-1919)." Journal of Transnational American Studies 2.1 (2009). (e-journal: https://escholarship.org/uc/item/92m7b409).

Sweet, Willaim W. A History of Latin America. New York: The Abingdon Press, 1919.

Weber, David. “Turner, the Boltonians, and the Borderlands.” American Historical Review 91.1 (1986): 66-81.

Whitaker, Arthur P. The Western Hemisphere Idea: Its Rise and Decline. Ithaca: Cornell University Press, 1954.

Williams, Mary W. The Peoples and Politics of Latin America. 1930. Boston and New York: Ginn and Co., 1938. 
Jane C. Desmond

U of Illinois at Urbana-Champaign, U.S.A.

\section{"And Never the Twain Shall Meet?": Considering the Legacies of Orientalism and Occidentalism for the Transnational Study of the U.S.}

\section{Introduction}

Around the world, tens of thousands of scholars share as our object of study the "United States." We approach this object of study as a geopolitical entity, as an economic juggernaut, as a territory with permeable borders, as a nation with an imperial history and some would say an imperial present, as a cultural imaginary that exerts its presence in so many parts of the world, as a military actor with bases around the globe, as the source of tangible and intangible commodities from computer code to Hollywood blockbusters, as the location of educational institutions of world prominence which many of us will have attended, and as a complex collective of many different communities and populations, past and present. People, ideas, things, and social practices. All of these cultural, political and economic realms are part of our shared purview as specialists on the "United States."

And yet, although we share this object of study in the most capacious sense, each scholar is positioned differently personally and intellectually in relation to this object. For myself, this includes being born in, raised in, and living most, but not all, of my life in the United States. My scholarly training for a Ph.D. in "American Studies" took place there as well. For many other scholars, there is less physical proximity between the territorial and experiential place of the referent and the production of scholarly knowledge about it. And because our knowledge is always produced in complex historically specific matrices of location, communities of scholars, scholarly traditions, epistemologies, politics of knowledge, and subjectivities, this means that what we think about and how we think it will likely not be the same. This is a crucial and valuable resource.

In working towards the formation of a transnational community of scholars specializing on the U.S. in all its multifaceted aspects, we cannot simply assume that our communications will be transparent. How do we come to know, acknowledge, and grapple with the differences in the social dimensions of our knowledge 
production? Of the differing "use values" of producing that knowledge-that is, what that knowledge means in our home contexts? Of the differing academic traditions and trajectories of which we are a part? In this article I want to begin an analysis of how these multifarious positionings and the perspectives they may give rise to can be understood through the ideological and epistemological legacies of Orientalism and Occidentalism. I want to urge us as scholars to be attentive to these frameworks and to take their presence and operation as part of our foci.

The origin of this article grew out of practical experiences in my scholarly life, especially as President of the International American Studies Association (IASA) from 2007-2011, and specifically the duties that position required to oversee the organization of IASA's Fourth World Congress, held in Beijing in September of 2009. IASA, founded in 2000 , is the first world-wide association of scholars working on the U.S. or the Americas more broadly. ${ }^{1}$ It is not a confederation of national scholarly organizations, but rather a collective of individual scholars who, through their membership, actively signal their commitment to engaging with their peers around the globe. We have hundreds of members in more than 30 countries so far, even though we are a young organization, and our rotating slates of officers and Executive Council members are drawn from dozens of countries. We are not a U.S.-based organization nor a European one, although many of our founding members hail from those countries.

Our first three bi-annual World Congresses had been held in Leiden (The Netherlands, 2003), Ottawa (Canada, 2005), and Lisbon (Portugal, 2007). After that, I and many of my colleagues felt strongly it was time to move out of the Euro-North American sphere for our next World Congress, and in 2007 the IASA Executive Council accepted a proposal from our colleagues in China to schedule the 2009 Congress in Beijing. ${ }^{2}$ Our collaborative planning processes over the next two years yielded concrete evidence of how the powerful, even intractable, frames of Orientalist and Occidentalist thought can still haunt us, having an impact upon the possibilities for scholarly relations between those of us based in "Asia" and those of us based elsewhere. These conceptual frames for understanding the world are so widespread and have such deep historical and political roots

1 The International Association of Inter-American Studies, founded in 2009, complements IASA's foci, and brings together scholars located in many nations who analyze relations among countries in all of the Americas: Central, North, and South.

2 The 2009 World Congress was held in Beijing (China), the 2011 World Congress was held in Rio de Janiero (Brazil), and the 2013 World Congress was held in Szczecin (Poland). The 2015 World Congress takes place in Seoul (Korea). 
that none of us is immune from their power. These are also deeply complex and politically sensitive issues, but ones that I think we must take on collectively.

\section{Practical Manifestations of Orientalism/Occidentalism}

Because part of our challenge is to understand how implicit frameworks shape not only large ideas but their more material and practical manifestations, let me give some very concrete, and seemingly small, examples before moving into widerscale theorizing in the next section.

I was first alerted that this framework of Orientalism/Occidentalism might be a problem when the possibility of holding our congress in China was broached. Several of my IASA colleagues from Europe or from North America exclaimed "but no one would go!" A second complaint was that "it's too far!" The obvious answer to these fears is that lots of people would go, although perhaps they would be different people-not as many from Europe or North America as had attended our three previous congresses in Leiden, Ottawa, and Lisbon. For instance, lots of scholars from China would go, whereas few had attended our previous congresses.

To the second worry- "It's too far!"- the answer is also a question-too far from where?! A truly decentered globe-a fiction perhaps, but still a desirable one when we envision a truly global community of scholars-does not have a given near and far, but rather complex sets of proximity and distance, of multiple centers and hence multiple peripheries, all of which are calculated relative to each other under changing conditions. My "near" may be your "far" for instance, and the center of my scholarly and daily world may be peripheral to yours. China is not far from Japan or Australia for example, although it is farther from Germany or Italy, say, than Lisbon was.

As the discussions of the Beijing option continued, it became apparent to me that the perceived distances were more conceptual than physical. Would the time and money invested to get there be "worth it" or not? That so few distinguished Chinese scholars of the Americas are read in Europe or in North America added to this sense of distance. Speaking more broadly about the intellectual imbalance in knowledge flows, Prof. Zi Zhongyun noted in Hong Kong at the 2005 China American Studies Network conference: "There is a conspicuous gap in how familiar Chinese and American academics are with each others' research and writing.... [O] ur American colleagues are acquainted with very few works that Chinese scholars have written on the United States" (46).

A different but related process emerged after the approval of the site selection, when the planning began. These differences were cast in the framework of the China way of doing things and the "international" way of doing things. Here 
already we are awash in the intellectual complexities and political quick sands of labeling. Were we planning a Chinese conference which invited IASA, or were we planning an IASA conference hosted in China? Would the normative practices for organizing conferences follow one model or the other (by the "other" I mean the models developed in the three previous IASA conferences in the Netherlands, Canada, and Portugal)? Food is a good example. My hosts explained to me during our May, 2008 planning meetings at Beijing Foreign Studies University that all of the meals must be provided for all participants and covered by the registration fee, since that is what scholars in China expect as the norm. In past congresses of IASA, some meals were on your own, and a fancy banquet was optional, and incurred a significant additional fee if one chose to attend, or could result in a lower registration fee if one did not. We went with the all-inclusive model.

The theme that runs through these telling details is the distinction drawn between a host/non-host way of doing things. We might expect this to some extent anywhere, but implicit here I think was a sense that we were uncertain how this would be a Chinese conference or-and here I introduce the largest booby trap of a word-a "Western" conference ... or a combination of both styles and, if so, what compromises would be made. I'm going to come back to this problem of the concepts of "the East" and "the West" later, but let me provide one final example of the tensions that challenged all of us working together.

When the time came for the program committee to construct a series of panels from individually offered papers, the IASA program committee with representatives from India, New Zealand, Turkey, and the U.S. received two spreadsheets carefully prepared by Professor Li Qikeng in Beijing who did so much work to make this conference happen. One was for the "international" scholars and the other was for the Chinese scholars-the latter had their names in Chinese characters, which only one member of the IASA committee could read. IASA is a hugely multilingual organization in terms of the languages that our members speak, write in, and read, but the only language we ALL have in common is English, or I should say world Englishes. That and our shared passions for our objects of investigation, whether it be the U.S. per se or the Americas more broadly, is what creates both the possibility and the reason for us trying to come together every two years for substantial discussions. Let me be clear here, I am certainly not promoting English as a world-wide language, rather I am noting that it is the only language among the dozens spoken by our membership that we all have in common to some degree.

In our grappling with two lists of accepted proposals, Chinese and nonChinese, we encounter a material manifestation of a conceptual framework of insiders and outsiders. In this case, I want to suggest that this divide is one that runs though many, many of our attempts to work together, to think together, to 
trust each other enough to debate together, and ultimately to try to understand our shared objects of study not from one but simultaneously from multiple points of view and scholarly standpoints. I recently argued for this conception of what I'm calling a "prismatic American Studies" in a 2007 issue of Safundi: The Journal of South African and American Studies (5-13).

I offer these small examples of practical, and not unexpected, ways of operating as a route into larger issues and harder intellectual work. A key question we must ask is this: Are we still tethered to and limited by conceptual maps of Orientalism and Occidentalism that create and sustain bi-modal concepts of the world, and if so, how does that limit what we expect of each other, of each other's scholarship, and of the ways we imagine working together as colleagues in the future to create new knowledge?

\section{Defining "Orientalism" and "Occidentalism"}

One of the many problems with this complementary set of ideologies-of "Orientalism" and "Occidentalism-is that they are mental mappings that masquerade as territorial referents, while simultaneously banishing much of the world from consideration. Is the entire continent of Africa, with its many countries, groups and languages, part of "the East" or part of the "West?" Or, are poor and poorly educated rural persons not mapped in this framework but the elite, trained often in the centers of their colonial pasts, part of a so called "cosmopolitanism" aligned with the imagined community of "the West?" What about Latin America? Not the East surely (despite the relatively large populations of Japanese or Chineseorigin citizens in Brazil and Peru), but not exactly those populations usually referenced by the term "the West." Or are the urban intellectuals and elites part of "the West" and the indigenous populations not? And where is "the West" anyway? As a referent, there are some places and populations that are undoubtedly "in" this category. Sweden, France, Italy, Ireland, Canada, the U.S. (but maybe not some of its post-colonial territories like Guam?). All of the growing EU? (What about Slovenia? Bosnia?). Are Muslims part of this conceptual imaginary? Or is it implicitly Christian and Jewish? What about South America-Uruguay for instance? Well-if the West is not a place but an idea, then what about the East? Who is definitely in-China certainly, and Japan (despite its membership in the G-8) and Southeast Asia. What about India? Iran? The eastern part of Russia around Vladivostock? The Aleutian islands and their indigenous populations? How about Tasmania?

When we try to locate the actual living populations and territorial sites referenced by these huge conceptual dividers of "the East" and "the West" we see the 
impossibility of doing so and reveal the power of the concepts as lying in part in this very ambiguity and in the ways that the "core" referents of the concepts are ALWAYS invoked by it, implicitly, thus dividing a world in half-while ignoring a great deal of it. We have some other emergent terms to cross-cut these conceptual territories, like the Global South or the circum-polar indigenous populations of Inuit and Sami. But none of these has the historical longevity or power of the East/West binary, itself a legacy of long colonial empire-building by both "sides."

And a binary it is, as Edward Said so eloquently and exhaustively convinced us in his 1978 book Orientalism, in which he sifted out the descriptors attached to "the East" by European and European-origin scholars over time, and revealed a set of ascribed characteristics that were alternately desirable and despised. Orientalism, as Said develops the concept, is not just a delineation of assumptions about someplace(s) termed "the Orient" by scholars in Europe. It is, more fundamentally, a whole episteme developed over multiple centuries. We can define it as: a complex of assumptions, facts, fictions, and ideologies that comprise, while purporting to explain, a scholarly and political imaginary, in this case an imaginary about a part of the world outside of Europe.

Said's preoccupations with excavating the beliefs undergirding European productions of knowledge about "the Orient" focused on the Middle East (another problematic term, because obviously it raises the question of "in the middle of where?" Between what or whom?). But he could have easily focused on other sites, like China, India, and Japan, each of which has a long, rich, and equally central legacy in this episteme of Orientalism in Europe and to varying degrees among some populations in the U.S. and the larger Americas.

Said describes this episteme as "a political version of reality whose structure promoted the difference between the familiar (Europe, "the West," "us") and the strange (the Orient, the East, "them")" (43). This act of "imaginative geography" both created and helped maintain a sense of two distinct worlds, and served as the ground for imperial and colonial relations (90). While Said sketched changes in this set of beliefs and presumptions over multiple centuries and in various scholarly discourses in Europe, he also asserted that there is still a powerful "latent Orientalism" at work today (206). This latent Orientalism still functions both within and outside of scholarly disciplines, he attested in 1978, and has remained remarkably consistent over several centuries. Is his assertion still correct and relevant 30 years later?

Said noted that among those characteristics assigned to the mythic "East" are the following: the "East" is supposedly primitive, childlike, irrational, chaotic, mysterious, backward, eccentric, and despotic. On the other hand, it is also stereotyped as: sensual, sexual, wise (as in the notion of "the wisdom of the East"), 
and as the site of unimaginable antiquity. A source of beauty, desire, and wisdom, it is also characterized in the Orientalist discourses Said analyzes as a place and peoples who are not to be trusted, are radically different in their beliefs and practices from those who write about them from "outside" the East, and who are always stuck in a past which may be seen as, alternately, glorious or infamous.

Implicitly, Orientalist views describe and create a sense of an "Occident" as the not-East as well. Orientalist discourses imply that the mythic place called "the West" is the opposite of "the East" rational, modern, forthright, trustworthy and functioning according to a transparent and just rule of law. A moment's reflection surely shows us the mythic nature of these claims, but does that mean they are not still functioning? Of course they are, although now perhaps more implicitly than explicitly, and hopefully in a more self-reflexive mode. Every time we take up the subject position of referring to "the East" or "the West" we activate a set of assumptions-and epistemes-through which we speak.

If, as Said suggested, Orientalism is still with us, what about Occidentalism? Now the positional calculus becomes even more complicated. As we saw above, characteristics ascribed to "the Orient" can be seen as either positive or negative: mysterious can be positive-intriguing, out of the ordinary-or it can be negative-unknowable, unpredictable, and thus, untrustworthy. The same can be said about characteristics ascribed to a mythic "West," which can be seen as modern and well off, or bullying, greedy, immoral, and imperial. Desirable or despicable. It depends on who is talking, to what ends, and, of course, on what the baseline for comparison is.

The companion episteme to Orientalism is Occidentalism, and this idea has been explored by Chen Xiaomei in her book Occidentalism: Theory of CounterDiscourse in the Post-Mao China. Chen suggests that although "Occidentalism" as an over-arching episteme is counterposed to Orientalism, valuing that which is undervalued in that episteme-it can be deployed for differing ends. Like concepts of Orientalism, Occidentalism can be used as a discourse to critique European and U.S. power, or it can be used by dissenters to critique the "Orient." For instance, some governments or communities might speak out against what they see as "Westernization," as a road to immoral secularism or rapacious capitalism. But the term has also been used to describe a set of passions for those characteristics determined to be desirable in a mythic "West" in contrast to local, home grown "Eastern" ones. For example, calls for "Westernization" in some countries may be used to leverage movements towards more democratic systems of government. Or, when mobilized by speakers residing in the territories associated with the mythic "West," it can refer to a discourse of self-endorsement. For example, someone might say "As a Westerner, I've always believed that ...." 
We see a similar use of "Orientalism" in the "West," where the codified differences can be used to support the groups in power-praising Occidentalism by contrasting it with situations in "the East." Alternatively, values associated with a mythic "Orient" can be invoked to critique dominant ideologies, philosophies, and artistic practices associated with Europe and the Americas, as we have seen in the U.S. in many historical periods - for instance, in the 1960s where the "wisdom of the East" was invoked in hippies' Indian print bedspreads, embraced by leading experimental artists like composer John Cage, and popularized in books like Robert M. Pirsig's Zen and the Art of Motorcycle Maintenance, which was really more about philosophy than motorcycles, just to draw a few examples from U.S. popular culture.

Are we as academics immune to these massive and powerful epistemes? Are we immune to the languages that promote them and offer us a subject position of Westerner or Easterner if only we will occupy them? Do we auto-Orientalize or auto-Occidentalize? Given the power and pervasiveness of such discourses it would be amazing if we did not. How can we recognize these discourses in play and what sorts of effects might they have to the detriment of our scholarly exchanges and engagements? First of all, we can make our understandings of these discourses more complex and strive to more fully grasp the instruments of cultural interaction that the binary discourses of Orientalism and Occidentalism depend upon. In the next section, I'd like to focus particularly on how these issues might relate to China.

In a persuasive 1996 article titled "Chinese History and the Question of Orientalism," Arif Dirlik, a U.S.-based historian of China, takes a metahistorical view of Orientalism. He asserts that although Said described Orientalism as a part of the problem of European modernity, it should also be seen as part of the problem of Asian modernity, part of which consisted of the circulation of Asian and European intellectuals in a "contact zone."3

Tracking a mutually influential relationship, although not claiming parity in those influences, Dirlik suggests that "to the extent that orientalism had become part of "Western" ideas by the early nineteenth century, the "Western" impact included also the impact on Asian societies of European ideas of the orient" (104). Coming closer to the present, he suggests that "it is in the twentieth century, however, that Euro-American Orientalist perceptions and methods become a visible

3 This is Mary Louise Pratt's succinct term for a long-standing anthropological concept of cultural meeting, exchange, change, and intermingling, often in situations of radical inequality. 
component in the formulation of the Chinese self-image, and Chinese perceptions of the past. The process was facilitated by the emergence of nationalism" (106). Noting the reductionist aspects of the Orientalist episteme and its parallel with the reductionism of cultural complexity and contestation that movements of nationalism often employ, he goes on to state that "nationalism shares much with the culturalist procedures of orientalism, now at the scale of the nation" (ibid).

If nationalist discourses often proceed through a process of homogenizing self-assertion in contrast to other nations (what "we" are vs. what "they" are), then we can see how the larger frameworks of European-manufactured epistemes of "Orientalism" may be pulled into play in the development of cultural nationalism in countries like China, just as notions of "the West" are used in U.S. nationalist discourses describing the U.S., for example, as the supposed height of "Westernized" "modernity." Just as the self is defined as not the other, then at the national level too we can see this process of differentiation and comparison as a part of the development of a distinctive discourse of cultural uniqueness, employed in the building of national identities, often masking historical complexities of change and exchange, and differences among sub-national groups.

But what about the present day? If we follow Dirlik further, he asserts that "what has changed [now] is the power relationship between China and EuroAmerica ${ }^{4}$ rather than the abolition of Orientalism" (108). In other words, the rise of the "New China" - the contemporary mainland China of rapidly expanding economic, military, and political power-does not mean the end of centuries-long epistemes of Orientalism, in both "the West" and "the East." Rather, we see now their reformulation and reconfiguration. Dirlik offers one example in the depiction of the New Confucianism as a positive "force in capitalism modernization" (109). A detailed and nuanced discussion of the ways in which such a reformulation is proceeding certainly requires the expertise of a specialist on China, not myself, but I offer his example here as one of many that might be further explored. I suggest here too that Orientalism as an episteme in Europe and the Americas is, similarly, not dying out but resurfacing in ways that we need to analyze and document as the "New China" plays a more and more central role on the world stage. Just as China "stages itself" anew as it literally did recently in the spectacular opening ceremony of the 2008 Olympics, so too is the notion of "China" and of the new "Orient" subject to revision outside of China.

4 For Dirlik, the term Euro-Americans refers not to Euro-Americans, per se, but rather to the complex of Europe and the United States. 
If Dirlik is right that Orientalism in China is being reformulated, not refuted, and if I am right that the deployment of the epistemes of "Orientalism" and "Occidentalism" retain their force even in the face of contemporary reconfigurations, then as scholars working across multiple national and regional configurations, we have much work to do. We need to be alert to the ways in which such positionings may influence our perceptions of each other's work. There are surely multiple scholarly traditions represented in our meetings and journals, and these shape indelibly the ways in which we conceive of "good" argumentation, of what counts as scholarly "evidence," and of what is an appropriate scale of posing a research question, just to offer a few examples. These scholarly practices are not just individual choices; they are part of the stated and unstated presumptions of the various scholarly worlds in which we are each embedded. Thus, as sociologist of knowledge Pierre Bourdieu might remind us, they become "doxa" in our own modes of operation and in the criteria we apply to analyze and assess intellectual work.

Wang Ning, professor of English and Director of the Center for Comparative Literature and Cultural Studies at Beijing's Tsinghua University, also takes on the question of the relationship between Orientalism and Occidentalism. Although China was not a prime focus in Said's formulation of Orientalism, Wang notes that Occidentalism has played a key role in anti-imperialist movements in China over time. However, he suggests that the continuing oppositional construct of Orientalism and Occidentalism (whether or not "the West" is conceived of as a dominating agent or an agent to be dominated) is a no-win situation. Writing in 1997, the year after Dirlik's article appeared, he asks: "Will there be no other way out of these simple modes of thinking characterized by binary opposition?" (64).

Comparing the discourses of Orientalism and Occidentalism, Wang suggests that Occidentalism is "far from a full-fledged episteme covering ... [as wide a] ... range of learning and representation as Orientalism [does]." He describes it rather as more of a response-a "strategy of discourse opposed to Western cultural hegemonism" (66). Whatever its origin and history, I suggest it is just as potentially limiting as the long shadow of Orientalism. The continuing presence of Occidentalism, Wang warns us, may well "do harm to our cultural communication and academic exchange with Western and international scholarship ... [and] ... since it [Occidentalism] is still prevalent in present-day China and some other Oriental countries ... it deserves study and analysis" (ibid). This warning was given ten years ago, so we should ask ourselves if the situation has fundamentally changed now or not? If not, what strategies might help us change this?

Building on Dirlik's 1996 arguments, Chu Yiu-Wai takes on these issues in his 2008 essay "The Importance of Being Chinese: Orientalism Reconfigured in Marietta Messmer and Armin Paul Frank - 978-3-653-98855-0 
the Age of Global Modernity." Chu opens a discussion of "Chineseness" in a new global century by rejecting a notion of "authentic" and "inauthentic" Chineseness, focusing his discussion on mass media representations, especially those produced in China and circulating elsewhere. The details of his argument, and the mass media contexts he discusses, are beyond the scope of this discussion, but I want to indicate the importance of the question - what and who is "Chinese" in a period of reconfigured Orientalism and Occidentalism? And I want to turn that question around to ask "what and who is not-Chinese" in this same period. Or, what and who is not European? Or "American?"

For this is part of our challenge as I see it: to become self-reflexively aware of the ways that our own scholarly work is always already embedded in frameworks of training, citational practices, analytical processes, reading lists, and implicit national formations that shape what we decide are important questions, urgent investigations, legitimate forms of argumentation, and persuasive evidence, based on our own political historical epistemes of knowledge productions. And then, looking outward, to try to understand the complexes of those epistemes and histories of academic production which are different from our own, whoever the "our" may be. Can we create what British sociologist Bryan Turner calls for: a contact zone of intellectuals with a shared object of study and a not fully shared, yet partially overlapping and partially contradictory, framework of modes of production, in this case, modes of intellectual production?

Many of us traverse several scholarly communities. We cross disciplinary boundaries, we work in several different languages, we collaborate with colleagues abroad, we obtain degrees in countries not originally our own, we teach as guests in different nations, we publish in journals outside our home countries or regions. Yet, for all of this, a majority of us operate on a daily basis in one intellectual community that exerts more pressure on us than the others. For myself, that community of scholars, a majority of my publication venues and conventions, all of my degrees, and a majority but not all of my faculty appointments, have been in the U.S. where I have lived most of my life. Each of us can make this calculus. And, each of us is shaped by it, because as post-structuralists have persuasively demonstrated, knowledge is always produced from somewhere. And I would add that those "somewheres" have histories and political frameworks that profoundly affect what we do as intellectuals.

We know this of course, and often investigate and critique these issues in our own scholarly work. But at the institutional level it is also a crucial resource to keep in mind as we endeavor to build global scholarly networks. Following Bryan Turner, we can look to Edward Said's efforts to chart a path out of the strictures of Orientalism and Occidentalism. Said urged us to work toward "an ethic of cosmopolitan 
care" (174). While many critics have focused on Said's highlighting of the existence and operation of the oppositional paradigms of Orientalism and Occidentalism, fewer have focused on his purposes in doing so, especially as articulated in his later works. As Turner states, "Said's vision of intellectuals .... offers a defense of cosmopolitanism which is the worldview of scholars in a political context where globalization, cultural hybridity and multiculturalism are re-writing the traditional Orientalist agenda" (176).

But cosmopolitans are not, I would hasten to add, untethered border-crossers in a utopian flow of de-politicized difference. I'm not suggesting that there are not important differences in the histories and presents of populations and of how we, as members of those communities, view the world. There are distinctive philosophical and intellectual traditions. There are distinctive political histories that shape those traditions. There are variable cannons and revolts against canons in different disciplines. But the invocation, whether implicit or explicit, of "THE West" and "THE East" actually mutes and even erases those particularities in favor of large generalizations. As scholars we owe it to ourselves to avoid these generalizations, except self-reflexively when we make them part of our objects of investigation in the constitution of new knowledge.

As intellectuals we have the privilege of seeking out and sustaining mutually challenging conversations, debates, and arguments that cross disciplinary, linguistic, national, and epistemological boundaries, while simultaneously tracking the power of those configurations. We do so in the material and political configurations of the present-from the H1N1 flu outbreak, to the worldwide recession, to the relocation of Guantanamo Bay prisoners, and the ongoing wars in the Middle East, just to name a few of the largest challenges. We have the privilege of becoming temporary migrants, not due to economic, human rights, or political necessity, as is so often the case when people migrate to escape a situation, but rather to embrace the difficult challenge of working together in mutually changing and mutually challenging collaborative productions of knowledge. Said's notion of an ethics of "care," and the implicit respect that it encapsulates, is a hallmark of what is necessary for that mutuality to occur as we work to build a truly transnational scholarly community.

A scholarly conference, a journal, a book series-all of these are material manifestations of an intellectual landscape for the production of debate, the exchange of opinions, and, hopefully, the production of new knowledge. Creating those arenas can be very challenging when we move away from zones of shared assumptions and practices into zones of more radical multiplicity. To do so successfully requires the type of double vision that $\mathrm{Du}$ Bois told us about, of being both enmeshed in our discourse and simultaneously stepping outside of it to 
watch it in action - to be alert for moments when our assumptions about what makes a good scholarly argument, what is an interesting intellectual question, and what it is important to know are set in high relief, and, to the extent possible, to see how our expectations of or encounters with each other just might be being shaped by the twin forces of Orientalism and Occidentalism. And, for the times when such frameworks seem to lessen our understandings of each other, or limit our abilities to engage intellectually, we step back, and just for that moment reject the notion of an EAST and a WEST_-and work against the legacies of Orientalism and Occidentalism that will surely continue to sing their siren songs for a long time to come.

A version of this work was first presented as the presidential address at the Fourth World Congress of the International American Studies Association meetings in Beijing, September 17, 2009. I thank all my colleagues in China and from around the world who worked so hard to make that Congress such a success.

\section{Works Cited}

Bourdieu, Pierre. Outline of a Theory of Practice. Cambridge: Cambridge University Press, 1977.

Chen, Xiaomei. Occidentalism: A Theory of Counter-Discourse in Post-Mao China. $2^{\text {nd }}$ ed. New York: Rowman and Littlefield, 1999.

Chu, Yiu-Wai. "The Importance of Being Chinese: Orientalism Reconfigured in the Age of Global Modernity." boundary 235.2 (2008): 183-206.

Dirlik, Arif. "Chinese History and the Question of Orientalism." History and Theory 35.4 (1996): 96-118.

Desmond, Jane. “Towards a Prismatic 'American Studies.” Safundi: The Journal of South African and American Studies 8.1 (2007): 5-13.

Du Bois, W.E.B. The Souls of Black Folks. New York: Penguin, 1989.

Pirsig, Robert M. Zen and the Art of Motorcycle Maintenance. New York: William Morrow, 1974.

Pratt, Mary Louis. Imperial Eyes: Travel Writing and Transculturation. London and New York: Routledge Press, 1992.

Said, Edward. Orientalism. New York: Pantheon Books, 1978.

Turner, Bryan. "Edward W. Said: Overcoming Orientalism." Theory, Culture and Society 21.1 (2004): 173-177.

Wang, Ning. “Orientalism versus Occidentalism?” New Literary History 28.1 (1997): 57-67. 
$\mathrm{Zi}$, Zhongyun. "How Far along the Road to Mutual Understanding Have We Come?" Bridging the Sino-American Divide: American Studies with Chinese Characteristics. Ed. Priscilla Roberts. Newcastle, U.K.: Cambridge Scholars Publishing, 2007. 42-47. 


\section{Inter-American Literary Studies in the Early Twenty-First Century: The View from the United States}

In the United States, the study of Inter-American literature has changed dramatically during the past ten to fifteen years. Before the 1990s, this field was practised only by a handful of scholars, mostly comparatists and Latin Americanists, and working mostly in isolation. Inter-American literary study did not yet exist as a widely recognized or officially sanctioned academic field. Indeed, it was looked at askance by many who felt that the vastness and diversity of the project made it impossible to do, or to do well. ${ }^{1}$ For its advocates and practitioners, however, the Inter-American paradigm made perfect sense and was, in fact, the natural and predictable result of several historical factors, including the disgraceful treatment of Native Americans, slavery, and the drive for independence, already at work in the Americas and inter-connecting them. And, thanks to the very democratic and non-hierarchical methodology provided by Comparative Literature, it was, and is, entirely "doable" (see Fitz, 1991). Although there are still some pockets of resistance, by 2014 it is clear that those holding this latter, more forwardlooking position, have carried the day. Though it is sometimes known now by other, sometimes differentiating names ("transnational studies," "hemispheric studies," "International American Studies," or the "Literatures of the Americas"), Inter-American study has firmly established itself as an accepted field of research and study in the American academy. It is now part of our twenty first century hemispheric consciousness.

During the last two decades especially, the Inter-American project has grown to include students and scholars working in a number of different fields, from literature to law, from environmental studies, music, and the plastic arts, and from bio-medical studies to engineering, sociology, economics, political science,

1 This was the gist of Edmundo O'Gorman's original objection to Bolton's vision of a transnational but historically interrelated America (see Bolton). 
and history. ${ }^{2}$ With respect to questions of literature and culture, the result of this steady growth is that now, in the midst of the second decade of the twenty-first century, we can see that the field of Inter-American literary study is dominated by scholars in three academic units: departments and programs of Comparative Literature, comparative Latin American Studies (a term I use judiciously to apply to those who are fluent in both Spanish and Brazilian Portuguese and who have studied the literatures and cultures of both Spanish America and Brazil) ${ }^{3}$, and American Studies. Four other groups, Native Americanists, Canadianists, Caribbeanists, and those scholars who, housed in departments of English, view the ken of "American" literature as being naturally transnational in nature, ${ }^{4}$ are also integrally involved in the Inter-American project. The approaches, outlooks, assumptions, and methodologies of these groups are quite different, however, as have been the results of the studies they have so far produced. These differences in professional expectations and outcomes, along with a few comments on what this may mean for the future development of our common field, are the topics I will be discussing in the remainder of my essay.

As we can see from the scholarship thus far produced, each approach brings with it certain advantages and disadvantages. To appreciate both the richness and the complexity of Inter-American literary study, and its potential for future development, it is perhaps worthwhile to examine what each approach brings to the field.

2 History was, in fact, the discipline that, in the Americas, first enunciated the viability of the Inter-American perspective. See Bolton; also, Barrenechea.

3 For many scholars, the question of whether Brazil should, or should not, be considered a Latin American nation is moot. For reasons of clarity, I suggest that we should use the term "Latin American" only when we wish to refer to both Spanish America and Brazil. Otherwise, we should speak of Brazil and Spanish America as separate traditions, much as "la littérature québécoise" and English Canadian literature are (though these have a stronger tradition of being studied comparatively). We must also recognize, however, that the designation "Spanish America" refers not to some monolithic entity but to a clutch of Spanish-speaking nations of greatly differing histories, cultures, and literatures (to say nothing of the very different kinds of Spanish spoken in them). For an excellent discussion of the Brazil-Spanish America-Latin America question, see Newcomb.

4 I am thinking here of such figures as Roland Greene, Renata R. Mautner Wasserman, Vera Kutzinski, and Antonio Barrenechea. 


\section{Comparative Literature}

The great strength that the Comparative Literature approach brings to the study of Inter-American literature is its disciplinary insistence that the doctoral student prepare herself or himself in at least three of the languages and literatures germane to the field (English, French, Spanish, Portuguese, and any Native American language the student wishes to present). For the professionally trained comparatist, this means extensive graduate seminar level course work done in at least three of these language with legitimate "reading knowledge" of a fourth or fifth highly recommended. The Comparative Literature doctoral student has thus read, discussed, and written about the literature of English-speaking North America, Spanish America, Brazil, and both Québec and the Francophone Caribbean in its original language and could, if necessary, teach this literature in the original language. This kind of serious linguistic, literary, and cultural expertise makes the person trained in Comparative Literature highly desirable as a potential hire not only for Comparative Literature programs per se but for the several national literature departments that are involved in the Inter-American project. ${ }^{5}$

The second outstanding strength of the Comparative Literature approach is its solid and objective methodological training, which does not depend on the alleged "exceptionalism" of any particular national literature for its efficacy. Trained in the application of such fully transnational questions as genre and form, theme ${ }^{6}$ and motif, period and movement, the relationship of literature to other humanistic disciplines (such as art, music, film, and history); patterns of influence and reception, literary history and theory, and translation, the comparatist understands the full range of possible approaches to Inter-American literary study and, thanks to

5 Many national literature departments are now hiring formally trained comparatists for this very reason.

6 The theme of racial mixing, for example, is endemic to the Americas (as it is, of course, to the rest of the world as well), though it receives very different treatments depending on which American culture it appears in. In Brazil, for example, miscegenation, the subject of many foundational Brazilian texts, has long been considered normative. The situation in Spanish America (which is a term we use to refer to a large group of nations with very different histories and cultures and speaking very distinctive kinds of Spanish) is generally similar, though with some notable exceptions. "In Canadian literature," however, to illustrate how this most basic of American themes can be contrasted, "miscegenation is generally represented in a negative manner" (Chanady, 2010, 99; see also 101), as it has been, historically speaking, in the United States. The theme of miscegenation in the literatures of the Americas could easily become the focus of an excellent course, at both the undergraduate and graduate level (see Fitz, "From Blood to Culture"). 
her extensive training in at least three of our American languages and literatures, is fully prepared to carry these approaches to a successful conclusion, one that does not privilege any specific nation, language, or culture. For the professionally trained comparatist, the question of nation hardly obtains. In practical terms, this means that a scholar thus prepared can speak of such topics as: the development of the novel in the Americas (see Fitz, "The First Inter-American Novels"); the theme of the New World as Utopia; our various American Modernisms; American literature and film; the influence of Gabriel García Márquez in both French and English-speaking Canada, the United States, and Brazil; the concept of "postcoloniality" as this pertains to our several, and differing, New World cultures; and the role translation has played in the evolution of Inter-American literary study (Lowe and Fitz 1-24; 135-162). The range of possibilities under these same rubrics is virtually limitless. Even more so are the possible studies that merge these categories, such as the role played by theater, or theatrical performance, during the European conquests of the Americas, the political ramifications of such movements as Romanticism and Modernism in the New World, border studies, ${ }^{7}$ or the question of personal identity and one's relationship to language, culture, and the American nation-state ${ }^{8}$ in the twenty first century. By virtue of having studied in several graduate seminars conducted in the languages of the American literatures presented for the degree (typically, Spanish, Portuguese, French, and English), the professionally trained comparatist is prepared to focus on certain New World texts and authors, and not others, and how to organize them into a coherent, productive comparative study. Thanks to her training in multiple languages and literatures, the comparatist is able to avoid a narrow focus on a single national literature and, among those three or four literatures selected for specialization, to apply a well honed rationale for knowing which texts to single our for close, comparative readings. Thus, what for other scholars might seem a hopeless welter of unfamiliar

7 The question of border studies, so important to U.S.-based American Studies scholars who, in recent years, have been coming to grips, particularly in the Southwest, with Hispanic culture in the United States, is, of course, no less important to the many other borders, linguistic, cultural, and political, that exist throughout the Americas and that tie us together even more than they keep us apart (see Stavins 2).

8 Although recent critical discussions have changed our concept of the nation-state, I see no evidence that nation states are withering away or that their influence is waning. I conclude, therefore, that the influence of nation-states on literary production will continue to be substantial, and most especially so with respect to questions of language use and identity, both private and public. Canadian and Brazilian scholars in particular have much to contribute to this discussion. 
names and titles, is, for the properly trained comparatist, a logically constructed list of known texts that, though written in different American languages, deal with a common American theme, form, period, or some other comparative topic (see Fitz, Inter-American Literature: A Concise History).

Finally, it is worth pointing out that comparatists have long recognized the validity and richness of the Inter-American field. In 1982, for example, the International Comparative Literature Association made Inter-American literary study the primary focus of its Xth Congress (see Balakian). Scholars from both Anglophone and Francophone Canada, the United States and Brazil convened with Native Americanists, Caribbeanists, and Spanish Americanists to hear presentations, to assess the field as it had already developed and to discuss how it might evolve in the future. The value of the comparative methodology was clearly evident as a way of avoiding the hegemony of any single nation or national literature. At present, the Inter-American project is hindered by the fact that we are all essentially products of - one might say prisoners of - our respective disciplines. Too often, we see what we are trained to see. In reference to the Inter-American project, students and scholars of a U.S.-based Americanism simply do not know which authors and texts from our New World neighbors to read or, in some logical form, how to learn about what literary riches they offer. This is where linguistically, literarily, and culturally polyglot comparatists have a clear and significant advantage over scholars trained in the literature of a single language.

The weakness of the Comparative Literature approach to the study of InterAmerican literary study is numerical. Relative to the number of departments of, for example, English, or Spanish-Portuguese (that also feature Brazilian literature, history, and culture), the number of Comparative Literature programs and departments is quite small. So while the professional training afforded by Comparative Literature best prepares the student to do Inter-American work, the number of young Inter-Americanists produced by this discipline tends to be rather small. But while their numbers are relatively low, in comparison to the numbers of doctoral students produced by the related national literature programs, professionally trained comparatists are the young scholars best prepared, linguistically, culturally, and literarily, to do the kind of at least three-sided work that needs to be done for the field of Inter-American literature to develop as felicitously as it should.

\section{Comparative Latin American Studies}

Having much in common, in terms of their professional training, with those who enroll in formal Comparative Literature programs, doctoral students in departments of Spanish and Portuguese, or in progressive Latin American Studies programs 
(that is, which stress the importance of both Spanish America and Brazil as well as French-speaking America), are the other group of young scholars who are well prepared to conduct Inter-American research in three or more American languages. As even a cursory survey of the extant bibliography on Inter-American literature clearly shows, comparative Latin Americanists are leading the development of this deeply inter-disciplinary new field. This is a big change from the 1960s when, from his post at Yale, Emir Rodríguez Monegal could rightly bemoan the "blind literary prejudice" shown by critics here in the United States against literature written in Spanish and Portuguese $e^{9}$ even when the "literarily revolutionary" writers of the "Boom" period were, at the very same time, being hailed and feted in Europe $(3 ; 13)$ as innovative artists who offered exciting new ideas about the nature of language and literature and about the relationship between literature, identity, and social progress. This disinclination to take the cultures of Canada, the Caribbean, Spanish America, and Brazil seriously, coupled with the deliberate concentration of American Studies on American English and on the United States alone, have played major roles in exacerbating the sense of hemispheric isolation that today plagues U.S.-based Americanists who desire to engage the field of hemispheric studies in a comprehensive way. Until very recently, we here in the United States have been a profoundly parochial and provincial culture (see Saldívar, 1990, 63), one not much interested in foreign cultures, in reading foreign literature, ${ }^{10}$ or in studying foreign languages. Perhaps this explains why the study of Comparative Literature here, in contrast to places like Germany, France, Canada, Mexico, or Brazil, ${ }^{11}$ has never been a popular or widely encouraged form of intellectual training. Emphasizing the crucial importance of precisely this kind of thorough and extended language and literary training to the Inter-American project, Lois Parkinson Zamora and Silvia Spitta argue, in fact, that,

9 According to Monegal, Edmund Wilson, for example, "has steadfastly refused to learn Spanish, because he was and still is convinced that nothing has been written in the language that would justify his exertions" (3). And, of Lionel Trilling, Monegal writes that Trilling once told one of his students that "he had read Latin American literature, and that in his judgement it had only an anthropological value" (3).

10 Statistics kept by international publishers routinely show that of the books published every year in the United States, only around 3\% are in translation. This figure contrasts sharply with many other countries, including Argentina, Mexico, Brazil, Canada, England, France, Germany, and Italy, where the percentage of books published in translation is consistently much higher.

11 Canadian literary study has long embraced the comparative method while Brazil boasts the "most powerful comparative literature association in the hemisphere" (Zamora and Spitta 204). 
Comparative Americas studies require a deep familiarity with several languages and cultures, gained from myriad forms of practice that allows us to think and know otherwise. Linguistic and cultural contacts have always been the basis of our discipline, but there are now scholars and students who work solely in English and yet claim to engage the Americas as a whole, a claim that inevitably absorbs and neutralizes alterity. The onus is on faculty members to assure that students experience American cultures other than their own and that they learn Spanish or French or Portuguese, not to mention the more difficult and urgent claims for Nahuatl or Quechua or Guaraní [sic]. Comparatists, along with our colleagues in U.S.-American Studies who are working to expand the standard U.S. definition of "America," must travel widely in the hemisphere, work across institutional boundaries, learn languages or add to those they already speak - in short, form relations with others elsewhere. (193)

Because Latin Americanists typically know both English and French, they are, even as they are specializing in either Spanish America or Brazil, or in some comparative framework that engages both, linguistically prepared to take graduate level seminars in both English and French, along with those in Spanish and Portuguese. This is a common feature of Ph.D. students in Latin American or Inter-American literature, and it is of immense value to them. ${ }^{12}$ Especially now, in the early twenty first century, Ph.D. programs in the United States that integrate, via the comparative method, the language and literatures of both Spanish America and Brazil, along with those of English and French-speaking America, are proliferating at a rate never before seen. This trend can be clearly seen in the recent, and rapid, growth of literary, cultural, and commercial relations between Canada, and most specifically Québec, and both Brazil and Spanish America.

The reason, of course, is the rapid rise of Brazil as a hemispheric and global economic, political, and cultural power. Although the ascendancy and importance of Brazil have passed almost unnoticed here in the United States, they have not been missed in Canada (see Braz; Bahia; and Hazleton) and in Spanish America. Throughout the Americas, Latin Americanists are acutely aware of this new type of Inter-American development (one in which Brazil plays a key role) and, in the second decade of the twenty first century, are scrambling to create doctoral programs wherein both Spanish and Brazilian Portuguese can (along with English and French) be studied in depth and in which advanced literary study in both languages can be pursued. To be sure, the rise of Brazil is also changing the nature of progressive departments of Spanish and Portuguese here in the United States, as well as how these progressive, forward-looking departments will relate

12 Vanderbilt University's Ph.D. track in "Inter-American Literature," housed in its department of Spanish and Portuguese, is of this type. 
to their sister academic departments and administrative units and to their sister New World cultures. Although not all colleges and universities have caught on to this exciting change, those who have clearly understand that comparatively inclined departments of Spanish and Portuguese are now more important to the Inter-American project than they have ever been.

And who, after all, is better situated, historically, culturally, and literarily, to understand the American experience, defined in its larger, hemispheric sense (that is, the good, the bad, and the ugly of it), than young scholars who know the language, history, and culture of the United States but who concentrate on Spanish America and Brazil? If one is in doubt about this, one has only to ask the Cubans, the Mexicans, the Guatemalans, the Salvadorans, the Panamanians, the Dominicans, the Chileans, the Argentines, and the Brazilians what they think about the history of the United States and its too often painful relationship with Latin America. And right behind them are the Canadianists, who have their own view of the United States and their own, distinctive version of the "American experience" as well. It is no accident that, here in the United States, the impetus for Inter-American study has long been a function of departments of Spanish and Portuguese.

As in the case of departments and programs in Comparative Literature, the weakness of the comparative Latin American studies approach is that, relative to the number of Ph.D.s produced by English and "American" literature departments and by American Studies programs in any given year, the number of doctoral students produced by departments that offer degrees in comparative Latin American Studies is still quite small. The problem, in other words, is not quality but quantity. And when one considers that, historically speaking, the United States has always held itself to be a stubbornly monolingual, Anglophone (and Anglophile) nation that is deeply skeptical of what at least its conservative element has regarded as the supposedly corrupting nature of foreign influences, it is not difficult to see why the influence within the United States of small numbers of comparatively trained Latin Americanists with an Inter-American bent is going to remain relatively marginal. And yet, and in spite of all this, the times are changing, as more and more young people throughout the Americas perceive Spanish America and, increasingly, Brazil and Canada, as becoming major players in the fast-evolving New World and global experience.

\section{American Studies}

As an academic discipline, American Studies finds itself, in 2014, in a moment of profound and contentious transition. Originally set up in 1951 as an academic unit that would, as an instrument of the Cold War era, encourage U.S. college students 
to concentrate on the history, culture, and "exceptionalism" of the United States of America alone, American Studies today has, in an irony of history, become something of a cultural and intellectual straightjacket. Its insularity has rendered it a discipline that, for some scholars, at least, is now struggling to divest itself of its founding principles (which tethered it to the study of a single American nation) and adopt a more hemispheric, or transnational, approach to its new and different place in our evolving Inter-American relationships. And to do so without being, or without seeming to be, appropriative, hegemonic, or imperialistic (see Gillman 196-214; see also Levander and Levine 399-400 and Siermerling and Casteel 9). In the post-World War II world, as our old thinking about the supposedly monolithic and stable nation-state began to change, and as new, non-WASPish voices began to enter the ken of U.S. literature, the United States took an inward turn. Stressed externally by the pressures and demands of an increasingly internationalized and interconnected new world and internally by the emergence of hitherto ignored sectors of American culture (Jews, Blacks, Southerners, and women, for example), writers and critics in the United States responded by concentrating on an "intraAmerican cultural pluralism and heterogeneity, emphasizing America's internal cultural and ethnic diversity and difference" (Messmer 50). Yet while this post-war inward turn, and the recognition of writers from new and different backgrounds that characterized it, successfully revised and broadened the canon of U.S. literature, it also contributed to the "silencing of historiographical interest in America's transnational or global interliterary and intercultural relations" (Messmer 51). Now, in 2014, Americanists who concentrate on the history and culture of the United States are seeking once again to redefine their discipline, this time, however, along more comparative, hemispheric, and transnational lines. This same conceptual upheaval within U.S.-based American Studies has also been closely monitored by colleagues throughout the hemisphere and elsewhere. As Canadian critics Winfried Siemerling and Sarah Phillips Casteel, write, for example:

If such questions trouble United States Americanists, they become of particular concern to scholars located outside the United States, who may note with some alarm that "America" tacitly continues to signify "United States" in a surprising number of avowedly hemispheric academic treatises. Indeed, it often appears to be taken for granted that the United States will remain at the centre of this academic enterprise and that the aim of hemispheric American studies is to rehabilitate United States studies as American studies rather than to decentre it. (10)

When one extends this same concern (that the current move toward hemispheric American Studies is little more than the latest fad and a new imperializing effort by U.S.-based Americanists) to Latin America and the Caribbean, it is easy to understand why the entire project is viewed with suspicion. Except for hard core 
traditionalists, who still wish to view the United States as the only true "America" and as the center of the American universe, the very idea of inter-americanitél inter-americanidad/inter-americanidade is, for Americanists here in the United States, both exciting and disconcerting.

This uncertainty as to how to proceed within our changing paradigm of Americanidade (as the Brazilians see it) is quite clear in the American Studies bibliography that we have seen since the late 1980s and, especially, from the 1990s. Even Carolyn Porter's landmark 1994 essay, "What We Know that We Don't Know: Remapping American Literary Studies," suffers from the problem Siemerling and Casteel note above. When, chastising her cohorts in the United States for failing to grasp the full scope of the issue in question, she writes that U.S.-based American Studies have traditionally stemmed from "an idealized cultural nationalism now set in relief by its own failures" (470), she can only be referring to the United States alone. Yet those of us who have long studied the Americas in toto know that many New World nations have struggled, in one form or another, with this problem of an "idealized cultural nationalism." The Brazilians and Argentines, to cite two well known cases, have long agonized over precisely this same question, though their reasons for doing so, and their responses to it, have been quite different from those at issue in the United States. The Brazilians in particular and the Spanish Americans in general have long cultivated a much more international approach in their efforts to define themselves. Something similar could be said of Québec and its historical development. Or of Canada's in general. Porter's statement, then, is not incorrect, but it does imply that in this process of disciplinary transformation the primary American nation state is, and will remain, the United States, even as its scholars are urged to consider "cultural, political, and economic relations between and among the Americas" (510). Thus, while Porter laudably argues for a more open approach to hemispheric American studies, her language seems to keep the United States at the heart of the undertaking, the model against which the "other" Americas will have to be judged.

This same hesitation about how to enter the Inter-American game, prodded by a growing realization that this new and expanded sense of what it means to be an "American" and an "Americanist" in the twenty first century is entirely justified and exacerbated by a realization that this is an old topic for many other New World scholars, continues on into the present time. In a nutshell, the problem for Americanists who specialize in the United States and who have attained their degrees here is that while they now in the main understand the legitimacy of the Inter-American, hemispheric, or transnational project, they are, because of their too limited linguistic, literary, cultural, and historical training, unprepared to write cohesive comparative studies that can get beyond the merely (and, by now, 
repetitiously) "theoretical" and actually engage authors, texts, and issues from Canada, Spanish America, Brazil or from the non-English-speaking Caribbean. The complication, then, is not a function of good intentions, which are warmly welcomed; the question has to do with how prepared one is, professionally speaking, to compare and contrast specific texts, literary or critical, from English and French Canada, the French (and Créole)-speaking Caribbean, Spanish America, and Brazil. When Porter wrote her essay, "What We Know That We Don't Know," she was, perhaps more than she realized, getting at the heart of the issue. This question about how much U.S.-based Americanists really know about Canadian, Caribbean, Spanish American, and Brazilian literature, is essential and cannot be taken lightly, brushed aside, or discounted. It must be faced. The support that U.S.based Americanists are now showing the Inter-American project is admirable, if (from the perspective of students and scholars in the rest of the Americas) long overdue. But until they can move from what now, in 2014, seem endless reiterations about why the larger, more hemispheric approach to things American is justified and valuable (we all know this and many in the Americas have known it for a long time; see Levander and Levine) to actually performing close comparative readings of disparate texts from the rest of the Americas, U.S.-based Americanists will struggle to participate in the on-going Inter-American dialogue as seriously as they should - and as seriously as they are needed to be.

Ten years after Porter's call for a more hemispheric understanding of American Studies, Claudia Sadowski-Smith and Claire Fox published an essay that also illuminates the obstacles that U.S.-based Americanists face in undertaking this disciplinary reformulation. Writing in the journal Comparative American Studies they point out, quite correctly, in my judgement, that:

If Americanists are to internationalize their field without becoming unwitting ambassadors of a US-inspired "world without boundaries" ... they need to travel abroad, engage in scholarly dialogue in languages other than English, and interest themselves in scholarship produced outside the United States and outside their own field. Until they do so, we fear that an Americanist-led hemispherism will only promote a vision of the Americas in which all academic disciplinary configurations are subordinate to those of the United States and in which every region outside of the United States is collapsed into a monolithic other. (23)

This is precisely the problem, and it will not be quickly or easily solved.

Although there are highly respected and influential voices within American Studies here in the United States who believe that American Studies is the most propitious academic home, the "optimal site," for our new hemispheric or transnational view of the Americas (Nelson 390), I respectfully disagree. In my opinion, both Comparative Literature, with its insistence that the Inter-American 
doctoral student have an in depth knowledge of the languages and literatures of at least three or four of our American cultures, and the discipline of comparative Latin American Studies, which makes similar demands on its doctoral students, are, now and in the future, in a better position to produce more sophisticated and more thoroughly trained scholars for the Inter-American project. With respect to things "American," moreover, both these disciplines have had checkered relationships with the discipline of American Studies as it was originally conceived and practised. The tension American Studies has had with Comparative Literature is particularly odd, since its conception of literature has always been decidedly international in nature. While Americanists who specialize in the United States are already making important contributions to our better understanding of InterAmerican literature (as the Canadianists, Caribbeanists, and Latin Americanists have long been doing), it is clear from contemplating the nature of the field that many, if not most, of the most fundamental connections that link the Americas "fall with the scope of comparative literature, which has historically been seen at least within U.S. studies - as a footnote to the more pressing issue of the national imagination. To the extent that these two frames differ ... both are essential components of a cultural history of the Americas" (Gruesz 4). Although I agree with this assessment, I do not see the still overwhelmingly monolingual (or, at best, bi-lingual in Spanish and English) discipline of American Studies, as it is practised here in the United States, at least, as ever demanding the same high level of linguistic fluency or the same extent of graduate seminar level literary study done in the several languages involved that is demanded of students in Comparative Literature and comparative Latin American Studies. And a very similar argument can be made for the strength of the Canadian Studies perspective on the study of American literature in a hemispheric context (see Chanady, 1999; Lamonde and Bouchard; Hazelton; and Imbert). I fear the discipline of American Studies is, in the main, still too closely tied to the United States of America, to that nation's "national imagination," and to the privileging of U.S. English, culture, and history. It is largely because of this that I am also dubious as to whether even well intended efforts to internationalize it will result in more extensive and serious attempts to make it truly multi-lingual to the degree necessary to study the literatures of the Americas and in a professionally well prepared sense (see, also, Messmer 53). Perhaps I am wrong. Time will tell. For the present, however, we know that requirements in "Reading Proficiency," even if they are taken seriously (which is rare enough), are no substitute for taking four or five graduate level seminars conducted in French, Spanish, or Portuguese on the literatures of Québec and the Francophone Caribbean, Spanish America, and Brazil. 
There will always be differences between these types of professional preparation and competency. At the same time, we must all recognize that these crucial differences in professional training are not going to stop individuals from engaging, however they can, in the Inter-American project. Academics will do what they wish to do, and scholars who are not fluent in any language but English will have important and useful things to say. And we will learn much from them. But differences between those who must work only in translation and those who work in a text's original language, or between those who know a particular American literary tradition by having studied it in a number of graduate seminars and in its original language and those who read only a text or two from it, are real and they must be recognized. This means that while the future of Inter-American Studies does not depend in any way on the participation of scholars from the United States, its future as an inter-disciplinary field will be affected, positively or adversely, by how upcoming generations of U.S.-based (Inter-)Americanists respond to the preparatory challenge that confronts them. To paraphrase (textually and thematically) what Orwell tells us in Animal Farm (1945), while all Inter-American pigs are equal, some will find it all too easy to regard themselves as being more equal than others.

\section{Native American Studies}

In very real ways, Native American Studies form the foundation of the entire Inter-American project (Fitz, "Native American" 124). These "First Peoples" inhabited the lands later to be called "America" for thousands of years before the first Europeans arrived, and they had developed a great diversity of cultures rich in myth, music, dance, storytelling, and poetry. Hundreds, perhaps thousands, of different languages were spoken by at least twenty million people and vastly different kinds of civilizations were erected. Some of these, such as those of the mound builders in central North America, the Aztecs in Mexico, the Mayas in the Yucatan and Guatemala, and the Incas in Peru and Ecuador, could boast of having developed brilliant cultures and, in the cases of the Aztecs, the Maya, and the Incas, of having erected fabulous cities as well. Other tribes, like the Iroquois, had developed social and political systems so sophisticated that they would influence such thinkers as Karl Marx and Benjamin Franklin. Although what we ordinarily think of as "literature" was, for these First Peoples, oral in nature, and although there is much we do not know about it, we are surely safe in assuming that it was robust, imaginative, and widely dispersed throughout the New World (which was, of course, an already ancient world for the millions of people inhabiting the Americas at the time of the European conquest). Many 
of these original "American" cultures endure today and exert strong presences in many of our twenty- first century American national literatures. Although their presences are more flourishing in some nations than in others, every American nation and region can boast of having a Native American component to its national history and culture. Guarani, for example, is, along with Spanish, one of Paraguay's two official languages, while Quechua, Nahuatl, and Maya-Quiché are all alive and well in their respective cultures and countries. Spanish America and Canada, especially, enjoy a special strength in terms of their native cultures and literatures, and many of their greatest writers work, directly or indirectly, with themes and motifs germane to their Native American experiences. Commenting on the Aztec-infused poetry of the great Mexican author and diplomat, Octavio Paz, for example, critic Brian Swann has written that he considers Paz's homeland to be both deeply Spanish and deeply Indian (xv-xvi), something that might also be said of such nations as Peru, Bolivia, and Guatemala, in addition to several others. Swann, like Paz before him, also contrasts the vitality of Native American culture in places like Mexico, Peru, and Canada to the situation in the United States, where, even today, the Native American presence is problematic $(\mathrm{xv}-\mathrm{xvi})$. Canada, too, has long celebrated its indigenous heritages and made space for them in the construction of its sense of national identity. In a striking New World contrast, the dominant culture of the United States has never found this sort of acceptance easy to countenance. Brazil, as always, is different still in that it never had indigenous civilizations as advanced and as sophisticated as the Aztecs, the Maya, and the Inca. Yet even there, the idea of the Indian has been fundamental to Brazil's development as a modern nation. As indicated earlier, and as we can see in our various New World literary histories, the tragic fate of these First Peoples after the arrival of the Europeans constitutes both one of the most shameful of our common American historical experiences and one of the great, foundational themes of Inter-American literature.

\section{Canadian Studies}

Like scholars in Comparative Literature and Comparative Brazilian, Spanish American, and Latin American Studies, Canadian scholars have long been concerned with the "parochialism of United States studies (conducted under the name 'American studies')" (Siemerling and Casteel 6; see also Williams 5) and with the appropriation of the label "America" itself. It is partly for this reason that, having struggled for so long to achieve a coherent sense of what it means to speak, even nationalistically, about Canadian literature, Canadian scholars have been understandably cautious about entering into the field of hemispheric American literature. 
Because of its dual European heritage (France and England), Canadian literature has benefitted from smart, productive applications of the comparative method. It was not until the 1960s, though, that both Anglophone Canadian literature and "la littérature québécoise" were able to gain a solid sense of identity, by themselves and in relation to each other and the world (Siemerling and Casteel 10). Since that time, the writers, artists, and intellectuals of Québec and Montréal have embraced a more comparative and hemispheric perspective as well. English-speaking Canada, perhaps less secure in its own sense of identity, has been more reluctant to take this same step into the Inter-American fray, though by the second decade of the twenty first century it, too, is moving in this direction (see Bahia; Chanady, Handley, and Imbert; and Siemerling and Casteel). Indeed, a spate of excellent new studies, including Québécois et Américains: La culture québébecoise aux XIX et XX siècles (Yvan Lamonde and Gérard Bouchard, eds., 1995), Amaryll Chanady's Entre inclusion et exclusion: La symbolisation de l'autre dans les Amériques (1999), Patrick Imbert's Trajectoires Culturelles Transaméricaines: Médias, Publicité, Littérature et Mondialisation (2004), America's Worlds and the World's Americas/Les mondes des Amériques et les Amériques du monde (Amaryll Chanady, George Handley, and Patrick Imbert, eds., 2006), Hugh Hazelton's Latinocanadá: A Critical Study of Ten Latin American Writers of Canada (2007), and Canada and Its Americas: Transnational Navigations (Winfried Siemerling and Sarah Phillips Casteel, eds., 2010), are demonstrating how productively Canada can participate in the InterAmerican dialogue and how it can do so without losing its sense of identity as a national literature (see Fitz, 2011).

French literature, after all, is no less French for also being European, and the same is true for our New World nations as well, including Canada, which, comparatively speaking, is no less Canadian for also being American. Long accustomed, in fact, as Brazilianists and Spanish Americanists are, to wielding the comparative method and to studying their texts in the context of other hemispheric, and world literatures, the Canadians bring a wealth of outstanding authors, texts, and critical issues to the Inter-American banquet (see Fitz, "Canadian Literature"). And there is no dearth of commentary on this very question from Canadian quarters or from the Canadian perspective. Sadowski-Smith and Fox, for example, have observed that " $[\mathrm{b}]$ ecause of its complex relationship to questions of state-sponsored nationalism and the nation-state as well as its long history of US domination, Canada constitutes an important location from which inter-Americas scholars in Canada, the United States, and other locations could rethink the role of the nation within theories of globalization" (19-20). Much the same could be said of Brazil.

Experienced Inter-Americanists know full well that, even now in 2014, when the field is finally catching hold in the American academy, "Canadian culture 
and criticism are frequently marginalized in hemispheric comparative work, in borderlands criticism, and even in North American studies" (Siemerling and Casteel 8; see also Bahia). As Canadian scholar Albert Braz puts it, "Canada is barely acknowledged in inter-American discourse," which, he points out, is largely because "hemispheric studies have become increasingly oriented along a United States-Hispanic America axis" (119), one that also elides Brazil (120) from what is fast becoming a distortingly binary approach to Inter-American thinking. Another prominent Canadian scholar and Inter-Americanist, Hugh Hazelton, comes to much the same conclusion, adding that, in fact, "Canada and Latin America have a long and complex literary relationship that includes both parallel historic, artistic, and cultural currents and a remarkable number of authors who have written about their mutual regions" (2010; 219). Pointing out that the "earliest known anthology of Canadian writing published in Brazil ... was a selection of Quebec [sic] poetry edited by Jean Désy, a Canadian diplomat, and published in French in São Paulo in 1943" (2010; 219), Hazelton also notes that the "first major Canadian novel to have an impact in Latin America was Malcolm Lowry's Under the Volcano" (2010; 220). Programs in Canadian Studies have proliferated in Brazil and Spanish America over the past twenty-five years or so and have helped to foment a great many "cultural and literary exchanges" as well as the development of a "comparativist dynamic and framework" $(2010 ; 221) .{ }^{13}$ One particularly notable outcome of this Canada/Latin America connection is Confluences littéraires Brésil/ Québec: Les bases d'une comparaison (1992), "a collection of essays compiled by Michel Peterson and Zilá Bernd” (Hazelton 221) that explores what has been the fascinating and fast growing relationship between Brazil and Québec (and Canada generally) as still marginalized American cultures.

\section{Caribbean Studies}

Encompassing "the first American lands to be explored, conquered, and colonized by Europe" (Benítez-Rojo 85), the Caribbean region, a "meta-archipelago" possessed of "neither a boundary nor a center" and "saturated with messages sent out in five European languages (Spanish, English, French, Dutch, and Portuguese)" plus several "aboriginal languages" and "different Créole tongues," functions in the Inter-American project as an "island bridge" that connects, "in 'another way',

13 The Brazilian association of Canadian Studies programs publishes the highly respected journal Interfaces Brasil/Canadá which encourages comparative studies, while in Mexico the Revista Mexicana de Estudios Canadienses promotes the same kind of Inter-American work. 
North to South America" (86). Both influenced by Martí and his "anticolonialist" stance in the face of "North American imperialism" (Dash 10), J. Michael Dash and Edouard Glissant envision a Caribbean identity that, in theoretical terms, embraces "an otherness that cannot be contained or appropriated" and that, like the Caribbean sea itself, is based on ceaseless "fluidity and movement" (Dash 11) as opposed to stasis. Dash also argues that for Glissant, the celebrated Martiniquean critic, Martî's 1891 essay, "Nuestra América," "is an early articulation of what Glissant would later call l'autre Amerique" (53). For Glissant and Dash, the crucial concept of "Créolite" (a term that evokes both creole and criollo) rests, then, not on the idea they feel lies behind "mestizaje," which both scholars understand as speaking to a static state of being, a "halfway" point "between two pure extremes" (Dash 12), but a process of "becoming" rather than a state of "being" (Dash 11). Although the concept of "métissage" is discussed throughout, there is no referencing of either the experience of the Canadian Métis or with the still more complicated concept of "mestiçagem" as it is known in Brazil. Once again, the Spanish presence in the Caribbean is the point of reference, though the French terms, "Créolité" and "métissage," are put forth as the more accurate terms for describing what Dash and Glissant contend is the unique biological, linguistic, and cultural mix of the Caribbean. In discussing his theory of the Caribbean as representing the "Other America," Dash also cites Glissant as praising the work of Alejo Carpentier, Gabriel García Márquez, and William Faulkner for sharing a sense of "unregimented and relational" space and time similar to his own and for writing texts that exemplify the kind of fluid, open writing he feels is characteristically Caribbean, and therefore "Other," in nature (13).

\section{American Literature as a Transnational Concept}

By way of concluding this essay, let me reiterate one critical point: In undertaking Inter-American literary studies, we must, except under special circumstances, reject the binary, two-sided study. It is simply inadequate to the task. By focusing on only two of our several American languages and literatures (English and Spanish, for example), we neglect the others and, in so doing, distort the entire project by making it more limited than it really is. This is the problem, as I see it, in three recently published studies: Kirsten Silva Gruesz's Ambassadors of Culture: The Transamerican Origins of Latino Writing (2002), Anna Brickhouse's Transamerican Literary Relations and the Nineteetnth-Century Public Sphere (2004), and José David Saldívar's Trans-Americanity: Subaltern Modernities, Global Coloniality, and the Cultures of Greater Mexico. All of these works, excellent though they are, concentrate on Spanish and English and demonstrate what Braz has aptly identified 
as the emergent "United States-Hispanic America axis" (119) in Inter-American scholarship. In doing this, these studies all but leave out both Canada and Brazil, as if these nations and cultures did not exist and as if they were not important enough to the Inter-American project to be taken into account. ${ }^{14}$

We need to guard against this tendency. While it is true that Spanish is now the second language of the United States, ${ }^{15}$ and while it is also true that Spanish and Latina/o culture are transforming how U.S.-based Americanists envision their nation, this does not mean that Spanish and English alone define the parameters of Inter-American literary study. They do not. And we must not assume that just because a person has a Spanish name and can read and write some Spanish she or he is knowledgeable in the literature of Spanish America or in its literary history. To know a language is not the same thing as having spent years studying literary texts written in it. There is no doubt that Spanish and English are now ushering U.S.-based American Studies into a new era, but they represent only a small part of the larger hemispheric picture. The danger, as we have seen, is that even the leaders in the trend to internationalize American Studies will, by virtue of their lack of training in the languages and literatures of the rest of the Americas, end up once again enshrining the literature and culture of the United States as the sine qua non of the entire Inter-American project, ${ }^{16}$ which it is not. Although it does

14 Gruesz's study, though, has the advantage of openly noting that she does not include Brazil in her discussion "for the simple reason" that she is "limited here to bilingual contexts of Spanish and English" (213). Neither does she discuss Canada, except insofar as it relates incidentally to one of the authors she discusses. By proceeding in this fashion, Gruesz makes it clear that she knows Brazil and Canada are major players in the Inter-American game but that she is not equipped to deal with them here.

15 That this would eventually be the case was obvious to comparatists and Latin Americanists as early as the 1960s, when this very point was being widely and openly discussed.

16 This is true, to a degree, even of Gruesz's study, which, according to its author, seeks "to imagine a new form of U.S. cultural history in general: one that would unseat the fiction of American literature's monolingual and Anglocentric roots and question the imperial conflation of the United States with America" (4). Comparative InterAmericanists and Latin Americanists have known for generations that the literature of the United States has never been "monolingual" and that (other than its indigenous peoples) its deepest roots are Hispanic, not English. Moreover, by placing the history, literature, and culture of the United States at the heart of the study, instead of coming at the question of Inter-American, or "transamerican," literary study from the less hierarchical perspective of the comparatist (that is, as a function not of nation but of such transnational categories as theme, period, genre, influence and reception, or translation), it is almost impossible to really dislodge it from what many still regard as its undeservedly hegemonic position in the Americas. 
have its place in Inter-American scholarship (specific instances of authorial or textual influence and reception, for example, or questions of literary history, as in Canada or Latin America), the dyadic model should therefore never form our basic, conceptual thinking about the Inter-American paradigm. The two-sided approach cannot ever fully encapsulate the diversity of the Inter-American project. Instead, we should always be reading and expanding our New World literary horizons, preparing ourselves intellectually to think more and more in terms of three, four, and even five-sided studies. And Canada and Brazil must not be left out. Such studies, more inclusive in nature, reflect more accurately the complexity and diversity of our common American experience.

And, it must be said, examples of this type of multi-sided approach to American literature are appearing, too. Some very recent examples include the following texts: Monique-Adelle Callahan's Between the Lines: Literary Transnationalism and African American Poetics (2011), Paulo Moreira's Modernismo Localista das Américas: Os Contos de Faulkner, Guimarães Rosa e Rulfo (2012), and Ignacio Infante's After Translation: The Transfer and Circulation of Modern Poetics across the Atlantic (2013). In contrast to so many U.S.-based studies on hemispheric or hemispherically transnational literature, these latter texts, done by professional comparatists schooled in the languages and literatures involved, concern themselves not with "theory" but close, comparative readings of specific New World authors and texts. Callahan's book, for example, focuses on three American poets, Frances Harper, Cristina Ayala, and Auta de Sousa and represents three very distinctive New World cultures (the United States, Cuba, and Brazil). The writers in question are cited in their original languages and, importantly, the texts are all discussed as they live and breathe in their original languages, with English language translations provided for Ayala and Sousa. Infante, another professionally trained comparatist, does much the same thing, except in an expanded and trans-Atlantic sense. Engaging with the venerable comparative question of influence and reception, he compares and contrasts specific poems (all cited in their original languages) and New World authors, including Vicente Huidobro (from Chile), Jack Spicer, Robert Duncan, and Robin Blaser (all three from the United States), Kamau Brathwaite (from Barbados), and the brothers Haroldo and Augusto de Campos (from Brazil). The great Portuguese modernist, Fernando Pessoa, is also discussed as is Spain's Federico García Lorca. Devoting his study to regionalist narrative in the United States, Spanish America, and Brazil, Moreira does much the same thing, closely comparing and contrasting short stories by Faulkner, Mexico's Juan Rulfo, and Brazil's Guimarães Rosa as exemplifying a certain, unique kind of New World modernity. Callahan, Infante, and Moreira spend very little time theorizing about their respective Inter-American projects, 
though they do offer some cogent comments about the value of the comparative method as it applies to the study of American literature in a multi-lingual and multi-cultural context.

By 2014, then, we can see that in the United States the field of Inter-American literary study finds itself characterized by three basic features: One, while American Studies scholars continue to struggle with the concept of hemispheric study and to ruminate about the importance of the Inter-American project to their hitherto exclusively nationalistic discipline, professional comparatists, comparative Latin Americanists (led by the Brazilianists), and now Canadianists, too, are actually undertaking the close, comparative readings of New World texts that we need to have more of; two, Brazil and Canada are still being routinely left out of these U.S.-based studies and theoretical expositions or given short shrift in them; and, three, the Inter-American project, here in the United States, at least, is fast becoming a function of only two languages (English and Spanish) and of two cultures, the Spanish-speaking United States and the English-speaking United States, with a few desultory references (too often involving only José Martí and "Nuestra América," a text that ignores both Brazil and Canada; see Newcomb) to an only vaguely understood entity called "Latin America" (meaning nearly always Spanish America alone) seemingly thrown in for good measure. There is, in short, a serious imbalance, or disconnect, between the type of work being done right now by even well intended U.S.-based American Studies scholars, for whom the question of hemispheric "transnationality" remains one of theoretical debate, and experienced, polyglot, and history-savvy Inter-American comparatists, Canadianists, and comparative Latin Americanists, for whom the question is a matter not of "theory" but of lived experience, fluency in the languages, literatures, and cultures involved, and long standing professional practice.

These same scholars, the comparative Inter-Americanists, the Canadianists, and the comparative Latin Americanists, have long been acutely conscious of the larger context of American history (a term which, for them, is understood as referring not only to the story of the United States but to what the United States has done to their nations as well). This is a serious point of difference between the American Studies approach to hemispheric relations, which, for many still seems appropriative and imperialistic (see Gillman), and that of the comparatists, Latin Americanists, and Canadianists. It also dramatizes why the threat, perceived or real, of being subsumed by the United States, of being relegated yet once again to second class status, or, even more insulting, to move from decades of being roundly ignored to now being patronized, is so sensitive a topic. To study Inter-American literature in its full hemispheric context is to enter into a highly charged political arena with deep historical roots, and if one is naive or ignorant of the many, 
often ugly realities and conflicts involved, then one is going to be in for a rude awakening. For a truly Inter-American perspective to flourish here in the United States in the upcoming decades of the twenty first century, U.S.-based American Studies scholars in particular are going to have to recognize that there are more languages and literatures and critical voices in the Americas than those working in just Spanish and English and that these, too, these long dismissed "others," have to be studied, read, and considered seriously in their studies. For these historically disparaged "others" have been studying the Americas for a long time and they have a great deal of value to say on the matter. By dint of their academic training and historical experience, comparatists, Canadianists, and comparative Latin Americanists have already engaged, at the level of textual analysis, many of the key similarities and differences that link the Americas together. As a result, it is no surprise that, in 2014, the field of Inter-American literary and cultural study is being led by them and their work and by scholars based "outside the Americas" entirely, such as the "Göttingen Research Group on Inter-American Literary Studies," directed by Armin Paul Frank, "as well as its predecessor, the Center for Advanced Study in the Internationality of National Literatures" (Messmer 42).

This is not to say the American Studies approach is not valid; it is, and indubitably so. But its practitioners have a lot of reading, thinking, and catching up to do. Its many years of concentrating on the United States alone have produced some wonderfully enlightening studies, but they have also hindered the ability of scholars concentrating on the United States alone to know what has been going on in the rest of the Americas, and this lacuna is, in 2014, coming to the fore as a serious handicap. With respect, for example, to a comparison between the by definition broadly transnational discipline of Latin American Studies and the, again by definition, narrowly nationalistic discipline of American Studies, Gruesz observed, in 2002, that the "modern discipline of Latin American literature originated in consciously transnational paradigms and in this respect has much to teach its U.S. counterpart, which consistently ignores comparative studies to pursue the white whale of the national character" (214 n. 5). More recent evidence, however, suggests that this situation is changing, and that good, solid comparative studies, embracing difference but based on the similarities that allow them to proceed, are making their marks.

And though it is often overlooked in discussions about our new hemispheric, transnational, and comparative approaches to American Studies and American literature, we here in the United States also need to pay much more attention to what our colleagues in Europe, in Canada, in Spanish America, in the Caribbean, and in Brazil have to say. The view of American Studies from London, Amsterdam, Paris, Göttingen, Edmonton, Toronto, Montréal, Kingston, Martinique, Buenos 
Aires, Mexico City, São Paulo, and Rio de Janeiro will be of immense value as we seek to deal with our rapidly changing discipline of American Studies. We who live and work here in the United States need to learn to see ourselves as others see us and not just to obsess over ourselves and our nation, as, thanks to the old myth of U.S. "exceptionalism," we are prone to doing. As Latin Americanists are painfully aware, something Samuel Putnam, a pioneering Inter-Americanist, said back in 1948 is still largely true today. Writing of how "English-speaking North Americans" have historically shown an "astonishing lack" of interest in Brazil and Spanish America, Putnam wonders if this disdainful attitude has to do with "a cultural isolationism that has led us to look more or less exclusively to the Old World for our importations and ... to look down upon our hemispheric neighbors and their intellectual productions" (vii; see also Williams 5-6; and Monegal 3-13). Although the deplorable situation Putnam describes has gotten better, it has not by any means withered away, not even in the academy. This simple fact explains why Inter-Americanists who are linguistically and culturally trained in the diversity of the New World remain skeptical about how effectively U.S.-based Americanists and American Studies scholars can participate in the discussion if they are limited to English (plus, possibly, some Spanish) and know little or nothing of the rich literatures and cultures of Spanish America, Brazil, French and English-speaking Canada, and the Caribbean and of our many Native American cultures in North, Central, and South America.

Still and all, many good people and excellent scholars are involved in the internationalization of American Studies, and they sincerely want to know more about their hemispheric neighbors. This is a positive trend and one in which we can all rejoice, even as "we must at the same time avoid paying lip service to a more inclusive vision of the Americas while reinscribing U.S. hegemony" (Zamora and Spitta 193). So, in spite of the obstacles that confront us, I believe we who are genuinely interested in a more unified and egalitarian (but not homogenized ${ }^{17}$ ) America are on the cusp of a bright future. We can look forward with optimism to being able to work together in the development of Inter-American study as a new and positive force in twenty first century American relations. Imagined as an endlessly inter-relating heptagon, one encompassing the cultures of Anglophone and Francophone Canada, the United States, the Caribbean, Spanish America, and Brazil, along with our many Native American cultures as well, we can more

17 The literatures and cultures of the Americas are far from being the same, and we must not allow our comparative hemispheric studies to suggest that they are. As professionally trained comparatists know, the crucial element in the comparative method is not similarity but difference, the uniqueness of each text and culture under consideration. 
easily understand why Inter-American study ranks as such an important project and why it needs to be done and done well. And it needs to be done as a communal effort, one undertaken by all Americanists, here in the New World, in Europe, in Central and South America, and in other parts of the world, working together, sharing information, and learning from each other. There will be differences, to be sure, between our methods and approaches, but the recognition and embracing of difference, after all, is the life blood of comparative work.

\section{Works Cited}

Bahia, Márcio. "Americanidad: Towards the Mapping of a Concept." Americas' Worlds and the World's Americas/Les mondes des Amériques et les Amériques du monde. Ed. Amaryll Chanady, George Handley, and Patrick Imbert. Ottawa: Legas, 2006. 23-33.

Balakian, Anna (coord. ed.). Proceedings of the $X^{\text {th }}$ Congress of the International Comparative Literature Association/Actes du Xe Congres de L'Association Internationale de Littérature Compareé. Ed. James J. Wilhelm. New York: Garland, 1985.

Barrenechea, Antonio. "Good Neighbor/Bad Neighbor: Boltonian Americanism and Hemispheric Studies." Comparative Literature 61.3 (Summer 2009): 231-243.

Benítez-Rojo, Antonio. “The Repeating Island.” Do the Americas Have a Common Literature? Ed. Gustavo Pérez Firmat. Durham: Duke University Press, 1990. 85-106.

Bolton, Herbert E. “The Epic of Greater America." American Historical Review 38 (1933): 448-474.

Braz, Albert. "Canada, America, and the Americas: The Quest for Continental Identity in the New World." Canadian Review of Comparative Literature 35.1-2 (2008): 121-130.

Braz, Albert. "Outer America: Racial Hybridity and Canada's Peripheral Place in Inter-American Discourse." Canada and Its Americas: Transnational Navigations. Ed. Winfried Siemerling and Sarah Phillips Casteel. Montréal: McGillQueen's University Press, 2010. 119-133.

Brickhouse, Anna. Transamerican Literary Relations and the Nineteenth-Century Public Sphere. Cambridge: Cambridge University Press, 2004.

Chanady, Amaryll. Entre inclusion et exclusion: La symbolisation de l'autre dans les Amériques. Paris: Honoré Champion, 1999.

Chanady, Amaryll. "Representations of the Native and the New World Subject." Canada and Its Americas: Transnational Navigations. Ed. Winfried Siemerling and Sarah Phillips Casteel. Montréal: McGill-Queen’s University Press, 2010. 85-101. 
Chanady, Amaryll, George Handley, and Patrick Imbert (eds). Americas' Worlds and the World's Americas/Les mondes des Amériques et les Amériques du monde. Ottawa: Legas, 2006.

Dash, J. Michael. The Other America: Caribbean Literature in a New World Context. Charlottesville: University Press of Virginia, 1998.

Fitz, Earl E. "Canadian Literature in the Twenty-First Century: The Emergence of an Inter-American Perspective." AmeriQuests 8.1 (2011). www.ameriquests.org.

Fitz, Earl E. "From Blood to Culture: Miscegenation as Metaphor for the Americas." Mixing Race, Mixing Culture: Inter-American Literary Discourse. Ed. Monika Kaup and Debra J. Rosenthal. Austin: University of Texas Press, 2002. 243-272.

Fitz, Earl E. "The First Inter-American Novels: Some Choices and Some Comments." Comparative Literature Studies 22.2 (1985): 361-376.

Fitz, Earl E. Inter-American Literature: A Concise History. The Scholar Collection, 2012. (473 pp.). www.academicpub.com.

Fitz, Earl E. "Native American Literature and Its Place in the Inter-American Project." Comparative American Studies 11.2 (June 2013): 124-147.

Fitz, Earl E. Rediscovering the New World: Inter-American Literature in a Comparative Context. Iowa City: The University of Iowa Press, 1991.

Gillman, Susan. “The New, Newest Thing: Have American Studies Gone Imperial?" American Literary History 17 (2005): 196-214.

Glissant, Edouard. Le discours antillais. Paris: Seuil, 1981.

Gruesz, Kirstin Silva. Ambassadors of Culture: The Transamerican Origins of Latino Writing. Princeton: Princeton University Press, 2002.

Hazleton, Hugh. Latinocanadá: A Critical Study of Ten Latin American Writers of Canada. Montréal: McGill-Queen’s University Press, 2007.

Hazleton, Hugh. "Transculturation and National Identity in the Novel Rojo, amarillo y verde by Alejandro Saraiva." Canada and Its Americas: Transnational Navigations. Ed. Winfried Siemerling and Sarah Phillips Casteel. Montréal: McGill-Queen's University Press, 2010. 219-230.

Imbert, Patrick. Trajectoires Culturelles Transaméricaines: Médias, Publicité, Littérature et Mondialisation. Ottawa: University of Ottawa Press, 2004.

Lamonde, Yvan, and Gérard Bouchard (eds.). Québécois et Américains: La culture québécoise aux XIX et XX siècles. Montréal: Fides, 1995.

Levander, Caroline F., and Robert S. Levine. "Introduction: Hemispheric American Literary History." American Literary History 18.3 (2006): 397-405.

Lowe, Elizabeth, and Earl E. Fitz. Translation and the Rise of Inter-American Literature. Foreword by Ilan Stavans. Gainesville: University Press of Florida, 2007. 
Messmer, Marietta. “Toward a Declaration of Interdependence; or, Interrogating the Boundaries in Twentieth-Century Histories of North American Literature." PMLA 118.1 (January 2003): 41-55.

Newcomb, Robert. Nossa and Nuestra América: Inter-American Dialogues. West Lafayette: Purdue University Press, 2012.

Nelson, Dana D. "From Manitoba to Patagonia." American Literary History 15.2 (Summer 2003): 367-394.

Paz, Octavio. "Reflections: Mexico and the United States." Trans. Rachel Phillips. The New Yorker (17 September, 1979): 136-153.

Porter, Carolyn. "What We Know That We Don't Know: Remapping American Literary Studies." American Literary History 6 (2004): 467-526.

Putnam, Samuel. Marvelous Journey: Four Centuries of Brazilian Literature. New York: Alfred A. Knopf, 1948.

Rodríguez Monegal, Emir. "The New Latin American Literature in the USA." Review '68. New York: The Center for Inter-American Relations, 1969. 3-13.

Sadowski-Smith, Claudia, and Claire F. Fox. "Theorizing the Hemisphere: InterAmerican Work at the Intersection of American, Canadian, and Latin American Studies." Comparative American Studies 2.1 (2004): 5-38.

Saldívar, José David. "The Dialectics of Our America." Do the Americas Have a Common Literature? Ed. Gustavo Pérez Firmat. Durham: Duke University Press, 1990. 62-84.

Saldívar, José David. Trans-Americanity: Subaltern Modernities, Global Coloniality, and the Cultures of Greater Mexico. Durham: Duke University Press, 2012.

Siemerling, Winfried, and Sarah Phillips Casteel (eds.). Canada and Its Americas: Transnational Navigations. Montréal: McGill-Queen's University Press, 2010.

Stavans, Ilan. Mutual Impressions: Writers from the Americas Reading One Another. Durham: Duke University Press, 1999.

Swann, Brian. "Introduction." Smoothing the Ground: Essays on Native American Oral Literature. Ed. Swann. Berkeley: University of California Press, 1983. xi-xix.

Williams, Stanley Thomas. The American Spirit in Letters. New Haven: Yale University Press, 1926.

Zamora, Lois Parkinson, and Silvia Spitta. "Introduction: The Americas, Otherwise." Special Issue of Comparative Literature 61.3 (Summer 2009): 189-208. 
Marietta Messmer and Armin Paul Frank - 978-3-653-98855-0 Downloaded from PubFactory at 01/11/2019 10:57:20AM via free access 
Josef Raab

University of Duisburg-Essen, Germany

\title{
Difference Matters: Toward an Inter-American Approach to 'Race,' Ethnicity, and Belonging ${ }^{1}$
}

\author{
Todo lo que divide a los hombres, todo lo que \\ especifica, aparta o acorrala es un pecado \\ contra la humanidad. \\ —José Martí, “Mi Raza” (1893)
}

Bruce Norris's Clybourne Park, winner of the 2011 Pulitzer Prize for Drama, the 2012 Tony Award for Best Play, and numerous other prizes, offers a critical assessment of U.S. American 'race' relations since 1959, the year when Lorraine Hansberry's classic civil rights era drama, A Raisin in the Sun, leaves off. Hansberry's vision of an African-American family's struggle for the American Dream-home ownership and upward mobility-ends moments before the movers take their belongings to their future home in Clybourne Park, a fictional white residential neighborhood in Chicago. In the wake of the news that a "negro" family has made a down payment for a house in their area, the local residents are coordinating their efforts in the Clybourne Park Improvement Association, whose idea of "improvement" is to prevent the black family's move. In Hansberry's play, the Association's representative, Karl Lindner, calmly and hesitantly explains to the black family, the Youngers, that hard-working white people like himself have their own American Dream to protect. He therefore proposes that the Youngers should sell the house to the Improvement Association rather than moving there while knowing that they are not welcome. The Youngers go through with the move nonetheless, and this is where the piece by the African American playwright Lorraine Hansberry ends and the piece by the Anglo-American playwright Bruce Norris starts.

With its first act set in the Clybourne Park home in 1959 and the second act in 2009, Norris's play interrogates from black and white perspectives the changes that have taken place in terms of 'race' dynamics in the U.S.A. and it evinces the

1 Some of the ideas presented in this essay first appeared in "Contested Americas," my introduction to the volume New World Colors: Ethnicity, Belonging, and Difference in the Americas. 
increasing fluidity of 'race' and racism as well as the dynamics of belonging and of superimposed identity markers (of which 'race' is just one). Clybourne Park asks how racialized discourses and modes of behavior were affected by the Civil Rights Movement, multiculturalism, political correctness, and a supposedly 'post-race' climate. ${ }^{2}$ The play illustrates that underneath a veneer of enlightened 'post-race' humanism 'race' and ethnicity continue to be used as markers of difference and continue to matter. It thus offers an update of Hansberry's A Raisin in the Sun, the first play written by a black woman to be produced on Broadway and the first Broadway play with a black director.

Norris's Clybourne Park also sets the stage for the argument of this essay, which is that the negotiation of 'race,' ethnicity, belonging, and difference in the United States is interconnected with 'race' issues elsewhere in the Western Hemisphere. Because of a shared condition of multi-ethnicity and as a consequence of interAmerican migration and transfer, 'race' dynamics-while they are always embedded in specific situations, power constellations, and histories-are interlinked in the Americas. Expanding our view beyond the borders of the U.S.A. or any other nation in the Western Hemisphere will reveal some of the multiple contestations that have been under way in processes of self-positioning and othering, in defining or defending a certain notion of self, community, or nation. In view of the multiple categories around which identity politics revolves, we may also ask whether, in the $21^{\text {st }}$ century, belonging might offer a more promising analytical focus than 'race.' Either way, an inter-American approach to the topic of 'race,' ethnicity, belonging, and difference enlarges the scope of the discursive contests staged in Norris's Clybourne Park; it will allow us to draw connections between scenarios in different parts of the Americas and to recognize the larger, transnational, inter-American developments under way in terms of identity politics. Considering what Herbert Eugene Bolton has called "the wider horizons" does not mean, however, homogenizing situations and constellations throughout the Western Hemisphere. Difference matters, as we try to place a particular scenario or text into its wider, inter-American contexts in a process that may reveal parallel developments and similarities or opposite trends and disparities. We will better understand the specific issue if we approach it not with tunnel vision but with an openness toward its wider ramifications, interconnections, and comparative

2 It is interesting to note in this respect that when Norris learned in 2012 that the Deutsches Theater in Berlin was planning to cast a white actress from Croatia in the role of the female black character in Clybourne Park, he withdrew the production rights. 
contexts. For example, we will better understand the ultimately futile attempts to circumvent 'race' in Clybourne Park in a politically correct manner if we place the play not only in the context of Hansberry's A Raisin in the Sun but also, for example, of 'race' dynamics in the Caribbean or Brazil, where-despite sharing a history of colonialism and slavery with the United States-the construction and significance of 'race' have evolved very differently.

Hansberry's play takes its title from a poem by Langston Hughes, the bestknown writer of the Harlem Renaissance, who assessed his own ethno-racial status in the United States in comparison to blackness and skin color elsewhere in the Americas. He wrote about his experiences in Mexico that "nothing is barred from me. I am among my own people, for ... Mexico is a brown man's country. Do you blame them for fearing a 'gringo' invasion with its attendant horror of color hatred?" (qtd. in Haas 181). Ethno-racial allegiance and national allegiance clash here, as Hughes feels closer to "my own people, ... a brown man's country" than to the "gringo" nation of which he is a citizen. This example demonstrates that in an individual's feeling of belonging and community factors like 'race' and nation (and many more) intersect. In fact, his own 'race' is itself already an intersection for Langston Hughes, who refers to himself as "colored me" but who also stresses his own mixed-race ancestry, as in his poem "Broadcast to the West Indies," where he writes: "HELLO WEST INDIES! / You are dark like me / Colored with many bloods like me / Verging ... from black to white like me" (qtd. in Haas 189). Distinctions are neither easy nor clear-in Langston Hughes's work, in Lorraine Hansberry's A Raisin in the Sun, and in Bruce Norris's Clybourne Park-because numerous categories (like 'race', class, gender, education, age, citizenship etc.) interact, so that belonging becomes temporary rather than absolute. The individual dynamics of belonging (e.g., as they are played out in Clybourne Park's 2009 Chicago) will become clearer if we relate them not only to the history of their site (Hansberry's 1959 Chicago) but also to their wider contexts (e.g., Hughes's experiences in Mexico and in the West Indies).

In his programmatic essay, "America and Its Studies," Djelal Kadir complains that defendants of a so-called post-nationalist New American Studies remain in the tradition of "the perennial nationalist project of self-affirmation through self-differentiation, broadened in its scope, base, and illusionary political unconscious to the identity formations of 'minorities' or 'disenfranchised groups"' (19). This "nationalist project," Kadir believes, runs the risk of trying to replace "difference" by "diversity" and homogenizing this diversity into a national identity: "The inclusionary reach toward the hitherto disenfranchised groups persists in its appropriative, assimilationist, and acculturating project, while the projective identity constructs of the professional American Americanist serve as instruments 
for homogenizing diversity into identity and interpellating alterity into ulterior sameness" (20). In order to evade this national(ist) impulse, writes Kadir, we need

to see that what we go on labeling America is a lexical and a historical malaprop, that America refers to a whole hemisphere and to over five hundred years of history, of which some 270 years antedate 15 November 1777 and the United States Articles of Confederation. ... America is only part of a larger physical and human geography of the Western Hemisphere properly called America, and, in a myriad of other ways, the United States is also in the rest of the world. And even if it were "only in America," America, even in the United States, is a heteronomy that, demographically diverse and culturally plural, complicates those unitary identity constructs that hark back uncritically to the hegemonically reductive naturalization of 15 November 1777. $(21)^{3}$

In the same way that we need to avoid homogenizing in the national context we also need to be mindful of difference in the larger, inter-American framework. Fittingly, Daniel Mato has warned against the conflation of (ethnic and cultural) identities in the age of globalization, exemplified through the creation of a panLatino identity:

Current representations of a US Latina/o identity as well as of a 'Latin' American identity and of an all-encompassing transnational US Latina/o-'Latin' American identity entail images that, according to several social actors' representations, obscure differences that are significant. ... [We need to heed] assertions of difference ..., be they related to race, ethnicity, class or socioeconomic status, gender, sexual orientation, local experiences, international and transnational relations of domination, or any other relations of power. (598-99)

Widening our focus to the inter-American contexts must not entail undue reductions and simplifications; difference matters in the narrow context and it multiplies in the larger framework.

A case in point is the designation "Hispanic" as it is used by the U.S. Census Bureau. Silke Hensel has referred to it as "an inappropriate label imposed 'from above"' (92). In her historical analysis she shows how throughout the twentieth century the invention and re-invention of 'race' has affected Mexican Americans and Puerto Ricans, whose own ideas of "raza" and "mestizaje" (closely tied to practices and ideologies elsewhere in the Americas) clashed with U.S. notions of 'race' and "whiteness." Hensel writes:

3 While Caroline F. Levander and Robert S. Levine concede that in studying New World phenomena the nation remains important as an entity, they underline that it needs to be seen as part of a larger entity. Hence, they write, it is important to "recognize the asymmetry and interdependency of nation-state developments throughout the Americas" (6). 
But race has not only been imposed from the outside; both groups brought their own understandings of "race" or rather "raza" with them and contested the hegemonic discourse. The comparison of the two Spanish-speaking groups whose experiences differed considerably further underlines that the invention of racial groups depends on social interaction with other groups and therefore on specific historical situations, an observation which clearly underscores the fluidity of collective identities. (92)

A Puerto Rican and a Mexican American who find themselves in the same location at the same time may well establish a sense of shared belonging in one respect, while underscoring their difference from each other in another. To understand this difference, an inter-American perspective that moves beyond the concepts of "U.S. Latina/o" or "Hispanic" as well as beyond 'race' is helpful.

But when we speak of 'race' (or belonging) in academic discourse, argues Ruth Hill, there is usually a national or regional focus rather than an attempt to see the bigger inter-American picture. While critical race studies has uncovered the constructedness of 'race' and its relation to power, writes Hill,

[f]ar too little ... has been done within critical race studies to problematize and conceptualize race in Latin America, and even less has been done to understand race in the Americas - that is, race as a floating signifier that means different things to different people, in the same place or in different places, at the very same time. As a nascent subfield of critical race studies, comparative racial and ethnic studies focus primarily on race and ethnicity in the United States, only rarely venturing across the mental and physical borders that divide what were commonly known in the nineteenth century as "North America" and "South America." In Latin America itself, race is often denied any ontological status whatsoever, and wherever comparative racial and ethnic studies are attempted, they tend to focus on different races or ethnicities in a specific country or area of Latin America. (110-11)

Whiteness, white supremacism, and blanqueamiento continue to overshadow debates on 'race' and interethnic interaction. As Mita Banerjee observed, "even where the norm finally grants emancipation to minority communities, its own image remains center stage.... [T] he same patterns of ethnic exclusion and white privilege occur throughout the twentieth century" (431). The privileges of whiteness are also central to Bruce Norris's Clybourne Park; they continue in the $21^{\text {st }}$ century in what Hazel Rose Markus and Paula M.L. Moya call "systems of social distinction." In their introduction to Doing Race, Markus and Moya write that while 'race' and ethnicity organize modern societies, they are the products of human action, of "social, historical, and philosophical processes ... actions that people do" (4). Thus Markus and Moya configure of "race as a doing" (17-20). Such a doing of 'race' through dialogues and interaction occurs in Clybourne Park. 
The play opens a few years into the Civil Rights Movement and it closes fifty years later, a year into the U.S.A.'s "Obamamania," in a social setting in which 'race' consciousness still plays a significant role but where it is much more nuanced and complex. Blatant racism has turned into latent racism, as the characters in the 2009 part of the plot are (at first) all very cautious in terms of the politically correct language they use, intent on avoiding anything that might possibly offend members of another group. They also realize that simple distinctions along the lines of only one identity marker (like 'race') no longer work because of the multiple belongings (based on 'race,' ethnicity, class, gender, sexual orientation, age, citizenship, religion, education etc.) that inform self-positioning, group formation, political correctness, and othering in the $21^{\text {st }}$ century. As the late Günter H. Lenz stated, "the interrelationships among various, often conflicting dimensions of difference (differentiation) in cultures, such as gender, race, ethnicity, class, religion, language, region, or age" complicate any attempts at categorization (362; italics in the original).

Two deaths set in the play's recent past symbolize that when Norris's Clybourne Park opens in 1959 the old ways of pre-Civil Rights Movement contestation and discrimination are vanishing: the ageing white couple, Bev and Russ, are grieving the death of their son, a veteran of the Korean War who killed himself in the house two years earlier, while Karl Lindner and his wife have to cope with the birth of a stillborn baby who was strangled by the umbilical cord. By the end of the play, half a century later, the house is to be torn down to make room for a new structure, signaling the beginning of yet another era, namely the gentrification of a formerly black neighborhood. Showing the effects of neglect, decay, hooliganism, and graffiti in a run-down area, the property is again being sold-this time to a young white couple expecting a child. The buyers have to negotiate local construction regulations with a black couple representing the neighborhood Owners Association. We find out that the white couple's lawyer, Kathy, is the daughter of Betsy and Karl Lindner (who, in Hansberry's A Raisin in the Sun, had offered the Youngers money for not moving into the neighborhood) and that the wife in the black couple is the great-niece of Lena Younger, the matriarch who had bought the house in Hansberry's play. In this manner, the setting, plot, and characters of Norris's Clybourne Park illustrate that there is both continuity and change. The playwright's decision to have the roles of all dramatis personae in Act II played by actors who had appeared in different roles in Act I and to have some characters in Act II repeat the same phrases that other characters had used in Act I further underlines this combination of continuity and change. In other words, the more things change, the more they stay the same.

In the first act of Norris's Clybourne Park the question of who belongs in a neighborhood and to whom the neighborhood belongs is raised for a 1950s scenario. Bev 
and Russ are packing for their imminent move. Especially Russ is still embittered about how the neighborhood residents failed to support their son Kenneth when he came back traumatized from Korea. He partly blames the community for the suicide that took place in the upstairs part of the house they are now selling, and he is indifferent to the future of Clybourne Park. Karl Lindner, on the other hand, wants to preserve the all-white character of their residential area. Having made inquiries about "what sort of people" the prospective future owners of the house are, Karl-irrespective of his claim that theirs "is a progressive community"-is scandalized to find out that "they're coloured" $(33,32) .{ }^{4}$ According to Karl, "fitting into a community is really what it all comes down to" (35; emphasis in this and all following quotations in the original). The Youngers, although they may have the money for a down payment, he is implying, could never fit in because of their skin color. Belonging is thus restricted on the basis of 'race.' Bev's feeble intervention, "I mean, in, in, in, in principle, don't we all deserve to-Shouldn't we all have the opportunity to, to, to-,", is met with Karl's "In principle, no question" and "But you can't live in a principle, can you? Gotta live in a house" (35). His exasperated reaction is: "Well, do the boundaries of the neighbourhood extend indefinitely? Who shall we invite next, the Red Chinese?" (36). Karl insists that "in the world, there exist certain differences" (39), citing the Scandinavian ethnic background of his wife as an example but actually referring to 'race' distinctions. Next, Bev and Russ's black housekeeper Francine and her black husband Albert are asked their opinion on the matter of mixed-race neighborhoods. Circumventing the issue of 'race' and addressing ostensibly an ethnic culinary preference, Karl asks Francine whether at the Clybourne Park store she "could find the particular foods your family enjoys" (40). The neighborhood pastor, Jim, brings up "differences in modes of worship" (40), and Karl underlines his plea for separation and segregation by stating that in all the years he has helped take the children of St. Stanislaus school skiing, "I have not once seen a colored family on those slopes" (41). In trying to prevent or dissuade the black family from moving into Clybourne Park, he claims to be acting out of "a responsibility to the community as a whole" (46).

The African American Francine seems to agree with Karl's position on the desirability of "racial" separation-but for entirely different reasons. When her husband Albert tries to intervene in the quarrel that Russ has with Karl and Jim, she reprimands him: "Let' em knock each other's brains out, for all I care. I'm done

4 The version of the play published by Nick Hern Books in London uses the spelling conventions of British English. 
working for these people two days from now, and you never worked for' em at all, so what the hell do you care what they do?" (51).

Through the character of Bev, playwright Bruce Norris illustrates veiled, unconscious, routine racism: although she initially refers to her black housekeeper Francine as her "friend" (24), she does not remember how many children Francine has and she feels insulted when Albert does not want to accept the fifty cents or the chafing dish that she offers him for his help. When he tells her "Ma'am, we don't want your things. Please. We got our own things," she protests that "if that's the attitude, then I just don't know what to say any more" (52). Her wounded pride (based on the routine privileging of whiteness and Bev's resulting belief that everyone should want what she has to give away) is challenged by Albert's declaration that they have "[their] own things" and by his refusal to accept a meager handout.

In Act II, set in 2009-also on a Saturday afternoon, this time two days before the scheduled demolition of the house-, the lawyer Kathy, played by the same actress who had played Bev in Act I, reveals that underneath the veneer of politeness and respect she shares the veiled racism that we saw with Bev fifty years earlier. Speaking into her cell phone, she tells the architect who will be in charge of planning what kind of new residence to build on the property, that they are at the house together with "the people from the neighbourhood thing. Propertyowners' ... thing" (59), referring to the black couple Lena and Kevin, with whom she and the white buyers of the property have to negotiate the dimensions of the structure that can be built there. In the middle of chaotic parallel conversations and of characters talking on their cell phones, Lena reminds everyone of the history of civil rights struggles that are connected, in her memory, to the neighborhood: "[T]here's just a lot of pride, and a lot of memories in these houses, and for some of us, that connection still has value ... And respecting that memory: that has value, too" (79). She refers to her great-aunt, after whom she is named and who is the protagonist in Hansberry's play, as "a pioneer" for being "one of the first people of colour to-" (80). When she declares that she "didn't mean to make it about [her] personal connection to the house. It's more about the principle," her husband Kevin uses the very same line used by Karl Lindner in Act I: "But you can't live in a principle" (86). In this way Bruce Norris demonstrates how discourses on 'race' and racism affect black and white alike and how they tend to be recycled-also cross-ethnically. Also, when the white lawyer Kathy remarks that in the seventies and eighties "there was trouble" in the neighborhood because of drugs and violence, she unwittingly associates this "trouble" with African Americans (82), thus illustrating the pervasiveness and continuity of veiled racism.

The new owners of the property, Lindsey and Steve, on the other hand, employ enlightened, politically correct language in discussing the situation of African 
Americans: Lindsey refers to "people [who] are systematically dehumanized" and proclaims that "half of [her] friends are black!" while Steve calls housing projects "some artificial semblance of a community ... [that] isolate[s] people" $(83,98)$. But soon afterward Steve gets tired of political correctness preventing them from saying what they are really thinking and he becomes frustrated with Lena's references to the historic value of the house and the neighborhood. He stammers:

Okay. Okay. If you really want to-It's... (Tries to laugh, then, sotto.) It's race. Isn't it? You're trying to tell me that that... (To LENA.) That implicit in what you said-That this entire conversation... isn't at least partly informed-Am I right? (Laughs nervously, to LENA.) By the issue of... (Sotto.) of racism? (97)

Lena's reaction is: "I'm fairly certain that I've been called a racist" (97). Steve, nonetheless, continues his explicitness and antagonism, lecturing Lena on racialized competition:

This is why we have wars. One group, one tribe, tries to usurp some territory-and now you guys have this territory, right? And you don't like having it stolen away from you, the way white people stole everything else from black America. We get it, okay? And we apologise. But what good does it do, if we perpetually fall into the same, predictable little euphemistic tap dance around the topic? ...

No. I'm sick of - No. Every single word we say is-is-is scrutinised for some kind of latent-Meanwhile you guys run around saying $\mathrm{N}$-word this and $\mathrm{N}$-word that and whatever. We all know why there's a double standard but I can't even so much as repeat a fucking joke that the one black guy I know told me-. (100-101)

When he finally tells the joke (about a white prisoner who is about to be raped by a black prisoner), a dead silence falls. Norris highlights the multiplicity of belonging when he has Tom (the white spokesperson of the Owners Association) announce that he is gay and that as a gay person he finds Steve's joke offensive. Kathy follows suit, remarking that as the sister of a woman who was raped she, too, is horrified by the tasteless joke. Lindsay accuses her husband Steve of being insensitive because of his privileged position: "You can't be offended, you moron ... because you've never been politically marginalised, unlike the majority of people in the world" (105). With these reactions Norris explores the ways in which multiple belonging and discrimination on the basis of gender or sexual orientation get interlaced with racism. Three white characters are offended by the joke told by a fourth white character about a white and a black prisoner-all for different reasons and all out of their own sense of belonging, which transcends whiteness.

Bruce Norris's Clybourne Park is based on the principles of difference and competition, which cause a contestation of claims. In 1959 (Act I) as well as in 2009 (Act II), characters compete with each other about their knowledge of geography 
and capitals; they bicker about their respective ideas of community; they quarrel about the right way of doing things; they spar with each other about domination; they react to the respective dynamics of residential segregation. ${ }^{5}$ Both acts of the play interrogate belonging and separation: Could a black family ever belong to the community of Clybourne Park depicted in Act I?, Which factors decide the relationship/separateness of the black couple Francine and Albert or of the disenchanted Russ to/from the community of Clybourne Park?, On which basis do the gay white Tom as well as the heterosexual black Lena and Kevin in Act II belong to the same in-group?, How do lingering and new prejudices prevent genuine interaction and a mutual agreement?, How does the issue of 'race' continue to impact the consciousness of black and white alike?, How do the 'race' dynamics of the play's Chicago compare to Toronto or Trinidad? The play suggests that the historical developments of the past half-century merely changed the nature of conflicts and contests but did not lessen the conflictive potential of 'race,' the color line, and racialized discourse. While in the play's 2009 scenario, group formation and belonging keep shifting and cross ethno-racial lines, 'race' continues to matter and difference becomes more multi-faceted.

At the center of Clybourne Park's engagement with belonging and segregation is the issue of 'race.' The play thus confirms and expands the view W.E.B. Du Bois had expressed in 1901, when he wrote: "The problem of the twentieth century is the problem of the color line; the relation of the darker to the lighter races of men in Asia and Africa, in America and the islands of the sea" (354). Although its dynamics differ from place to place and over time, the color line is essential to social and political life and differentiation/inequality throughout the Americas. As Black Atlantic writer Caryl Phillips stated in his essay "American Tribalism" in 2003, "[a]s long as non-white men and women in the United States cannot buy or sell a house, raise and educate their children or get a job without having to factor in race, then there will always be 'aggressive' loyalty to racial and ethnic identity that no amount of talking can ever hope to redress" (33). While the dynamics of inequality take on a different shape elsewhere in the Americas, they are often no less severe there. Born in Saint Kitts/Saint Christopher Island in the West Indies and raised in England before returning to Saint Kitts off and on starting at age 22 and then accepting various professorships in the United States, Phillips is in a unique position to consider the wider horizons of 'race' and ethnicity. When he speaks of an "aggressive' loyalty to racial and ethnic identity" in the United States,

5 For a discussion of how unevenly residential segregation affects different ethnic groups (especially in the United States), cf. Massey. 
there is an implicit comparison to the situation he has encountered in the Caribbean with its higher percentages of Afro-Caribbean and mixed-race individuals and its different 'racial' and ethnic dynamics. It is also interesting in this respect to note that, according to Stephan Palmié and Francisco Scarano, the Caribbean became the seedbed for global racism as well as for global anti-racism.

Taking up Shelley Fisher Fishkin's argument for "broadening the frame" of our academic practice transnationally and for "exploring the cross-fertilization of cultures" ( 31 ; italics in the original), I propose to expand to the Western Hemisphere the issues that Bruce Norris's Clybourne Park raises. Viewing the Americas as an interlinked terrain in terms of 'race,' ethnicity, belonging, and difference will allow us to unveil inter-American similarities and contrasts and will prevent us from an insular approach to issues that have much wider ramifications than the city, region, or nation in which they are played out.

Although the Western Hemisphere had been characterized by interculturalism and by rivalries between different communities, tribes, and peoples long before it came to be called "the New World," social movements, mobility, transnationalism, and the demise of dictatorships have brought (inter-)ethnic issues, belonging, and difference to the forefront since the 1950s. ${ }^{6}$ While social structures and political constellations differ sharply within the Americas, the whole bi-continental "New World" has been experiencing quarrels of belonging-to a community or to a nation-, contestations about access to resources or media, and struggles for domination, territory, or recognition. Among the factors that contribute to making the Americas contested continents are their experience of colonialism, coloniality and slavery, ${ }^{7}$ migration to and within the Western Hemisphere, pluricultural and inter-ethnic societies, social hierarchies (often linked to 'race'), the dynamics of

6 For a discussion of intercultural issues in $20^{\text {th }}$ - and $21^{\text {st }}$-century Canada, U.S.A., Mexico, and beyond, cf. Raab/Greiffenstern, Interculturalism in North America.

7 For a comprehensive, varied perspective of how slavery shaped different societies in the New World, cf. The Oxford Handbook of Slavery in the Americas, edited by Robert L. Paquette and Mark M. Smith. The editors state in their introduction how vast and varied an area of research slavery in the Americas constitutes:

Slavery, wherever it existed, evolved with no predictable trajectory under dynamic pressure from a complex battery of internal and external forces. They stamped each New World slaveholding society with a distinctive profile so that, for example, the countenance of slavery in Brazil, the country that imported African slaves in numbers that approached half of the total, was, in any number of important ways, quite different from that in the United States, the Dutch Caribbean, or the slaveholding societies established and fostered by the French and the Spanish. 
capitalism and labor (exploitation), and the interdependence of transnational developments with local and regional issues. ${ }^{8}$ These phenomena are also of particular interest to Inter-American Studies since a conventional, nationally oriented approach to them would at best yield only a partial analysis of all the factors involved. ${ }^{9}$

An inter-American approach to the topic does not imply any kind of conflation or homogenization. Difference matters, and the differences between and within North America, the Caribbean, Central America, and South America have to be kept in mind. Even in neighboring countries that belong to the same geographical area-such as Argentina and Brazil-the situations in terms of 'race,' ethnicity, belonging, and difference diverge sharply. Clara E. Rodríguez has presented a very useful set of basic distinctions between Latin America and the United States (well aware that the term "Latin America" unduly lumps together very distinct societies). Among the similarities she mentions:

First, both Americas have histories of indigenous conquest, slavery, and immigration. Second, in both Americas, race has been constructed to reflect and support class and power relations. Each country in Latin America has developed its own racial constructions, but in all cases, they have tended to benefit those in power. (111)

As the three main differences in the construction of 'race' in the Western Hemisphere Rodríguez points out that (1) whereas in the United States there is a stronger sense of 'race' as something passed down from parents to children, "[i]n the Spanish Caribbean and Latin America, ancestral 'blood' is only one variable determining one's race;" (2) while skin color tends to be the only factor used in "racial classification" in the United States, Latin American approaches to 'race' also consider "[o]ther physical and social characteristics, such as facial features,

Slavery in the Americas pre-dated Columbus, but once taking root in the Americas under western European auspices, acquired a predominantly commercial character whose benefaction to the sustained economic growth of the Western world no serious scholar can any longer doubt. (4)

8 While José Vasconcelos, in 1925, had diagnosed that in the Western Hemisphere "[o]ur age became, and continues to be, a conflict of Latinism against Anglo-Saxonism” (A86), our notions of rivaling communities and traditions have become much more complex in the $21^{\text {st }}$ century. Olaf Kaltmeier has appropriately spoken of multiple inter-American "entanglements."

9 Inter-Americanists will be reminded of Herbert Eugene Bolton's claim, made in his 1932 Presidential Address to the American Historical Association, "The Epic of Greater America," that in the same way that European history cannot be studied by looking at only one nation, American history cannot be adequately dealt with in exclusively national frameworks. 
hair texture, social class, dress, personality, education, linguistic identity, cultural modes of behavior, relation of the referent to the speaker, and context" to be important; and (3) "in many parts of Latin America, race is more openly reported as able to change over time and space. That is, in some countries, a person may be born 'brown' but become 'white' with upward mobility, whereas in the United States, race is more static and is often considered to be an ascribed characteristic" (107-09). It is not surprising, therefore, that while the U.S. Census Bureau, in 2010, distinguished between five "race categories" plus "some other race," "[i]n Brazil, for example," as Rodríguez reports, "an open-ended question about race in a survey can yield more than 140 categories of answers" (108)..$^{10}$

Historical parallels, the flow of goods, people, and ideas to, from, and within them, and participation in global exchanges and developments make the Americas an interconnected space, while their cultural and ethnic diversity, the role of indigenous peoples, and the geographic proximity of the so-called developed world to the so-called developing world account for the unique position of the Western Hemisphere on the globe. The "New World" is a place of many colors-also skin colors - that at different times and in different places compete with each other, alternate, shine bright, fade, are superimposed, mix, and bleed. As they touch each other and become superimposed, difference continues to matter since the result of interethnic and intercultural contact is not a uniform mass but a dynamic interaction-sometimes conflicting, sometimes hybrid. Walt Whitman's words from his "Song of Myself" also apply to 'race,' ethnicity, and belonging in the Americas:

Do I contradict myself?

Very well then I contradict myself,

(I am large, I contain multitudes.) (Sect. 51)

The multitudes of 'race' and ethnicity in the Western Hemisphere account for different interactions and compositions in different arenas-some conflictive, others harmonious. But usually ethno-racial difference also marks a difference in social class.

10 In the 2010 U.S. Census, individuals were first asked whether they considered themselves to be "of Hispanic, Latino, or Spanish origin." Clarifying that "[f]or this census, Hispanic origins are not races," the questionnaire went on to ask for self-identification as "White, Black or African American, American Indian or Alaska Native, Asian, [or] Native Hawaiian or Other Pacific Islander" or as belonging to "Some Other Race." Individuals were able to check more than one box, which, according to the Census Bureau means that " $[t]$ here are 57 possible multiple race combinations involving the five OMB [Office of Management and Budget] race categories and Some Other Race" (Humes/Jones/Ramirez 2). 
Although the Spanish caste system and the enslavement of individuals of indigenous or African descent have been overcome, ${ }^{11}$ the New World continues to be marked by difference and hierarchies. While this difference used to be felt predominantly in terms of 'race' and ethnicity ${ }^{12}$ (as illustrated in Lorraine Hansberry's A Raisin in the Sun), the focus has broadened to also include differences on the basis of national origin, citizenship status, language, religion, class, gender, sexual orientation, political affiliation, education, or access to media and resources (some of which are taken up in Bruce Norris's Clybourne Park). Differences shade and shape the New World-sometimes with sharp contours between the individual colors, sometimes with the colors superimposed or mixing. These New World colors coexist and compete with each other, as communities assert their distinctiveness and as individuals feel a sense of belonging to multiple groups.

As Aníbal Quijano points out, the idea of 'race' was imposed "as the basic criterion for social classification of the entire world's population" around the same time (at the turn from the $15^{\text {th }}$ to the $16^{\text {th }}$ century) that colonialism began in the Americas and that European capitalism came to dominate "the global distribution of labor and trade" (45). ${ }^{13}$ This is how, according to Quijano, "racism," "the most obvious and the most omnipresent" manifestation of what he calls "the coloniality of power," evolved and "has remained the principal arena of conflict" in the Americas ever since (46). Especially in "societies founded on the basis of colonial power relations, the victims fight for equality between the 'races"' (47). ${ }^{14}$ Walter D. Mignolo adds that from its early usage on, 'race' was entangled with social class, gender, and power:

[E] thnoraciality became the machinery of colonial difference. Beginning with the expulsion of the Moors and the Jews, it was configured from the debates over the place of the

11 The process of abolition in the Americas took almost a century, "from the abolition decree of the French revolutionary commissioner Léger-Félicité Sonthonax in SaintDomingue in 1793 to the Golden Law signed by the Princess Regent Isabel in Brazil in 1888. Between these two years, revolutions, independences, counterrevolutions, and civil wars upset the region, often putting slavery and the fate of emancipated slaves in the forefront" (Helg 247).

12 On the origins and differentiation of "race" and ethnicity, cf. Sollors, "Ethnicity and Race."

13 For a comprehensive account of the origins, history, and pervasiveness of racism, cf. the Oxford Reader on Racism, edited by Bulmer and Solomos.

14 Lois Parkinson Zamora holds a somewhat more optimistic view of what those suffering from colonial rule can achieve. Analyzing Alejo Carpentier's El Siglo de las luces (1962), she concludes that the novel illustrates "both the European colonial legacy-still monumental in Latin America-and the explosive energy that continues to transform that Old World legacy in the New World" (84-85). 
Amerindians in the economy of Christianity, and, finally by the exploitation and silencing of African slaves. It was with and from the Atlantic commercial circuit that slavery became synonymous with blackness. (55)

On this basis, the continuing coloniality of societies and nations in the Western Hemisphere, writes Quijano, creates conditions in which 'race' is largely assumed to be a "natural" phenomenon rather than a social construct. This view becomes the basis for white ${ }^{15}$ supremacy and other forms of inequality, which in turn determine political representation. ${ }^{16}$

By relating Jorge Juan and Antonio de Ulloa's Noticias Secretas to Thomas Jefferson's Notes on the State of Virginia Ralph Bauer has further shown how the early modern Spanish American idea of "creolization" evolved into Jefferson's "creole patriotism - that would ultimately become the dominant ideology of nineteenthcentury nationalism throughout the Western world in the process of hemispheric and transatlantic cultural diffusions" (37). Bauer explains that

In their engagement with early modern neoclassical natural history, creole patriots throughout the Americas realigned the discursive economy of human identity and difference by shifting the rationalization from the eighteenth-century scientific debate about "creolization" to a nineteenth-century scientific debate about race. This engagement with early modern natural history was not primarily a local or national, but rather a circumatlantic, debate with a distinctly hemispheric genealogy, as the idea of the "creole" traveled from sixteenth-century Brazil, to viceregal Spanish America, to the French circumcaribbean, as well as to the North American British colonies. In the course of these travels throughout the hemisphere, however, the idea of the Spanish American creole, with its connotations of cultural and biological mestizaje, remained the constant alter ego of the idea of "whiteness" in the creoles' social imaginary from the eighteenth century onward. (53-54)

15 In his monumental study, Buying Whiteness: Race, Culture, and Identity from Columbus to Hip Hop, Gary Taylor delves into the changed associations of whiteness: "[i]n the ancient and medieval world, whiteness was achieved, not received," when it referred to moral or spiritual purity or innocence. However, this moral meaning came to be conflated with the reference of whiteness to skin color, which meant that "white" ended up being used "in a positive ethnic sense, as a self-identifying badge of belonging to an esteemed community" (241-42).

16 Quijano also links gender inequalities to coloniality and to the continuing impact of dualistic Eurocentric thinking. He believes that "without rejecting the shackles of the Eurocentric worldview ... we will not get very far in the struggle to free ourselves decisively from the idea of 'race' and of 'racism,' nor from that other form of the coloniality of power, the relation of domination between 'genders'. The decolonization of power, in whatever frame of reference, signifies from the outset the decolonization of all dimensions of consciousness" (53). 
The idea of whiteness and the privileges attached to whiteness came under attack in the United States during the Harlem Renaissance through the concept of the "new negro" and in the second half of the twentieth century through the Civil Rights Movement, the Chicano Movement, and the American Indian Movement. Especially in the $21^{\text {st }}$ century, social and political movements have challenged old hierarchies and privileges in Latin America.

The election of Evo Morales to the presidency of Bolivia in 2005 as well as the victory of Barack Obama in the presidential races of the U.S.A. in 2008 and 2012 mark drastic changes in these two countries in terms of the role that 'race' plays in political representation. The Aymara Morales has declared himself the first fully indigenous head of state of Bolivia since its Spanish colonization-a contested statement because there have been previous Bolivian presidents who had partly indigenous ancestry. He foregrounds his ethno-racial background as a basis for claims to resources and leadership and uses it as symbolic capital in the national and international competition for recognition and assets. The African American Barack Obama, on the other hand, tries to move beyond 'race.' He proclaimed in his March 17, 2008 "Speech on Race" in Philadelphia his "firm conviction ... that working together we can move beyond some of our old racial wounds, and that in fact we have no choice if we are to continue on the path of a more perfect union" (no pag.). While Morales stresses ethnic difference and has embarked on a redistribution of economic and symbolic capital by inverting colonialist hierarchies, Obama seeks to unite his nation under the motto of "e pluribus unum."

Behind these opposing approaches to ethnic identity lie diverging strategies in dealing with each nation's internal logic of difference. While Morales emphasizes difference, foregrounding ethnicity and using it to demand changes in the distribution of resources, ownership, and capital, Obama-although astutely aware of difference-tries to unite his nation in the pursuit of common goals.

It is this typically optimistic and forward-looking strategy that has produced comparisons at the beginning of his first presidency between Barack Obama and the Founding Fathers of the United States: On the cover of its first issue after Obama's inauguration, The New Yorker magazine depicted the President with the wig and garments typical of George Washington and Thomas Jefferson (Fig. 1). This comment invokes the possibility of overcoming ethnic boundaries in the pursuit of a more equitable nation and in the return to the nation's democratic foundation. It points toward the perceived "whiteness" of Obama. ${ }^{17}$

17 For a humorous evocation of Obama's “whiteness," cf. comedian Chris Rock's "Message for White Voters" at http://www.youtube.com/watch?v=EDxOSjgl5Z4—with over ten million clicks on YouTube. 
Figure 1: Cover of The New Yorker magazine, Figure 2: Official Portrait of Evo Morales Jan. 26, 2009
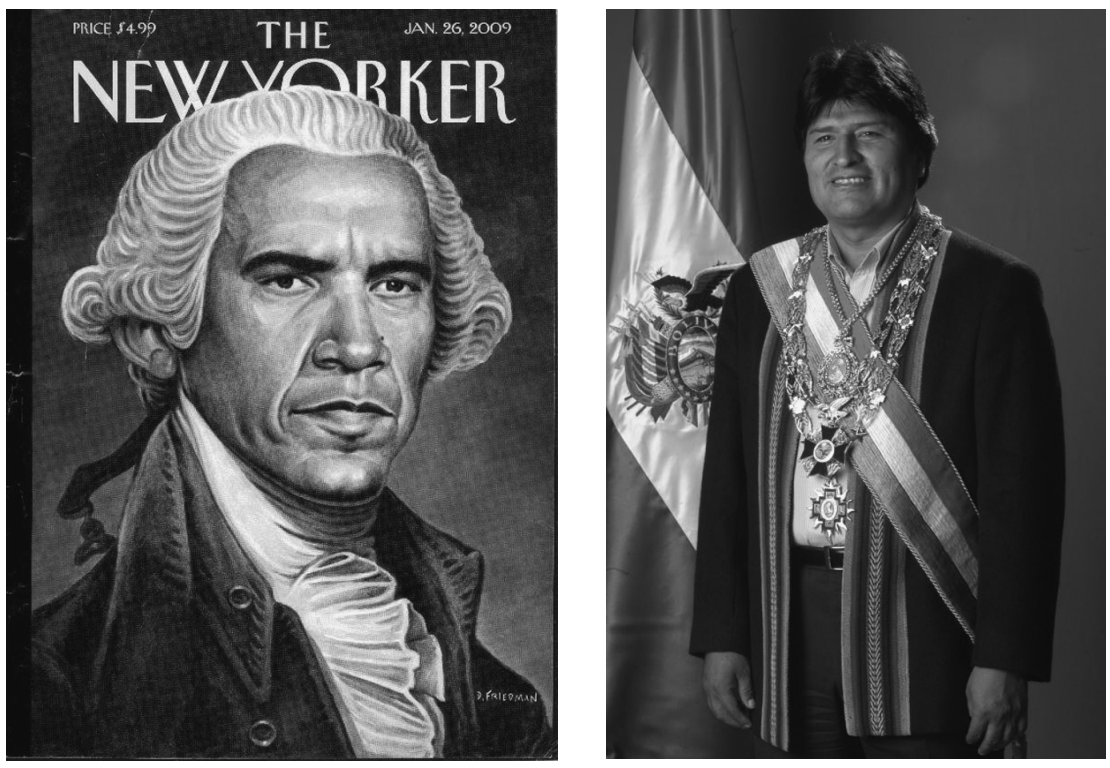

In contrast to this non-essentializing representation of Obama by the New Yorker, Evo Morales likes to stress his indigeneity in official portraits and public appearances. The depiction in figure 2 combines markers of indigeneity (the knitted front of his coat) with those of nation (flag and sash) and leadership (decorations). By adding an ethnic component to the traditional invocations of nation and power in presidential portraits, Morales voices a counter-discourse against the earlier, nonindigenous power elites of Bolivia (supported by and supportive of U.S. political and economic interests); he deliberately appropriates the insignia of postcolonial rule and combines them with a valorization of indigeneity. Stressing his multiple belonging and redefining the nation, he underscores the indigenous basis of the nation and he proclaims that an indigenous ancestry is not incompatible with active participation in the nation and with the right to govern. The nation, he is implying, rightfully belongs to the indigenous.

The New Yorker's depiction of Barack Obama also stresses multiple belonging, suggesting that blackness and participation in the nation's foundational principles are not mutually exclusive. While Obama has taken over for himself and his policies the idealistic doctrines of the U.S. Founding Fathers, the former union leader and socialist Morales opposes neo-colonial power structures and wants to bring 
about radical change. Whereas for Barack Obama "change" means a return to the Enlightenment ideals of the United States' Declaration of Independence, Evo Morales's ideals of change aim to undo some of the evils of five centuries of colonialism, coloniality, and neo-imperialism. Both presidents, however, use strategies of self-fashioning and ideas of multiple belonging in pursuing their political goals.

The contrary positions of Evo Morales and Barack Obama toward the logic of difference which ethnicity provides are by no means developments of the $21^{\text {st }}$ century. Issues of ethnic identity and communal belonging have concerned the Americas at least since the Conquest. Affiliations are dynamic, often used as strategic resources disassociated from territory or 'race.' Identity politics in the Americas and elsewhere are played out in alliances as well as in competition and contests. For example, through their different approaches to national and interAmerican issues, presidents Morales and Obama reveal stark differences in their ideas about nation and belonging. But both presidents, in their speeches and self-fashioning, also comment on inter-American relations and thus implicitly on their respective counterpart's approach to hierarchies and affiliations.

With the de-territorialization of ethnic and cultural groups as a consequence of transnational ethnoscapes and mediascapes as well as multiple affiliations it becomes increasingly difficult to pin down difference. Difference remains, but it is articulated and lived in a complex web of belonging. Because of the superimposition of identity markers, group identifications and coalitions keep shifting. At the "Primer Encuentro de Autoridades Indígenas de América" held in La Paz, Bolivia in January 2006, for example, Evo Morales highlighted his own Aymara descent while at the same time including in his own proposed group identity other indigenous communities inside and outside of Bolivia. He said:

Y nos damos cuenta, Evo Morales Aima, nacido en la nación aymara, mi nacimiento político-sindical en la zona quechua, agradecer a los hermanos del departamento de Cochabamba, al movimiento cocalero y acá ven, aymaras, quechuas, chapacas, conduciendo el país, desde la Presidencia de la República, desde la presidencia de las Cámaras correspondientes, por eso nuevamente quiero decirles, hermanos y hermanas, quienes apostaron por las reivindicaciones, la dignificación del movimiento indígena originaria, no solamente de Bolivia, no solamente desde el movimiento indígena sino también personalidades, la gente de la ciudad, intelectuales, no se equivocaron, no nos hemos equivocado. ("Primer Encuentro" n. pag.)

Morales speaks of his biological as well as of his political birth and he is well aware of the variety of group identities to which he belongs: Aymara, indigenous, Bolivian, socialist etc.

Although he has appointed himself the spokesperson of indigenous people, Morales also forges alliances with other groups with whom he shares certain 
practices or positions. For example, in his April 21, 2008 speech to the United Nations in New York City, Morales at first presented himself as the representative of indigenous people, demanding his right to be heard: "Los pueblos indígenas no nos vamos a callar hasta lograr un verdadero cambio" (no pag.). But then he went on to include in the group for which he was speaking all anti-capitalists, envisioning a transnational kind of belonging with a political basis. He claimed that "[1]os grandes efectos de los cambios climáticos no son producto de los seres humanos en general, sino del sistema capitalista vigente, inhumano, con desarrollo industrial ilimitado, por eso siento que es importante acabar con la explotación a los seres humanos y acabar con el saqueo de los recursos naturales" (no pag.). When Evo Morales foregrounds (ethnic, cultural, political, national) difference, he does so with respect to a changing series of factors and positions. What exactly the distinctive marker of collective identity is, depends on the situation and issues at hand. As Sebastian Thies and Olaf Kaltmeier have pointed out, "in the postmodern age ... fixed categories are challenged and identity formation is described as a strategic, situationally flexible, and inconsistent process" (27). ${ }^{18}$

Almost a quarter of a century ago, Werner Sollors stressed the dynamic quality of categories like "ethnicity," "race," and "nation" and the continuing tendency to keep inventing such categories. He asked provocatively:

Is not the ability of ethnicity to present (or invent) itself as a "natural" and timeless category the problem to be tackled? Are not ethnic groups part of the historical process, tied to the history of modern nationalism? Though they may pretend to be eternal and essential, are they not of rather recent origin and eminently pliable and unstable? (Invention xiv)

Ethnic groups, Sollors maintains, keep emerging and they keep redefining themselves; consequently, we should abandon any notions of ethnic "originality," "authenticity" or essentialism. Ethnicity, I would add, can become performative or can be used as a strategic resource in the competition for provisions, positions, prestige, or power. In this competition, the declaration and/or performance of (varying degrees of) difference is essential. ${ }^{19}$ Passing as well as black-, red-, and

18 With recourse to Bourdieu they suggest that "social, political, or cultural conflicts [are to be described] in terms of relational positions and positionings characterized by the access to different types of capital, whether economic, cultural, social, or symbolic." Thies and Kaltmeier conclude that in "the field of identity politics the actors struggle over the distribution, valuation, and accumulation of what we like to call 'identitarian capital"' (27).

19 As Sollors adds, "It is not any a priori cultural difference that makes ethnicity" (Invention xvi, italics in the original). Difference is invented, constructed, and used as a resource. Ethnicity, therefore, according to Sollors, "does not serve as a totalizing 
yellowface rely on the close link between ethnoracial categorization and cultural as well as economic capital. ${ }^{20}$

In both separatist and integrative approaches to difference, the individual, by establishing his/her own identity and the identity of his/her group in terms of ethnicity, class, gender, language, political leaning, sexual orientation, and other factors, assumes the right to self-assertion and can use his/her proclaimed and professed identity and affiliation to claim certain forms of cultural, symbolic, political, or economic capital in the name of his/her community. In such claims and acts of self-positioning, ethnicity plays an increasingly central role in the Americas today-from the struggles for sovereignty of First Nations in Canada ${ }^{21}$ to the claims by the U.S. descendants of African slaves for reparation payments and the demand for full citizenship rights by the Mapuche in Chile and Argentina. But while the insistence on social and economic goods (e.g., Evo Morales) or political autonomy (e.g., the Zapatistas in Chiapas, Mexico) tends to rely on essentialist notions of ethnicity, current academic discussions commonly de-essentialize ethnicity. Most prominently, David A. Hollinger's formula of "affiliation by revocable consent" has questioned the focus on communities of descent. In the 2005 postscript to his classic study, Postethnic America, Hollinger writes:

The practice of confidently telling people what their identity is or isn't has gone into precipitous decline as more and more Americans recognize that identity is performative. Identity is a code word for solidarity: to prescribe an identity for someone is to tell that person with whom they should be affiliating. (220)

metaphor but simply as a perspective onto psychological, historical, social, and cultural forces" (Invention xx).

20 For a discussion of black-, red-, and yellowface in the Americas, see Jill Lane, "ImpersoNation." She highlights the redface of the Boston Tea Party, the blackface of Cuban writer José Crespo y Borbón's pseudonym of Creto Gangá representing Asian Cuba, and the statement by James K. Kennard, Jr. in 1845 that a truly American poetry would need to be black. Lane concludes: "The evidence suggests that racial impersonation-acting in the name and place of the other through such practices as blackface, redface, yellowface, cross-dressing, and drag-has played a particularly important role in the imagination and aesthetic articulation of national communities across the Americas" (1730).

21 For a differentiated analysis of questions of belonging as they affect First Nations and other ethnic and social groups in the Canadian model(s) of diversity, multiculturalism, and integration, cf. Banting/Courchene/Seidle. 
Hollinger maintains that after the end of 1990 s multiculturalism, ${ }^{22}$ which had assumed that "individuals would naturally accept the cultural, social, and political habits popularly ascribed to their communities of descent, rather than form their own associations to the extent that their life-circumstances permitted choices" we have come to realize that "descent-defined solidarities" are not to be considered "natural consequences of human difference but in their capacity as chosen instruments for political action and social support" (220). He concludes that

Such affiliations, designed to advance some common purpose, can be vital means of seeking political justice and providing individuals with a life-sustaining sense of belonging, but they need not be permanent, need not be exclusive of other affiliations, and need not carry the pernicious assumption that color and culture go together. (220)

This view is supported by the multiple affiliations that Evo Morales seeks as well as by the shifting dynamics of belonging played out in Bruce Norris's Clybourne Park.

Barack Obama has likewise downplayed his belonging to a singular community of descent. He underlines his own and his wife and daughters' multiple descent and affiliations, a strategic resource in calling for a post-race national solidarity. In his "Speech on Race" he remarked:

I am the son of a black man from Kenya and a white woman from Kansas. I was raised with the help of a white grandfather who survived a Depression to serve in Patton's Army during World War II and a white grandmother who worked on a bomber assembly line at Fort Leavenworth while he was overseas. I've gone to some of the best schools in America and lived in one of the world's poorest nations. I am married to a black American who carries within her the blood of slaves and slave-owners-an inheritance we pass on to our two precious daughters. I have brothers, sisters, nieces, nephews, uncles and cousins, of every race and every hue, scattered across three continents, and for as long as I live, I will never forget that in no other country on Earth is my story even possible... [I]t is a

22 Sherrow O. Pinder argues that "if multiculturalism is the tool used to carve out a new American cultural identity, it is bound to fail. A close examination of multiculturalism shows that its concern is not about incorporating racialized ethnic groups into America's cultural oneness, but to recognize and celebrate cultural manyness. America's cultural manyness should be recognized and celebrated. However, when cultural manyness is looked on as un-Americanness, the racialized implications that un-Americanness entails and assumes are brought to the forefront. It is not surprising, then, that multiculturalism is limited in dealing with America's problematic race relations" (155). Only a "denormalization of whiteness" and an end to the "de-Americanization of racialized ethnic groups," Pinder believes, would allow for an age of postmulticulturalism, in which "America's cultural oneness" would be challenged by "recognizing and celebrating America's cultural manyness" (159). 
story that has seared into my genetic makeup the idea that this nation is more than the sum of its parts - that out of many, we are truly one. (Obama, no pag.)

Obama uses his own mixed-race background to relativize the divisive potential of 'race' and he invokes the Founding Fathers' motto of e pluribus unum to rally for a new group cohesion that crosses racial divides, a national community based on what Hollinger calls "affiliation by revocable consent." Despite the moving images of interethnic celebration after the election victory of Obama in 2008, his rallying efforts were only partly successful: in 2008 only 43 percent of whites voted for him and in 2012 only 39 percent. As countless incidents from the arrest of Henry Louis Gates in Cambridge, MA (2009) to the shootings of Trayvon Martin in Sanford, FL (2012) and of Michael Brown in Ferguson, MO (2014) as well as statistics on income and employment suggest, racialized practice has not changed significantly in the United States since Barack Obama took office in 2009. Eduardo Bonilla-Silva contends,

Obama's ascendancy to the presidency is part and parcel of the "new racism" in the United States since the early 1970s. We have seen the rise of a few, carefully chosen minorities who are willing to propound a happy version of the American story, and the elevation of these minority politicians as "evidence" that America has overcome. This fairy tale is the most popular way to explain American racial politics, despite the depressing statistics telling a different story about what it means to be a minority in America in 2011. (256)

The feeling of belonging that Obama has tried to create transcends markers of identity like 'race,' gender, class, age, region, or education. As Joanna Pfaff-Czarnecka has observed, "[b]elonging together-whether sharing collective identity or notmeans sharing experience and the tacit self-evidence of being, of what goes without saying; means jointly taking things for granted, and sharing common knowledge and meanings" (204). Social practices of everyday life like racial profiling, ${ }^{23}$ the unequal treatment of individuals at points of entry into a country depending on their citizenship and 'race,' or anti-government protest (like in Brazil against how much the Soccer World Cup and the Olympic Games are costing the nation) reveal

23 On the role that 'race' plays in policing and the justice system of the U.S.A., cf. Davis. She argues that "[w]hen the structural character of racism is ignored in discussions about crime and the rising population of incarcerated people, the racial imbalance in jails and prisons is treated as a contingency, at best as a product of the 'culture of poverty', and at worst as proof of an assumed black monopoly on criminality. The high proportion of black people in the criminal justice system is thus normalized and neither the state nor the general public is required to talk about and act on the meaning of that racial imbalance" (265). 
that despite a common sense of belonging to a collective, there is still a high degree of difference within any such collective.

Despite ongoing racism and the continuing privileging of whiteness throughout the Western Hemisphere ${ }^{24}$-including in a supposedly "post-racial" United States (cf. Bush; Kaplan; Metzler ${ }^{25}$ ) - some progress has been made in 'race' relations and in the rights and recognition of minorities over the past few decades, as illustrated, for example, by the opening of the Centro de Estudios Judaícos at the Universidad de Chile in Santiago in 1968, by Canada adopting multiculturalism as an official policy in 1971, by the electoral success of Evo Morales and Barack Obama, or by a 2012 law passed in Peru that requires "prior consultation" with "indigenous and tribal peoples" on extraction projects that affect their rights. ${ }^{26}$

Although incomplete, the U.S.A., over the time period covered in Bruce Norris's Clybourne Park, has experienced a certain shift toward Hollinger's vision of "affiliation by revocable consent," which is also reflected in Bruce Norris's Clybourne Park. ${ }^{27}$ Nonetheless, white privilege remains intact in the United States as well as elsewhere in the Americas. ${ }^{28}$ It may be telling in this regard that while the U.S.A. did

24 Jonathan W. Warren and France Winddance Twine state that while, over the past two decades, there has been a significant increase in critical race studies in Latin America that take on "the multiple dimensions of white supremacy," the broader impact of 'race'-centered scholarship in Latin American studies remains limited (538).

25 Christopher J. Metzler calls a "post-racial America" "but an apparition of a collective imagination" (141), and H. Roy Kaplan states that "racism, the domination and exploitation of people of color by whites, with accompanying social and psychological justifications for doing so ... endures even in the best of times and flourishes in the worst" (6). As Melanie E.L. Bush writes, the hard facts about the role which 'race' plays in housing, education, health care, policing, or hiring in the United States "challenge discourse that conveys we are increasingly less racialized and more equal" (250).

26 Sadly, the implementation and supervision of that law are still inadequate.

27 Writing in 1997, during the presidency of Bill Clinton, Kimberlé Williams Crenshaw saw the United States as still having a long way to go toward 'racial' and ethnic equality. She spoke of "the continuity in law between the former period of explicitly endorsed, state-sponsored white supremacy, and today's more benign version of formal equality," which is, however, still impacted by the "separate but equal" ruling in Plessy v. Ferguson by the U.S. Supreme Court in 1896, a ruling that lends itself to "the manipulability of concepts such as equality" (281).

28 Cf. Banton 92. Howard Winant warns, however, that although "[w]hite privilege-a relic of Herrenvolk democracy-has been called into question in the post-civil rights period ..., the white 'politics of difference' is now being trumpeted as an ideology of victimization" by the white political right warning of challenges to U.S. national identity (105). 
not have a non-white president until 2009, Mexico had been ruled for five presidential terms by the Mayan Benito Juárez from 1858 to 1872. Whereas the U.S. Supreme Court's "separate but equal" decision of 1896 (overturned only in 1954) cemented racial segregation in the U.S.A., Mexico's former Secretary of Public Education and later presidential candidate José Vasconcelos argued in La raza cósmica (1925) for racial mixture as natural and desirable. ${ }^{29} \mathrm{He}$ wrote:

The future race will not be a fifth, or a sixth race, destined to prevail over its ancestors. What is going to emerge out there is the definitive race, the synthetical race, the integral race, made up of the genius and the blood of all peoples and, for that reason, more capable of true brotherhood and of a truly universal vision.... The fifth race does not exclude but accumulates life. For this reason, the exclusion of the Yankee, like the exclusion of any other human type, would be equivalent to an anticipated mutilation, more deadly even than a later cut. (A95, A97-A98)

In the context of Brazil, it was Gilberto Freyre who, eight years after the publication of Vasconcelos's Raza cósmica, presented racial mixing as one of the strengths of that country in his Casa-Grande e Senzala (1933), which was the first study to value the contributions that Afro-Brazilians had made to national identity. According to Juan E. De Castro,

Casa-Grande e Senzala gained acceptance as an egalitarian reconceptualization of Brazilian identity. Miscegenation became synonymous with a racial democracy that presented a historical version of Brazil formed by the contributions of its three constitutive races-Indian, black, and white-and, thus, implied the validation and acceptance of these originating racial and cultural groups (even if the Amerindian cultural contribution is undervalued by Freyre). (61)

More recent analyses of 'race' issues in the history of Brazil, reveal, however, that despite an alleged scale of valor attributed to skin color, which meant that "no absolute social or racial dichotomy was enforced," the founding of the republic

29 There is no equivalent in the United States for a political figure of José Vasconcelos's stature proclaiming the benefits and great future of miscegenation the way Vasconcelos did for mestizaje in Mexico. For an excellent illustration of the development of miscegenation laws in the United States from 1863 to 2000, see Peggy Pascoe, What Comes Naturally. Pascoe argues that "[e]very successive [U.S.] American racial regime, beginning with slavery, but continuing with the taking of Indian lands, the establishment of segregation, and the development of [U.S.] American immigration restrictions, expended a great deal of energy making its racial notions appear so natural that they could not be comprehended as contradictions to a society ostensibly based on equality" (313). 
in 1889 and the formal abolition of slavery a year earlier were not followed by ethnic egalitarianism but by a continuing privileging of whiteness (Marx 160)..$^{30}$

Despite academic studies like those by Vasconcelos and Freyre, racial distinctions and the use of difference in the service of maintaining or challenging hierarchies vanished neither in Brazil nor in Mexico nor elsewhere in the New World. For the past two decades, for example, new indigenous movements contesting post-colonial forms of political representation have arisen in Ecuador and Bolivia; the debates on ecological consequences of industrialization and on intellectual property rights have put indigenous groups from the Amazonian region on international agendas; and the (primarily Mayan) Ejército Zapatista de Liberación Nacional (EZLN) in Chiapas, Mexico has claimed autonomy from the Mexican state and control over territory and resources (Fig. 3).

Figure 3: Proclamation of Zapatista Self-Rule

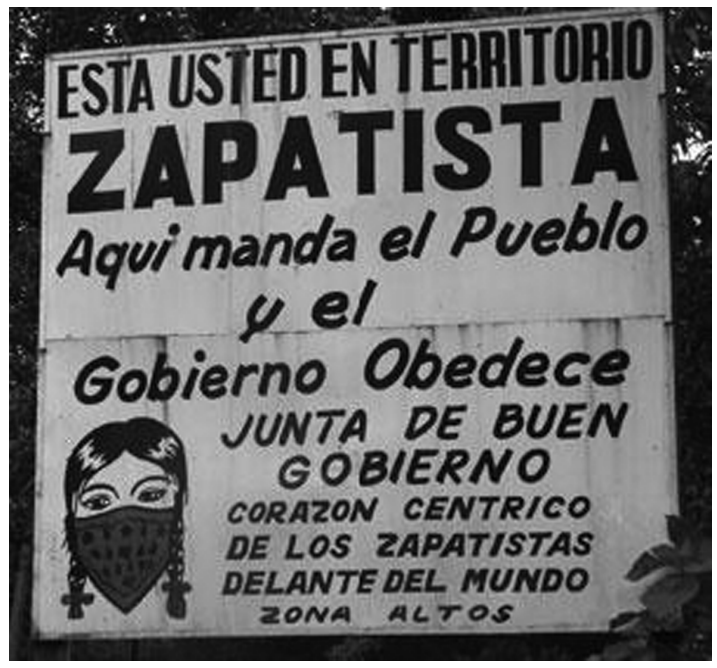

30 Anthony W. Marx writes in his comparative study of 'race' and nation in the development of the United States, Brazil, and South Africa that in late $19^{\text {th }}$-century Brazil "[p] eaceful abolition and republican federalism provided little pressure or capacity for central state intervention to assist freed slaves. Neglect of those slaves earlier manumitted set the pattern. ... Not only were blacks abandoned to their fate, but their prospects were diminished by official efforts to further encourage European immigration. The end of slavery and rising industrialization had produced great demand for free labor, which the Brazilian elite preferred to fill with imported whites rather than by training and advancing blacks" (161-62). 
In the contestation of established power and in the creation of solidarity communities for strategic purposes, 'race' is a factor, to be sure, but not an absolute one that alone decides on exclusion or inclusion. For example, the former spokesperson and military commander of the Zapatista movement in Chiapas, Subcomandante Marcos, is alleged not to be indigenous, while the movement itself is foremost an indigenous movement. Group cohesion in the EZLN is established independently of ethnic background on the basis of a belonging that is sustained by shared Marxist political leanings, the demand to respect the rights of the indigenous, a claim to territory and self-rule, as well as an opposition to the Mexican government, to capitalist exploitation, and globalization. And although the movement is a regional phenomenon, it has national and transnational dimensions as well: people in urban areas outside of Chiapas have rallied in support of EZLN's goals, the movement's website creates the possibility of worldwide support, and the U.S. economic policies toward Mexico are likewise affected, seeing that the Zapatista movement started as a reaction against the North American Free Trade Agreement, when that accord went into effect in 1994.

In analyzing the role which ethnicity and belonging play in the EZLN or in identity politics in individual American nations, a transnational, inter-American perspective is most illuminating. The movement can be seen in the context of a hemispheric tradition of ethno-racially motivated political activism from the founding of APRA (Alianza Popular Revolucionaria Americana-Partido Aprista Peruano) by Víctor Raúl Haya de la Torre in Mexico in 1924 and in Peru in 1930, that of the La Raza Unida Party by José Angel Gutiérrez and Mario Compean in Texas in 1970 or that of the First Peoples National Party of Canada in Ontario in 2004.

Inter-American mobility, multi-ethnicity and pluri-culturality, as well as the growing differentiation of lifestyles in the Americas are altering traditional constellations of ethnic identity and notions of belonging. ${ }^{31}$ The symbolic capital attached to identity designations in different social or medial contexts and especially migration also changes the ways in which individuals identify themselves as members of communities. ${ }^{32}$ Ingrid Kummels has presented the following example:

31 As Michał Krzyżanowski and Ruth Wodak write, "questions of who belongs and who does not belong legally in/to contemporary societies and polities have become crucial problems in defining the current and future roles of citizenship in a world characterized by transnationalism ... and increased human mobility" (100).

32 Depending on the legal, economic, and social situation of migrants, their experiences will differ sharply. As David Theo Goldberg and John Solomos write: "The trends identified by some commentators toward globalization of labor and the emergence of transnational 
In the rural home communities of Oaxaca, such as in the Mixteca region, individuals would first self-identify as members of their rural community, occasionally consider themselves to be campesinos, but would never label themselves as mixtecos. However, members of different Mixtec-speaking communities would move in together when living and working in the United States. In the late 70s they began highlighting a new, broader ethnic identity as Mixtecs, Zapotecs or as indígenas in opposition to the non-indigenous population. They appropriated a label formerly used by linguists, anthropologists and the Mexican government, utilising the latent identity horizon of their shared mother tongue. (263)

Belonging and self-identification thus always depend on the contexts and on the perceived need of differentiation from other groups, be they "Mexican," "Chicano," or "Anglo" (cf. Kummels). Self-identification and group belonging may constitute reactions against experiences of discrimination and exclusion, but they also carry symbolic capital and can be used as a resource to strengthen collective demands.

Other factors that impact identity politics in the Americas are the technological revolution of the conditions of media production, distribution, and reception as well as the formation of global consumer cultures, which, according to Manuel Castells, has led to a "network society." The revolution in media technology and the acceleration of social processes has brought about a space-time compression, in the context of which de- and re-territorializations occur in the competition for goods and resources. And where old structures and borderlines become tenuous and murky, the number of conflicts in terms of identity politics will rise. The conflictive potential of these cultural transformations manifests itself in particular where (post-)colonial structures of power are in place: in the politicization of ethnic identities, the break-up of patriarchal social regimes, new modes and motives of belonging, and changes in religion-based forms of social hegemony. In this context, communal identities are increasingly used in a strategic manner when it comes to social, political, and economic conflicts in the contested American continents. To this end, video technology and the Internet have been employed by very diverse groups. For example, as mentioned by Kevin A. Yelvington,

[r]ecent decades have seen Indians mobilize as indigenous people with common goals throughout Latin America. ... A number of pan-Indian organizations have sprung up.

citizenship are real enough. It is also clear, however, that for everyone who can claim to enjoy global or flexible citizenships ..., there are so many more who are shut out from every aspect of citizenship, local and global .... These different forms of exclusion emanate from the restrictions of the nation-state" (10). Steve Garner agrees that nationstates have been "racializing their populations across time and place" in addition to institutionalizing divisions on the basis of class, gender, and other factors (57). 
And they speak in a language that power can understand. For example, some Amazonian Indian groups have utilized video and Internet technology to press their claims in the court of world opinion and to establish solidarity with indigenous groups elsewhere. (258)

Transnational mediascapes, digital technology, and migration help create networks of overlapping and superimposed collectivities. Because of contemporary means of communication and transportation, according to Stephen Castles and Alastair Davidson, "no longer is it implied that migration means forgetting where one belonged before joining the host culture. This is so from both the emigration and immigration societies' points of view" (159).

The interrelation of different markers of identity ${ }^{33}$ - ethnicity, class, gender, sexual preference, religion, age, language, education, political leaning, regional background, nationality, consumer orientation etc.-needs to be taken into account in examining how individuals and groups of social actors resort (in changing constellations) to discourses and performances of different identities and constitute what Stuart Hall has termed "new identities." As Ingrid Kummels writes, in order

[t]o be able to trace these diverging processes of collective identity construction, it is instrumental to conceptualise ethnicity as a sense of belonging, that is, as a flexible way of creating emotional attachments to various collectivities and groupings in the context of hegemonic categorisations at certain socio-historical moments. (264)

Belonging transcends ethnicity, it is dynamic and it depends on the shifting contexts in which the individual or group feels a need for contradistinction.

Such contradistinction, however, is never easy or one-dimensional since difference is always multiple. Stuart Hall explains that we have

not simply to appreciate the historical and experiential differences within and between communities, regions, country and city, across national cultures, between diasporas, but also to recognize the other kinds of divergence that place, position, and locate black people. The point is not simply that, since our racial differences do not constitute all of us, we are always different, negotiating different kinds of differences-of gender, of sexuality, of class. It is also that these antagonisms refuse to be neatly aligned; they are simply not reducible to one another; they refuse to coalesce around a single axis of differentiation.

33 Michael Banton has suggested that we may need a new analytical framework in order to account for the interrelatedness and simultaneity of various factors that are the basis of social formations and trends: "The presently available conceptions of race relations, whether they start from discrimination, from racism, or from some other key concept, will have to be subsumed within some more powerful sociological theory, such as, perhaps, the theory of collective action ..., which will explain the special features of race relations within a framework that also explains other kinds of group relations" (96). 
We are always in negotiation, not with a single set of oppositions that place us always in the same relation to others, but with a series of different positionalities. (30-31)

While Stuart Hall is referring to black identity, Kevin Yelvington likewise points out with regard to contradistinction in Latin American and Caribbean contexts that, depending on the particular scenario, different aspects can assume prominence:

Determining who one is and where one fits in Latin American or Caribbean society depends on a number of factors. Physical appearance counts, but it can be overridden. Perhaps more profoundly, one's class position and status in society are determining factors. The reverse is also true; one's class and status are determined, at least in part, by one's "race" and ethnicity. Furthermore, conceptions of nationalism and the destiny of the nation are infused with notions of whose culture and whose "racial" and ethnic identity are most representative of the nation and, in turn, those to whom the nation really belongs. (245)

Whoever has or assumes the authority to define the nation or the collective gives prominence to particular markers over others. ${ }^{34}$ With changes in terms of who is in a position of power there will also be changes of what is foregrounded and what are deemed to be the constitutive factors of a communal identity. For example, in Mexico, the colonial Spanish dogma of "limpieza de sangre" (purity of blood), which had been the basis for a caste system, was supplanted in José Vasconcelos's notion of a "raza cósmica" ("cosmic race") by the idea of "mestizaje" (racial mixture) as the most promising model for the nation (cf. Yelvington 252). ${ }^{35}$ As Rafael Pérez-Torres has remarked, "[a]s the mestizo is given voice, as meaning is ascribed to notions of mestizaje, one can trace numerous transformations in the significance of the term. Meaning moves from the racial to the cultural, from the body to the text" (181).

34 How one and the same marker, namely "rhythm," has been used throughout the history of the Americas as a category in counter-distinction is revealed by Martin Munro, who writes: "Moving through slavery, revolution, Emancipation, world wars, nationalist uprisings, the end of colonialism, dictatorships, and various black power movements, ... in diverse locales and at different times in New World history, rhythm has been one of the most persistent and malleable markers of race, both in racist white thought and in liberatory black counter-discourse" (5).

35 Juan E. De Castro points to the ongoing impact that the concept of "mestizaje" has in the Americas. He argues that "the discourse of mestizaje can be seen as both a forerunner of and an influence on some important postmodern and multicultural versions of identity proposed during recent decades" (xiv). 
Mestizaje, métissage, mestiçagem, créolité, and miscegenation have also entered the literature of the Western Hemisphere since the $19^{\text {th }}$ century, where, as Earl E. Fitz believes, they have become "a metaphor for the Americas." Fitz states that

From Spanish America, where this movement can be traced from the cultural significance of "La Malinche" through Sab (1841) and Cecilia Valdés (1882), to the twentieth-century work of Vasconcelos, Pietri, Arguedas, and Márquez, to Brazil, where the issue of miscegenation has long been a thematic staple, and from Haiti to Canada and the United States, which, as a culture has never been comfortable with the issue of racial mixing (a point reaffirmed in Peter Brimelow's Alien Nation), this alternative approach to race relations in the Americas has, I believe entered a new phase of development, one that has moved beyond both a fascination with and a horror of interracial sexual relations and toward a greater, more comprehensive sense of human solidarity, one in which what has happened in the Americas can, in fact, be read as a trope for the entire human experience. ("Blood," 246)

Not only on the U.S. census form but also in many other scenarios of the Western Hemisphere is multiple heritage (whether ethnoracial or other) increasingly being acknowledged.

Especially in recent decades there has been a growing fragmentation and hybridization; identity-based classifications that result from processes of uprooting, marginalization, and heteronomy have emerged as fluid and dynamic. Numerous affiliations and markers are recognized as playing into an individual's set of allegiances. Gloria Anzaldúa, in her groundbreaking Borderlands/La Frontera: The New Mestiza, gives the following account of her own mestiza position:

As a mestiza I have no country, my homeland cast me out; yet all countries are mine because I am every woman's sister or potential lover. (As a lesbian I have no race, my own people disclaim me; but I am all races because there is the queer of me in all races.) I am cultureless because, as a feminist, I challenge the collective cultural/religious male-derived beliefs of Indo-Hispanics and Anglos; yet I am cultured because I am participating in the creation of yet another culture, a new story to explain the world and our participation in it, a new value system with images and symbols that connect us to each other and to the planet. Soy un amasamiento, I am an act of kneading, of uniting and joining that not only has produced both a creature of darkness and a creature of light, but also a creature that questions the definitions of light and dark and gives them new meanings. (80-81)

With Anzaldúa individual identity has come to be seen as fluid, as "an act of kneading," in which ethnicity is just one factor that interacts with many others in shaping a person's sense of herself or himself. Fragmentation, hybridization and the fluidity of classifications and affiliations make multiple belonging possible. "The new mestiza," writes Anzaldúa, needs to be able to live with contradictions, be "a crossroads." This is because she is an individual who is not only determined by 'race' or ethnicity but also by gender, sexual preference, class, language, place, 
religion, and many more factors. From this point of view, essentialist approaches to identity and ethnicity are revealed to be reductionist and over-simplifying; the foregrounding of difference centered on any one marker of identification (e.g., ethnicity) may unduly obfuscate multiple belonging.

A transnational approach is particularly important in light of the massive current social and cultural changes occurring in the Americas and their accompanying conflicts of identity and processes of cultural hybridization. ${ }^{36}$ Chinese restaurants are not indigenous to Vancouver, a Cinco de Mayo parade is not indigenous to Los Angeles, the Oktoberfest is not indigenous to Milwaukee, a Caribbean Street Day is not indigenous to Brooklyn, reggae music is not indigenous to Rio de Janeiro, and gangsta rap is not indigenous to Buenos Aires. Yet all of these cultural practices have become de-essentialized in terms of location and ethnicity in the course of their transnational migration and their adoption by individuals and communities from very different (national, ethnic, class etc.) backgrounds.

The current social, cultural, and political processes of change in the Americas are part of an informational and economic globalization, the emergence of transnational forms of collectivization, and the relativizing of ethnic and national categories in transnational contexts. Much research has been done-especially by sociologists-on questions of migration in general, global contexts, as they relate to transnational spaces, translocation, diaspora, issues of belonging, and "long-distance nationalism."

Beyond these general tendencies, the Americas show a specific (inter-American) momentum that cannot be reduced to the worldwide globalization processes. This momentum is based on the shared colonial history and postcolonial condition of the societies of the Western Hemisphere; it is determined by (a) the continent's social, political, religious, and linguistic common ground; (b) the massive interAmerican migration flows between South and North America in the $20^{\text {th }}$ and $21^{\text {st }}$ centuries; (c) the growing transnational integration of the culture and media industries; and (d) the strong, if asymmetrical, economic and political interdependence of Western Hemisphere locations and nations. The articulation of regional/ ethnic/cultural/political/economic/social difference becomes a complicated issue

36 In a prize-winning article, Earl E. Fitz has recently made a convincing case for transnational, hemispheric approaches to Native American literature, calling this literature "the very foundation of the inter-American project" and "our common American denominator." As Fitz explains: "Stretching back in time to long before the arrival of the first Europeans in the New World and yet still flourishing even today, Native American literature, both oral and written, unifies the American experience as nothing else can" ("Native," 124-25). 
in view of the commonality and regional overlap with regard to so many other markers of identity. ${ }^{37}$

The recent academic reorientations in both North American cultural studies and Latin American estudios culturales from nation-centered approaches toward transnational area and cultural studies respond to the growing complexity of ascertaining "difference" and cultural/ethnic/national identity in the Western Hemisphere. While Evo Morales foregrounds within Bolivia his own ethnic difference as indigenous Aymara and his political difference as socialist anti-U.S., he has, since 2006, also forged alliances with indigenous groups in the United States and Canada, downplaying national difference and highlighting a transnational kind of belonging. With massive migration, the rapid change of neighborhoods in the metropolitan areas of the Americas, the spread of diasporic communities, the growing medial and technological interconnectedness across long distances, and the intensifying interpenetration of the local, the national, the supranational and the global, a de-territorialization of identity practices has occurred. With the growing number of mixed-race individuals and with an event like 9/11 triggering Islamophobia and thus creating a new outsider group, the color line is superimposed by categorizations beyond 'race.' Since a definition of belonging based on space or 'race' is fading, difference is getting harder to pinpoint. But as Pierre Bourdieu wrote in Homo Academicus, the establishment of difference and the nature of an individual's habitus are essential to societies and to the constitution of culture and communities: "There is no way out of the game of culture, and one's only chance of objectifying the true nature of the game is to objectify as fully as possible the very operations which one is obliged to use in order to achieve that objectification" (12). What we should seek to understand are the "operations" at work in identity politics and the strategies used in maximizing or minimizing difference.

In this context it may be appropriate to replace 'race' and ethnicity by belonging, a sense of a shared, dynamic, non-exclusive community. Joanna Pfaff-Czarnecka has defined "belonging" as "an emotionally charged social location" that combines

37 I therefore applaud Edna Acosta-Belén's impassioned plea for a "hemispheric approach" to societies and cultures of the Americas that is comparative and cross-disciplinary and that analyzes differences as well as commonalities. Acosta-Belén observes that "the incessant intersections between the local, the national, and the transnational are producing new forms of interaction and socioeconomic relations and structures that influence the nature of social and political movements and the construction and reconfiguration of cultures and identities in the Western hemisphere" (241). Our academic practice needs to heed these intersections and interconnections. 
three factors: "(1) perceptions and performance of commonality; (2) a sense of mutuality and more or less formalised modalities of collective allegiance, and (3) material and immaterial attachments that often result in a sense of entitlement" (201). "Belonging," she points out, denotes both "an individual's belonging to a collective" and the "togetherness" of a group, which suggests that tensions between individual agency on the one hand and the collective's negotiation, performance or definition on the other are unavoidable. Also, while "belonging" may foster a practice of distinguishing between insiders and outsiders, it recognizes a multiplicity of factors with changing parameters of inclusion..$^{38}$ According to Pfaff-Czarnecka, the notion of belonging should help us "uncover the multiple, subtle and shifting modalities of forging and thinking the collective dimensions of the social life and the dynamic nature of social boundary-making" (203).

We need to ask how belonging, 'race,' ethnicity and difference play into the construction of individual and collective identities and how they determine questions of community, of inclusion and exclusion in/from a group, a social movement, or a nation. And we need to do so with an inter-American frame of reference rather than with national(ist) or regional tunnel vision. As Pablo Neruda said in his 1971 Nobel Prize acceptance speech: "All paths lead to the same goal: to convey to others what we are" (no pag.). But not everywhere in the Americas do such expressions of individual or collective identity meet with respect and recognition. Deviance from the norm or mainstream is often sneered at, punished, or negated. For those cases, Toni Morrison spoke in her 1993 Nobel Prize lecture of "lethal discourses of exclusion blocking access to cognition for both the excluder and the excluded" (19). In many parts of the contested Americas difference is still a long way from being considered an enrichment and an opportunity rather than an obstacle or a threat. ${ }^{39}$

Regardless of whether it is deemed a blessing or a burden, difference matters (whether established through 'race' or other factors). This position is also central to Bruce Norris's play Clybourne Park. The drama goes beyond a black and white

38 Pfaff-Czarnecka believes that whereas "identity politics have time and again revealed the exclusionary properties entailed in this notion," the politics of belonging, while "equally prone to effecting social exclusion," can also go in the opposite direction, "widening borders, incorporating, defining new common grounds" (203).

39 Whether difference will be intensified or diminished in the Western Hemisphere in coming decades is a question open to debate. Thomas E. Skidmore and Peter H. Smith, for their part, believe, with regard to Latin America, that the power of media (especially television), cultural homogenization, and continuing urbanization will diminish regional and ethnic distinctiveness (452-53). 
difference within the United States. It demonstrates how other markers of difference from age to sexual orientation and from class to dis/ability are superimposed onto ethno-racial markers. ${ }^{40}$ At one point in Act II, the lawyer Kathy receives a call on her cell phone from Hector, the architect whom the buyers of the property have hired to plan their future residence, which is to replace the existing house. When the assembled characters are struck by Hector's persistence, Lindsay "rolls her eyes at the others" and Steve explains "Spaniards" (60). This explanation is followed by a dialogue between Anglo-American Steve and African American Kevin:

KEVIN (to STEVE). Spaniards?

STEVE. Architect, ya know.

KEVIN. Spanish.

STEVE. Temperamental.

KEVIN. Toro toro.

STEVE. Exactly.

While the ethno-racial difference between the black Kevin and the white Steve seems to be sublated in this inter-ethnic assessment of "Spaniards," another realm of difference is opened up, namely the one between "Spaniards" and nonSpaniards.

Talking of Spaniards leads in this scene of the play to a conversation about past holiday destinations and the capitals of countries. In trying to determine the capital of Morocco, there is confusion about Rabat, Timbuktu, Mali, and Bali, to which Kathy answers, "Same difference" and Lindsey concurs: "And who gives a shit, any-?" (67). But playwright Norris underlines that difference does matter, having Steve reply: "Uhhh, no? The difference - ... is that they happen to be three distinct countries so, I guess I give a shit-" (67). It seems obvious that in the 2009 setting of Act II, talking of "Spaniards" is influenced by the changed demographics of the United States and the increase in the Latino population. In 2010 there are

40 Cordelia Chávez Candelaria came to a similar conclusion with regard to Henry Roth's Call It Sleep, Zora Neale Hurston's Their Eyes Were Watching God, and Rudolfo Anaya's Bless Me Ultima, in which she examines the tension between living inside an ethnic community (or "anticommunity") and outside of it: "This dialectical tension subsumes more than a conflict between a depicted pastoral of lost possibility and an ironic real world of material experience, more than a contrast between a privileged many and a marginalized minority, more even than the opposition of civilized versus primitive worldviews. The tension emerges from all these polarities amalgamated and also from the psychological and cultural web of effects implicit in their dichotomization of identity" (186). She concludes that there is a "difference and distance from one single determinable referent ... [or a] différance in articulating 'community"' (201). 
eight times as many Latinos living in the United States as there were in $1960 .^{41}$ Due more to migration than to birth rates, this demographic change needs to be seen in an inter-American framework that includes the changing stereotypes of Latinos, ${ }^{42}$ which the play's characters extend to Spaniards, and the brain drain from Latin America and Europe to the United States. In these contexts, difference continues to matter-whether marked by 'race,' ethnicity, nationality, or other factors. Fittingly, Norris has the above declaration by Steve followed by attempts to blame the alleged rudeness of the buyers and their lawyer on ethnic backgrounds:

LINDSEY. We're totally rude.

KEVIN. No, you're not.

LINDSEY. It's my family. Irish Catholic, you know? Blarney.

KATHY (raising a hand). Please, my husband? Half-Jewish, half-Italian.

KEVIN. Is that right?

KATHY. Get a word in edgewise.

KEVIN. I believe that. (67-68)

Bruce Norris seems to agree with Djelal Kadir, who wrote that "America ... is not reducible to the discrete and differentiated identity formations that would eradicate otherness, its own or others', and thereby elide or co-opt diversity, internal and external" (21). It also underlines the statement by Monika Kaup and Debra J. Rosenthal that "mixture and multiculturalism" are "an all-American reality" (xviii).

In the new millennium and with changing ethnoracial power hierarchies in various sites throughout the Americas, the notion of "post-race America(s)" has been advanced. While it is hard to pin down a commonly accepted meaning of this term, there seems to be a trend of shifting the focus from the experience of living as ethnoracial individuals (that was instrumental, for example, in the Civil Rights Movement and in multiculturalism) to the idea of 'race' and its socio-political significance and impact. While Ramón Saldívar acknowledges that "race and racism, ethnicity and difference are nowhere near extinct in contemporary America," he discovers a new engagement with 'race' in $21^{\text {st }}$-century U.S. ethnic fiction, an engagement that develops "a new racial imaginary" and that demonstrates "a

41 Over the half-century that lies between Lorraine Hansberry's play and Frank Norris's, the Hispanic population of the United States rose from six million ( $3.24 \%$ of the population) in 1960 to 50.5 million ( $16 \%$ of the population) in 2010 (Census; Gutiérrez).

42 For a comprehensive discussion of how 1960s stereotypes of the Latino underdog (or criminal) changed to self-assured presentations of latinidad on U.S. television, cf. Raab, "From Spic to Spice: Latinas and Latinos on U.S. Television." 
conceptual shift to the question of what meaning the idea of 'race' carries in our own times" $(574,575)$. Saldívar writes:

Today race remains a central question, but one no longer defined exclusively in shades of black or white, or in the exact manner we once imagined. That is, apart from the election of Barack Obama, one other matter marks the present differently from the racial history of the American past: race can no longer be considered exclusively in the binary form, black/white, which has traditionally structured racial discourse in the US. If for no other reason than the profoundly shifting racial demographics of early twenty-first-century America, a new racial imaginary is required to account for the persistence of race as a key element of contemporary American social and cultural politics. For these reasons, the term "postrace" does not mean that we are beyond race; the prefix "post" here does not mean a chronological "superseding," a triumphant posteriority. Rather, the term entails a conceptual shift to the question of what meaning the idea of "race" carries in our own times. The post of postrace is not like the post of post-structuralism; it is more like the post of postcolonial, that is, a term designating not a chronological but a conceptual frame, one that refers to the logic of something having been "shaped as a consequence of" imperialism and racism. (574-75; italics in the original)

Curiously, Saldívar locates this post-race aesthetics exclusively in works of what he calls "ethnic writers." We may ask: Does not such a racialization revert to essentialist, divisive modes of thinking about 'race'? A work like Clybourne Park (written by a white U.S. American) and the findings of whiteness studies suggests that we need to move beyond such assumptions of essential differences between "ethnic" and "non-ethnic/white" writers.

At the end of Clybourne Park, in a kind of epilogue, there is a flashback to the day on which Kenneth, the son of Bev and Russ-sticking out in the community as different because of his PTSD—, kills himself. As Kenneth is writing his suicide note to his parents, his mother, unaware of what is going on, tells him: "I really believe things are about to change for the better" (115). The statement is bitterly ironic since the audience is aware of Kenneth's imminent suicide. Bev's words refer not only to the situation of her family but they also comment bitterly on the development of 'race' relations and questions of belonging that the play has illustrated. While much has changed between 1959 and 2009 in the play's fictional Chicago and while the civil rights movement, political correctness, and a sense of post-racial equality and respect have left their marks in the conversations and interactions we observe on stage, difference is still very obvious in the play's 2009 scenario. It is a difference that is no longer primarily marked by 'race'-the way it had been in 1959-; we are more conscious of how gender, social class, sexual orientation, age, educational background, national origin, and other markers of identity intersect with distinctions in terms of 'race' and ethnicity. In the Western Hemisphere of the $21^{\text {st }}$ century, as illustrated by Bruce Norris's Clybourne Park, 
difference has not necessarily decreased; but it has become more dynamic and complex. In an interview, Norris said that the play is really about "war and territoriality and why we fight over territory." An inter-American context is established when we consider that Norris describes himself as a "whitey" who grew up in an all-white neighborhood in Houston, TX (a city that underwent massive demographic changes while Norris was living there) and who recalls that when reading A Raisin in the Sun in school "the only character I could identify with was Karl Lindner," the representative of the Clybourne Park Improvement Association, who tries to prevent the move of a black family into his white neighborhood (Seymour, no pag.). So both Hansberry's A Raisin in the Sun and Norris's Clybourne Park are in one way or another related to Langston Hughes's use of "my own people" to refer to dark-skinned Mexicans rather than to "gringos."

\section{Works Cited}

Acosta-Belén, Edna. "Reimagining Borders: A Hemispheric Approach to Latin American and U.S. Latino and Latina Studies." Color-line to Borderlands: The Matrix of American Ethnic Studies. Ed. Johnnella E. Butler. Seattle and London: $\mathrm{U}$ of Washington P, 2001. 240-64.

Anzaldúa, Gloria. Borderlands/La Frontera. San Francisco: Aunt Lute Books, 1987. Banerjee, Mita. Race-ing the Century. Heidelberg: Universitätsverlag Winter, 2005. Banting, Keith, Thomas J. Courchene, and F. Leslie Seidle, eds. Belonging? Diversity, Recognition and Shared Citizenship in Canada. The Art of the State. Vol. 3. Montebello, Quebec: The Institute for Research on Public Policy, 2007.

Banton, Michael. "Race Relations." A Companion to Racial and Ethnic Studies. Ed. David Theo Goldberg and John Solomos. Malden, MA \& Oxford: Blackwell, 2002. 90-96.

Bauer, Ralph. "The Hemispheric Genealogies of 'Race." Hemispheric American Studies. Ed. Caroline F. Levander and Robert S. Levine. New Brunswick, NJ: Rutgers UP, 2008. 36-56.

Bolton, Herbert Eugene. "The Epic of Greater America." The American Historical Review 38. 3 (1933): 448-74.

Bonilla-Silva, Eduardo. Racism without Racists: Color-blind Racism and the Persistence of Racial Inequality in the United States. Fourth edition. Lanham, MD: Rowman \& Littlefield, 2014.

Bourdieu, Pierre. Homo Academicus. 1984. Trans. P. Collier. Cambridge: Polity P, 1988.

Bulmer, Martin, and John Solomos, eds. Racism. New York \& Oxford: Oxford UP, 1999. 
Bush, Melanie E.L. Everyday Forms of Whiteness: Understanding Race in a "PostRacial" World. Second edition. Lanham, MD et al.: Rowman \& Littlefield Publishers, Inc., 2011.

Castells, Manuel. The Rise of the Network Society. The Information Age: Economy, Society, and Culture. Vol. 1. Second edition. London: Wiley-Blackwell, 2009.

Castles, Stephen, and Alastair Davidson. Citizenship and Migration: Globalization and the Politics of Belonging. Houndmills et al.: Macmillan, 2000.

Chávez Candelaria, Cordelia. "Différance and the Discourse of 'Community' in Writings by \& about the Ethnic Other(s)." An Other Tongue: Nation and Ethnicity in the Linguistic Borderlands. Ed. Alfred Arteaga. Durham: Duke UP, 1994. 185-202.

Crenshaw, Kimberlé Williams. “Color Blindness, History, and the Law." The House That Race Built. Ed. Wahneema Lubiano. New York: Vintage Books, Random House, 1998. 280-88.

Davis, Angela Y. "Race and Criminalization: Black Americans and the Punishment Industry." The House That Race Built. Ed. Wahneema Lubiano. New York: Vintage Books, Random House, 1998. 264-79.

De Castro, Juan E. Mestizo Nations: Culture, Race, and Conformity in Latin American Literature. Tucson: U of Arizona P, 2002.

Du Bois, W.E.B. “The Freedman's Bureau.” The Atlantic Monthly 87.519 (1901): 354-65.

Fisher Fishkin, Shelley. "Mapping Transnational American Studies." Transnational American Studies. Ed. Udo J. Hebel. Heidelberg: Universitätsverlag Winter, 2012. 31-74.

Fitz, Earl E. "From Blood to Culture: Miscegenation as Metaphor for the Americas." Mixing Race, Mixing Culture: Inter-American Literary Dialogues. Ed. Monika Kaup and Debra J. Rosenthal. Austin: U of Texas P, 2002. 243-272.

Fitz, Earl E. "Native American Literature and Its Place in the Inter-American Project." Comparative American Studies 11.2 (2013): 124-47.

Freyre, Gilberto. Casa-Grande \& Senzala. 1933. Rio de Janeiro: Editora Record, 1998.

Garner, Steve. Racisms: An Introduction. London et al.: Sage, 2010.

Goldberg, David Theo, and John Solomos. "General Introduction." A Companion to Racial and Ethnic Studies. Ed. Goldberg and Solomos. Malden, MA \& Oxford: Blackwell, 2002. 1-12.

Gutiérrez, David G. "An Historic Overview of Latino Immigration and the Demographic Transformation of the United States." National Park Service: American Latino Theme Study.http://www.nps.gov/latino/latinothemestudy/immigration. htm. 
Haas, Astrid. "A Continent of Color: Langston Hughes and Spanish America." Expanding Latinidad: An Inter-American Perspective. Ed. Luz Angélica Kirschner. Trier: Wissenschaftlicher Verlag Trier \& Tempe, AZ: Bilingual P, 2012. 177-94.

Hall, Stuart. "What Is This 'Black' in Black Popular Culture?” Black Popular Culture. Ed. Gina Dent. New York: Dia Center for the Arts, 1992. 21-34.

Hansberry, Lorraine. A Raisin in the Sun. New York: Random House, 1959.

Helg, Aline. "Abolition and Afro-Latin Americans." A Companion to Latin American History. Ed. Thomas H. Holloway. Malden, MA \& Oxford: Wiley-Blackwell, 2011. 247-63.

Hensel, Silke. "The Construction of Race in $20^{\text {th }}$-Century U.S.-Latino History." Hybrid Americas: Contacts, Contrasts, and Confluences in New World Literatures and Cultures. Ed. Josef Raab and Martin Butler. Münster: LIT Verlag \& Tempe, AZ: Bilingual P, 2008. 91-103.

Hill, Ruth. "Primeval Whiteness: White Supremacists, (Latin) American History, and the Trans-American Challenge to Critical Race Studies." Teaching and Studying the Americas: Cultural Influences from Colonialism to the Present. Ed. Anthony B. Pinn, Caroline F. Levander, and Michael O. Emerson. New York: Palgrave Macmillan, 2010. 109-38.

Hollinger, David A. Postethnic America: Beyond Multiculturalism. Tenth Anniversary Edition. New York: Basic Books, 2005.

Humes, Karen R., Nicholas A. Jones, and Roberto R. Ramirez. "Overview of Race and Hispanic Origin: 2010.” 2010 Census Briefs. U.S. Census Bureau. http:// www.census.gov/prod/cen2010/briefs/c2010br-02.pdf.

Kadir, Djelal. "Introduction: America and Its Studies." PMLA 118.1 (2003): 9-24.

Kaltmeier, Olaf. "Transnational Americas: Envisioning Inter-American Area Studies in Globalization Processes." Transnational Americas: Envisioning InterAmerican Area Studies in Globalization Processes. Trier: Wissenschaftlicher Verlag Trier \& Tempe, AZ: Bilingual P, 2013. 1-14.

Kaplan, H. Roy. The Myth of Post-Racial America: Searching for Equality in the Age of Materialism. Lanham, MD et al.: Rowman \& Littlefield Publishers, Inc., 2011.

Kaup, Monika, and Debra J. Rosenthal. "Introduction.” Mixing Race, Mixing Culture: Inter-American Literary Dialogues. Ed. Kaup and Rosenthal. Austin: U of Texas P, 2002. xi-xxix.

Krzyżanowski, Michał, and Ruth Wodak. "Multiple Identities, Migration and Belonging: 'Voices of Migrants."' Identity Trouble: Critical Discourse and Contested Identities. Ed. Carmen Rosa Caldas-Coulthard and Rick Iedema. Houndmills \& New York: Palgrave Macmillan, 2008. 95-119.

Kummels, Ingrid. "Cine Indígena: Video, Migration and the Dynamics of Belonging between Mexico and the USA." Etnicidad, ciudanía y pertenencia: prácticas, 
teoría y dimensiones espaciales / Ethnicity, Citizenship and Belonging: Practices, Theory and Spatial Dimensions. Madrid and Frankfurt: Iberoamericana Vervuert, 2011. 259-81.

Lane, Jill. "ImpersoNation: Toward a Theory of Black-, Red-, and Yellowface in the Americas." PMLA 123.5 (2008): 1728-31.

Lenz, Günter H. "Border Cultures, Creolization, and Diasporas: Negotiating Cultures of Difference in America." Negotiations of America's National Identity. Vol. 2. Ed. Roland Hagenbüchle, Josef Raab, and Marietta Messmer. Tübingen: Stauffenburg, 2000. 362-86.

Levander, Caroline F., and Robert S. Levine. "Introduction: Essays Beyond the Nation." Hemispheric American Studies. Ed. Levander and Levine. New Brunswick, NJ: Rutgers UP, 2008. 1-17.

Markus, Hazel Rose, and Paula M.L. Moya, eds. Doing Race: 21 Essays for the $21^{\text {st }}$ Century. New York: W.W. Norton \& Co., 2010.

Marx, Anthony W. Making Race and Nation: A Comparison of South Africa, the United States, and Brazil. Cambridge: Cambridge UP, 1998.

Massey, Douglas S. "Residential Segregation." A Companion to Racial and Ethnic Studies. Ed. David Theo Goldberg and John Solomos. Malden, MA \& Oxford: Blackwell, 2002. 348-54.

Mato, Daniel. "On the Making of Transnational Identities in the Age of Globalization: The US Latina/o-'Latin’ American Case." Cultural Studies 12.4 (1998): 598-620.

Metzler, Christopher J. The Construction and Rearticulation of Race in a "PostRacial America." Bloomington, IN: AuthorHouse, 2008.

Mignolo, Walter D. "Coloniality at Large: The Western Hemisphere and the Colonial Horizon of Modernity." Teaching and Studying the Americas: Cultural Influences from Colonialism to the Present. Ed. Anthony B. Pinn, Caroline F. Levander, and Michael O. Emerson. New York: Palgrave Macmillan, 2010. 49-74.

Morales, Evo. "Discurso del Presidente de Bolivia Evo Morales Ayma ante el Foro Permanente para las Cuestiones Indígenas de las Naciones Unidas.” April 21, 2008. http://walidator.net/see/374/form/.

Morrison, Toni. Lecture and Speech of Acceptance, Upon the Award of the Nobel Prize for Literature, Delivered in Stockholm on the Seventh of December, Nineteen Hundred and Ninety-Three. New York: Alfred A. Knopf, 1999.

Munro, Martin. Different Drummers: Rhythm and Race in the Americas. Berkeley \& Los Angeles: U of California P, 2010.

Neruda, Pablo. “Towards the Splendid City." Nobel Lecture. 1971. http://www. nobelprize.org/nobel_prizes/literature/laureates/1971/neruda-lecture.html.

Norris, Bruce. Clybourne Park. London: Nick Hern Books, 2010. 
Obama, Barack. "Barack Obama's Speech on Race." Transcript. The New York Times. March 18, 2008.http://www.nytimes.com/2008/03/18/us/politics/18text-obama. html?pagewanted=1\&_r=1.

Palmié, Stephan, and Francisco A. Scarano, eds. The Caribbean: A History of the Region and Its Peoples. Chicago: U of Chicago P, 2011.

Paquette, Robert L., and Mark M. Smith, eds. The Oxford Handbook of Slavery in the Americas. Oxford: Oxford UP, 2010.

Pascoe, Peggy. What Comes Naturally: Miscegenation Law and the Making of Race in America. Oxford: Oxford UP, 2009.

Pérez-Torres, Rafael. "Chicano Ethnicity, Cultural Hybridity, and the Mestizo Voice." Mixing Race, Mixing Culture: Inter-American Literary Dialogues. Ed. Monika Kaup and Debra J. Rosenthal. Austin: U of Texas P, 2002. 163-84.

Pfaff-Czarnecka, Joanna. "From 'Identity' to 'Belonging' in Social Research: Plurality, Social Boundaries, and the Politics of the Self." Etnicidad, ciudanía y pertenencia: prácticas, teoría y dimensiones espaciales / Ethnicity, Citizenship and Belonging: Practices, Theory and Spatial Dimensions. Madrid and Frankfurt: Iberoamericana Vervuert, 2011. 199-219.

Phillips, Caryl. Colour Me English: Selected Essays. London: Harvill Secker, 2011.

Pinder, Sherrow O. The Politics of Race and Ethnicity in the United States: Americanization, De-Americanization, and Racialized Ethnic Groups. New York: Palgrave Macmillan, 2010.

"Primer Encuentro de Autoridades Indígenas de América: Discurso de clausura de Evo Morales Aima." Fondo Indígena. Jan. 26, 2006. http://www.fondoindigena. org/notiteca nota.shtml? $\mathrm{x}=10601$.

Quijano, Aníbal. “Questioning 'Race.” Socialism and Democracy 21.1 (2007): 45-53.

Raab, Josef. "Deviance and Exclusion in Toni Morrison's Paradise." Millennial Perspectives: Lifeworlds and Utopias. Ed. Brigitte Georgi-Findlay and Hans-Ulrich Mohr. Heidelberg: Universitätsverlag Winter, 2003. 211-25.

Raab, Josef. "From Spic to Spice: Latinas and Latinos on U.S. Television." New World Colors: Ethnicity, Belonging, and Difference in the Americas. Ed. Raab. Trier: Wiessenschaftlicher Verlag Trier \& Tempe, AZ: Bilingual P, 2014. 49-116.

Raab, Josef. "Introduction: Contested Americas." New World Colors: Ethnicity, Belonging, and Difference in the Americas. Ed. Raab. Trier: Wiessenschaftlicher Verlag Trier \& Tempe, AZ: Bilingual P, 2014. 1-32.

Raab, Josef, and Alexander Greiffenstern, eds. Interculturalism in North America: Canada, the United States, Mexico, and Beyond. Inter-American Studies | Estudios Interamericanos. Vol. 8. Trier: Wissenschaftlicher Verlag Trier \& Tempe, AZ: Bilingual P, 2013. 
Rock, Chris. "Message for White Voters." YouTube. http://www.youtube.com/ watch? $\mathrm{v}=\mathrm{EDxOSjgl5Z4}$.

Rodríguez, Clara E. Changing Race: Latinos, the Census, and the History of Ethnicity in the United States. New York \& London: New York UP, 2000.

Saldívar, Ramón. "Historical Fantasy, Speculative Realism, and Postrace Aesthetics in Contemporary American Fiction." American Literary History 23.3 (2011): 574-99.

Seymour, Gene. "Bruce Norris, Scourge of Political Correctness." Los Angeles Times 23 January 2011. http://articles.latimes.com/2011/jan/23/entertainment/ la-ca-bruce-norris-20110123.

Skidmore, Thomas E., and Peter H. Smith. Modern Latin America. Sixth edition. New York \& Oxford: Oxford UP, 2005.

Sollors, Werner, ed. The Invention of Ethnicity. New York: Oxford UP, 1989.

Sollors, Werner. "Ethnicity and Race." A Companion to Racial and Ethnic Studies. Ed. David Theo Goldberg and John Solomos. Malden, MA \& Oxford: Blackwell, 2002. 97-104.

Taylor, Gary. Buying Whiteness: Race, Culture, and Identity from Columbus to Hip Hop. New York \& Houndmills: Palgrave Macmillan, 2005.

Thies, Sebastian, and Olaf Kaltmeier. "From the Flap of a Butterfly's Wing in Brazil to a Tornado in Texas?: Approaching the Field of Identity Politics and Its Fractal Topography." E Pluribus Unum?: National and Transnational Identities in the Americas/Identidades nacionales y transnacionales en las Américas. Ed. Sebastian Thies and Josef Raab. Münster: LIT Verlag \& Tempe, AZ: Bilingual P, 2009. 25-46.

U.S. Census Bureau. “The Hispanic Population: 2010” http://www.census.gov/ $\mathrm{prod} / \mathrm{cen} 2010 / \mathrm{briefs} / \mathrm{c2} 2010 \mathrm{br}-04 . \mathrm{pdf}$.

Vasconcelos, José. "Mestizaje." From The Cosmic Race. The Norton Anthology of Latino Literature. Gen. ed. Ilan Stavans. New York: W.W. Norton, 2011. A83-A98.

Warren, Jonathan W., and France Winddance Twine. "Critical Race Studies in Latin America: Recent Advances, Recurrent Weaknesses." A Companion to Racial and Ethnic Studies. Ed. David Theo Goldberg and John Solomos. Malden, MA \& Oxford: Blackwell, 2002. 538-60.

Whitman, Walt. Leaves of Grass and Other Writings. Ed. Michael Moon. Norton Critical Edition. New York: W.W. Norton, 2002.

Winant, Howard. "Racial Dualism at Century's End." The House That Race Built. Ed. Wahneema Lubiano. New York: Vintage Books, Random House, 1998. 87-115. 
Yelvington, Kevin A. "Patterns of 'Race, Ethnicity, Class, and Nationalism." Understanding Contemporary Latin America. Ed. Richard S. Hillman. Third edition. Boulder, CO: Lynne Rienner Publishers, Inc., 2005. 237-71.

Zamora, Lois Parkinson. "Magical Ruins/Magical Realism: Alejo Carpentier, François de Nomé, and the New World Baroque." Poetics of the Americas: Race, Founding, and Textuality. Ed. Bainard Cowan and Jefferson Humphries. Baton Rouge \& London: Louisiana State UP, 1997. 63-103. 
Marietta Messmer and Armin Paul Frank - 978-3-653-98855-0 Downloaded from PubFactory at 01/11/2019 10:57:20AM via free access 


\section{Amós Nascimento \\ University of Washington, Tacoma, U.S.A. \\ Inter-(African-Latin-)American: An Experiment in "Inter-Location"}

American Studies has been criticized not only because of its bias towards scholarship located in North America and influence by Anglophone discourses but also for its neglect of the African American experience of dislocation across the Americas. This essay reflects on the various experiences of peoples of African descent in distinct locations within the New World and discusses these experiences in light of the new proposal of "Inter-American Studies." Taking the differentiated collective experience of Africans in the Americas as a paradigmatic case of moving "in between" contexts, we can assess initiatives in fields such as American Studies, African American Studies, and Latin American Studies, and explore the idea expressed in the title: Inter-(African-Latin-)American: An experiment in inter-location.

\section{Introduction: Inter-(African-Latin-)American?}

The first and perhaps most important question we should ask refers to the meaning of a small prefix that makes a big difference: inter. What is gained by adding this term to an already recognized field of studies? To answer this question and contribute to the discussion on the future of American Studies, ${ }^{1}$ this essay will use the concept of location as a marker for both the geographical limits and the disciplinary boundaries that are now being questioned. ${ }^{2}$

1 See, for instance, Pease, D. and Wiegman, R. (eds.), The Futures of American Studies, Durham, Duke University Press, 2002. Fitz, E., Rediscovering the New World: InterAmerican Literature in a Comparative Context, Iowa City, University of Iowa Press, 1991.

2 On "location," see the contrast between Wise, G., "Paradigm Dramas' in American Studies: A Cultural and Institutional History of the Movement," in American Quarterly, Vol. 31, Number 3 (1979), pp. 293-337, and Maddox, L. (ed.), Locating American Studies: The Evolution of a Discipline, Baltimore, Johns Hopkins University Press, 1999 on the one hand. On the other, see Bhabha, H., The Location of Culture, New York, Routledge, 1994, and Mignolo, W., Local Histories/Global Designs: Coloniality, Subaltern Knowledges, and Border Thinking, Princeton, Princeton University Press, 2000. These are different ways of affirming the classical hermeneutical point according to which one's situation in a particular place informs one's practices and theories. 
Once we include the discussion on the meaning of the prefix "inter," we also need to question the second term, America. Which America is at stake? Is it homage to Americo Vespucci or a reference to the gold of the Amerrique Mountains once visited by Vespucci and Columbus in Nicaragua ${ }^{3}$ America has also been equated to the United States of America, an assumption that has been largely criticized. ${ }^{4}$ One possible way to avoid this semantic problem is to focus on geographical markers, requiring more specification about a particular area: South, Central, or North America. Again, even this subdivision is not enough to dissipate the problem because Mexico is often not included as part of North America, but rather seen as part of the Latin American culture, which is supposedly different from the Anglo-American culture of the United States and Canada. To avoid this problem I will use the term "Americas" as a reference to the whole continent. ${ }^{5}$

Thus far, I have asked questions about nomenclature and geographical categorization, but a discussion about culture is also necessary. By turning to the study of the cultures and traditions in the Americas, attention is brought to the difference between Anglo-American and Latin American. For instance, it is possible to see parts of Canada and the United States as forming a continuum that reveals the British colonial influence on Anglo-American culture. But, why not include Jamaica? Although the British influenced this country as much as the United States, we use a different marker in this case: Caribbean. There is a clear arbitrariness in our terms and categories. ${ }^{6}$ Similarly, the emphasis on Latin America has shed light on cultural differences and similarities among several areas and groups in the Americas (including parts of the United States) ${ }^{7}$ but has often forgotten the French part of Canada and Haiti, occluded the Caribbean, marginalized Brazil, and frozen sub-Artic or sub-Antarctic regions inhabited by distinct ethnic groups. How should we identify the archipelago in the Southern Patagonian coast:

3 See George C. Hurlbut (1888), “The Origin of the Name 'America," in Journal of the American Geographical Society of New York, 20, pp. 183-196.

4 Among key publications on this issue, see Pease, D., National Identities and PostAmericanist Narratives, Durham (NC), Duke University Press, 1994; Rowe, J.C. (ed.), Post-National American Studies, Berkeley (CA), University of California Press, 2000; Kaplan, A., The Anarchy of Empire, Cambridge (MA), Harvard Univesity Press, 2002.

5 On this, see McClennen, S., "Inter-American Studies or Imperial American Studies?," in Comparative American Studies. An International Journal, Vol. 3(4), 2005, pp. 393-413.

6 DeGuzmán, M., Spain's Long Shadow: The Black Legend, Off-Whiteness, and AngloAmerican Empire, Minneapolis, University of Minnesota Press, 2005.

7 Mignolo, W., The Idea of Latin America, Malden (MA), Blackwell, 2005. See also Mendieta, E., Global Fragments: Latinamericanisms, Globalizations, Critical Theory, Albany (NY), State University of New York Press, 2007. 
Malvinas, Malouines, or Falklands? This question has been answered in specific geopolitical terms and according to hegemonic interests. ${ }^{8}$ Thus, terms such as Cuban Studies, Canadian Studies, Brazilian Studies, and other areas have emerged as a way to identify cultures within the boundaries of a specific nation-state within the Americas. ${ }^{9}$

However, we also have disciplines addressing particular topics that transcend specific geographical borders, such as Gender Studies, Women's Studies, Ethnic Studies, Race Studies, African American Studies, and other fields. ${ }^{10}$ Relying on these areas, I would like to center my attention upon one particular issue: the experience of peoples of African descent located and dislocated in the Americas as a particular point of study. This would allow me to transgress the strict borders of African American Studies as a discipline focused on the United States. Similarly, I will show how Latin American Studies has often neglected the African dimension in the Americas, despite many studies about slavery and racism. Only recently have there been studies on Afro-Latinos. ${ }^{11}$ Thus, defining people of African descent in the whole Americas as African Americans and considering their differentiated locations and perspectives would not only enlarge our framework but also offer complementary answers to recurring common problems related to slavery, racism, and the struggle for citizenship.

By considering the specific case of African Americans in different contexts and localities within the Americas, I understand Inter-American Studies as an interdisciplinary, international, and intercultural framework. Such a framework

8 In the eighteenth century, Thomas Jefferson used the term British America to refer to the colonies seeking independence from Britain. See A Summary View of the Rights of British America, Monticello, The Thomas Jefferson Memorial Foundation, 1993 [Monticello Monograph Series].

9 On the problem of focusing American Studies and Latin American Studies on the nation-state, with a special emphasis on literature, see Porter, C., "What We Know that We Don't Know: Remapping American Literary Studies," in American Literary History, Vol. 6(3), 1994, pp. 467-526; and Levander, C. and Levine, R., "Introduction: Hemispheric American Literary History," in American Literary History, Vol. 18(3), 2006, pp. 397-405.

10 For a discussions of this issue see McClennen, S., "Area Studies Beyond Ontology: Notes on Latin American Studies, American Studies, and Inter-American Studies," in A - Contra corriente. A Journal on Social History and Literature in Latin America, Vol. 5, No. 1, Fall 2007, pp. 173-184.

11 See Andrews, G.R., "Afro-Latin America: The Late 1900s," in Journal of Social History, Vol. 28 (2), Winter 1994, pp. 363-379, and Afro-Latin America: 1800-2000, New York, Oxford University Press, 2004. 
allows us to transcend boundaries, consider different places, recognize various cultures, and use plural approaches in the study of many historical and contemporary themes that seem isolated and disconnected. ${ }^{12}$ This process of recognizing different locations while articulating diverse experiences of dislocation of African Americans and the possibility of conceiving of "Inter-(African-Latin-)American" identities can be called an "experiment in interlocation."

\section{An Expanded Framework: Considering Diaspora, Syncretism, and Multiculturalism}

If we recognize the slavery of Africans in many locations in the Americas as a key theme in the history of the continent, it is surprising that the debate on the very meaning of American Studies and Inter-American Studies rarely considers the situation of African Americans as something central. The African American experience has been subtly dislocated to the periphery of scholarly interest. ${ }^{13} \mathrm{We}$ need to expand the framework used in these areas in order to call into question the boundaries of "national" locations and move towards what I define as interlocation, which shall shed light on what is being displaced, i.e. what does not fit into imposed narrow categories.

One concept that helps us to understand the African American experience is diaspora, a Greek word originally meaning "dispersion," as in the case of seeds being thrown to all corners by the wind. After the persecution and dispersion of the Jewish people through the centuries, this term gained a social and political meaning, related to the search for a point of reference in time and space that would enable the affirmation of the Jewish collective identity. ${ }^{14}$ Today the word diaspora acquires a new meaning as we realize that the dispersion of Africans by a violent process of enslavement during the European colonization of the Americas still has an impact on their descendants. The term African American diaspora refers to

12 An important initiative in this regard is Gerald Horne's study, The Deepest South: The United States, Brazil, and the African Slave Trade, New York, New York University Press, 2007. As Horne states on the first page: "This book argues that U.S. slavery is better understood in hemispheric terms - the Slave South sought in an alliance with Brazil a formidable hedge against a future relationship to the North."

13 For similar issues in other areas of academic research see Twine, F.W. and Warren, J. (eds.), Racing Research, Researching Race: Methodological Dilemmas in Critical Race Studies, New York, New York University Press, 2000.

14 See for example Wasserstein, B., Vanishing Diaspora: The Jews in Europe since 1945, Cambridge (MA), Harvard University Press, 1996. 
Africans who were displaced and brought to the Americas, and to Americans who still search for a place, a location where they can express their identity. Therefore, diaspora can be understood as a process of dislocation.

Another term that has often been related to the African American experience is syncretism. This post-slavery concept has a biological connotation and was used together with the words hybridity, mestizaje, and miscegenation to imply an allegedly positive encounter and interaction among Native, African, and European cultures as well as the forging of a new multicultural identity in the "New World." However, this new identity displaces and negates Natives, assimilates Africans in the diaspora, imposes one biological, historical, linguistic, or cultural ideal of a nation that remains Eurocentric and suspends the plural perspectives or claims of different groups and subjects. Therefore, in order to bring the neglected aspects of the African American experience to the surface it is necessary to question this emphasis on assimilation without losing sight of the inter-relations that take place among different groups. This questioning also implies recognizing the problems of categories limited to a nation-state.

Yet another concept is multiculturalism, a more recent attempt to integrate the African American experience while avoiding the problem of forced assimilation. This concept has a philosophical connotation that goes back to Georg Friedrich Hegel's discussion of the "struggle for recognition" [Kampf um Anerkennung], which is based on the dialectical relationship between master and slave. Although Hegel defined this dialectics as a central question that emerges in modern societies ${ }^{15}$ this issue remained forgotten for quite some time. Only recently we observe philosophical discussions on this topic by Charles Taylor, Axel Honneth, Jürgen Habermas and especially Iris Young and Charles Mills, among others, who included a reflection on non-assimilatory "inclusion" and recognition of oppression as a necessary complement to liberal politics. ${ }^{16}$ Progressively, these ideas are receiving wider attention, coming to orient new proposals for identity politics or

15 Hegel, G.F., Werke, Frankfurt, Suhrkamp, 1979.

16 Taylor, Ch., Hegel and Modern Society, Cambridge, Cambridge University Press, 1979, and Taylor, Ch. et al., Multiculturalism and The Politics of Recognition, Princeton, Princeton University Press, 1992. Honneth, A., Kampf um Anerkennung, Frankfurt, Suhrkamp, 1992, pp. 154ff.; Habermas, J., Der philosophische Diskurs der Moderne, Frankfurt, Suhrkamp, 1985. On Hegel and Habermas, see Baynes, K., "Freedom and Recognition in Hegel and Habermas," in Philosophy and Social Criticism, Vol. 28(1), 2002, pp. 1-17. Young, I., Justice and the Politics of Difference, Princeton, Princeton University Press, 1990. Mills, Ch., The Racial Contract, Ithaca (NY), Cornell University Press, 1997. 
politics of recognition, which in turn inspire new movements opposing racism and color-blindness while defending racial and cultural consciousness. ${ }^{17}$ Although multiculturalism was identified with Canada and Canadian Studies, this concept was also used to characterize the existence of several minority groups in the United States, polyethnic societies around the world, or multinational democracies in Europe.$^{18}$ For our discussion, the relevance of this term is political, indicating the tension that arises in liberal democracies when one affirms the right to a cultural (African) identity within a particular (American) nation. As Kymlicka indicates in his discussion of this topic, the situation of African Americans is quite distinct: "In any event, most blacks do not have or want a distinct national identity. They see themselves as entitled to full membership in the American nation," but at the same time they reject the assimilationist model that subsumed other ethnic groups into the national identity of the United States. ${ }^{19}$ In light of the African American experience in the United States and elsewhere in the Americas, the concept of multiculturalism becomes problematic and, therefore, it has been criticized as well.

Despite the shortcomings of the concepts mentioned above, it is still possible to retrieve a basic common condition that should be central to our framework of interpretation. In all cases, people experiencing dislocation are acknowledged to have a multiplicity of experiences, with possible inter-relations among them, as exemplified in the multifarious perspectives on African American history. This implicit plurality represents an alternative to diasporic dislocation, as well as to assimilation through syncretism, and lack of interactions among different parts. The focus on plurality could function as an antidote to the singular reductionist model of nation and contradict ideas such as "melting pot," "racial democracy," and other terms that reduce African Americans to a given national boundary. Therefore, an important task in the process of discussing the possibility of developing "Inter-(African-Latin-)American" perspectives in Inter-American Studies and highlighting interlocation is to consider how African and African American elements have been negated and neglected in certain areas of study, only to emerge in others. For instance, many topics and themes have appeared within discussions on African American identity in Anglo America and resurfaced in Latin America. Thus, scholars began to study the African diaspora in different locations in South America, to recognize the importance of themes such as syncretism and mestizaje

17 See Kymlicka, W. Multicultural Citizenship, Oxford, Clarendon Press, 1995, Appiah, A. and Gutmann, A., Color Conscious: The Political Morality of Race, Princeton: Princeton University Press, 1996.

18 See Kymlicka, W. Multicultural Citizenship, Oxford, Clarendon Press, 1995, pp. 11-25.

19 Ibid., p. 25. 
in several countries, to compare the multicultural experiences in places like the United States and Brazil, and thus to identify the connection among different African American experiences. This indicates not only the "dislocation" of peoples and meanings, but also their "trans-location," which generates new meanings. ${ }^{20}$ Thus, a simple semantic shift can lead to changes in several directions.

Recognizing this trans-location is important, ${ }^{21}$ but not enough. We need a plural approach that recognizes different cultures, identities, and discourses located peripherally, which are not only in confrontation or contrast with a given center, but also in a complementary relation to each other. Thus, what could be defined as external locations needs to be assessed in a multifarious way and measured in relation to the internal discourses and local actors who establish inter-relations and transcend previous limits and borders. We need a wider framework beyond certain approaches that rely too heavily on categories bound to a nation-state. Inter-American Studies has the potential to become this wider framework if we are able to acknowledge various forms of understanding the "local" (as a place, as a symbol, as a culture and so on) being able to subvert the imposition of hegemonic categories, to observe exchanges beyond localities, and to promote a more intensive form of interaction at different levels (including the level of theoretical observation and conceptual elaboration). It is at this point that the connector "inter" becomes relevant. Besides the local dimension, we also need to consider the inter-locality or inter-location of the African American experience, similar to what Bhabha defines as being "in between," always on the move. In this way, we can also account for the spatiality and critical geopolitical aspects of our interpersonal, inter-national, inter-cultural, and inter-geographical relations.

The framework I am proposing here considers the inter-location of cultures and discourses as well as their possible communication. This should enable us to criticize the imposition of one single biological, historical, linguistic, or cultural marker that negates plurality while exploring ways of using the tools of academic fields such as American Studies, African American Studies, Caribbean Studies, Latin American Studies, and Brazilian Studies to understand the plurality of African American experiences in the Americas. Conversely, I will use the African

20 One example of this process is the immigration of Black workers from the United States to Guatemala between the 1880 s and 1910s, who may have returned to the United States in 1990s as Guatemalan immigrants. See Opie, F.D., "Black Americans and the State in Turn-of-the-Century Guatemala," in The Americas, Vol. 64(4) April 2008, pp. 583-609.

21 Mignolo, W., Local Histories/Global Designs: Coloniality, Subaltern Knowledges, and Border Thinking, Princeton, Princeton University Press, 2000. 
American experience as a common denominator connecting different contexts and highlighting problems related to Inter-American Studies.

\section{A Plural View of African American Studies: The Inter-African American Experience}

Thus far, I have worked in two steps. First, I questioned the fallacious equation of the United States with "America" and the reduction of African American Studies to the research on people of African descent in this particular country. Moreover, I suggested that we speak more generally about "the Americas" and include the plurality of peoples, spaces and locations that can then be articulated in terms of inter-location. Secondly, I defined this inter-location in terms of a wider framework that allows for plural interactions, so that we can consider the African American experience not simply as a reference to African American Studies in the United States, but in terms of a polyphony of commonalities and differences in relation to various contexts in the Americas. In a third step, I want to provide examples pointing towards an Inter-(African-Latin-)American perspective. In the same way one defines African Americans (as referring to the United States), there are also Afro-Cubans and Afro-Brazilians, but less emphasis is placed on AfroHaitians or Afro-Canadians. To avoid problems with such nomenclatures, we can insist on the term African Americans as both applicable to the whole context of the Americas and specific to particular locations.

Rather than presenting and discussing empirical details about these specific locations here, ${ }^{22}$ my goal is to explore the possibility of articulating such examples beyond the mere comparison of singularities. For example, the case of African Americans in Cuba is not simply an interesting sociological fact to be distinguished from the demographic fate of African Americans in Argentina. ${ }^{23}$ Rather,

22 For studies on different perspectives on African American Studies in the whole Americas which rely on concepts of diaspora, multiculturalism, and other plural perspectives, see Chambers, D., "Ethnicity in the Diaspora: The Slave-Trade and the Creation of African 'Nations' in the Americas," in Slavery \& Abolition, 22:3 (2001), pp. 25-39; Hall, G. Slavery and African Ethnicities in the Americas: Restoring the Links, Chapel Hill (NC), University of North Carolina Press, 2005; Heywood, L. (ed.), Central Africans and Cultural Transformations in the American Diaspora, Cambridge, Cambridge University Press, 2002; Franklin, J.H., "On the Evolution of Scholarship in Afro American History," in Clark Hine, D. (ed.), The State of Afro-American History, Baton Rouge (LA), Louisiana State University Press, 1986, pp. 13-22.

23 See George Reid Andrews, The Afro-Argentines of Buenos Aires: 1800-1900, Madison (WI), University of Wisconsin Press, 1980. 
both are particular aspects of a wider structural element. If in the nineteenth century, this common structural element was slavery and in the twentieth century, it was institutional racism, we now have different issues at work that can be better grasped by an "Inter-(African-Latin-)American" perspective. Although specific cases could be studied by considering historic elements and recent trends in African American Studies in Brazil, Colombia, Cuba, Jamaica, Uruguay, or Venezuela and other countries, an Inter-American framework would go beyond the particularities of these cases to explore the importance of interactions. The importance of the preposition "inter" is that it helps us to understand the routes of exchanges between Africa and the Americas, the different locations where the impact of these exchanges was felt, the mutual influences that occur because of these exchanges, and the transformations they underwent and continue to undergo. Therefore, providing examples of these interactions can help us explore this possibility.

\section{a) African American Studies in the United States}

Black Studies and (later) African American Studies were one of the first disciplines to question the supremacy of American Studies and its neglect of alternative voices and locations. ${ }^{24}$ However, African American Studies is now a contested terrain as well, criticized for being limited to an Anglophone perspective, although it has recently been applied to Latin American and Caribbean contexts. In a text for a special issue of The Americas, "Introduction: Africa (Black) Diaspora History, Latin American History," Ben Vinson III addresses this issue. Writing in 2006, he notices not only a reinvigoration of Black Studies in the past several years, but also the emergence of concepts such as diaspora, Black Atlantic, and others that also affected the historiography of Latin America. ${ }^{25}$ Another example can be found in the field of literature, which began to include slave narratives, women's voices, and the experiences of workers, youth, and communities as objects of their studies. Similarly, a new field began to emerge in Latin American Studies, focusing on Afro-Hispanic language, poetry, and literature. ${ }^{26}$ Let us briefly review this process.

24 See Daniel, Ph., "Black Studies: Discipline or Field of Study?", in The Western Journal of Black Studies 4 (Fall 1980): 195-99. Norment, N. (ed.), The African American Studies Reader, Durham (NC), Carolina Academic Press, 2001.

25 Vinson III, B. (guest ed.), "Special Issue: The African Diaspora in the Colonial Andes," in The Americas, Vol. 63 (1), July 2006.

26 Afro-Hispanic denotes a language, not an ethnic category. Examples of studies in this area can be seen in Lewis, M., Afro-Hispanic Poetry 1940-1980: From Slavery to "Negritud" in South American Verse, Columbia (MO), University of Missouri Press, 1983, who collects 
One of the founding elements of African American Studies in the United States is the research on slavery. Although this same topic has been studied from the perspective of history, economics, sociology, and many other disciplines, one of the contributions of African American Studies in the United States was to focus on narratives that provide a direct account of this period. It is not surprising, therefore, that many studies started with Frederick Douglass' writings in order to reveal how his political practices and personal reflections deal with issues of emancipation and recognition that go beyond his individual experience and affect the lives of many African Americans in the United States. ${ }^{27}$

Douglass represents the first African American modernist figure in the context of the United States, a former slave who coined his new post-slave surname from a literary work (Sir Walter Scott's The Lady of the Lake) and insisted on the need to supplant the archaic institution represented by the plantation. Douglass' own narrative provides elements that are not necessarily geopolitical, but rather related to collective psychology. As Gates has shown, even with his successful life as writer and politician, Douglass was still searching for the Self at the end of his life, since he did not know his real name or birthday. ${ }^{28}$ This points to yet another meaning of dislocation.

Although this kind of research was foundational in the establishment of African American Studies, it was immediately expanded in at least three ways. First, there emerged a backward-looking archeological process of revealing earlier forms of slave narratives. These narratives do not only constitute a genre, but also a rich source of information on social, economic, political, and cultural slave practices. ${ }^{29}$

texts by African American authors in several countries, from Colombia to Uruguay. See Jackson, Shirley M., "Afro-Hispanic Literature: A Valuable Cultural Resource," in Foreign Language Annals, Vol. 11 (1978), pp. 421-25. This has led to an increasing interest in and definition of Afro-Latin Culture. Jackson, Richard L., Black Writers and Latin America: Cross-Cultural Affinities, Washington (DC), Howard University Press, 1998.

27 Douglass, F. The Life and Writings of Frederick Douglass [edited by Ph. Foner], New York, International Publishers, 1854/1950.

28 Gates Jr., H., Figures in Black: Words, Signs and the 'Racial Self', New York, Oxford University Press, 1985, pp. 98ff.

29 Henry Gates Jr. has developed a whole project on slave narratives. Aptheker was one of the first to write on maroon communities in South and North Carolina, Virginia, Louisiana, Florida, Georgia, Mississippi, and Alabama. See Aptheker, H., American Negro Slave Revolts, New York, International Publishers,1963. Certainly, these studies also refer to the classic by Olaudah Equiano, published in 1789, The Interesting Narrative of the Life of Olaudah Equiano, the African, Written by Himself. New studies have dealt with the narrative and authenticity of this work. 
Second, many researchers followed the case of Douglass as a prototype of key individual figures in the history of the United States, role-models who were able to express their views at key moments of the history of the United States, such as Martin Delany, Richard Wright, Booker T. Washington, W.E.B. DuBois, Alain Locke, Marcus Garvey, Malcolm X, and Martin Luther King Jr., among many others. ${ }^{30}$ The importance of this research is undeniable, but the fact that this list includes only "men" became evident as well. Therefore, third, new studies began to focus on the role of women, groups (such as youth, workers, churches, etc.) and other social actors that had previously been disregarded. The lack of studies on Black women was much criticized. As Angela Davis states in a seminal article on this topic, "The paucity of literature on the black woman is outrageous on its face. Nevertheless, we must also contend with the fact that too many of these rare studies must claim as their signal achievement the reinforcement of fictitious clichés. They have given credence to grossly distorted categories through which the black woman continues to be perceived." ${ }^{11}$

These examples show some internal challenges within the field of African American Studies in the United States. Yet another challenge would be more external: How to relate these discussions to the experiences of African Americans elsewhere? One danger is to affirm that these issues are essential to any African American experience. The other danger is to insist on the locality and relativity of particular ineffable experiences. Yet the question above shows a limitation within African American Studies and points to the alternatives opened up by the concept of "Black Atlantic."

\section{b) The Black Atlantic}

Even if the focus on Anglophone scholarship could be justified as a necessary side effect of a social division of labor, it is undeniable that the English-speaking Caribbean and Canada were disconnected from the reflections on the African American experience in the Americas. In his book The Black Atlantic, ${ }^{32}$ Gilroy

30 See, for example, Delany, M., The Condition, Elevation, Emigration and Destiny of the Colored People of the United States, Politically Considered, Philadelphia, 1852; W.E.B. DuBois, The Souls of Black Folk: Essays and Sketches, Chicago, A.C. McClurg \& Co., 1903.

31 Davis, A., "Reflections on the Black Woman's Role in The Community of Slaves", in The Black Scholar Vol. 3, Number 4 (Dec. 1971), pp. 3-15, citation from p. 3. See also Davis, A., Women, Race, and Class, New York, Vintage, 1983.

32 Gilroy, P. The Black Atlantic: Modernity and Double Consciousness, Cambridge (MA), Harvard University Press, 1993. 
helps us establish an interesting basic structure or framework that could allow us to move beyond the national scope and relate different aspects involved in the quest for an African identity in the meeting of cultures in the Americas and in Europe:

The specificity of the modern political and cultural formation I want to call the Black Atlantic can be defined, on one level, through [a] desire to transcend both the structures of the nation state and the constraints of ethnicity and national particularity. These desires are relevant to understanding political organizing and cultural criticism. They have always sat uneasily alongside the strategic choices forced on black movements and individuals embedded in national and political cultures and nation-states in America, the Caribbean, and Europe. ${ }^{33}$

Gilroy succeeds in rescuing neglected aspects in the historical reconstruction of the African influence upon North America and the Caribbean; in revealing the direct contacts of African Americans with European culture; in relating modernity and postmodernity to Cultural Studies and African Studies in Britain and in the United States; in stressing the role of Africa in the genealogy of modernity; in challenging both cynical Eurocentrism and naïve Afrocentrism at once; in establishing a cross-cultural and non-reductive space of interrelations between Africa, the Americas, and Europe - the "Black Atlantic"; in stressing communication and the artistic tradition in the diaspora as a non-geopolitical connecting element that binds these different contexts together; and in revealing the political implications of this process. The important point in Gilroy's approach is that he shows how the search for identity remains present in diasporic movements across the board. As he observes commonalities among different contexts, he promotes a form of interlocation. ${ }^{34}$

Gilroy also explores other areas (such as sociology and literature) in his analysis of African American culture, broadly conceived. For example, the connections between the experiences of Jewish and African diasporas. ${ }^{35}$ In observing Douglass, DuBois, and others in their search for an original and inherently African time and space within the Americas, Gilroy arrives at a more general definition of diaspora as a "utopian eruption of space into the linear temporal order of modern black politics." ${ }^{36}$ Negro Spirituals represent the tension between a politics of fulfillment and transfiguration. They are the best example of the connection and the parallel

33 Ibid., p. 19.

34 Ibid., p. 37.

35 Gilroy, The Black Atlantic, pp. 205-217.

36 Ibid., p. 198. 
between African and Jewish diasporas. They also provide Gilroy with an extra element for his model of communication and his chronotope of ships in motion between Europe, the Americas, and Africa, since they suggest a dialectics of going in and out of given national boundaries that generates an intercultural exchange. In this way, the process of shaping African American identity can be seen more generally as confrontation and interaction with other cultures, compatible to what I defined as interlocation. Along these same lines, Homi Bhabha offers an interesting counterpoint and complement to Gilroy's views as he stresses the "moments or processes that are produced in the articulation of cultural differences" 37 and adds the spatial dimension of these encounters. ${ }^{38}$ Based on the discussion of The Black Atlantic we can see that symbolic forms have not only provided a reference of time and space for the affirmation of identity in the diaspora, but also supplied resources for African American resistance to assimilation and annihilation. However, there are also limits to this approach.

The reflection on Caribbean identity and its relationship to Europe, Africa, and the Americas is central to African American Studies because this is a multicultural context in which the majority of the population is of African ancestry ${ }^{39}$ However, beyond the British and Dutch colonization we need to relate this discussion to French colonialism as well. The revolution and independence of Haiti is one of the first moments in which the tension between French and African elements arises in the Americas ${ }^{40}$ This is an under-studied topic, although it has been the subject of reflection by Aimé Césaire, Frantz Fanon, Édouard Glissant, and others who discussed the négritude movement, Antillanité, and créolité in relation to Africa and Europe. ${ }^{41}$ Moreover, these elements need to be related to Spanish America, a

37 Bhabha, H., The Location of Culture, p. 1, see pp. 40-52, 60-65.

38 Ibid., p. 30, where he quotes Gilroy, There Ain't no Black in the Union Jack, London, Hutchinson, 1987, p. 214. Cf. Gilroy, The Black Atlantic, pp. 31-36.

39 For more details see Henry, P., Caliban's Reason: Introducing Afro-Caribbean Philosophy, New York, Routledge, 2000; and Lewis, G., “Theorising Race and Racism in an Age of Disciplinary Decadence," in Shibboleths: Journal of Comparative Theory, Vol. 1, Number 1 (2006), pp. 20-36.

40 The classic is James, C. L. R., The Black Jacobins: Toussaint L'Ouverture and the San Domingo Revolution, New York, 1989. See also Dubois, L., A Colony of Citizens: Revolution and Slave Emancipation in the French Caribbean: 1787-1804, Chapel Hill (NC), University of North Carolina Press, 2003.

41 See Dash, J.M., "Farming Bones and Writing Rocks: Rethinking a Caribbean Poetics of (Dis)Location," in Shibboleths: Journal of Comparative Theory, Vol. 1, Number 1 (2006), pp. 64-71. 
context that seems forgotten here as well. ${ }^{42}$ One point to be mentioned could be the similarities between the Southern United States, the Caribbean, and South America regarding the culture of the plantations ${ }^{43}$ and the different religious expressions, including Santería, Voodoo, and Candomblé. ${ }^{44}$ Another example would be the religious and musical traditions in Jamaica, which could be compared to Cuba and Argentina. ${ }^{45}$ Ifeoma Nwankwo's book Black Cosmopolitanism: Racial Consciousness and Transnational Identity in the Nineteenth Century Americas, partially suggests ways to overcome the limits of the Black Atlantic approach by focusing on literary elements. She relies on slave narratives in the United States, Haiti, Cuba, and the West Indies to show how the search for identity and citizenship became a multinational quest for people of African descent in the Americas. She refers especially to a process after the Revolution in Haiti and includes interesting cross-references to Frederick Douglass, who served as the United States Consul to Haiti. ${ }^{46}$ However, we still lack a framework based upon which we can integrate and articulate different parallel experiences. In an attempt to move beyond these limits and at least refer to concomitant facts, we should turn our attention to Latin

42 Bowser, F., “The African in Colonial Spanish America: Reflections on Research Achievements and Priorities," Latin American Research Review (LARR), Vol. 7, Number 1 (1972), pp. 77-94. See also Bennett, H., “The Subject in the Plot: National Boundaries in the History of the Black Atlantic," in African Studies Review, Vol. 43, Number 1, 2000, pp. 101-24; Zeleza, P., "Rewriting the African Diaspora," pp. 35-68; and Pier M. Larson, "African Diasporas and the Atlantic," in Cañizares-Esguerra, G. and Seeman, E. (eds.), The Atlantic and Global History, New York, Prentice Hall, 2006; Torres, A. and Whitten Jr., N. (eds.), Blackness in Latin America and the Caribbean: Social Dynamics and Cultural Transformations, Volume 2: Eastern South America and the Caribbean, Bloomington, Indiana University Press, 1998.

43 Moreno Fraginals, M., "Plantations in the Caribbean: Cuba, Puerto Rico, and the Dominican Republic in the Late Nineteenth Century," in Shepherd, V.A. and Beckles, H. (eds.), Caribbean Slavery in the Atlantic World: A Student Reader, Princeton, Marcus Wiener Publishers, 2000, pp. 494-505.

44 See Narciso Hidalgo, "Las creencias de origen africano en el Nuevo Mundo," in AfroHispanic Review, Spring 2007, Vol. 26(1), pp. 11-18. In their seminal works, Fernando Ortiz and Lydia Cabrera compare the many similarities between Cuba and Brazil, especially in terms of religion and myths.

45 Petras, E., Jamaican Labor Migration: White Capital and Black Labor: 1850-1930, Boulder (CO), Westview, 1988.

46 Nwankwo, I., Black Cosmopolitanism: Racial Consciousness, and Transnational Identity in the Nineteenth-Century Americas, Philadelphia, University of Pennsylvania Press, 2005 . 
American Studies, bringing both the Caribbean and the Latin American dimension to the process of interlocation. ${ }^{47}$

\section{c) Latin American Studies}

After considering recent discussions on African American Studies in the United States, the debates on the "Black Atlantic," and references to the Caribbean context, I will now expand our view of the Americas as a scenario upon which a continuous movement of interlocation occurs. ${ }^{48}$ Upon this base, I will attempt a historical reconstruction of Africans' struggles for the inclusion and recognition in Spanish and Portuguese colonies in the Americas, which were later defined as Latin America. ${ }^{49}$ The term used to identify African Americans in this area is Afro-Latinos. ${ }^{50} \mathrm{An}$ important task of this reconstruction is to avoid the limitations of certain geopolitical notions as well as the imposition of a single form of syncretism that contradicts plurality, systematically negates African elements, and does not open up venues for inter-relations.

In the Latin American context, the encounter and interaction among Native, African, and European cultures has been manipulated to either negate African elements or to assimilate them and forge a new "multicultural" identity for the sake of a nation-building process in the New World. If we consider this process in the Caribbean, Colombia, Peru, Venezuela, Brazil, and Uruguay, we can observe how this idea pervades the whole continent, albeit with different names and processes. The multicultural character of the American continent has been traditionally defined in slogans such as "racial democracy" in Brazil or "café con leche" in Venezuela, "mestizo society" in Colombia or "unidad de las razas" in Cuba, the new "cosmic

47 This also applies to Florida, past and present. See Tepaske, J., “The Fugitive Slave: Intercolonial Rivalry and Spanish Slave Policy, 1687-1764," in Proctor, S. (ed.), EighteenthCentury Florida and Its Borderlands, Gainesville (FL), The University Press of Florida, 1975, pp. 1-12; Landers, J., "Gracia Real de Santa Teresa de Mose: A Free Black Town in Spanish Colonial Florida," in American Historical Review, Vol. 95(1), February 1990, pp. 9-30, and Black Society in Spanish Florida, Urbana, University of Illinois Press, 1999.

48 For a comprehensive history of the African diaspora in the Americas, see Whitten, N. and Torres, A. (eds.), Blackness in Latin America and the Caribbean, Bloomington (IN), Indiana University Press, 1998.

49 Rout, L., The African Experience in Spanish America: 1502 to the Present Day, London, Cambridge University Press, 1976.

50 Andrews, G.R., Afro-Latin America: 1800-2000, Oxford, Oxford University Press, 2004. 
race" in Mexico or "the meeting of cultures" elsewhere. ${ }^{51}$ What lies underneath all these terms is the assumption that mestizaje, miscegenation, hybridity, and the melting process of different races will bring about a newer and better people and nation..$^{52}$ This is a form of syncretism that displaces Natives and assimilates Africans and other ethnic groups in the diaspora, imposing a single biological, historical, linguistic, or cultural ideal of nation that remains Eurocentric and disregards different groups and subjects. ${ }^{53}$

However, peoples of African descent in Latin America, or Afro-Latinos, can be observed in larger numbers in those countries that participated more actively in the slave trade and the Black Atlantic: Brazil, Cuba, Colombia, Panama, the Dominican Republic, Puerto Rico, and Venezuela as well as specific regions of Ecuador, Honduras, Guatemala, Peru, and Uruguay. In each one of these locations, African Americans developed a distinct cultural identity. Therefore it seems scandalous to study Latin America without referencing the African diaspora, its impact, and the interactions it produced. Only recently has there emerged a steady publication of systematic studies on the African American population

51 See Butler, K., Freedoms Given, Freedoms Won: Afro-Brazilians in Post-Abolition São Paulo and Salvador, New Brunswick (NJ), Rutgers University Press, 1998; Sheriff, R., Dreaming Equality: Color, Race, and Racism in Urban Brazil, New Brunswick (NJ), Rutgers University Press, 2001; Helg, A., Liberty and Equality in Caribbean Colombia: 1770-1835, Chapel Hill (NC), University of North Carolina Press, 2004; Howard, D., Coloring the Nation: Race and Ethnicity in the Dominican Republic, Boulder (CO), Lynne Rienner, 2001; Wright, W.R., Café con Leche: Race, Class, and National Image in Venezuela, Austin (TX), University of Texas Press, 1990; Wade, P., Blackness and Race Mixture: The Dynamics of Race Mixture in Colombia, Baltimore, Johns Hopkins University Press, 1993; and Bennett, H., Africans in Colonial Mexico: Absolutism, Christianity and Afro-Creole Consciousness: 1570-1640, Bloomington: Indiana University Press, 2003.

52 Martinez-Eschazabal, L., "Mestizaje and the Discourse of National/Cultural Identity in Latin America: 1845-1959," in Latin American Perspectives, Vol. 25(3), May 1998, pp. 21-42.

53 Nascimento, A., "African (Latin) American Identities in Conflict," in Peace Review (December 1997), pp. 489-496; Nascimento, A. and Sathler, J., "Black Masks on White Faces: Liberation Theology and the Quest for Syncretism in the Brazilian Context," in E. Mendieta, L. Lorentzen, D. Batstone \& Hopkins, D. (eds.), Liberation Theology and Postmodernity in the Americas, London, Routledge, 1997, pp. 95-122; and Review of Gracia, J., Latin/Hispanic Identity (Blackwell) in Manuscrito (2000), pp. 205-217. 
in these different regions. ${ }^{54}$ One interesting case is Cuba, for it brings together Spanish colonization, its location in the Caribbean, a high percentage of African Americans in the population, and the immigration of Cubans to the United States, among other factors.

Historically, it is impossible to refer to Cuba without mentioning José Martí. The reference to his name is important not only because of his pan-American vision of a "nuestra América" - which seems compatible with the idea of InterAmerican Studies - but also because he experienced the continuous movement of a desterrado in the Americas, moving from country to country, searching for an ideal land or location. Such a land would be neither closed enough to become hermetically circumscribed by a limiting territorial jurisdiction nor naïvely open enough to become prey to the colonial and imperialist disrespect for sovereignty. This experience of desterritorialización, however, is not limited to his rebel and sensitive subjectivity, and not even particular to Cuba. This dislocation is a continuous experience in the Americas, in groups whose descendants are now spread throughout the Americas, questioning borders and markers that were arbitrarily imposed on them. Martí acknowledged this. However, he did not relate this aspect to the African American experience, but rather subsumed it under a political project, thus somewhat occluding the African dimension in Cuban culture. Echoing the ideology of syncretism, he said: "Cuban is more than white, more than

54 See Díaz, M.E., The Virgin, the King, and the Royal Slaves of El Cobre: Negotiating Freedom in Colonial Cuba, 1670-1780, Stanford, Stanford University Press, 2000; de la Fuente, A., A Nation For All: Race, Inequality, and Politics in Twentieth-Century Cuba, Chapel Hill (NC), University of North Carolina Press, 2001; Restall, M. (ed.), Beyond Black and Red: African-Native Relations in Colonial Latin America, Albuquerque (NM), University of New Mexico Press, 2005; Vinson III, B. and King, S., "Introducing the 'New' African Diasporic Military History in Latin America," special issue, Journal of Colonialism and Colonial History, Vol. 5, Number 2 (2006); Sweet, J., Recreating Africa: Culture, Kinship, and Religion in the African-Portuguese World: 1441-1770, Chapel Hill (NC), University of North Carolina Press, 2003; Herrera, R., Natives, Europeans, and Africans in SixteenthCentury Santiago de Guatemala, Austin (TX), University of Texas Press, 2003; Falola, T. and Childs, M. (eds.), The Yoruba Diaspora in the Atlantic World, Bloomington, Indiana University Press, 2004; Walker, D., No More, No More: Slavery and Cultural Resistance in Havana and New Orleans, Minneapolis (MN), University of Minnesota Press, 2004; Aguirre, C., Agentes de su propia libertad: Los esclavos de Lima y la desintegración de la esclavitud: 1821-1854, Lima, Pontificia Universidad Católica del Perú, Fondo Editorial, 1993. Moreover, see Howard, D., Coloring the Nation: Race and Ethnicity in the Dominican Republic, Boulder (CO), Lynne Rienner, 2001; and Sagás, E., Race and Politics in the Dominican Republic, Gainesville (FL), University of Florida Press, 2001. 
mulatto, more than Negro." ${ }^{55}$ Similar views were held by other political authorities who warned of a "black peril" - the danger of Cuba becoming a Black Republic like Haiti - and advocated the need to disregard race or be color-blind in the process of constructing a new nation. Recent scholarship has stressed that this foundational discourse, referred to as "the myth of racial equality," imposed an ideological construction that negated Afro-Cuban identity. ${ }^{56}$ Despite the fact that the African American population had a profound impact on Cuban history and culture at the beginning of the $20^{\text {th }}$ century, the Cuban government implemented a whitening process by promoting immigration from Spain and an ideology of "racial fraternity" and "unidad de las razas." This would later be questioned by the Afro-Cuban movement and has been the subject of recent studies. ${ }^{57}$

If we take the case of peoples of African descent in Cuba as one important example of the African American experience in Spanish America and the Caribbean, new light is shed on a series of issues that escaped the perspective of African American Studies in the United States and the concept of Black Atlantic. For example, it brings to the surface the experience of Spanish colonialism, the interactions among different countries, the tensions between local American hopes and hegemonic European interests, and the perilous proximity to the historic revolution in Haiti. At the same time, the particular case of Cuba contributes to the study of the African experience in other contexts also. We can observe an interesting mixture of issues, including the slave trade that brought people from Yorubaland in West Africa to plantations in the Caribbean. There is an interaction between the mores and language that characterize, for example, the Latin American culture in Puerto Rico (as opposed to, say, Jamaica - where the reference is to British culture), and that of peoples of African descent within the immigrant Cuban community in the United States. These interactions can be studied, for example, in comparisons between religious expressions such as Santería in Cuba

55 De la Fuente, A., "Race, National Discourse, and Politics in Cuba: An Overview," in Latin American Perspectives, Vol. 25.3 (May 1998), pp. 43-69, and "Race and Inequality in Cuba: 1899-1981," in Journal of Contemporary History 30 (1995), pp. 131-168.

56 Helg, A., Our Rightful Share: The Afro-Cuban Struggle for Equality: 1886-1912, Chapel Hill (NC), University of North Carolina Press, 1995; Kutzinski, V., Sugar's Secret: Race and the Erotics of Cuban Nationalism, Charlottesville (VA), University Press of Virginia, 1993.

57 Moore, R., Nationalizing Blackness: Afro-Cubanismo and Artistic Revolution in Havana, 1920-1940, Pittsburgh, University of Pittsburgh Press, 1997. See also Anderson, Th., "Inconsistent Depictions of Afro-Cubans and Their Cultural Manifestations in the Early Poetry of Marcelino Arozarena," in Afro-Hispanic Review (Fall 2008), 9-44. 
and Candomblé in Brazil. This also reminds us that Brazil is often disregarded in Latin American Studies because it was colonized by the Portuguese and could not be considered under the same categories that were used to study the different contexts within so-called Spanish America.

For decades, the Journal of Negro History published many studies on African Americans in Latin America. Nevertheless, in an article on "The Status of the Negro in Northern South America," published in 1964, Randall Hudson complained that historians had "completely avoided identifying the Negro as a separate element in society. Unlike the Brazilians, who have written many studies on the influence of the Negro on Brazil, the studies produced in Venezuela, Colombia, and Ecuador relate only to slavery and abolition." ${ }^{58}$ Four decades later, in 2006, Ben Vinson III would show a positive increment in research and publications dealing with Blackness and the African American experience in Latin America. Yet, he came to a similar conclusion: "Still, to the best of my knowledge, apart from Brazil, there were limited attempts to bridge the evolving diasporic discourse in Black Studies with emerging Latin American research on blackness." ${ }^{29}$ These considerations give us an occasion to turn our attention to research on African Americans within Brazilian Studies.

\section{d) Brazilian Studies}

The African American experience in Brazil is similar, in many ways, to the cases of the United States and Cuba. In the same way as the term Afro-Latinos was used to highlight the particular situation of peoples of African descent in Latin America and Afro-Cuban was proposed to give visibility to African culture and influence in the Cuban community, the term Afro-Brazilian emerged in Brazil. These parallel developments provide a good case for an "Inter-(African-Latin-) American" perspective.

As in many other regions, slavery is the starting point of the African American experience in Brazil. Slavery brought ten times as many Africans to work in the regions once colonized by Portugal as to the parts colonized by Spain, France,

58 Hudson, R., “The Status of the Negro in Northern South America: 1820-1860," in The Journal of Negro History, Vol. 49, No. 4 (Oct., 1964), pp. 225-239, citation from p. 226.

59 Vinson III, B. and King, S., "Introducing the 'New' African Diasporic Military History in Latin America," special issue, Journal of Colonialism and Colonial History, Vol. 5:2 (2006), p. 11. 
Holland, and Britain. ${ }^{60}$ As a matter of fact, the displacement of Africans had already been explored earlier by Pierre Verger in his book Flux et Reflux de la traieté des Negres entre le Golfe de Benin et Bahia, du XVII au XIX siècle. ${ }^{61}$ The exact number of slaves who were brought from Africa or born in captivity is not known, and researchers have given various estimates ranging from 2,000,000 to $14,000,000$. Rather than relying on numbers, however, our discussion can focus on examples of African American cultural expressions and forms of resistance against slavery and other forms of oppression that prompted the African and African American resistance in Brazil.

One early example of resistance is a series of maroon communities, quilombos, established deep in the jungle, to where the escaped slaves fled, especially in the Brazilian Northeast. The most famous of them was the "Palmares Quilombo" in the state of Pernambuco, whose leader was Zumbi. Forty runaway slaves formed Palmares in 1604 and resisted decades of constant attacks by the Dutch and the Portuguese, until their settlement was destroyed and Zumbi was killed on November $20,1695 .{ }^{62}$ Similar to other movements that wanted to establish a political structure independent of the nation, ${ }^{63}$ the quilombos were considered an "African Republic" within Brazil and, therefore, could not be tolerated. ${ }^{64}$

60 Curtin, R., The Atlantic Slave Trade: A Census, Madison, University of Wisconsin Press, 1969 , p. 268. There is an ongoing discussion about the underestimated numbers of the slave trade in Brazil. See Horne, G., The Deepest South: The United States, Brazil, and the African Slave Trade, New York, New York University Press, 2007, p. 28.

61 Verger, P., Flux et Reflux de la traieté des Negres entre le Golfe de Benin et Bahia, du XVII au XIX siècle, Paris, Mouton, 1968. See also Verger, P., Orixás: Deuses Iorubás na África e no Novo Mundo, Salvador, Corrupio, 1981.

62 Freitas, D., Palmares: A Guerra dos Escravos, Rio de Janeiro, Ed. Movimento, 1982. For a general view see Chiavenato, J., O Negro Brasileiro: Da Senzala à Guerra do Paraguay, Sao Paulo, Brasiliense, 1987, especially p. 57. See also Kent, R. K., "Palmares: An African State in Brazil," in Journal of African History, no. 6 (1965), pp. 161-175; Schwartz, S., Slaves, Peasants, and Rebels: Reconsidering Brazilian Slavery, Urbana, University of Illinois Press, 1992; and Anderson, R., "The Quilombo of Palmares: A New Overview of a Maroon State in Seventeenth-Century Brazil," in Journal of Latin American Studies, Vol. 28, No. 3 [Brazil: History and Society] (Oct., 1996), pp. 545-566.

63 Cf. Nascimento, A., "Quilombismo: The African Brazilian Road to Socialism," in Asante, M.K. \& Asante, K.W. (eds.), African Culture: The Rhythms of Unity, Westport (CT), Greenwood Press, 1985.

64 Much has been written and much research is yet to be done on this theme, especially with an analytical differentiation between cangaço, quilombo and many messianic movements. See Queiroz, M.V., Messianismo e Conflito Social, Sao Paulo, Atica, 1981; 
Another example, related to urban contexts, is the formation of brotherhoods of former slaves. In the cities, a slave could buy his or her liberty (Alforria). For this reason, many cities contained a population of former slaves that outnumbered those of European origin. One of the few forms of association allowed to these former slaves were the religious brotherhoods and sisterhoods. The fact that many rebellions occurred in Brazilian colonial cities between 1780 and 1840 such as the Revolution of Tailors (1798); the Inconfidence in Minas Gerais (1789), the Revolution in Pernambuco (1817) and the Rebellion of the Malês (1835), indicates that these groups of Afro-Brazilians in urban settings were not merely members of religious groups but important part of an organized structure of resistance that involved a great number of individuals. ${ }^{65}$ Observing these events from an InterAmerican perspective would yield important information about revolutionary efforts, for similar events occurred all through the Americas decades before the revolution in Haiti. ${ }^{66}$ However, even though these rebellions involved different groups such as the bourgeoisie, workers, and slaves in the fight for independence, in the end those of African descent were left out of the nation-building process. Thus, in Cuba and elsewhere, the nation-building process enforced assimilation through miscegenation, hybridity, and syncretism as forms of "whitening" the country. ${ }^{67}$ Similarly, when emancipated slaves at the end of the nineteenth century had to find their place vis-à-vis an exclusivist Brazilian nationality, they had two

Monteiro, D.T., Os Errantes do Novo Século, Sao Paulo, Duas Cidades, 1974; Martins, J.S., Os Camponeses e a Política no Brasil, Petrópolis, Vozes, 1983.

65 Reis, J.J., Rebelião Escrava no Brasil: A História do Levante do Malês: 1835, Sao Paulo, Brasiliense, 1987. In the night of January 24, 1835, hundreds of slaves took to the streets of Salvador and were repressed by the police, in the largest slave rebellion ever to happen in the Americas. According to contested official numbers, seventy slaves were killed and fifty more were severely punished.

66 See, for instance, Genovese, E., From Rebellion to Revolution: Afro-American Slave Revolts in the Making of the Modern World, Baton Rouge (LA), Louisiana State University Press, 1979; Geggus, D. P., "Slave Resistance in the Spanish Caribbean in the Mid-1790s," in Gaspar, D.B. and Geggus, D.P. (eds.), A Turbulent Time: The French Revolution and the Greater Caribbean, Bloomington (IN), Indiana University Press, 1997; and Townsend, C., "'Half My Body Free, The Other Half Enslaved': The Politics of the Slaves of Guayas at the End of the Colonial Era," in Colonial Latin American Review 7, no. 1 (1998), pp. 105-128.

67 See Rodrigues, N., Os Africanos no Brasil [1904], Brasília, ed. Universidade de Brasília, 1988. For a description, see Skidmore, Th., Black Into White: Race and Nationality in Brazilian Thought, New York, Oxford University Press, 1974. For a recent critique, Schwarcz, L., O Espetáculo das Raças, São Paulo, Cia. das Letras, 1992. 
options: either separatism, as they turned to a utopian "African nation" (after having lost their connections to the African continent) or assimilation into the Brazilian syncretic model.

The third example of a strategy used by Afro-Brazilians to resist different forms of oppression can be seen in a new religion, which was a fictional way of establishing an imaginary location, an ideal African context within the Brazilian context. Because African culture was not taken as constitutive part of the nation-building process, and the negation of African identity and culture was implicit in the process of constructing a national identity in Brazil, African culture could survive mainly in a mythical niche occupied by this new religion: Candomblé. Based mostly on Yoruba cosmology, ${ }^{68}$ African religious beliefs persisted as one of the most influential West African worldviews in the New World and survived within the Catholic Church. ${ }^{69}$ Finally, the terreiros de candomblé were segregated and limited to suburban areas. This actually enabled Africans from different regions to organize themselves around their original language, religion, and culture in the periphery of society. Women were active participants in these associations, and it was three old ex-slave women who established the first terreiro de candomblé in the first half of the nineteenth century.

From a historical point of view - and according to the framework established at the outset - the quilombos, confrarias, and terreiros de candomblé represent three (rural, urban, suburban) ways of searching for the location of an African American identity in Brazil and of resistance to assimilation and reduction to a nationalist model at three different moments. The terreiro is a relevant example because it is a physical space, a consecrated location where rituals "take place" and people not only interact with each other, but also imagine an alternative African location. This particular experience is not isolated, but related to similar places in

68 Morton-Williams, P., "An Outline of the Cosmology and Cult Organisation of the Oyó Yoruba," in Africa 34, 1964, pp. 243-261; Bascom, W.R., Sixteen Cowries: Yoruba Divination from Africa to the New World, Bloomington, Indiana University Press, 1980; Barnes, S. (ed.), Africa's Ogun: Old World and New, Bloomington (IN), Indiana University Press, 1989; and Apter, D., Black Critics and Kings: The Hermeneutics of Power in Yoruba Society, Chicago, The University of Chicago Press, 1992.

69 See Nascimento, A. and Sathler, J., "Black Masks on White Faces: Liberation Theology and the Quest for Syncretism in the Brazilian Context," in E. Mendieta, L. Lorentzen, D. Batstone \& Hopkins, D. (eds.), Liberation Theology and Postmodernity in the Americas, London, Routledge, 1997, pp. 103-109. More recently, Matory, J.L., Black Atlantic Religion: Tradition, Transnationalism, and Matriarchy in the Afro-Brazilian Candomble, Princeton, Princeton University Press, 2005. 
Haiti, the United States, Jamaica, and Cuba. From an Inter-American perspective, these strategies can be related to similar processes all over the Americas. Moreover, in all of these cases there is a dimension of spatiality at play, as the location of these forms of resistance is always in the periphery of society, a process that can be observed concomitantly in several places. This perspective, however, did not seem to have had a strong impact on Brazilian Studies.

The first studies on Afro-Brazilians relied on anthropological research and defended a cultural syncretism. As Sílvio Romero affirmed in a polemical tone, "[a]ll Brazilians are mestizos, if not in their blood, for sure in their ideas."70 At the beginning of the twentieth century, the focus was on the scientific syncretism of the positivism promoted at military academies, which created scientific centers, museums, research institutes, and hospitals that turned to biological categories and concentrated their interest on the "racial question." Disciplines at the turn of the century such as phrenology, eugenics, anthropometry, craniology, criminology, and ethnology followed Darwinist determinism to establish a hierarchy of the races and arrive at the synthesis of "racial perfectibility" through the Americas. ${ }^{71}$ Beyond this model, an alternative approach to the study of Afro-Brazilians emerged when Gilberto Freyre published Casa Grande \& Senzala in 1933, a book in which he reconstructed the different aspects of Brazilian culture (food, health, climate, etc.) to see how they came to a synthesis in the "conciliation of the races."72 Despite his emphasis on the "sexual ethics" that allowed such a mestizaje and led to

70 Romero, S., O Naturalismo em Literatura, São Paulo, Lucta, 1882, pp. 85, 149. These ideas have parallels beyond the Brazilian boundaries, as for example in Argentina where José Ingenieros defended ethnical cleansing - and in Mexico - where the hybrid inheritance of the Malinche was defined in terms of a proud "cosmic race" by the philosopher José Vasconcelos. Therefore, despite their defense of something purely Latin American, there is a need to be cautious with these thinkers and recognize that they remained tied to the prejudices of their time. Although their position may represent a critique of Eurocentrism already at that time, they still maintain a hierarchical view of the "races" proper to positivism.

71 Schwarcz, L., O Espetáculo das Raças, pp. 43-66. This utopia of a "perfect race" is a complementary element of what Franz Hinkelammert criticized as the conservative doctrine of "cosmic mimesis" and "perfect plausibility" at the economic and political level - see Crítica a la razón utópica, San José, DEI, 1984, pp. 47-52 - and rests on the same metaphysical assumptions behind positivistic "social engineering." However, the relation of this issue to slavery in the Americas is a topic that still needs to be examined.

72 Freyre, G., Casa Grande \& Senzala [1933], Rio de Janeiro, J. Olympio, 1987. For a critique cf. Fernandes, Fl., A Integração dos Negros na Sociedade de Classes, São Paulo, Ed. Ática, 1978. 
the "racial democratization of the country", and despite his sympathetic interpretation of the African influence in Brazil, he was later criticized by a whole generation of Marxist sociologists who questioned the idea of "racial democracy" and highlighted the exploitation of African Americans at the bottom of a class society. ${ }^{73}$

Still, the questioning of these assumptions required the consideration of and comparison to other contexts, but those conducting research in the field of what was later called Brazilian Studies still focused on nationalistic models that did not allow them to see the bigger picture. In this context, we can see the polemic relevance of the so-called Brazilianists, scholars who were funded by agencies in the United States to develop comparative studies in Brazil. One of the most important publications by Brazilianists, Thomas Skidmore's Black into White, was one of the first studies to systematically review theories on "racial democracy," show their implications, and question their assumptions. What is often forgotten, however, is the need to take into account a series of events related to the civil rights movement in the United States, which inspired Skidmore to question the widely held beliefs of many scholars on Brazil. ${ }^{74}$

This brief overview of the field of Brazilian Studies and the consideration of Afro-Brazilians within it is enough to highlight several aspects: First, the African American experience is marked by the challenge of slavery, but it is not limited to this historical event. Rather, challenges are renewed by new strategies and events that are often forgotten in contemporary studies. Secondly, we can also see the importance of interlocation here. What we see in Brazil is not only the dislocation of African Americans to the periphery, but also the dislocation of theoretical perspectives that force the comparison with other experiences that shed light on topics that do not seem to be caught by an internal view. Finally, we can observe an inter-American interaction of various elements (cultural, geographical, and political, among others), that result in a shift of perspective, such as the consideration

73 See Fernandes, A Integração dos Negros na Sociedade de Classes, and Cardoso, F.H., Capitalismo e Escravidão, São Paulo, Difusão Européia do Livro, 1962. Cardoso, who was elected Brazilian president in 1994, was the first politician to publicly recognize and to address the issue of racism in Brazil. See also Thales de Azevedo, Cultura e Situação Racial no Brasil, Rio de Janeiro, Civilização Brasileira, 1966; Moura, C., O Negro: De Bom Escravo a Mal Cidadão?, Rio de Janeiro, 1977; Ianni, O., Escravidão e Racismo, Sao Paulo, Atica, 1978; Nascimento, A., O Genocídio do Negro Brasileiro, Rio de Janeiro, Paz e Terra, 1978.

74 See Skidmore's interview reflecting on these issues in Dávila, J. and Morgan, Z., "Since Black into White: Thomas Skidmore on Brazilian Race Relations," in The Americas, Vol. 64, Number 3, January 2008, pp. 409-423. 
of Afro-Brazilians through the lenses of the civil rights movement in the United States. This interlocation is both theoretical and practical because it refers to experiences that are not simply limited to Brazil, but need to be understood in a wider perspective across the Americas. This is what prompts us to go beyond the limits of Brazilian Studies and nationalist boundaries in search of an Inter-American framework of interpretation. The Brazilian case leads us back, therefore, to our initial considerations on Inter-American Studies.

\section{What is Inter in Inter-American Studies?}

In this essay, I have focused on the specific case of African Americans in several parts of the Americas and performed a brief tour through the continent. In this attempt at seeing the bigger picture that is often neglected, we can not only reflect on several locations that are generally seen in terms of nationalist categories, but also observe the different fields of study that center their attention on particular issues, themes, and geographies. Following recent discussions and questions concerning the limits, reach, and meaning of American Studies, it is possible to consider some key points that have emerged in African American Studies, the concept of the "Black Atlantic," Caribbean Studies, Latin American Studies, and studies on Brazil. In each case, I hope to have shown not only the particularity of each area, but also its limitations as well as its complementarity with other fields of research. Although my attempt runs the risk of erasing boundaries and becoming vague or unspecified, I centered my attention on the African American experience and used this topic as the measure to guide our explorations.

I have also made a proposal for an Inter-American framework, with a set of criteria that would allow us to move in and out of these different areas of study and geographic contexts. While acknowledging the promises and perils of terms such as diaspora, syncretism, and multiculturalism, I decided to move beyond these categories and affirm the need for a plurality of voices and experiences. Thus, the test performed at each stage was based on a simple question: what had been forgotten or neglected when particular areas of study dealt with aspects of the African American experience throughout the continent? First, I pointed to the ambiguity of the very term "African American" and proposed to expand it, using it to refer to all of the Americas - although I eventually used terms such as Afro-Cubans and Afro-Brazilians. I also noticed that African American Studies has generated a series of important discussions focusing on slave narratives, individual and collective identities, and gender issues, a positive movement of inclusiveness that needs to be expanded to include the African American experience in other contexts. Similar considerations led to a discussion of the concept of the "Black Atlantic" and its 
application to highlight the continuous diasporic movement of African Americans between different locations. In reconstructing these journeys, however, I observed the need for more archeological work to rescue lost connections.

This alone would be a good argument in favor of the need for a wider framework to guide interactive studies and more communication among disciplines. The diagnostics is simple: There is information available, there is archeological and genealogical evidence, there are vestiges of previous interactions, but the urge for specialization and a concomitant focus on very specific topics or national markers blocks the possibility of communication and the perception of wider systemic structures at play. In each case, it was possible to detect problems in narrowing structures and promises in interactions. Thus, I conclude that it is possible and necessary to search for a wider framework such as the one proposed here in terms of an Inter-American perspective.

Nonetheless, we should not limit our attention to these examples. Going beyond the focus on North America and the Caribbean and applying this same InterAmerican framework, we can ask the same questions again and detect missing elements in many other fields. In the same way the role of Haiti and its revolution has been neglected for decades - as the fate of that country is seen as an isolated event disconnected from similar events in Ecuador, Cuba, the United States, and Uruguay - we also find many Afro-Cuban elements neglected that have been coming to light only recently. Similarly, only recently have we seen a few discussions on Afro-Latinos, a field that will certainly emerge as an important area of research to shed new light on the history and contemporary situation of African Americans in what was once called Spanish America. For sure, much of this awakening is the result of the application of new categories developed in the United States with the emergence of African American Studies. However, studies on Afro-Latinos in all of the Americas should also influence the way African American Studies are performed in the United States. This is especially relevant in the context of recent waves of immigration and the growing importance of Latinos and Latinas, Chicanos and Chicanas, as well as the so-called Hispanics and ethnic communities from other countries in the Americas that are now captured in data generated by the United States Census Bureau. This interaction will also illuminate the relations between the United States and Haiti in the 1800s, the liberating strategies exercised by Simón Bolivar in what was once seen as "one America," the connections between the United States and Brazil in the slave trade, the roles of slaves and former slaves at revolutionary moments, and the persistence of conditions of poverty, exploitation, and segregation in several locations. Moreover, events such as the election of Barack Obama as President of the United States certainly generated other possible connections that need to be studied. 
Finally, I related this discussion to African American Studies in Brazil. In showing the practical example of quilombos, confrarias, and terreiros de candomblé, I argued that the actualization of the struggle against racism in different stages, presupposes a construction and reconstruction of non-reductive spaces and locations in particular contexts. This, however, is not particular to Brazil, but similar to other places in the Americas where African Americans experienced the diaspora as a process of displacement, were exploited by the practices of slavery, were forced to become assimilated by the strategies of syncretism, and still struggle for recognition and citizenship. From a theoretical point of view, we could also show the limits of studies that focus on Afro-Brazilians but see them within the boundaries of national perspectives.

These cases and examples offer good justifications for an Inter-American framework and perhaps even a defense of Inter-American Studies. If we focus on the African American experience and use this wider framework, what comes into view is the displacement, appropriation, and non-recognition of claims that reveal any connection with Africa - because they appear to contradict what is considered American - anywhere, from Argentina to Canada. Thus, an Inter-American framework expands our views of the African American experience. Similarly, an African American perspective that is informed by a reflection on the diaspora, syncretism, and multiculturalism makes us aware of the need to uphold plurality and may influence the definition of Inter-American Studies. The issue is no more the affirmation of a pure identity and culture in terms of ethnicity, nationality, or race, but the coming in and out of different spaces and locations that can be understood as simultaneous and interactive.

Taken in its broader aspects, Inter-American Studies may become a powerful interdisciplinary tool that brings together historical, literary, artistic, linguistic, anthropological, and philosophical issues at once and is not limited to questions of individual and national identity. The focus on the African American experience, in turn, is a good test case to evaluate the applicability of this tool.

\section{Conclusion: An Experiment in Interlocation}

There is no doubt that the African American experience in the Americas is a case of constant dislocation - in the widest sense of the term. This creates great difficulties for American Studies, especially if this field is understood in its traditional fashion and focused on one specific geographical location. One of the greatest challenges in studying the African American experience is the fact that the focus of study is a moving target that transcends boundaries and refuses to become assimilated. What I tried to show is that American Studies alone does not seem to be 
able to capture the variety of issues at play in this constant movement. Similarly, Brazilian Studies seems to fail in this same task. These fields certainly provide important insights and complementary information, but still miss the interactions that occur among displaced subjects, beyond given borders. The attempt to use an Inter-American framework to capture the neglected or unseen elements of the African American experience appears, therefore, as a great research opportunity. Inter-American Studies could help us to understand what happens "in between" and connect the dispersed, diasporic locations. This attempt is what I call an experiment in interlocation that connects American, African, and Latin American elements.

When we evaluate these approaches, it becomes clear that a process of complementary and mutual criticism is possible, provided that these different discourses are recognized and related to a wider framework that transcends their previous limitations and borders without losing sight of the real interlocutors. This is neither a focus on the location of culture nor simply a trans-location that shifts meanings, subjects, and events, displacing them to other locations. The emphasis here is on the connector "inter," which becomes relevant as an important practical element that complements the theoretical aspect of Inter-American Studies. Besides the local and the trans-local, we need to acknowledge interlocation as the insertion of different American identities and discourses in between these different elements, interstices, and spaces. These insertions need to make sense of other types of relations and interactions that can be interpersonal, international, intercultural and interesting, instead of being limited by old geopolitical markers.

\section{Works Cited}

Aguirre, C. Agentes de su propia libertad: Los esclavos de Lima y la desintegración de la esclavitud: 1821-1854. Lima, Pontificia Universidad Católica del Perú: Fondo Editorial, 1993.

Anderson, R. "The Quilombo of Palmares: A New Overview of a Maroon State in Seventeenth-Century Brazil." Journal of Latin American Studies 28.3 (Oct. 1996): 545-566.

Anderson, Th. "Inconsistent Depictions of Afro-Cubans and Their Cultural Manifestations in the Early Poetry of Marcelino Arozarena." Afro-Hispanic Review (Fall 2008): 9-44.

Andrews, G.R. Afro-Latin America: 1800-2000. New York: Oxford University Press, 2004.

Andrews, G.R. "Afro-Latin America: The Late 1900s." Journal of Social History 28.2 (Winter 1994): 363-379. 
Andrews, G.R. The Afro-Argentines of Buenos Aires: 1800-1900. Madison (WI): University of Wisconsin Press, 1980.

Appiah, A., and Gutmann, A. Color Conscious: The Political Morality of Race, Princeton: Princeton University Press, 1996.

Apter, D. Black Critics and Kings: The Hermeneutics of Power in Yoruba Society. Chicago: University of Chicago Press, 1992.

Aptheker, H. American Negro Slave Revolts. New York: International Publishers, 1963.

Barnes, S., ed. Africa's Ogun: Old World and New. Bloomington (IN): Indiana University Press, 1989.

Bascom, W.R. Sixteen Cowries: Yoruba Divination from Africa to the New World. Bloomington: Indiana University Press, 1980.

Baynes, K. "Freedom and Recognition in Hegel and Habermas." Philosophy and Social Criticism 28.1 (2002).

Bennett, H. "The Subject in the Plot: National Boundaries in the History of the Black Atlantic." African Studies Review 43.1 (2000): 101-24.

Bennett, H. Africans in Colonial Mexico: Absolutism, Christianity and Afro-Creole Consciousness: 1570-1640. Bloomington: Indiana University Press, 2003.

Bhabha, H. The Location of Culture. New York: Routledge, 1994.

Bowser, F. "The African in Colonial Spanish America: Reflections on Research Achievements and Priorities." Latin American Research Review (LARR) 7.1 (1972): 77-94.

Butler, K. Freedoms Given, Freedoms Won: Afro-Brazilians in Post-Abolition São Paulo and Salvador. New Brunswick (NJ): Rutgers University Press, 1998.

Cardoso, F.H. Capitalismo e Escravidão. São Paulo: Difusão Européia do Livro, 1962.

Chambers, D. "Ethnicity in the Diaspora: The Slave-Trade and the Creation of African 'Nations' in the Americas." Slavery \& Abolition 22.3 (2001): 25-39.

Chiavenato, J. O Negro Brasileiro: Da Senzala à Guerra do Paraguay. Sao Paulo: Brasiliense, 1987.

Curtin, R. The Atlantic Slave Trade: A Census. Madison: University of Wisconsin Press, 1969.

Daniel, Ph. "Black Studies: Discipline or Field of Study?" The Western Journal of Black Studies 4 (Fall 1980): 195-99.

Dash, J.M. "Farming Bones and Writing Rocks: Rethinking a Caribbean Poetics of (Dis)Location." Shibboleths: Journal of Comparative Theory 1.1 (2006): 64-71.

Dávila, J. and Morgan, Z. "Since Black into White: Thomas Skidmore on Brazilian Race Relations." The Americas 64.3 (January 2008): 409-423. 
Davis, A. "Reflections on the Black Woman's Role in The Community of Slaves." The Black Scholar 3.4 (Dec. 1971): 3-15.

Davis, A. Women, Race, and Class. New York: Vintage, 1983.

De Azevedo, Th. Cultura e Situação Racial no Brasil. Rio de Janeiro: Civilização Brasileira, 1966.

De la Fuente, A. "Race and Inequality in Cuba: 1899-1981." Journal of Contemporary History 30 (1995): 131-168.

De la Fuente, A. "Race, National Discourse, and Politics in Cuba: An Overview." Latin American Perspectives 25.3 (May 1998): 43-69.

De la Fuente, A. A Nation For All: Race, Inequality, and Politics in TwentiethCentury Cuba. Chapel Hill (NC): University of North Carolina Press, 2001.

DeGuzmán, M. Spain's Long Shadow: The Black Legend, Off-Whiteness, and AngloAmerican Empire. Minneapolis: University of Minnesota Press, 2005.

Delany, M. The Condition, Elevation, Emigration and Destiny of the Colored People of the United States, Politically Considered. Philadelphia: n.p., 1852.

Díaz, M.E. The Virgin, the King, and the Royal Slaves of El Cobre: Negotiating Freedom in Colonial Cuba, 1670-1780. Stanford: Stanford University Press, 2000.

Douglass, F. The Life and Writings of Frederick Douglass. 1854. Ed. Ph. Foner. New York: International Publishers, 1950.

Dubois, L. A Colony of Citizens: Revolution and Slave Emancipation in the French Caribbean: 1787-1804. Chapel Hill (NC): University of North Carolina Press, 2003.

DuBois, W.E.B. The Souls of Black Folk: Essays and Sketches. Chicago: A.C. McClurg \& Co., 1903.

Falola, T. and Childs, M., eds. The Yoruba Diaspora in the Atlantic World. Bloomington: Indiana University Press, 2004.

Fernandes, Fl. A Integração dos Negros na Sociedade de Classes. São Paulo: Ed. Ática, 1978.

Fitz, E. Rediscovering the New World: Inter-American Literature in a Comparative Context. Iowa City: University of Iowa Press, 1991.

Franklin, J.H. "On the Evolution of Scholarship in Afro American History." In The State of Afro-American History. Ed. Clark Hine, D. Baton Rouge (LA): Louisiana State University Press, 1986. 13-22.

Freitas, D. Palmares: A Guerra dos Escravos. Rio de Janeiro: Ed. Movimento, 1982.

Freyre, G. Casa Grande \& Senzala. 1933. Rio de Janeiro: J. Olympio, 1987.

Gates Jr., H. Figures in Black: Words, Signs and the 'Racial Self.' New York: Oxford University Press, 1985. 
Geggus, D. P. "Slave Resistance in the Spanish Caribbean in the Mid-1790s." In A Turbulent Time: The French Revolution and the Greater Caribbean. Ed. Gaspar, D.B. and Geggus, D.P. Bloomington (IN): Indiana University Press, 1997.

Genovese, E. From Rebellion to Revolution: Afro-American Slave Revolts in the Making of the Modern World. Baton Rouge (LA): Louisiana State University Press, 1979.

Gilroy, P. The Black Atlantic: Modernity and Double Consciousness. Cambridge (MA): Harvard University Press, 1993.

Habermas, J. Der philosophische Diskurs der Moderne. Frankfurt/Main: Suhrkamp, 1985.

Hall, G. Slavery and African Ethnicities in the Americas: Restoring the Links. Chapel Hill (NC): University of North Carolina Press, 2005.

Hegel, G.F. Werke. Frankfurt/Main: Suhrkamp, 1979.

Helg, A. Liberty and Equality in Caribbean Colombia: 1770-1835. Chapel Hill (NC): University of North Carolina Press, 2004.

Helg, A. Our Rightful Share: The Afro-Cuban Struggle for Equality: 1886-1912. Chapel Hill (NC): University of North Carolina Press, 1995.

Henry, P. Caliban's Reason: Introducing Afro-Caribbean Philosophy. New York: Routledge, 2000.

Herrera, R. Natives, Europeans, and Africans in Sixteenth-Century Santiago de Guatemala. Austin (TX): University of Texas Press, 2003.

Heywood, L., ed. Central Africans and Cultural Transformations in the American Diaspora. Cambridge: Cambridge University Press, 2002.

Hidalgo, N. "Las creencias de origen africano en el Nuevo Mundo." Afro-Hispanic Review 26.1 (Spring 2007): 11-18.

Honneth, A. Kampf um Anerkennung. Frankfurt/Main: Suhrkamp, 1992.

Horne, G. The Deepest South: The United States, Brazil, and the African Slave Trade. New York: New York University Press, 2007.

Howard, D. Coloring the Nation: Race and Ethnicity in the Dominican Republic. Boulder (CO): Lynne Rienner, 2001.

Hudson, R. "The Status of the Negro in Northern South America: 1820-1860." The Journal of Negro History 49.4 (Oct. 1964): 225-239.

Hurlbut, G.C. "The Origin of the Name 'America." Journal of the American Geographical Society of New York 20 (1888): 183-196.

Ianni, O. Escravidão e Racismo. Sao Paulo: Atica, 1978.

Jackson, Richard L. Black Writers and Latin America: Cross-Cultural Affinities. Washington (DC): Howard University Press, 1998. 
Jackson, Shirley M. "Afro-Hispanic Literature: A Valuable Cultural Resource." Foreign Language Annals 11 (1978): 421-25.

James, C. L. R. The Black Jacobins: Toussaint L'Ouverture and the San Domingo Revolution. New York: Vintage Books, 1989.

Jefferson, T. A Summary View of the Rights of British America. Monticello. The Thomas Jefferson Memorial Foundation, 1993 [Monticello Monograph Series].

Kaplan, A. The Anarchy of Empire. Cambridge (MA): Harvard Univesity Press, 2002.

Kent, R. K. "Palmares: An African State in Brazil." Journal of African History 6 (1965): 161-175.

Kutzinski, V. Sugar's Secret: Race and the Erotics of Cuban Nationalism. Charlottesville (VA): University Press of Virginia, 1993.

Kymlicka, W. Multicultural Citizenship. Oxford: Clarendon Press, 1995.

Landers, J. Black Society in Spanish Florida. Urbana: University of Illinois Press, 1999.

Landers, J. “Gracia Real de Santa Teresa de Mose: A Free Black Town in Spanish Colonial Florida." American Historical Review 95.1 (February 1990): 9-30.

Larson, P.M. "African Diasporas and the Atlantic." In The Atlantic and Global History. Ed. Cañizares-Esguerra, G. and Seeman, E. New York: Prentice Hall, 2006.

Levander, C. and Levine, R. "Introduction: Hemispheric American Literary History." American Literary History 18.3 (2006): 397-405.

Lewis, G. "Theorising Race and Racism in an Age of Disciplinary Decadence." Shibboleths: Journal of Comparative Theory 1.1 (2006): 20-36.

Lewis, M. Afro-Hispanic Poetry 1940-1980: From Slavery to "Negritud" in South American Verse. Columbia (MO): University of Missouri Press, 1983.

Maddox, L., ed. Locating American Studies: The Evolution of a Discipline. Baltimore: Johns Hopkins University Press, 1999.

Martinez-Eschazabal, L. "Mestizaje and the Discourse of National/Cultural Identity in Latin America: 1845-1959." Latin American Perspectives 25.3 (May 1998): 21-42.

Martins, J.S. Os Camponeses e a Política no Brasil. Petrópolis: Vozes, 1983.

Matory, J.L. Black Atlantic Religion: Tradition, Transnationalism, and Matriarchy in the Afro-Brazilian Candomble. Princeton: Princeton University Press, 2005.

McClennen, S. "Area Studies Beyond Ontology: Notes on Latin American Studies, American Studies, and Inter-American Studies." A - Contra corriente. A Journal on Social History and Literature in Latin America 5.1 (Fall 2007): 173-184.

McClennen, S. “Inter-American Studies or Imperial American Studies?” Comparative American Studies 3.4 (2005): 393-413. 
Mendieta, E. Global Fragments: Latinamericanisms, Globalizations, Critical Theory. Albany (NY): State University of New York Press, 2007.

Mignolo, W. Local Histories/Global Designs: Coloniality, Subaltern Knowledges, and Border Thinking. Princeton: Princeton University Press, 2000.

Mignolo, W. The Idea of Latin America. Malden (MA): Blackwell, 2005.

Mills, Ch. The Racial Contract. Ithaca (NY): Cornell University Press, 1997.

Monteiro, D.T. Os Errantes do Novo Século. Sao Paulo: Duas Cidades, 1974.

Moore, R. Nationalizing Blackness: Afro-Cubanismo and Artistic Revolution in Havana, 1920-1940. Pittsburgh: University of Pittsburgh Press, 1997.

Moreno Fraginals, M. "Plantations in the Caribbean: Cuba, Puerto Rico, and the Dominican Republic in the Late Nineteenth Century." In Caribbean Slavery in the Atlantic World: A Student Reader. Ed. Shepherd, V.A. and Beckles, H. Princeton: Marcus Wiener Publishers, 2000. 494-505.

Morton-Williams, P. "An Outline of the Cosmology and Cult Organisation of the Oyó Yoruba." Africa 34 (1964): 243-261.

Moura, C. O Negro: De Bom Escravo a Mal Cidadão? Rio de Janeiro: n.p., 1977.

Nascimento, A. Review of Gracia, J. Latin/Hispanic Identity (Blackwell). Manuscrito (2000): 205-217.

Nascimento, A. "African (Latin) American Identities in Conflict." Peace Review (December 1997): 489-496.

Nascimento, A. “Quilombismo: The African Brazilian Road to Socialism." In African Culture: The Rhythms of Unity. Ed. Asante, M.K. and Asante, K.W. Westport (CT): Greenwood Press, 1985.

Nascimento, A. O Genocídio do Negro Brasileiro. Rio de Janeiro: Paz e Terra, 1978.

Nascimento, A. and Sathler, J. "Black Masks on White Faces: Liberation Theology and the Quest for Syncretism in the Brazilian Context." In Liberation Theology and Postmodernity in the Americas. Ed. E. Mendieta, L. Lorentzen, D. Batstone \& Hopkins, D. London: Routledge, 1997. 95-122.

Norment, N., ed. The African American Studies Reader. Durham (NC): Carolina Academic Press, 2001.

Nwankwo, I. Black Cosmopolitanism: Racial Consciousness, and Transnational Identity in the Nineteenth-Century Americas. Philadelphia: University of Pennsylvania Press, 2005.

Opie, F.D. "Black Americans and the State in Turn-of-the-Century Guatemala." The Americas 64.4 (April 2008): 583-609.

Pease, D. National Identities and Post-Americanist Narratives. Durham (NC): Duke University Press, 1994. 
Pease, D. and Wiegman, R., eds. The Futures of American Studies. Durham: Duke University Press, 2002.

Petras, E. Jamaican Labor Migration: White Capital and Black Labor: 1850-1930. Boulder (CO): Westview Press, 1988.

Porter, C. "What We Know that We Don't Know: Remapping American Literary Studies." American Literary History 6.3 (1994): 467-526.

Queiroz, M.V. Messianismo e Conflito Social. Sao Paulo: Atica, 1981.

Reis, J.J. Rebelião Escrava no Brasil: A História do Levante do Malês: 1835. Sao Paulo: Brasiliense, 1987.

Restall, M., ed. Beyond Black and Red: African-Native Relations in Colonial Latin America. Albuquerque (NM): University of New Mexico Press, 2005.

Rodrigues, N. Os Africanos no Brasil. 1904. Universidade de Brasília: Brasília ed., 1988.

Romero, S. O Naturalismo em Literatura. São Paulo: Lucta, 1882.

Rout, L. The African Experience in Spanish America: 1502 to the Present Day. London: Cambridge University Press, 1976.

Rowe, J.C., ed. Post-National American Studies. Berkeley (CA): University of California Press, 2000.

Sagás, E. Race and Politics in the Dominican Republic. Gainesville (FL): University of Florida Press, 2001.

Schwarcz, L. O Espetáculo das Raças. São Paulo: Cia. das Letras, 1992.

Schwartz, S. Slaves, Peasants, and Rebels: Reconsidering Brazilian Slavery. Urbana: University of Illinois Press, 1992.

Sheriff, R. Dreaming Equality: Color, Race, and Racism in Urban Brazil. New Brunswick (NJ): Rutgers University Press, 2001.

Skidmore, Th. Black Into White: Race and Nationality in Brazilian Thought. New York: Oxford University Press, 1974.

Sweet, J. Recreating Africa: Culture, Kinship, and Religion in the African-Portuguese World: 1441-1770. Chapel Hill (NC): University of North Carolina Press, 2003.

Taylor, Ch. Hegel and Modern Society. Cambridge: Cambridge University Press, 1979.

Taylor, Ch. et al. Multiculturalism and the Politics of Recognition. Princeton: Princeton University Press, 1992.

Tepaske, J. "The Fugitive Slave: Intercolonial Rivalry and Spanish Slave Policy, 1687-1764." In Eighteenth-Century Florida and Its Borderlands. Ed. Proctor, S. Gainesville (FL): The University Press of Florida, 1975. 1-12. 
Torres, A. and Whitten Jr., N., eds. Blackness in Latin America and the Caribbean: Social Dynamics and Cultural Transformations, Volume 2: Eastern South America and the Caribbean. Bloomington: Indiana University Press, 1998.

Townsend, C. "'Half My Body Free, The Other Half Enslaved': The Politics of the Slaves of Guayas at the End of the Colonial Era." Colonial Latin American Review 7.1 (1998): 105-128.

Twine, F.W. and Warren, J., eds. Racing Research, Researching Race: Methodological Dilemmas in Critical Race Studies. New York: New York University Press, 2000.

Verger, P. Flux et Reflux de la traieté des Negres entre le Golfe de Benin et Bahia, du XVII au XIX siècle. Paris: Mouton, 1968.

Verger, P. Orixás: Deuses Iorubás na África e no Novo Mundo. Salvador: Corrupio, 1981.

Vinson III, B., guest ed. "Special Issue: The African Diaspora in the Colonial Andes." The Americas 63.1 (July 2006).

Vinson III, B. and King, S. "Introducing the 'New' African Diasporic Military History in Latin America." Special issue of the Journal of Colonialism and Colonial History 5.2 (2006).

Wade, P. Blackness and Race Mixture: The Dynamics of Race Mixture in Colombia. Baltimore: Johns Hopkins University Press, 1993.

Walker, D. No More, No More: Slavery and Cultural Resistance in Havana and New Orleans. Minneapolis (MN): University of Minnesota Press, 2004.

Wasserstein, B. Vanishing Diaspora: The Jews in Europe since 1945. Cambridge (MA): Harvard University Press, 1996.

Whitten, N. and Torres, A., eds. Blackness in Latin America and the Caribbean. Bloomington (IN): Indiana University Press, 1998.

Wise, G. "'Paradigm Dramas' in American Studies: A Cultural and Institutional History of the Movement." American Quarterly 31.3 (1979): 293-337.

Wright, W.R. Café con Leche: Race, Class, and National Image in Venezuela. Austin (TX): University of Texas Press, 1990.

Young, I. Justice and the Politics of Difference. Princeton: Princeton University Press, 1990. 
Marietta Messmer and Armin Paul Frank - 978-3-653-98855-0 Downloaded from PubFactory at 01/11/2019 10:57:20AM via free access 


\section{University of Leipzig, Germany}

\section{Transnationality and Temporality in Early African American Texts}

Recent work in American Studies has sought to move beyond the paradigm of nationhood by investigating "transnational" or "postnational" spaces such as the Borderlands of the Southwest, the "Black Atlantic," and the Pacific Rim. As scholars such as Donald Pease, Paula Moya, and Ramón Saldivar have called for the invention of a radical political "trans-American imaginary" (Saldívar/Moya) that would account for the experiences of "deterritorialized and extraterritorial peoples" (Pease) they have suggested that a movement beyond the nation is also a movement away from a particular territory, implying that American nationalism is inherently territorial. This fixation in Transnational Studies on the (problem of the) territorial often goes along with what critic Anna Brickhouse has called the "presentism" of transnational analyses (Brickhouse 407) - i.e. the neglect of historical dimensions in the study of transnational phenomena. In fact most transnational critics have focused their investigations on rather recent developments, implying that, as Brickhouse observes, "literary transnationalism in the Americas and the critical perspectives it invites are natural outgrowths of the massive human migrations, urban pluralism, and cultural globalization the hemisphere has witnessed over the course of the twentieth century" (408). However, as she argues, many of the literary configurations that are linked by critics to the $20^{\text {th }}$ century, "were in fact addressed by writers in the Americas as explicit questions and problems well before the modern and contemporary periods to which they have largely been consigned" (408).

The fixation on space and the neglect of history in the study of transnationalism have also been a source of concern for scholars in the field of ethnic studies. In a debate about "Ethnic Studies in the Age of Transnationalism," led in a 2007 issue of the Modern Language Association's journal PMLA and based on a roundtable discussion during the 2006 MLA convention in Philadelphia, various scholars voiced their anxieties about what they perceived as an ongoing dehistoricization of ethnic experiences as a result of the "transnational turn." ${ }^{\prime}$ As traditional ethnic studies gradually become displaced by transnational studies, these scholars feared, the

1 On the "transnational turn" see e.g. Fisher-Fishkin, 2005, and Elliott, 2007. 
focus on the deterritorializing momentum of globalization and diasporic movements will obscure more traditional ethnic studies approaches that are invested in the task of returning to subjugated knowledges and experiences. As a result, these forgotten and dominated histories and local knowledges will remain unstudied. In this spirit, R. Radhakrishnan pointed out that it is "unconscionable to jump on the bandwagon of transnationalism when there is so much work to be done in local regions and forgotten and dominated histories" (809). Juana María Rodriguez observed that the institutional shift towards transnationalism has often been used "to erase or dismiss the continued intellectual and political necessity of ethnic studies as a discipline and area of specialization" (811). While it is not a question of positing ethnic studies against transnationalism, as Rodriguez advocated, it remains crucial to consider "multiple frames of inquiry" (ibid.) to understand the complexity of ethnic experiences. For scholars in African American Studies, as Mark Sanders suggested, the discourse of transnationalism fails to "account fully for the historical practice of transcontinental, transcultural, or comparative scholarship in African American studies and its links to activism" (912).

The tendency of transnational studies to privilege space over time complicates the investigation of early ethnic texts from a transnational perspective. Given that the critical vocabulary and the major strategic approaches of transnational studies have developed over the past few decades, the question arises what it means to look at transnationalism historically. Can we just replace national perspectives on earlier periods in American history and culture with transnational ones, and what do we gain by doing so? Taking up this question, Frank Kelleter has poined to the fact that a mere application of contemporary critical methods to the study of the early national period is not very productive. As he states, "transnational approaches [...] in their current form and institutionalization [...] trigger critical practices unable to answer - and sometimes even to ask - the relevant questions" (Kelleter 29). One reason for this, Kelleter observes, is that transnational scholarship usually proceeds from the assumption of a constructed coherent national identity (which it then sets out to deconstruct), without asking how and under which circumstances this construction has emerged (30). A historical transnational research, argues Kelleter, needs to study the conditions and specific situations guiding the emergence of the nation and of national identity constructions. The increased interest in the deconstruction of the ideological foundations of American exceptionalism has, however, according to Kelleter, privileged approaches that view the nation as an ideological fiction and whose main interest lies in exposing the nation to be not an inherent, but an "imagined community." Following this logic, the transnational study of ethnic experiences within the nation has largely focused on this deconstructive moment, privileging the "fuzzy edges" of the nation, e.g. the American 
Borderlands, as well as experiences of diaspora, migration and forced dislocation of ethnic peoples, as subjects of research.

In my essay I take up the question Kelleter puts forward - how to study transnational phenomena in a historical context - as well as the concerns voiced by scholars of ethnicity about the dehistoricization of ethnic experiences. I argue that it is necessary to complicate spatial approaches to nationality by an acknowledgment of the equally important function of temporality in the imaginative constructions of the nation. Moreover, I contend that the movement "beyond the nation" is not necessarily only a movement away from a particular territory but that it can also be a movement away from a particular temporal narrative. While territory and space have been immensely important in the construction of American nationality, the category of temporality has been almost completely displaced by spatiality in recent decades. I suggest that more attention needs to be paid to the diversity of temporal discourses in the construction of community and nationhood.This becomes particularly relevant in the early national period, an era when many narratives privilege time, not space, in the definition of collective identity. It is relevant, moreover, for the experience of "minority" groups, who only partially identified with the nation's tenets, often saw themselves excluded from citizens' rights and who developed their own "timelines" from which they made sense of their past experiences and visions of the future. ${ }^{2}$

Saskia Sassen has noted that "much of social science has operated with the assumption of the nation-state as a container, representing a unified spatiotemporality" (Sassen 215). To give a prominent example, one of the central premises in Benedict Anderson's concept of the nation as an imagined community is the idea that modern national groups move forward together through a shared historical simultaneity, based on the uniformity of time dictated by the clockwork rationality of the capitalist market. However, as scholars from Johannes Fabian to Thomas Allen have pointed out, time, no less that space, is culturally constructed. ${ }^{3}$ Unsurprisingly, then, the discourses of the early American nation fail to confirm the assumption of the nation-state as following a unified temporality. Rather they give evidence, as Thomas Allen observes, of a multiplicity of temporal narratives, which include both millennial and secular visions of time, and which display in many cases an intersection of different temporal modes (Allen 4). In the decades after the American Revolution, national identity was in the process of being negotiated among the

2 My interest in this issue was inspired by a workshop organized by Michelle Burnham at the 2009 Biennial Conference of the Early American Studies Association in Hamilton, Bermuda, which focused on the issue of "temporality and the revolution."

3 See especially Fabian, 1983, and Allen, 2008. 
various sections and groups of the population who translated their experiences of the new nation into their respective horizons of understanding and value systems. ${ }^{4}$ In this process, the different groups also brought different temporalities - ways of being in time and imagining one's position in time - into the debate. Research into these temporal discourses has barely started.

In order to explore how ethnic discourses of transnationalism are shaped and modified by temporal narratives in the early national period, I will focus on a body of texts written by African Americans in the period between the 1780s and the 1850s. These texts are specific in that they were written by free black subjects, that they were abolitionist in focus, and that many of them were speeches, lectures, and newspaper articles addressed to both black and white audiences, facts that need to be pointed out in view of the extraordinary diversity of black experiences and discourses in the period between the American Revolution and the Civil War. Harvard historian Walter Johnson refers to the complexity of visions emanating from the different circumstances African Americans found themselves in - depending on their free or enslaved status, their place of birth in Africa or the Americas, their religious convictions and a multitude of other factors - a complexity that also resulted in different ways of making sense of what was happening to them and how they tried to imagine themselves into time (Johnson 152). While slaves were often displaced into a temporal limbo where they remained intentionally deprived of a sense of their place in time, ${ }^{5}$ free African Americans (especially as they lived in the North) identified with the promise of liberation made by the Revolution, relating it to their own situation.

4 On the diversity of collective identity constructions in the post-revolutionary period, see e.g. Michael Warner, The Letters of the Republic: Publication and the Public Sphere in Eighteenth Century America, Cambridge, Harvard University Press, 1990; Bruce Burgett, Sex, Gender, and Citizenship in the Early Republic, Princeton, Princeton University Press, 1998; Linda Kerber, Women of the Republic: Intellect and Ideology in Revolutionary America, Chapel Hill, University of North Carolina Press, 1997; Joyce Appleby, Liberalism and Republicanism in the Historical Imagination, Cambridge, Harvard University Press, 1992; Gary B. Nash, Forging Freedom: The Formation of Philadelphia's Black Community, 1720-1840, Cambridge, Mass., Harvard University Press, 1988.

5 It is no coincidence that the beginning of Frederick Douglass' narrative emphasizes his own disorientation as a result of his ignorance about his date of birth and his ancestry. Significantly, many slave texts, e.g. spirituals, invested slaves' everyday lives with temporal purpose by reinterpreting the Christian narrative of exodus and salvation. They read the United States as Egypt Land where Africans suffered in bondage under a new Pharao before they would be saved. 
The texts I would like to investigate in the following display a marked divergence, in their temporal construction of history and in their spatial points of reference, from the white master narrative of providence and progress that privileged the American Revolution as a turning point taking Americans into modernity and which identified the United States as the epitome of progressive movement. African American writers such as John Marrant, Prince Hall, John Russwurm, William Wells Brown, James Holly, and Martin Delany produced spatiotemporal narratives that pointed to the failure of the U.S. American nation to include African Americans into its vision of progress, and that located a meaningful past and future - and in some cases a vision of the "promised land" - not in the United States, but in other parts of the hemisphere or the world. While many of these texts appropriated the dominant idioms of nationalism and millennialism, they developed a different spatiotemporal axis from that propagated by white nationalist writings, creating collective narratives that circled around the presence and absence of slavery.

In the years before and after the American Revolution, Anglo-American authors such as Joel Barlow, Hugh Henry Brackenridge, and Philip Freneau envisioned the Revolution as an event of epic proportions. In epic poems such as The Rising Glory of America, The Columbiad, or "The Vision of Columbus" they linked Christian and Enlightenment temporalities, combining the idea of progress in the context of America's quest for liberty and future happiness with earlier Puritan visions of America as a 'city upon a hill.' In American civil religion, the Revolution was commonly seen as the "final act of the Exodus from the old lands across the waters" (Bellah 176). Freneau's and Brackenridge's 1786 version of The Rising Glory of America ${ }^{6}$ creates a line from America's pre-Columbian past to its glorious millennial future. It positions Columbus at the beginning of a narrative of progressive history of the continent that culminates in a vision of the United States as a land predestined to be the site of a new paradise due to its 'innocent' character. In a similar vein, Joel Barlow's epic “The Vision of Columbus" (1787) has Columbus look both backward to the Incan civilizations and forward to the emergence of a magnificent American empire that eclipses the achievements of European civilization. These texts were based on the assumption of a progressive universal history the apex of which were the United States, a country designed to bring progress and civilization to the rest of the continent and the world.

6 The 1771 version of the poem differs slightly from the second version. For a closer inspection of the differences, see Wertheimer, 17-52. 
Free African Americans had also regarded the Revolution as a moment of promise (Sale 11) as it proclaimed, in the Declaration of Independence, that "all men are created equal." In the beginning, this promise seemed to come true at least for some black men. The spirit of the Revolution, coupled with black military service during the War of Independence, inspired a wave of manumission laws that freed several thousands of blacks. However, the position of the free black population within the new nation was a contested issue. While slavery, as David Brion Davis has shown, could be integrated into the national vision of innocence and progress - the proponents of slavery argued that slavery was economically productive and morally beneficial for African Americans, helping them to improve themselves -, free African Americans were an uncomfortable presence because they jeopardized the racial hierarchies based on the "natural" superiority of whites. In many Republican texts about liberty, justice, and equality, blacks therefore simply remained invisible. When they did become part of public discourse, they were usually framed as essentially different "others" who were not part of the national collective, and were thus excluded from the national temporal narrative of progress. At best, as the discourses of the colonization movement show, they could be exported back to Africa where they would not interrupt the vision of the progressive movement in the U.S. When the free black abolitionist authors under study here started writing themselves into space and time, their search for a relationship with their spatial surroundings as well as with their past and their search for a meaningful vision of the future became important factors in the way they positioned themselves in the new nation. While their narratives, in their rhetoric, intersected with those propagated by Anglo-American nationalist writers, they also differed in important aspects as they saw themselves unable to wholly share the dominant notion of the United States as an exceptional site or as a biblical city upon a hill. In their vision of America, the completion of God's will in the United States was still outstanding. Although the Revolution had brought that vision closer to fulfilment, it had left crucial work undone, since slavery still existed and African Americans were denied the basic rights of humanity. Black writers linked the idea of human progress to the necessity of an end to slavery; the enslavement of black Africans was incompatible with their idea of a civilized society. As a result, the United States emerge as a site of unfulfilled prophesy and of limitations in relation to more progressive regions in the hemisphere. As black abolitionists transgressed the spatial borders of the nation for the construction of a meaningful past and future, they perceived such civilized societies in the Caribbean and in South America. In their narratives, historical developments such as the Haitian slave rebellion and the foundation of the new Latin American republics became crucial temporal signifiers and symbols of a future free from slavery. 
One of the major early tools in crafting a consciously African-American genealogy based on biblical and historical evidence that allowed Blacks to articulate racial pride and to develop their own vision of progress was Black freemasonry. Prince Hall and John Marrant, a free black artisan and a preacher, were the founders of the first African Lodge of freemasons, one of the first institutions in Massachusetts to call for the abolition of slavery. After Hall had unsuccessfully petitioned to become a member of Boston's Masonic Lodge in 1775, he and fourteen other free black men succeeded in being initiated into a British Lodge and subsequently were allowed to form a Lodge of their own in 1784. Seven years later, Lodge no. 459 became a Grand Lodge in its own right, with Prince Hall as its first Grand Master and John Marrant as its chaplain. Achieving the status of a Grand Lodge gave Hall and his brethren the authority to create subordinate Lodges (Summers 553). Black freemasonry offered African-American males a way to social self-creation, allowing them to develop a self-image very different from the contemporary stereotype of blackness where, as Maurice $\mathrm{O}$. Wallace points out, the most common image of a black man was that of a fugitive slave (Wallace 61). In their speeches to the African Lodge that were delivered at public celebrations of Masonic holidays, Hall and Marrant countered the white supremacist narratives of the history of civilization and claimed for black peoples a central role in that history. They derived this role from the biblical prophesy in Psalms 68:31, which said that "Princes shall come out of Egypt; Ethiopia shall soon stretch out her hands unto God," and envisioned a glorious future for people of African descent.

In John Marrant's Sermon ${ }^{7}$ to the African Lodge preached on the occasion of the Festival of St. John the Baptist in June of 1789, he situates the ancient site of Paradise between four African rivers, ${ }^{8}$ as "the principal part of African Ethiopia." This gesture allowed Marrant to fashion African-Americans and the African Lodge of Freemasons as the rightful heirs of Paradise and the chosen people of God:

Concerning this garden, there have been different opinions about it by the learned, where it was, but the [sic] most of them agree that it was about the center of the earth, and that

7 A Sermon, preached on the $24^{\text {th }}$ Day of June 1789. Being the Festival of St. John the Baptist, at the Request of the Right Worshipful the Grand Master Prince Hall and the Rest of the Brethren of the African Lodge of the Honorable Society of Free and Accepted Masons in Boston by the Reverend Brother Marrant, Chaplain, Boston, 1789.

8 As Joanna Brooks (128) observes, the rivers Marrant refers to are Ganges, Nile, Euphrates, and Tigris. Marrant here signifies on the parallel histories of the Masonic orders, the Old Testament Patriarchs, and Western civilization which he claims for the African Lodge and for African Americans in general. 
the four rivers parted or divided the four quarters of the world [...] These are the four grand land marks which the all-wise and gracious God was pleased to draw as the bounds and habitation of all nations which he was about to settle in this world; if so, what nation or people dare, without highly displeasing and provoking that God to pour down his judgments upon them. - I say, dare to despise or tyrannize over their lives or liberties, or incroach on their lands, or to inslave their bodies.

To colonize, invade, enslave, or abuse the "nations" of this "African Ethiopia," even those scattered across the African diaspora, in Marrant's argument is to act against the order of Creation. Defying the notion of blacks as excluded from God's grace, this early instance of Ethiopianism, a concept that was later developed further by David Walker and other black abolitionists, provided the basis for a common sense of destiny and identification between African peoples in North America, the Caribbean, Europe, and on the African continent. ${ }^{9}$

It was Prince Hall, however, who, in his best-known speech, A Charge, Delivered at the African Lodge, at Metonomy, of 1797, not only situated the oppression of free blacks and slaves in the United States in a wider, circum-Atlantic context but who also included the ongoing slave rebellion in the West Indian Saint Domingue into his argument about the coming redemption of African peoples. In view of the liberationist struggle of Blacks on Haiti, he proposes that the situation for Africans in the U.S. might change soon:

[...] it now begins to dawn in some of the West-India islands; which puts me in mind of a nation (that I have somewhere read of) called Ethiopians, that cannot change their skin: but God can and will change their conditions, and their hearts, too; and let Boston and the world know, that He hath no respect of persons; and that the bulwark of envy, pride, scorn, and contempt, which is so visible to be seen in some and felt, shall fall, to rise no more. (Hall 1110)

As he integrates the revolt in the Caribbean into his vision of black destiny and future, Hall presents the revolt as an illustration of black agency endorsed by God. This interpretation of the rebellion in Saint Domingue as "dawn" and as a sign for hope sharply contradicts the presentations of the revolt in most contemporary public discourses, which linked the bloodshed of the Haitian Revolution to the pre-modern, backward, "primitive" nature of the Africans on the island. Bryan Edwards' report of the revolt, which was published in London in 1797 (the same year that Hall gave his speech) and found wide distribution, compared the black

9 Critics usually locate the beginnings of Ethiopianism in the nineteenth century, in texts by William Walker or Robert Alexander Young, but the roots of this transnational discursive tradition can be traced back to eighteenth-century texts such as Marrant's and Hall's. 
rebels to "famished tygers thirsting for human blood" (Edwards 63) and extensively dwelled on the atrocities committed by them which in his opinion, as in that of many of his contemporaries, were a result of the "primitive" nature of blacks. Like Africa, the Caribbean represented all those features that were incompatible with the concept of modernity and civilized republicanism: the primitive and the irrational, the tropical and the impulsive, the absence of manly virtues such as fortitude and self-control. The Caribbean, in other words, was frozen in its own backwardness and could never aspire to gain independence and self-government such as the United States had achieved.

Hall's text suggests just the opposite. His vision, in A Charge, of a divine history that endows black people with a special role recalls the millennialism that characterized much of the rhetoric surrounding the American Revolution in texts by white Americans of the era. But Hall appropriated this millennialist rhetoric for his own liberationist purposes, claiming that black people played an important part in a god-given history of struggle between tyranny and liberty, slavery and freedom. While white revolutionary writers saw the new American nation as the symbol of progress, liberty, and fulfillment, to Hall the slave rebellion in Saint Domingue, an event that sent shock waves of terror all over the slave-holding Americas, was a sign of God's Providence. Using the Ethiopianist vision of a future glory of black people, Hall linked the biblical vision of the Ethiopian princes to the rebellion in Haiti, proposing an empowering view of black future. The indication of a possible change of conditions - by the will of God - situates African Americans on a timeline that is meaningful in two ways: on the one hand it gave Hall's fellow Masons a vision of a better future, encouraging them to remain patient and hopeful at a time when they had scarce possibilities to effect a change of their conditions. On the other hand, it reminded a white audience of the limitations of their progressive narrative that sanctioned slavery and excluded blacks from citizenship. Describing the change of conditions in Saint Domingue as an act as natural as the change from night to day, Hall employs the same Enlightenment rhetoric as the proponents of the American Revolution before him:

My brethren, let us not be cast down under these and many other abuses we at present labour under: for the darkest is before the break of day. My brethren, let us remember what a dark day it was with our African brethren six years ago, in the French West Indies. Nothing but the snap of the whip was heard, from morning to evening. Hanging, breaking on the wheel, burning, and all manner of tortures were inflicted upon those unhappy people [...] But, blessed be God, the scene is changed. (Hall 1112-1113, italics mine)

Drawing attention to the fact that the Haitian Revolution and the final liberation of blacks in the United States follow natural laws while the present conditions 
under which blacks live are connoted as "unnatural," Hall links his biblical discourse with the natural law rhetoric of revolutionary public narratives, claiming the ideals of the American Revolution for the Revolution in Haiti and assuring his readers of the inevitability of a change not only for Haitian slaves but also for U.S. American blacks.

Whereas in the oppressive social climate of the 1790s, Hall was one of the very few African Americans who wrote about the Saint Domingue rebellion, by the 1820s the successful revolution in Haiti and the black republic rising from it had grown to be a discursive presence in many black writings. Freedom's Journal, the first newspaper compiled and published by African Americans, stands out as a forum for the distribution of black thought in this early period. Co-edited by John Russwurm and Samuel Cornish between 1827 and 1829, it provided international, national, and regional information on current events and contained editorials denouncing slavery, lynching, and other injustices. Many articles in Freedom's Journal continue to revise the U.S. American narrative of progress in the early $19^{\text {th }}$ century by locating hopes for the future not in the United States but in the Caribbean as well as in Latin America. While both regions in this period, as the expansionist venture takes shape, emerge as signifiers of savagery and premodernity in Anglo-American nationalist discourses, in African American texts they become sites where the promise of a liberated future has already been fulfilled.

In the inaugural editorial of Freedom's Journal, Cornish and Russwurm claim that their cause was inspired by "the establishment of the Republic of Hayti" as well as by "the advancement of liberal ideas in South America, where despotism has given place to free governments, and where many of our brethren now fill important civil and military stations" (Russwurm and Cornish 1). Both Haiti and the new Latin American republics that had gained independence from Spain in the 1820s (Mexico, Colombia, and Brazil) emerge as sites promising a future for people of African descent. All three states had abolished or at least announced the intention to abolish slavery. References to the West Indies and to Latin America continue to emerge in subsequent issues. On April 20, 1827, an undisclosed New York contributor to Freedom's Journal reminds readers of the promise of liberty contained in the Declaration of Independence and the clash between this promise and the reality in the U.S.:

The truth is, the new Republics of North and South America have set us an example on the subject of slavery, which we should do well to imitate, under such modifications as our peculiar circumstances render necessary. If we remember right, the last slave in Colombia is to be emancipated within the present year. Peru has essentially lightened the burdens that for centuries have oppressed the poor Indians; and Mexico evinces, by her decision in enforcing the law in [sic] behalf of enslaved Africans, that she is determined not to be 
behind her sister Republics in this cause of justice, humanity and religion. Meanwhile the United States, where the torch of liberty was first kindled - the United States, who claim to be the freest and happiest people on the face of the earth, are cherishing in their bosom nearly 3,000,000 of wretched slaves, and as a nation, are doing nothing to mitigate the evil! (Freedom's Journal, April 20, 1827, n.p.)

Presenting the Latin American republics as exemplary in their implementation of human equality, the author lets the United States appear as lagging far behind her neighbors on the continent in terms of basic democracy. Contrary to the image of Latin America as a backward place in Anglo-American writings, the region here emerges as a point of comparison that embodies a future still denied to African Americans in the United States.

In an editorial published in December, 1828, John Russwurm declared: “The Haytians [...] have fought the good fight of Liberty and conquered; and all that is now required of them is to enjoy this invaluable blessing, as accountable beings," and calls the Haitians a people that can "look forward to what man, even the descendant of Africa, may be, when blessed with Liberty and Equality and their concomitants" (Russwurm 1828, n.p.). Black authors writing in Freedom's Journal also focused on the leader of the Haitian rebellion, Toussaint L'Ouverture, as a hero of the black community who was seen as proof of the dignity and heroism and of the intellectual capabilities of black people as well as of the progressive development on Saint Domingue. By lionizing Toussaint L'Ouverture as an example of black virtue, black writers were able to counter the assumption of black inferiority and backwardness. The May 4, 1827 issue of Freedom's Journal contains an article on Toussaint L'Ouverture by the pseudonymous writer "Africanus." In this text, the black revolutionary leader is presented as an example for the "splendor of native and original greatnesse" (Africanus, "Hayti, No. III") of the black people of Saint Domingue. L'Ouverture is called "one of the most extraordinary men of his age" and a "Spartacus." The writer takes pains to construct him as a character "marked by sedateness and patience of temper" (ibid.) and as an emblem of discipline, thus rejecting the image of Toussaint L'Ouverture as a bloodthirsty and violent black rebel that dominated white press reports on the rebellion. Using the black leader as an epitome of virtue, "Africanus" counters the racist notion that blacks are creatures lacking humanity and intellect. "The transactions in that Island," he states, "have presented the most incontestible [sic] proofs, that the negro is not, in general, wanting in the higher qualifications of the mind" (ibid.).

The potential for their own future that U.S. blacks saw in Haiti also becomes visible in the writings of David Walker, arguably the most radical of the 1820s black abolitionists and the Boston agent for the distribution of Freedom's Journal. In one of his addresses to the black community in Boston which was printed in 
the journal, Walker referred to Haitians as "our brethren" and announced that blacks will soon "take a stand among the nations of the earth," and that "God has something in reserve for us which [...] will repay us for all our suffering and miseries" (Walker 1828, 205/206). In his much more radical Appeal to the Colored Citizens of the World (1829), which was a call for slaves to revolt against their masters, he referred to Haiti as "the glory of the blacks and terror of tyrants" (Walker 1829), advising African Americans who wanted to leave the country to "go to our brethren, the Haytians, who, according to their word, are bound to protect and comfort us" (ibid.). Walker believed that in the case of a black rebellion in the U.S., the Haitians would support the struggles of U.S. blacks. This was not an uncommon conviction among black insurgents, as is pointed out by Walter Johnson when he observes that the black slave rebel Denmark Vesey imagined his own history as a continuation of the revolution begun in Haiti (Johnson 158). Quoting from the official report about the slave conspiracy organized by Vesey in South Carolina, Johnson stresses that Vesey recruited slaves for his rebellion by reading to them newspaper reports about the Haitian Revolution and by advertizing that he had written to Haiti for military support. Vesey also referred to Haiti as a model for the way in which he envisioned the revolt to be carried out. Asked by his fellow-conspirators if they should also kill ministers, women, and children, he responded in the affirmative because "this was the plan they pursued in St. Domingo" 10 (Johnson 159). This radical rebel thus saw himself as executor of a revolutionary idea that had its origin in the Caribbean but that would spread in the United States, bringing liberty to black people there as it had on Saint Domingue. Moreover, Vesey also framed the experience of African American slaves in the biblical context of the exodus narrative, advising the exodus of black slaves to Haiti once the rebellion had succeeded. He even tried to make contact with the Haitian president Jean Pierre Boyer, sending a letter to him via a middleman and requiring his assistance (Kennedy and Parker 70-71). Apparently, as witnesses in court testified, Vesey expected armed Haitian vessels to escort and protect African Americans when they sailed from the United States (Pearson 187).

10 In this period, both the French name of the island and the Spanish name - St. Domingo or Santo Domingo - were used. While the entire island of Hispaniola had been in Spanish possession until the $17^{\text {th }}$ century, at the time when the slave rebellion broke out in 1791 only the eastern part of the island was Spanish. On 22 July 1795, Spain ceded to France the remaining Spanish part. Nevertheless the name "Santo Domingo" was often used to refer to Hispaniola, as is also the case in the lecture given by William Wells Brown discussed later in this essay. 
In texts by black abolitionists, the historical significance of the Haitian Revolution was often held against that of the American Revolution, frequently in favor of the former. Already in 1826, in the midst of the celebrations around the fiftieth anniversary of the Declaration of Independence, John Russwurm, the editor of Freedom's Journal who was also the second black college graduate in the United States, ${ }^{11}$ had delivered a commencement address about the importance of the Revolution - significantly, not the American Revolution but the Revolution in Haiti. In this speech, entitled "The Conditions and Prospects of Haiti," he presented Haiti as a model republic, foregrounding the fact that blacks in Haiti enjoyed the privileges of citizenship that were denied them in the United States. While Russwurm thus pointed out Haiti's relative modernity in comparison to the United States, he also emphasized the inevitability of liberty for black people, framing his argument in metaphors of uncontainability:

A principle of liberty is implanted in [Man's] breast, and all efforts to stifle it are as fruitless as would be the attempt to extinguish the fires of Etna. It is in the irresistible course of events that all men who have been deprived of their liberty shall recover this precious portion of their indefeasible inheritance. It is in vain to stem the current; degraded man will rise in his native majesty and claim his rights. (Russwurm 102)

Declaring that men deprived of their liberty and striving to regain it can no more be controlled than a volcano or a current of water could, Russwurm raises the specter of an eruption - i.e. a major slave revolt - within the United States themselves.

Even more rigorously than in Russwurm's address, the widespread temporal vision of the United States as the most modern state in the hemisphere and of Haiti as a backward and "primitive" place was challenged in a number of texts written during the decade before the Civil War. In this decade, black orators such as Theodore Holly and William Wells Brown delivered speeches about the significance of the Haitian Revolution in public places, fostering the memory of the Caribbean slave revolt as a signifier of black pride and urging on the radicalization of the abolitionist movement. These public lectures not only celebrated the violent tactics that Toussaint L'Ouverture and his followers had used against whites but they also predicted and called for their repetition in the United States (Clavin 131).

William Wells Brown, author of the first African American novel, ${ }^{12}$ in a lecture on St. Domingo: Its Revolutions and Its Patriots that he delivered in London and in

11 The first black college graduate was Edward Jones, who received his degree from Amherst College in 1826. Russwurm graduated from Bowdoin College in the same year.

12 Clotel, or The President's Daughter (1853). 
Philadelphia in 1854, describes the Haitian Revolution as clearly superior to the American Revolution, drawing a direct comparison between the leaders of the two revolutions. While he admits that both the black leader Toussaint L'Ouverture and the white leader George Washington led an "oppressed and outraged people" (25) to war against a strong enemy, Brown is clear about what each of them achieved for black people: Toussaint abolished slavery while Washington kept black people in bondage.

Toussaint's career as a Christian, a statesman, and a general, will lose nothing by a comparison with that of Washington. Each was the leader of an oppressed and outraged people, each had a powerful enemy to contend with, and each succeeded in founding a government in the New World. Toussaint's government made liberty its watchword, incorporated it in its constitution, abolished the slave-trade, and made freedom universal amongst the people. Washington's government incorporated slavery and the slave-trade, and enacted laws by which chains were fastened upon the limbs of millions of people. Toussaint liberated his countrymen; Washington enslaved a portion of his, and aided in giving strength and vitality to an institution that will one day rend asunder the UNION that he helped to form. Already the slave in his chains, in the rice swamps of Carolina and the cotton fields of Mississippi, burns for revenge. (Brown 25)

Dwelling on the model function of the Haitian Revolution for the slaves in the American South, Brown concludes that "[n]o revolution ever turned up greater heroes than that of St. Domingo" (33) and he sees similar heroes - "a Toussaint, a Christophe, a Rigaud, a Clervaux, and a Dessaline" - (all leaders of the Haitian rebellion) - waiting to grow up and ripe into action in the South. "If we are not mistaken," he declares, "the day is not far distant when the revolution of St. Domingo will be reenacted in South Carolina and Louisiana" (33). Again, freedom for black people is used as the crucial indicator on a timeline that leads from bondage to liberation, and in which Haiti functions as a signifier of progress. At the same time, in Brown's vision slave revolts such as those that had happened in the South before and were to be expected in the future are reframed from instances of black brutality into expressions of a black revolutionary spirit. Brown links the rebels' yearning for liberty to that of the revolutionaries in the fight for American independence when he claims about the prospective slave rebels of the South: "That their souls are thirsting for liberty, all will admit. The spirit that caused the blacks to take up arms, and to shed their blood in the American revolutionary war, is still amongst the slaves of the South" (32). In a brilliant strategic move, Brown employs the concerns of white political leaders such as Thomas Jefferson about the explosive potential of slavery to emphasize the justness of black rebellion. He quotes Jefferson's well-known exclamation "I tremble for my country when I reflect that God is just; that his justice cannot sleep forever" (37/38), which reflects Jefferson's anxiety about possible slave 
revolts ${ }^{13}$; and he concludes that if such a revolt takes place, "the God of Justice will be on the side of the oppressed blacks" (38). Finally, he compares the slave rebels of St. Domingo and those of the American South to the Helots of Sparta who also liberated themselves in a bloody war against their masters. "What the Helots were to Sparta at the time of the earthquake, ${ }^{14}$ the blacks were to St. Domingo at the time of the French Revolution. And the American slaves are only waiting [sic] the opportunity of wiping out their wrongs in the blood of their oppressors" (33). Only then, Brown proposes, will the American Revolution have found its conclusion, only then would its claims be realized, and only then would "our government [...] no longer be the scorn and contempt of the friends of freedom in other lands, but would really be the LAND OF THE FREE AND HOME OF THE BRAVE" (38, emphasis in original). Pointing to the uneasy position of the United States between its ambitions of being the most liberal and most democratic country on earth and its reality of perpetuated chattel slavery, Brown makes clear that the American Revolution had neither met its claims nor could it match the promise of freedom for black people that the Haitian revolution sent to slaves throughout the hemisphere.

Theodore Holly, a former shoemaker who became an Episcopal minister and a prominent participant in the colonization movement, was another contributor to this revisionist discourse about progress and the significance of the American and the Haitian Revolutions. In his speech A Vindication of the Capacity of the Negro Race for Self-Government, and Civilized Progress (1857) that he gave in Connecticut and Ohio, the author referred to the Haitian Revolution as

the grandest political event of this or any other age. In weighty causes, and wondrous and momentous features, it surpasses the American revolution, in an incomparable degree. The revolution of this country was only the revolt of a people already comparably free, independent, and highly enlightened. (290)

The reasons for the American Revolution, so Holly, were comparatively insignificant, its catalyst being "the imposition of three pence per pound tax on tea," while the Revolution in Haiti was "a revolt of an uneducated and menial class of slaves, against their tyrannical oppressors, who not only imposed an absolute tax

13 Jefferson, who, like many other American revolutionaries, had hoped for a spread of the British colonies' rebellion against oppression, and who had wished that the example of the colonies in the New World would prove contagious, in view of the Haitian Revolution, warned against "the revolutionary storm [...] sweeping the globe," and prophesied that "[i]f something is not done, and soon done, we shall be the murderers of our own children" (qtd. in Zuckerman 184).

14 The Helots, an unfree population group in Sparta, used the confusion ensuing after a major earthquake to rise up against their owners, the citizens of Sparta. 
on their unrequited labor, but also usurped their very bodies" (291). Therefore, as Holly declared,

[T] he obstacles to surmount, and the difficulties to contend against, in the American revolution, when compared to those of the Haytian, were, (to use a homely but classic phrase,) but a "tempest in a teapot," compared to the dark and lurid thunder storm of the dissolving heavens. (Holly 291)

While many supporters of the Colonization Movement favored repatriation to Africa, Holly encouraged emigration to Haiti. Visiting the country several times and finally settling there for good with his family and a group of African Americans in 1861, he called Haiti "the Eden of America" (Holly 303) and appealed to African Americans to follow him and invest their energies into building the Haitian Republic rather than to "indolently remain" (303) in the United States where the quest for black political rights was futile because even if these rights were granted, social prejudice would prevent African Americans from using them. The future for African Americans, so Holly, did not lie in the United States but in Haiti, where they could contribute "to the continued advancement of this Negro nationality of the New World until its glory and renown shall overspread and cover the whole earth and redeem and regenerate by its influence in the future the benighted fatherland of the race in Africa" (Holly 303). Haiti was the place of the future from which liberty and "glory" could spread, not the United States. Only Haiti, according to Holly, had the power to "lift the black race throughout the world" (ibid.). Therefore he appealed to African Americans to leave the United States and move to the "Eden of America." Taking up the biblical images of paradise and missionarism, Holly, who died in Haiti in 1911, decentered and rewrote them, characterizing black people as one of God's people deserving of freedom and equality.

While early writers such as Prince Hall made their point very cautiously, orators such as Holly and Brown boldly set Haiti as an example for a revolt abolishing slavery in the U.S. and presented Haiti as the most progressive and advanced place in the hemisphere. By encouraging a second Haitian Revolution in the U.S., and by glorifying Toussaint L'Ouverture as superior to George Washington, these orators continued and radicalized the rhetorical strategies of their predecessors, celebrating the Haitian Revolution as a more significant event than the revolution that established the thirteen colonies' independence from England.

Black writers also returned to Latin America as a discursive site of comparison during the 1850s. Martin Robison Delany, before he became a supporter of emigration to Africa, spoke in favor of black emigration to Central and South America. He considered these regions as welcoming to North American blacks 
and assumed (admittedly, somewhat naively) that they would be ready to accept the black population of the United States. He even envisioned - 40 years prior to José Marti's vision of "Nuestra America" - a pan-American confederation of Latin American States, significantly a confederation that included black emigrants from the United States:

[L]et us go to whatever parts of Central and South America we may, we shall make common cause with the people, and shall hope, by one judicious and signal effort, to assemble one day - and a glorious day it will be - in a great representative convention, and form a glorious union of South American States, "inseparately connected one and forever." (Delany 196)

Delany dedicated a special chapter of his book to Nicaragua and New Granada, ${ }^{15}$ because he thought that African Americans would be particularly welcome there and would be regarded as equals: "In these countries," he observes, "colored men now fill the highest places in the country: and colored people have the same chances there, that white people have in the United States" (202). For African Americans, then, this would be the place to go if they wanted a future for themselves: "All that is necessary to do, is to go, and the moment your foot touches the soil you have all the opportunities for elevating yourselves as the highest, according to your industry and merits" (Delany 202/203). It is interesting to note that only three years after Delany envisioned black emigration to Nicaragua, in 1856, the American adventurer and expansionist William Walker, in a filibustering venture supported by U.S. southern politicians, invaded that country, declared himself president and tried to reintroduce slavery there. Walker wanted Nicaragua to form the basis of a U.S. colony in Central America. His call for Nicaragua's annexation by the United States as a slave state was supported by United States proslavery forces and only failed because the U.S. Government feared that an annexation of Nicaragua as a new slave state would fuel the sectional conflicts between slave states and free states within the United States. Historian Robert May points out that the filibustering expeditions of Walker met with wide public acclaim in the U.S., observing that " $[\mathrm{m}]$ any Americans simply assumed that the superiority of their race and governmental institutions gave them the moral right to filibuster abroad" (May 862). Walker was discussed in newspapers as "the hero of the times," and his exploits even became the topic of a stage production in New York entitled

15 The Republic of New Granada was a short-lived republic that comprised much of present-day Colombia and Panama and smaller parts of present-day Venezuela and Ecuador. It was created after the dissolution of Gran Colombia in 1830 and was replaced by the Granadine Confederation in 1858 . 
Nicaragua, or Gen. Walker's Victories (May 860). May quotes from a poem published in a newspaper that describes the attitude of Americans toward Nicaragua:

Just South of Texas is a Land,

We call it Nicaragua, and

Men live there who but little know

How they should rule. (qtd. in May 862)

While Delany saw Nicaragua as a land of opportunity for blacks where the hopes of African Americans for a free future could fulfill themselves, U.S. American public opinion regarded Central America as a place in need of American rule, once again framing it in images of backwardness and inferiority.

In the decades between the American Revolution and the Civil War, for the African American abolitionist writers discussed in this essay progress lay not in the United States but was imagined in Colombia, Mexico, and Nicaragua, and, most prominently, in Haiti. The texts by these writers reinterpret the story of progress underlying the American national narrative by shifting the focus to black freedom. Their revisionist discourses construct Africa, Latin America, and the Caribbean not as sites of barbarity, but of hope and pride. These texts provide evidence for the conclusion that the post-revolutionary and antebellum periods can be described in terms of various competing "imagined communities" with quite different imagined origins and envisioned temporal developments. Research into the various temporal narratives in the early national period can thus provide evidence for the contradictions of national identity formation. Temporality emerges as a category that allows us to imagine nationality, as Thomas Allen puts it, "as an ongoing negotiation of heterogeneous temporal modes" (Allen 4). Relevant historical transnational research needs to study the conditions and specific situations that guided the emergence of the nation, including the complex cultural history of temporal experience and the narratives this process has engendered, narratives of past and future and of cause and consequence within and without the nation's borders.

\section{Works Cited}

Africanus. "Hayti, No. III: From the Scrap-Book of Africanus." Freedom's Journal, May 4 (1827): 30. African-American Newspapers and Periodicals, Wisconsin Historical Society. http://www.wisconsinhistory.org/libraryarchives/aanp/ freedom/index.asp (last accessed August 22, 2010).

Allen, Thomas. A Republic in Time: Temporality and Social Imagination in Nineteenth Century America. Chapel Hill: University of North Carolina Press, 2008. 
Anderson, Benedict. Imagined Communities: Reflections on the Origin and Spread of Nationalism. London: Verso Editions/NLB, 1983.

Appleby, Joyce. Liberalism and Republicanism in the Historical Imagination. Cambridge: Harvard University Press, 1992.

Burgett, Bruce. Sex, Gender, and Citizenship in the Early Republic. Princeton: Princeton University Press, 1998.

Barlow, Joel. The Vision of Columbus. 1787. Ed. Fredo Arias. Mexico: Frente de Afirmación Hispanista, A.C., 1992.

Bellah, Robert. Beyond Belief: Essays on Religion in a Post-Traditional World. New York: Harper \& Row, 1970.

Brickhouse, Anna. "The Writing of Haiti: Pierre Faubert, Harriet Beecher Stowe, and Beyond." American Literary History 13.3 (2001): 407-444.

Brooks, Joanna. American Lazarus: Religion and the Rise of African-American and Native American Literatures. New York: Oxford University Press, 2003.

Brown, William Wells. St. Domingo: Its Revolutions and Its Patriots: A Lecture, Delivered before the Metropolitan Athencum, London, May 16, and at St. Thomas' Church, Philadelphia, December 20, 1854. Boston: Bela Marsh, 1855.

Davis, David Brion. Slavery and Human Progress. New York: Oxford University Press, 1984.

Delany, Martin Robison. The Condition, Elevation, Emigration, and Destiny of the Colored People of the United States and Official Report on the Niger Valley Exploring Party. 1852. Amherst, N.Y.: Humanity Books, 2004.

Edwards, Bryan. An Historical Survey of the French Colony in the Island of St. Domingo, Comprehending a Short Account of Its Ancient Government, Political State, Population, Productions, and Exports: A Narrative of the Calamities Which Have Desolated the Country ever since the Year 1789 ... and a Detail of the Military Transactions of the British Army in That Island to the End of 1794. London: Stockdale, 1797.

Elliott, Emory. "Diversity in the United States and Abroad: What Does It Mean When American Studies Is Transnational?” American Quarterly 59.1 (2007): $1-22$.

Fabian, Johannes. Time and the Other: How Anthropology Makes Its Object. New York: Columbia University Press, 1983.

Fisher-Fishkin, Shelley. "Crossroads of Cultures: The Transnational Turn in American Studies - Presidential Address to the American Studies Association, November 12, 2004." American Quarterly 57.1 (2005): 17-57.

Freneau, Philip. The Rising Glory of America. 1786. The Poems of Philip Freneau. Written Chiefly During the Late War. Philadelphia 1786. 42-58. Early American 
Imprints. Series I: Evans, 1639-1800, 42-58. http://infoweb.newsbank.com (last accessed September 20, 2009).

Hall, Prince. A Charge, Delivered at the African Lodge, at Metonomy, of 1797. The Heath Anthology of American Literature.Vol. 1. Ed. Paul Lauter. Boston, New York: Houghton Mifflin, 2002. 1109-1115.

Holly, Theodore. A Vindication of the Capacity of the Negro Race for Self-Government, and Civilized Progress. 1857. Lift Every Voice: African American Oratory, 1787-1900. Ed. Philip S. Foner and Robert James Branham. Tuscaloosa: The University of Alabama Press, 1998. 288-304.

Johnson, Walter. "Time and Revolution in African America." Rethinking American History in a Global Age. Ed. Thomas Bender. University of California Press, 2002. 148-167.

Kelleter, Frank. "Transnationalism: The American Challenge." Review of International American Studies (RIAS) 2.3 (2007): 29-34, 29.

Kennedy, Lionel, and Thomas Parker. Official Report of the Trials of Sundry Negroes, Charged with an Attempt to Raise an Insurrection in the State of South Carolina. 1822. Introduction John Oliver Killens. Boston: Beacon, 1970.

Kerber, Linda. Women of the Republic: Intellect and Ideology in Revolutionary America. Chapel Hill: University of North Carolina Press, 1997.

Marrant, John. A Sermon, preached on the $24^{\text {th }}$ Day of June 1789. Being the Festival of St. John the Baptist, at the Request of the Right Worshipful the Grand Master Prince Halland the Rest of the Brethren of the African Lodge of the Honorable Society of Free and Accepted Masons in Boston by the Reverend Brother Marrant, Chaplain. Boston, 1789. Web Supplement for Peter P. Hinks. "John Marrant and the Meaning of Early Black Freemasonry." William and Mary Quarterly LXIV (2007): 1. @ 2007 by the Omohundro Institute of Early American History and Culture.http://oieahc.wm.edu/wmq/Jan07/Hinks.pdf (last accessed August 21, 2010).

May, Robert. "Young American Males and Filibustering in the Age of Manifest Destiny: The United States Army as a Cultural Mirror." The Journal of American History 78.3 (Dec., 1991): 857-886.

Moya, Paula, and Ramon Saldivar. "Fictions of the Trans-American Imaginary." MFS Modern Fiction Studies 49.1 (2003): 1-18.

Nash, Gary B. Forging Freedom: The Formation of Philadelphia's Black Community, 1720-1840. Cambridge, Mass.: Harvard University Press, 1988.

Pearson, Edward A., ed. Designs Against Charleston: The Trial Record of the Denmark Vesey Slave Conspiracy of 1822. Chapel Hill: University of North Carolina Press, 1999. 
Pease, Donald. "Dislocations: Transatlantic Perspectives on Postnational American Studies. Postnational Politics and American Studies." $49^{\text {th }}$ Parallel: An Interdisciplinary Journal of North American Studies. http://www.49thparallel.bham.ac.uk/ back/issue8/pease.htm (last accessed August 22, 2009).

Radhakrishnan, Rajagopalan. "Ethnic Studies in the Age of Transnationalism." PMLA 122.3 (2007): 808-810.

Rodriguez, Juana María. “Ethnic Scholarship, Transnational Studies, Institutional Locations.” PMLA 122.3 (2007): 810-812.

Russwurm, John Browne. "The Condition and Prospects of Haiti." [Commencement Address at Bowdoin College, 6 Sept. 1826]. Lift Every Voice: African American Oratory, 1787-1900. Ed. Philip S. Foner and Robert James Branham. Tuscaloosa: University of Alabama Press, 1998. 101-104.

Russwurm, John Browne. Editorial. Freedom's Journal (December 12, 1828): n.p. African-American Newspapers and Periodicals, Wisconsin Historical Society. http://www.wisconsinhistory.org/libraryarchives/aanp/freedom/index.asp (last accessed August 22, 2010).

Russwurm, John Browne, and Samuel Cornish. “To Our Patrons.” Freedom's Journal (March 16, 1827): 1. African-American Newspapers and Periodicals, Wisconsin Historical Society. http://www.wisconsinhistory.org/libraryarchives/ aanp/freedom/index.asp (last accessed August 22, 2010).

Sale, Maggie Montesinos. The Slumbering Volcano: American Slave Ship Revolts and the Production of Rebellious Masculinity. Durham, N.C.: Duke University Press, 1997.

Sanders, Mark A. "Brief Reflections on the Discourse of Transnationalism and African American Studies." PMLA 122.3 (2007): 812-814.

Sassen, Saskia. "Spatialities and Temporalities of the Global: Elements for a Theorization." Public Culture 12.1 (2000): 215-232.

Summers, Martin. "Diasporic Brotherhood: Freemasonry and the Transnational Production of Black Middle-Class Masculinity." Gender \& History 15.3 (2003): 550-574.

Walker, David. "Address Delivered Before the General Colored Association at Boston.” Freedom's Journal (December 19, 1828): 205-206. African-American Newspapers and Periodicals, Wisconsin Historical Society. http://www. wisconsinhistory.org/libraryarchives/aanp/freedom/index.asp (last accessed August 22, 2010).

Walker, David. Walker's Appeal, in Four Articles; Together with a Preamble, to the Coloured Citizens of the World, but in Particular, and Very Expressly, to Those of the United States of America, Written in Boston, State of Massachusetts, September 
28, 1829. Electronic edition. Documenting the American South. http://docsouth. unc.edu/nc/walker/walker.html. 24. (last accessed January 6, 2010).

Wallace, Maurice O. Constructing the Black Masculine: Identity and Ideality in African American Men's Literature and Culture, 1775-1995. Durham and London: Duke University Press, 2002.

Warner, Michael. The Letters of the Republic: Publication and the Public Sphere in Eighteenth Century America. Cambridge: Harvard University Press, 1990.

Wertheimer, Eric. Imagined Empires: Incas, Aztecs, and the New World of American Literature, 1771-1876. Cambridge: Cambridge University Press, 1999. 17-52.

Zuckerman, Michael. Almost Chosen People: Oblique Biographies in the American Grain. Berkeley: University of California Press, 1993. 
Armin Paul Frank

Göttingen University, Germany

\section{A Rationale for a Comprehensive Study of the History of United States Literary Culture}

International connections of American literature written in English have often been studied, sometimes in extensive bilateral surveys. American writings in a number of languages other than English have also received attention - recently in a few plurilateral explorations of remarkable compass. ${ }^{1}$ Yet international courage tends to dwindle, even to disappear, as does international expertise, when literary history is the object of study. There are some respects in which historiographical nationalism is more insistent now that the new Cambridge History of American Literature has appeared than at the time of the old.

In an effort to call attention to this scaling down of the scope of literary historiography and to suggest an alternative approach, I offer a set of ideas that originated in a cooperative project on an international history of literatures in the Americas in which I had the honor and pleasure to participate for a number of years. ${ }^{2}$ They also apply, I submit, to more limited projects such as an international history of literatures written in different languages in the colonies of North America and in the subsequent United States and Canada. ${ }^{3}$ A case in point is Ole Edvart Rölvaag's work. It is true that I do not read Norwegian and am but poorly versed in Norwegian literature in translation. These shortcomings, however serious, are, perhaps, offset by the fact that Rölvaag is the one US American minority writer who is not only best connected but also best examined in English, pace Friedrich Gerstäcker, Charles Sealsfield, and Isaac Bashevis Singer. I gratefully acknowledge Fritz Paul's expert advice in Norwegian matters. Errors are, of course, my own fault.

Rölvaag has been quoted to the effect that Norwegian-American writers are American authors using Norwegian as their literary medium. ${ }^{4}$ His career suggests an alternative possibility: that he is a Norwegian author who resided in the North Central United States and wrote on the fate of immigrants from Norway. Whatever the case may be, these two extremes circumscribe the following discussion.

\footnotetext{
1 Cf. Sollors, Shell.

2 Cf. Buchenau/Paatz.

3 Cf. Frank/Mueller-Vollmer.

4 Cf. Øverland, p. 351.
} 


\section{American Beginnings According to American Literary Historiography}

The beginning of an American literature in a language in which the literature of an overseas country has been written for centuries causes an obvious problem: When and how did American literature written in this language begin? The extant histories of US American literature in English usually opt for a mythical moment. The editors of the Literary History of the United States (@ 1946) felt that

the literary history of this nation began when the first settler from abroad of sensitive mind paused in his adventure long enough to feel that he was under a different sky, breathing new air, and that a New World was all before him with only his strength and Providence for guides. ${ }^{5}$

It is a mythical moment because it is ascribed great national importance but offers hardly a clue to an answer to the seven topical questions which circumscribe an action: Who did what, where, when, how, with what instruments, and why?

The editors of the Columbia Literary History of the United States (1988) are even less helpful because they retrojected contemporary concepts onto prehistory:

The literary history of this nation began when the first human being living in what has since become the United States used language creatively. Presumably, that moment occurred many centuries ago when one of the members of the numerous Native American tribes formulated a poetic expression or told a story. ${ }^{6}$

What if this mythical culture hero was himself a "settler from abroad?" Possibly hailing from Asia? Or from Egypt?

The new Cambridge History of American Literature (first volume 1994) overlaps with the other two since the geographical scope is also "the United States, or the territories that were to become part of the United States." The editors insisted that "[o]ur History is fundamentally pluralist: a federated histories of American literatures." Yet what are the articles of this literary confederation? Furthermore, the pluralism is quite a limited one, for the Cambridge History focuses on "writing in English in this country - 'American literature' as it is commonly understood here and abroad in its national implications." America thus figures as "a semiotics of exclusion, closing out not only the Old World but also all other countries of the Americas, North and South, as well as large groups within the United States." The limitation of US literary citizenship to English-speaking Americans results

5 Spiller, p. xix.

6 Elliott, Columbia Literary History, p. xv.

7 Bercovitch, p. 3; also the next three quotations. 
in a version of "American" literary history that is, if not merely convenient, based on staunchly held presuppositions and ingrained prejudices.

The excluded groups consist of readers, speakers, and writers of languages other than English or of those who have learned to do their daily business in English but continue to write in their native language. O. Øverland's "complete narrative" of Norwegian-American literature (1996) begins with a characteristic though not unique immigrants' genre: letter writing. Many of the private experiences were of public interest. Letters also speak to prospective emigrants outside the family circle, and they can equally serve interests that aim at dissuading emigration. According to Øverland, the first important group of published letters was compiled by G. G. Hovland and dates from the spring of 1835, when continuous, large-scale migration from Norway was finally under way. ${ }^{8}$

It is hard to tell whether US literatures in other languages are not yet ready for a survey such as Øverland's or whether there is no scholar or small group of scholars willing and able to undertake such a project. In the case of German-American writing, there are not only a number of special studies on record but also the comparatively more tentative, problem-oriented collection of essays edited by W. Fluck and W. Sollors in 2002. ${ }^{9}$ A French companion piece might take its departure from the cultural surveys through 1900 by H. M. Jones and H. Blumenthal, and from a number of doctoral dissertations.

Taking note of this one-language, one-literature approach to writing in the United States, one may well begin to wonder whether literary life was equally departmentalized. Did Americans writing in whatever language remain isolated in their particular reading culture? Or were they aware of each other across language, literature, and culture lines? What do the plots tell about possible cooperation or counteroperation across these dividing lines? Did American authors, in the writing of their own works, make use of literature written in other languages? In the original or in translation? Given the state of research and documentation, what can be gathered about such interrelations and interactions? I suggest to pursue one and a half strands of the "federated histories of American literatures" invoked but not undertaken in the new Cambridge History.

\section{Causes of Plurality}

A literary culture promoted by immigrants (and, later, their descendants) begins when the literate and the literary minded among their number bring along their

8 For “complete narrative," cf. Øverland, p. x; on Hovland, p. 20, on immigration p. 3.

9 From now on, whenever the work cited is identified in the main text, a note is omitted. 
tastes and favorite texts. Whatever the settlers' impression of the different sky may have been, they had, for good reasons, a tendency to hold on to these familiarities, these cultural securities. Far from being a burden, their literary past remained a presence that they cherished in their own writings or translations, as did, for instance, the early Massachusetts Bay colonists when they made the Bay Psalm Book (1640) conform to their idea of true doctrine at the expense of ornament.

The formula of tastes and texts - admittedly a bit flashy - follows the distinction between objects of the mind and material objects. Taste includes such things as reading habits, reading preferences, and ideas about reading matter. A text, when read, goes beyond its evident materiality.

The following argument also depends on a distinction between reading matter that is ideally accessible and that which is physically so. In principle, readers are qualified to read everything in the language(s) they are familiar with. Yet in practice, they have access only to what is available at their place and time. This practical limitation applies in particular to the time prior to the global mobility of the twentieth century. It remains to be seen whether the instant global accessibility of the electronic age will make this distinction obsolete. In this perspective, there are, in the settlement of North America, three causes of literary plurality, two of them of major historical significance. To begin with the less important one:

\subsection{The pre-Columbian population}

Enjoyed a variety of oral literatures employing a number of recording systems short of alphabetical script. As such, they did not have much of a chance to survive. To the best of my knowledge, the most advanced was Sequoiah's syllabary, which contributed significantly to the part English, part Cherokee political and literary culture of the Cherokee nation. It became a historical reminiscence after most of the Cherokee people and their culture were brutally eradicated by US authorities in the late 1820 s.

\subsection{Importation of printed matter}

If colonists hail from different language communities, each bringing along literary tastes and favorite texts of their own, the result is a co-existence not of the entire literatures of origin but of the imported parts. A good way of studying these matters is to regard the literate and literary transactions in a given language community as its "reading culture." It consists of five distinctive activities: the making, distributing, reading, discussing, and the evaluating and preserving of written and printed material as well as sound recordings; a sixth kind, transfer, with translating as its most distinctive form, serves to establish connections between 
reading cultures. Each of these activities is based on reading, and five go beyond it in characteristic ways.

The transfer from country of origin to colony is more than just a move across geographical space. To bring part of one's literature along is, on the whole, to preserve its homogeneity. And yet, insofar as this is only a part, the colony's literature is but a synecdoche writ large, whose component parts do not have the same relative weight as back home. The plain style in early New England writings can, of course, be identified by the same criteria as in Old England. But in the colony, it was culturally more central because other modes of English literature were marginalized or entirely omitted. There are, of course, good reasons why Renaissance and Elizabethan theater, flourishing in London, did not, could not find a place in Boston. Fragmentation in transfer, it appears, is equally a form of transformation.

Though the agencies and institutions differ in colony and metropolis, they continue to cooperate in the same reading culture. The transfer of tastes and texts is more than a matter of new beginnings. Because of the paradoxes of transfer, modes of homogenization and transformation and their outcome go on to form part of the interliterary processes. For if literary innovation happens in the former home country, even a literary "revolution" such as the Romantic Reversal has a modest local beginning and becomes truly revolutionary in literary terms only in a complex, extended, and controversial process of reception and further development. But when it is brought along into a colony or a former colony that is beset by problems that go to the very roots of its existence, this literary revolution will come at a later point in the historical process. Therefore, it is likely to appear more as a surprising innovation than as the continued contribution to trans-oceanic homogeneity, which it is as well.

\subsection{Writing strategies}

Undoubtedly, the most important differentiation of a reading culture occurs when writers feel moved to assert a new identity in literary terms. In the long run, this impetus resulted in the making of distinctive American literatures in the languages of the older European counterparts. The dissociation of the Atlantic reading culture in English into an American and a British sphere has been studied in some detail. To put it succinctly: Programmatic statements - "declarations of literary independence" - are important primarily as documents of aspiration, not of achievement. As far as literary achievements are concerned, the actual writing strategies permit a classification under five categories that fit in with the morphology of the German verb for writing, schreiben: nachschreiben, weiterschreiben, 
umschreiben, gegenschreiben, and vorbeischreiben. Not all of them contribute to dissociation; but it may be of interest briefly to survey the entire range.

Both Nachschreiben and Weiterschreiben are a writer's methods of keeping the Atlantic reading culture homogeneous. An American work either remains completely within the scope of a model taken from the European literature written in the same language (Nachschreiben) or goes somewhat beyond it, but always in keeping with the telos of the model (Weiterschreiben). Another form of Weiterschreiben is for the American writer to take more than one model and to combine them without going beyond them. Umschreiben is a half-way house in which the American writer adopts a model from the respective European literature but adapts it to an American subject-matter, while at the same time adapting the subject-matter to the model. Gegenschreiben and Vorbeischreiben, finally, are methods of dissociating the Atlantic reading culture. The first subsumes a variety of ways of linking the emergent American work with one or several written overseas in the same language in such a way as to reduce the latter from model to point of departure for a literary structure or pattern which alienates the European correlative work or works as part of a foreign literature. Vorbeischreiben, finally, amounts to linking the emergent work to one in a different language so that whatever is being brought into the American literature in question by writing, translating, paraphrasing, etc. differs to begin with. Activities of this nature have been studied for both British and German to English-American transfer; there is published evidence that the distinctions also work in the Italian to English-American and Spanish to Spanish-American domains..$^{10}$ I see no reason why it should not work in the other areas as well, at least in some respects.

\section{Cultural Islands, Enclaves/Exclaves, and Dividing Lines}

A good starting point for developing the conceptual framework of a comprehensive study of the reading cultures which, combined or separated in cooperation, counteroperation, or in ignorant, benign, or proud disregard, make up North American colonial and, subsequently, United States and Canadian literary cultures, is the idea of a cultural island. It was mentioned in passing in the chapter that made far-reaching claims on United States literatures written in languages other than English, which a team directed by H. A. Pochmann contributed to the Spiller Literary History. ${ }^{11}$ If I prefer the term enclave, I do so remembering one of Pochmann's examples, Willa Cather's immigrant novels. There, the lives of the

10 Cf. Peach, Weisbuch, Frank/Mueller-Vollmer, Francini, Buchenau/Paatz.

11 Spiller, p. 678. 
Nebraska Czechs and Germans are not only lived within their own group and in relation to Irish and other English-speaking Nebraskans, but are also linked - even if only in memory and surviving habits, but often by letter-writing, too - in an exclave relation with their relatives and acquaintances in the region or country of origin. Though English "enclave" and "exclave" refer primarily to tracts of land separated from the land they belong to and enclosed by foreign parts, the enclave/exclave situation, in a dynamic migrants' society, differs in two important respects. It is not determined by geographical borderlines alone, and perhaps not even primarily by considerations of habitat, but by linguistic, literary, cultural, religious dividing lines as well as by borders of national consciousness. And the cultural centers of such an en/exclave are, as a rule, more easily identified than the location of a dividing line. Points of contact and transfer that link en/exclaves are important for the literary life in a plurilingual situation. My emphasis is on mental spaces rather than geographical space.

\subsection{Dividing lines: Language barriers}

The status of dividing lines differs considerably. Divisions that are mental or spiritual or both are capable of dividing absolutely. Whenever my Czech acquaintances are over their ears in voluble conversation, I stand silently by, admiring the wisdom of their language that made the word for German, nèmec, so similar to nèmý, deaf and dumb. It is in the nature of language that its en/exclaves are cut out in mental and in spiritual space, im geistigen Raum, as I would put it in German, a language that ties the English words "mental" and "spiritual" together in a single one: geistig. In Peder Seier (1928, Peder Victorious), Ole Edvart Rölvaag told about what he regarded as the "tragedy of emigration," the deep human tragedy of language difference disrupting the core family. ${ }^{12}$ It is the "child that slips into a world where his mother cannot go. She can no longer make herself understood to her own children, while the child has its family roots cut."

In the opening paragraphs, which focus on the relationship between the American-born son of Norwegian immigrants and his mother, Rölvaag set his major theme in the image of three rooms, two of them defined in terms of language, the third the room of religion. ${ }^{13}$ In the plot, he traced Peder's attempts to move from the drab Norwegian family room, where he respected Mother but was ashamed because, after so many years, "she couldn't talk decent English yet," to the English room, about which he easily learned at school together with his

12 Rölvaag, Peder, p. xii; also next quotation.

13 Cf. Rölvaag, Peder, pp. 1-3. 
pal, an Irish boy. This is the room of his joys, dreams, and aspirations. ${ }^{14}$ In the logic of Rölvaag's novel, the two rooms represent the past unreconciled with the future; it is the tragedy of the immigrants' children and their incapability to lead a satisfying life in the present. Part of Peder's attempted move coincides with a thoroughgoing refurnishing and refurbishing of the room of religion; ultimately, it is cleaned out completely.

A single prominent instance such as Rölvaag's suffices to make the point; but there is supporting evidence. Another important Norwegian-American writer, Waldemar Ager, gave religious sanction to the continued use of the Norwegian language among second-generation settlers when he claimed that to speak and write Norwegian was required by the commandment to honor one's parents, because this was the only way in which they could live on in their children. ${ }^{15}$ And in a different, in the German-American en/exclave, Edna Fern (i.e. Fernande Richter, born 1861, migrated $1881^{16}$ ) evoked the rift between the immigrant and the first American-born generation as the tragedy of Americans of German descent, who suffer a variety of estrangements. In thirty-six lyrical lines under the title "Deutschamerikaner," the settlers are introduced as estranged from their home without having become children of the foreign land in which they now live. The high aspirations of their youth, associated in their minds and hearts with the rustle of German forests, are now no more than a remembered echo. The center of the poem is, in my reading, the stanza focusing on this estrangement between parents and children ("Deiner Heimat Laute" refers to the parents' native language):

Und dies, worauf Dein Hoffen baute:

Die Kinder - achten, wo Du liebst,

Sie kennen Deiner Heimat Laute,

Doch fremd ist ihnen, was Du giebst [!]. ${ }^{17}$

Indeed, for the second generation merely to respect what the immigrants lovingly cherish and to experience as foreign what their parents have to offer is precisely what happens in the family in Rölvaag's novel: It is rent apart by the hyphen. For even if the parents come to love the country of their children's birth, there is no longer a path for the whole family to walk on side by side. According to Fern: "doch ist der Weg verloren, / Auf dem ihr eng zusammengeht." In the contemporary world

14 Cf. Rölvaag, Peder, p. 3.

15 Cf. Gulliksen, p. 9.

16 Cf. Deutsch-amerikanischer National-Bund, p. 389.

17 Deutsch-amerikanischer National-Bund, p. 409; also next quotation. 
of accelerated change, the alienation between generations no longer depends on migration.

Incidentally, the language barrier between American English and German has been hilariously depicted in light verse: by Kurt M. Stein (Die schönste Lengevitch, 1925) the way it looks and sounds from the German side and by Dave Morrah (Fraulein Bo-Peepen and More Tales Mein Grossvader Told, 1953), from the English. ${ }^{18}$

\subsection{Dividing lines: Cultural barriers}

If the rise of disruptive language barriers is an experience that immigrant writers focused on, cultural dividing lines combined with geographical ones are another important theme in their art. As I see it, there is a communal and a personal aspect of culture to be taken into account. In its communal application, I suggest to regard ${ }^{1}$ culture ${ }^{1}$ as the aggregate of acts of thinking, doing, and making, either habitual or exceptional, enacted in accordance with, in opposition to, or in disregard of, pertinent norms, characterized by degrees of permanence and change, on the part of members of a given community acting either in or outside the pertinent institutions, together with the results and products of these acts. Focusing on persons, I take ${ }^{2}$ culture $^{2}$ to embrace the actions of the intellect and the imagination as well as the training of the sensibilities which identify a person as a member of a given ${ }^{1}$ culture ${ }^{1}$, and also the resultant state of mind and feeling, irrespective of whether the particular person makes contributions to ${ }^{1}$ culture ${ }^{1}$ or not. An important idea and practice originated with Herder, Goethe, Schiller, and Jean Paul: Selbstbildung, usually rendered as self- ${ }^{2}$ culture ${ }^{2} .{ }^{19}$ It caught on with many nineteenth-century American writers, particularly those of a transcendentalist persuasion.

In this understanding of culture, the long years of severe depression suffered by Beret, the central mother figure in Rölvaag's settler saga, are an extreme form of culture shock. From the very first page, Nature constantly exerts an overwhelming power over culture, though it will eventually be tamed and cultivated. In the beginning, though, the prairie almost literally swallows up the Hansas' westering wagon as the trampled grass, strong and resilient, rises up again in its wake, and "instead of widening out astern it close[s] in again." ${ }^{20}$ Their eventual adoption of a family name, Holm, to replace the husband's patronym Hansa/en is a first sign of Americanization.

18 Cf. Frank, "Borderline Cases," pp. 224-27.

19 Cf. Shelley.

20 Rölvaag, Giants, p. 3. 
Whereas Per Hansa/Holm is always guided by his conviction that a rich farmer's future awaits them - the Biblical "Pastures of Goshen" -, his wife is constantly beset by a great, vague fear that "here something was to go wrong."21 She is convinced that the Great Plains are not fit for humans to live on, and she finds her fears confirmed time and again. Thus, when a huge swarm of locusts, which are "fiendish shapes" for her and which the American West is still capable of producing in mitigated form, destroys most of the harvest, anyone who has experienced such a calamity will not be surprised that Beret, half-crazed, hides within a material remnant of her native culture, the Norwegian heirloom of a big sea chest, with which she blocks the door of their sod shanty. Her first words when her husband finds her are: "Hasn't the devil got you yet? He has been all around here today."22 In terms of her pietistic Protestantism, she senses the presence of the "evil one" out there so intensely that she continuously lives in hell.

If readers should feel that for Beret to live in the Dakota Territory is to have crossed all geographical, cultural, and spiritual dividing lines in one go, they will find a confirmation in one of the poor woman's experiences. Shortly after her arrival, when her husband is away on an errand, she is alone with her children for a few days. Returning from a lookout point,

the air of the place had suddenly filled with terror and mystery. The wagons had floated like grey specks in the dust; and all at once it had seemed as if the whole desolation of a vast continent were centring there and drawing a magic circle about their home. She had even seen the intangible barrier with her own eyes ... had seen it clearly ... had had to force herself to step across it. ${ }^{23}$

On a later occasion, Beret felt that she was imprisoned by the surrounding line of the horizon - a potent image of captivity since the horizon can never be reached nor stepped across because it moves with the person who observes it.

\subsection{Dividing lines: Literary matters}

Interliterary differences are of a nature that makes it inadvisable to think of them in terms of barriers, though they surely are demarcations in mental and imaginative space. One of the reasons is that literary matters are closely bound up with language differences, although they do not end there. Every reader of a foreign text has made the experience that there is a stage when basic language difficulties in vocabulary, morphology, syntax, etc. - need to be cleared up before literary

21 Rölvaag, Giants, p. 28; cf. Øverland, p. 359.

22 Rölvaag, Giants, p. 348; “fiendish shapes," p. 349.

23 Rölvaag, Giants, p. 57. 
inferents - narrative situation, plot, character, thought, etc. - can become meaningful. Progress in foreign-language competence is easier to ascertain than in literary competence. The number of unfamiliar words will noticeably decrease in the course of time, but there is no easy gauge for assessing what a reader continues to miss in literary terms.

Among the easiest literary matter to miss are references to extant literature inscribed into the writer's own work. Together with other literary devices, they have a tendency to disappear in translation. But where they show, interliterary difference looms large. In Peder Victorious, whenever Beret opens her Bible, the reader comes upon a Black Letter text:

Having dressed as usual, she took the Bible, paging a long while before she found what she was looking for:

2lnd it was so, when the danes of their feasting were gone about, that $\mathfrak{J}_{0} b$ sent and sanctifted them, and rose up early in the morning [... ${ }^{24}$

Some readers may have difficulties spelling this out, to begin with. Even when mastered, the passage is bound to produce an impression of quaintness. It will probably appear old-fashioned and outdated.

In the original Norwegian text, however, the implications of the Bible passages in Dano-Norwegian Black Letter were different. For this is how the wellthumbed family Bible looked. This is what they were familiar with, what they loved, this was their religious home, and, by extension, that of their family. By the later nineteenth century and in Rölvaag's novels, the clergy was divided. To Beret's chagrin, Reverend Gabrielsen, in Peder Seier/Peder Victorious, gave away English Bibles to young Norwegian-Americans whom he wanted to encourage to live a Christian life. He would, no doubt, have agreed that the Norwegian text is outdated. Yet in Den signede dag/Their Fathers' God, Reverend Kaldahl (whose English was "downright terrible"25) extolled the glory of Viking traditions and stood by the traditional Bible. The name reminded E. Haugen of J. N. Kildahl, "Rölvaag's first college president and admired hero." ${ }^{26}$ The implication, I submit, is that this minister speaks with particular authority.

In Rölvaag's Norwegian text, the Bible passages in Black Letter pinpoint a significant religious controversy between an unquestioningly heartfelt and soul-saving adherence, on the one hand, and, on the other, a rejection for being

24 Cf. Rölvaag, Peder, p. 232; the spelling "dayes" is correct. The quotation Beret found was, of course, in Norwegian.

25 Rölvaag, God, p. 210.

26 Haugen, p. 107. 
inappropriate to modern, to American ways. Neither the English text - even if explicated - nor its Norwegian source can now convey the immediacy and intimacy that the Norwegian text had for many of Rölvaag's contemporaries. It is the fate of every literary work that eventually its meaningful context needs to be recovered.

If borderlines, lines of demarcation, are places and instruments for identifying difference, such discriminations, in the logical sense of the term, are made in the context of lingual, literary, cultural, national, and geographical space and must take the time factor into account as well.

\section{En/Exclave Relations of Vesterheimen}

By bringing along their native language and parts of their nation's literature and culture, and often a sense of national identity, immigrants inevitably establish their settlements as cultural extensions of their countries of origin. But insofar as the focus - le foyer - of their lives is now their new home in America, and since they are now subject to the laws and regulations and, perhaps to a lesser extent, the customs and habits of their adopted land, a degree of adaptation, though not necessarily assimilation, is inevitable. For the language of communication outside the immigrant community is always English. Staunch religious groups such as the Old Order Amish in Pennsylvania, who even today live the simple life and speak a variant of a German dialect of the seventeenth century, certainly adapted, but never assimilated to their "English" neighbors with whom they traded. As pacifists, they resisted ideological and political pressure, even when it was particularly strong during international crises such as the First World War. In sum, I find it helpful for focusing on a particular en/exclave literature to observe how the settlers were able to graft their American experience on a particular old-country term and idea: The Norwegian-Americans began to think and feel about their new Western home as vesterheimen, the Old Norse word for America. The term, O. Øverland explained, became current in the late 1870s and "was used by Norwegian Americans as a fond epithet for their own vaguely defined and unstable ethnic niche within the larger, multi-ethnic Western home." ${ }^{27}$ He noted that $J u l i$ Vesterheimen was the name of a Christmas annual from 1911 to 1975.

As long as it existed, vesterheimen was triply related: to Norway, to Englishspeaking America, and to other en/exclaves. Yet its culture, Øverland asserted, was marginal and transitory. ${ }^{28}$ This means that, in the course of time, the connection with the country of origin weakened significantly. Norway was the "Old Home"

27 Øverland, p. 5.

28 Cf. Øverland, pp. 3-15.

Marietta Messmer and Armin Paul Frank - 978-3-653-98855-0

Downloaded from PubFactory at 01/11/2019 10:57:20AM 
of the immigrant generation only. The real home even of the first American-born generation is a part of America, and their relation to Norway has become indirect: It is, at best, their family's former home. To the extent that the language of their schooling and socialization was English, their mother tongue became more and more remote, indeed, foreign. Even if the old country kept up a special interest in its emigrants and if this interest was reciprocated by residents of vesterheimen, it was bound to diminish. Overseas family ties fade, and cultural ties tend to become formulaic, epiphenomenal. I remember a Chicago Oktoberfest in 1959. Catching up with a young man who wore a kind of blazer sporting an eagle and the inscription Turnverein, I addressed him in German but drew a blank: He did not speak the language. It was obvious that he did not have the slightest inkling of the historical importance which these athletic organizations had in post-Napoleonic times, when they campaigned to overthrow the monarchies and to establish a democratic and unified German republic.

The historical fact is that the connections which residents of vesterheimen had with English America became more extensive and intensive, and not merely in practical terms or for administrative purposes. In literary terms, a fundamental turn took place when members of a nationality gave up their native language for English not only as the sole means of communication but also as a literary medium. From this moment on, they contributed to English-American literature.

The awareness of, and the interrelations with, other en/exclaves have so far not received the attention they deserve. The focus of research has, after all, been primarily on single American reading cultures. Part of my purpose is to pick up the few desultory observations that exist on Norwegian-American literature in the hope of coming at least upon traces of the "federated histories of American literatures."

\subsection{Norwegian settlement}

"Migration from Norway to the United States began in 1825," Øverland wrote in 1996. ${ }^{29}$ In 1990, A. W. Andersen had, more cautiously, described this arrival of a group of Quakers on the sloop Restauration as the beginning of "group migration" from Norway. ${ }^{30}$ At any rate, the "America fever" did not strike in earnest before the 1830s. Not in absolute figures but in relation to a native population, in 1845 , of 1.3 million living in a poor agricultural country, emigration from Norway was

29 Øverland, p. 3.

30 Andersen, pp. 23-24.

Marietta Messmer and Armin Paul Frank - 978-3-653-98855-0

Downloaded from PubFactory at 01/11/2019 10:57:20AM 
surpassed only by that from Ireland..$^{31}$ R. B. Morris listed almost 475,000 Norwegians migrating to the United States through 1900, and noted that statistics from 1820 to 1868 show combined figures for Norway and Sweden. ${ }^{32}$ The peak decade was the 1880s. Another 325,000 - or more than 10,000 per year - arrived through 1930, when there was an unprecedented drop to less than 5,000 in the entire next decade. Norwegians settled for the most part in agricultural Illinois, Wisconsin, Iowa, Minnesota, and South and North Dakota, with an overspill to the Pacific Northwest.

\subsection{Norwegian-Americans as readers and writers}

Norwegian settlers, most of them members of the Lutheran State Church, were particularly avid readers, certainly of the Bible and devotional literature, and turned out to be prolific writers on all sorts of topics. Both the periodical press and the book market attest to a vibrant Norwegian-American reading culture.

\subsubsection{The Norwegian-American periodical press}

As far as Norwegian-language newspapers are concerned, N. T. Eckstein asserted that they were essential to communications in and between the numerous isolated rural settlements. ${ }^{33}$ Factual observations offered by A. W. Andersen provide a good outline:

About five hundred titles came and went in the seventy-five years following 1847, the year in which Nordlyset (Northern Light) was founded in Racine County, Wisconsin. The average life span was ten years. About one-third survived a year or less. Cities most productive in publication were Minneapolis with about one hundred newspapers; Chicago with about seventy; and little Decorah, Iowa, with over thirty. A number of denominational periodicals, mainly Lutheran, were among the publications. Leading states in NorwegianAmerican journalism were Minnesota with about two hundred newspapers, Illinois and Wisconsin with about eighty, North Dakota and Iowa with over fifty, and Washington and New York with thirty-five and twenty-five, respectively. [...] Apparently the peak of publication came between 1877 and 1906. Since then the establishment of new journals has declined sharply. In the 1980s, only three Norwegian-language papers were being published, with much of their content in English. ${ }^{34}$

31 Cf. Øverland, p. 4.

32 Cf. Morris, p. 655.

33 Cf. Eckstein, p. 27.

34 Andersen, p. 214; for the German-American serial press, cf. Arndt/Olson. 
Most newspapers, it appears, were weeklies or bi-weeklies, with an annual subscription fee of $\$ 1$ or $\$ 2$ at the most. The number of dailies was extremely small. A complementary corpus, Øverland's, which, as part of a comprehensive literary history, lists individual contributions of a literary nature to serial publications of all types, confirms the geographical spread and the relative importance of the countryside as against the large urban centers. ${ }^{35}$ Some very few Norwegian-Americans were also published in Norway. A comparison with the German-American en/ exclave pattern is of some interest because it suggests possibilities of cooperation.

The number of German-American periodicals exceeded five thousand. ${ }^{36}$ Both the problems and the historical contour of the en/exclave press appear to have been similar. L. J. Rippley asserted that success in introducing German immigrants to American ways often resulted in the neglect of matters pertaining to the old country. As each generation of immigrants became one of old settlers, editors were caught between their German-American interests and the EuropeanGerman preferences of the newcomers. The mortality rate of German-American newspapers was about the same as that of Norwegian-American ones. ${ }^{37}$

But the "golden age of German-language newspapers" between 1848 and 1860 does not have a precise counterpart in the Norwegian-American en/exclave, mainly because immigration history differs. Disgruntled and persecuted supporters of the failed German revolution of 1848 arrived in numbers. Their radical democratic ideas found an outlet in journalism. There were approximately forty German newspapers in the United States in 1840, nearly twice the number at the end of the decade, and well over 250 in 1860. At the same time, the number of subscribers jumped, in the case of the daily New York Staatszeitung, from 4,800 in 1851 to 15,300 in 1856. Rippley also noted "major improvements in tone, substance, quality of editing, and layout." ${ }^{38}$

Rippley's account of the peak period at the end of the nineteenth century is similar to A. W. Andersen's summary of the Norwegian-American press between 1877 and 1906 cited above:

We note that in 1876 there were seventy-four German dailies, which had a total circulation of just under 300,000 . There were 374 weeklies, which had a combined list of subscribers in excess of one million. Thirty-one monthlies accounted for an additional 156,000 subscribers. In 1885, German papers represented 79 percent of all foreignlanguage publications in the United States. In 1890, the sum of German publications

35 My survey is based on 17.5 percent (letters A and B) of Øverland's author-based corpus.

36 Cf. Fluck/Sollors, p. 4.

37 Cf. Rippley, p. 161.

38 Cf. Rippley, p. 163. 
reached 727 - and this rose further to over 800 in 1894 [which in a single year amounts to 160 percent of the Norwegian-American press during its entire run]. This was the summit year for German journalism in the United States. Thereafter a decline set in, gradual at first, then more rapid. ${ }^{39}$

English-language magazines of the time also included a considerable number of extremely short-lived ones ${ }^{40}$; but there was no decline around 1900. In fact, both the number of magazines and their circulation figures steadily increased at a very high level of incidence. For 700 magazines (excluding newspapers) in 1865 and 1,200 in 1870, J. Tebbel and M. E. Zuckerman recorded more than 5,000 in 1895, and slightly over 6,000 in $1905 .{ }^{41}$ In the first decade of the twentieth century, the Ladies' Home Journal was the first magazine to reach a total circulation of one million, and in 1918, the Saturday Evening Post bested it with two million, with a few one-million magazines close behind. ${ }^{42}$ The decline, after 1900, of both the German-American and the Norwegian-American press appears to have had different reasons. For the number of German immigrants decreased, whereas Norwegian immigration continued at a very high level. There may also have been a common cause for the decline of the non-English press: Perhaps the almighty advertising dollar that now went into the English-language press made the difference.

After so many figures - what was the content of the Norwegian-American press? The immediate predecessors of early Norwegian-American newspapers - Øverland mentioned the very first one, Nordlyset (Muskego, Wisconsin, 1847) and, later, Skandinaven (Chicago, 1866) - started as correspondence societies formed in order to correct false perceptions of America. ${ }^{43}$ Newspapers were printed in the customary Black Letter, a font difficult to come by in the United States. This holds true also of the weekly Emigranten (Inmansville and Madison, Wisconsin), whose title looks back to the old country. This particular newspaper is characteristic in another respect, too. Run by the Scandinavian Press Association, it was, like many other and later periodicals, also a place for book publications. ${ }^{44}$ The periodical press contributed to the dissemination of literature in a more specific sense: The first of a large number of serialized novels is Julius Monson's Pleiedatteren (The foster

39 Cf. Rippley, p. 164.

40 Cf. Tebbel/Zuckerman, pp. 57-58.

41 Cf. Tebbel/Zuckerman, pp. 57, 68.

42 Cf. Tebbel/Zuckerman, pp. 68, 79.

43 Cf. Øverland, pp. 32-33.

44 Cf. Øverland, pp. 39-40. 
daughter) in Faderelandet (1867). ${ }^{45}$ In some instances, such serials seem to have helped tide over a newspaper during a lull in subscriptions.

The emphasis on letter writing in many periodicals suggests that the NorwegianAmerican press was not always a one-way communication. And it was not restricted to American matters. Of course, there were "new-country headline stories"; but there was space for "old-country lore" as well. ${ }^{46}$ Norwegian-language newspapers continued to look to their readers for the prototypical immigrants' writing, i.e. letters telling of their experience of cutting loose, of crossing the ocean, of getting there, of struggling to make it, and finally of settling down or failing to do so. ${ }^{47}$ Rölvaag's first work consists of such fictional - though near-autobiographical letters attributed to one P. A. Smevik and published under the name of Paal Mørck (the dark one) in 1912 (English version 1971). Letters, as O. T. Gulliksen has pointed out, were also received from regular correspondents whom Norwegian-American newspapers retained in those districts of Norway from which a large number of immigrants had come.

In Eckstein's view, the Norwegian-American press also served an important national purpose. The American township community had enabled Norwegians to keep essential parts of their native bygd culture alive: the dialects and regional customs of rural life in Norway. And though there was a revival of bygd regionalism in the early twentieth century, the press, according to Eckstein, was instrumental in finding a common denominator in the settlers' identity as Norwegians. ${ }^{48}$

\subsubsection{The Norwegian-American book market}

A good way of assessing the Norwegian-American reading culture is to compare it with the most extensive en/exclave literature, the one in German. Since no comparative studies exist, something like a rough sketch must do. Unfortunately, there is, in research, a constant discrepancy between what ought to be done and what can be done. No doubt, a good quantitative indicator would be book production - number of titles as well as sizes of print runs - in relation to the number of potential readers. Yet total publication figures of any precision are unavailable, and even basic statistics are wobbly at best.

45 Cf. Øverland, p. 98.

46 Gulliksen, p. 5.

47 Cf. Gulliksen, p. 5.

48 On the bygd revival, cf. Øverland, esp. p. 189; on national self-awareness, cf. Eckstein, p. 25. 
Much depends on who is recognized as an en/exclave author. Øverland included writings in Norwegian and, late in the career of some of these writers, in English, by "those who are American by choice or by birth." ${ }^{49}$ There is no exact German-American counterpart. For in his comprehensive bio-bibliographical compilation, R. E. Ward, less restrictive in this respect, included not only permanent settlers, but immigrants who returned to their native land after only a few years, globetrotters who arrived via Polynesia, stayed for two years, and went on to Brazil, travelers whose reports were published in German, and other such birds of passage. Their number is by no means negligible.

Corpora based on diverse criteria do not compare well. What can reasonably be done is to compare salient features of subcorpora for the decades when Norwegian-American literature was particularly strong, 1850-1930. In this way, it should be possible to identify trends or tendencies, pending later confirmation. With this in mind, I have examined letters A-B or 17.5 percent of Øverland's author-based bibliography of Norwegian-American writings of a literary nature, the hard facts in G. E. Condoyannis' unpublished Columbia University Ph.D. dissertation on German-American prose fiction, 1850-1914, Ward's uneven, incomplete data for letters A-B or 15 percent, 1850-1930, which offer neither quantitatively nor qualitatively reliable information, and a small but, I believe, particularly telling corpus: English-American literature in German translation, published in the United States, 1848-1912.

Letters A-B of Øverland's bibliography comprise 106 books of every description. An amazing 48 percent were privately printed. This is not, as one might assume, an instance of vanity publishing but, as Øverland asserted, a consequence of the rural residence of the reading public. A good part of the books was sold by mail order, and authors often preferred to gamble on an uncertain direct income that would, they hoped, turn out to be higher than the pittance publishers tended to offer for the rights. ${ }^{50}$ Geographically, 15 percent hailed from Chicago, 10 from Minneapolis; the rest came from rural Wisconsin, Minnesota, Washington, and Iowa, with the exception of one from Boston and another one from a Southern town with the beautiful Nordic name of Thorsby, Alabama.

The books published professionally in the United States date from 1847 to 1933. The geographical spread of publishers is similar in the sense that, again, only a minority of publishing houses were located in urban centers (Chicago, Minneapolis, Brooklyn, N.Y.), while most of them operated from rural Wisconsin, Minnesota,

49 Øverland, p. ix.

50 Cf. Øverland, p. 51. 
Washington, and Iowa. Altogether, 10 percent were published in Norway (Oslo, Bergen, Kristiansund), either as joint ventures or exclusively; one title appeared in Canada (Winnipeg). Only a handful or so were also published in English.

The salient factors of Condoyannis' German-American corpus are quite different. My observations are based on the sixty-four titles he was able to examine personally; about the same number proved unverifiable, including a fair number of serializations. ${ }^{51}$ The most striking difference, in my view, is that almost half of the titles, including three joint trans-Atlantic ventures, were published in Germany and Switzerland. Pending case studies, all one can do is entertain hypotheses: It may be that German-American authors continued to feel a strong allegiance to their literary home, which, much more so than in the Norwegian-American case, was reciprocated: Many German-language publishers, including leading houses, seem to have acted in the belief that there was indeed an interest in Germany in the literary fate of emigrants. Also, there are indications that the trans-Atlantic book trade with Germany was particularly active, and German-American authors had reason to expect that their books published in Europe would also sell in the United States. ${ }^{52}$

A quantitatively minor point of potentially great interest is the fact that three German-American novels appeared under the imprint of English-American publishers. What is more, one book published by G. Munro of New York in 1882 appeared in a series sporting a title straight from Die schönste Lengevitch: "Die Deutsche Library." I take this to suggest that the belief in a ready German-American market was not only held by duty-bound German-American publishers, but also by enterprising English-American ones. Simultaneously, the German-American publisher Steiger of New York ran two series, "Deutsch-amerikanische Bibliothek" and "Bilder aus dem Leben von Deutschen in Amerika"; for the 1890s, Condoyannis documented two series for young Christians, the one originating in St. Louis, Missouri, the other in Cleveland, Ohio.

Private printing was negligible; so was rural publication. I am not aware of any English translations. Cumulated with the German-American translations of English-American literature examined below, German-American works were published in a diamond-shaped area between Milwaukee, Wisconsin, in the North and Cincinnati, Ohio, in the South, and, on the East-West axis, between Boston, Massachusetts, and St. Louis, Missouri.

51 Cf. Condoyannis, pp. B625-29; I am indebted to J. Mittendorf for assistance, beyond the call of professional duty, in making an illegible microfilm decipherable.

52 Cf. Trommler, p. 34, presumably based on Cazden. 
German-American translations of English-American books form two subcorpora. The one is, I take it, close to definitive. It was compiled by H. Eßmann as part of a comprehensive survey of collections of poetry in German translation. It embraces eight titles of anthologies of translations of British and EnglishAmerican short poetry and collections of individual German-American poets' work, including translations. There are another three collections, two of translations of English-American poetry only and one of poetry from several literatures including English-American. They were translated and compiled by the GermanAmerican K. Knortz (1841-1918, migrated in 1864, Professor of German, author, translator) and published in Germany and Switzerland respectively. The second sub-corpus, eight volumes of English-American long poems, novels, and romances in German translation published in the United States, has been collected in a more haphazard fashion. As in Condoyannis' fiction corpus, the American publishers were all located in urban centers; three of the sixteen titles appeared under the imprint of an English-American publisher.

I studied this material on an earlier occasion, and these are the findings pertinent to the present inquiry ${ }^{53}$ : (1) To publish German translations of EnglishAmerican literature in the United States is to subscribe to the belief that there is a sizable German reading audience that has an interest in English-American literature but cannot read the language. I wonder whether translators in other en/exclaves shared this interest in the English-American literature around them. (2) I take it as a sign of an active reading culture that translations were made and poems composed not only by professional writers such as journalists but also by men in the professions and by tradesmen, on the side, as it were. ${ }^{54}$ (3) Indeed, a self-confident constituency of Germans defined by their language, literature, and culture was an American presence in the second half of the nineteenth century. Its interconnected co-existence with an English-American reading culture which was still not completely sure of its own ways can, in retrospect, perhaps be regarded as a form of encouragement: There was a definite interest in English-American literature, documented by the extra effort of translating and of publishing these translations, in the very country of origin. (4) By the evidence of published translations, the belief in the staying power of the German-American en/exclave culminated in the 1880s, well before the Great War put the fate of German-Americans in jeopardy. It is not easy to see why the interest in translations should diminish earlier

53 Cf. Frank, “Borderline Cases," pp. 231-32. My thanks go to W. Kindermann for allowing me to reuse this material.

54 Cf. Leser. 
than that in original work. Could it be that mediators in the service of a second literature and their publishers notice such shifts earlier than those who proudly promote literary self-interest? I am afraid the question cannot yet be answered.

\subsection{Relations, mostly literary, between the Norwegian-American en/exclave and Norway}

Extant studies make it possible to say relatively much about the relationship with Norway and precious little about connections with English-American literature and with some of the other en/exclaves. The termination of the union with Sweden in 1905 found "unanimous [...] support" in the Norwegian-American press. ${ }^{55}$ In a sense, the 1914 centenary of independence from Denmark was a festive conclusion of the political liberation of the Old Country.

In literary terms, Norway was also, in one way or another, a constant presence for many Norwegian-American writers. Some, like Ole A. Buslett, noted a dual foreignness-relation: "Our [Norwegian-American] literature 'is foreign to them [the Norwegians] - just as Norwegian literature is foreign to NorwegianAmericans, except for a few educated ones." 56 The alleged lack of education of Norwegian-American farmer-readers is, not without some justification, another recurrent theme and was, by the Church and Church-related bodies, often invoked to justify protective censorship. ${ }^{57}$ Rölvaag had noticed a variant of the dual foreignness point as early as in 1912 in his Amerika-breve (Briefe aus Amerika).

The opposite view, namely that a Norwegian-American literature was possible only by modeling itself on the literature of the Old Country, was entertained as well..$^{58}$ The question is, On what part of Norwegian literature? In the high-minded view of N. T. Eckstein, Norwegian-American writers owed much to the "unique cultural and national awakening which their homeland experienced during the latter half of the nineteenth century," and he explained:

The cultural renaissance in Norway can be seen as a natural corollary to the long struggle for nationhood, which the Norwegian people experienced throughout the nineteenth century, and finally achieved in 1905 . The more sensitive and literary-minded of the Norwegian-Americans were heavily indebted to such Norwegian writers as Bjørnstjerne Bjørnson and Henrik Ibsen, and, in almost every instance, the immigrant writers were

55 Øverland, p. 187.

56 Øverland, p. 191.

57 Cf. Øverland, p. 194.

58 B. A. Schmarling (1876), cf. Øverland, p. 104; J. B. Wist (1904), cf. Øverland, p. 193. 
much more thoroughly versed in Norwegian literature than they were in American and British literature. ${ }^{59}$

Bjørnson and Ibsen were writers around whom the controversy about realism raged. Many Norwegian-American critics blamed them for griselitteratur (something like "pigsty literature") and praised Norwegian-American writers who eschewed their influence for providing purer and more wholesome works. ${ }^{60}$

Eckstein's view that Norwegian-American authors had only a limited knowledge of English-American literature is at contretemps with a claim made by $\mathrm{O}$. T. Gulliksen at the beginning of his survey of Rölvaag criticism. He was sure that "Norwegian-American immigrant authors enjoyed the privilege of writing from a position in which they inherited the literature of two nations as their own." ${ }^{61} \mathrm{I}$ will take up this issue below in its appropriate context of Rölvaag criticism. All I need to say here is that there is precious little extant criticism and scholarship on connections between Norwegian-American and English-American literature. Øverland occasionally noticed a parallel with an English-American work but is never certain whether it is accidental or part of the writer's art.

\subsection{As for connections with other en/exclave literatures}

There are a few notes in Øverland that suggest potentially promising further inquiries. Advertisements for bookstores in Wisconsin selling both German and Norwegian books indicate cooperation of the two reading cultures in the distribution sector. $^{62}$ Was there also cooperation between printers and publishers? The family magazine For hjemmet is on record for fiction and poetry "from Dano-Norwegian, English, and German sources." And in 1884, a collection of poems by C. Rasmussen was graced by an "introductory lyric in German." ${ }^{63}$ Given the international prestige of German literature, admittedly somewhat dusty at the time, it may be worthwhile to explore the Norwegian-American interest in German literature as manifest in literary and cultural magazines. It is, after all, certain that the GermanAmerican reading culture was observed by some Norwegian-Americans. A case in point is the fact that R. B. Andersen, a professor of Scandinavian languages at the University of Wisconsin, recommended following the German-American

59 Eckstein, p. 26.

60 Cf. Øverland, p. 191.

61 Gulliksen, p. 185.

62 Cf. Øverland, p. 47.

63 Øverland, pp. 56, 228.

Marietta Messmer and Armin Paul Frank - 978-3-653-98855-0

Downloaded from PubFactory at 01/11/2019 10:57:20AM 
example of publishing "the literature of their country." ${ }^{44}$ It might make sense to begin by studying the editorial policy of Scandinaven's "husbibliothek" and Steiger's "Deutsch-amerikanische Bibliothek."

\section{Ole Edvart Rölvaag in Literary Historiography}

Born Ole Edvart Pedersen in 1876 and a Lofoten fisherman by trade, the later professor and writer emigrated in 1896 and adopted the family name of Rölvaag in $1898 .^{65}$ (I should, perhaps, add that I vary between this American spelling employed by the author for his English-American translations and its Norwegian counterpart, Rølvaag, depending on the context.) After working for two years as a farmhand, he was able to refund his uncle for the trans-Atlantic ticket which he had received. In 1898, he began his professional training by attending highschool and continuing on to St. Olaf College in Northfield, Minnesota. After a year of advanced studies in Kristiania (now Oslo), he became professor of Norwegian at St. Olaf in 1906. This pattern of an American college degree, a period of advanced study in Europe, and the return to a professorial appointment had been set by G. Bancroft, H. W. Longfellow, and others in the 1820 s.

Rölvaag's work is clearly connected with three of the four pertinent contexts: the Norwegian-American one in the United States (enclave), the old country (exclave relation), and the encompassing English-American one. Links to other literatures have, to the best of my knowledge, never been explored systematically. His first book was, to his chagrin, rejected by a Norwegian publisher so that his first four novels eventually appeared in Norwegian in America in the years 1912 to 1922 under the imprint of the official publisher of the United Norwegian Lutheran Church, Augsburg in Minneapolis, Minnesota. The four volumes of his settlers' saga were published by Aschehoug in Oslo, 1924-31. English versions appeared near-contemporaneously as Giants in the Earth, Peder Victorious, and Their Fathers' God. A small indicator of the en/exclave relation is the anomaly that the Hansa/Holm family story is a tetralogy in the original Norwegian but a trilogy in English translation.

\subsection{Rölvaag in Norwegian-American literary historiography}

In Øverland's literary history of vesterheimen, Rölvaag, the only NorwegianAmerican writer reasonably well known outside his en/exclave, is the subject of

64 Cf. Øverland, p. 58.

65 Cf. Haugen, p. [xiii]. 
the last and longest of six essays in the concluding section on individual authors. The contour of his life's work follows the development of the immigrant, Per Smevik, in his first, epistolary novel, Amerika-breve (1912): alienation and acculturation. ${ }^{66}$ It is, I take it, characteristic of the career of Norwegian-American literature as seen by Øverland that the fictional addressees of Smevik's letters reside in Europe, whereas the second novel, Paa glemte veie (1914 On forgotten paths) "addressed itself to the immigrant community."67 Though this argument depends on a confusion between fictional and implied addressees, it makes sense insofar as Paa glemte veie focuses on a conflict within the Norwegian-American Lutheran community between traditional piety and the new social gospel. The latter is, of course, not an exclusively Norwegian-American phenomenon. Rölvaag, therefore, "mediat[ed] between his ethnic group and a larger America." In a novel written in a variety of Norwegian, this mediation could, of course, work only for readers of the language. And the idea of mediation underlines Øverland's point that Rölvaag wrote specifically for Norwegian-American readers.

The next two novels, To tullingers (1920, Two fools) and Loengselens baat (1921, The boat of longing), Øverland averred, exemplify the new critical position Rölvaag had developed after the Great War. They are often regarded as American literature in Norwegian, as American fiction with an ethnic background..$^{68} \mathrm{I}$ hesitate to use "ethnic" in contexts such as these because it suggests an ethnological difference between English-Americans and members of an en/exclave, which certainly does not exist in the case of most immigrants from Europe. Despite this unfortunate terminology, Øverland, making extensive use of A. Moseley's studies, characterized the two novels as though they were English-American. ${ }^{69}$ The two fools destroy their lives by hoarding their money while they live as paupers. Øverland identified this theme of greed as a "quintessential American theme," though it is quintessentially Dickensian, too. He found it developed in such characters as Henry Sutpen, Jay Gatsby, and Bigger Thomas as well as in the naturalistic downward spiral not only of Frank Norris' McTeague (1899) but also of Erich von Stroheim's Hollywood version, Greed (1924). ${ }^{70}$ And Nils Vaag, the dangling (immigrant) American of Lengselens baat, is compared with Jimmy Herf, alone and on the road at the end of John Dos Passos' Manhattan Transfer (1925). I wonder whether scrupulous comparative analyses of point of view, theme, plot, character,

66 Cf. Øverland, p. 348.

$67 \varnothing$ verland, p. 350; also next quotation.

68 Cf. Øverland, p. 351.

69 Cf. Moseley; cf. Gulliksen, pp. 200-01.

70 Cf. Øverland, p. 352. 
description and style might not bring to light similar intimate connections with Norwegian literature, particularly since Rölvaag continued to teach it.

In this view, the immigrants' saga - I de dage (1924, In those days) and Riket grundloegges (1925, The kingdom's foundations), both combined in an English version as Giants in the Earth (1927), and Peder Seier (1928, Peder Victorious) and Den signede dag (1931, The blessed day, translated in the same year as Their Fathers' God) -, which tells of the "bitter struggles of Beret" and the "broken dreams of her husband and her youngest son," is also a story of "misspent lives."71 Again, it is characteristic that the sequence is linked with English-American literary culture when Per Hansa is identified as an American Adam: as a character who is able to cut loose from his European past (with which Beret remains painfully entangled), who lives pragmatically, and "can take pleasure in what is to come," particularly by wresting wealth from the American soil.

Again, Øverland found an English-American context for the 1931 volume. It portrays a "marriage that in its claustrophobic self-destruction may be compared to that of Jim and Ella in O'Neill's All God's Chillun Got Wings (1924)." But if attention is paid not only to similarities but also to differences, a careful reader will notice that the play cannot be dissociated from its black American theme. It differs significantly insofar as Ella's neurotic behavior effectively reduces Jim ("Crow") to a simple-minded, good-hearted "Uncle Tom.” Though Per Hansa's ambitions also come to naught, he does not really suffer a similar debilitating fate. And while in the play, fate is acted out exclusively between Ella and Jim, important destructive action in Den signede dag originates outside the core family, as in the bitter satire of the double baptism: The secret baptism according to the Lutheran rite of Peder's and his Catholic-Irish wife's son is arranged for by his Lutheran grandmother Beret, and the Catholic baptismal rite is initiated by his Catholic grandfather on his mother's side and also administered without the father's knowledge. If it is a matter of finding a parallel, a better one might be the early Puritan jeremiad, in the sense that - in the view of the other immigrants - Peder's materialistic falling away from the faith of his fathers is the "quintessential" sin of the first Americanborn generation. ${ }^{72}$

Two points are, however, more important for Øverland's interpretation of Rölvaag's representative career. The one concerns the English language: Den signede dag is the only one of the novels whose English translation appeared in the same year. And it seems that at the end of his career the author "toyed with

71 Cf. Øverland, p. 357; next two quotations pp. 360, 364.

72 On the jeremiad in Rölvaag, cf. Gulliksen, pp. 157-58. 
the idea of making English his language" when he used it for his fragmentary autobiography. ${ }^{73}$ The other point is connected with the fact that Peder's career as a politician fails dismally before it has even begun, and his young marriage breaks up, due to a large extent to the fact that his wife served as informant for his political adversaries. It may well be that the ending of Their Fathers' God can be read as a symbol of the termination of literary vesterheimen as an active reading culture. But then, Rölvaag seems to have had a sequel in mind. ${ }^{74}$

\subsection{Rølvaag in Norwegian literary historiography}

In the literary histories accessible to me, I found Rølvaag discussed only in recent ones. In the volume edited by H. L. Naess (University of Nebraska Press, 1993), he figures in the chapter "In Search of Norway's Soul." The emphasis is on "artists with organicist notions of culture" in the traditions of J. G. Herder and N. R. S. Grundtvig, who focus on the "folk soul," which cannot be found in the alienated urban proletariat but only in the "rootedness" of "local, rural cultures." 75

Rølvaag fits this description only insofar as one important interest in the Hansa/Holm saga concerns the settlers' psychology in building a culture that is rural and, at first, emphatically local. But it is a psychology that needs to come to grips with the experience of uprootedness and the pioneers' struggle not only to make the uncultivated land their own but to make themselves over to meet the demands of the new land and its plurinational society. Complications of this sort make Naess realize that Giants in the Earth is not an "allegory through which Norway might perceive itself."76 The settler family's saga is, rather, identified as a "classic of American Midwestern fiction" about the "hidden cost imposed by the melting pot." This view was to be expected from a literary history emerging in the Midwest. But if one takes a leaf from Reverend Kaldahl in Their Fathers' God, the "emigrant[s]" do, indeed, display Norwegian spirit: the indomitable spirit of Vikings, though this time not as seafarers but on the rolling prairie. Rølvaag is reported to have called the Norwegian settlers "the Vikings of the Middle West." ${ }^{\prime 7}$

73 Øverland, p. 368.

74 Cf. Haugen, p. 98.

75 Naess, p. 226.

76 Naess, p. 236; also next quotation.

77 Cf. Haugen, p. 96.

Marietta Messmer and Armin Paul Frank - 978-3-653-98855-0

Downloaded from PubFactory at 01/11/2019 10:57:20AM 
Even more than Naess's literary history, the multi-volume one edited by E. Beyer in 1975 roped Rølvaag into the European-Norwegian context. ${ }^{78}$ (I have had access to the 1995 edition.) In a chapter on the New Realism, he is depicted as an emigrant who always regarded emigration as a great tragedy and who made nostalgia for the land of his fathers his perennial theme. I de dage and Riket grundlogges, taken together, are compared with an Icelandic family saga, encapsulating a thousand years of Norwegian cultural and social life within the space of a single generation. And quoting G. H. Gvåle to the effect that the two volumes offer "one of the most beautiful and searching contributions to the literary charting of the psychic character of our nation," the author incorporated the Norwegian-American writer completely into the literary and cultural concern with a "Norwegian soul," from which he was excluded in Naess's literary history.

The world and life of the first American-born generation, Peder Seier and Den signede dag, are unlocked by the English title of the latter volume, Their Fathers' God. From one point of view, it evokes the ancestry still alive in the present generation. But insofar as the Lutheran Norwegian's marriage with an Irish Catholic girl ends in catastrophe, there are passages where the title phrase comes close to reading, their fathers' gods. Instead of accepting this disruptive ending, the literary historian preferred a conciliatory one: He characterized Beret's leave-taking and death as one of the greatest scenes in Norwegian New Realism, full of pathos but not sentimental, and reminded his readers that the title, Den signede dag, is a quotation from a Grundtvig hymn, which culminates in praise extended "til vårt fedreland": to the country of our forefathers.

\subsection{Rölvaag in English-American literary historiography}

It is an interesting point in the relation between an en/exclave and the encompassing culture that Rölvaag is considered an English-American author on the strength of translations, not on that of original work. It is a central idea in the chapter on the "Mingling of Tongues" in Spiller's Literary History that the authors writing in languages other than English eventually fall into step with the march of EnglishAmerican literature. So it may not come as a surprise that, on the strength of Amerika-breve and the three volumes of the immigration saga in English translation, Rölvaag figures as a representative American author, one who told the "story of the immigrant's part in the making of the great new nation" as though it were

78 Cf. Beyer, pp. 363-66. I am greatly indebted to Fritz Paul for steering me through the Norwegian text. 
a single story. ${ }^{79}$ In the two pertinent Columbia volumes, Rölvaag appears under the label of ethnicity: In the comprehensive Columbia Literary History, he is listed, together with Abraham Cahan, Anzia Yezierska, and Henry Roth, as among the "nation's first major ethnic writers." ${ }^{80}$ And in the Columbia History of the American Novel, in the chapter on "Ethnicity and the Marketplace," he is cited for the same works as in Spiller, but now for their Norwegian rather than their American traits. The fact that the name of the "female protagonist" of Giants in the Earth is given as "Beret Holm" and that of "her husband" as "Per Hansa" is not the only puzzler in these comments on Rölvaag's books. ${ }^{81}$

Little has been done on the translations. It is hardly of interest to have a bilingual reader expatiate upon how good or faithful the translations are because the idea of what makes for good and faithful translating varies considerably. However, it would be good to know in what ways the imagined world evoked by the translation differs from the one evoked by Rölvaag's Norwegian text.

\subsection{Critiques of the Hansa/Holm saga}

A promising approach is O. T. Gulliksen's. He proposed that Norwegian-American literature involves no less than two languages and three cultural contexts: the Norwegian-American, the European-Norwegian, and the English-American one. It should be added that the world of the Hansa/Holm saga actually involves yet another nationality at the same level as the Norwegian-American, i.e. the Irish, because, though English-speaking, they did not really represent English America, since their Roman Catholicism was felt to be un-American. Even so, it makes sense to study Gulliksen's threefold contextualization in the light of his presuppositions. If I see it correctly, he claimed that such contexts are equally made by authors and critics. ${ }^{82}$ He was certain that Norwegian-American "[r]eaders and writers, from the relatively anonymous to professionals like Ager and Rølvaag, all developed a 'double consciousness."'83 This was so, he thought, because "Norwegian-American immigrant authors enjoyed the privilege of writing from a position in which they inherited the literature of two nations as their own." It follows that Giants in the Earth presupposes firsthand knowledge of two national bodies of text. In his novels, Rølvaag combined his reading of old-country sagas

79 Spiller, pp. 689-90 at 690.

80 Cf. Elliott, Columbia Literary History, p. 726.

81 Elliott, Columbia...Novel, pp. 389-91 at 390.

82 Cf. Gulliksen, pp. 185, 192.

83 Gulliksen, p. 185; also next quotation. 
and fairy tales, his familiarity with Knut Hamsun and Søren Kierkegaard, with his memory of stories told by earlier Norwegian immigrants in the Midwest, and with his knowledge of American frontier farmers. ${ }^{84}$

I take exception, both in general and in particular terms. In the first place, inheriting even a single literature is not as easy as Gulliksen seems to think. Under Civil Law, inheriting is what happens to a person. Whenever literature and culture are concerned, it is a matter of intensive, prolonged, and joyful activity, on the part of the "recipient," so-called. Here, Goethe's thoughtful adage applies, which, unfortunately, did not make it into the Oxford Book of Quotations (1955): "Was du ererbt von deinen Vätern, erwirb es, um es zu besitzen" - What you inherited from your fathers, acquire it so that you may possess it.

While Norwegian-Americans may well have realized that their lives involved two languages and, indeed, two ways of life, that of the Norwegian cotter and the American farmer, the reading knowledge of the majority, though intense, was, as a rule, fairly limited: to the Bible and devotional literature. The limitations of Norwegian-American farmer-readers and writers are a constant theme in Øverland. ${ }^{85}$ And in the practical application to Giants in the Earth, the "two national bodies of text" dwindle considerably. While it is true that critics can recognize the presence, in a work under study, of only such other literary works as they have read, it is equally true that not everything they bring to their reading makes sense. Only the author can inscribe contexts into a work. All that critics can do is read correctly, or misread. What they read into a work may help to characterize their approach but not necessarily the work in question. It is in this cautionary sense that I examine Gulliksen's construction of the three contexts.

\subsubsection{European-Norwegian perspectives}

Gulliksen identified G. H. Gvåle and I. R. Kongslien as scholars writing from a European-Norwegian perspective. ${ }^{86}$ Their approach consists in "giv[ing] Rølvaag a place in the formation of a Norwegian canon." ${ }^{87}$ Gvåle, he averred, "delineate[d] Rølvaag's Norwegian nineteenth-century cultural ballast" - the "national-romantic ideology of which Rølvaag was a product" -, which "had no chance of being

84 Gulliksen, pp. 185-86; he gave two dates for Rölvaag’s death, 1931 (p. 185) and, erroneously, 1939 (p. 193).

85 Cf. Øverland, pp. 75, 77, 78, etc.

86 Cf. Gulliksen, pp. 188-92; "European Norwegian” is not his term.

87 Gulliksen, p. 192, cf. pp 188, 191. 
transplanted." 88 And it is Gvåle's contention that what Rølvaag may have reaped from American culture was only there to strengthen what she considered the best of his Norwegian roots. This curious argument has also been brought forward by American literary nationalists when they claimed that American Transcendentalists borrowed from German literature only what they had already developed on their own. As to the literary company that Rølvaag kept, Gvåle found that Arne Garborg, Bjørn Bjørnson, Henrik Ibsen and Aasmund O. Vinje provided the foundation on which he built; after all, he "constantly referred" to them. ${ }^{89}$ Gvåle also named Henrik Wergeland and featured "[Nobel laureate] Sigrid Undset and Olaf Duun's masterpieces of the 1920s" as the writers and works that "inspired [him] most of all." There are other works which Gvåle mentioned as "influential" though they were not recognized by Gulliksen. I refer in particular to Gustav Frenssen’s Jørn Uhl (1901), primarily for the similarity in its description of the link between man and soil..$^{90}$ Another Nobel laureate, Knut Hamsun, has on occasion been described as an object of Rølvaag's anxiety of influence. ${ }^{91}$

The company that I. R. Kongslien chose for Rølvaag consists of writers of "novels of emigration," among them Johan Bojer, Vilhelm Moberg, and Alfred Haugen. But it is evident that the perspective of a novel of emigration is contrary to that of an immigrants' novel. ${ }^{92}$ Gulliksen felt that to emphasize "the tragedy of the emigrant," as Kongslien did, and to assume that "leaving Norway is a tragic act" are hallmarks of the European-Norwegian perspective. This is, I submit, too easy a lineup. As already mentioned, Gvåle noted quite a different tragedy in Peder Victorious: Language difference eventually destroys one of the most intimate ties, that between mother and child. ${ }^{93}$ By holding on to her Norwegian language and religious and moral heritage, Beret is, in a sense, the emigrant in a family of immigrants. Is this conflict a personal matter? Is it characteristic of Norwegian immigrants? Is it an American experience shared by immigrants to the rural Midwest? The evidence at hand suggests that only the first case applies.

88 Gulliksen, pp. 188-89; next quotation p. 189.

89 Gulliksen, p. 190; also next quotation.

90 Cf. Rölvaag, Peder, p. xviii.

91 Cf. Haugen, pp. 72-73.

92 Cf. Gulliksen, p. 191; next quotation, p. 192.

93 Cf. Rölvaag, Peder, p. xii. 


\subsubsection{The Norwegian-American perspective}

Gulliksen felt, is difficult to identify. He reserved this category for "those readers who, at the time of the Midwestern Norwegian-American written culture, knew Rølvaag personally and placed him in a Norwegian-American context," irrespective of whether they read him in Norwegian or English. ${ }^{94} \mathrm{He}$ named, in particular, E. Haugen, T. Jorgenson \& N. O. Solum, F. K. Paulson, and R. L. Stevens, and referred to the oral observations by C. Clausen. ${ }^{95}$ The criterion of personal acquaintance is unfortunate and, I believe, unnecessary, particularly since it excludes the most thoroughgoing study of Norwegian-American literature, O. Øverland's. Gulliksen then discussed Norwegian-American criticism in his sense of the word under four heads: adulation ${ }^{96}$; the dilemma of language, i.e. to write Norwegian in America was to write for oblivion. ${ }^{97}$ Under the head of realism, Gulliksen listed testimonies to the effect that some immigrants faulted parts of Rølvaag's novels because they ran counter to their own experience..$^{98}$ Finally, he collected opinions saying that the immigrant experience was not tragic. ${ }^{99}$

\subsubsection{English-American perspectives}

Characterizing it as a "history of ideas"-approach which "consider[s] Rølvaag to be part of the American literary canon," Gulliksen found this "contemporary approach to Rølvaag to be the most pertinent, fruitful, and exciting for the future."100 One of its anomalies is that a translation can become a "standard text" either because critics do not know Norwegian or because they "rightfully" consider it as such. The first stipulation is accidental and therefore not a good reason, the second is problematic. There is, of course, no objection to reading a translation if one does not know the language. This is, after all, what translations are for. But as far as comments on translations are concerned, both monolingual critics and monolingual readers simply cannot understand in what respects the particular translation reinterprets the original. The differences between languages, literatures, and cultures make deviations from the original inevitable even if its author

94 Gulliksen, p. 188, n. 5.

95 Cf. Gulliksen, pp. 192-99.

96 Cf. Gulliksen, p. 193.

97 Cf. Gulliksen, p. 194.

98 Cf. Gulliksen, pp. 196-97.

99 Cf. Gulliksen, p. 198.

100 Gulliksen, p. 199; also next quotation.

Marietta Messmer and Armin Paul Frank - 978-3-653-98855-0

Downloaded from PubFactory at 01/11/2019 10:57:20AM 
had a hand in the translation, as Rølvaag did in the case of most volumes of the Hansa/Holm saga.

But the authenticity of the text is not Gulliksen's concern. The links with English-American literature that he is interested in have not necessarily come about by "conscious borrowing on Rølvaag's part" nor, one should add, by purposive response strategies. He is satisfied to find "merely suggestions for possible comparative reading." ${ }^{101}$ Among the critics who provided such suggestions, three are most prominent: A. Moseley, for whom it is important to analyze not Rølvaag's Norwegian-American characters - women and men, parents and children - but "how his fiction reveals the American character as a whole," i.e. the problematic national character known from earlier phases of American Studies ${ }^{102}$; R. Scholes, whose "concern is how Beret makes sense to American readers today" 103 ; and H. P. Simonson, who has

a way of implicitly suggesting thematic connections and pointing to parallels in his own reading of American literature. He, like Scholes, is making his own Rølvaag text by combining texts in his literary consciousness, as the only way to make the immigrant writer present.

In a later essay,

Simonson defines his neo-orthodox reading more specifically. Beret's religious faith undergoes "terrible tests" on the prairie [...], terrible because, at least in the beginning, they necessarily occur outside and beyond the protection of cultural ties she has been accustomed to at home. She therefore comes to dramatize a Barthian contrast between culture and faith.

My reading of Moseley and Simonson is different. In her effort to recommend the English Rølvaag to English-Americans, Moseley placed the Norwegian-American author in relation to several English-American writers and to prominent AmericanStudies interpretations. At one point, she linked him with the "basic American situation" interpreted in terms of R. W. B. Lewis' description of the "American hero as an American Adam - 'an individual emancipated from history, happily bereft of ancestry."' 104 Taking up this cue, Gulliksen extolled Per Hansa as "in more than one sense, the very incarnation of the ideal American in Lewis's mythology" and quoted "happily bereft of ancestry," together with a considerable part of the context. ${ }^{105}$ But in

101 Gulliksen, p. 200.

102 Moseley, p. 6.

103 Gulliksen, p. 201; next two translations, pp. 204, 206.

104 Mosely, p. 14; Lewis, p. 5.

105 Gulliksen, pp. 200-01. 
order to accommodate Rølvaag, Moseley had, unlike Gulliksen, gone on to modify Lewis by drawing on the major modern theme of alienation, defined as a state of "being unhappily 'bereft of ancestry."'106 In other words, Rølvaag did quite the opposite of perpetuating the myth of the American as the migrant who, in order to become a new man, gladly shakes off the yoke of European history. And with due respect to Moseley, Per Hansa is not Crèvecoeur's American farmer either. Perishing a few years after settlement, he leaves the farm to his wife to realize his dream, with improvements of her own added on. Unlike in Crèvecoeur, the success, which this female American farmer has in the end, derives not from cutting her European roots but precisely from keeping them intact. This conclusion is in keeping with Rölvaag's conviction that emigration is a tragedy when the immigrants disregard or forget their roots.

\section{An Invitation}

Where has this survey of Ole Edvart Rölvaag as Norwegian-American writer taken us? What perspective does it open on the literary culture of the British colonies in North America and the subsequent United States? Can it serve as something like a blueprint for the "federated histories of American literatures," for a comprehensive, integrated historical study of this particular literary culture? Can I encourage readers to develop such an approach by building on the case of Rölvaag, on K. Mueller-Vollmer's and my study of the literature of British America and the United States, 1770s to 1850s, on an ambitious project, Do the Americas have a Common Literary History?, edited by B. Buchenau and A. Paatz, or on the reader's own particular expertise? In any event, I can vouch for the fact that comprehensive American Studies succeed best as a team effort.

\subsection{Generating research perspectives from the concept of reading culture}

Guided by this concept, it is possible to identify a number of questions or inquiries that promise to achieve the intended purpose. In the end, their validity depends, of course, on the circumstances of each particular case. The subsequent roll call is not a complete listing but focuses on the most important issues.

As will be remembered, "five plus one" activities, together with the appropriate agents and institutions, make up a reading culture: the making, distributing,

106 Moseley, p. 14; italics in the text.

Marietta Messmer and Armin Paul Frank - 978-3-653-98855-0

Downloaded from PubFactory at 01/11/2019 10:57:20AM 
reading, discussing, evaluating for the purpose of preservation, and transferring of literature.

Authors are not born. Rather, citizens and taxpayers become writers by producing literary work. For Norwegian-American literature as part of the comprehensive American literature, the most significant methods of writing are, in descending order of importance, those which engage the following bodies of literature: other Norwegian-American works, the literatures of Norway, English America, other en/exclaves, and other literatures of the world. A critical point is reached when an en/exclave writer gives up his native language and adopts English as his medium. It stands to reason that this spectrum is applicable to other immigrants from Europe.

This engagement potentially involves all levels of a work as well as all "inferents," all imaginative constructs such as point of view, theme, character, unit of action, etc. that can be inferred from the text. Identical and highly similar features suggest a writer's familiarity with a given work, differences characterize the way in which the work is placed in a culture or between cultures. Does it lean more towards the Norwegian or the American side of the hyphen? Does it recognize other en/exclave cultures? As competitive or cooperative? Does it stabilize, expand, or dissolve Norwegian-American literature? A list of perspectives for generating pertinent questions for research is provided in K. Mueller-Vollmer's and my The Internationality of National Literatures in Either America: Transfer and Transformation..$^{107}$

Studies of distribution may well begin by compiling statistics for book and periodical publication. A more inquisitive interest extends to agents and agencies that make literary work available to potential readers. Such studies help to identify centers of a given reading culture and to recognize the "open field publishing" that characterizes Norwegian-American literature. Does a publisher specialize in a single en/exclave literature? Does he serve more than one? If a publisher of English-American literature also handles one or more en/exclaves, is this a matter of economic expediency or an act of confidence in the staying power of these literatures in America?

The periodical press provides an excellent testing ground. Are there statements of editorial intent? How do they correlate with editorial practice? Is the editorial policy monocultural or pluricultural? Monolingual or plurilingual? What do the texts themselves and their arrangement tell about how the editorial board positioned itself in the cultural configuration of comprehensive American 
literature? In religion? In politics? Do editorial decisions correlate with publication figures?

Whenever editorial policy extends to several en/exclaves and, possibly, to the encompassing literature as well, there is excellent material for a comparative study in terms of both statistics and the interpretation of actual texts. If NorwegianAmerican periodicals paid attention to German or German-American literature, as a few of them did, did German-Americans reciprocate? Or is the relationship between the two en/exclave literatures asymmetrical? If so, precisely in what way and for what reasons?

Reading as such is an elusive matter. Acts of reading can, at best, be estimated by the study of critical pronunciations and historical interpretations. The historian can often learn more about the capabilities - not the actual performance of readers by examining school and college curricula and such documents as valedictory addresses or articles on teaching. In this way, one can obtain a sense of the preparedness of the potential reading audience.

As far as discussing or commenting is concerned - critical, interpretative, or historical, and sometimes in the form of responsive works by other writers: all this is welcome as a guide to the reading culture in question. In pursuit of a comprehensive history of literatures in America, the more telling documents are responses across the usual set of dividing lines, because they offer insights into such facets as potential or actualities, engagement or neglect, inclusion or exclusion, cooperation or counteroperation, appropriation or rejection.

Evaluation, in one of its senses, is part of commenting, and frequently controversial and combative. Evaluation in view of preservation in archives and libraries for the purpose of future use differs in an important way. The investment of labor and resources in the establishment and maintenance of these storehouses of the past usually places the seal of social approval on the preceding critical discussion. Anthologies are particularly important because they combine preservation with actualization. Libraries as reservoirs of writing and print culture, sonic recordings included, are an interesting reminder that, unlike in oral cultures, mediation from past to future is not a matter of tradition, of handing down from generation to generation but a gathering up of ideas, forms, devices, quotations, etc. on the part of writers - of promising young women and men or seasoned war horses of literature alike -, any place, any time. To insist that, in literate and literary cultures, there is no tradition to speak of, only recovery - a term fresh enough to redirect the attention in ways which the overworked "reception" no longer can - may contribute to the phasing out of ideas associated with oral cultures that no longer make sense in a print culture, print here referring to any kind of material record. 
Finally, the linking of reading cultures is a matter of transfer, with translation the most effective activity. The classical and neo-classical practice of imitatio veterum was an early prestige form. It makes sense to subsume, under transfer, considerations of agents and agencies, networks and regimes, and the shipment of literary goods, all of which promotes international literary commerce. A literary translation can be identified as such wherever an actual writer's name is linked with the title of a work in a language other than the one in which it was written. Categories for the study of translations in view of a cultural history of this interliterary practice have been discussed in my encyclopedia article on this matter. ${ }^{108}$ With a comprehensive history of American literatures in view, it makes sense to identify the argumentative and imaginative differences between source text and translation because they throw a light on the translators' attitudes towards their authors and their literatures.

\subsection{Connections: Inscriptions in Rölvaag's works}

A thorough study of the range and precise nature of Rölvaag's inscriptions can, of course, draw on extant research. It is clear that Rölvaag made considerable use of European-Norwegian literature in writing his own works, but at best an insignificant one of Norwegian-American and English-American literature, and hardly any of other literatures, whether en/exclave or national. Before striking out into new areas, it may be a good idea carefully to reexamine the literature on this subject in view of the important distinction between relationships that are due only to the critic's reading and actual inscriptions on the author's part. Rølvaag's boyhood reading and reading preferences are known. So is, I believe, his reading when a student at St. Olaf College around the turn of the century, and use was made of his class notes as professor of Norwegian language and literature. Given the time of his most intensive training, N. T. Eckstein's suggestion to examine his work in relation to the "unique cultural and national awakening which [his] homeland [Norway] experienced during the latter half of the nineteenth century" is decidedly a good idea. ${ }^{109}$ E. Haugen and others have also called attention to his use of the work of the eminent (near-) contemporaries, among them Nobel laureates Knut Hamsun and Sigrid Undset. ${ }^{110}$

Inquiries of this kind are particularly meaningful when they are dynamic, not static. When they aim at establishing a state of affairs, there is a tendency to make

108 Cf. Frank, “Translation research.”

109 Eckstein, p. 26.

110 Cf. Haugen, p. 72.

Marietta Messmer and Armin Paul Frank - 978-3-653-98855-0

Downloaded from PubFactory at 01/11/2019 10:57:20AM 
protagonists disappear in systems. When the objective is to outline a complex set of actions and transactions and their eventual outcome, there is a good chance of depicting literary life as it was.

\section{Works Cited}

Andersen, Arlow W. Rough Road to Glory: The Norwegian-American Press Speaks Out on Public Affairs, 1875-1925. Philadelphia, Penn.: Balch Institute Press, 1990.

Arndt, Karl J. R., \& May E. Olson. German-American Newspapers and Periodicals, 1732-1955. Heidelberg: Quelle \& Meyer, 1961.

Bercovitch, Sacvan, gen. ed. The Cambridge History of American Literature, vol. 1, 1590-1820. Cambridge, Engl.: Cambridge Univ. Press, 1994.

Beyer, Edvard, ed. Norges Literaturhistorie. Vol. 4. Oslo: Cappelen, 1995.

Blumenthal, Henry. American and French Culture, 1800-1900: Interchanges in Art, Science, Literature, and Society. Baton Rouge, La.: Louisiana State Univ. Press, 1975.

Buchenau, Barbara, \& Annette Paatz, in cooperation with Rolf Lohse \& Marietta Messmer, eds., and with an Introduction by Armin Paul Frank. Do the Americas Have a Common Literary History? Interamericana 1. Frankfurt a. M.: Lang, 2002.

Cazden, Robert E. "Der Nachdruck deutschsprachiger Literatur in den Vereinigten Staaten, 1850-1918." Archiv für Geschichte des Buchwesens 31 (1988): 193-202.

Condoyannis, George E. “German American Prose Fiction from 1850-1914." Unpubl. Columbia Univ. Ph.D. dissertation, 1953.

Deutsch-amerikanischer National-Bund, ed. Das Buch der Deutschen in Amerika. Philadelphia, Penn.: Walther, 1909.

Eckstein, Neal T. The Marginal Man as Novelist: The Norwegian-American Writers H. H. Boyesen and O. E. Rølvaag as Critics of American Institutions. New York: Garland, 1990.

Elliott, Emory, gen. ed. Columbia History of the American Novel. New York: Columbia Univ. Press, 1991.

Elliott, Emory, gen. ed. Columbia Literary History of the United States. New York: Columbia Univ. Press, 1988.

Eßmann, Helga, ed. Anthologien mit Dichtungen der britischen Inseln und der USA - mit einem Anhang: Amerikanische Short Stories in deutschsprachigen Anthologien. Vol. 3 of Helga Eßmann \& Fritz Paul, eds. Übersetzte Literatur in deutschsprachigen Anthologien: Eine Bibliographie. Stuttgart: Hiersemann, 2000 . 
Fluck, Winfried, \& Werner Sollors, eds. German? American? Literature? New Directions in German-American Studies. New York: Lang, 2002.

Francini, Antonella. "In the Longfellow Line: Some Contemporary American Poets as Translators of Eugenio Montale." Unpubl. Drew University Ph. D. Dissertation, 1985.

Frank, Armin Paul. “'Borderline Cases': On the Uneasy Relations Between English and Non-English Writing in United States Literary Culture." Anglo-American Awareness: Arpeggios in Aesthetics. Ed. by Gisela Hermann-Brennecke \& Wolf Kindermann. Münster: Liт Verlag, 2005. 218-43.

Frank, Armin Paul. "Translation research from a literary and cultural perspective: Objectives, concepts, scope.” Harald Kittel, et al, eds. Übersetzung, Translation, Traduction: Ein Internationales Handbuch zur Übersetzungsforschung. Vol. 1. Berlin: de Gruyter, 2004. 790-851.

Frank, Armin Paul, \& Kurt Mueller-Vollmer. The Internationality of National Literatures in Either America: Transfer and Transformation. Vol. I/2. British America and the United States, 1770s-1850s. Göttingen: Wallstein, 2000.

Gulliksen, Oyvind T. Twofold Identities: Norwegian-American Contributions to Midwestern Literature. New York: Lang, 2004.

Haugen, Einar. Ole Edvart Rölvaag. Boston: Twayne, 1983.

Jones, Howard Mumford. America and French Culture, 1750-1848. Chapel Hill, N.C.: Univ. of North Carolina Press, 1927.

Jorgenson, Theodore, \& Nora O. Solum. Ole Edvart Rölvaag: A Biography. New York: Harper's, 1939.

Knortz, Karl. Amerikanische Gedichte der Neuzeit. Leipzig: Wartig, 1883.

Knortz, Karl. Lieder aus der Fremde. Glarus: Vogel, 1887.

Knortz, Karl. Poetischer Hausschatz der Nordamerikaner. Oldenburg: Schultze, 1902.

Leser, L. L. “Deutsche Dichtkunst in den Vereinigten Staaten.” Deutsch-amerikanischer National-Bund 369-96.

Lewis, R. W. B. The American Adam: Innocence, Tragedy and Tradition in the Nineteenth Century. Chicago, Ill.: The Univ. of Chicago Press, 1955.

Morris, Richard B., ed. Encyclopedia of American History: Bicentennial Edition. New York: Harper \& Row, 1976.

Moseley, Ann. Ole Edvart Rølvaag. Western Writers Series 80. Boise, Ida.: Boise State University Press, 1987.

Mueller-Vollmer, Kurt. "How Brockhaus' Conversations-Lexicon became the Encyclopedia Americana: A Fresh Look at Nineteenth-Century German-American 
Cultural Transfer." Ilona Slawinski, ed. Der Mnemosyne Träume: Festschrift für Joseph Strelka zum 80. Geburtstag. Tübingen: Francke, 2007. 209-23.

Naess, Harald S., ed. A History of Norwegian Literature. Lincoln, Nebr.: Univ. of Nebraska Press, 1993.

Øverland, Orm. The Western Home: A Literary History of Norwegian America. Urbana, Ill.: The Univ. of Illinois Press, 1996.

Paulson, Kristoffer F. “Ole Rølvaag's Giants in the Earth: The Structure, the Myth, the Tragedy." Norwegian-American Studies 34 (1995): 201-15.

Paulson, Kristoffer F. "Rølvaag as Prophet: The Tragedy of Americanization." Gerald Thorson, ed. Ole Rølvaag: Artist and Cultural Leader. Northfield, Minn: St. Olaf College Press, 1975. 57-64.

Peach, Linden. British Influence on the Birth of American Literature. London: Macmillan, 1982.

Price, Kenneth M. Whitman and Tradition: The Poet in His Century. New Haven, Conn.: Yale Univ. Press, 1990.

Rippley, La Verne J. The German-Americans. Boston: Twayne, 1976.

Rölvaag, Ole Edvart. Giants in the Earth. With an Introduction by Vernon L. Parrington. New York: Harper, 1929.

Rölvaag, Ole Edvart. Peder Victorious: A Tale of the Pioneers Twenty Years Later. Translated from the Norwegian by Nora O. Solum \& the Author. With an Introduction by Gudrun Hovde Gvåle, Translated from the Norwegian \& adapted by Einar Haugen. Lincoln, Nebr.: Univ. of Nebraska Press, 1983.

Rölvaag, Ole Edvart. Their Fathers' God. Translated by Trygve M. Ager. Lincoln, Nebr.: Univ. of Nebraska Press, 1938.

Scholes, Robert. "The Fictional Heart of the Country: From Rølvaag to Gass." Gerald Thorson, ed. Ole Rølvaag: Artist and Cultural Leader. Northfield, Minn.: St. Olaf College Press, 1975. 1-13.

Simonson, Harold P. "Beret's Ineffable West." Ole Karlsen \& Renne Waare, eds. Rapport fra Rølvaag-konferansen I Sandnessjoen 7.-8. august 1995. Nesna, Nordland, Norway: Høgskolen i Nesna, 1995. 105-14.

Simonson, Harold P. Prairies Within: The Tragic Trilogy of Ole Rølvaag. Seattle, Wash.: Univ. of Washington Press, 1987.

Shell, Marc, ed. American Babel: Literatures of the United States from Abnaki to Zuni. Cambridge, Mass.: Harvard Univ. Press, 2002.

Shelley, Philip Allison. "A German Art of Life in America: The American Reception of the Goethean Doctrine of Self-Culture." Shelley et al., eds., AngloGerman and American-German Crosscurrents 1. Chapel Hill, N.C.: Duke Univ. Press, 1957. 241-92. 
Sollors, Werner, ed. Multilingual America: Transnationalism, Ethnicity, and the Languages of American Literature. New York: New York Univ. Press, 1998.

Spiller, Robert E., et al., eds. Literary History of the United States: History. New York: Macmillan, ${ }^{4} 1974$.

Stevens, Robert Lowell. "Ole Edvart Rølvaag: A Critical Study of His NorwegianAmerican Novels.” Unpubl. Univ. of Illinois Ph.D. dissertation, 1955.

Tebbel, John, \& Mary Ellen Zuckerman. The Magazine in America, 1741-1900. New York: Oxford Univ. Press, 1991.

Trommler, Frank. "Literary Scholarship and Ethnic Studies: A Reevaluation." Fluck/Sollors 25-40.

Ward, Robert E. A Bio-Bibliography of German-American Writers, 1670-1970. White Plains, N.Y.: Kraus, 1985.

Weisbuch, Robert. Atlantic Double-Cross: American Literature and British Influence in the Age of Emerson. Chicago, Ill.: The Univ. of Chicago Press, 1986.

Wellek, René. Confrontations: Studies in the Intellectual and Literary Relations Between Germany, England, and the United States During the Nineteenth Century. Princeton, N.J.: Princeton Univ. Press, 1965.

Wellek, René, \& Austin Warren. Theory of Literature. London: Cape, 1949. 


\section{Daniel Göske \\ Kassel University, Germany \\ The Literary World in the "American Renaissance" and the International Context of American Studies}

The late 1840s and early 1850s were formative years in the history of American literature and culture. A century later, F.O. Matthiessen famously called this era The American Renaissance, and his readings of Emerson's, Thoreau's, Hawthorne's, Melville's, and Whitman's major works helped to establish and institutionalize the academic discipline of American (literary) Studies after the Second World War. Even though Matthiessen emphasized the ideal of a democratic American culture, his "insistence on aesthetic principles" prevented him from favoring an overly nationalist perspective. ${ }^{1}$ He included extended discussions of his authors' responses to selected writers from the English Renaissance and, in some cases, to continental Romanticism. Matthiessen's magisterial readings were, in later decades, followed up by U.S.-based scholars like Gilmore, Pease, or Railton, who included Poe, Fuller, Beecher Stowe and other writers. Most of these studies concentrate on a unilateral approach, situating their authors almost exclusively in the immediate national context. Historical evidence suggests, however, that the recent move towards an internationalization of American Studies has its often overlooked precedent, or rather its historical foundation, in the internationalisation of the American and transatlantic literary scene around 1850.

The flowering of American literature in mid-nineteenth-century resulted, at least partly, from a vigorous, often nationalist, response to the British tradition, or better, to certain writers who dominated it. ${ }^{2}$ It also coincided with and, as Chai, Leypoldt, and others have argued, benefited from, an increased awareness of the literary world at large, mainly of continental European writers, artists, and musicians. Indeed, Frank and Mueller-Vollmer have clearly outlined the "exceptional internationality" of American literature at that time, situating its emergence firmly in an "Atlantic reading culture" and discussing numerous aspects of the "transfer" (through "agents

1 Vanderbilt, 476. On the enduring impact of American Renaissance see also Gunn, 68-83, and Pease, 246-70.

2 See Lease, Weisbuch, Grey, Frank/Mueller-Vollmer, Giles (2001), Winship, and others. 
and activities, institutions, media, networks, and environments") and "transformation" (through individual American writers) of British and German culture in the United States. Moreover, they have indicated the extent to which German culture in particular may have been seen, from the 1830 s on, as an alternative tradition which could complement or qualify the still dominant impact of British publications on the American market. ${ }^{3}$ This assumption is borne out by the surprising number of editions and translations of German works which were published and reviewed in antebellum America. Hence the debate in major literary magazines around 1850 provides rich material for Americanists who, rejecting what Lawrence Buell has called a "cisatlantic hermeticism," want to explore the inter-national horizon of American print culture in this formative era. ${ }^{4}$

The intricate interplay between European, British, and American literature, still acknowledged in the old Cambridge History of American Literature (1917), was increasingly marginalized in the latter half of the $20^{\text {th }}$ century, when American literary studies became "a patriotic subject in methodology as well as in thematic content." 5 The trend towards a unilateral master narrative of American literature that foregrounds the national elements while obfuscating their international contexts and transatlantic networks, is clearly visible in the major histories by Spiller (1948, 1953), Elliott (1988), Bercovitch (1994-2005), and even in Marcus' and

3 Frank/Mueller-Vollmer, 13-15. Unfortunately, I have not been able to draw on MuellerVollmer's forthcoming study on Transatlantic Crossings and Transformations: Studies in German-American Cultural Transfer from the End of the $18^{\text {th }}$ to the End of the $19^{\text {th }}$ Century. My contribution focuses on the transfer of culture in an essentially hybrid medium, the literary journal. Less ephemeral than newspapers and distributed more widely, the new quality magazines of the 1840s and early 1850s supported American writing but were themselves embedded in the Atlantic reading culture. The increasingly international network of periodical literature of this era has not yet been adequately studied. For a narrow, national view see Price / Smith; for an excellent survey of the German contribution to the early history of the book in the U.S. see Roeber.

4 "The restriction of focus to the national field is regulated in terms of notions of American cultural distinctiveness used to sort authors and texts in or out according to a criterion of emerging indigenousness that fails to take account of such factors as the interpenetration of the 'indigenous' and the 'foreign"' (Buell, 412). Frank and MuellerVollmer put it thus: "[T] he national or sub-continental contextualizations that predominate in literary historiography are much too narrow for a representation of what really went on in the making of a(n American) literature" (14).

5 Giles (2007), 45. This trend coincided with a linguistic homogenization, as Sollors observes in his book on "transnationalism, ethnicity, and the languages of American Literature" (3-7). Here, however, I am concerned mainly with the inter- and transnational literary scene in English language periodicals. 
Sollors' openly anecdotal New Literary History of America (2009). Moreover, the international outlook of American literature in general and the literary scene around 1850 in particular has been almost completely disregarded in recent bibliographies and other reference books. Even though many major articles on German literature in $19^{\text {th }}$-century American magazines were listed by Goodnight and Haertel more than a century ago, they were mostly excluded from Daniel Wells' indices to $19^{\text {th }}$-century periodicals, especially for the two decades preceding the Civil War.

Hence I want to explore the intriguing complexity of what could be termed the internationalist interval in the antebellum American print culture by discussing relevant material in selected periodicals before 1850. I want to focus especially on the weekly Literary World (1847-1853) and the United States Magazine and Democratic Review (1837-1859), a monthly that functioned as the mouthpiece of the so-called Young America movement. Less scholarly and more versatile than the old quarterlies like the venerable Edinburgh Review (which was widely read in the U.S.) or its American counterpart, the North American Review, these two New York journals boosted home-grown authors while also commenting on recent developments overseas. They were highly influential before large middlebrow monthlies like Harper's or Putnam's Monthly Magazine began to dominate the scene in the 1850 s. $^{6}$

\section{“Dignify patriotism, use foreign literature": Metropolitan (Inter)Nationalism}

The Literary World was modeled on the London Athenaeum but paid particular attention to American fiction, poetry, nonfictional prose (travel, history, religion, science, medicine), drama, music, and art. It was committed, particularly in the beginning, to a recognizably national literature that would "elevate what is familiar around us, attach us to home, dignify patriotism, use foreign literature as a means to these ends, not seek to supplant what is native by the European, and make us

6 On Harper's and Putnam's see Perkins and Ljungquist. Other periodicals with an internationalist outlook were Littell's Living Age, a Boston weekly founded in 1844, which relied heavily on reprints from quality British periodicals, aiming "to include all the comment of British journals on American affairs" (Chlebek 225), or the International Monthly Magazine of Literature, Science and Art (see below). Some of these periodicals can easily be accessed through the "Making of America" database at Cornell University; the Literary World and others are only available in good research libraries. 
absentees from America at our own firesides."7 Except for a rather bland interim period from May 1847 to September 1848, when it was run by the poet and journalist Charles Fenno Hoffman, the World was edited by Evert Duyckinck and his younger brother George, close friends, for a while, of Melville's. ${ }^{8}$ The Duyckinck brothers purchased the journal in October 1848 from its original owners, the publishers John Wiley, George P. Putnam, and Daniel Appleton. The World's weekly appearance in, as the editorial of the second volume had it, "the metropolis of our book-world, on this side of the Atlantic," allowed it to stay au courant with the literary news of the day. ${ }^{9}$ Short notices, anecdotes, or downright gossip, appearing under rubrics like "What is Talked About," "Miscellany," or "Literary Intelligence" ("foreign" and American), provided entertaining reading, while editorials, reviews, and countless excerpts from forthcoming books made the journal indispensable for ambitious readers, serious writers, and professional publishers alike. Informing the public about the literary scene at home and abroad and providing the publishing industry with "a forum in its inexpensive advertising pages in addition to book notices," the Duyckinck brothers "blended a newsletter tone with intellectually responsible commentary. The high quality of the World's contents was as unique for the period as its omnibus coverage." ${ }^{10}$ Among the topics that were usually discussed in their international ramifications were the vexed problem of copyright and the Atlantic book trade, the expansion of libraries, learned societies, universities, and other institutions of higher education, the advance of

7 “The Edinburgh Review on an American National Literature," Literary World (6 March 1847): 101.

8 Melville's essay on "Hawthorne and His Mosses" appeared in August 1850, but his "assertive nationalism is actually not in keeping with the Literary World's more moderate position on the nationalism issue" (Yannella 226). Even Duyckinck's first editorial was characteristically pragmatic and low-key: "There is a religious, a political, a mercantile world; why not a literary one?" His journal set out "to determine with impartiality, the relative position and virtues in all book transactions of the three great parties: the Author, the middle man the Publisher, and the Reader. The question of Literary Property [i.e., copyright], whether affecting the rights of the Native or the Foreign Author [...], will be fully discussed." See Literary World (6 February 1847): 5.

9 Thanks to "constant supplies of the best foreign journals," the journal "offers at once the most complete and authentic weekly compendium of what is new or interesting in Science, History, and Art." Literary World (7 August 1848): 5.

10 Yannella, 224. American contributors included Bryant, Fuller, Hawthorne, Irving, Longfellow, Melville, Poe, Simms, and Whittier, but many of the mostly unsigned reviews and essays cannot be traced to individual authors. 
science, ethnological and archaeological research, the impact of liberal theology (usually German) on organized religion and, indeed, the nationality of literature.

Of course, the political upheavals in Britain and on the continent, particularly in and after 1848, were also mentioned, although less often and more indirectly than in the United States Magazine and Democratic Review. This monthly was at first published in Washington by the Jacksonian journalist John O'Sullivan (of "manifest destiny" fame) and his brother-in-law Samuel Langtree. They conceived the Democratic as a "national periodical that would represent the interests of the Democratic party and combat the 'literary toryism' of the nation's leading magazines," claiming to be "partisan in politics and neutral in literary matters." As the full title indicates, the journal tried to combine the features of a quarterly review with the miscellany material of a monthly magazine, and the editors wanted to rival the best British journals where "political controversy and belles-lettres went hand in hand." ${ }^{11}$ In 1841 the Democratic moved to New York, and both editors, serious about literary neutrality, managed to attract numerous established as well as up and coming writers. They printed poetry by Bryant, Lowell, Whittier, or Simms, criticism by Poe, Duyckinck, or Parke Godwin, some 25 stories and essays by Hawthorne, and numerous melodramatic tales by one Walter Whitman. Even after O'Sullivan withdrew in 1846, the journal continued to be an important presence, not least because it was "more hospitable to French and German writers than most American magazines."12 Indeed, it may have been the editors' anti-British nationalism which favored, at least for a time, a strong interest in continental, especially German, culture and literature.

This interest, however, and the possible interpenetration of cultural nationalism and international awareness, have largely been neglected. In his brilliant study on the Young America movement, Widmer places the "American" contributions to World and the Democratic in the immediate political and cultural context that

11 Weiner, 425. On the launching and the editorial politics of the Democratic see Widmer, 34-63. Its rival, The American Whig Review (1845-1852), advocated "'the permanent maintenance of Whig principles and improvement of American literature" (Menides 29) yet also printed a few articles on or translations of German writers like Lessing, Goethe, Schiller, Uhland, Heine, or Freiligrath.

12 The criticism of foreign authors, however, was "usually derivative" (Weiner, 429). But the Democratic specialized, at least from the early 1840 s to 1850 , in extended articles about, reviews of, or lengthy translations from foreign authors, artists, and composers. On the reception of Haydn, Mozart, and Beethoven within the international context of periodical literature see Leypoldt's brilliant analysis of the "Antebellum Discourse of Musical Nationalism" (134-48). 
Hawthorne, Melville, Whitman and others worked in. He pays almost no attention to the wealth of "foreign" material: critical essays, short book notices, lengthy reviews, and translations. In the revolutionary year of 1848 alone, the Democratic discussed, always with an eye on the American situation, topical issues like the revolutionary events in Paris, the fate of Prince Napoleon Louis Bonaparte, or industrial reform and the increasing poverty of the working classes in Britain, France, and Ireland. Political events in the German-speaking countries, however, were not seriously covered. Only an anonymous wit poked fun at "Poor dear old Germany! - turned topsy-turvy by a mob of greasy, beer-drinking students, and Socialist professors!"13 The apparent chaos in the notoriously disunited German states seems to have strengthened the romantic image of Germany as the seat of high culture. Hence the Democratic of 1848 made use of its ample format and printed long works by classic German writers: Moses Mendelssohn's "Phaidon; or, the Immortality of the Soul," Schiller's ballad “The Diver," Goethe's "Hermann und Dorothea," and even Lessing's tragedy Emilia Galotti.

In the late 1840s and early 1850s, monthlies like the Democratic, the American Whig Review or Holden's Dollar Magazine, and weeklies like the World provided ample material for American readers who wanted to stay abreast with the literary and cultural scene in the Old World. Extensive reviews, articles, translations, and uncounted news items about European authors testify to the editors' and contributors' lively interest in, and awareness of, what Goethe had called, in 1827 and after, 'world literature' - and their own, still young nation's place in it. ${ }^{14}$ Poe, who was deeply embedded in and dependent on the periodical market, but also

13 “Touching the Teutons," Democratic Review 23 (October 1848): 317-20, 317. Duyckinck's journal remained more aloof from politics but mentioned news items that were connected to literary men, as in "Arrest of Ferdinand Freiligrath," Literary World (7 October 1848): 709. On the importance of the French and Italian revolutions of 1848-49 for the American literary Renaissance see Reynolds.

14 Neither Widmer nor Wells situate the "American" contributions in their proper international context although the Democratic featured extended translations from contemporary French and German writers: prose from Balzac, Hugo, Alexandre Dumas Père, Brentano, Goethe, Hauff, Hoffmann, Tieck, and Zschokke, verse by Béranger, Gautier, Heine, Herwegh, Schiller, Uhland and others, and even complete plays by Lessing, Goethe, and Schiller. The only non-English authors listed in Wells' "Index" to the Literary World (1978) are Balzac, De Tocqueville, and Goethe, even though the journal featured numerous translations from and reviews of French and German writers like Béranger, Michelet, Lamartine, George Sand and Gerstäcker, Gutzkow, Halm, Heine, Herder, Leibniz, Jean Paul, Rückert, Schiller, Friedrich Schlegel, Tieck, or Zschokke. 
writers like Fuller, Hawthorne, Whitman, and Melville benefited from it, and new insights can be gained if we consider their work in this international context.

\section{Networks, "Influence," and the Individual Talent: Melville and the World}

Let me cite the example of the World. Duyckinck tried to cover European literature extensively, mainly drawing on British and selected French periodicals, but also recommending new German journals that could be obtained at Westermann's, Garrigue's and other German bookshops in New York. ${ }^{15}$ As the Duyckinck Papers at the New York Public Library show, numerous attempts were made to link up with important publishers in Europe in order to establish connections and exchange material. In this early era of international cultural relations and transfer, friends and contributors literally acted as go-betweens. For instance, Duyckinck asked Melville's travelling companion in 1849-50, the German-American philologist George J. Adler, to approach the famous French critic Philarète Chasles, editor of the Revue des deux mondes and lecturer on modern literature at the Collège de France, in this matter. But the times were, Adler reported from Paris, too agitated to engage in full-fledged joint-ventures, although Chasles was quite happy to be one of Duyckinck's occasional contributors. ${ }^{16}$

15 “New German Periodical: Deutsches Museum," Literary World (26 April 1851): 337f. On Westermann, New York's most efficient German bookseller, and Garrigue, whose translation of Typee came out in 1847 and who published his lists of German books regularly in the World, see Cazdan, 160-64, 189-194. Among the German newspapers and magazines the World quoted from explicitly are the Augsburg Gazette, the Carlsruhe Gazette, or the Leipzig Blätter für die literarische Unterhaltung. Most news items about German literature, however, seem to have been taken from the British press. For Duyckinck's keen interest in continental views on America see "A French Critic's Opinion on American Literature and Authors," Literary World (19 January 1850): 49-52.

16 Adler's letters from 2 April, 20 June, 5 August 1850, “Duyckinck Papers," Berg Collection, New York Public Library. The World had already reprinted Chasles' long and rather insightful essays - first published in the Revue des deux mondes - on Melville, whom the French critic praised as "a curious novelty, an American Rabelais." "The Actual and Fantastic Voyages of Herman Melville," Literary World (4 August 1849): 89. For Duyckinck, the Parisian critic's positive response to Mardi, fairer than any British review, was a big boost: "[I]t vastly enlarges the motives of an American author, when he can look to an influential European journal on the Continent for so cordial, appreciative a reception. It is something for a young American writer to have the way thus cleared for his introduction to the literary society of the old world - to be read in 
Melville's close connection with Duyckinck and Adler can serve as an example of just how difficult it is to ascertain precisely the "influence" (a problematic metaphor, to begin with) that any source, foreign or otherwise, may have had on an individual American author at the time. It seems safe to assume that oral communication in literary salons or intimate talk among friends was probably as decisive in steering an ambitious author on a new course. ${ }^{17}$ Melville's many visits in Duyckinck's Manhattan home may have been as important to his intellectual development as his private reading of books or journals. We know little about their talks, though, and can take our cue only from their correspondence and the articles in the World before February 1852, when Melville discontinued his subscription.

His intense, spirited conversations with Adler on the boat to England in October 1849 present another intriguing case. They must have resonated deeply, as Melville's journal testifies: "We talked metaphysics continually, \& Hegel, Schlegel, Kant \& c were discussed under the influence of the whiskey." In the following weeks, during the transatlantic passage but also in London and Paris, Melville and Adler were "riding on the German horse again." 18 Those intellectual joyrides

Paris, St. Petersburgh, and Madrid, as well as London and Edinburgh." Literary World (11 August 1849): 103. Chasles' essays on American culture were soon to be published in book form, moreover. Scribner's brought out a translation of his Etudes sur la littérature et les moeurs des Anglo-Américains aux XIXe siècle (Paris, 1851) as Anglo-American Literature and Manners (New York, 1852). This is another sign of a deep interest in a European, non-British assessment of America's culture. The anonymous translator, who praised the French critic's "profound thoughtfulness and discriminating delicacy," omitted only some extracts about English writers, "analyses of such familiar works as Melville's Typee," and the chapter on Major André and General Arnold in the War of Independence, which Chasles had based on Bancroft's History and Emerson's Essays (“Translator's Note”, v f).

17 Hawthorne's close connection to the editor of the Democratic is another example (see Widmer, 64-81). For almost twenty years O’Sullivan advised Hawthorne, who "appreciated his friend's abilities as a con-artist" and even made him godfather of his first child (Miller, 150).

18 Journals (8f). Adler is one of the many forgotten middlemen of European culture in America. A German Jew from Leipzig, he immigrated to the States at the age of twelve in 1833 and graduated from the University of New York in 1844. Since he could not secure a position in his favorite fields, classical and oriental studies, Adler served as an unsalaried professor of German (1845-54), published books, gave public lectures, and contributed to literary journals. Little is known about this, as Melville wrote, "fine scholar whose society is improving in a high degree" (Journal 7). In 1853, Adler became paranoid and had to be institutionalised, but this did not prevent him from serious 
may well have included Goethe, Schiller, Jean Paul, and many of those German writers Adler himself translated, edited, or wrote about. ${ }^{19}$ Most of his contributions to the World, however, were not signed. But Duyckinck published excerpts from Adler's version of Goethe's Iphigenia, advertising it as "a novelty for the stock of American literature." ${ }^{20}$ And in April and May 1851, while Melville was feverishly working on Moby-Dick in the Berkshires and occasionally visiting New York, the World featured Adler's translation of parts of Jean Paul's Vorschule der Ästhetik. The sections on the "Definition of the Ludicrous" and "Theory of the Sublime" may have informed parts of Moby-Dick which Melville was just in the process of writing. Indeed, the German writer most often named in conjunction

scholarly work. He published an anthology of German literature (1854), a voluminous Latin grammar, and a translation of Fauriel's History of Provencal Poetry (both 1860), notes on Aeschylus' Agamemnon and a book on Wilhelm von Humboldt's Linguistical Studies (1866). Adler died in 1868 before his projected bilingual edition of Goethe's Faust was finished.

19 When George Duyckinck introduced him to Melville, Adler had already published several German textbooks and grammars and just completed a massive, two-volume Dictionary of the German and English Languages (New York, 1849), which the Literary World of January 1849 hailed as "the most extensive and valuable philological work ever issued from the American press" (29). The dictionary was offered, Adler's preface said, as a contribution "towards bringing the Anglo, as well as the Saxon, to a new and proud consciousness of their primeval identity of origin and mind" (xii). Marovitz has speculated on the impact that Adler's emphasis on the "importance of language as a categorizing agent" may have had on the future author of Moby-Dick. Moreover, Adler's emphasis on the "German supremacy in contemporary thought and letter" over even British literary culture may have inspired Melville's brief liaison with literary nationalism: "In 'Hawthorne and His Mosses,' Melville would substitute America for Germany when asserting that England's literary influence over the young nation would soon be superseded" (Marovitz, 378f).

20 He praised Goethe's classicism because it spoke of "primary and universal conditions of man," beyond the pale of nationalist agendas: "The Majesty of Antiquity fills to the echo the trump which sounds forth even the unlettered woes of our plebeian life. What a splendid proof of the unity of the race does this Greek literature offer while scientific men are groping about for their evidences in the dust of tombs [...], a Goethe takes down the strangely fashioned harp from the wall, and, as he rekindles its ancient melodies, is more demonstrative than all the ethnologists." "Goethe's Iphigenia in Tauris," Literary World (4 January 1850): 2. Whether Adler talked to Melville about his translation is not known but in January of 1851 he presented him with an inscribed copy. 
with Melville's philosophically ambitious and stylistically diverse romances was Jean Paul Richter. ${ }^{21}$

Melville's precise knowledge and use of his work, however, is difficult to assess and requires further investigation. We know that he had read Carlyle's essay on Jean Paul and borrowed, shortly before embarking on the composition of Moby-Dick, the Scottish writer's edition of German Romance from Duyckinck. This anthology included Carlyle's version of Jean Paul's Quintus Fixlein as well as Flower, Fruit, and Thorn Pieces, Edward H. Noel's translation of Siebenkäs. The only remark about Jean Paul in Melville's correspondence, however, dates from 1864, after he had conversed with a Union general, behind the lines in Virginia, about Titan (in Charles Timothy Brooks' version of 1851): "The worst thing I can say about it is," Melville reported back to a friend, "that it is a little better than 'Mardi."'22 In view of the older Melville's usually brief and disparaging remarks

21 Most critics felt that Mardi (1848), Moby-Dick (1851) and Pierre (1852) suffered from Melville's admiration of Jean Paul and similar British writers. Ripley called Mardi "a monstrous compound of Carlyle, Jean-Paul [!], and Sterne." According to Philarète Chasles, only Sterne, Jean Paul, and Cervantes had accomplished that "rarest product of art," a "humoristic book" - and Melville failed. Duyckinck himself, at a loss to submit Moby-Dick to a "distinct classification as fact, fiction, or essay," remarked caustically: "Something of a parallel may be found in Jean Paul's German tales, with an admixture of Southey's Doctor." And when Pierre appeared in 1852, the American Whig Review fumed: "Mr. Melville's style of writing in this book is [... precisely what a raving lunatic who had read Jean Paul Richter in a translation might be supposed to spout under the influence of a particularly moonlight [!] night." See Higgins/Parker, 225, 245, 384, and 447.

22 Correspondence 392. His interest, however, must have been sparked much earlier, by Adler and the material in the Literary World. Matthiessen speculates that it was Jean Paul's "surprising contrasts of fantastic speculation and deep feeling" that fascinated Melville and his contemporaries (120), but he sees only "superficial points of comparison" (291), for instance in Melville's famous rhapsody on "The Whiteness of the Whale." In this context, it is intriguing to cast a look at Brooks' excerpt from Titan in his anthology of German Lyric Poetry (Boston, 1842), a blank verse description of a "scene in the polar regions," from (as Brooks writes) "this vast and voluminous writer, this 'Titan' of German authors" (394). Jean Paul's poetic prose about "white-winged sea-birds" and the "pale sun," a "while angel" above the "silent, ice-walled cloister of the pole," suggests something like cosmic chill: "I gaze / Down on the dreary winter of the world. / How dumb and endless is it down below!" (216). The "gorgeous spectacle" of the "Aurora" (216), however, saves the speaker from Ishmael's "thought of annihilation, when beholding the white depths of the milky way," his horrified aversion from the "wretched infidel," who "gazes himself blind at the monumental shroud that wraps 
about his own work, this doesn't help us much. One would have to study Carlyle's, Noel's, Brooks' and other translators' versions closely, side by side with Melville's metaphysical romances, in order to gauge the extent to which the German novelist's example, stylistic and otherwise, may have informed his own fiction. And one should also take into account the many snippets of Jean Paul's works that were used as fillers in the World and other journals of the day.

Source hunting is not my main object here, however, even though a case of borrowing from or transformation of a single text may provide interesting insights into how a major writer's mind works. ${ }^{23}$ I suspect that most authors thrive just as much on hearsay, partial knowledge, and an awareness of the general debate. For writers like Melville or Hawthorne, who lived far apart from any metropolitan center in those years, journals could provide necessary stimuli and context for their work. Moreover, if one wants to assess the general debate about nationality around 1850, periodicals are particularly useful tools. I hope to show that the American literary scene, certainly in the major publishing centers of New York, Boston, and Philadelphia, offered an intellectual climate that was surprisingly diverse and international, thanks to growing migration, increasing transatlantic contacts, and - in the absence of an international copyright - piracy. A brief survey of several journals between 1847 and 1850 displays a comparatively keen interest in German culture, as I want to indicate in the following.

all the prospect around him" (Moby-Dick, 195). Melville's symbolist evocations of the "mystic ocean," the "inscrutable tides of God" (Moby-Dick, 159) provide another telling contrast to Brook's eloquent rendering of Jean Paul's pantheistic hymns to the Mediterranean, its "Divine overfulness and intermingling with the world as before me." "Naples: Midnight and Morning. From an Unpublished Translation of Jean Paul's Titan," Literary World (6 April 1850): 352.

23 In "Benito Cereno," for instance, Melville compares the ominously beclouded sun with "a Lima intriguante's one sinister eye peering across the Plaza from the Indian loop-hole of her dusk saya-y-manta" [!] (Piazza Tales, 47). This graphic image perhaps echoes the German naturalist J. von Tschudi, whose Travels in Peru, quoted in the World, contain a description of this exotic garment: "The Manta is a veil of thick black silk fastened by a band at the back of the waist, where it joins the saya. From thence it is brought over the shoulders and head, and drawn over the face so closely that only a small triangular space, sufficient for one eye to peep through, is left uncovered. [...] The Saya y Manta are found to be very useful auxiliaries in the numerous intrigues in which the Limaens frequently engage." Literary World (27 February 1847): 81. Perhaps Melville drew on Tschudi's Peruvian travels for related passages in Moby-Dick or the Piazza Tales. 


\section{The World, the Democratic and the "rich treasures of the Teutonic mind"}

Thanks to the centralized book and periodical culture in London and Paris, American editors and critics had few problems in reporting on the British and French literary scene. The German-speaking countries, however, lacked a cultural capital and were thus more difficult to survey directly. Hence British magazines like the London Athenaeum, Literary Gazette, Fraser's Magazine or Blackwood's Magazine as well as the big quarterly reviews remained the chief sources of information. Not always were these British intermediaries openly acknowledged. Often, however, American editors and critics took issue with them. This resulted in significantly deviating responses, to individual authors as well as in terms of general assessments, and these responses would not have evolved had a direct line of communication between the United States and Germany been in place. Indeed, even the many instances of a bilateral stock-taking of anglophone cultures, written with the intention of defining America's peculiar achievement against the backdrop of the "British branch of Anglo-Saxonhood," contained side glances at continental European culture. ${ }^{24}$ Ample occasion for comparative glances across the Atlantic was provided by reviews of literary histories, like Sismondi's on the South of Europe, Talvi's on the Slavic Nations, Ticknor's on Spanish, and Menzel's on German Literature. Major (multi)national anthologies like Longfellow's Poets and Poetry of Europe (1847), Rufus Griswold's Poets and Poetry of America (1842, revised 1847), Poets and Poetry of England (1844) and Prose Writers of America (1847), Chambers' Cyclopedia of English Literature (1847) or Hedge's Prose Writers of Germany (1847) invited further comparison.

Much the same is true for new ventures like Wiley and Putnam's popular " $\mathrm{Li}$ brary of Choice Reading," which was edited by Evert Duyckinck and published in both London and New York. When the publishers decided to issue an "American rival alongside of their foreign series," a critic of the Democratic complained that this "provoked comparisons rather unpleasant to our pride as Americans." Although there were "more readers in the United States - readers in the highest

24 The critic rejected the "humbug of Anglo-Saxonism" and noted that thanks to immigration from the "Celtic races" and "Continental Europe," only a little more than "half of our people are of Anglo-Saxon descent": "Our forefathers were plucked from amid that strange insular ishmaelitish people by the hand of Providence itself, and placed upon this broad continent, as a nucleus around which the representatives of all races of Europe might rally, to form a new and peculiar branch of the human family." "England and America," Literary World (19 June 1847): 465-67, 465f. 
sense - than in any modern nation, except Germany," a "flourishing literature" at home was virtually impossible as long as Congress refused to pass an internationally binding copyright law and the American author, unable to compete with cheap British imports, was forced to rely on the "irregular methods of the amateur." 25

Even translations of important authors were embroiled in patriotic polemics about piracy and plagiarism. An editorial of the Literary World in the fall of 1848 used the famous question by Sidney Smyth, favorite foe of American nativists (and many later Americanists), to highlight two "cases of gross piracy in England": the prestigious series of "Bohn's Standard Library" had published translations of Schiller's Wilhelm Tell and Goethe's autobiography which, the critic suggested, had clearly been lifted, in large parts, from earlier American versions. ${ }^{26}$ Such cases rankled critics like the reviewer of Parke Godwin's translation of Dichtung und Wahrheit, who saw in literary translation (not just of "Goethe, Schiller, and Jean Paul") a peculiar opportunity for Americans: "[S]urely this is a field in which English authors can have little advantage over us." ${ }^{27}$ No wonder that, when Goethe's Autobiography was reissued in 1850, the World printed a sharp protest against the "bold appropriation" of Godwin's version by the "London translator (so called)" John Oxenford and his publisher Bohn. The American translator and his publisher had known that their book, which first appeared in Wiley and Putnam's "Library of Choice Reading" in 1846, "was not likely to have an extensive sale in the American market." But they had (like most American authors at the time)

25 “The Library of Choice Reading, Democratic Review 20 (March 1847): 239f. The critic blamed the "imperfect efforts" of Simms, Poe, Cornelius Matthews and others for the "inferiority of the American series" and claimed that only a few volumes - Hawthorne's Mosses, Melville's Typee, or Fuller's Papers on Literature and Art - could rival the works of the foreign series. On the "Library of American books" as a "watershed in American history" see Widmer (103-11), who, however, does not take this and other critical reactions into account.

26 He reprinted several extracts from the American (1837) and British (1846) version of Tell which proved "not only that English litterateurs and compilers do now and then 'read an American book', but that even the labors and rights of a fellow-subject are not respected, if his book be published in America." "Who Reads an American Book?" Literary World (16 September 1848): 641-43, 643.

27 The article contains a long argument in favor of literary translation and suggests that "peculiar circumstances of our origin and population, formed from every civilized nation, [...] and the absence of any strong and decided nationality [...] may have predestined this nation, for a time, to a certain eclecticism of character, that we may gather and select from the past and the old world, the scattered rays of light and truth [...]." "The Autobiography of Goethe," Literary World (18 September 1847): 149-51. 
"confidently relied upon the English market for their remuneration." By merely changing a few words here and there, Oxenford had robbed them of their intellectual property and financial investment: the American version had effectively been "reprinted as an original English translation." Perfidious Albion? Not quite. In the absence of an international copyright law, this kind of "reciprocal free-booking" was practised, the American reviewer had to admit, on both sides of the Atlantic. ${ }^{28}$

Clearly, the (inter)nationality of the book market and the nationality of literature were much discussed in those years. Even within a single nativist journal, however, the debate was far from unanimous. In March 1847, the Democratic compared the young republic's "intellectual servitude" to Britain with the "despotic influence of the writers of France over those of Germany" before Goethe appeared and "Germany was delivered from this degrading intellectual bondage." 29 Drawing on De Stael's De l'Allemagne, the critic countered the universalist stance of the North American Review by claiming: "Nationality in literature is only one of the many forms of patriotism" (270). Voicing his hope for a truly national poet in the future yet almost despairing of the present situation, he concluded:

If there is anything peculiar in our institutions and condition, we would have some native bard to sing, some native historian to record it. [...] What we complain of is, the unnational spirit of our writers; that they slavishly adhere to old and foreign models; that alike in their subjects, and in their method of handling them, they are British, or German, or something else than American. (271)

28 "Goethe's Autobiography: The American and English Version," Literary World (17 August 1850): 132f. Book historians have shown that "transatlantic textual transfers were not all in one direction. [...] If the United States was an offshore publisher of British titles, Britain was an offshore publisher of American titles. The London and Edinburgh publishers seem mostly to have chosen not to weaken their demand for international copyright by unauthorised reprintings of texts first published in the United States, and they too resorted to various devices, in association with American partners." After 1840, there was "a huge British readership for Longfellow, destined to become, by far, the most popular poet of the British Victorians," and more than 1,5 million "offshore copies" of Uncle Tom's Cabin were sold in Britain in the early 1850s. After 1842, "American books and magazines were among the few sources of texts which could be printed to be sold cheaply in Britain." New ventures like William Hazlitt's (junior) Romancists and Novelist's Library included numerous texts from the United States, France, and Germany, "including the works of Fenimore Cooper, a special favourite" (St Clair, 391f).

29 The United States, however, were not ready for that kind of cultural revolution: "Overmastered by the literature of England, we have consented to remain in a state of pupilage." "Nationality in Literature," Democratic Review 20 (March 1847): 264-72, 266. 
Walt Whitman, the young editor of the Brooklyn Eagle, who often clipped from the Democratic, may have rejoiced over this appeal to literary patriotism, as Widmer claims (109). But its anxious questioning and dire diagnosis, its failure to grasp the consequences of multiethnic immigration and its fuzzy demand for a peculiarly American "method" of "home themes" and "home thoughts" were a far cry from Whitman's confident, all-encompassing "Salut Au Monde," ten years later.

Other articles in the Democratic handled the issue of America's (inter)nationality in letters differently. An essay on "English and American Literature" in March 1848 harped on America's "enterprising spirit" and "free trade principle," not least in its "periodical literature," and proudly emphasized the reciprocal changes that the "approximation of America to Europe is annually producing in all the commercial, political and social relations of the old world." ${ }^{30}$ But although the Democratic continued its crusade against Britain's "oppressive" press laws and a residual "sensitiveness of Americans in respect to foreign opinion" (210f), it also printed long translations from some French and several "celebrated German writers." This unusual procedure was justified by the fact that "Western Europe, more especially Germany, is daily drawing near to us in commercial, political and social affinities, and the taste, which of late has rapidly gained strength for her literature, has not been gratified by popular republications of her eminent writers." ${ }^{31}$

Half a year later, another article conceded that "our intercourse with England and France is so direct and so frequent, that London and Paris is more easily reached or heard from than some parts of our own country." But, the critic maintained, "our education will not be complete until we have attended the third of the three great European schools - until we have added to our own native and acquired wealth also the rich treasures of the Teutonic mind." In contrast to the "practical and commercial" English and the "volatile and changeful" French, the Germans "have mingled little in political affairs and the so-called reforms and social improvements of the day." This seemed to make German culture particularly and providentially apt for importation: "Were poetry, religion and philosophy banished from the earth, we might almost trust to the Germans to re-create and restore them. These appear to be pre-eminently their lot and portion on the earth. [...]

30 "English and American Literature," Democratic Review 22 (March 1848): 207-15, 207, 213. The critic crowed: "The number of readers here is doubling every twenty-five years, and another generation may find 20,000,000 democratic readers of English on this continent, against 500,000 aristocrats in England. Where will then be the market for literature?"(208).

31 Headnote to "Emilia Galotti," Democratic Review 22 (June 1848): 511. 
We may call them a nation of students, and their country the land of books and libraries, which are easily accessible to all." ${ }^{32}$

By the late 1840s, responses to German culture in influential literary journals became more frequent, and this coincided with a flurry of German books about the United States which were often published in America and carefully scrutinized by American critics. ${ }^{33}$ Rapidly increasing immigration, not least of German intellectuals and writers, numerous American travellers in and correspondents from Europe, and the first direct steamer connection to Bremen in 1847 provided a more direct access to German publications and, indeed, mail services. ${ }^{34}$ Yet this new interest in the periodical press was also based, to a considerable extent, on publications by Americans who had actively pursued the transfer of culture in earlier decades.

32 "Some Characteristics of the Germans and Their Literature," Democratic Review 24 (January 1849): 44-48, 44, 46f.

33 Their authors were travel writers and novelists (Gerstäcker), historians (von Raumer, Löher), or German-American emigrants (Fleischmann, Ludewig). See Friedrich von Raumer's America and the American People (New York, 1845), praised by Margaret Fuller in the New York Tribune (in Bean 277-84) and respectfully noted in the Democratic Review 17 (December 1845): 477, or Friedrich Gerstäcker's Wanderings and Fortunes of some German Emigrants (New York, 1848), which showed, the World wondered, "how whole communities of strangers remain long among us with all their distinct national peculiarities, continuing to mask them without being fairly absorbed among the American population, for at least a generation." Literary World (20 May 1848): 305. See also the collective review of Franz Löher's groundbreaking History and State of the Germans in America (Cincinnati, 1847), Charles L. Fleischmann's North American Farmer (New York, 1848), Hermann Ludewig's Report on Emigration Matters in Germany (New York, 1848) in "German Publications in the United States," Literary World (2 December 1848): 870-72.

34 The World celebrated "this nearer and newly opened intercourse with Germany" and praised the post-office at Bremen for planning to "distribute our mails over the whole North of Europe, through Russia, Denmark, Norway, Sweden, over all Germany” and, thanks to the railroad, further southeast. "The practical operation of this would be, that the German resident in Iowa, could go up to the village nearest his farm, drop his letter in the post-office, and, postage paid or not, it would go direct to his friend in the heart of Silesia, on the banks of the Danube, or on the borders of the Black Forest." “The First American Steamer to Germany," Literary World (2 October 1847): $208 f$. 


\section{"The idealism we require to balance our utilitarianism": Transcendentalist Mediators}

The first generation of American mediators were "cultural explorers" who had studied at the universities of Göttingen and Berlin in the 1820s and 1830s. ${ }^{35}$ Later aficionados of German culture took their cue from the American edition of Madame de Staël's Germany (De l'Allemagne), which had first appeared in 1814. In contrast to the first group, they championed German literature and philosophy rather than German contributions to political and cultural history, education, and the sciences. Many of these writers, clergymen, and educators belonged to, or sympathized with, the Transcendentalists. In important though not widely distributed journals like the Christian Examiner and the Dial, they offered translations and sophisticated assessments of German literature and philosophy to readers mostly in New England. ${ }^{36}$ Apart from Emerson, the main champions of cultural transfer from Germany were Margaret Fuller, James Freeman Clarke, George Ripley, Charles T. Brooks, and Frederic Henry Hedge.

In July 1836, Fuller published a seminal essay on the "Present State of German Literature" in the American Monthly Magazine, which was based on her fascinated reading of Heine's Romantische Schule and Jean Paul. ${ }^{37}$ One of the "principal

35 Mueller-Vollmer in Frank/Mueller-Vollmer, 228. Among the earliest Göttingen alumni were George Bancroft, the father of American historiography, Joseph Cogswell, who changed Harvard's college library into a modern research institution after the Göttingen model, George Ticknor, first professor of romance languages at Harvard, and Henry Wadsworth Longfellow, his successor and soon a bestselling poet and professional man of letters. This first phase of cultural transfer seems to have been largely academic. Indeed, almost 140 of the 225 American students who attended German universities between 1815 and 1850 would later hold professorships at colleges and universities in the U.S. - roughly 60 percent. See also Mueller-Vollmer (2003) and Buckley.

36 See Mueller-Vollmer in Frank/Mueller-Vollmer, 247f. The Boston quarterly Dial (1840-44), edited by Fuller and Emerson, never exceeded 300 subscribers; the Christian Examiner (1824-69), a bimonthly from Boston, had a longer run but was only moderately successful (Chielens 130 and 106). See Buckley for the reception of Goethe and Schiller in these New England journals.

37 In April 1835, Fuller confided to Clarke: "Did you ever hear of Henri [!] Heine? - I have seen some extracts from a work of his on modern German belles lettres which are highly amusing. Have been fascinated into reading Richter's Flegel Jahre [!] - and cannot resist the original mind when I am with it though not of the kind I naturally like [...]." Letters, 41. On Fuller's "transnational project" of education and her use of German literature see Maas’ fine study. 
means of knowledge is comparison," she wrote. And a comparative look abroad showed that most British writing was informed "by the same utilitarian tendencies with our own," whereas "French belles lettres of the present day can afford little gratification to decent society" and "the literature of Italy is dead."

To whom, then, can we look with more propriety than to the true-hearted Germans for the needful admonitions that "man cannot live by bread alone," and the idealism we require to balance our utilitarianism? The Germans have their faults, but these faults, pointed out with so much acuteness by Heine the "progress-man," are as good as virtues to us, since, being the exact opposites of our own faults, they may teach us the most important lessons. And Germany may be said, in a sense to be our only contemporary. South America is younger, and all Europe, with the exception of Russia, older than we. Germany dates her present magnificent intellectual life from the same period that we date our present no less magnificent political life.

"We ought to be acquainted and sympathize as far as we can," Fuller added, and Heine's book offered "some excellent material for the bridge between Germany and us." ${ }^{38}$ In the following years she published a voluminous translation of Eckermann's Conversations with Goethe (1839) and important essays on Goethe, Schiller, Jean Paul, E.T.A. Hoffmann, Freiligrath, and Beethoven. From 1844 to 1846, Fuller covered the European scene for the New-York Tribune, and her Papers on Literature and Art (1846), praised by the fervently nationalist Democratic, were informed by her candid appraisal of the American scene in the context of an Atlantic book culture. ${ }^{39}$

Fuller's transcendentalist friends joined in this campaign to counterpoise American utility by German idealism, and many of their efforts had a lasting impact. Clarke published the germanophile Western Messenger in Louisville, and Ripley, a leading member of Brook Farm, edited a series of Specimens of Foreign Standard Literature (1838-1842), with ten of the 14 volumes, including Fuller's Conversations with Goethe and Menzel's literary history, exclusively devoted to German writers. Reverend Brooks, who authored a much reprinted anthology of

38 "Present State of German Literature." The American Monthly Magazine 8 (July 1836): 1-13, 3-5. See Williams on this New York journal (1833-38), which was then edited by Charles Fenno Hoffman and featured, among other articles, frequent translations from German and French authors.

39 The Democratic praised Fuller's "true, genuine, invincible Americanism" but suspected that "the age for a national literature has not yet arrived": "[W]here are our Burns, Beranger, or Moore, as these authors represent the life of Scotland, or France, or Ireland? We have no national minstrel." "Miss Fuller's Papers on Literature and Art," Democratic Review 19 (1846): 198-202 and 316-20, $201 \mathrm{f}$. 
German Lyric Poetry in 1842 and contributed many items to Duyckinck's Literary World, was a prolific translator in many genres. Among his best-known works are his version of Schiller's Wilhelm Tell (1838), Jean Paul's Titan (1851) and Goethe's Faust (1856). Hedge was the founder and "exacting praeceptor germanicus" of the "Transcendental Club." ${ }^{30} \mathrm{He}$ edited a comprehensive anthology of the major Prose Writers of Germany (567 pages in double columns) for the well-known Philadelphia publisher Carey and Hart in 1847. The book appeared as a companion to similar collections of American, English, and European literature by Griswold, Longfellow, and other editors.

Like the other volumes of this series, Hedge's Prose Writers of Germany was extensively reviewed, and its impact on impressionable writers like the young Whitman is well known. Indeed, Hedge's anthology must be seen as a landmark in the history of German-American literary relations. ${ }^{41} \mathrm{I}$ use it here as a stepping stone for a brief survey of American responses, some reprinted from British sources, to continental and especially German literature between 1846 and 1850 . Hedge's anthology collected short biographies and texts by 28 authors from Luther, Jacob Böhme, Abraham a Sancta Clara to Schelling, E.T.A. Hoffmann, and Chamisso. Goethe is by far the best represented in terms of the pages allotted him; Schiller's only contribution is the essay "Upon Naive and Sentimental

40 For brief remarks on Hedge's and Ripley's projects see Mueller-Vollmer, in Frank/ Mueller-Vollmer, 243 and 283f; on Brooks see Frantz, 204-10.

41 On Whitman's foraging in Hedge's collection (or in excerpts provided in reviews) see Pochmann, 462. A. P. Peabody penned the most extensive response to Hedge's Prose Writers of Germany for the prestigious North American Review 67 (October 1848): 464-86. He portrayed German literature as informed by censorship and political suppression yet also by a peculiar depth and richness. As if in response to Emerson's address, Peabody stated: "The German scholar is cosmopolitan in his knowledge, taste, and appreciation" (473). He praised Hedge's excellent editorial work and the "fine specimens of translations [...] in good, vernacular English" (476) and reprinted extracts from Lessing's "Education of the Human Race" and - a remarkable choice - Jean Paul's "Dream." For other responses to Hedge's collection see the reviews in The Christian Examiner 44 (1848): 263-74 and the Literary World (29 January 1848): 625-28. The latter review contains a long extract of Sancta Clara and biographical sketches of Wieland and Kant with this "destructive, world-to-pieces-crushing thought" (627). For young American writers "just entering upon the wild domain of a new Literature," the critic said, the collection was "of essential value" (628), much better than Burnet's collection of English Prose Writers and Chambers's Cyclopaedia of English Literature." The Democratic, while less enthusiastic, also saw Hedge's collection as proof that "the influence of German literature upon our own is daily becoming more marked." "Prose Writers of Germany," Democratic Review 22 (February 1848): 192. 
Poetry." Among Hedge's most daring selections are long excerpts from Goethe's Elective Affinities, for American critics like Fenton a "licentious and detestable" novel of adultery, and Jean Paul's "Dream," i.e. the "Rede des todten Christus vom Weltengebäude herab, daß kein Gott sei," from the Siebenkäs, in Noel's version. ${ }^{42}$

Some of the translations in Hedge's American anthology of German prose had been made by British writers. Indeed, much of what Hedge and his friends learned about German culture came through foreign mediators like Coleridge, Madame de Stael, and Emerson's friend Thomas Carlyle. It is an important fact, moreover, that only Hedge had a firsthand knowledge of German culture. Emerson and his disciples lacked personal experience through extended travel or study in Germanspeaking countries. Yet Emerson's German streak was an important element in the public debate about the nationality of the U.S.s literature. Outside of New England, it seems to have been perceived as part and parcel of an all too narrow-minded campaign for cultural self-reliance. In May 1847, for instance, the Literary World carried a spirited plea for a concept of world literature that rejected Emerson's allegedly "opposite view":

If we are to have a literature that shall be called American, and which shall do honor to Americans, it must, we apprehend, have a foundation deeper and broader, and far more difficult to be laid, than many who write on this subject, seem to have conceived. [...] [I]n literature and philosophy, we must master and make our own what has already been produced, and from this elevation commence our onward and upward course. [...] [I]n literature, as in commerce, we become enriched by all the nations with whom we have active intercourse.

The New York critic was aware that "the author of 'Self-Reliance' [...] has presented with much emphasis the opposite view" but suggested: "[P]erhaps we have no finer illustration of the advantage to be derived from the study of foreign literature, than he himself affords". ${ }^{43}$ Clearly, cultural self-reliance was not an option for the critic

42 Felton's review of 1842 is quoted in Pochmann, 330. Jean Paul's "amazingly strong" American reception, inaugurated by Carlyle and fostered by Fuller, can be seen in magazine references of the period where Jean Paul ranked third among all German authors. A total of 46 books of his were issued in English translation after 1810, half of them, however, only after 1864 (Pochmann, 332).

43 "Walt and Vult," Literary World (29 May 1847): 387f. Parts of the article were copied in the Democratic, introducing a Select Library of German Classics which printed, in several instalments, lengthy translations of "the best and most attractive works of the master minds of German literature": Goethe's idyls Hermann and Dorothea and Alexis and Dora, parts of Iphigenia, and the complete text of Lessing's Minna von Barnhelm. "Select Library of the German Classics," Democratic Review 23 (1848): 260. With the 
of the Literary World. As a former colony and a young, modern, hybrid nation, the U.S. simply did not have a strong national character. It could not look back to an earlier "stage of isolation" in which the "Scotch, Irish, Swiss, and German, acquired their peculiar traits." Americans who are looking for a "distinctly American literature" should, the critic advised, "bestow greater attention upon the production of our Teutonic kindred" in order to avoid an undue influence by British writers "- whom if we follow, we can never hope to equal, much less exceed. If we would compete with England, we must avoid that insular exclusiveness and prejudice against everything foreign." The "youthful aspirant" of culture must follow a different course, and the critic asked:

And why should not our country, which is at home the freest, and in her intercourse with others the most generous and unrestricted, - receiving into her bosom the exile and unportioned of every land, - be also the most Catholic in taste and spirit, and gather treasures of wisdom and philosophy, of science and letters, from every people and every language? (387)

This spirited plea for literary internationalism served as the introduction to a review of Eliza Buckminster Lee's translation of Jean Paul's Flegeljahre, and while Carlyle's earlier efforts were duly noted, the World welcomed the fact that the "genial Jean Paul" was now "presented to the American public" by an American (387).$^{44}$ If the "genial" German remained a favorite in Duyckinck's journal, Goethe was clearly seen as Germany's master writer and an important "novelty" for American literature. Indeed, among the classical and contemporaneous German authors discussed in the World, he is by far the best represented, with more than a hundred items, including numerous reviews of Iphigenie, Clavigo, Werther, Hermann und Dorothea, Wilhelm Meister, Faust, and, last but not least, Dichtung und Wahrheit. This is quite significant since Goethe, like Heine a few years later, was seen as an

translation of Stifter's novella "Condor" in 1850, this project of printing German classics apparently ended.

44 Lee is one of the forgotten female mediators of German culture in this era. Among her publications are a Life of Jean Paul Richter (1842), a translation of Grillparzer's Sappho (1846), and Berthold Auerbach's "Dorfgeschichten" from the Black Forest. She also wrote Sketches of a New England Village (1838) and a historical romance about the Puritan persecution of Quakers, which was praised in the New York World for the light it cast on the "comparative merits of our Puritan and Dutch ancestors." "Naomi; or Boston Two Hundred Years Ago," Literary World (1 January 1848): 542. 
immoral, ambiguous character by many American critics, and not just those of the powerful religious press. ${ }^{45}$

When the Auto-Biography of Goethe, the first complete English version, came out in 1846, it provoked, among guarded praise, quite hostile reactions. Wiley and Putnam published the 2-volume set as part of their prestigious "Library of Choice Reading" series, and Godwin, Bryant's son-in-law and later contributing editor of Putnam's Monthly, functioned as the "editor" of a veritable consortium, with four translators rendering one part each of Dichtung und Wahrheit. ${ }^{46}$ Their version was intended to "supply what may be considered a great deficiency in English literature" and to counter the "disgraceful imposture" of an unreliable English translation which had been little more than "a poor copy of a wretched French version," as Godwin wrote in his preface: "Goethe is the hardest of all Germans to translate" because "he is such a consummate master of form" (1: ix). For Americans, "the First European Poet and Literary Man of the Nineteenth Century" was particularly important, and his autobiography showed "the growth of the greatest of German minds, and at the same time the whole progress of German literature" (x).

Despite this rather exaggerated praise, Godwin was at some pains to distance himself from Goethe's more questionable attitudes: "The translators are not of course to be held responsible for any opinions expressed in the course of the work" (1: $\mathrm{x})$. This disclaimer hints at the problematic nature of the undertaking. The critic of the American Whig Review called Goethe "the friend and approver of despotism, the inventor of new superstitions, more subtle and more heathenish; the exemplar of a court-bred insolence advancing itself even against the Divine

45 The review of Die Wahlverwandtschaften in the American Review of 1812 marks, says Pochmann, "the beginning of the long history of mingled praise and censure, the note of acrid controversy that governs American comment on Goethe to 1864" (330). Ever since Madame de Stael's criticism of Goethe's moral shortcomings, he had been attacked by Everett, Bancroft, and others, and the "qualified approval" by Emerson, Longfellow, Parker, and Motley had not helped much. Wolfgang Menzel's partisan history of German literature (1827), translated by C.C. Felton for Ripley's Specimens of Foreign Standard Literature series, portrayed him as politically indifferent and morally ambiguous. Godwin and his friends were clearly fighting an uphill battle. On Heine's early reception in Britain and the U.S., see Göske.

46 Godwin apparently translated books 1-5, John Henry Hopkins, Charles A. Dana, and John S. Dwight the other sections. Godwin's ambitious plans for an annotated edition and further translations of Goethe's "Annals," "Italian Journey" and correspondence did not materialize. The Auto-Biography of Goethe. Truth and Poetry: From My Life, ed. Parke Godwin. 2 vols. (New York, 1846-47), "Note by the Editor," 2: 117. 
Idea." And about Dichtung und Wahrheit he wrote: "For a total absence of that charming element of autobiographies, the loss of self in age, country, and pursuits, it seems to be without its equal. [...] In fine, we as much admire the skill as detest the spirit of this autobiography." ${ }^{47}$ And while the World extolled its "cheering and earnest views," emphasizing Goethe's "beneficial influence upon our too anxious and excited minds," Duyckinck's more outspoken private diary betrays an uneasy fascination:

His knowledge of life seems to have in it something of the demon, that "knowledge of things good and evil" which Satan promised to Eve. [...] In reading Goethe I have an instinct of an immense reservoir of self in his character into which he pours his vast contemplation and experience of life. An egotism which escapes our view in its breath. ${ }^{48}$

The "First European Poet and Literary Man of the Nineteenth Century" remained a highly controversial figure in the following years. Even Emerson's remarks in Representative Men did not help much, as a review in the World indicates: "A character more selfish and despicable could not be painted. Indeed, there is something demoniac about both Napoleon and Goethe as here represented, and Mr. Emerson's portraits are flattering enough." ${ }^{49}$ Emerson's collection of essays on Plato, Swedenborg, Montaigne, Shakespeare, Napoleon, and Goethe was itself a product of America's exceptional internationality. Partly inspired by Carlyle's book On Heroes, Hero Worship and the Heroic in History (1841), which excluded Goethe, it was based on lectures that the sage of Concord had delivered in the U.S. and in Britain from 1845 to 1848 , "emerging from the mists of transcendentalism into the robust daylight of New York and London." ${ }^{50}$

47 “Goethe's Autobiography," American Whig Review 5.5 (March 1847): 539-40. More sympathetic reviews appeared in the Democratic Review 19 (1846): 443-55; 20 (1847): 14-22; and 21 (1847): 283-89; the Literary World (1 May and 18 September 1847): 296f. and 149-51; Southern Quarterly Review 11 (1847): 441-67; and the International Monthly Magazine 1.7 (12 August 1850): 194. For more see Haertel, 97ff.

48 “The Autobiography of Goethe," Literary World (1 May 1847): 296. Duyckinck's diary entry, quoted in Yanella/Yanella (232), contrasts sharply with a later review which detects hardly any "egotism and dogmatism." "The Autobiography of Goethe," Literary World (18 September 1847): 150.

49 “Representative Men," Literary World (Feb. 1850): 123f, 124. In December 1847 and January 1848, the World had reported several times on British responses to Emerson's lectures.

50 Williams (1987), xxvii. Emerson's essay on Goethe, whom Carlyle had excluded, was a "late and uncertain choice" (xxxiv), but it certainly fit the new interest in the German writer, not least in the periodical press. 


\section{"A learning nation": America's Exceptional Internationality}

"Nationality in Literature" remained a key issue in those years but the World had slightly softened its earlier crusade for American nationalism. In July 1849, the Duyckincks reprinted, under that title, an excerpt from a long review of Longfellow's Kavanagh, which had just appeared in the North American Review. Renouncing a cultural variant of the Monroe doctrine, it claimed that the "demand for a nationality bounded historically and geographically by the independent existence and territory of a particular race or fraction of a race, would debar us of our rightful share in the past and the ideal" (11). The North American upbraided "our advocates of nationality" for "assigning geographical limits to the poet's range of historical characters as well as to his natural scenery." Rather, they should adopt, like major writers throughout the world, a universalist stance: "There is no time or place in human nature; and Prometheus, Coriolanus, Tasso and Tell are ours if we can use them, as truly as Washington or Daniel Boone" (12). This passage invites comparison with Melville's celebration of a new nation in Redburn, his fourth novel that he dashed off at that very time, in July 1849. In chapter 33 , the sight of a group of devout, sober German emigrants in the Liverpool docks, triggers off, in the young title hero's mind, an almost eschatological vision of America as a nation of nations:

Our ancestry is lost in the universal paternity; and Caesar and Alfred, St. Paul and Luther, and Homer and Shakspeare [!] are as much ours as Washington, who is as much the world's as our own. We are the heirs of all time, and with all nations we divide our inheritance. On this Western Hemisphere all tribes and people are forming into one federated whole; and there is a future which shall see the estranged children of Adam restored as to the old hearth-stone in Eden. (169)

Melville seems vaguely to grope for a transnational concept of America, yet the conclusion to the chapter does not envision a multicultural, multilingual "federated whole." Neither, however, does it echo the notion of a technologically advanced, global culture the anonymous critic had foreseen. ${ }^{51}$ Rather, Melville falls back on universal, Biblical myths. In a curious typological interpretation of Scripture he celebrates a new world which will evolve "in the fullness and mellowness of time," many generations hence: "Then shall the curse of Babel be revoked, a new Pentecost come, and the language they shall speak shall be the language of Britain. Frenchmen, and Danes, and Scots; and the dwellers on the shores of the Mediterranean,

51 "The newspaper, the railroad, and the steamship are fast obliterating the externals of distinct and hostile nationality. The Turkish soldier has shrunk into coat and pantaloons, and reads Dickens." "Nationality in Literature," Literary World (7 July 1849): 12. 
and in the regions round about; Italians, and Indians, and Moors; there shall appear unto them cloven tongues as of fire" (169). English appears here not as the emerging lingua franca of international trade (not least in litteris) but as a mystical form of communication of mankind. This is of course a far cry from the American realities around 1850 .

Yet mass immigration, improved communication, and emerging publishing networks across the Atlantic seem to have fostered, if only for a brief interval before the panic of 1857 and the outbreak of the Civil War, a new, powerful interest in the literary world overseas. In the early 1850s, other periodicals in New York and elsewhere in the country emerged that were committed to furthering the cause of American literature within a broader, Atlantic context. One of the most interesting though least known cases is The International Monthly Magazine of Literature, Science and Art, published in New York between July 1850 and April 1852 before it was absorbed by Harper's New Monthly. It was an eclectic and largely derivative journal which, however, contributed to the extraordinary awareness of foreign literature among American writers and readers in the early 1850s. Little is known about its operation. Apparently edited by Rufus Griswold and his assistant Charles Godfrey Leland, the translator of Heine, the International carried numerous articles on European and especially German issues and writers. Since it often named the provenance of its material, this short-lived, illustrated monthly indicates the emerging publishing networks in the increasingly diverse Atlantic reading culture. ${ }^{52}$

In August 1850, for instance, the International featured a piece on "German Criticism on English Female Romance Writers," translated from a letter by the London correspondent of the Cologne Gazette, and an article on "The Theater in Russia and Poland," taken from the Leipzig Grenzboten. But foreign material was mingled with original pieces on American topics, often seen through the eyes of foreign authors. In "America as Abused by a German," the anonymous reviewer saw A. Kirsten's Skizzen aus den Vereinigten Staaten von Nord Amerika as the work of a "paid hireling" intoning the "old song" of many European governments: "Depreciation of America, as far as applicable to the prevention of emigration" (448). Yet the critic maintained his journal's editorial policy to "faithfully report all that is said of our country by foreign travelers or journalists." Giving the familiar notion of American exceptionalism an internationalist spin, he added:

52 On Griswold's and Leland's role see Exman, 310, and Leland, 197. For its foreign items, the International acknowledged not only British but also French and German sources like the Revue des deux mondes, Journal de debats, Allgemeine Zeitung, Preußische Zeitung, or Grenzboten. 
[...] we are certain that a higher feeling than mere nervous, sensitive vanity, induces in us the desire 'To see ourselves as others see us', since there is no nation which more readily avails itself of the remarks of others, even when by far too bitter or unjust to improve. True to our national character of youthfulness, we are ever ready to act on every hint. We are, par excellence, a learning nation. (448)

The very mixture of native and foreign points of view makes this journal a valuable tool for an international American studies approach. In December 1851, the International featured a severely critical piece on "the Rise and Progress of Mormonism," a review of George von Ross' "Des Auswanderers' [!] Handbuch, or, The Emigrants' Hand-book: a True Sketch of the United States of America," John R. Brodhead's lecture, in the New York Historical Society, on "The Dutch Governors of Niew Amsterdam," an article on educational institutions in Calcutta, taken from Bentley's Miscellany in London, Cooper's remarks on "American and European Scenery Compared," reprinted from the Home Book of the Picturesque, just published by Putnam, and a survey of British reviews of Melville's Moby-Dick, "the new nautical story by the always successful author of Typee" (602). If one wants to study the transfer of cultures and the internationality of the American literary scene, at least in its New York variety shortly after 1850, the International is a good point to start.

However, weeklies like the World and monthlies like the International or the Democratic had only a circulation of less than 2,000. After 1850, new ventures like Harper's Monthly Magazine reached a much larger audience, cheaply reprinting literature by British and European writers. Harper's started off with 7,500 copies in 1850 but, thanks to many pirated texts from popular British writers like Dickens, Thackeray, or Bulwer-Lytton, the circulation soared to 50,000 copies within half a year and then, on average, to 110,000 between 1850 and 1865. That of Putnam's Monthly, Harper's immediate and ambitious rival, peaked in 1855 at a much lower but still impressive 19,000 copies. (Later its sales declined, and the magazine folded in the financial panic of 1857.) As the subtitle indicates, Putnam's Monthly Magazine of American Literature, Science, and Art championed, first and foremost, native authors, printing major works by Cooper, Thoreau, Longfellow, Melville, Bryant, James Russell Lowell, and Bayard Taylor. ${ }^{53}$ Despite its avowed program of literary nationalism and perhaps in order to offset the influx of British writing, Putnam's also covered continental European literature extensively. German culture in particular played a large role.

53 See Ljungquist, 328-31 and, for Harper's, Perkins, 167f. In the 1850s, Harper's was “the most successful magazine in America with its combination of English serials, its wide variety of shorter work, and its many illustrations" (Tebbel, 109). 
Indeed, a direct comparison of the editorial sections of both magazines in the year 1853 reveals remarkable differences. Harper's editorials featured notices of 53 British books (and news items on their authors), followed by 45 American, 25 French and only 19 German publications. In contrast to this strong AngloAmerican bias, Putnam's listed and reviewed a total of 169 German books in the same year. This extraordinarily large contingent was followed by 154 American and 110 French publications - and trailed by only 52 British books, less than half of the French allotment. ${ }^{54}$ In later issues, the presence of European literature is much less pronounced, yet in the mid 1850s, Putnam's offered its readers a lot of information on continental writing. Clearly, the precise nature of the transatlantic networks and the impact of the German element during the internationalist interval of antebellum American print culture need further investigation.

"American national identity," Janice Radway maintained in 1999, "is constructed in and through relations of difference" (54). This is, of course, easier said than put into critical practise, if one wants to go beyond essentialist and historically inaccurate identity politics and move towards a "critical transnationalism" that can, as Giles suggests, "illuminate our understanding of where the culture of the United States is positioned within a framework of broader global affairs" $(2007,47)$. The medium of literary journals around 1850, however, provides both rich (and still largely unknown) material and a precise focus for looking at those constructions, or better, notions of American nationality as they evolved in a surprisingly international context. Weeklies like the Literary World and monthlies like the United States Magazine and Democratic Review, which helped to foster the intellectual climate for the "American Renaissance" in the early 1850s, were informed by the intricate interdependence of American and British, but also German and French cultures. They reported and commented on foreign ideas, works, and institutions by situating them in the on-going debate about U.S. culture and society. Reciprocally, they viewed American topics and individual works in the specifically generic, broadly critical, or plainly commercial context of an Atlantic reading culture. By combining new databases with the book and microfilm holdings of old research libraries, antebellum periodicals can now be read as polyphonic and heterogeneous sites of cultural transfer, transnational exchange, and intra-cultural differentiation. They provide ample opportunities for detailed investigations into the networks of $19^{\text {th }}$ century print culture, the negotiations of different concepts of nationality, and individual responses, by American authors, to foreign works of literature. Seen in a simultaneously national and international context, these

54 I am grateful to Anja Hansen and Anna Weitemeyer for these findings. 
journals offer test cases for the interdisciplinary approach of American Studies in an era of increasing globalization and decreasing linguistic ability. In order to make good use of them, however, historians of American literature and culture need to cooperate not only with scholars of British, French, or German culture but also with experts in the fields of comparative literature, translation studies, book history, media studies, and the like. This is a tall order but an exciting one.

\section{Works Cited}

Bean, Judith Mattson, and Joel Myerson, eds. Margaret Fuller, Critic. Writing from the New-York Tribune, 1844-1846. New York: Columbia UP, 2000.

Buckley, Thomas L. "The Bostonian Cult of Classicism: The Reception of Goethe and Schiller in the Literary Reviews of the North American Review, Christian Examiner, and the Dial (1817-1865)." In Elfe, Wolfgang, James Hardin, and Gunther Holst, eds. The Fortunes of German Writers in America: Studies in Literary Reception. Columbia: U of South Carolina P, 1992. 27-40.

Buell, Lawrence. "American Literary Emergence as a Postcolonial Phenomenon." ALH 4 (1992): 411-42.

Cazden, Robert E. A Social History of the German Book Trade in America to the Civil War. Columbia, SC: Camden House, 1984.

Chai, Leon. The Romantic Foundations of the American Renaissance. Ithaca, NY: Cornell UP, 1987.

Chielens, Edward E., ed. American Literary Magazines: The Eighteenth and Nineteenth Centuries. New York: Greenwood P, 1986.

Chielens, Edward. “The Dial." In Chielens 127-32.

Chielens, Edward. "The Christian Examiner." In Chielens 103-07.

Chlebek, Diana A. "Littell's Living Age." In Chielens 222-25.

Exman, Eugene. The Brothers Harper: A Unique Partnership and Its Impact on the Cultural Life of America from 1817 to 1853. New York: Harper \& Row, 1965.

Frank, Armin Paul, and Kurt Mueller-Vollmer. The Internationality of National Literatures in Either America: Transfer and Transformation. Vol. I/2: British America and the United States, 1770s-1850s. Göttingen: Wallstein, 2000.

Frantz, Adolf Ingram. Half a Hundred Thralls to Faust: A Study Based on the British and American Translators of Goethe's Faust 1823-1949. Chapel Hill: U of North Carolina P, 1949.

Fuller, Margaret. Selected Letters. Ed. Robert N. Hudspeth. Ithaca, NY: Cornell UP, 2001.

Giles, Paul. Transatlantic Insurrections: British Culture and the Formation of American Literature, 1730-1860. Philadelphia: U of Pennsylvania P, 2001. 
Giles, Paul. "Transnationalism and Classic American Literature." In Manning, Susan, and Andrew Taylor, eds. Transatlantic Literary Studies: A Reader. Edinburgh: Edinburgh UP, 2007. 44-52.

Gilmore, Michael T. American Romanticism and the Marketplace. Chicago: U of Chicago P, 1985.

Göske, Daniel. „Salonliterat im Freyheitsstall: Heine in anglo-amerikanischen Kulturzeitschriften vor 1856." In Achim Barsch et al., eds. Literatur - Kunst Medien. München: Meidenbauer, 2008. 225-42.

Goodnight, Scott Holland. German Literature in American Magazines Prior to 1846. Madison: U of Wisconsin, 1907.

Grey, Robin. The Complicity of Imagination: The American Renaissance, Contests of Authority, and Seventeenth-Century English Culture. Cambridge: Cambridge UP, 1997.

Gross, Robert A., and Mary Kelley, eds. A History of the Book in America. Vol. 2: An Extensive Republic: Print, Culture, and Society in the New Nation, 1790-1840. Chapel Hill: U of North Carolina P, 2010.

Gunn, Giles B. F. O. Matthiessen: The Critical Achievement. Seattle: U of Washington $\mathrm{P}, 1975$.

Haertel, Martin H. German Literature in American Magazines 1846 to 1880. Madison: U of Wisconsin, 1908.

Higgins, Brian, and Hershel Parker, eds. Herman Melville: The Contemporary Reviews. Cambridge: Cambridge UP, 1995.

Lease, Benjamin. Anglo-American Encounters: England and the Rise of American Literature. Cambridge: Cambridge UP, 1981.

Leland, Charles Godfrey. Memoirs. New York: Appleton, 1893.

Leypoldt, Günter. Cultural Authority in the Age of Whitman: A Transatlantic Perspective. Edinburgh: Edinburgh UP, 2009.

Ljungquist, Kent. “Putnam's Monthly Magazine." In Chielens 328-33.

Maas, Christel-Maria. Margaret Fullers transnationales Projekt: Selbstbildung, feminine Kultur und amerikanische Nationalliteratur nach deutschem Vorbild. Göttingen: Universitätsverlag, 2006.

Marovitz, Sanford E. "More Chartless Voyaging: Melville and Adler at Sea." Studies in the American Renaissance (1986): 373-84.

Matthiessen, F. O. American Renaissance: Art and Expression in the Age of Emerson and Whitman. London: Oxford UP, 1979.

Melville, Herman. Redburn: His First Voyage. Eds. Harrison Hayford et al. Chicago: Northwestern UP, 1969. 
Melville, Herman. The Piazza Tales and Other Prose Pieces. Eds. Harrison Hayford et al. Chicago: Northwestern UP, 1987.

Melville, Herman. Moby-Dick or The Whale. Eds. Harrison Hayford et al. Chicago: Northwestern UP, 1988.

Melville, Herman. Journals. Eds. Howard Horsford and Lynn Horth. Chicago: Northwestern UP, 1989.

Melville, Herman. Correspondence. Ed. Lynn Horth. Chicago: Northwestern UP, 1993.

Menides, Laura J. “The American Whig Review.” In Chielens 29-34.

Miller, Edwin Haviland. Salem Is My Dwelling Place: A Life of Nathaniel Hawthorne. Iowa City: U of Iowa P, 1991.

Mueller-Vollmer, Kurt. "Every Ship Brings a Word": Cultural and Literary Transfer from Germany to the United States in the First Half of the Nineteenth Century. Berlin: John F. Kennedy-Institut, 2003.

Mueller-Vollmer, Kurt. Transatlantic Crossings and Transformations: GermanAmerican Cultural Transfer from the $18^{\text {th }}$ to the End of the $19^{\text {th }}$ Century. Frankfurt/ Main: Peter Lang Publishing, forthcoming 2015.

Pease, Donald. Visionary Compacts: American Renaissance Writings in Cultural Context. Madison: U of Wisconsin P, 1987.

Perkins, Barbara. “Harper's Monthly Magazine." In Chielens 166-71.

Pochmann, Henry. German Culture in America: Philosophical and Literary Influences 1600-1900. Madison: U of Wisconsin P, 1957.

Price, Kenneth, and Susan B. Smith, eds. Periodical Literature in NineteenthCentury America. Charlottesville: UP of Virginia, 1995.

Radway, Janice. "What's in a Name?” In Pease, Donald E., and Robyn Wiegman, eds. The Futures of American Studies. Durham, NC: Duke UP, 2002. 45-75.

Railton, Stephen. Authorship and Audience: Literary Performance in the American Renaissance. Princeton, NJ: Princeton UP, 1991.

Reynolds, Larry J. European Revolutions and the American Literary Renaissance. New Haven: Yale UP, 1988.

Roeber, A. Gregg. "Readers and Writers of German.” In Gross 471-82.

Sollors, Werner, ed. Multilingual America: Transnationalism, Ethnicity, and the Languages of American Literature. New York: New York UP, 1998.

St Clair, William. The Reading Nation in the Romantic Period. Cambridge: Cambridge UP, 2004.

Tebbel, John, and Mary Allen Zuckerman. The Magazine in America. Oxford: Oxford UP, 1991. 
Vanderbilt, Kermit. American Literature and the Academy: The Roots, Growth, and Maturity of a Profession. Philadelphia: U of Pennsylvania P, 1986.

Weiner, Bruce I. "The United States Magazine and Democratic Review." In Chielens 425-32.

Wells, Daniel A., and Jonathan Daniel Wells, eds. The Literary and Historical Index to American Magazines, 1800-1850. Westport, CT: Praeger, 2004.

Wells, Daniel A., comp. The Literary Index to American Magazines, 1850-1900. Westport, CT: Greenwood P, 1996.

Wells, Daniel A. "An Index to American Writers and Selected British Writers in Duyckinck's Literary World, 1847-1853." Studies in the American Renaissance (1978): 259-78.

Weisbuch, Robert. Atlantic Double-Cross: American Literature and British Influence in the Age of Emerson. Chicago: U of Chicago P, 1986.

Widmer, Edward L. Young America: The Flowering of Democracy in New York City. Oxford: Oxford UP, 1999.

Williams, Kennedy. “The American Monthly Magazine." In Chielens 15-19.

Williams, Wallace E. "Historical Introduction." The Collected Works of Ralph Waldo Emerson. Ed. Joseph Slater. Vol. 4: Representative Men: Seven Lectures. Cambridge, MA: Harvard UP, 1987. xi-lxv.

Winship, Michael. "The Transatlantic Book Trade and Anglo-American Literary Culture in the Nineteenth Century." In Fink, Steven, and Susan S. Williams, eds. Reciprocal Influences: Literary Production, Distribution, and Consumption in America. Columbus: Ohio State UP, 1999. 98-122.

Yanella, Donald, and Kathleen M. Yanella. "Evert A. Duyckinck's 'Diary: May 29 November 8, 1847"' Studies in the American Renaissance (1978): 207-58.

Yanella, Donald. “The Literary World.” In Chielens 224-30. 
Marietta Messmer and Armin Paul Frank - 978-3-653-98855-0 Downloaded from PubFactory at 01/11/2019 10:57:20AM via free access 


\section{Reprinted Essays}


Marietta Messmer and Armin Paul Frank - 978-3-653-98855-0 Downloaded from PubFactory at 01/11/2019 10:57:20AM via free access 


\author{
Earl E. Fitz
}

Vanderbilt University, U.S.A.

\title{
Inter-American Studies as an Emerging Field: The Future of a Discipline ${ }^{1}$
}

Inter-American Studies is an exciting and fast developing new field, one that has the potential to revolutionize not only how we think about the Americas (including their relationships with Europe ${ }^{2}$ and Africa and their pre-Columbian worlds) but about the various disciplines - from literature to economics, from politics to law, and from anthropology to music - that link them together. Although we must credit historians like Herbert E. Bolton with having charted the original conceptual framework for this undertaking early in the twentieth century, and though we have seen interest in the Inter-American project wax and wane through the years, we are now living in a time when, for a variety of reasons, interest in Inter-American relations suddenly looms larger and more urgent than it ever has before. Concerned with a wide range of issues and agencies, such as NAFTA, popular music, literature, and law, the Americas have become, in the early years of the twenty-first century, a deeply interconnected site of tremendous energy and potential. And of conflict.

However, as an emergent (and therefore disruptive) intellectual discipline, Inter-American Studies must also be considered part of the larger process of "globalization" that, like the arrival of the banana company train in García Márquez’s Cien años de soledad [One Hundred Years of Solitude], is causing so much upheaval and consternation in so many places. Major players in this vast international game, the Americas are taking note of each other as never before, and the Inter-American paradigm (understood as involving both Francophone and Anglophone Canada, the United States, Spanish America, Brazil and the Caribbean) offers an excellent, though by no means foolproof, method of ensuring that this difficult process of

1 This essay was first published in Rethinking the Americas: Crossing Borders and Disciplines, ed. Cathy L. Jrade. Special issue of Vanderbilt E-Journal of Luso-Hispanic Studies 1 (2004): 13-28. Reprinted here with permission.

2 See Jean Morency, "Forms of European Disconnection in Literature of the Americas," Topia: A Canadian Journal of Cultural Studies 2 (1998): 11-21. 
rediscovery and reconsideration proceeds with fairness and accuracy. This is our challenge.

But nowhere is the pressure of change being felt as acutely, perhaps, as in the closely related fields of American Studies and American literature, mainstream academic areas involving vast numbers of students and where "a broad critique of the narrow, nationalist conflation of the American and the United States has sparked vigorous efforts to resituate the study of United States literature and culture in a hemispheric or Pan-American context."3 Although our understanding of what it means to speak even of the literature of the United States has, since the 1970s, itself been steadily evolving, Inter-American Studies is fast becoming an integral part of this process and, as such, seems certain to change the ways traditional units, such as Anthropology, English and American literature, African American Studies, History, French, Economics, Law, Spanish and Portuguese, and Comparative Literature, envision their missions, their subject matter, and their relationships with each other. It is a rare opportunity to be able to help shape the development of a new and still relatively uncharted field, but that is precisely what we, the authors of the essays in this collection, feel we have before us.

Rather than trying to sum up what we already know about Inter-American Studies as an academic discipline - that it is appealing to some and subversive to others and that it is both immensely complicated and, quite often, contentious, for example - I would like, in this essay, to enumerate what I take to be the five major problems that eventually have to be confronted and dealt with before even a well-intended program in Inter-American Studies can flourish - in any discipline. Some of these issues deal with course content and orientation while others deal with philosophic and methodological matters, but all are crucial, I believe, to the healthy growth and development of this field. It is my hope that by raising these issues at the outset, they will serve as a kind of theoretical and procedural backdrop against which the reader can better consider the particular issues raised by each of our distinguished contributors.

\section{The Language Problem}

Perhaps the greatest obstacle we must confront is what some are terming the "language problem," the fact that in order to perform teaching and research that engages even two or three of our American cultures, we need linguistic competency in, as I will argue, at least three of our New World languages, a grouping

3 See Paul Jay, "Beyond Discipline? Globalization and the Future of English," PMLA 116: 1 (2001): 32-47. 
that includes our numerous Native American languages as well as our Europeanbased tongues (in alphabetical order): English, French, Spanish, and Portuguese. This issue is a problem because many of us simply have not had extensive, serious linguistic training in our own doctoral programs. Those who would like to get into Inter-American Studies are all too often mono (or, in some cases, bi) lingual, simply ill-equipped, in terms of language preparation, to do so. But, in truth, we cannot allow ourselves to be derailed by this problem, which, if it cannot be quickly overcome, can certainly be mitigated.

In the short run, the easy solution is to use translations. While this is not an altogether adequate solution, especially when issues of style, authorial development, or cultural context are involved, it does have the advantage of getting more scholars immediately involved in the Inter-American project. And it is a realistic recommendation since many of us will simply elect to use translations anyway. Then, too, the question of whether to rely on translated material or not is more of a problem for some disciplines than others. Speaking from the perspective of a literary scholar, I see little value in arguing that we should remain totally ignorant of great New World writers like Guimarães Rosa, Clarice Lispector, Nicole Brossard, Maryse Condé, Neruda, or Borges simply because we feel we cannot - or should not - use an existing translation. We should take some care, of course, with the particular translation we use (the Scott-Bucchleuch/Penguin translation of Machado de Assis's great Dom Casmurro simply omits certain key chapters from the original, for example), and we should always be cognizant of what inevitably "gets lost" in even the best translations, but, in the end, we should feel that it is better to know an author even partially via a good translation than not to know her at all. A similar argument pertains for other disciplines as well, I believe, though its particularities will certainly vary.

In the long run, however, we need to change the ways we train our graduate students. Specifically, we need to require them to have real proficiency (if not necessarily native fluency) in at least three of our American languages. This is absolutely imperative for the long term development of Inter-American studies as a field because of the growing pressure of what might be termed the "binary model," the methodological approach that I fear is fast establishing itself as the norm in InterAmerican Studies (which, even in its incipient form, is coming to be dominated by what some in the academy, in a moment of high irony for Latin Americanists, are now referring to as the "imperialism" of both English and Spanish) and that calls for linguistic competence in only two languages, and then perhaps only minimally. To be able to work only in, say, English and Spanish, is simply unacceptable because it ignores the profound linguistic diversity of our Americas while at the same time restricting the greater scope of the overall Inter-American initiative. Methodologically 
and conceptually, two languages simply constitute too narrow a perspective for this project. We know only too well that people in the United States have never been much interested in serious language training, but the signs are all around us that the times are indeed changing, and that this old isolationist and parochial attitude is dying out. We can only hope so. And, as a new field of intellectual inquiry (one that both relates to and connects many different disciplines), Inter-American Studies could well play a major role in its demise.

In practical terms, however, to demand that our doctoral students in InterAmerican studies must be able to work in at least three languages means, of course, that not everyone who applies will have the requisite background and training necessary to enter into this type of doctoral program. We will have to be very selective, therefore, choosing only those students who are naturally bi or tri lingual or who have studied enough language in undergraduate school (and, if we are serious about this, in elementary and secondary school as well) that they could pick up at least their third (or, depending on their areas of interest, perhaps fourth) required language as part of their doctoral course work. Given the extreme importance of verifiable language competency, then, to our project, the selection of students for advanced study in Inter-American Studies will thus be a most painful one, with many otherwise excellent candidates not being chosen, but if we are to properly chart our discipline's future course of development, it is absolutely essential that we maintain the highest entrance requirements. To fail here will be to fatally imbalance the development of Inter-American Studies as a methodologically valid field of intellectual inquiry by allowing it to become the near exclusive province of only one or two languages. This scenario, which privileges certain languages (and their cultures) while relegating others to second and third class status, must be avoided at all costs.

As they are currently configured, many departments of English and American literature (to speak of the obstacles one particular - and absolutely essential - unit will have to overcome very quickly) are finding themselves in an unexpectedly precarious situation in this regard. Unless they are rash enough to "confuse," as Stephen Greenblatt observes, "the globalization of literary studies" with "American triumphalism and an insurgent English-language parochialism," ${ }^{3}$ programs in American literature are finding it necessary to confront and deal with the fact that the United States is itself deeply and irrevocably pluralistic, that it is only one of several, interrelated Americas, and that, replete with their own voices, histories, and cultures, these are now demanding recognition and attention, acknowledgment of

4 Stephen Greenblatt, "Racial Memory and Literary History”, PMLA 116: 1 (2001): 48-63. 
their rightful places in the New World sun. Innovative, engaging literature has long been written throughout North, Central, and South America in languages other than English, and if English department faculty and students do not know at least two or three of these hitherto "Other" tongues they run the very real risk of being left behind, limited to texts originally written in English or to what they can glean from what translated materials exist. How large, influential units like English accommodate this sea change in our approach to the entire concept of what it means to be "American" constitutes a great challenge for our traditional programs in American literature (as it does for a great many other disciplines, history, for example, or political science), and their response to it will almost immediately emerge as one of the decisive factors in the development of Inter-American Studies generally.

It must be said, in this same regard, that, at least initially, bi- or tri- lingual Canadianists and Latin Americanists could enjoy distinct advantages as the field of Inter-American Studies develops since, in terms of the requisite language preparation, they are also natural and experienced comparatists, having long studied their literatures (those of English and French-speaking Canada, Portuguese-speaking Brazil, and Spanish America) in terms of other, more "canonical" texts and literary traditions. Something very similar can be said of scholars working in a variety of other disciplines as well, I suspect. What this means, in realistic terms, is that Latin Americanists and Canadianists have long had to know more - much more - about the literature, culture, and history of the United States and Europe than students of European and "American" literature (meaning that of the United States alone) have traditionally had to know about Canadian or Latin American literature, culture, and history. Thus, another problem we face here (one well known to comparatists) is that of balance, of knowing one thing very well but another, closely related thing not at all, and feeling compelled to examine them both together.

Beyond this issue (daunting as it is), it is interesting to consider the "language question" with respect to Canadian and Latin American literature and culture themselves. No where in the Americas, perhaps, has language been more viscerally connected to issues of cultural identity than in Quebec, though giant Brazil, too often overlooked even within the larger context of Latin America, has long defined itself on the strength of its mellifluous and quirky language as well, though perhaps not as militantly. Indeed, interest in Brazil/Québec studies has been steadily rising in recent years (as work by Zilá Bernd, Yvan Lamonde, Gérard Bouchard, and others admirably demonstrates), ${ }^{5}$ with some scholars coming to regard these

5 For information regarding Professor Bernd's new CD on Inter-American literature, go to the following address: www.ufrgs.br/cdrom. See, also, La nation dans tous ses états: 
two very unique New World cultures as the most marginalized of all, the two cultures most consistently - and most conspicuously - ignored in the Inter-American purview. Yet on balance it also seems likely that there has been closer linguistic and literary interaction between England and France in Canada than between Spain and Portugal in Latin America, a cultural and historical setting in which Spanish America and Brazil have evolved separately and "apart, since the first days of the discovery and conquest of the New World."

In sum, one must conclude that, as the complex and demanding field of InterAmerican Studies continues to develop, we will need to think in terms not of the past, and the ways we were trained as doctoral and professional students in our respective disciplines, but of the future and the new kinds of training (particularly linguistic training) that we want our graduates to have. If we are to make them successful Inter-Americanists, we must train them better than we were trained, and we must remain steadfast in insisting that certain standards be met (foremost being the linguistic requirement). This, I believe, is essential, for in truth we are preparing a new generation of scholars for a multi-dimensional, fluid, and rapidly evolving new field, and we must ensure that they are prepared to deal with it fully and properly, to become, in short, leaders in the field.

\section{Programmatic Cohesion}

Since I am adamantly in favor of requiring our doctoral students in Inter-American studies to work with at least three separate languages, I also favor requiring them to work with the three culture groups associated with them. The goal here, I believe, is to help our students select courses that will allow them to develop, semester by semester, a coherent, logically unified program, one that, with careful planning, will enable the student to develop a primary area of specialization (out of which a dissertation might well arise) as well as secondary and tertiary areas of teaching and research interest. Advising will thus become of paramount importance, as will the issue of the course selection for each student's program. For the student, then, as well as for the advisor, the goal, always, must be the creation of a unified, cohesive program of study, one that coalesces in meaningful, professional ways, that avoids

Le Québec en comparaison, Yvan Lamonde and Gérard Bouchard, editors. Montréal: Harmattan, 1997.

6 Emir Rodríguez Monegal, The Borzoi Anthology of Latin American Literature, vol. 1 (New York: Knopf, 1984): xiii.

7 This is a point that Robert K. Martin has made as well. See, Martin, "North of the Border: Whose Postnationalism?," American Literature 65: 2 (1993): 358-361. 
being merely a conglomeration of disconnected courses, credits, and topics, and that clearly features the student's primary area (or areas) of interest.

But until Inter-American Studies develops as a separate field to the point that it begins to produce a job market calling, specifically, for Inter-Americanists, I also believe that we must insist that our students ground themselves in the requirements of a traditional doctoral program. This, for me, would reflect the student's primary area of specialization, though, this, too, would have a clear and fundamental Inter-American dimension to it. For the time being, at least, I therefore feel we should be training Inter-Americanists who can compete successfully in the job markets that currently exist for more traditional Ph.D.s in these same areas. Inter-American literature, for example, enjoys a close affinity with Comparative Literature in that both require that work be done in more than one language and both rest on issues of methodology, on how and why certain texts can be brought together for study (by genre, theme, period, or movement, for example). Yet as we have seen, Inter-American scholarship is also very germane to the type of work being done by Latin Americanists, by Canadianists, and by Caribbeanists, all of whom possess particular areas of expertise and specialization that could be of keen interest to a wide range of academic units, including some not normally considered in this context, such as law, education, and medicine. In contrast to trends and developments in the job market, the academic structure of the university changes very slowly and so we would want our fledgling Inter-Americanists to be trained so that they would be immediately attractive to a college of Law, Medicine, Music, Business, or Education as well as to a typical department of History, Comparative Literature, English, French, Ethnomusicology, Political Science, Economics, African American Studies, or Spanish/Portuguese.

There are at least two reasons why they should be: first, our students would be prepared to teach the traditional courses required of such a department and, second, they would also be prepared to offer new courses in a vibrant and rapidly evolving new field - Inter-American history, literature, anthropology, politics, law, education, and music, to mention just a few of the most immediately promising possibilities. Such a person will, I think, be highly desirable for any department seeking to remain current and up to date or to forge ahead into new areas, which, as we all know, is a worthy goal of nearly every college and university.

\section{Course Coverage and Faculty Expertise}

Operating, once again, at the level of the practical, my concern here is with how an actual Inter-American course is structured, how it is organized, and how it selects certain texts and readings and not others. My comments here stem from my 
own experiences in designing and teaching courses in Inter-American literature, which I have done now for nearly twenty-five years. Although the same organizing principles may not work for every discipline when it comes to the construction of Inter-American courses, I am strongly in favor of breadth rather than depth, excluding, of course, graduate seminars that focus on more limited or specific Inter-American issues. At all levels, however, I advocate courses that have representation from all five of our New World literatures (English and French Canada, the United States, Spanish America, and Brazil), and including both our Native American heritage and the Caribbean, a region rightly understood by many people as the "crossroads of the Americas" and one fully emblematic of both the potential and the challenge of the entire Inter-American enterprise. The responsibility of the professor is to demonstrate to the students that the very concept of Inter-American Studies necessarily involves all of the Americas and not just a few selected parts of it. Research papers and areas of future specialization can certainly be scaled down to reflect each student's linguistic preparation and area of interest, but a basic conceptual and organizing principle of each Inter-American class should be a commitment to inculcating in the student the need to reach beyond narrow, binary thinking, the kind that produces the two-sided, two-language scholarship that, unfortunately, we are seeing more and more of in this type of study. It is, I believe, critical that in our courses we expose our students to issues that manifest themselves, often in very different ways, in all our New World nations and cultures and that we continuously remind them of the Americas' extraordinary diversity as well as of their common (but not identical) heritage.

In doing this, however, I am not claiming that everyone needs to be an expert in everything, for to do so would be fatuous in the extreme. Rather, I am claiming, via the inclusiveness of our courses, that to be a properly trained InterAmericanist of any particular stripe (literature, history, economics, law, religion, music, etc.) it is necessary to possess at least a rudimentary understanding of how any given topic plays out in the rest of the Americas. To do anything else, to organize courses only centering on, say, certain English and Spanish speaking sectors of "nuestra América" (as Martí put it in his seminal 1891 essay), is to fatally undercut the very argument of hemispheric commonality that we use to justify the entire Inter-American outlook. While the primary thrust of the course may well be limited to three of our New World cultures, we, as faculty, should take the time and trouble to ensure that our students at least consider, if only in passing, how the topic under consideration relates to the other American cultures, the ones not being focused upon in more detail. To be sure, this is never an easy task, and few (if any) of us were ever trained to do it. And, it must be said, to gain even this minimal level of knowledge about our sister American cultures means that we 
must commit to doing a lot of reading and research, to educating ourselves about the histories, traditions, and cultures of hemispheric neighbors we have hitherto known little or nothing about but whom we should know much better. In short, we must show our students (and ourselves!) that, for all their very real differences and for all the ways they can be compartmentalized into separate, isolated classes and programs (this being the typical model in most universities), the Americas share a common historical background, one that, to paraphrase Bolton's famous argument, ${ }^{8}$ continues to dramatize the interconnectedness of our often fractious but ongoing epic experience.

But while it is one thing to stretch one's intellectual horizons and organize a course that involves texts from the other Americas, it is quite another thing to try and teach these texts (which, per force, will often be in translation), or, at least, to do so in a way that connects them, in meaningful ways, with their often very different social and cultural contexts. The obstacle here that must be overcome is, once again, the nature of the graduate training that most of us received, linguistic and otherwise. Since most of us were not taught to think about our disciplines in broad, Inter-American terms (indeed, many of us were taught to think only in terms of narrow specializations), we must rethink and retrain ourselves as InterAmericanists, and this is not easy to do, even if we are inclined to do so.

One very effective way to do it, however, is simply to commit large amounts of time reading in the areas in which we find ourselves insufficiently prepared. For me, this was chiefly the literature of Anglophone and Francophone Canada, and I spent the better part of twenty years putting myself on a rather rigorous reading program in Canadian literature. This was great fun and I gained immensely from the experience (my reading skills in French grew exponentially, for example), but it was time consuming in the extreme. And it was often difficult to maintain in the face of the many other demands made upon our time. Still, to be able to read deeply and systematically in another of our New World literatures was an invaluable experience, and I recommend it to everyone.

A second possibility is to establish funding for some sort of "release time" program that would enable faculty to study, to take classes, or to travel to places where more specialized training could be gotten. Although more dependent on institutional largess and foresight, the "release time" method has the advantage of structure, control, and, above all, focus, all these being critical for a time-pressed faculty member seeking if not thoroughgoing expertise then at least basic competence in

8 See Herbert E. Bolton, “The Epic of Greater America," The American Historical Review 38: 3 (1933): 448-474. 
some important and hitherto missing aspect of the Inter-American course that is being envisioned.

Finally, faculty wishing to begin participating in an Inter-American studies program might well wish to organize team-taught courses, or courses organized by a single person but built around a series of carefully integrated and coordinated guest speakers. The team-teaching approach is becoming increasingly popular, at least at universities in the United States, as faculty realize that no single person has the full expertise needed to develop an Inter-American course with both the breadth and depth it should have. The flaw to be avoided here, however, is, once again, the binary approach, the urge we seem to have to seek only two professors to constitute the "team" rather than the three, or even the four, that are really needed. To go beyond four to five, however, is to begin to risk the loss of control, focus, and integration that are nearly always the hallmarks of a successful course. Thinking, again, of the need always to engage at least three of the New World's languages and cultures, it is easy to see how a team-taught course involving faculty from three interlocking areas, programs, or departments could be very successful, however, especially if it were able to take advantage of the new technologies, such as video conferencing, that are available.

The development of an entire Inter-American program is always greatly aided by an administration open to the suggestion that, in order to avoid the problem of having to ask people to take on overloads, all participating faculty be given credit for teaching a full course. If such an agreement could be worked out, and if the faculty member charged with actually writing the syllabus and organizing each day's session could rely on the cooperation and flexibility of the other participants, perhaps this triadic approach (with occasional forays into the other New World cultures) will eventually emerge as the most efficacious model, the one that best serves the needs of successful the Inter-American seminar, its students, and its faculty.

\section{Courses, New and Revised}

As Inter-American Studies evolves into an organic and definable field of study, new courses will have to be developed while many existing courses will have to be modified to fit the demands of a changing curriculum. In order for InterAmerican Studies to develop into a full-fledged discipline, however, it seems likely that the creation of new courses will prove to be the more crucial undertaking, the one that will have the greatest impact in the years to come. While courses that are currently on the books can often be modified at least somewhat in order to cultivate their Inter-American connections and relevancies, it is not easy to do 
this without sacrificing much of the course's original intended purpose. Still, with careful planning, it can be done successfully, and when it is, it adds a great deal to the intellectual scope of the course.

As an example, I offer my own course on Brazilian literature from its origins through the $19^{\text {th }}$ century. Traditionally, I have taught this course by focusing only on Brazilian authors and texts. These days, however, I have sought to expand the cultural context of the course to include references to and, on occasions, brief discussions of literary issues pertinent not only to Brazil but to Brazil's hemispheric neighbors as well. In short, I now teach this course by focusing, clearly and consistently, on Brazil's literary development but also by calling attention to the many parallels and differences that link it to its New World neighbors. Because many of them are already familiar with the literatures and cultures of both Spanish America and the United States, I consistently find that my students greatly appreciate this comparative and Inter-American perspective and find it exciting. As many of them have said, it helps them see the uniqueness of Brazil, its literature and culture, and at the same time to see it in a larger international perspective, as part of the world's community of nations.

Some examples of topics that have lent themselves to this type of comparative discussion include the following: the famous and very different "cartas" written by Christopher Columbus, Pêro Vaz de Caminha, and John Smith; the Jesuit Catholicism of New Spain, New France, and Brazil (and the differences within these) versus the Protestant Puritanism of New England and the nature of the societies these founded; race relations and contrasting views of miscegenation; the oratory and political thought of such individual figures as Vieira, de Las Casas, and Mather; Romanticism in the Americas (including the Confederation Poets) and the figure of the Indian (the pairing of Alencar and Cooper make for a fascinating paradigm in this respect, particularly as this issue relates to nation building and national identity in the nineteenth century); Machado de Assis, Henry James, and the development of the novel in the New World; and the as yet unexplored question of the "new novel" in the Americas of the 1960s, a subject that, in addition to the United States and Latin America, must include both the English Canadian production of the period (Leonard Cohen's extraordinary Beautiful Losers, for example, Malcolm Lowry's Under the Volcano, or Sheila Watson's The Double Hook ${ }^{9}$ ) and the French Canadian tradition of the same turbulent

9 The Double Hook, first published in 1959, is often referred to as the first Canadian novel to break free of the strictures of rote realism and regionalism and to create an intensely symbolic and mythically grounded new narrative. 
era, which features such culturally volatile and technically iconoclastic "textes" as Hubert Aquin's Prochain épisode, Réjean Ducharme's L'Avalée des avalés [The Swallower Swallowed], Marie-Claire Blais's Une saison dans la vie d'Emmanuel [A Season in the Life of Emmanuel], and Jacques Godbout's Le Couteau sur la table [The Knife on the Table].

In a more contemporary context, one might also wish to argue that a new literary genre is rapidly emerging in the Americas, a form that we might well wish to term the "Inter-American Novel," a type of extended narrative that is being practiced in very distinctive fashion by such New World masters as Carlos Fuentes ( $\mathrm{La}$ frontera de cristal/The Crystal Frontier; Gringo Viejo/The Old Gringo; and Los años con Laura Díaz/The Years with Laura Díaz), Isabel Allende (Hija de la fortuna/ Daughter of Fortune and El plan infinito/The Infinite Plan), Alberto Fuguet (The Movies of My Life), Silviano Santiago (Stella Manhattan and Keith Jarrett no Blue Note), Ann Patchett (Bel Canto), Margaret Atwood (Surfacing), Harriet Doerr (Stones for Ibarra), and Jacques Poulin (Volkswagen Blues), among many others. What we need here is something akin to what Ralph Freedman did for the "lyrical novel," 10 that is, to recognize it, define it, and then to carefully discuss the texts that most prototypically manifest it, showing, in the process, how it differs from other sub-categories of this most protean of literary genres, how it developed, and why it is so endemic to the American, or New World, experience.

While I do not have enough time in a typical class session to do much more than bring these issues up with my students, this is often sufficient to at least whet their interest and allow them to see that the nations of the New World are linked together in many more ways than they had originally supposed. Indeed, these Inter-American connections often generate very interesting research papers and presentations at the end of the semester, projects that permit the students to delve much more deeply into these issues and which they seem to find quite fascinating. And for graduate students, courses structured in this fashion can become career altering experiences, involving choices about subjects and areas of interest that perhaps had never before been considered. We cannot, of course, even pretend to be authoritatively knowledgeable in everything germane to the Americas (nor should we), but, by dint of extensive reading and research, we can most certainly call certain issues to the attention of our students, to help direct their own investigations, and, in the process, to aid them in their breaking of new scholarly and disciplinary ground.

10 See, Ralph Freedman, The Lyrical Novel: Studies in Hermann Hesse, André Gide, and Virginia Woolf, Princeton: Princeton University Press, 1963. 
The alternative to modifying long standing courses is, of course, the creation of new ones, and, as I suggested earlier, this would seem to be the undertaking that will, in the long run, most facilitate the development of Inter-American Studies as a coherent field of study, one replete with its own methodologies, its own bibliographies, its own theoretical issues and traditions, and its own identifiable areas of specialization. To this end, I have created, for Vanderbilt University's Program in Comparative Literature, a series of three interlocking new courses which, if taken in sequence or in their totality, will provide the student with a complete overview of Inter-American literature. The first course discusses the nature of pre-Columbian Native American literature (as well as its force as a constant factor in New World literature up to the present moment), the literature of the Conquest, and the development of colonial literature in the Americas; the second course, more chronologically limited, examines nineteenth century literature in the Americas and begins to follow some of the lines of influence and reception that are already developing; the third deals with New World literature in the twentieth century, when Inter-American literary studies really comes into its own as a viable academic discipline. Additional courses are envisioned on such topics as the New World novel, Modernism in North, Central, and South America, a history of drama in the Americas, and Inter-American film, poetry, and music. Methodologically, the constant for all these courses is breadth of coverage; the reading list for each one carries at least one work from each of the New World's major linguistic and cultural groups, ${ }^{11}$ and they are to be selected because at least some of them deal with the same topic or engage each other in different ways. ${ }^{12}$ The creation of new, distinctly Inter-American courses will, I am sure, become

11 This means, normally, that each course features at least one text from each of the following groups: English and French speaking Canada, the United States, Spanish America, and Brazil. In certain cases, the Caribbean, arguably the epitome of the Inter-American experience, may be considered an additional group and therefore merit a text on its own. These numbers are often somewhat adjusted in accordance with a particular theme or issue that the professor in charge might wish to feature in the course. Thus, there might be more than one text from a single country, though, again, balance is what we are seeking in these courses.

12 For example, a recent Honors Seminar that I gave at Vanderbilt (Spring, 2002) featured Margaret Atwood's Surfacing, Faulkner's The Bear, and Alejo Carpentier's The Lost Steps (Los pasos perdidos), along with four other novels, because these three works all deal, in different ways, with the symbolism of the land in the New World and with the conflict between the wilderness and what we normally think of as civilization. The entire course could have been developed around this theme, though I wanted to pursue other issues with the other texts. 
the key element as Inter-American Studies continues to evolve and develop as an academic field. Whatever the discipline, the need for new courses that, through their content and structuring, tie the Americas together will only grow.

As we have seen, more traditional courses can, to some extent, be altered in order to at least recognize their relevance to the Inter-American enterprise, but care should be taken that they not be changed so much that they lose their originally intended focus. Inter-American Studies cannot succeed unless, at the same time that it sees its new and intrinsically comparative courses becoming available, it can also rely on the student's ability to take courses that focus intensely on issues germane to particular countries. To be well-grounded (and therefore well-trained) Inter-Americanists, our students will need a mix of courses, some exclusively (or primarily) national in nature, others more deliberately Inter-American in design and coverage. And, by requiring our students to be registered in a traditional department or program and that they develop specialities and sub-specialities within these traditional academic units, we help ensure that they will be well prepared not only for the current job market but for its future permutations as well. We must not allow our programs in Inter-American Studies to be synonymous with superficiality or vagueness, for to do so would be disastrous, and we are best able to obviate this potentially ruinous problem by insisting that our students ground themselves in a standing discipline.

\section{The Inter-American Dissertation}

The culmination of a carefully constructed Inter-American doctoral program, the dissertation must, like the program that engenders it and the committee that oversees it, involve at least three New World language groups and must advance an argument, or thesis, that is truly Inter-American in terms of its argumentation, structuring, and cultural grounding. That these requirements are met must, ultimately, be the responsibility of the thesis director and/or the chair of the thesis committee. Inherently comparative in nature, the Inter-American dissertation must establish the salient similarities between its constituent parts while also undertaking a detailed explication and analysis of the many differences that distinguish them and that make them unique. In order to avoid the problem of "homogenization" that plagues so many studies of this type (that is, of seeming to regard very different texts or issues as exactly the same thing and to be too quick to reach exactly the same conclusions about them), this step is absolutely critical, whatever the discipline involved. It cannot be successfully taken, however, unless the student is prepared linguistically to read her texts in their original language and to discuss them in the full range of the historical, social, and cultural differences that pertain 
to the issue being focused upon. As in any good comparative study, these essential and distinctive differences must be carefully and accurately accounted for while also maintaining the more comprehensive and international perspectives that tie our texts together and that manifest and validate the larger critical contexts in which we are able to compare and contrast them. In Inter-American work, then, as in Comparative Literature scholarship generally, the differences between texts are often more important, more revealing of a particular text's uniqueness, than the similarities that connect them, and we must be careful to give these essential differences their full critical due.

The goal of the Inter-American dissertation, again following the model of the Inter-American doctoral program, should also provide clear evidence of expertise in a subject that is of direct value to a traditional academic program while also demonstrating that the candidate in question truly has a larger, Inter-American perspective, one that would allow her to create new courses for a program or department that wished to develop Inter-American Studies as part of its regular curriculum or as part of its regular degree tracks. The potential to do this should be clearly apparent in the dissertation, which should also reflect the student's primary and, perhaps, secondary areas of specialization and interest.

The properly done Inter-American dissertation should therefore also provide the student with a sense of direction for the writing of the publications that are so crucial to success in the academic world. Reflecting the nature of the dissertation itself, the student will be prepared to publish in at least two complimentary fields, the traditional area of expertise and the newer area of Inter-American studies, however this latter field comes to be defined in the context of the student's particular discipline. This, too, is an area in which the student's doctoral committee can be of special importance and utility, providing advice and counsel that is invaluable to the young scholar who is preparing to enter the not infrequently arcane academic world. Thus, even at this late date in her graduate school training, the fledgling Inter-Americanist can be alerted to the need to publish both as a traditional scholar in a particular discipline and as a pioneer in a new field, someone anxious to help an established discipline connect with a fast evolving and multi-disciplinary new enterprise. Such advice, especially if framed in the context of the standard demands of academic tenure and promotion procedures, could be invaluable to our Inter-American students.

We who seek to investigate it recognize that for however much Inter-American Studies is a compelling and fascinating new field, it is also one that, for a number of reasons, will not reach its full potential without overcoming some formidable obstacles and without our remaining vigilant with respect to the basic requirements we deem necessary. At the same time, I have every confidence that it will. Indeed, 
it is already doing so. Our task, then, as teachers, researchers, and mentors is to facilitate this process, to consider both the exciting possibilities and the daunting problems inherent in Inter-American scholarship and, by coming to grips with these in a logical, coherent way, to help shape its growth and development as a vital, new academic discipline.

\section{Works Cited}

Bolton, Herbert E. "The Epic of Greater America." American Historical Review XXXVIII (1933): 448-474.

Bolton, Herbert E. A History of the Americas. New York: Ginn and Company, 1928.

Fitz, Earl E. Rediscovering the Americas: Inter-American Literature in a Comparative Context. Iowa City: University of Iowa Press, 1991.

Fitz, Earl E. Inter-American Literature and Criticism: An Electronic Annotated Bibliography. Iowa City: University of Iowa Press, 1998. www.uiowa.edu/ uipress/ interamerican.

Hanke, Lewis, ed. Do the Americas Have a Common History?: A Critique of the Bolton Theory. New York: Alfred A. Knopf, 1964.

Jay, Paul. "Beyond Discipline? Globalization and the Future of English." PMLA 116. 1 (January 2001): 32-47.

Martin, Robert K. "North of the Border: Whose Postnationalism?" American Literature 65. 2 (June 1993): 358-361.

Miller, J. Hillis. PMLA 115.7 (December 2000): 2062.

Pérez Firmat, Gustavo, ed. Do the Americas Have a Common Literature? Durham: Duke University Press, 1990.

Retamar, Roberto Fernández. Para una teoría de la literatura hispanoamericana. México: Nuestro Tiempo, 1977. 
Claudia Sadowski-Smith

Texas Tech University, U.S.A.

Claire F. Fox

University of Iowa, U.S.A.

\section{Theorizing the Hemisphere: Inter-Americas Work at the Intersection of American, Canadian, and Latin American Studies ${ }^{1}$}

Much recent work has promoted the internationalization of American studies as a means of overcoming the deeply problematic nationalist assumptions underlying the discipline. Calls for "comparative American studies" that reside at the heart of the publication in which this article appears, however, attest to the sheer theoretical complexity involved in attempts to rethink the field outside and beyond national boundaries. While some US-based Americanists have understood internationalization to mean more comparative work on US ethnic and racial groups (Patell, 1999), others have equated it with a hemispheric perspective (Sandoval, 2002), while still others have employed it in reference to the global study of the United States as an area, emphasizing foreign-based scholarly perspectives on US culture and thereby resituating the field's traditional institutional sites of power (Desmond and Domínguez, 1998).

These divergent understandings of internationalization point to un-resolved tensions between attempts to be more inclusive of international perspectives on the United States on the one hand and new Americanist concerns with domestic issues of race and ethnicity and their trans-national expansion through emergent geographical models, such as the Americas, the trans-Pacific, the black Atlantic, and the circum-Atlantic on the other. ${ }^{2}$ In this article, we explore one such geographic

1 This essay was first published in Comparative American Studies 2.1 (2004): 5-38. Reprinted here with permission.

2 The hemispheric perspective within American studies has been shaped by Chicana/ o-Latina/o and border studies (e.g. Kaplan, 1993; Porter, 1994; Wald, 1998), though these have, however, rarely entered into dialogue with Mexico-based border studies or with social science-oriented forms of border cultural studies. (See Irwin, 2001 for a critique of US-based border studies.) Other transnational models, such as the trans-Pacific 
configuration in depth, the hemispheric perspective. Under the rubrics of literature of the Americas, New World, or North American studies, several models of hemispheric inquiry have already brought into focus new topics and research questions, attracted specialists in all periods, and become visible in the US academy in curriculum reform, hiring practices, conferences, publications, and the establishment of research centers. ${ }^{3}$ Hemispheric perspectives are mainly understood to facilitate a certain rapprochement between English and foreign language departments in the US academy. ${ }^{4}$ This project, with its somewhat limited focus on literary and cultural

(Lowe, 1996; Ong, 1999), the trans-Atlantic (Gilroy, 1993), and the circum-Atlantic (Roach, 1996), are linked to Asian American and black studies.

3 The term "literature of the Americas" emerged within American studies. In Paul Jay's usage (1998), it replaces the field's national focus with an emphasis on sub-regions or transnational cultural zones of the Americas. Comparativist Roland Greene (1998) has used the phrase "new world studies" more broadly than Joseph Roach (1996) has as a label for scholarship that encompasses Latin America, the Caribbean and, at least on a programmatic level, Canada. John Carlos Rowe (2000) has mapped a geographically limited "North American studies," focusing on the United States, Mexico and, programmatically, Canada. The term "North American studies" also draws on the comparative emphasis on Canada-US relations that has emerged in Canadian studies and Canadian universities, and it has been used to describe the joint focus on the United States and Canada in several institutions of higher learning in Europe. Although we note a preponderance of research focusing on the pre-Columbian, colonial, and contemporary periods, the $19^{\text {th }}$ and $20^{\text {th }}$ centuries have also inspired promising inter-American scholarship, such as the innovative cultural and historical studies of Kazanjian (2003), Dunkerley (2000), and Gruesz (2002). Jay (1998) and Greene (1998) have theorized inter-American perspectives that span periods from the colonial to the contemporary. At the institutional level, inter-American studies are becoming more visible in terms of hiring, and hemispheric research centers have been established at universities like Duke, SUNY Buffalo, SUNY Stony Brook, New York University, and Michigan State. The English department at Arizona State University recently reorganized its undergraduate major into a Literatures and Cultures of the Americas section and a World Literatures in English section. Rowe (2000), Jay (1998), and Greene (1998) also consider curricular questions posed by inter-American research. The University of Virginia Press, University of Minnesota Press, and Peter Lang have created special series dedicated to inter-American issues.

4 The Modern Language Association conference on "English and the Foreign Languages" held in New York in April 2002, for example, featured distinguished scholars of Chicana/o and Latina/o literatures such as Arnaldo Cruz-Malavé of Fordham University and Tey Diana Rebolledo of the University of New Mexico to represent the field of literature of the Americas. The conference's focus on the bilingualism and biculturalism that informs Latina/o and Chicana/o expressive culture in the United States suggests that organizers 
studies, draws on the wave of 1990s inter-American scholarship that emerged within Chicana/o studies, comparative literature, Latin American studies, and to a much smaller extent, American studies in the United States. ${ }^{5}$

In the following, we propose a more synthetic "inter-Americas studies" that would enable the collaboration of a larger number of institutionalized (including non US-based) fields which have traditionally studied the hemisphere, including Latin American and American studies, comparative literature, Canadian studies, Caribbean studies, history, Latina/o and other ethnic studies, each with its own specific historical and theoretical entry points into the subject. Given the impossibility of surveying all of these disciplines, we will limit our scope to the subject of our particular training and interests, namely the potential contributions of Latin American and Canadian studies to an inter-Americas framework. ${ }^{6}$ While Canadian studies, as they have emerged in Canada, have been largely excluded from hemispheric studies, Latin America is often represented, even though neither USnor Latin America-based studies scholarship is adquately considered. Given its focus on Canadian and Latin American studies, this article should not, therefore, be understood as a definitive account of inter-Americas studies, but rather as an invitation for dialogue about a field that we conceive as a complement to other emergent national, regional, and global perspectives in American, Canadian, and Latin American studies. ${ }^{7}$ We realize that a project like this cannot be exhaustive and hope that others will take our examination further.

envisioned literature of the Americas as a bridge field between English and the foreign languages.

5 For earlier examples of inter-American research, see Pérez-Firmat (1990), Fitz (1991), Saldívar (1991), and Spillers (1991). For overviews of the intersections between comparative literature and Latin American studies, see Fitz (2002), McClennen (2002), and McClennen and Fitz (2002). For other studies by Latin Americanists and comparatists, see Valdés (1985), Chevigny and Laguardia (1986), Zamora (1993, 1997), Cohn (1999), and Sommer (1999).

6 The authors are US-trained scholars in the fields of comparative literature and English, respectively. We work in the contemporary period, and our research cuts across American, Latin American, and Canadian studies.

7 In Latin American studies, inter-American work is one of several emerging approaches, including trans-Atlantic, inter-Latin American, or comparative postcolonial perspectives. While the trans-Atlantic theorizes connections between Latin America and the Iberian peninsula as well as the European and African continents more generally, the inter-Latin American model enables comparative work specifically on Latin America, including Brazil. Canadian studies are either becoming part of a social science-oriented North American studies paradigm, or they are developing toward a more comparative 
Latin American studies, Canadian studies, and American studies are currently undergoing their own respective crises. So, rather than reify traditional area studies models, we advocate a long overdue dialogue among the inter-disciplines that could transform each field. ${ }^{8}$ In the face of the hemisphere's vast inequalities and different disciplinary configurations, any call for transnational scholarly dialogue or assumptions of inter-American unity threatens to replicate the long history of US imperialism in the hemisphere which date back to the Monroe Doctrine and the territorial expansion of the United States in the mid- $19^{\text {th }}$ century. ${ }^{9}$ We therefore advocate close collaboration among the three inter-disciplines and a "critical internationalist" awareness of our own institutional locations so as to position the United States' neighboring geographies and the fields that study them as protagonists rather than mere recipient sites of US policies and of US-based theoretical perspectives and comparative paradigms. ${ }^{10}$

Since their inception, Latin American and Canadian studies have encompassed comparative "inter-American" or "North American" orientations without being themselves scholarship on the United States. The two fields are thus well situated to challenge many of the exceptionalist premises that, despite New Americanist

discipline that includes international scholarship on Canada. There have also been attempts to combine several of the fields we examine into more global perspectives. Examples include the Ford Foundation's program "Crossing Borders" (Volkman, 1998), and the "Transculturalisms Canada" project supported by the International Council for Canadian studies.

8 We realize, of course, that only Latin American studies fit the traditional description of area studies, which is charged with providing knowledge to the state about foreign policy (Bové, 2002). We employ the term in a broader sense to designate a particular discipline's assumed geographical boundaries, be they national or transnational.

9 Desmond and Domínguez (1998) have, however, challenged the idea that American studies work from abroad will offer radically different approaches from US-based scholarship solely by virtue of its location. Similarities in the two perspectives stem from long-standing connections between many American studies programs abroad and US institutions as well as the uncritical promotion of US-based theoretical approaches abroad (see also Horwitz, 1993).

10 For a discussion of “critical internationalism," see B. Lee (1995). Mariscal (1990) notes that the 1814 appointment of the first chair in Hispanic literature at Harvard University marks a shift toward the United States' emerging orientalist fascination with Spain and its South American colonies. In his study of John Lloyd Stephens and Frederick Catherwood's archaeological expeditions in southern Mexico during the 1840 s, Gollnick likewise finds a rhetoric of conquest underwriting their enterprise, in which they claimed the artifacts of an indigenous past as part of an elitist "American" history (Gollnick, 1998). 
efforts, continue to inform post-national American studies work on the hemisphere. ${ }^{11}$ These assumptions include tendencies to privilege the United States as primary interlocutor vis-à-vis other countries in the hemisphere, to focus on Anglophone material, to marginalize other fields' perspectives, and to extend US-based research paradigms to the hemispheric level. In particular, we find that post-national American studies have stressed the internationalization of US models of race and ethnicity at the expense of adequately addressing the roles of contemporary US foreign policy and transnational capitalist expansion.

Our discussion of Canadian and Latin American studies in this respect highlights several key and problematic critical terms, such as ethnicity, post-nationality, globalization, and postcoloniality in order to demonstrate how these concepts circulate differently in each field. We advocate multilingual models of hemispheric inquiry that include European, indigenous, and New World languages and that do not necessarily privilege the United States' relation to other countries or areas. In so doing, we hope to place race and ethnicity among a host of new objects of study relevant to historical and contemporary political, economic, and social developments in the Americas. More importantly, we argue that the different usage and degree of importance ascribed to the critical terms within each field must be recognized in order to arrive at more nuanced theories of inter-American dynamics.

Hemispheric work within American studies, a field with a strong tradition in the humanities, is largely rooted in postcolonial theory. Characterizing globalization as a continuation of colonialism and imperialism, its assumptions enable comparative studies of US race and ethnicity within transnationally expanded models (Gikandi, 2001: 635). In contrast, Latin American studies are deeply engaged with social scientific theories of globalization and the legacy of dependency theories that rose to prominence in the 1950s and 1960s in opposition to US-based developmentalism. The current interest in hemispheric perspectives within both Latin American and Canadian studies is often linked to examinations of continental integration under the North American Free Trade Agreement (NAFTA), other regional trade agreements, and the proposed integration of the hemisphere under the Free Trade Area of the Americas (FTAA). The focus of Canadian postcolonial models on local forms of ethnicity and on Canada's settler-colony status complicates the transnationalization of US racial and ethnic categories, and could form the basis for comparative studies of US settler colonialism and imperialism. Likewise, efforts within Latin American and Canadian

11 For a cogent critique of the US Americanist use of the term "Americas," see Kadir (2003). 
studies to understand ongoing US cultural, economic, and military domination in the hemisphere according to postcolonial or dependency models question the American studies tendency to characterize the nation-state mainly as consolidator of colonial, repressive, and assimilationist ideologies and to expand US-based left intellectual critiques of nationalism to other geographies. These assumptions are challenged by existing perspectives within Latin American and Canadian studies that view the nation-state more positively as a potential vehicle for the protection of its citizenry against neoliberal forms of corporate globalism and as a guarantor of sovereignty from the United States.

We hope that attention to historically divergent forms of nation-state formation and intellectual analyses of nationalism in the Americas will enable scholars to examine the impact of neoliberalism on hemispheric cultures and on the academy, and to become active in policy debates concerning hemispheric citizenship, immigration law, language rights, foreign policy, educational reform, and territorial rights, among other issues. In its emphasis on such questions, an inter-Americas perspective can also interface with other emerging global or regionally organized models of study.

\section{Post-Nationalism and Latin Americanism}

For Latin Americanists today, the task of producing alternative narratives about a region over which the United States exerts overwhelming dominance makes embracing a hemispheric perspective a complicated undertaking. ${ }^{12}$ In many Latin American countries, globalization is often considered to be synonymous with Americanization (Brunner, 1993: 41, 51; Hale, 2000: 131), and Latin Americanists are likely to greet calls to "post-nationalism" with ironic questions about when exactly the "national" transpired. The use of the term in the essays of Mexican

12 The different visions of the Americas promoted by Cuban independence leader José Martí and US historian Herbert Eugene Bolton in the late $19^{\text {th }}$ and early $20^{\text {th }}$ centuries, respectively, exert contradictory pressures on contemporary inter-American scholarship that bear especially upon Latin American studies' orientation toward inter-Americas studies. For Martîs relevance to studies of race and ethnicity in the United States, see Saldívar (1991) and Spillers (1991). For other contemporary studies of Martís US writings, see Ramos (1989), Avelar (1997), Belknap and Fernández (1998), and Rotker (2000). Bolton articulates his synthetic, hemispheric perspective toward American history in his 1932 American Historical Association presidential keynote address (Bolton, 1964) and in his widely used syllabus for a history of the Americas (Bolton, 1935). For contemporary work on Bolton, see Hanke (1964), Hurtado (1993, 1995), Magnaghi (1998), and Truett (in press). 
critic Roger Bartra, for example, signifies neither after nor beyond the national, but rather the potential for popular democratic renewal that might emerge from Mexico's profound political crisis. In contrast to the New Americanist emphasis on transnational communities, Bartra explicitly cautions his international readers, "[W]hen I point out the need to overcome cultural unease, I am not proposing as a cure an integration of the Anglo-American world parallel to the economic agreements on free trade with the United States and Canada" (Bartra, 2002: 63). Like Bartra, many Latin American intellectuals regard the nation-state (rather than nationalism or the national-popular) as a yet unfulfilled project through which it may be possible to articulate public interests and protect natural resources in the face of transnational corporate expansion, massive external debt, and US foreign policy.

The continued salience of the national is also evident in Latin American academies, where most humanistic scholarship is conducted within a national framework, and where the humanities have, in recent decades, suffered devastating losses due to neoliberal downsizing of Latin American universities. When Latin American scholars have articulated regional, inter-regional, or continental approaches to humanistic study, they have tended to be aligned with anti-colonialist agendas (e.g. Cornejo Polar, 1994; Rama, 1982). These factors, among others, make some Latin Americanists suspicious of transnational theoretical models identified with the US academy, especially those that have arisen in seeming ignorance of the long history and diverse traditions of Latin American scholarship. For Latin Americanists working in the United States, the contradictions between opportunistic area studies and the substance of teaching and research sometimes produce a sort of self-deprecating irony about one's work, as Santiago Colás explains:

In the tight job market of the humanist academy in the United States, my future prospects as a young Latin Americanist may best be secured by the significant interest in things Latin American sure to follow the imperialism and internal colonization that is announced with each new privatization, free-trade zone, or foreign investment. The North American Free Trade Agreement (NAFTA) has already brought to the Spanish 101 classrooms of my department a kind of baby boom of future students for my Latin American literature courses. (Colás, 1995: 392)

Colás does not assume that a hemispheric perspective is inherently plural ist with respect to other geographical models; rather, he suggests that the emergence of new spatial categories may presage the disappearance of others even as it endows them with a certain market-driven cultural cachet.

In spite of these pitfalls, we propose that an inter-Americas perspective is a useful complement to existing research frameworks, through which it is possible 
to historicize and strategize Latin America's relation to the United States and Canada. Brazil-based Americanist Sonia Torres has observed that research about the United States produced in Latin America tends to be implicitly comparative, "privileging issues such as dependency and neocolonialism ... [as a] means of reading the dominant nation but also a means of reading ourselves" (2003: 12). Likewise, Latin Americanists who have adopted an inter-American perspective utilize comparative approaches in order to understand and respond critically to historical phenomena of a hemispheric nature or to propose alternative networks to those imagined by neoliberalism and free trade. The Inter-American Cultural Studies Network (IACSN), founded in 1993, was one effort to unite scholars working on the Americas through an internet-based community. Supported by cultural studies programs at universities in Buenos Aires, Rio de Janeiro, New York, and Mexico City, the Network's founders envisioned the promotion of "collaborative and comparative work" about the Americas to be one of its main purposes (IACSN, 1993: 1). By encouraging dialogue about the different histories and practices of cultural studies in the United States and Latin America, the Network also challenged the notion that cultural studies was an exclusively US or British phenomenon. ${ }^{13}$

The scholarly profile of Néstor García Canclini, a Mexico City-based sociologist who participated in the IACSN, serves as another example of how Latin Americanists have engaged in hemispheric study. García Canclini has advocated the establishment of a regional federalist government in Latin America that would protect its constituent states from the effects of neoliberal restructuring. He arrived at this position, not at all coincidentally, through his pioneering research on the cultural implications of North American free trade and in Mexico-US border studies. In his book La globalización imaginada, he proposes that there is enough of a shared historical tradition among Latin American countries to justify speaking of a "Latin American cultural space in which many identities exist," but he insists that such a space cannot be "ethnically predetermined" (García Canclini,

13 The Network's founding documents were drafted by George Yúdice, Stanley Aronowitz, Juan Flores, and Néstor García Canclini at a conference held in Mexico City in May 1993. Among the results of the IACSN's activities is the Biblioteca Virtual, housed at the Federal University of Rio de Janeiro (http://acd.ufri.br/pacc/) and a series of books on "studies and other intellectual practices in culture and power" published by Daniel Mato, former chair of the CLASCO working group on culture. As the IACSN is now defunct, many of its functions have been incorporated into George Yúdice's Cultural Policy Center at NYU. We thank George Yúdice for providing information about the IACSN. 
1999: 103). He finds, on the other hand, that the recent trade agreements linking Latin American economies to those of Europe and the United States, respectively, also make it possible to speak in a qualified manner of "Euro-American space" and "inter-American space" (García Canclini, 1999: 104). ${ }^{14}$ García Canclini’s proposals to regulate Latin American cultural expression in order to ensure Latin American countries' greater self-representation on the domestic and global levels form part of a promising new wave of cultural policy studies in the Americas. ${ }^{15}$

Although we have cited the relative absence of social scientific globalization theory in New Americanist positions, Latin American studies are deeply engaged with the issue and are currently in a position to help Americanists consider the political and economic implications of the transnational turn. The establishment of the United Nations Economic Commission for Latin America (ECLA) under the directorship of Argentine economist Raúl Prebisch in the late 1940s challenged many assumptions about international trade and paved the way for a host of dependency theories that continue to be elaborated by Latin Americanists and other scholars working from peripheral perspectives (Larrain, 1989: 14). The history of trade and colonization in the hemisphere has also been fundamental to the development of world systems theory (Quijano and Wallerstein, 1992). At present Latin Americanists working on the cultural dimensions of globalization have bridged the humanities and social sciences by employing a variety of postdependency theoretical frameworks (González Stephan, 1996).

Before we discuss some of the other ways in which Latin American studies may interconnect with inter-Americas research, we must first underscore the vastness of this field. It incorporates disciplines ranging from law to cultural anthropology, each of which possesses diverse national and institutional manifestations. The field's configuration differs from American and Canadian studies in three significant respects: first, it undertakes the study of more than one country; second, its traditional bases of power have been situated outside the area under investigation;

14 In García Canclini's view, Mexico's membership in NAFTA and the European trade agreements with Mercosur countries make those two Latin American regions the ones primarily affected by the inter-American and Euro-American categories. As for the "real" impact of globalization on Latin America, David Felix argues that its effects have been most evident in the financial sector and in policy-making, rather than in "the actual volume of internationally traded goods" (Felix, 1998: 193). At the time of our writing, Argentina, Venezuela, and Brazil are among the Latin American countries witnessing a rise in economic nationalism in response to financial and political crises. These movements, in turn, may cloud the future of free trade initiatives.

15 See Miller and Yúdice for a useful overview of this scholarship. 
and third, English is not the area's primary language. These factors have led to different and sometimes opposing practices of Latin American studies from within and outside of Latin America. Rather than presume to map the field in its entirety, we will highlight some recent debates that consider the United States' role as a broker of knowledge about Latin America.

One of these debates concerns the constitution of the field's very object of study. Latin America's claims to coherence as an area have been problematized from numerous perspectives. ${ }^{16}$ Nevertheless, the appeal to Latin American identity has been a recurrent motif in arts, letters, and civic discourse over the past two centuries, and has been especially pronounced in the face of looming external threats. The dream of a Spanish American federation is most often associated with the independence leader Simón Bolívar, and, for subsequent generations of intellectuals, invoking the patria grande over the patria chica often connotes antiimperialism, as in the writings of Cuban independence leader José Martí. In recent years, critics have begun to scrutinize the identitarian rhetoric of "Latin Americanism" utilized by Martí and others (Moreiras and Embry, 1997-8). Just as the presumed unities of Whitman's "I" have been challenged by New Americanists, Latin Americanism's "nosotros" has been subjected to critiques that expose the silences and representational violence implied by the condensation of complex social systems into a national or continental essence. ${ }^{17}$ This wave of scholarship is part of an ongoing inquiry regarding the socio-historical underpinnings of Latin American intellectual authority and the project of forging alternative, non-elite accounts of Latin American "modernity from below." ${ }^{18}$

Another current of Latin Americanism that is presently undergoing similar allegations of false unities and cultural essentialism is that which is principally associated with US-based area studies. According to this usage, Latin Americanism refers to the transnational networks of intellectuals - most of whom are situated in the US academy - who are dedicated to the circulation and critical appraisal of

16 The term "Latin America" was coined in the mid-19 $9^{\text {th }}$ century by Louis Napoleon in order to justify French rule in Mexico. For critiques of Latin America as a concept and as an area designation, see O'Gorman (1961), Berger (1995), Larsen (1995), and Mignolo (2000).

17 See Avelar (1997), Richard (1997, "Intersectando" and 1997, "Mediaciones"), de la Campa (1999), and Moreiras (2001). For comparative studies of Whitman and Martí, see Molloy (1996) and Sommer (1998).

18 For critiques of intellectual authority, see Rama (1984), Avelar (1997), and Miller (1999). For theories of "modernity from below," see Rowe and Schelling (1991). See also Latin American Subaltern Studies Group (1994) and Rodríguez (2001). 
ideas about Latin America. In this view, Latin America is merely a realm of raw materials and experience to be processed or plundered by Latin Americanism (de la Campa, 1999; Richard, 1997 "Intersectando" and 1997, "Mediaciones"). This Latin Americanism has its roots in the US academic area studies models that gathered institutional force during the Cold War (Berger, 1995; Hershberg, 1998). Among these, Latin American studies distinguished themselves by developing in seeming opposition to the Cold War agendas they were supposed to uphold. The Latin American Studies Association (LASA) was founded in 1965 in opposition to US foreign policy in Latin America, and is now the major US-based organization of Latin Americanists (Berger, 1995: 173). The anti-Vietnam War movement in the United States and the rise of dependency paradigms in Latin America galvanized the field and marked its divergence from US political agendas. ${ }^{19}$ Differing political interests between state and academy and the wave of institutional downsizing that took place in the 1970s and 1980s have precipitated a financial and epistemological crisis in US Latin American studies (Hershberg, 1998: 121). While globalization and competitiveness serve as new justifications for the field at the level of funding and policy-making (Hershberg, 1998: 123), the professional literature is currently marked by critical doubts regarding the field's historical strengths and weaknesses as well as its future. Some scholars in the field note that "armchair" methodologies, especially those associated with cultural studies, threaten Latin American studies' tradition of intensive fieldwork, links with local scholars, and linguistic competence, while calling for more comparative research as an antidote to "national (or regional) myths of exceptionalism" (Smith, 2002: 7-8) and orientalism on the part of US-based academics (Hershberg, 1998: 125; Skidmore, 1998: 116-17; Smith, 2002: 8). Thus, while the field has moved toward greater hemispheric integration at the professional and theoretical levels, the most pressing agenda for inter-American research within the field is developing along inter-Latin American lines.

Nonetheless, hemispheric dynamics are quite palpable in contemporary scholarly debates about the ubiquity and relative value of US-identified critical methodologies and analytical categories for the study of Latin American phenomena, such as those pertaining to race and gender (Bourdieu and Wacquant, 1999). Postcolonial theory has been particularly controversial in this regard. Whereas

19 LASA's membership continued to grow significantly even through the lean decades of the 1970s and 1980s (Mesa-Lago, 1980: 3). Today, LASA is a broadly interdisciplinary organization, with a tradition of concentration in the social sciences. Its membership totals approximately 5,500, 30\% of whom reside outside the United States (http://lasa. international.pitt.edu/). 
it became linked to American studies through research on ethnicity and race, as in some currents of Mexico-US border studies, postcolonial theory entered Latin American studies in response to the failures of traditional left nationalist movements in Latin America, notably the Sandinista electoral defeat in 1990. The predominantly US-based Latin American Subaltern Studies Group (LASSG) was founded in 1992 in order that scholars could explore issues such as peasant and indigenous movements, gender and sexuality, and urban popular cultures in Latin America while explicitly challenging literary and intellectual authority. Modeled on the South Asian Subaltern Studies Collective, the LASSG has continually stressed a critical self-awareness of the "elite space of the North American academy" (Kokotovic, 2000: 295). ${ }^{20}$

Debates about Latin American postcolonial studies are often characterized by "US" versus "Latin American" rhetorical positions even though these often do not correspond to the participants' geographical or institutional locations. According to LASSG member Alberto Moreiras (2001: 240):

A number of Latin American intellectuals have sharpened their critical knives on what they regard as a major Latin Americanist sellout of Latin America into the global market taking place primarily, if not exclusively, through the US academy, and in particular through Latin Americanist subaltern and postcolonial studies, sometimes - not always simply identified with metropolitan-led "cultural studies" tout court.

Moreiras examines such accusations in light of the diminished coherence of Latin American nationalist and national-populist intellectual positions in the era of globalization. His call for oppositional cultural studies in the present juncture has been challenged forcefully by other prominent critics. Beatriz Sarlo, for example, defends the continued viability of literary study in Latin America and Latin Americans' right to produce cultural objects worthy of aesthetic criticism rather than anthropological analysis, ${ }^{21}$ while Mabel Moraña views postcolonial theory as

20 Kokotovic notes that Latin Americanist historians who work with postcolonial theory do so differently than the literary critics who form the membership of the Latin American Subaltern Studies Group. He likens these orientations to diverging foci in the South Asian Group, from the Gramscian influence manifest in Ranajit Guha's writing to the deconstructionist approach evident in Gayatri Spivak's work. For postcolonial work in Latin American history, see Mallon (1994), Hispanic American Historical Review (1999), Berger (2000), Delpar (2000), and Knight (2002).

21 The debate between Moreiras and Sarlo appeared in the Journal of Latin American Cultural Studies 8.1 (1999). A revised version of Moreiras's contribution, "On the Order of Order," was subsequently published as a chapter of his book, The Exhaustion of Difference (2001). 
another metropolitan project intended to mark "the space of the periphery with the perspective of a critical neo-exoticism that keeps Latin America in the place of the other, a pre-theoretical, calibanesque, and marginal place, with respect to metropolitan discourses" (Moraña, 1998: 216-17).

The debates surrounding postcolonial studies form an arena in which an interAmericas perspective that is attentive to sites of intellectual production within a hemispheric framework might move the arguments beyond facile homologies between academic positions and entire nations or regions. Scenarios from the 1960s and 1970s describing a unilateral brainwashing of Latin Americans through US media have been significantly complicated by factors that make pre-lapsarian categories of North and South seemingly untenable. At the academic level, the impact of neoliberalism on Latin American universities has resulted in a dramatic increase in the number of Latin Americans who receive post-graduate training in the United States or who are employed in the US academy. ${ }^{22}$ Furthermore, a select number of Latin America-based intellectuals regularly participate in US academic forums and see their work translated into English. ${ }^{23}$ These developments in the configuration of Latin American studies make universities, museums, and other professional arenas in the hemisphere points of debate concerning who has the right to represent Latin America. ${ }^{24}$ The current debates about methodologies and their origins require closer attention to scholarly affinity groups and their ideological orientations, as well as the social and institutional locations of intellectual work.

An inter-Americas perspective might additionally provide an opportunity for Latin Americanists to respond to the overtures of scholars in US ethnic studies to forge connections among issues such as migration, transnational markets, and media studies. ${ }^{25}$ While some universities have sponsored innovative joint ventures

22 For debates about cultural imperialism, see Mattelart and Dorfman (1975) and Tomlinson (1991).

23 Such scholars include Jorge Castañeda, Beatriz Sarlo, Néstor García Canclini, Jesús Martín Barbero, Roger Bartra, Enrique Dussel, Martín Hopenhayn, Roberto Schwartz, and Silviano Santiago.

24 The orientalist legacy of Latin American area studies in the US academy takes a peculiar form in the humanities - especially outside of Spanish and Portuguese departments where magical realism and the "Boom" novels are commonly considered paradigmatic of all Latin American literature (see Fuguet and Gómez, 1996, and Reati and Ocampo, 1998).

25 For studies about the growth of transnational Latina/o consumers, see García Canclini (1995) and Dávila (2001); on transnational migration, see Rouse (1991, 1992, 1995), Sassen (1998), and Martínez (2001). 
between Latina/o studies and Latin American studies (Cabán and Aparicio, 2003; Fox, 2003), Román de la Campa notes that, in general, the Latin American literary establishment has been reluctant to embrace such projects, for reasons that appear to have as much to do with fear of diminished cultural capital as they do with anti-imperialism (de la Campa, 2002). ${ }^{26}$ An inter-Americas perspective opens up another area of comparative research that could bypass the United States to focus on commonalities with Canada. ${ }^{27}$ Not only has Canada pursued independent trade agreements with Latin American countries, but it has maintained relatively open relations with Cuba and has been more accepting of Central American and other Latin American refugees than the United States. The contemporary profiles of both Canadian studies and Latin American studies emerged in the context of anti-Americanism during the Vietnam War and are linked to leftist intellectual traditions of nationalism rooted in efforts to understand the relationship to the United States via dependency, cultural imperialism, or postcolonial models. And, in both Canada and Latin America the association between the United States and cultural imperialism rose to renewed prominence as free trade initiatives were negotiated in the 1990s. John Tomlinson's assertion that "various critiques of cultural imperialism could be thought of as (in some cases inchoate) protests against the spread of (capitalist) modernity" (Tomlinson, 1991: 173) needs to be further explored for its specific relevance to Canada and Latin America in an era of hemispheric trade liberalization.

\section{Post-Nationalism North of the Border}

The anti-imperialist underpinnings of Latin American studies have found somewhat parallel manifestations in the academic study of the northern part of the hemisphere as it has emerged in Canada. From its early origins in the 1940s, the Canadian studies project has been shaped by attempts to articulate the specificity of Canadian nation- and statehood in relation to the United States. A constant theme in debates about Canadian nationhood has been its relationship to various forms of colonialism, most recently US cultural imperialism. Originally rooted, like American studies, in nationalist attempts to link literary production to the

26 De la Campa insightfully observes that "[Most US Latino cultural forms] are rejected or resisted in Latin America, particularly in literary circles. For many scholars there, and some here, the inclusion of Latino mapping constitutes a distortion, if not a threat, to Latin Americanism, both in terms of literary history and disciplinary markets" (de la Campa, 2002: 3). For a promising effort to bridge the gap, see Poblete (2003).

27 Valdés (1985) and Spillers (1991) stress such connections. 
nation-state, Canadian studies have therefore always been a comparative, North American undertaking that focuses on both the United States and Canada. ${ }^{28}$ Canada's specific form of nationalism, its welfare state, the 1960s emergence of notions of cultural nationalism and cultural imperialism, Canada's various postcolonial and ethnic racialized identities, as well as ongoing attempts to forge a distinctly Canadian form of postnationalism are among the subjects that could constitute areas of intersection with inter-Americas studies.

Whereas US-based Americanists who advocate hemispheric work have begun to respond to scholarship in Latin American studies, they have almost completely ignored North American perspectives emerging outside the United States. The exclusion of Canada from hemispheric frameworks is often grounded in assumptions about the country's internal homogeneity and similarity to the United States. ${ }^{29}$ Satirized in Canadian Bacon (1994) in which one of the characters declares that Canada is "even whiter than the United States," this view overlooks the country's development of a pluralist national identity, manifested in official (if flawed) policies of multiculturalism and in the admission of a proportionately larger number of immigrants and refugees..$^{30}$ Moreover, the treatment of Canadian diversity as an extension of US theoretical paradigms assumes processes of racialization in Canada to be similar to those in the United States.

Both approaches fail to consider Canada's tradition of weak nationalism and the association of state-sponsored nationalism after the Second World War with politically left-leaning intellectual traditions, which differ from the more patriotic

28 American studies have a slightly more complex history, which includes radical roots in the 1930s and 1940s (Denning, 1996). The field grew under the conditions of Second World War nationalism and patriotism, and was eventually institutionalized during the Cold War. The New Americanists largely reacted against the prevailing "myth and symbol school" of the 1960s, which aimed to define the distinctiveness of the US national character against what were believed to be its exclusively European origins.

29 John Carlos Rowe, for example, theorizes a "North American studies" model that would demand "investigations of how the many different Americas and Canada have historically influenced and interpreted each other" (Rowe, 2000: 13). In referring to Canada in the singular but to the United States in the plural, Rowe reiterates the common view of Canada as an internally homogeneous nation. We are indebted to Traister (2002) for making this same point.

30 Compared to $9.3 \%$ of the US population that was foreign-born in 1997, $14 \%$ of Canada's population was made up of recent immigrants and refugees at the time of the 1996 census (Statistics Canada, 1999; US Census Bureau, 2002). Canada's official policy of multiculturalism has been widely critiqued as a means to undercut Québec's demands for special recognition by bestowing recognition on other cultural groups. 
US versions that post-nationalist American studies has been trying to overcome. Canada has been described as a "nation without nationality" (Spicer, 1991), a "statenation" where state, business, and elite interventions were needed to create a sense of national identity (Gwyn, 1995). Canada's historically weak sense of nationalism can be linked to the country's relatively short history as an independent nationstate (as formalized in the 1931 Statute of Westminster), its historical, cultural, and economic similarities with the United States, and its internal diversity, including its French- and English-speaking divide. Québec has described itself as a separate nation in a way that resembles Canadian rhetoric about the country's difference from the United States. Thus, nationalism in its supposed pan-Canadian form has almost exclusively been an English-Canadian notion. Whereas Québécois studies are common in French-language universities, Canadian studies have mainly become institutionalized in English-speaking institutions of higher learning.

As is the case with many Third World countries or regions, the Canadian search for a stronger form of nationalism since its transition from colony to independent nationhood has been affiliated with leftist positions, while anti-nationalists have been situated on the right of the political spectrum (Heninghan, 2002: 174). After the Second World War, state intervention in economic, social, political and cultural life increased to the extent that it became one of the chief characteristics of the Canadian nation (Mackey, 1999: 53). A growing spirit of nationalism among Canadian elites, which turned any economic, social, or cultural challenge into an assertion of autonomy and which was linked to ideas of US cultural imperialism, supported the creation of a strong social-democratic welfare state and the expansion of public enterprise and public service economies (Clarkson, 2002: 415).

Even though attempts at establishing a sense of progressive state-sponsored nationalism originated in the period after the Second World War, Canadian studies programs and Canadian specializations in traditional departments only emerged in the 1960s and 1970s amid intensified fears of Americanization and in the general context of rising anti-Americanism fuelled by the Vietnam War. ${ }^{31}$ The most important benchmark in the formalization of Canadian studies was a 1973 report by the Commission on Canadian studies. Entitled To Know Ourselves, the report declared that Canada's post-secondary institutions had not sufficiently assisted Canadians in understanding and appreciating their country's heritage, contemporary

31 Efforts to protect Canadian culture after World War II were manifested in the establishment of four major commissions. The Massey Commission (1949) focused on the arts, letters, and science; the Fowler Commission (1955) on radio and television broadcasting; the O'Leary Commission (1961) on magazine publishing, and the Laurendeay Commission (1963) on bilingualism and biculturalism (Mackey, 1999: 54). 
character, problems, and potential (Cameron, 1996: 21). Throughout the 1960s and 1970s, scholars of history, literature, sociology, and political science set out to define "Canadianness" by offering narratives of national development, accounts of Canada's emergence as a world player, and theories of national identity. Although Canadian studies have been better integrated across the humanities and social sciences than American studies, the nationalist movement was especially influential in the field of literature and culture. A number of literary critics and other prominent literary figures such as Northrop Frye, Margaret Atwood, and W.H. New became involved in attempts to establish Canadian literature as a separate field of study and to forge a sense of a literary nationalism where not much of one had previously existed. ${ }^{32}$ These efforts were also supported by the Canadian state and often framed in terms of cultural protectionism directed at the regulation of US cultural presence in Canada. In its attempt to differentiate between two national North American identities, the cultural nationalist movement constructed a white (mostly British) Canadian settler identity that largely excluded considerations of internal Canadian ethnic and racial differences.

By the 1980s, however, the nationalist movement in Canadian studies along with popular and elite support for the country's welfare state and its various policies of cultural protectionism came to an end. In the 1970s, the Canadian state established an official policy of multiculturalism to recognize and manage issues of internal cultural diversity without endangering its project of nation building. As Canada's national identity became de-linked from the welfare state, it became associated with the image of the "multicultural mosaic." With the implementation of various Canada-US trade agreements starting in the early 1990s, the Canadian state increasingly weakened through integration into an unevenly liberalized hemispheric economy dominated by the United States, and the search for stronger forms of Canadian nationhood diminished. In Canadian studies, a unified national perspective was replaced by a variety of approaches including environmental studies, regional studies, and work on race and ethnicity. The latter framework and its tenuous connection to state-sponsored multiculturalism in particular has encouraged efforts to rethink Canada as a model "post-national" state by adding Canada's growing internal diversity to the acknowledgement of the country's historically weak sense of national integration (Davey, 1993; Gwyn, 1995). Rather

32 For a concise characterization of the Canadian literary tradition and its relationship to cultural nationalism, see Davey (1993). The process of canon formation included an increase in Canadian literature courses in public schools and universities, growing government support for writers and for library purchases of Canadian literature, and the re-publication of out-of-print $19^{\text {th }}$-century Canadian texts (Lecker, 1993: 40-42). 
than attempting to move beyond the nationalist roots of the field as in American studies, Canadian post-nationalism, then, also aims to recast the country's weak sense of nationhood in terms of its increasing internal heterogeneity.

Throughout the 1980s, the postcolonial focus on Canada's status as a settlercolony expanded to include theories of ongoing domination by the United States and to describe the identities of Québécois, indigenous peoples, and some of Canada's other racialized groups. ${ }^{33}$ Especially indigenous Canadians as well as South Asian and Caribbean communities that grew after the elimination of racist immigration legislation in the late 1960s have become associated with postcolonial theory. ${ }^{34}$ In contrast, Canada's longstanding black and East Asian communities - and their association with slavery, $19^{\text {th }}$-century exploitation, and exclusionary immigration law - have been primarily imagined through US ethnic studies frameworks.

In fact, the connection of Asian and African Canadian communities with US ethnic studies theories has actually delayed their status as independent objects of study. ${ }^{35}$ East Asian literary productions, such as the work of the Eaton sisters and of Joy Kogawa, were incorporated into the US Asian American literary tradition to construct a sense of Asian American pan-ethnic literature. Within African American studies, on the other hand, Canada was invoked as a means to challenge the US history of slavery (Lo, 2001). Scholars like George Elliott Clarke (1996) and Rinaldo Walcott (1997) have shown that, except for acknowledging the role of Canada as a haven for runaway slaves, African American and black diaspora studies have either considered black Canadians an extension of African American culture or continued to exclude African Canadians from their increasingly more transnational theoretical paradigms (as has Paul Gilroy's influential model of the black Atlantic). This simple extension of US-based paradigms has thus failed to recognize the distinctiveness of Canada's ethnic and racial communities.

33 For examples of work on Canada as a "newly postcolonial country," see Bennett (1993-4). For criticism of this approach's tendency to overlook significant distinctions between a Commonwealth settler colony and Third World postcolonial nations, see Hutcheon (1989) and Chanady (1994). The application of postcolonial theory to Québec is, however, widely resisted (Heninghan, 2002: 81).

34 See, for example, Fee's argument that indigenous Canadians, unlike other ethnic groups in Canada, have been primarily interested in constructing a sense of pan-nationalism and protecting their status as sovereign nations (Fee, 1994: 684).

35 On the belated, mid-1990s development of Asian Canadian studies, despite similar exploitation of Chinese labor in the $19^{\text {th }}$ century, the exclusion of Chinese immigrants during most of the first half of the $20^{\text {th }}$ century, the internment and repatriation of Japanese Canadians during World War II, and the exclusion of immigrants from India between 1908 and 1951, see Miki (1995), Beauregard (1999), and Goellnicht (2000, “Long Labor”). 
Except for Native or First Nations studies, which now exist at universities in almost every Canadian province, the analysis of racialized cultures has not become widely institutionalized in the form of separate programs or departments. ${ }^{36}$ Canada's weak nationalism, in addition to a variety of other factors, has discouraged the emergence of oppositional models of ethnic identity and consequently of radical movements centered on identity and race (with the exception of Québécois separatism) that would have urged the creation of such programs. As Donald Goellnicht asks, "is Canada itself so devoid of a national identity, the collective psyche so divided and splintered, the nation so geographically regionalized, that it is virtually impossible for a national ethnic minority identity to assemble itself in a Canadian context?" (Goellnicht, 2000, "Long Labor": 19).

Because of its fragile nationalist mission and its much shorter institutional history compared to American and Latin American studies, Canadian studies today are not firmly entrenched at Canadian universities in the form of separate academic departments or programs. Compared to literary studies, history and the social sciences have been able to maintain greater public interest in their disciplinary focus on Canadian historical and political development (Maclulich, 1984-5: 33). For example, while the demand for Canadian foreign policy classes increased throughout the 1980s and 1990s (Nossal, 2000: 103), Canadian studies courses have generally disappeared from university curricula and entire programs have folded (Symons, 2000: 29).

Manifesting the decline of cultural nationalist orientations in Canadian studies, then, the turn toward post-nationalism in Canada represents a move beyond simplistic notions of US cultural imperialism that originally neglected Canada's internal heterogeneity and promoted ideas about the country's supposed superiority vis-à-vis its neighbor. In some of its less progressive forms, however, Canadian post-nationalism also signals the acceptance of an increasingly weakened Canadian welfare state and of continuing US economic, political, and cultural domination.

36 The examination of Native peoples has largely been separated from the analysis of other Canadian "visible minorities." To this day indigenous peoples constitute a much higher proportion of Canada's total population than they do of the United States, largely because British colonial policies recognized aboriginal land rights in North America and afforded Canada's First Nations greater integrity and cultural persistence than many US tribes (J. Miller, 1993: 373). The first full-time, degree-granting Native Studies program was created at Trent University in Peterborough, Ontario in 1969 (Price, 1978: 9), and others soon followed. In contrast, there exist few other ethnic studies programs, such as an Asia-Canada studies minor program at Simon Fraser University, British Columbia and a Centre for the Study of Black Culture at York University, Ontario. 
The acquiescence to what is, as in the Latin American context, described as "Americanization" even allows for the celebration of Canada's eventual "dissolution" and its potential economic and political incorporation into the United States through adoption of the US dollar and/or abolition of the Canada-US border.

This understanding of post-nationalism overlooks the potential for the emergence of alternatives to neoliberalism from a specifically Canadian standpoint. Such alternatives could be rooted in the country's experiences of a strong and progressive welfare state with a comparatively weak sense of nationalism, its attempts at the official recognition of ethnic and racial diversity, its relatively marginal status on a global scale, and its continued oppositional stance vis-à-vis the United States. As Imre Szeman has argued, any form of Canadian post-nationalism will need to continually return to the idea of the nation because of the country's peripheral status (Szeman, 1998: 32). Or, as Richard Cavell has put it, Canadian post-nationalism will always find itself in the paradoxical situation of having to "celebrate the nation as a function of dismissing it" (Cavell, 2000: 10).

In writer Stephen Heninghan's words, the Canadian experience of globalization has entailed "the traumatic demolition of our national sense of being by Free Tradeand NAFTA-based "harmonization," to the point where our particular individual experiences of society have become intangible and inexpressible" (Heninghan, 2002: 178). Canadians have experienced globalization primarily as an intensified assault on national policies and identity in favor of US institutions, norms and values (Cameron, 1996: 9), especially on the country's social welfare policies and its more liberal immigration legislation. Exhibiting a degree of direct foreign (US) ownership unparalleled anywhere on the globe, Canada has also reaped far fewer benefits from economic integration under 1990s trade agreements than the United States has, in terms of increased market share and job creation (Panitch, 1996: 82).

The examination of such questions appears to have moved into the realm of popular culture, where much of the declining field's cultural nationalistic rhetoric is being recycled. As of late, the most popular items of Canadian mass culture have been a series of Molson beer commercials articulating the particularity (and often the superiority) of Canadian culture as opposed to that of the United States. In the most famous commercial "I am Canadian," for example, Canadians are extolled for believing in "peace keeping not policing" and for supporting concepts of "diversity, not assimilation." ${ }^{37}$ While it may appear a return to 1960 s nationalism and

37 While work in Canadian communication or media studies was greatly influential in 1960s cultural nationalist debates, little scholarship on Canadian popular culture or cultural studies exists today. The Canadian Association of Cultural Studies was founded 
to ideas of cultural imperialism, the commercial manifests a sense of Canadian opposition to globalization, expressed in the awareness that North American integration has obliterated too much of Canada's cultural and political particularity.

Drawing on the left-leaning traditions of Canadian nationalism, political scientist Stephen Clarkson has recently argued for a "post-globalist" Canadian state rooted in the specificities of the country's political culture. Clarkson does not recommend that Canada return to its 1960s welfare state or to its policies of cultural and economic nationalism. Instead he proposes that the Canadian state recuperate its unused powers by establishing a more equitable society and by rebuilding a degenerated public infrastructure, his plans including increasing support for public schools and universities, universal health care, and Canadian cultural expression (Clarkson, 2002: 427). Clarkson also highlights the positive effects of protectionist cultural policies that would ensure Canada greater representation on a global and regional level. He concedes that such changes will require the cooperation of hemispheric and global systems of governance with similar post-globalist values. Similar to Latin American thinkers like Roger Bartra, Clarkson emphasizes the nation-state's unfulfilled potential to represent public interests vis-à-vis neo-liberal forms of globalization. Because they are rooted in specific manifestations of nationalism in regions of the Americas outside the United States, these counter-narratives to neoliberal forms of globalization could become a useful starting point for more sophisticated theories of corporate transnational expansion and US domination in a hemispheric context.

Because of its complex relationship to questions of state-sponsored nationalism and the nation-state as well as its long history of US domination, Canada constitutes an important location from which inter-Americas scholars in Canada, the United States, and other locations could rethink the role of the nation within theories of globalization. Unlike Latin American studies, however, Canadian studies have not yet been considered a potential component of US-based hemispheric models of study. And despite a longstanding tendency to question the motivations behind US scholarship on Canada and to lament the presence of US scholars in Canadian academia, Canada-based Canadianists currently do not seem to view hemispheric paradigms as a threat. ${ }^{38}$ The case may be different for US-based Canadianists, some

as recently as 2002, and a Canadian journal of cultural studies called TOPIA was inaugurated the same year.

38 Canadianists often construe US scholars' motivations for their work on Canada as a prelude to takeover (Winks, 1993: 3). At the highpoint of cultural nationalism, these attitudes hardened to the point that US Canadianists were largely ignored for committee positions in professional organizations (Winks, 1993: 7). 
of whom are affiliated with the few Canadian studies programs that have existed at US institutions since the 1960s. ${ }^{39}$ In contrast to most US area studies programs including Latin American studies, Canadian studies originally developed without significant federal or foundational support and have remained relatively small (Alper and Monahan, 1997: 173). Scholarship in history, literature, and political science produced in these institutional sites has not significantly influenced the inter-American framework that has emerged in the US academy, possibly because, as Donald K. Alper and Robert L. Monahan have argued, it has not been sufficiently comparative (Alper and Monahan, 1997: 176). ${ }^{40}$

Nevertheless, Canadian studies programs, especially those situated in US institutions near the border or in universities with a long history of Canadian inquiry, are still active today, some having expanded into more social science-oriented North American studies programs that sometimes also encompass Mexico or Latin America ${ }^{41}$ These recent developments promise the reinvigoration of Canadian studies from within the United States at the same time that they also support the emergence of comparative and internationalist work which includes perspectives from abroad.

\section{Future Directions for Inter-Americas Studies}

The preceding analysis shows that Latin American and Canadian area studies models have encountered markedly different theoretical issues than American studies when entering into a hemispheric perspective. While American studies have yet to engage deeply with the social sciences' theories of globalization, the social sciences figure more prominently in Latin American studies and have also been strong in Canadian studies. In these two fields, the current push for hemispheric

39 US-based scholarship on Canada emerged in the 1940s and 1950s and was centered in history departments. Throughout the 1980s, interest shifted to economics, business, political science, economic geography, law, and on occasion, anthropology or sociology (Winks, 1993: 7-8). Today US-based Canadian studies are represented by the Association for Canadian Studies in the United States (ASCUS), which produces the American Review of Canadian Studies and has a national secretariat in Washington, DC.

40 The extensive work on Canada-US borderlands, produced with the support of the Canadian-American Center at the University of Maine, constitutes a notable exception. In general, there exists more comparative scholarship in economics and business than in history or literature (Lipset, 1993: 407).

41 In 1998, for example, Duke's Center for North American Studies broadened its original focus from Canadian studies to include comparative and international relations research about the United States, Canada, and Mexico. 
frameworks is often linked to developments toward continental integration under NAFTA and other regional trade agreements. Postcolonial theory has also entered the three disciplines in different ways. Postcolonial rethinkings of US ethnicity within Chicana/o-Latina/o and border studies frameworks have become central to the emergence of New Americanist positions and, more recently, to the hemispheric perspective within American studies. The postcolonial inquiry into the cultures of Latin America within Latin American studies, in contrast, has been modeled after the South Asian Subaltern Studies Group and has yet to fully explore that the US-Mexico border cuts both ways (Romero, 1995: 796) - that is, that issues of trans-national ethnicity may also be of interest to area studies. And in Canadian studies, postcolonial theory has foregrounded Canada's status as a settler-invader colony, described the country's subordinate relationship to the United States, and facilitated the study of some of its linguistic and racialized communities.

In addition, individual disciplines have been shaped by differing valuations of nationalism and conflicting attitudes toward the role of the nation in cultural production. American and Canadian studies both originated in nationalist projects that set out to link literary production to the nation-state. In Canadian studies (as in Latin American studies), however, the nation-state is often theorized as a guarantor of sovereignty from the United States and as a potential means of advancing alternative forms of globalization. While Latin American studies have been characterized by perennial tensions among national, regional, and continental perspectives, national studies remain strong, especially in Latin American countries. Despite the field's general rejection of reductive area studies models dating from the 1920s, Latin America still tends to be represented in many US academic disciplines as though it were a single country. We hope that the recognition of the singular and distinctive in the disciplines we have addressed will provide inter-Americas scholars with strategies for theorizing the role of the United States in the hemisphere and for guarding against possible US domination of the emerging field.

We only have space to mention a few examples of recent work on the Americas that make us optimistic about the possibilities of this incipient research area. Spanning the fields of American studies, comparative literature, and Latina/o studies, Kirsten Silva Gruesz's Ambassadors of Culture (2002) develops an alternative version of the American Renaissance that broadens its purview beyond US events like the Civil War and Reconstruction to include an analysis of the development of US expansionism. While Gruesz primarily emphasizes the Latin American-US relationship, her book also addresses the importance of Niagara Falls, a Canada-US border region, for $19^{\text {th }}$-century Latin American poets. In addition to this literary historical perspective, comparative approaches to historical 
and contemporary issues in North America have emerged that revolve around intra-ethnic or diasporic questions. Such work focuses comparatively on indigenous American peoples, explores Asian immigration and settlement in the Americas, and advances research on histories of slavery and more generally on the black presence in the hemisphere. ${ }^{42}$ Other scholarship has answered longstanding calls to examine similarities between various ethnic and diasporic communities. For example, in her work on early $20^{\text {th }}$-century undocumented Chinese immigration across the Canada-US and Mexico-US borders, historian Erika Lee (2002) has reconceived these movements as precursors of Mexican immigration and as indicators of future border enforcements. A third trajectory for hemispheric Americas scholarship has been the focus on contemporary developments in the hemisphere and their relationship to cultural production. Pamela Maria Smorkaloff (1994), for example, has placed hemispheric literary production, publishing, and distribution in the context of developments associated with NAFTA, discussing Latin American, US Latina/o, and Canadian artists and writers, as well as inter-sections between Latin American and Canadian border narratives. ${ }^{43}$ In addition, scholarship in communication studies spearheaded by José Manuel Valenzuela Arce (1994) and Emile McAnany and Kenton Wilkinson (1996), among others, has traced the impact of economic trade agreements on national and crossborder media industries in Canada, the United States, and Mexico.

While adopting a hemispheric perspective asks scholars to rethink the meaning of disciplinary scholarship in general, the work of these scholars also suggests some additional future trajectories for inter-Americas studies. Among other topics well-suited to the hemispheric perspective are the interrelationship among social, political, cultural, and economic developments in the Americas; migration, cultural production, and change in border areas; transnational cultural exchange within and among specific ethnic and racial groups; and comparative historical accounts of nation-state formation and national, regional, and ethnic identities. Additionally, inter-Americas studies may foster scholarship on contemporary

42 For examples of comparative work on indigenous peoples in Canada and the United States, see Price (1978) and Nichols (1998). For comparative scholarship on Asian Canadians and Asian Americans, see Goellnicht (2000, "Bones"). For work on Asians in Latin America, see Ong (1999), Hu-DeHart (1999), and Rachel C. Lee (1999). For work on hemispheric histories of slavery, see Handley (2000) and Cox (2001). For work on the Latina/o presence in Canada, see Basok's research (2002) on Mexican migrant workers.

43 For work that comparatively addresses cultural productions about the Mexico-US and Canada-US borders, see Brégent-Heald (2003). 
issues such as the evolution of radical politics on the continent, environmentalism, workers' rights, feminism, and movements challenging NAFTA and its planned extension into the FTAA. ${ }^{44}$ Still other perspectives may draw on comparative urban studies in the hemisphere, incorporating architecture and concepts of public space (e.g. Herzog, 1999). Material culture studies that focus on products of the Americas, from cocaine to bananas, would also stand to gain from an expanded geographical framework capable of tracing the entire circuit of commodity production and consumption. ${ }^{45}$

Scattered throughout the United States, Latin America, Canada, and other international sites, inter-Americas scholars need to establish closer contact with one another across disciplinary, regional, and national borders and to urge the reconfiguration of existing interdisciplinary fields in the United States and elsewhere. We put our faith in interdisciplinarity, for, as Linda Kerber has put it, while the marginal position of interdisciplinary programs always implies great risks, it also promises great potential (Kerber, 1989: 425). As inter-Americas studies become a more formalized area of research, however, they will also need to maintain their current openness vis-à-vis other emerging models of transnational and global studies.

By way of conclusion, we call for a collaborative and dialogic model of interAmericas studies that moves across the various geographies of the Americas or that allows for more comparative views on the hemisphere to emerge. We envision inter-Americas studies to be a framework that will enable scholars to explore hemispheric phenomena in depth, rather than a new paradigm that seeks to displace national (and other) geographic categories of analysis. Given our own disciplinary locations, we are interested in the United States' role in the hemisphere; however, we do not imagine that all inter-Americas scholarship will necessarily contain a US component. In our view, inter-Americas studies could also draw on comparative analyses developed by Canadianists on Latin America or by Latin Americanists on Canada, not to mention other potential projects developed by specialists in fields not covered in this article. ${ }^{46}$ The new transnational geographical models emerging

44 For comparative social sciences approaches to economic and immigration issues involving Mexico, Canada, and the United States, see Drache (1993) and Driscoll (1995).

45 Virginia Scott Jenkins' Bananas: An American History (2000) and Steven Soderbergh's movie Traffic (2000), for example, would have been enriched by focusing more on the sites that produce the commodities they study. For examples that do utilize an expanded frame of analysis, see Barrientos et al. (1999) and Brandt (1999).

46 Although the topic lies outside the scope of this article, inter-Americas research also needs to interface with work on the hemisphere and its trans-Atlantic European 
in the US academy are to a degree consistent with US economic policies promoting globalization, and they have been supported by large-scale initiatives on the part of traditional area studies funding institutions (Bérubé, 2003; Cumings, 2002). US Americanists are in a position to respond either critically or complacently to these developments; it seems that manifesting a greater interest in the political and economic implications of globalization would be a positive first step. If Americanists are to internationalize their field without becoming unwitting ambassadors of a US-inspired "world without boundaries" (Cumings, 2002: 286), they need to travel abroad, engage in scholarly dialogue in languages other than English, and interest themselves in scholarship produced outside the United States and outside their own field. Until they do so, we fear that an Americanist-led hemispherism will only promote a vision of the Americas in which all academic disciplinary configurations are subordinate to those of the United States and in which every region outside of the United States is collapsed into a monolithic other. ${ }^{47}$

\section{Note}

We would like to thank our colleagues who graciously offered their comments and suggestions on various drafts of this essay: Rachel Adams, Richard Cavell, Jane Desmond, Donald C. Goellnicht, Brian Gollnick, Charles A. Hale, Robert McKee Irwin, Djelal Kadir, Misha Kokotovic, Ruedi Kuenzli, Priya Kumar, David Laurence, Kathy Lavezzo, Marie Lo, Joel Pfister, Laura Rigal, Reginald C. Stuart, Sam Truett, Priscilla Wald, Doris Witt, the anonymous reviewers of Comparative American Studies and its editor R.J. Ellis. We also thank Jenna Hammerich for her careful manuscript editing. All translations from the Spanish are by Claire F. Fox.

connections. Such projects are under way at the University of Central Lancashire's Department of Cultural Studies, at the Center for Advanced Study on the Internationality of National Literatures at the University of Göttingen, Germany, and at the Maastricht Center for Transatlantic Studies, launched in 1995 by a consortium of universities from the United States, Mexico, and Europe (Buchenau and Messmer, 2001). In Mexico, the National Autonomous University (UNAM) has a Center for US Studies, while throughout Latin America individual scholars in literary and cultural studies have dedicated themselves to US-oriented American studies. Thank you to Virginia Domínguez for this last piece of information.

47 We thank Robert McKee Irwin for his insightful comments on this section. 


\section{Works Cited}

Alper, Donald K. and Monahan, Robert L. "The Attraction of a New Academic Frontier: The Case of Canadian Studies in the US." In Alternative Frontiers. Ed. Allen Seager, Leonard Evenden, Rowland Lorimer and Robin Mathews. Montréal: Association for Canadian Studies, 1997. 173-183.

Avelar, Idelber. “Toward a Genealogy of Latin Americanism.” Dispositio/n 22.49 (1997 [2000]): 121-133.

Barrientos, Stephanie, Bee, Anna, Matear, Ann and Vogel, Isabel. Women and Agribusiness: Working Miracles in the Chilean Fruit Export Sector. New York: St. Martin's Press, 1999.

Bartra, Roger. “The Malinche's Revenge: Toward a Postnational Identity." In Blood, Ink, and Culture: Miseries and Splendors of the Post-Mexican Condition. By Roger Bartra. Trans. Mark Alan Healey. Durham, NC: Duke University Press, 2002. 61-64.

Basok, Tanya. Tortilla and Tomatoes: Transmigrant Mexican Harvesters in Canada. Montreal: McGill-Queen's University Press, 2000.

Beauregard, Guy. “The Emergence of 'Asian Canadian Literature': Can Lit's Obscene Supplement?" Essays on Canadian Writing 67 (Spring 1999): 53-75.

Belknap, Jeffrey and Fernández, Raúl, eds. José Martîs 'Our America': From National to Hemispheric Cultural Studies. Durham, NC: Duke University Press, 1998.

Bennett, Donna. "English Canada's Postcolonial Complexities." Essays on Canadian Writing 51-2 (1993-94): 164-210.

Berger, Mark T. Under Northern Eyes: Latin American Studies and US Hegemony in the Americas, 1898-1990. Bloomington, IN: Indiana University Press, 1995.

Berger, Mark T. "Specters of Colonialism: Building Postcolonial States and Making Modern Nations in the Americas." Latin American Research Review 35.1 (2000): 151-171.

Bérubé, Michael. "American Studies without Exceptions." PMLA 118.1 (2003): 103-113.

Bolton, Herbert Eugene. History of the Americas: A Syllabus with Maps. $2^{\text {nd }}$ edn. Boston: Ginn, 1935.

Bolton, Herbert Eugene. "The Epic of Greater America." In Do the Americas Have a Common History? A Critique of the Bolton Theory. Ed. Lewis Hanke. New York: Knopf, 1964. 67-100.

Bourdieu, Pierre and Wacquant, Loïc. "On the Cunning of Imperialist Reason." Theory, Culture and Society 16.1 (1999): 41-58. 
Bové, Paul A. “Can American Studies Be Area Studies?” In Learning Places: The Afterlives of Area Studies. Ed. Masao Miyoshi and H.D. Harootunian. Durham, NC: Duke University Press 2002. 206-231.

Brandt, Deborah, ed. Women Working the NAFTA Food Chain: Women, Food and Globalization. Toronto: Second Story Press, 1999.

Brégent-Heald, Dominique. "Pop Goes the Border: Visual Representations of the North American Borderlands in Hollywood, 1929-1960." PhD dissertation, Duke University, 2003.

Brunner, José Joaquín. "Notes on Modernity and Postmodernity in Latin American Culture." boundary 220.3 (1993): 34-54. Special issue on "The Postmodern Debate in Latin America." Ed. John Beverley and José Oviedo.

Buchenau, Barbara and Messmer, Marietta. "An Introduction to Intercultural Negotiations in the Americas and Beyond." CLCWeb: Comparative Literature and Culture: A WWWeb Journal 3.2 (2001). URL (consulted June 2002): http:// clcwebjournal.lib.purdue.edu/ clcweb012/introduction01-2. html.

Cabán, Pedro and Aparicio, Frances. "The Latino in Latin American Studies." LASA Forum 33.4 (2003): 10-11.

Cameron, David. Taking Stock: Canadian Studies in the Nineties. Montréal: Association for Canadian Studies, 1996.

Canadian Bacon. Dir. Michael Moore. Perf. John Candy, Dan Aykroyd, and Rhea Perlman. Gramercy Pictures, 1994.

Cavell, Richard. "Where Is Here Now?" Essays on Canadian Writing 71 (2000): 6-13.

Chanady, Amaryll. "Canadian Literature and the Postcolonial Paradigm." Textual Studies in Canada/Etudes Textuelles au Canada 5 (1994): 15-21.

Chevigny, Bell Gale and Laguardia, Gari, eds. Reinventing the Americas: Comparative Studies of Literature of the United States and Spanish America. Cambridge: Cambridge University Press, 1986.

Clarke, George Elliott. "Must All Blackness Be American?: Locating Canada in Borden's 'Tightrope Time,' or Nationalizing Gilroy's The Black Atlantic." Canadian Ethnic Studies 27.3 (1996): 56-71.

Clarkson, Stephen. Uncle Sam and Us: Globalization, Neoconservatism, and the Canadian State. Toronto: University of Toronto Press, 2002.

Cohn, Deborah H. History and Memory in the Two Souths: Recent Southern and Spanish American Fiction. Nashville, TN: Vanderbilt University Press, 1999.

Colás, Santiago. "Of Creole Symptoms, Cuban Fantasies, and Other Latin American Postcolonial Ideologies." PMLA 110.3 (1995): 382-396.

Cornejo Polar, Antonio. Escribir en el aire: ensayo sobre la heterogeneidad sociocultural en las literaturas andinas. Lima: Horizonte, 1994. 
Cox, Timothy J. Postmodern Tales of Slavery in the Americas: From Alejo Carpentier to Charles Johnson. New York: Garland, 2001.

Cumings, Bruce. "Boundary Displacement": The State, the Foundations and Area Studies during and after the Cold War. In Learning Places: The Afterlives of Area Studies. Ed. Masao Miyoshi and H.D. Hartoonian. Durham, NC: Duke University Press, 2002. 261-302.

Davey, Frank. Post-National Arguments: The Politics of the Anglophone-Canadian Novel since 1967. Toronto: University of Toronto Press, 1993.

Dávila, Arlene. Latinos, Inc.: The Marketing and Making of a People. Berkeley: University of California Press, 2001.

De la Campa, Román. Latin Americanism. Minneapolis, MN: University of Minnesota Press, 1999.

De la Campa, Román. "Latin American Studies: Literary, Cultural and Comparative Theory." CLCWeb: Comparative Literature and Culture 4.2 (2002). URL (consulted June 2002): http://clcwebjournal.lib.purdue.edu/clcweb02-2/ delacampa02.html.

Delpar, Helen. "Inter-American Relations and Encounters: Recent Directions in the Literature." Latin American Research Review 35.3 (2000): 155-172.

Denning, Michael. The Cultural Front: The Laboring of American Culture in the Twentieth Century. New York: Verso, 1996.

Desmond, Jane C. and Domínguez, Virginia R. "Resituating American Studies in a Critical Internationalism.” American Quarterly 48.3 (1998): 475-490.

Drache, Daniel. "The Future of NAFTA in the Post-National Era." Review of Radical Political Economics 25.4 (1993): 30-44.

Driscoll, Barbara A. "Comparative Migration Issues." Critical Sociology 21.2 (1995): 67-74.

Dunkerley, James. Americana: The Americas in the World, around 1850 (or 'Seeing the Elephant' as the Theme for an Imaginary Western). London: Verso, 2000.

Fee, Margery. "What Use is Ethnicity to Aboriginal Peoples in Canada?" Canadian Review of Comparative Literature 22.3 (1995): 683-691.

Felix, David. "Is the Drive toward Free-Market Globalization Stalling?" Latin American Research Review 33.3 (1998): 191-216.

Fitz, Earl E. Rediscovering the New World: Inter-American Literature in a Comparative Context. Iowa City, IA: University of Iowa Press, 1991.

Fitz, Earl E. "Brazilian and Spanish American Literature in an Inter-American Perspective: The Comparative Approach." CLCWeb: Comparative Literature and Culture 4.2 (2002). URL (consulted June 2002): http://clcwebjournal.lib. purude.edu/clcweb02-2/fitz02.html. 
Fox, Jonathan. "Bridging Latin American and Latino Studies: Juntos pero no revueltos." LASA Forum 33.4 (2003): 12.

Fuguet, Alberto and Gómez, Sergio, eds. McOndo. Barcelona: Grijalbo Mondadori, 1996.

García Canclini, Néstor. Consumidores y ciudadanos: conflictos multiculturales de la globalización. Mexico City: Grijalbo, 1995.

García Canclini, Néstor. La globalización imaginada. Buenos Aires: Paidós, 1999.

Gikandi, Simon. "Globalization and the Claims of Postcoloniality." South Atlantic Quarterly 100.3 (2001): 627-658.

Gilroy, Paul. The Black Atlantic: Modernity and Double Consciousness. Cambridge, MA: Harvard University Press, 1993.

Goellnicht, Donald C. “Of Bones and Suicide: Sky Lee’s Disappearing Moon Café and Fae Myenne Ng's Bone." Modern Fiction Studies 46.2 (2000): 300-330.

Goellnicht, Donald C. "A Long Labour: The Protracted Birth of Asian Canadian Literature." Essays on Canadian Writing 72 (2000): 1-41.

Gollnick, Brian. "The Archaeology of American Identity: Subaltern History and Elite Identities in the Nineteenth Century." In "The Bleeding Horizon: Subaltern Representations in Mexico's Lacandón Jungle." By Brian Gollnick. PhD dissertation, University of California, San Diego, 1998. 68-118.

González Stephan, Beatriz, ed. Cultura y tercer mundo. 2 vols. Caracas: Nueva Sociedad, 1996.

Greene, Roland. "New World Studies and the Limits of National Literatures." Stanford Humanities Review 6.1 (1998): 88-110.

Gruesz, Kirsten Silva. Ambassadors of Culture: The Transamerican Origins of Latino Writing. Princeton, NJ: Princeton University Press, 2002.

Gwyn, Richard. Nationalism without Walls: The Unbearable Lightness of Being Canadian. Toronto: McClelland and Stewart, 1995.

Hale, Charles A. "Globalization and Americanization in Historical Perspective: The Case of Mexico." In Localismo y globalización: Aportes para una historia de los intelectuales en Iberoamérica. Ed. Mariano Plotkin and Ricardo González Leandri. Madrid: Consejo Superior de Investigaciones Científicas, 2000. 117-131.

Handley, George B. Postslavery Literatures in the Americas. Charlottesville, VA: University of Virginia Press, 2000.

Hanke, Lewis, ed. Do the Americas Have a Common History? A Critique of the Bolton Theory. New York: Knopf, 1964.

Heninghan, Stephen. When Words Deny the World: The Reshaping of Canadian Writing. Erin, Ontario: Porcupine Press, 2002. 
Hershberg, Eric. "From Cold War Origins to a Model for Academic Internationalization: Latin American Studies at a Crossroads." Dispositio/n 23.50 (1998 [2002]): 117-131.

Herzog, Lawrence A. From Aztec to High Tech: Architecture and Landscape Across the Mexico-United States Border. Baltimore, MD: Johns Hopkins University Press, 1999.

Hispanic American Historical Review. Special issue on 'Mexico's New Cultural History: ¿Una lucha libre?' 79.2 (1999).

Horwitz, Richard, ed. Exporting America: Essays on American Studies Abroad. New York: Garland, 1993.

Hu-DeHart, Evelyn. Across the Pacific: Asian Americans and Globalization. Philadelphia, PA: Temple University Press, 1999.

Hurtado, Albert L. "Herbert E. Bolton, Racism, and American History." Pacific Historical Review 62.2 (1993): 127-142.

Hurtado, Albert L. "Parkmanizing the Spanish Borderlands: Bolton, Turner, and the Historians' World.” Western Historical Quarterly 26.2 (1995): 149-167.

Hutcheon, Linda. "Circling the Downspout of Empire: Postcolonialism and Postmodernism." Ariel 20.1 (1989): 149-175.

Inter-American Cultural Studies Network. "Proposal for the Establishment of an Electronic Network Relating to Cultural Studies (Cultnet)." Submitted by Programa Avançado de Estudos Contemporáneos, Universidade Federal do Rio de Janeiro, and Inter-American Cultural Studies Network, Center for Cultural Studies, City University of New York, 1993. Unpublished document, personal copy.

Irwin, Robert McKee. "Toward a Border Gnosis of the Borderlands: Joaquín Murrieta and Nineteenth-Century US-Mexico Border Culture." Nepantla: Views from South 2.3 (2001): 509-537.

Jay, Paul. "The Myth of 'America' and the Politics of Location: Modernity, Border Studies, and the Literature of the Americas." Arizona Quarterly 54.2 (1998): 165-192.

Jenkins, Virginia Scott. Bananas: An American History. Washington, DC: Smithsonian Institution, 2000.

Kadir, Djelal. "America and Its Studies." PMLA 118.1 (2003): 9-24.

Kaplan, Amy. "Left Alone with America: The Absence of Empire in the Study of American Culture." In Cultures of United States Imperialism. Ed. Amy Kaplan and Donald E. Pease. Durham, NC: Duke University Press, 1993. 3-12.

Kazanjian, David. The Colonizing Trick: National Culture and Imperial Citizenship in Early America. Minneapolis, MN: University of Minnesota Press, 2003. 
Kerber, Linda K. "Diversity and Transformation of American Studies." American Quarterly 41 (1989): 415-431.

Knight, Alan. "Subalterns, Signifiers and Statistics: Perspectives on Mexican Historiography." Latin American Research Review 37.2 (2002): 136-158.

Kokotovic, Misha. "Intellectuals and Their Others: What Is to Be Done?" Diaspora 9.2 (2000): 287-308.

Larrain, Jorge. Theories of Development. Cambridge: Polity Press, 1989.

Larsen, Neil. Reading North by South: On Latin American Literature, Culture, and Politics. Minneapolis, MN: University of Minnesota Press, 1995.

Latin American Subaltern Studies Group. "Founding Statement." Dispositio/n 19.46 (1994 [1996]): 1-12.

Lecker, Robert. "Privacy, Publicity, and the Discourse of Canadian Criticism." Essays on Canadian Writing 51.2 (1993): 32-82.

Lee, Benjamin. "Critical Internationalism." Public Culture 7.3 (1995): 559-592.

Lee, Erika. "Enforcing the Borders: Chinese Exclusion along the US Borders with Canada and Mexico, 1882-1924." Journal of American History 89.1 (2002): 54-86.

Lee, Rachel C. The Americas of Asian American Literature. Princeton, NJ: Princeton University Press, 1999.

Lipset, Seymour Martin. "Canadian Studies in the United States: A Summary." In Northern Exposures: Scholarship on Canada in the United States. Ed. Karen Gould, Joseph T. Jockel and William Metcalfe. Washington, DC: Association for Canadian Studies in the United States, 1993. 397-416.

Lo, Marie. "Canada as 'Way Station' in Bharati Mukherjee's Isolated Incidents." Paper presented at the annual meeting of the Association for Asian American Studies, Toronto, March 2001.

Lowe, Lisa. Immigrant Acts: On Asian American Cultural Politics. Durham, NC: Duke University Press, 1996.

Mackey, Eva. The House of Difference: Cultural Politics and National Identity in Canada. London: Routledge, 1999.

Maclulich, T.D. "What Was Canadian Literature? Taking Stock of the Canlit Industry." Essays on Canadian Writing 30 (1984-1985): 17-34.

Magnaghi, Russell M. Herbert E. Bolton and the Historiography of the Americas, Studies in Historiography 5. Westport, CT: Greenwood, 1998.

Mallon, Florencia. "The Promise and Dilemma of Subaltern Studies: Perspectives from Latin American History." American Historical Review 99 (1994): 1491-1515. 
Mariscal, George. "An Introduction to the Ideology of Hispanism in the US and Britain." In Conflicts of Discourse: Spanish Literature in the Golden Age. Ed. Peter Evans. Manchester: Manchester University Press, 1990. 1-25.

Martínez, Rubén. Crossing Over: A Mexican Family on the Migrant Trail. New York: Metropolitan, 2001.

Mattelart, Armand and Dorfman, Ariel. How to Read Donald Duck: Imperialist Ideology in the Disney Comic. New York: International General, 1975.

McAnany, Emile G. and Wilkinson, Kenton T., eds. Mass Media and Free Trade: NAFTA and the Cultural Industries. Austin, TX: University of Texas Press, 1996.

McClennen, Sophia A. "Comparative Literature and Latin American Studies: From Disarticulation to Dialogue." CLCWeb: Comparative Literature and Culture 4.2 (2002). URL (consulted June 2002): http://clcwebjournal.lib.purdue. edu/clcweb02-2/mcclennen02.html.

McClennen, Sophia A. and Fitz, Earl E., eds. Special issue on "Cultural Studies and Latin America." CLCWeb: Comparative Literature and Culture 4.2 (2002). URL (consulted June 2002): http://clcwebjournal.lib.purdue.edu/clcweb02-2/ contents02-2.html.

Mesa-Lago, Carmelo. Latin American Studies in the 1980s: Establishing LASA Priorities and Policies. Pittsburgh, PA: Consortium of Latin American Studies Programs, 1980.

Mignolo, Walter. Local Histories/Global Designs: Coloniality, Subaltern Knowledges, and Border Thinking. Princeton, NJ: Princeton University Press, 2000.

Miki, Roy. "Asiancy: Making Space for Asian Canadian Writing." In Privileging Positions: The Sites of Asian American Studies. Ed. Gary Y. Okihiro, Marilyn Alquizola, Dorothy Fujita Rony and K. Scott Wong. Pullman, WA: Washington State University Press, 1995. 135-151.

Miller, Jay. "Canadian Native Studies in the United States." In Northern Exposures: Scholarship on Canada in the United States. Ed. Karen Gould, Joseph T. Jockel and William Metcalfe. Washington, DC: Association for Canadian Studies in the United States, 1993. 373-381.

Miller, Nicola. In the Shadow of the State: Intellectuals and the Quest for National Identity in Twentieth-Century Spanish America. London: Verso, 1999.

Miller, Toby and Yúdice, George. Cultural Policy. London: Sage, 2002.

Molloy, Sylvia. "His America, Our America: José Martí Reads Whitman.” In Breaking Bounds: Whitman and American Cultural Studies. Ed. Betsy Erkkila and Jay Grossman. New York: Oxford University Press, 1996. 83-91.

Moraña, Mabel. "El Boom del Subalterno." Cuadernos americanos 12.67 (1998): 214-222. 
Moreiras, Alberto. "The Order of Order: On the Reluctant Culturalism of AntiSubalternist Critiques." Journal of Latin American Cultural Studies 8.1 (1999): 125-145.

Moreiras, Alberto. The Exhaustion of Difference: The Politics of Latin American Cultural Studies. New York: Routledge, 2001.

Moreiras, Alberto and Embry, Marcus, eds. Special issues on "The Cultural Practice of Latin Americanism." Dispositio/n 22 (1997-8 [2000]): 49-50.

Nichols, Roger L. Indians in the United States and Canada: A Comparative History. Lincoln, NE: University of Nebraska Press, 1998.

Nossal, Kim Richard. "Home-Grown IR: The Canadianization of International Relations." Journal of Canadian Studies 35.1 (2000): 95-114.

O'Gorman, Edmundo. The Invention of America: An Inquiry into the Historical Nature of the New World and the Meaning of Its History. Bloomington, IN: Indiana University Press, 1961.

Ong, Aihwa. Flexible Citizenship: The Cultural Logics of Transnationality. Durham, NC: Duke University Press, 1999.

Panitch, Leo. "Globalization, States, and Left Strategies." Social Justice 23.1-2 (1996): 79-90.

Patell, Cyrus R.K. "Comparative American Studies: Hybridity and Beyond." American Literary History 11.1 (1999): 166-186.

Pérez-Firmat, Gustavo, ed. Do the Americas Have a Common Literature? Durham, NC: Duke University Press, 1990.

Poblete, Juan, ed. Critical Latin American and Latino Studies. Minneapolis: University of Minnesota Press, 2003.

Porter, Carolyn. "What We Know that We Don't Know: Remapping American Literary Studies." American Literary History 3 (1994): 467-526.

Price, John A. Native Studies: American and Canadian Indians. Toronto: McGrawHill, 1978.

Quijano, Aníbal and Wallerstein, Immanuel. "Americanicity as a Concept, or the Americas in the Modern World-System." Social Science Journal 44.4 (1992): 549-557.

Rama, Angel. Transculturación narrativa en América Latina. Mexico City: Siglo Veintiuno, 1982.

Rama, Angel. La ciudad letrada. Hanover, NH: Ediciones del Norte, 1984.

Ramos, Julio César. Desencuentros de la modernidad en América Latina: Literatura y política en el siglo XIX. Mexico City: Fondo de Cultura Económica, 1989. 
Reati, Fernando and Ocampo, Gilberto Gómez. "Académicos y gringos malos: la universidad norteamericana y la barbarie cultural en la novela latinoamericana reciente." Revista Iberoamericana 64.184-5 (1998): 587-609.

Richard, Nelly. "Intersectando Latinoamérica con el latinoamericanismo: Discurso académico y crítica cultural.” Revista Iberoamericana 180 (1997): 345-361.

Richard, Nelly. "Mediaciones y tránsitos académico-disicplinarios de los signos culturales entre latinoamérica y el latinoamericanismo." Dispositio/n 22.49 (1997 [2000]): 1-12.

Roach, Joseph. Cities of the Dead: Circum-Atlantic Performance. New York: Columbia University Press, 1996.

Rodríguez, Ileana, ed. The Latin American Subaltern Studies Reader. Durham, NC: Duke University Press, 2001.

Romero, Lora. "Nationalism and Internationalism: Domestic Differences in a Postcolonial World." American Literature 67.4 (1995): 795-800.

Rotker, Susana. The American Chronicles of José Martí: Journalism and Modernity in Spanish America. Hanover, NH: University Press of New England, 2000.

Rouse, Roger. "Mexican Migration and the Social Space of Postmodernism." Diaspora 1.1 (1991): 8-23.

Rouse, Roger. "Making Sense of Settlement: Class Transformation, Cultural Struggle, and Transnationalism among Mexican Migrants." Annals of the New York Academy of Sciences 645 (1992): 25-52.

Rouse, Roger. "Thinking through Transnationalism: Notes on the Cultural Politics of Class.” Public Culture 7.2 (1992 [1995]): 353-402.

Rowe, John Carlos, ed. Post-Nationalist American Studies. Berkeley, CA: University of California Press, 2000.

Rowe, William and Schelling, Vivian. Memory and Modernity: Popular Culture in Latin America. London: Verso, 1991.

Saldívar, José David. The Dialectics of Our America: Genealogy, Cultural Critique, and Literary History. Durham, NC: Duke University Press, 1991.

Sandoval, Anna M. "Unir Los Lazos: Braiding Chicana and Mexicana Subjectivities." In Decolonial Voices: Chicana and Chicano Cultural Studies in the $21^{\text {st }}$ Century. Ed. Arturo J. Aldama and Naomi H. Quinonez. Bloomington, IN: Indiana University Press, 2002. 202-228.

Sarlo, Beatriz. "Cultural Studies and Literary Criticism at the Crossroads of Values." Journal of Latin American Cultural Studies 8.1 (1999): 115-124.

Sassen, Saskia. Globalization and Its Discontents: Essays on the New Mobility of People and Money. New York: New Press, 1998. 
Skidmore, Thomas E. "Studying the History of Latin America: A Case of Hemispheric Convergence." Latin American Research Review 33.1 (1998): 105-127.

Smith, Peter. "Area Studies in a Global Age." LASA Forum 32.4 (2002): 7-9.

Smorkaloff, Pamela Maria. "Shifting Borders, Free Trade, and Frontier Narratives: US, Canada, and Mexico." American Literary History 6.1 (1994): 88-102.

Sommer, Doris. “José Martí, Author of Walt Whitman.” In José Martîs 'Our America’: From National to Hemispheric Cultural Studies. Ed. Jeffrey Belknap and Raúl Fernández. Durham, NC: Duke University Press, 1998. 77-90.

Sommer, Doris. Proceed with Caution, When Engaged by Minority Writing in the Americas. Cambridge, MA: Harvard University Press, 1999.

Spicer, Keith. Citizen's Forum on Canada's Future: Report to the People and Government of Canada. Ottawa: Supply and Services Canada, 1991.

Spillers, Hortense J., ed. Comparative American Identities: Race, Sex, and Nationality in the Modern Text. New York: Routledge, 1991.

Statistics Canada. "Immigrant Population, by Place of Birth Showing Periods of Immigration, 1996 Census." 1999. URL (consulted April 1999): http://www. StatCan.Ca/english/Pgdb/People/Population/demo25a.htm.

Symons, T.H.B. "The State of Canadian Studies at the Year 2000: Some Observations." Journal of Canadian Studies 35.1 (2000): 27-51.

Szeman, Imre. "The Persistence of the Nation: Interdisciplinarity and Canadian Literary Criticism." Essays on Canadian Writing 65.1 (1998): 16-37.

Tomlinson, John. Cultural Imperialism. Baltimore, MD: Johns Hopkins University Press, 1991.

Torres, Sonia. "US Americans and 'Us' Americans: South American Perspectives on Contemporary American Studies." Comparative American Studies 1.1 (2003): 9-18.

Traffic. Dir. Steven Soderbergh. Perf. Michael Douglas, Benicio Del Toro, and Catherine Zeta-Jones. Bedford Falls Productions, Initial Entertainment Group, and USA Films, 2000.

Traister, Bryce. "Border Shopping: American Studies and the Anti-Nation." In Globalization on the Line: Culture, Capital, and Citizenship at US Borders. Ed. Claudia Sadowski-Smith. New York: Palgrave, 2002. 31-52.

Truett, Samuel. "Epics of Greater America: Herbert Eugene Bolton and the Quest for a Transnational American History." In Paradigms and Paradigmas: Histories and Historians of the Spanish Colonial Past. Ed. Christopher Schmidt-Nowara and John Nieto-Phillips. Durham, NC: Duke University Press (in press).

United States Census Bureau. "1997 Population Profile of the United States." 2002. URL (consulted August 2002): http://www.census.gov/prod/3/98pubs/ p23-194.pdf. 
Valdés, M.J., ed. Inter-American Literary Relations. Proceedings of the $\mathrm{X}^{\text {th }}$ Congress of the International Comparative Literature Association, New York, 1982. Vol. 3. New York: Garland, 1985.

Valenzuela Arce, José Manuel. “Tijuana: la recepción audiovisual en la frontera.” In Los nuevos espectadores: cine, televisión y video en México. Ed. Néstor García Canclini. Mexico City: Consejo Nacional para la Cultura y las Artes and Instituto Nacional de Cinematografía, 1994. 298-329.

Volkman, Toby Alice. "Crossing Borders: The Case for Area Studies." The Ford Foundation Annual Report (Winter 1998): 28-29.

Walcott, Rinaldo. Black Like Who?: Writing, Black, Canada. Toronto: Insomniac Press, 1997.

Wald, Priscilla. "Minefields and Meeting Grounds: Transnational Analyses and American Studies." American Literary History 10.1 (1998): 199-218.

Winks, Robin W. "Imagining Canada." In Northern Exposures: Scholarship on Canada in the United States. Ed. Karen Gould, Joseph T. Jockel and William Metcalfe. Washington, DC: Association for Canadian Studies in the United States, 1993. 1-17.

Zamora, Lois Parkinson. Writing the Apocalypse: Historical Vision in Contemporary US and Latin American Fiction. Cambridge: Cambridge University Press, 1993.

Zamora, Lois Parkinson. The Usable Past: The Imagination of History in Recent Fiction of the Americas. Cambridge: Cambridge University Press, 1997. 
Marietta Messmer and Armin Paul Frank - 978-3-653-98855-0 Downloaded from PubFactory at 01/11/2019 10:57:20AM via free access 


\section{Liam Kennedy \\ University College, Dublin, Ireland \\ American Studies Without Tears, or
What Does America Want?}

I want to start with a simple proposition: America does not make Americanists happy. As Americanists, we commonly approach "America" with suspicion, fear, even anger; we view it as a powerful, duplicitous force to be denounced or demystified. ${ }^{2}$ I want to speculate on why this might be so and in particular to consider what I see as the troubled relationships at the heart of this dilemma-relations between pleasure and knowledge, and between sentiment and critique. This trouble is evident in the difficulties we experience in working through this relationship in our critical approaches, the difficulties in balancing intellectual comprehension and emotional apprehension of America. I will be reflecting on aspects of our intellectual relationships to America as an object of knowledge, to American studies as the field formation that frames that object, and to the field imaginary that shapes American studies. I will posit the field imaginary as a sphere of collective knowledge that is regulated by disciplinary practices but also as a field of less-regulated desires. And so I also want to consider what the construction of a field imaginary leaves out, what it represses or disavows, in producing America as an object of knowledge. In an attempt to illustrate some of these rather abstract considerations in relation to critical practice, I will conclude by looking at a photographic image.

To propose that America does not make Americanists happy is not to suggest we do not take pleasure in selected aspects of American culture-indeed, that pleasure is often defining of the topics we choose to write about-but this pleasure, I suggest, is itself a sublimation of the troubled relationship we have to our primary object of knowledge, "America," which for all our theoretical acumen and critical demystifications remains a stubborn, defining totality. Of course, part of the problem here is that our object of knowledge is not innocent; it is a geopolitical

1 This essay was first published in the Journal of Transnational American Studies 1.1 (2009): 1-13. Reprinted here with permission.

2 The references to "Americanists" and the use of third-person identifications with this category are intended to designate my own emplacement and identification as a European Americanist. 
entity, and so, critical perspectives in American Studies are always caught up in mirroring the mutations of this entity, while the field imaginary remains tethered to formations of state power, haunted by and compulsively reiterating the cold war origins of the field.

For many Americanists, critical distance is a mirror of intellectual and emotional distance-we are wary of sentiment, we are wary of nationalism - and antipathy toward or suspicion of America can function as an ethical stance. But I want to suggest that this is a pathological stance, a positionality conditioned by our troubled sense of the relationship between pleasure and knowledge and characterized by the hermeneutics of suspicion that underlies much of our critical practice. All too often, we treat our object of knowledge as a problem to be solved or, what amounts to the same thing, we project its meaning in the frame of our interpretations. The urge, often, is to demystify, to reveal the truth, the horror of American power. This can be a productive and enlightening approach, but there are other ways to engage the object, ways that are less involved in acts of interpretive mastery and that make the relationality of critic and object a key component of the field of investigation. ${ }^{3}$

The idea is to turn analysis of America toward questions of process and affect and to put in question the critic's position: what demand, desire, or need is expressed by America? Who or what is the target of that demand, desire, or need? What demand, desire, or need do we express in return? In following this idea, somewhat speculatively, I will posit America as a phantasm-an imaginary projection of our disciplinary knowledge and of our less-disciplined desires-to argue that America often functions to condition our sense of the Real (including our "passion for the real") and so also functions as a vanishing mediator of our identities, ethical, political, and critical. ${ }^{4}$

\section{The Trouble with American Studies}

We are not surprised at the allure of America in the real and imaginary worlds of others (indeed, some of us analyze this allure, often via the study of popular

3 This is hardly an original suggestion. By suggesting we shift our critical encounters with America from a model of interpretation to a model of recognition, I am building on distinct theoretical models, including psychoanalytical and feminist forms of cultural analysis. See, for example, Jessica Benjamin, Shadow of the Other: Intersubjectivity and Gender in Psychoanalysis (New York: Routledge, 1998).

4 On the concept of a "passion for the real," see Alain Badiou, Century, trans. Alberto Toscano (London: Polity, 2007). 
culture), but what happens to that allure, that fascination, in our own worlds as American studies scholars and students? Were we not once hailed by America (interpellated by America); was this not some part of the reason why we chose to study America? What happens to that allure and fascination? One answer, of course, is that it becomes tempered, perhaps curtailed, certainly disciplined, through our academic studies of America. It becomes an object of knowledge; we learn different ways to frame it, to write about it, to talk about it. Different paradigms emerge to reframe that object, and these are constantly shifting under pressure of new knowledge formations. American studies has arguably been more prone to "paradigm dramas" than most disciplines, a state of perpetual conceptual transformation that characterizes the field imaginary.

The allure of America within the formation of American studies is of course differently conditioned and rooted in different parts of the world. It can pose a reflexive relationship to the disciplinary field that is much less commonly invoked in Europe than it is in the United States. U.S. Americanists have a more selfconscious relationship to the history and boundaries of the field; we might even say an obsessive relationship. The cold war origins of the discipline and the contingent associations with nationalism and exceptionalism have been widely perceived as an intellectual burden by U.S. Americanists. The so-called New Americanist movement of the 1980s and 1990s took much of its intellectual energy from formulating and deconstructing this narrative of burden. The result is that the field imaginary in the U.S. is marked by a powerful sense of agonism, which for the U.S. Americanist is both strategic and libidinal-strategic in that it allows them to continuously renew their field operations and libidinal in that this is often an obsessional or spectacular activity with its own rites and rituals. One such ritual is the presidential address of the annual American Studies Association conference, a genre in which the expectation is that the new president will revisit the origins and history of the field to discuss the blindnesses and insights of its development and to provide a corrective vision on current paradigm dramas. Such ritual returns to origins as a means to envision a better future have suggestive symmetries with the genre of the jeremiad. One of the most absorbing articulations was Janice Radway's famous presidential address in 1998, "What's in a Name?"-rhetorical evidence, if it were needed, that U.S. Americanists wear America on their chests like a scarlet letter. ${ }^{5}$

In Europe, on the other hand, it is relatively rare to find Americanists obsessing about the history of the field. This is not to suggest that European American studies

5 Janice A. Radway, "What's in a Name? Presidential Address to the American Studies Association, 20 November 1998," American Quarterly 51.1 (1999): 1-32. 
does not have its own complex histories of intellectual affiliation and disavowal, but it has only barely begun to acknowledge its origins as a "Euro- American" paradigm of knowledge formation shaped by the cultural wakes of the Second World War and the geopolitical emergence of the cold war. ${ }^{6}$ To be sure, the field of American studies in Europe has become more questioning of American exceptionalism in recent years, engaging some of the academic discourses that seek to dislocate the nation as axis of focus-the transnational, the postnational, the transatlantic, the Black Atlantic, the circumatlantic-which all offer frames that European Americanists are becoming keen to discuss, and I believe these more comparative frames offer promising grounds for the critical inquiries about American empire that are needed to make European American studies critically commensurate to the current international crises.

However, the legacies of "Euro-American" studies still linger and require comment. For much of the last fifty years, European Americanists have tended to write as though part of a transatlantic intellectual class and in so doing have not questioned but lent support to the authority of U.S.-centered knowledge based in American institutions and publishers. Until recent years they have been generally disinclined to engage homegrown theoretical movements until after those movements had been digested by U.S. American studies and fed back to Europe. The German Americanist Heinz Ickstadt makes the point that "although European theories (structuralism and poststructuralism, or the sophisticated socialism of the Frankfurt School) had a considerable impact in the United States, they influenced American studies in Europe only after they had been absorbed and recycled as deconstructionism, or new historicism, or feminist theory."7 The relation of American studies in Europe to American and European circuits of knowledge production are of course much more complex than Ickstadt summarizes, but his point has force in reminding us of the spell of intellectual authority cast by American academia.

European Americanists find themselves in a peculiar bind; after all, "America" is our purported object of study, the raison d'etre of our professionalization, and the privileged medium for our passions for the Real. By this last comment I do not mean to suggest that European Americanists are bound to false consciousness; rather, there is a tendency within European-based American studies (differentially located and articulated) to study the sign of America as a locus of otherness or

6 See Liam Kennedy, "Spectres of Comparison: American Studies and the United States of the West," Comparative American Studies 4.2 (2006): 135-50.

7 Heinz Ickstadt, “Teaching American Studies Abroad: The European Experience," U.S. Society and Values 1.15 (1996), http://usinfo.state.gov/journals/itsv/1096/ijse/icks.htm. 
difference, without pursuing what I think is the necessary concomitant of such study: asking how this passion for the Real structures our intellectual frames of inquiry (not to mention our cultural fantasies) - here I am thinking, for example, of the romance or fetishization of the trope of race in European studies of American culture. What might we learn about the investment in race (most commonly translated as "blackness") by European Americanists as they constructed various national syllabi of American studies in the 1950s and 1960s, say? Why has there been such overdetermined attention to African American history and culture in the canons of European American studies? Why is it that, in Europe, the "problem" of race is so often identified as the problem of America? In part, I suggest, it is because race offers an opportunity to productively disidentify with America-that is, to identify with, to take pleasure in, exploring what America has seemingly disavowed in its own identity.

I intend no summary judgment; rather I want to draw attention to this aspect of European American studies as evidence of the troubled relationships between pleasure and knowledge, between sentiment and critique, which I referred to earlier. For many years American studies has functioned as a marginal or alternative academic space throughout Europe, attracting scholars, teachers, and students who wanted to work beyond the boundaries of what had come to seem traditional disciplines. This sense of a marginal or alternative academic perspective that American studies can lend in many institutional settings outside the U.S. should not be underestimated as a very valuable impetus for (critical) study of the U.S., but it can also function as a prison-house of representation, reproducing an American exceptionalism through the valorization of American culture as sites of marginality, of dissent, of the new and subversive. In short, the field imaginary of American studies in Europe has all too often coalesced with the marginalized self-image of faculty and displaced more local, nonacademic concerns onto the phantasm called "America."

For Europeans who purport to write as Americanists, a more careful attention to our frames and grounds of interpretation is required. This means that European Americanists should be wary of the Atlantic divide as a device of disengagement. Writing in American Quarterly, Heinz Ickstadt suggests that European scholars "can look at the United States as an object of political, social, and cultural analysis without running the risk of being considered chauvinistic or parochial," a privileged "outside- position"- but this is the privilege of a view from nowhere, and I do not think European Americanists should endorse it as a way to frame "America." ${ }^{8}$ Rather,

8 Heinz Ickstadt, "American Studies in an Age of Globalization," American Quarterly 54.4 (2002): 543-62. 
we should look to understand the dialectics and dynamics of our investments in our object of knowledge as they shape and are shaped by the field imaginary.

This privileged "outside-position" assumed by European Americanists is an illusion that facilitates certain ways of thinking about and writing about America, and is further sustained by a fallacy of critical distance that misrecognizes the relationship between the subject and the object of knowledge. This fallacy has begun to show signs of strain in recent years, in part due to the emergence of transnational paradigms of American studies and more recently due to the imperial extensions of American power under conditions of national security as the state pursues a war on terror. This advent of the American empire has made it more difficult to maintain the illusion of a view from nowhere. The U.S. government's stated commitment to a "war of ideas" as a crucial component of the "war on terror" has deeply politicized the production and dissemination of knowledge. This includes the production and dissemination of the meanings of "America," a matter of some importance for those associated with the field of American studies. This "war of ideas" is a sublimated political warfare, a cultural front of America's hegemonic ambitions. It is a war that American studies should not ignore as "we" are already caught up in it. It is a war that (ex)poses the question of American studies' relation to the state.

\section{Beware of the Chickens}

The U.S. Americanist Paul Bové has written a troubled reflection on the complicity of "progressive' American studies" with "the business of the state." Bové poses the question, "Can American studies be area studies?" to answer "No," because it does not "exist to provide authoritative knowledge to the state" and because "American studies best serves the interests of the nation-state in terms of hegemony and culture rather than policy." While he stresses the impossibility of American studies becoming area studies, he uses this question to underline his view that American studies intellectuals misrecognize the workings of the state: "American studies scholars have principally focused on matters of culture and history, the areas of 'civil society' or 'the public sphere,' acting as if, in this way, they were accessing the U.S. state through its extensions.... nor do they take the fact of the U.S. state as itself an agent that must be confronted, in itself, by means of detailed, concrete, material and theoretical analyses."

9 Paul A. Bové, “Can American Studies Be Area Studies?” in Learning Places: The Afterlives of Area Studies, ed. Masao Miyoshi and Harry Harootunian (Durham, NC: Duke University Press, 2002), 222, 206. 
I believe Bové is right to argue that American studies scholarship has not tended to recognize the specificity of the state in formations of "American" power and knowledge, but I question his need to bracket off "the theory of the extended state" as the terrain of civil society and redundant cultural theorizing. His realist model of state power is limiting and suggestive of a parochial vision. To some degree, Bovés pained skepticism is symptomatic of a very American American studies perception of the global immanence of an empire that has no externality. Bové summons the unipolar specter of the American imperium to ask: "If America has had this structural intent to be identical to the world-for what else can it mean to be the world's only remaining superpower-then where can American studies people stand to get a view of all this?" (232). The spatial logic of Bovés question-that there is nowhere for American studies scholars to stand, given their epistemological blindness-verifies the unipolarity of U.S. global power.

This is bleak and I think ultimately unhelpful, though Bovés essay is a brave and challenging intervention-its title, "Can American Studies Be Area Studies?" is one of the two most important rhetorical questions posed of American studies in the last ten years; the other is Janice Radway's "What's in a Name?" It is fitting to mention them together because they both exist in a curious dyadic relation to their object of knowledge - they share a conceptual bind, a corner into which many U.S. Americanists paint themselves once they interrogate the aporia of America as the locus and focus of American studies. A similar point may be made of the New Americanists more generally—as Donald Pease has recently remarked, they worked to imagine new ways of "becoming Americanist otherwise," a postnational project that worked to dislocate the nation from its geopolitical and intellectual axes while remaining in a complex supplementary relationship with the national narratives of American studies. ${ }^{10}$ (This double bind is the inverse to the fallacy of critical distance enjoyed by European Americanists-the Americans see themselves as trapped within the signage of the nation, and the Europeans see themselves observing it from afar-both are deluded.)

Need this double bind be debilitating in producing critical knowledge about the U.S.? I think not. Because the state abjures critical knowledge-it is turning increasingly to advocacy-oriented think tanks for legitimations of its own policiesthis does not mean we should abdicate "anthropological study of civil society," as Bové suggests. ${ }^{11}$ Rather we should work to understand and acknowledge our own

10 Donald E. Pease, "After 9/11, or, Whither the New Americanists?" Comparative American Studies 4.4 (2006): 421-45.

11 Bové, "Can American Studies," 222. 
positions in the circuits of power and knowledge-this should include questioning the idea that critical distance is a precondition of critical analysis and insight. ${ }^{12}$ And so we should open ourselves to what we disavow in order to create the illusion of distance-we should know what binds us to America-and we need to recognize our critical and libidinal investments in the object of knowledge and know that at certain points these may be one and the same thing.

This is no simple matter of stating belief or disbelief. The Slovenian philosopher Slavoj Žižek alerts us to what is at issue in his discussions of the limits of freedom of thought. In one such discussion Žižek relays a classic joke:

A man who believes himself to be a grain of seed is taken to the mental institution where the doctors do their best to finally convince him that he is not a grain of seed but a man; however, when he is cured (convinced that he is not a grain of seed but a man) and allowed to leave the hospital, he immediately comes back trembling - there is a chicken outside the door and he is afraid that it will eat him. "Dear fellow," says his doctor, "you know very well that you are not a grain of seed but a man." "Of course I know that," replies the patient, "but does the chicken know it?"13

For Žižek, the joke illustrates the true stake of psychoanalytic treatment and confronts us with the externality of belief. To put this in more parochial (Americanist) terms: even if we don't believe in God, patriotism, or America, we cannot differentiate our identities from these symbolic systems. What Žižek's joke also underlines is our stake in the fantasy that is America. The situation it describes is suggestive of that of the analysand in the grip of fantasy. Fantasy, in the Lacanian schema, does not name our desire for the Other but rather posits the question of what the Other wants, and our identities and actions are shaped by the response to this question. ${ }^{14}$ I have already suggested that America has long functioned as a phantasm of Americanists' disciplinary desires and knowledge formations in Europe. To critically understand America as fantasy is to begin to respond to the question of what the Other wants and to compose our Americanist identities in terms of this response.

While we cannot simply differentiate our identities from our symbolic systems-this is the point of Žižek's joke-we can work to strategically acknowledge the fantasy that structures our sense of the Real. To ask the question "What does

12 See Eva Cherniavsky, "Project for a New American Studies: State Narratives after Bourgeois Nationalism,” unpublished paper, especially 7-9.

13 Slavoj Žižek, "Notes Towards a Politics of Bartleby: The Ignorance of Chicken," Comparative American Studies 4.4 (2006): 385.

14 See Jacques Lacan, The Four Fundamental Concepts of Psychoanalysis, trans. Alan Sheridan (New York: Norton, 1978), 214. 
America want?" is to foreground the field imaginary and shift the axis and focus of American studies critique. It is to not ask "What is the meaning of America?" an originating question of American studies as a field. The question "What does America want?" is a question of desire rather than meaning. It is also a strategic question that moves us away from the hermeneutics of suspicion and demystification toward forms of cultural and political critique that impel recognition of the limits of critique.

So, with this question in mind, I return to Bovés challenging question: "If America has had this structural intent to be identical to the world-for what else can it mean to be the world's only remaining superpower-then where can American studies people stand to get a view of all this?" The question presents suggestive visual metaphors, suggesting that the potential for critique is an issue of perspective. Another way of formulating Bovés question is "How and from where can we see American empire?" By way of conclusion I want to suggest one possible answer by commenting on a photographic image that might be said to represent a primal scene of American empire.

\section{Between Care and Domination}

I turn to a photographic image for several reasons. Firstly, the image world of contemporary globalization is the sphere in which fantasies of America are most powerfully projected and consumed today. Secondly, photographs as a medium foreground what I have described as the troubled relations in the field imaginary of American studies between pleasure and knowledge, sentiment and critique. Photographs do not explain the world to us but offer us an emotional apprehension of the world represented, and so the viewer has the task of working out the relation between emotion and knowledge. ${ }^{15}$

This image is a photograph by Jean-Marc Bouju, a French photographer working for the Associated Press, who was embedded with the $101^{\text {st }}$ Airborne Division in Iraq. ${ }^{16}$ It depicts a man and child in a POW camp in Najaf. This photograph won the World Press Photo of the Year Award in 2003. Bouju has said the boy was crying when his father was arrested, so the American soldiers allowed the two to stay

15 See Susan Sontag, On Photography (New York: Farrar, Straus and Giroux, 1977).

16 "WorldPressPhotooftheYear:2003,"WorldPressPhoto,http://www.worldpressphoto.org/ index.php?option $=$ com_photogallery\&task=view\&id=202\&Itemid=115\&bandwidth $=$ high. This image is widely reproduced on the Web. See, for example, "World Press Photo 2004: Jean-Marc Bouju, France," Guardian, http://arts.guardian.co.uk/pictures/ image/0,8543,-10104910720,00.html. 
together and then cut off the father's plastic handcuffs so he could hold his child. We can read the photograph as a symbol of compassion (of the soldiers toward the prisoner, of the father toward the son) but we could also read it as evidence of a lack of compassion. ${ }^{17}$ The admixture of cruelty and kindness signified by the image is disconcerting. The dissonance is indicative of the ambiguities inherent in using photography as a documentary witness. We traffic back and forward between the particular and the universal, between the humanistic and the imperial, between care and domination, between sentiment and critique-where does our gaze rest?

The dissonance is in part due to the complex interplay of formal conventions and ethical considerations that characterize the production, display, and perception of photojournalistic images of subjugated bodies. Photojournalism has long assumed an ethical function to bear witness to the suffering or degradation of others, and often photographers have directed this function to arouse concern and perhaps even action. This ethical function, though, is complexly embedded within ideas of the human and of humanitarianism that shadow the ideologies of imperial governance and expansion by European and American powers since the mid-nineteenth century. ${ }^{18}$ Today, this function needs to be understood in the contexts of shifting conditions of relationality, which shape the looking relations (of recognition and identification) that configure our affective responses to images of suffering. Today, these conditions of relationality are significantly shaped by the effects of new media technologies on global communications and by the geopolitics of liberal capitalist expansionism, and in particular by the emergent frames of humanitarianism in the wake of the endings of the cold war. Accordingly, some theorists of globalization now argue that the spaces of our emotional imagination have been expanded in a transnational sense as we are connected (virtually) to new spaces of empathy and aggression. ${ }^{19}$ Certainly, the image world of globalization is also our shared world of affective human attachments. As this image world becomes more and more saturated by images of corporeal violence and vulnerability, it becomes imperative to consider the aesthetics and ethics of the claims the suffering bodies of others make upon us.

17 See Susie Linfield, “The Treacherous Medium: Why Photography Critics Hate Photographs," Boston Review, September-October 2006, http://bostonreview.net/BR31.5/ linfield.html.

18 See Susan D. Moeller, Shooting War: Photography and the American Experience of Combat (New York: Basic Books, 1989).

19 See Ulrich Beck, Cosmopolitan Vision, trans. Ciaran Cronin (Cambridge: Polity, 2006), $5-6$. 
And so, back to the Bouju photograph. What can we say about the image? That it depicts the dialectics of freedom and oppression in the activity of empire? Perhaps, but that only begs further questions. Where does "freedom" reside in this photograph? Does it reside in the motivations of the captors? Does it reside in the transcendent humanism of the parent and child's embrace? Does it reside in the very act of looking? This last question entails a whole history of looking relations surrounding imagery of subjugated bodies and bodies in pain, particularly those framed by colonial or postcolonial conditions of power and conflict. In such instances the subjugated body is the focus of mute testimony. As Allen Feldman observes, "geographies of alterity [are] intimately linked to [their] authentication in material violence"; a "buried truth is located in the body" sited in the "postcolonial peripheries" and must be brought up to the surface in modes of exposure and display. ${ }^{20}$ Documentary photography is one such mode of creating this display, which is to say that this photograph works off a long history of photojournalistic imagery of violent conflict, using a frame and conventions common to the genre. The pieta posture, for example, is a commonplace in such imagery.

However, there is considerable ambiguity about the truth being displayed by the subjugated body in this image. What is being more complexly displayed here is an overdetermined performance of compassion. This includes the compassion of the father in relation to the son, the compassion of the American soldiers in relation to the father and the son, and the compassion of viewers in relation to the scene. It is also a performance of the power of the American military to humanize and dehumanize, a performance of an unlimited power that "promises to liberate the other from his non-existence." ${ }^{21}$ What this visual performance of compassion enacts is the ethical knot in viewing relations conditioned by American imperialism. Is this a scene of care or a scene of domination? Part of the difficulty in making a judgment about this is that the postures of care and domination draw on the same foundation, the primal scene of human vulnerability. ${ }^{22}$ This nexus of care and domination has become a prominent and disturbing feature of the image world of globalization and of the geopolitical world of war, conflict, and human rights abuses that this image world often, if unevenly, represents. In mass media, images of domination and vulnerability meld into one another. Think, for example, of the image banks of famine, sustainable development, and ethnic warfare that

20 Allen Feldman, "Memory Theaters, Virtual Witnessing, and the Trauma-Aesthetic," Biography 27. 1 (2004): 182.

21 Alain Badiou, Polemics, trans. Steve Corcoran (London: Verso, 2006), 29.

22 See Judith Butler, Precarious Life: The Powers of Mourning and Violence (London: Verso, 2006). 
overflow one another. In international relations, the discourse of humanitarianism inflates the demand for care as an issue of liberal governance of failing states and as a legitimate rationale for intervention. In this discourse, the meanings of care and domination are carefully parsed to meet dominant politico-economic interests. Wherever we look, we find that the political structures of domination intersect with ethical structures of care. ${ }^{23}$ This is what the photograph re-presents, the performance of that intersectionality-as such, it exceeds interpretation.

The photograph fails to provide us with an interpretive frame that might allay or organize our confused thoughts and feelings as we look at it. The ambiguities of the image and its very failure to provide answers make it valuable as an indicator of the limits of our knowledge formations and ethical imaginations..$^{24}$ This is where photographic images can be a useful pointer for Americanists, for they are suggestive of how we might understand the role of affective relationality, of how we might integrate it into analysis and not simply subdue it through analysis. As already observed, the image world that is the surface of globalization is also our shared world of affective human attachments. The critical task is not to get behind this surface but to give it definition through our critical work. This is to say that the error of Bovés question is to assume that there is a position in which we can see American empire in some revelatory way, that the truth of American power can be revealed. I don't think this is how we apprehend American empire. Our critical task is not iconoclastic, tearing away the veil of empire to reveal the truth of its horrors; rather it is to stretch the image surface and understand our own investments in its workings. ${ }^{25}$ It is to acknowledge the limits of our capacity to make sense of our object of study, even as we interrogate the emergence and the vanishing of America as a mediator of identities, including our own as critical

23 See Rochelle M. Green, Bonnie Mann, and Amy E. Storey, "Care, Domination, and Representation," Journal of Mass Media Ethics 21.2-3 (2006): 177-95.

24 Such photographs trouble the more conventional evocations of human empathy to produce a more challenging perspective, one in line with Judith Butler's conception of regard for "precarious life" amidst "conditions of heightened vulnerability and aggression" following 9/11. Addressing photographic representation in the last few pages of her book, Butler argues that representation only succeeds when it fails, when "the ethical claim of the other is not pinned down, exhausted and therefore silenced by the ... image." Butler, Precarious Life, 126.

25 See Susan Buck-Morss, "Visual Studies and Global Imagination," Papers of Surrealism 2 (2004), http://www.surrealismcentre.ac.uk/publications/papers/journal2/acrobat_files/ buck_morss_a rticle.pdf. 
intellectuals and as sensate citizens. It is to reinvigorate Americanist projects of critique by asking not what America means but what does America want.

\section{Note}

This is the text of a paper presented at the interdisciplinary seminar on "The Pursuits of Happiness," which took place at the Centro Studi Americani in Rome in May 2007. I am grateful for the invitation from Donatella Izzo to participate in this gathering and for her inspiring, ongoing dialogue on the perils and pleasures of pursuing American studies in Europe. This essay retains many of the oral registers of its original presentation.

\section{Works Cited}

Badiou, Alain. Century. Trans. Alberto Toscano. London: Polity, 2007.

Badiou, Alain. Polemics. Trans. Steve Corcoran. London: Verso, 2006.

Beck, Ulrich. Cosmopolitan Vision. Trans. Ciaran Cronin. Cambridge: Polity, 2006.

Benjamin, Jessica. Shadow of the Other: Intersubjectivity and Gender in Psychoanalysis. New York: Routledge, 1998.

Bové, Paul A. "Can American Studies Be Area Studies?” In Learning Places: The Afterlives of Area Studies. Ed. Masao Miyoshi and Harry Harootunian. Durham, NC: Duke University Press, 2002. 206-230.

Buck-Morss, Susan. "Visual Studies and Global Imagination." Papers of Surrealism 2 (2004). http://www.surrealismcentre.ac.uk/publications/papers/journal2/ acrobat_files/buck_morss_article.pdf.

Butler, Judith. Precarious Life: The Powers of Mourning and Violence. London: Verso, 2006.

Feldman, Allen. "Memory Theaters, Virtual Witnessing, and the TraumaAesthetic." Biography 27.1 (2004): 163-202.

Green, Rochelle M., Bonnie Mann, and Amy E. Storey. "Care, Domination, and Representation." Journal of Mass Media Ethics 21.2-3 (2006): 177-95.

Ickstadt, Heinz. "American Studies in an Age of Globalization." American Quarterly 54.4 (2002): 543-62.

Ickstadt, Heinz. "Teaching American Studies Abroad: The European Experience." U.S. Society and Values 1.15 (1996). http://usinfo.state.gov/journals/itsv/1096/ ijse/icks.htm.

Kennedy, Liam. "Spectres of Comparison: American Studies and the United States of the West." Comparative American Studies 4.2 (2006): 135-50. 
Lacan, Jacques. The Four Fundamental Concepts of Psychoanalysis. Trans. Alan Sheridan. New York: Norton, 1978.

Linfield, Susie. "The Treacherous Medium: Why Photography Critics Hate Photographs.” Boston Review, September-October 2006. http://bostonreview.net/ BR31.5/linfield.html.

Moeller, Susan D. Shooting War: Photography and the American Experience of Combat. New York: Basic Books, 1989.

Pease, Donald E. "After 9/11, or, Whither the New Americanists?" Comparative American Studies 4.4 (2006): 421-45.

Radway, Janice A. "What's in a Name? Presidential Address to the American Studies Association, 20 November 1998.” American Quarterly 51.1 (1999): 1-32.

Sontag, Susan. On Photography. New York: Farrar, Straus and Giroux, 1977.

Žižek, Slavoj. "Notes Towards a Politics of Bartleby: The Ignorance of Chicken." Comparative American Studies 4.4 (2006): 385. 